\title{
CATALYTIC MULTI-STAGE LIQUEFACTION
}

(CMSL)

Doe/PC/92147-T2-Vo/. 2

DE-AC22-93PC92147

\section{FINAL REPORT}

\section{VOLUME II}

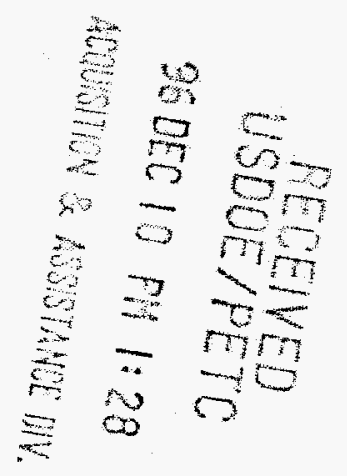

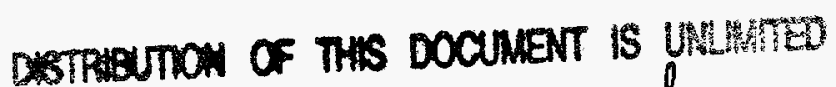

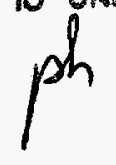

Hydrocarbon Technologies, Inc.

1501 New York Avenue

Lawrenceville, NJ 08648

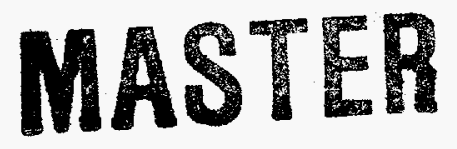

November, 1996 
CATALYTIC MULTI-STAGE LIQUEFACTION OF COAL (CMSL) FINAL REPORT

VOLUME II

SECTION II (CONTINUED)

EVALUATION OF A SULFATED IRON-MOLY DISPERSED SLURRY CATALYST FOR TWO-STAGE LIQUEFACTION OF A SUBBITUMINOUS COAL

RUN CMSL-6 


\section{DISCLAMMER}

Portions of this document may be illegible in electronic image products. Images are produced from the best available original document. 


\section{DISCLAIMER}

This report was prepared as an account of work sponsored by an agency of the United States Government. Neither the United States Government nor any agency thereof, nor any of their employees, make any warranty, express or implied, or assumes any legal liability or responsibility for the accuracy, completeness, or usefulness of any information, apparatus, product, or process disclosed, or represents that its use would not infringe privately owned rights. Reference herein to any specific commercial product, process, or service by trade name, trademark, manufacturer, or otherwise does not necessarily constitute or imply its endorsement, recommendation, or favoring by the United States Government or any agency thereof. The views and opinions of authors expressed herein do not necessarily state or reflect those of the United States Government or any agency thereof. 
VOLUME II

SECTION II RUN CMSL - 6

TABLE OF CONTENTS

RUN CMSL-6 (227-83)

EVALUATION OF A SULFATED IRON-MOLY DISPERSED SLURRY CATALYST FOR TWO-STAGE LIQUEFACTION OF A SUBBITUMINOUS COAL

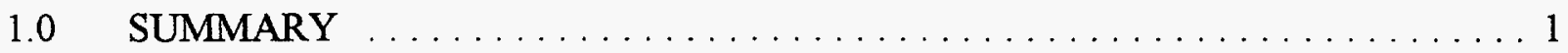

2.0 BACKGROUND, OBJECTIVE AND SCOPE OF WORK $\ldots \ldots \ldots \ldots \ldots \ldots$

3.0 PROGRAM ANALYSIS AND RESULTS $\ldots \ldots \ldots \ldots \ldots \ldots \ldots \ldots$

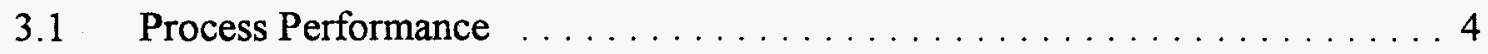

3.2 Product Distribution . . . . . . . . . . . . . . . . . . . . . . . 5

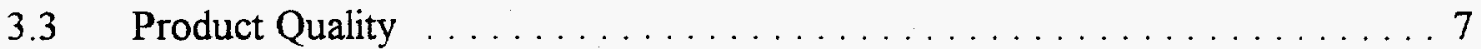

4.0 ANALYSIS OF EFFECTS OF OPERATING PARAMETERS $\ldots \ldots \ldots \ldots \ldots 8$

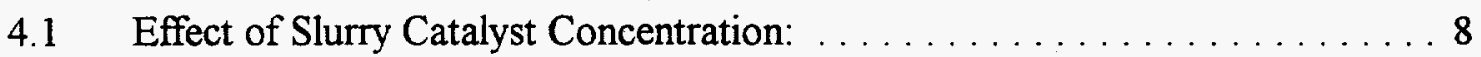

4.2 Effect of CAS Bottoms Ashy Recycle: . . . . . . . . . . . . . . . . 9

4.3 Effect of Reaction Severity: . . . . . . . . . . . . . . . . . . 9

4.4 Comparison Of Performance Of Different Dispersed Slurry Catalysts ..... .9

4.5 Evaluation Of Performance Of Different First Stage Catalysts---Part I . . . 10.

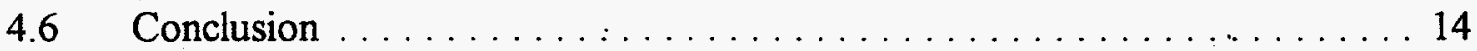

4.7 Evaluation Of Performance Of Different First Stage Catalysts--Part II $\ldots \ldots 15$

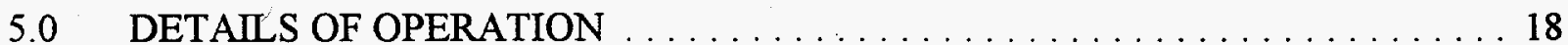

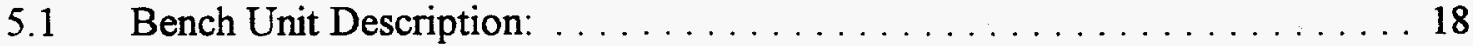

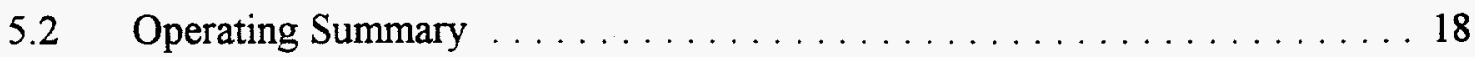

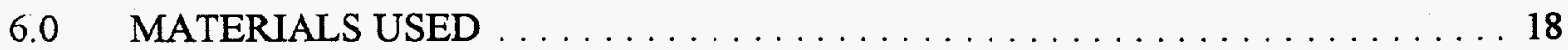

$6.1 \quad$ Feed Coal . . . . . . . . . . . . . . . . . . . . . . . . . 18

$6.2 \quad$ Startup/Makeup Oil $\ldots \ldots \ldots \ldots \ldots \ldots \ldots \ldots \ldots \ldots \ldots \ldots$

6.3 First Stage Slurry Dispersed Catalyst $\ldots \ldots \ldots \ldots \ldots \ldots \ldots \ldots \ldots$

6.4 Supported Catalyst . . . . . . . . . . . . . . . . . . . . . . . . . . 19

6.5 Hydrotreater Catalyst . . . . . . . . . . . . . . . . . . . . . . 19

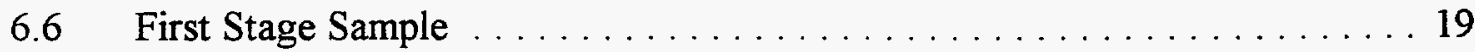

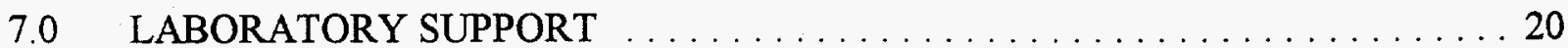

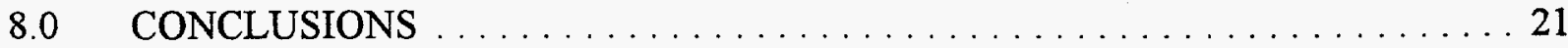

9.0 RECOMMENDATIONS FOR FUTURE WORK $\ldots \ldots \ldots \ldots \ldots \ldots \ldots 22$ 
VOLUME II

\section{SECTION II - RUN CMSL-6}

\section{LIST OF TABLES}

Table

Page

2.6.1 Bench Run CMSL-6 Run Plan . . . . . . . . . . . . . . . . . . . 23

2.6.2 Process Performance During CMSL-1 vs. Operating Conditions . . . . . . . 24

2.6.3 CMSL-6: Separator Overhead (SOH) Inspection . . . . . . . . . . . . . 25

2.6.4 CMSL-6: Properties of the Pressure Filter Liquid (2nd Stage) . . . . . . . 26

2.6.5 CMSL-6: Inspection of the Pressure Filter Solids (2nd Stage) . . . . . . . 27

2.6.6(a) Detailed Analyses of TBP Fractions

Run No. 227-83 - Period No. 6 - CMSL-6 . . . . . . . . . . . . . . . 28

2.6.6(b) Detailed Analyses of TBP Fractions

Run No. 227-83 - Period No. 9 - CMSL-6 . . . . . . . . . . . . . . 29

2.6.6(c) Detailed Analyses of TBP Fractions

Run No. 227-83 - Period No. 12 - CMSL-6 . . . . . . . . . . . . . 30

2.6.6(d) Detailed Analyses of TBP Fractions

Run No. 227-83 - Period No. 17 - CMSL-6 . . . . . . . . . . . . . . 31

2.6.7 Properties of First and Second Stage Samples . . . . . . . . . . . . . . 32

2.6.8 CMSL-6: Properties of the Pressure Filter Liquid (1 st Stage) . . . . . . . . . 33

2.6.9 CMSL-6: Inspection of the Pressure Filter Solids (1 st Stage) . . . . . . . . . 34

2.6.10 Slurry Catalyst Concentration (in wppm of Feed Coal) during CMSL-6 . . . . 35

2.6.11 Dispersed Slurry Catalysts Tested at HTI . . . . . . . . . . . . . . . . 36

2.6.12 Operating Conditions During Comparison Runs . . . . . . . . . . . . 37

2.6.13 Process Performance Comparisons . . . . . . . . . . . . . . . . . 38

2.6.14 Analysis of Feed Coal and Make-up/Start-up Oil . . . . . . . . . . . . . . . 39

2.6.15 Laboratory Support for CMSL-6

Sulfated Fe-Mo Catalysts and their Surface Areas . . . . . . . . . . . . . 40

2.6.16 Laboratory Support for CMSL $-6 \ldots \ldots \ldots \ldots \ldots \ldots \ldots \ldots \ldots \ldots$

2.6.17 Microautoclave Testing of Catalyst for CMSL-6 Operation . . . . . . . . . 42 
VOLUME II

\section{SECTION II - RUN CMSL-6}

\section{LIST OF FIGURES}

Figure

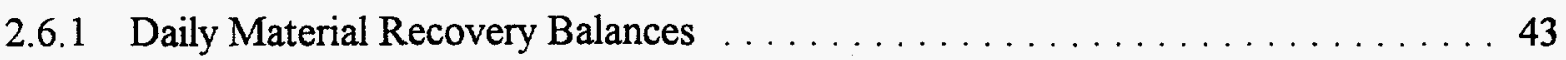

2.6.2 Daily Operating Conditions, Temperatures \& Space Velocities . . . . . . . . . . 44

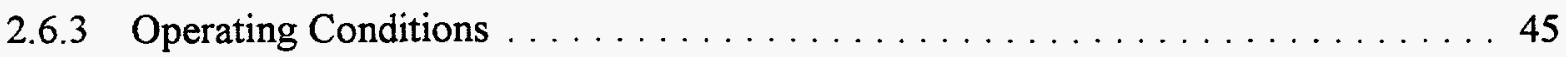

2.6.4 Slurry Catalyst Concentration (Fresh + Recycle) vs. Operating Conditions . . . . 46

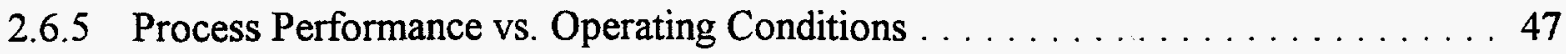

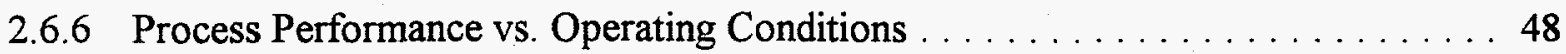

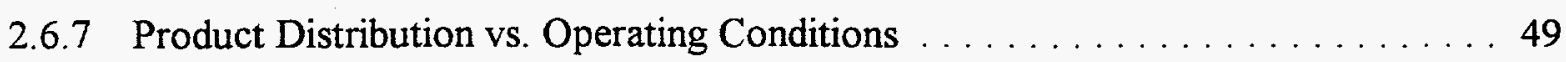

2.6.8 524 C+ Resid Content of the Atmospheric Still Bottoms Product . . . . . . . . . 50

2.6.9 PFL Properties vs. Slurry Cat Concentration and Other Conditions . . . . . . 51

2.6.10 Effect of Cas Bottoms (Ashy) Recycle on Process Performance . . . . . . . . 52

2.6.11 227 Unit Run 79 - Two Stage with Interstage Separation . . . . . . . . . . . 53 
RUN CMSL-6 (227-83)

\section{EVALUATION OF A SULFATED IRON-MOLYBDENUM DISPERSED SLURRY CATALYST FOR TWO-STAGE LIQUEFACTION OF A SUBBITUMINOUS COAL}

\subsection{SUMMARY}

The 17-day bench run CMSL-6 (227-83), on Black Thunder Mine subbituminous coal and with an approximate space velocity of $481 \mathrm{~kg} / \mathrm{hr} / \mathrm{m}^{3}\left(30 \mathrm{lb} / \mathrm{hr} / \mathrm{ft}^{3}\right)$, tested the performance of a dispersed slurry catalyst in powdered form added to the first stage thermal reactor. This catalyst, based on molybdenum-containing sulfated iron oxide prepared at HTI, had about $15 \%$ moisture, $43 \% \mathrm{Fe}$ and $7 \%$ Mo with a BET surface area of about $40 \mathrm{~m}^{2} / \mathrm{g}$. The second stage reactor had a partially deactivated Shell S-317 catalyst (initial age $=520 \mathrm{~kg}$-coal $/ \mathrm{kg}$-catalyst) to make the effects of the slurry catalyst more apparent and to attain a realistic equilibrium catalyst age sooner. An in-line hydrotreater was successfully employed during this run to treat atmospheric still overhead and separator overhead products. No interstage product separator was utilized in this run.

For the first run condition, the catalyst additive rate was $1400-4300$ ppm (of coal) Fe with $200-700$ ppm Mo using a slurrying oil recycle consisting of $60 \%$ of filtered product slurry and $40 \%$ of ashy recycle (unfiltered product slurry) at a relatively low severity with first and second stage temperatures of $427^{\circ} \mathrm{C}$ and $413^{\circ} \mathrm{C}\left(800^{\circ} \mathrm{F}\right.$ and $\left.775^{\circ} \mathrm{F}\right)$, respectively. After that the additive rate was lowered to $700 \mathrm{ppm}$ Fe with $100 \mathrm{ppm}$ of Mo and the severity was increased with first and second stage temperatures of $441^{\circ} \mathrm{C}$ and $427^{\circ} \mathrm{C}\left(825^{\circ} \mathrm{F}\right.$ and $\left.800^{\circ} \mathrm{F}\right)$, respectively. The proportion of ashy recycle was maintained at $40 \%$ in Condition 2 , and it was lowered to $25 \%$ in Condition 3 . In Condition 4 , the proportion of ashy recycle was set at $50 \%$, but, because of slowing of the product slurry filtration, vacuum distillate recycle (and makeup oil) was substituted for the filtered liquid constituent of the recycled oil. With the changes of the proportion of ashy recycle the total slurry catalyst in the system (added and recycled) ranged from 860 to $6345 \mathrm{ppm}$ Fe with 140 to $1030 \mathrm{ppm}$ Mo.

The following concepts were investigated during this bench run:

1) Activity of freshly added dispersed slurry catalyst at two different reaction severities.

2) Performance of the dispersed catalyst at three different levels of its addition rates to the coalfeed slurry; these corresponded to using about 100, 200, and $700 \mathrm{ppm}$ Mo with about 615 , 1230 , and $4300 \mathrm{ppm}$ Fe respectively in the fresh feed relative to coal.

3) The effect of the "recycled" dispersed slurry catalyst was also evaluated by varying the amount of the solids-containing CAS bottoms recycle stream in an ashy-recycle mode of operation.

4) The impact of the use as recycled slurrying oil of vacuum distillate, containing no residual oil, in place of filtered liquid containing a high proportion of residual oil. 
Performance of the dispersed sulfated catalyst tested in this run for the operation using filtered liquid recycle was found to be either equal to or better than any other iron or molybdenum-based dispersed catalysts tested to date at HTI on the bench scale. Overall coal conversions remained throughout the run between 93.5 and $94.5 \mathrm{~W} \% \mathrm{MAF}$ with resid conversions between 83 and 90 $\mathrm{W} \% \mathrm{MAF}$. The distillate yields $\left(\mathrm{C}_{4}-524^{\circ} \mathrm{C}\right)$ varied between 62 and $66 \mathrm{~W} \%, \mathrm{MAF}, 2$ to $5 \%$ higher than those obtained under comparable reaction severities either during CMSL-1 or CC-15. These earlier bench runs evaluated the impregnated iron catalyst with and without separately added molybdenum.

The process performance degraded, though not significantly, upon decreasing the dispersed catalyst concentration in the feed from $700 \mathrm{ppm} \mathrm{Mo} \mathrm{(and} 4300 \mathrm{ppm} \mathrm{Fe}$ ) to about $100 \mathrm{ppm}$ Mo (and 615 ppm Fe). Coal conversion was still at $94 \%$ while resid conversion was $83 \%$ and distillate yields of $63 \% \mathrm{MAF}$ were obtained at low catalyst concentrations. Even at a high process severity (Periods 8-17), gas yields were on the low side (10-12 W\% MF) and thus, overall hydrogen consumption was also low (6-7.5 W\% MF).

The Condition 4 operation using vacuum distillate recycle had coal conversion at the level obtained earlier in the run, but resid conversion was only $67 \%$, with a five-fold increase in residual oil yield and net distillate yield of only $38 \%$ of MAF coal. This change is consistent with the consequent lowering of residual oil concentration in the reactors and lower opportunity for secondary reaction of residual oil to distillate oil products.

The first stage samples revealed a coal conversion range of 92.5 to $93.5 \mathrm{~W} \%$ MAF for the first stage and a resid conversion range of 69 to $74 \mathrm{~W} \% \mathrm{MAF}$. These relatively high values were due to the activity of the sulfated dispersed catalyst, added at $100 \mathrm{ppm} \mathrm{Mo}$ and about $615 \mathrm{ppm}$ Fe to feed.

The "recycled" catalyst, i.e., the slurry catalyst in the ashy CAS bottoms recycle was not found to have any significant impact on the overall activity of the total dispersed catalyst system (fresh+recycled together). This is based on the similar yields and conversion numbers obtained during conditions when the amount of CAS bottoms recycle was varied to vary the total dispersed catalyst concentration in the system to correspond to 133,166 , and $216 \%$ of the fresh catalyst added with the feed. These results indicate that the recycled catalyst did not have any significant residual catalytic activity.

Throughout this run, excellent heteroatom removals were obtained, with HDS (organic) of about $97-98 \mathrm{~W} \%$ and HDN of between 88 to $94.3 \mathrm{~W} \%$. The in-line hydrotreater was operated both at 368 and at $379^{\circ} \mathrm{C}$ with a mixture of high pressure hot separator overhead and ASOH with unit knockouts as its total feed. The hydrotreater product was a clean colorless or light straw colored oil with less than $30 \mathrm{ppm}$ nitrogen and $10 \mathrm{ppm}$ sulfur. 


\subsection{BACKGROUND, OBJECTIVE AND SCOPE OF WORK}

The CMSL Project is set up to evaluate different novel processing concepts in catalytic coal liquefaction to complement the larger scale process demonstration, "Proof-of-Concept", Studies for the U.S. DOE. The new ideas being explored in this program include low temperature pretreatments, more effective catalysts, in-line hydrotreating, new feedstocks, other (cheaper) sources of hydrogen, more concentrated coal-slurry feeds, etc.

The bench run CMSL-6 run was carried out using POC-02 subbituminous Black Thunder coal ( $11 \%$ moisture), an iron-and-molybdenum-containing sulfated dispersed slurry catalyst additive to the first stage back-mixed reactor, and an aged Shell-317 extrudate catalyst in the second stage ebullated bed reactor. It had the following technical objectives:

1. To investigate the effect of using a finely divided, high surface area sulfated slurry catalyst additive (containing iron and molybdenum) at two different concentration levels on the overall process performance.

2. To determine the effect of high coal space velocities $\left[481 \mathrm{~kg} / \mathrm{hr} / \mathrm{m}^{3}\right.$ catalyst $\left(30 \mathrm{lb} / \mathrm{hr} / \mathrm{ft}^{3}\right.$ reactor)] on process performance in the presence of dispersed slurry catalysts.

3. To provide the feasibility support for the upcoming PDU run POC-04 with a low rank coal using a dispersed slurry catalyst.

An in-line hydrotreater was used during this run. Both the separator (O-1) overheads including knockouts and the ASOH were sent through the hydrotreater. The Run Plan included four Run Conditions that were selected to meet the technical objectives, specified above. The intended run plan is shown in Table 2.6.1. However, the actual operating plan was modified, as shown in Table 2.6.2 which summarizes the operating results, in the final Condition 4 where vacuum distillate recycle with some make-up oil was substituted for the filtered liquid recycle that had been used in the previous conditions. This change was made when the filtration of product slurry had slowed so that it was not possible to obtain sufficient filtered liquid for preparing the feed slurry.

A solvent/coal ratio of 1.2-1.6 was used throughout the run. The high-low temperature profile for the operation of the CMSL- 6 was chosen so that activity comparisons could be made between the sulfated iron-moly dispersed catalyst (to be used here) and several other iron-molybdenum slurry catalysts used in bench scale operations at HTI in the past.

In order to possibly improve the coal conversions further and to build up the dispersed catalyst concentration in the reactor slurry, an ashy recycle mode was to be used throughout this run. To accomplish this, about $25-50 \mathrm{~W} \%$ of the CAS bottoms was recycled along with part of the process PFLs to slurry the feed coal.

The dispersed catalyst, $\mathrm{Mo} / \mathrm{FeOOH} / \mathrm{SO}_{4}$, was synthesized by aqueous precipitation in the solution containing both the sulfate and the molybdate anions. 


\subsection{PROGRAM ANALYSIS AND RESULTS}

The conversions and yields of different products, process performance, and product quality for CMSL- 6 are addressed in this Section. The calculation of daily material recovery balances, coal conversions, normalized product yields, and other process performance-related indicators were carried out using programs available in the CTSL database (some programs were also modified as per the requirement of the process schematic). An average material recovery balance of $98.2 \mathrm{~W} \%$ was obtained (Figure 2.6.2) for the entire Bench Run CMSL-6. The Operating Summary of individual Periods during CMSL-6 is shown in Table 2.6.2. Figure 2.6.2 shows the operating conditions during CMSL- 6 in terms of coal space velocities, reactor temperatures. The other operating conditions, in terms of the W\% CAS bottoms recycled, relative process severity, and the total (fresh+recycle) concentration of the slurry catalyst (iron and molybdenum) relative to coal are shown in Figures 2.6.3 and 2.6.4.

\subsection{Process Performance}

\section{Coal Conversion}

Typical coal conversions, obtained (for both the stages) during equilibrated Periods of different Conditions of CMSL-6 are shown in Figure 2.6.5. As shown in Figure 2.6.5, the coal conversions (W\% MAF coal) were steady with a little variation between 93.5 and 95 W\% throughout the course of the Run. The coal conversion did not show any sensitivity to process severity, the slurry catalyst concentrations investigated during the course of this run, or the change in the recycle solvent material in Condition 4.

\section{$524^{\circ} \mathrm{C}^{+}$Residuum Conversion}

During Conditions $1 \mathrm{~A}$ and $1 \mathrm{~B}$, at lower process severity, resid conversion decreased from about $87-88 \%$ to about $82-83 \%$ MAF coal upon reducing the slurry catalyst concentration in the feed. At higher process severity Conditions 2 and 3, resid conversions were typically between 88 and 90 W\% MAF coal, as shown in Figure 2.6.5. Resid conversion levels, in general, did not change much when the amount of slurry catalyst recycled was changed during this run. The only variables that affected the resid conversion were the process severity and the slurry catalyst concentration in the fresh feed. As the supported catalyst used in the stage 2 reactor, $\mathrm{K}-2$, was already an aged catalyst, the decline in resid conversion levels with time, which is typical for deactivation of a freshly presulfided supported catalyst, was not observed during this portion of the run.

In Condition 4 , with vacuum distillate recycle substituted for filter liquid recycle, $524^{\circ} \mathrm{C}+$ residuum conversion was about $20 \%$ lower at $67 \%$ of MAF coal. This change follows the lowered residual concentration in the reactors, to about $28 \mathrm{~W} \%$ from $38 \mathrm{~W} \%$, because of the low amount of recycle of residual oil, and the consequent lowered opportunity for secondary reaction of the residual oil. 


\section{Hydrogen Consumption/Efficiency}

For the operations with filtered liquid recycle, the hydrogen consumption (based on the hydrogen-content of the feed and products), obtained from the normalized yield program, varied between 7.0 to $8.0 \mathrm{~W} \% \mathrm{MAF}$ coal (Figure 2.6.6). With vacuum distillate recycle, the hydrogen consumption was lower by $1 \mathrm{~W} \%$. This value of hydrogen consumption was in good agreement with that obtained from the metered hydrogen balance.

Hydrogen Efficiency, defined as the W\% MAF yield of distillate $\left(\mathrm{C}_{4}-524^{\circ} \mathrm{C}\right)$ per unit W\% MAF $\mathrm{H}_{2}$ consumed, varied between 8 to $9.5 \mathrm{~kg}$ distillates $/ \mathrm{kg}_{2} \mathrm{H}$ (Figure 2.6.6). This value of hydrogen efficiency was higher for CMSL- 6 than that for some of the other Bench runs on Black Thunder Mine subbituminous coal using a dispersed slurry catalyst. For the Condition 4 operation, the hydrogen efficiency was $5.8 \mathrm{~kg} / \mathrm{kg}$

\section{Heteroatom Removal}

The use of an in-line hydrotreater resulted in light distillates with very low levels of heteroatoms. Typically nitrogen and sulfur contents of about $25 \mathrm{ppm}$ or less were obtained. As shown in Figure 2.6.6, the $\mathrm{HDN}$ varied from $91.5 \mathrm{~W} \%$ to over $93.5 \mathrm{~W} \%$ during the course of the run; similar ranges were observed with the organic sulfur removal also (HDS $=96.7$ 98.7 W\%).

\section{Slurry Catalyst Recycle}

The recycled catalyst in Run CMSL-6, i.e., the slurry catalyst in the ashy CAS bottoms recycle was not found to have any significant impact on the overall activity of the total dispersed catalyst system (fresh + recycled together). This is based on the similar yields and conversion numbers obtained during conditions when the amount of CAS bottoms recycle was varied to vary the total dispersed catalyst concentration in the system to correspond to 133,166 , and $216 \%$ of the fresh catalyst added with the feed.

These results indicate that the recycled catalyst did not have any significant residual catalytic activities. It is apparent that slurry catalyst additives deactivates at a much faster rate than the extrudate catalysts would.

\subsection{Product Distribution}

\section{$\underline{\mathrm{C}}_{1}-\mathrm{C}_{3}$ Gas Yields}

As shown in Figure 2.6.6, the normalized $\mathrm{C}_{1}-\mathrm{C}_{3}$ gas yields for CMSL-05 varied between about 8 and $13 \mathrm{~W} \% \mathrm{MAF}$ coal. The light gas yields were lower $(8 \%)$ at low process severity, but once the process severity was increased in Condition 2 , the gas yields increased substantially, suggesting excessive thermal cracking of resid and heavier distillates, especially in the first reactor. 


\section{$\mathrm{C}_{4}-177^{\circ} \mathrm{C}$ Naphtha Yields}

These yields are shown in Figure 2.6.7. As shown in Figure 2.6.7, the yields of naphtha fraction varied between $13-20 \mathrm{~W} \% \mathrm{MAF}$ coal. The yields were generally higher for the higher process severity. The yield was very nearly the same for the Condition 4 operation witht the modified type of recycled solvent.

\section{$177-343^{\circ} \mathrm{C}$ Middle Distillate Yields}

As shown in Figure 2.6.7, the middle distillate yields were the highest selectivity yields among the distillate products. These varied between 26 and $38 \mathrm{~W} \% \mathrm{MAF}$ coal. The highest middle distillate yield was obtained for Periods 12-13 (Condition 3, with the lowest proportion of ashy recycle). For the Condition 4 operation, using vacuum distillate recycle, this yield was in the range of those of the other conditions.

\section{$343-524^{\circ} \mathrm{C}$ Heavy Distillate (Gas Oil) Yields}

The heavy distillate yields for Condition 1 through 3 varied between $10-22 \mathrm{~W} \%$ as shown in Figure 2.6.7. Conditions 2 and 3 resulted in lower yields of heavy distillates, primarily the result of increased reaction severity. In Condition 4, there was a net negative yield of this component because of the reaction of the portion of the make-up oil that was used.

\section{$\underline{524^{\circ} \mathrm{C}^{+} \text {Residual Oil Yields }}$}

For the Condition 1, 2, and 3 operations, using filtered liquid recycle, the residuum yields ranged from 5 to $11 \mathrm{~W} \%$ of MAF coal, with the lowest yields for the higher severity operations of Conditions 2 and 3, as summarized in Figure 2.6.7. For the Condition 4 operations, using vacuum distillate recycle, this yield increased to $26 \mathrm{~W} \%$ of MAF coal. This increase follows the lower residual oil concentrations in the reactors, and the lower potential of secondary reaction of the residual oil to distillates, resulting from the lower amount of residual oil being recycled during the Condition 4 operation. It is estimated that the concentrations of residual oil in the reactors were $37-40 \mathrm{~W} \%$ during the Condition 3 operation, and $27-28 \mathrm{~W} \%$ during the Condition 4 operation.

\section{$\mathrm{C}_{4}-524^{\circ} \mathrm{C}$ Distillate Yields}

High distillate liquid yields $\left(\mathrm{C}_{4}-524^{\circ} \mathrm{C}\right)$ were obtained during Run CMSL- 6 operation that recycled filtered liquid. These varied typically between 62 and $66 \mathrm{~W} \% \mathrm{MAF}$ coal during the course of the run. The first two run conditions, $1 \mathrm{~A}$ and $1 \mathrm{~B}$, with low process severity yielded 63-65 W\% distillates, while the yields during later high severity run conditions remained at about $64-66 \mathrm{~W} \%$. During the Condition 4 operation, using vacuum distillate recycle, this net yield fell to $38 \mathrm{~W} \%$ of MAF coal, although the yield of $\mathrm{C}_{4}-343^{\circ} \mathrm{C}$ distillate was $49 \mathrm{~W} \%$ of MAF coal. As shown in Figure 2.6.5, the trend in distillate yields paralleled the resid conversions. 


\subsection{Product Quality}

Different product fractions (Total SOH, PFL, and PFC) from Periods 6, 9, 12, and 17 were analyzed in detail for their composition. The analyses of these products are listed in Tables 2.6.3 through 2.6.5.

\section{Separator Overhead Product}

As shown in Figure 2.6.11, the configuration of the separation section during CMSL-6 was such that the hot separator overhead vapors, ASOH and any unit knockouts were being fed to an in-line hydrotreater. After exiting the hydrotreating unit, the vapors were condensed in a cold separator and the liquid cold separator bottoms were called the $\mathrm{SOH}$. This product was further separated from water, and the light oil was analyzed in detail. Table 2.6.3 lists the properties of the $\mathrm{SOH}$-oil fraction in terms of D-86 distillation, and elemental analysis. As seen from this Table, the SOH-oil product had high API gravities and boiled in the $70-370^{\circ} \mathrm{C}$ range. The $\mathrm{H} / \mathrm{C}$ ratio was fairly high, around 1.75 , indicating good hydrogenation. More importantly, the heteroatom content, $N$ and $S$ levels, were very low, averaging between 20 and $50 \mathrm{ppm}$ for $\mathrm{S}$ and between 10 and 40 for $\mathrm{N}$.

\section{Pressure Filter Liquid and Pressure Filter Cake}

The pressure filter liquids obtained during CMSL- 6 were consistently very viscous, high boiling, and contained significant amounts of asphaltenes and preasphaltenes, especially Condition 2 onwards, when the fresh slurry catalyst addition rate was reduced to correspond to only 100 $\mathrm{ppm} \mathrm{Mo}$ and $615 \mathrm{ppm}$ Fe relative to coal. The increase in the process severity did not seem to affect the properties of the PFL much. In general, PFL throughout the Run (Table 2.6.4) had about $40 \mathrm{~W} \%$ resid and an API gravity of about -6 . The partially deactivated second stage supported catalyst used in CMSL-6, the nature of high-low reactor temperature profile, and high (40 W\%) recycle rate of the CAS bottoms could be considered among the factors contributing to the heavy, viscous nature of the PFL during operations. Low slurry catalyst concentrations (added freshly), coupled with the finding that the recycled catalyst did not have as high of an activity as expected, probably rendered the PFL (or CAS bottoms) so high in both asphaltenes and preasphaltenes. The resid content in the CAS bottoms material during Periods 1-12 is shown in Figure 2.6.8 (Periods 13-17 are not shown as significant amounts of make-up oil were used during this time). The high viscosity of the filtered liquid resulted in very slow filtrations, so that filtration was abandoned in Period 13 and vacuum distillation was started to obtain recycle oil.

24 to $28 \mathrm{~W} \%$ of the pressure filter cake was insoluble organic matter; this corresponded to high conversion levels of $93-95 \mathrm{~W} \%$ MAF coal. The other properties, as shown in Table 2.6.5, were very consistent throughout the run.

\section{Analysis of TBP Fraction of Liquid Products}

The light product oils were combined and sent through the hydrotreater. The product stream from the hydrotreater was fractionated into four true boiling (TBP) fractions. A series of analyses, including API gravity, elemental, compound class type (PONA) on the lighter 
fractions, bromine number, aniline point and flash point, was performed. The results of these analyses are reported in Tables 2.6.6a-d.

The initial boiling point of the hydrotreater product samples range from $48^{\circ}$ to $74^{\circ} \mathrm{C}$. The distribution of the four TBP fractions from these samples are compared in Table 2.6.6a-d. Over $93 \mathrm{~W} \%$ of the materials in these samples boiled below $343^{\circ} \mathrm{C}$.

The compound class type distribution in the two lightest fractions are presented in Table 2.6.6ad. The largest component in the IBP $-177^{\circ} \mathrm{C}$ fraction is the naphthenics which is consistent at 68.59 to $70.62 \mathrm{~V} \%$. The next largest component is the paraffins which varies from 21.56 to $23.70 \mathrm{~V} \%$. The largest component in the $177-260^{\circ} \mathrm{C}$ fraction generally the naphthenics which vary from 40.84 to $49.74 \mathrm{~V} \%$. The next largest component is the aromatics which varies from 37.10 to $44.96 \mathrm{~V} \%$.

\section{First Stage Samples}

The first stage samples are the samples of the slurry that are withdrawn from the ebullating line on the reactor. These samples shed light on the performance of the first stage reactor in terms of coal and resid conversions. The samples of the product slurry from the first stage reactor were collected during Periods 7A, 10A, 13A, and 17C to represent Work-up Periods in each of the selected Run Conditions. The first stage samples were pressure filtered hot and both the filtered liquid \& the cake were analyzed and worked-up separately. Pressure filtered liquids were subjected to ASTM D-1160 distillation and the cakes were extracted with quinoline to determine the coal conversions. Table 2.6.7 lists all the information that was derived from the first stage samples analyses. Tables 2.6 .8 and 2.6.9 also show the detailed inspections of the liquids and cakes obtained from the first stage samples.

From Table 2.6.7, which compares the performance of the first stage reactor with the two-stage overall configuration, it is evident that almost $98 \%$ of the total two-stage coal conversion took place in the first stage. The resid contents of the first stage liquid remained around $44 \mathrm{~W} \%$ (except for Period 17, when makeup oil was used) whereas the two-stage PFL generally contained $40 \mathrm{~W} \%$ resid. The asphaltene and preasphaltene contents of the first stage liquid oil were only slightly higher than those of the overall two-stage PFL oil, indicating lack of any substantial hydrocracking in the reactor $\mathrm{K}-2$ (which had an aged supported $\mathrm{Ni}-\mathrm{Mo} / \mathrm{Al}_{2} \mathrm{O}_{3}$ catalyst). Similar minor differences in the other properties (API, CCR, H/C ratio, etc) of the PFL material are observed in comparing first stage samples with the two-stage samples. This may also suggest improper temperature sequencing of reactors and/or the deactivated nature of the second stage supported catalyst.

\subsection{ANALYSIS OF EFFECTS OF OPERATING PARAMETERS}

\subsection{Effect of Slurry Catalyst Concentration:}

The original goal for CMSL-6 was to determine the effects of varying slurry catalyst concentration between 100 and $200 \mathrm{ppm}$ molybdenum and 2500 and $5000 \mathrm{ppm}$ iron relative to feed coal. The iron-to-molybdenum ratio of the prepared slurry catalyst was different than the 
projected so that the actual concentration range was between 100 and $700 \mathrm{ppm}$ Mo and between 615 and $4300 \mathrm{ppm} \mathrm{Fe}$. Because an ashy recycle mode of operation was adopted during CMSL-6, with the recycle of the CAS bottoms, the total effective steady state catalyst concentration was higher. These total catalyst concentrations actually obtained in the system, based on the analysis of individual CAS bottoms, are listed in Table 2.6.10. The projected values of concentration, estimated using the steady-state calculations, are also listed in the same Table. The slurry catalyst concentrations at individual operating conditions are also shown in Figure 2.6.4. In going from Periods 3-4 to Periods 5-6, when catalyst concentration was reduced more than a third, process performance, in general, deteriorates (Figures 2.6.5 and 2.6.6). The distillate yields and resid conversions decreased and the asphaltene and preasphaltene contents increased during this change. Further lowering the catalyst concentration to correspond to only $100 \mathrm{ppm} \mathrm{Mo} \mathrm{in} \mathrm{feed,} \mathrm{did} \mathrm{not} \mathrm{seem} \mathrm{to} \mathrm{affect} \mathrm{the} \mathrm{overall}$ process performance in terms of resid conversions and distillate yields. This could be because the effect of reducing slurry catalyst concentration was countered by the increase in the process severity during Period 7. In any case, further increase in the asphaltenes and preasphaltene contents of the PFL was observed (Figure 2.6.9). This could be attributable to both the reduced slurry catalyst concentration and further deactivation of the second stage supported catalyst.

\subsection{Effect of CAS Bottoms Ashy Recycle:}

One of the variables studied during CMSL- 6 was the ashy recycle. It is generally believed that the recycled slurry catalyst that results from the insitu sulfidation of the precursor that has remained in the reactor for a while, is more active than the fresh precursor/freshly presulfided catalyst. The amount of recycled slurry catalyst in the system during CMSL- 6 was controlled by varying the amount of the ashy CAS bottoms recycled. As shown in Table 2.6.10 and Figure 2.6.11, the amount of the CAS bottoms recycled was varied between 25 and $50 \mathrm{~W} \%$ of the total CAS bottoms production rate. No apparent effect on the process performance was observed due to this change (Figure 2.6.10), although the recycle oil became increasingly heavier at higher $(50 \mathrm{~W} \%)$ recycle of the CAS bottoms.

\subsection{Effect of Reaction Severity:}

CMSL-6 was conducted in a high-low temperature mode of operation. As indicated in Table 2.6.2 and Figures 2.6.2 and 2.6.3, the reaction severity was low at the beginning. It was increased in Condition 2 (Period 7). Not much of an impact was observed of changing the severity; it only eased the recycle operation a little in Condition 2. An alternate low-high temperature mode of operation at equivalent total process severity should be investigated in the future.

\subsection{Comparison Of Performance Of Different Dispersed Slurry Catalysts}

One of the goals of this bench run, CMSL-6, was to obtain process performance data for the activity of sulfated iron-molybdenum slurry catalysts and compare it with some of the other dispersed catalysts tested earlier at the bench scale at HTI. A list of HTI bench runs that were conducted using iron and/or molybdenum based slurry catalysts and a Black Thunder subbituminous coal, is given Table 2.6.11. As seen from this Table, the slurry catalysts ranged from a powdered iron oxide/pyrrhotite to a coal-impregnated form of iron oxyhydroxide. These 
bench runs used partially deactivated or fresh Ni-Mo/Alumina supported catalysts either in stage $\mathrm{K}-2$ alone or in both reactor stages in some cases.

Table 2.6.12 summarizes the operating conditions during different bench runs that have been chosen for comparisons of the process performance with different slurry catalysts. The bench run CMSL-6, as compared to other bench runs in this Table, seems to have a higher relative severity, although the second stage catalyst age is also higher (i.e., the catalyst is more deactivated) for CMSL-6. Specific operating periods from bench runs CC-1 and CC-15 were chosen so that catalytic/catalytic and thermal/catalytic configurations can also be compared on the same basis. The bench run CC-15, during most of its operation, had used about $5000 \mathrm{ppm}$ of impregnated iron as slurry catalyst precursor, while the bench run CMSL-1 had used either ammonium heptamolybdate (AHM) alone, as a molybdenum precursor, or both impregnated $\mathrm{FeOOH}$ and AHM (at $5000 \mathrm{ppm} \mathrm{Fe}$ and $300 \mathrm{ppm}$ Mo relative to coal). Note that CMSL-6, which employed $\mathrm{Mo} / \mathrm{FeOOH} / \mathrm{SO}_{4}$ as dispersed catalyst, used only $100 \mathrm{ppm}$ Mo and $615 \mathrm{ppm}$ Fe relative to feed coal. As noted at the bottom of this Table, due to the recycle of the ashy CAS bottoms to the feed slurry, the effective steady-state concentration of catalyst was about $892 \mathrm{ppm} \mathrm{Fe}$ and $145 \mathrm{ppm}$ Mo relative to coal. Thus, these catalysts concentrations are the lowest for both iron and molybdenum employed in the HTI bench testing so far.

The actual process performance comparison, listed in Table 2.6.13, indicates that the highest total coal conversions were obtained for both reactor stages during the CMSL- 6 bench run. The resid conversion was also on the high side of the range, and the distillate yield was higher under comparable operating conditions. The hydrogen consumption, in spite of high hydrocarbon gas yield (due to higher reaction severity), was in the same range as the other bench runs. This comparison definitely attests to the superiority of the sulfated ironmolybdenum slurry catalysts over the other slurry catalysts shown in the Table. In order to further establish their activity for subbituminous coal liquefaction, an alternate low-high reactor temperature mode of operation should be tested. Also important will be the testing of another slurry catalyst precursor such as Molyvan-L, an oil-soluble compound, in the same bench run as the sulfated slurry catalyst; this will render a one-to-one comparison of the activities of these two catalytic systems for coal liquefaction possible.

\subsection{Evaluation Of Performance Of Different First Stage Catalysts---Part I}

\section{First Stage Catalyst Performance Comparison:}

To study the relative performance of different first stage catalyst additives, the product yields, conversion and hydrogen consumption data for a few selected periods of the Runs 227-75 (CC15), 227-77 (CMSL-1) and 227-55 (CC-1)were compared. All these runs used subbituminous coal from the Black Thunder Mine. They also used Shell S-317 1/32" extrudate Ni-Mo catalyst in the second stage. However, they used different catalysts in the first stage. Run 227-77 (CMSL-1) used molybdenum additive with or without predispersed iron catalysts in the first stage. Run 227-75 used predispersed iron catalyst or no catalyst in the first stage. Run 227-75 used Shell S-317 Ni-Mo catalyst extrudates in both stages.

Because of the variation in operating conditions and catalyst age in the selected periods of these runs, their product yield and conversion data cannot give a clear picture of the effects of 
different first stage catalysts on process performance. It is necessary to compare the results of these runs with those of standard case projected runs at those operating conditions in order to determine the relative performance of the first stage catalyst additives.

Coal liquefaction performance using Shell S-317 Ni-Mo 1/32" extrudate catalysts in both stages and Black Thunder Mine subbituminous coal as feed was chosen as the standard case for comparison with the performance of the selected runs.

Using earlier experimental data and correlations, a simulation computer program was developed at HTI to make projection for product yields, conversion, and hydrogen consumption in two stage coal liquefaction process using Shell S-317 1/32" extrudate Ni/Mo catalysts in both stages. This simulation program was utilized to project the process performance of the standard case at the operating conditions and catalyst age of the selected runs mentioned earlier.

These projected data are compared with the actual process performance data for a few selected periods of these runs. The difference $\left(D^{*}=\right.$ actual - projected for CTSL with extrudate catalyst in both stages) of actual and projected yields, conversion, and hydrogen consumption data for different selected periods will compare the performance of different first stage catalysts with the selected standard.

In order to verify the accuracy of the simulation program, projections for three standard cases are compared with the actual experimental results from Runs 227-55-6, 227-55-15, and 227-55-16 using Shell S-317 extrudate catalyst in both stages. Runs 227-55-15 and 227-55-16 had topped separator bottom recycle operation. The $D^{*}$ values for these runs are presented in the following Table:

$\begin{array}{lccc} & \begin{array}{c}\text { Run 227-55-6 } \\ \mathrm{D}^{*}\end{array} & \begin{array}{c}\text { Run 227-55-15 } \\ \mathrm{D}^{*}\end{array} & \begin{array}{c}\text { Run 227-55-16 } \\ \mathrm{D}^{*}\end{array} \\ & & & \\ \mathrm{C}_{4}-524^{\circ} \mathrm{C}, \mathrm{W} \% \mathrm{MAF} & -0.86 & 2.26 & -2.1 \\ \text { Coal Conversion, W\% MAF } & -0.14 & 1.03 & 0.78 \\ \text { Resid, W\% MF } & 0.43 & -0.06 & -0.54 \\ \mathrm{C}_{1}-\mathrm{C}_{3}, \mathrm{~W} \% \mathrm{MF} & 0.18 & -0.54 & 1.06 \\ \mathrm{C}_{4}-199^{\circ} \mathrm{C}, \mathrm{W} \% \mathrm{MF} & -1.77 & -1.61 & -2.03 \\ 199-524^{\circ} \mathrm{C}, \mathrm{W} \% \mathrm{MF} & 1.82 & 3.7 & 0.06 \\ \text { Hydrogen Consumption, W\% MF } & 0.19 & 0.00 & 0.32\end{array}$

The $\mathrm{D}^{*}$ values for Run 227-55 show an excellent agreement between actual and projected data considering accuracy range of experimental data. The $\mathrm{D}^{*}$ for coal conversion, $\mathrm{C}_{4}-524^{\circ} \mathrm{C}$ yield, hydrogen consumption, $\mathrm{C}_{1}-\mathrm{C}_{3}$ gas yield, and resid yield are all within $+1 \mathrm{~W} \%$ range. The $\mathrm{D}^{*}$ for $\mathrm{C}_{4}-199^{\circ} \mathrm{C}$ and $199-524^{\circ} \mathrm{C}$ liquid product yields are in the $+2 \mathrm{~W} \%$ range.

The $\mathrm{D}^{*}$ values for Run 227-55-15 and 227-55-16 also show good agreement between actual and projected values. The $D^{*}$ data for coal conversion, hydrogen consumption, $\mathrm{C}_{1}-\mathrm{C}_{3}$ gas yield and resid yield are all within $+1 \mathrm{~W} \%$ range. The $\mathrm{D}^{*}$ data for $\mathrm{C}_{4}-524^{\circ} \mathrm{C}$ yield are within $+2.3 \mathrm{~W} \%$ range. 
Similar comparison was made for Run 227-75-11T using no catalyst in the first stage and Shell S317 extrudate catalyst in the second stage. The only purpose for this comparison was to determine the effect of reactor volume occupied by the extrudates on coal conversion. Because of the volume occupied by the extrudate catalysts, the projected case has less residence time in the reactor resulting in lower coal conversion. Reaction kinetic estimate shows that coal conversion can be lower by $2.0 \mathrm{~W} \%$ due to this effect. However, the $\mathrm{D}^{*}$ for coal conversion was $4.06 \mathrm{~W} \%$. The $\mathrm{D}^{*}$ of $4.0 \mathrm{~W} \%$ will be selected as standard for the case of first stage not using extrudate catalyst.

Run 227-75-14T used predispersed iron catalyst in the first stage and Shell S-317 catalyst in the second stage and the Run 227-77-14T (CMSL-1) used molybdenum slurry catalyst in the first stage and Shell S317 catalyst in the second stage. The $D^{*}$ values for these runs compare the relative performance of iron catalyst and molybdenum catalyst in the first stage for the two stage coal liquefaction process.

For the convenience of discussion, the relevant $\mathrm{D}^{*}$ values for the iron-case and for the molybdenum-case are presented below:

$$
\mathrm{D}^{*} \text { For Fe-Case } \quad \mathrm{D}^{*} \text { For Mo-Case }
$$

$\begin{array}{lrr}\mathrm{C}_{4}-524^{\circ} \mathrm{C}, \mathrm{W} \% \mathrm{MAF} & -2.18 & -1.58 \\ \text { Coal Conversion, W\% MAF } & 6.96 & 5.86 \\ \text { Resid, W\% MF } & 5.05 & 1.18 \\ \mathrm{C}_{1}-\mathrm{C}_{3}, \mathrm{~W} \% \mathrm{MF} & 1.74 & 2.58 \\ \mathrm{C}_{4}-199^{\circ} \mathrm{C}, \mathrm{W} \% \mathrm{MF} & -4.18 & 0.15 \\ 199-524^{\circ} \mathrm{C}, \mathrm{W} \% \mathrm{MF} & 2.15 & -1.63 \\ \text { Hydrogen Consumption, W\% } & 0.7 & 1.24\end{array}$

The above table shows that coal conversions are significantly higher in both Fe-case and Mo-case than those in the standard case. Taking into consideration of reactor volume effect, at least $2-3 \mathrm{~W} \%$ of coal conversion can be credited to the effect of dispersed iron and molybdenum catalysts. These results indicate that the intimate contact of catalyst active sites and coal molecules does enhance coal conversion.

The $\mathrm{C}_{4}-524^{\circ} \mathrm{C}$ distillate yield is $1-2 \mathrm{~W} \%$ lower than the standard case due to high resid yield and $\mathrm{C}_{1}-\mathrm{C}_{3}$ gas yield in iron and molybdenum catalyst cases. Hydrogen consumptions in these two case are approximately $1 \mathrm{~W} \%$ higher than the standard case. It appears that although more coal is converted in Fe-case and Mo-case, the converted coal ends up in the resid and gas yields.

The above comparison shows that beside coal conversion, the performance of the iron catalyst or molybdenum catalyst in the first stage are not in any respect better than that of the standard case. In overall performance, the standard case appears to be somewhat superior to the Fe-case or Mo-case. 
Relative comparison of the Fe-case with the Mo-case shows that relative coal conversion is slightly higher for the Fe-case, but resid yield is significantly lower in the Mo-case and relative $\mathrm{C}_{4}-524^{\circ} \mathrm{C}$ distillate yield slightly lower in the Fe-case. The Fe-case has lower $\mathrm{C}_{4}-199^{\circ} \mathrm{C}$ light distillate yield but higher $199-524^{\circ} \mathrm{C}$ heavy distillate yield than the standard case. The Mo-case has higher relative $\mathrm{C}_{4}-199^{\circ} \mathrm{C}$ light distillate yield and lower $199-524^{\circ} \mathrm{C}$ heavy distillate yield. The relative $C_{1}-C_{3}$ gas yield is slightly higher for the Mo-case than that for the Fe-case.

In overall performance comparison, the Mo-case is slightly better than the Fe-case particularly in terms of resid conversion and light distillate yield.

Run 227-75-8T used predispersed iron catalyst in the first stage and Shell S317 catalyst in the second stage, and the Run 227-77-7T (CMSL-1) used molybdenum slurry catalyst as well as predispersed iron catalyst in the first stage and Shell S-317 catalyst in the second stage. The D* values for these runs will compare the relative performance of iron/moly catalyst (Fe-Mo Case) catalyst and iron catalyst (Fe Case) in the first stage for the two stage coal liquefaction process. For the convenience of discussion, the relevant $\mathrm{D}^{*}$ values for $\mathrm{Fe}-\mathrm{Mo}-\mathrm{Case}$ and $\mathrm{Fe}-\mathrm{Case}$ are presented below:

$$
\text { D* For Fe-Mo-Case } \quad D^{*} \text { For Fe-Case }
$$

$\begin{array}{lrr}\mathrm{C}_{4}-524^{\circ} \mathrm{C}, \mathrm{W} \% \mathrm{MAF} & -0.64 & 0.72 \\ \text { Coal Conversion, W\% MAF } & 8.02 & 6.17 \\ \text { Resid, W\% MF } & 1.94 & 3.18 \\ \mathrm{C}_{1}-\mathrm{C}_{3}, \mathrm{~W} \% \mathrm{MF} & 2.44 & 1.69 \\ \mathrm{C}_{4}-199^{\circ} \mathrm{C}, \mathrm{W} \% \mathrm{MF} & 0.30 & -3.03 \\ 199-524^{\circ} \mathrm{C}, \mathrm{W} \% \mathrm{MF} & -1.17 & 3.68 \\ \mathrm{H}_{2} \mathrm{O}, \mathrm{W} \% \mathrm{MF} & 2.36 & -0.97 \\ \text { Hydrogen Consumption, W\% } & 0.94 & 1.02\end{array}$

The above table shows that coal conversions are significantly higher in both Fe-Mo-Case and Fe-case than that in the standard case. At least $2-4 \mathrm{~W} \%$ of coal conversion can be credited to the effects of Fe-Mo and Fe catalysts in the first stage. The $\mathrm{C}_{4}-524^{\circ} \mathrm{C}$ distillate yields are more or less equivalent in all cases considering experimental uncertainty.

Resid yield and gas yield are higher in both Fe-Mo-case and Fe-Case than those in the standard case. Hydrogen consumptions are also higher for Fe-Mo-Case and Fe-Case than that in the standard case.

The above comparison shows that beside coal conversion, the performance of the Fe-Mo-Case or Fe-Case are not in any respect superior to that of the standard case. Relative comparison of the Fe-Mo-Case with the Fe-Case shows that resid yield and $199-524^{\circ} \mathrm{C}$ heavy distillate yield are higher for the Fe-case, and $\mathrm{C}_{4}-199^{\circ} \mathrm{C}$ light distillate yield and $\mathrm{C}_{1}-\mathrm{C}_{3}$ gas yields are higher for the Fe-Mo-Case. Water yield is almost 3.3 W\% higher for the FE-Mo-Case than that for the $\mathrm{Fe}-\mathrm{Case}$, which is possibly not truly the case. 
Apparently, the overall performance of these two cases are not significantly different from each other. It appears that the presence of molybdenum catalyst in the first stage improves resid conversion and light distillate yield. Considering higher coal conversion and higher resid conversion for the Fe-Mo-Case, the overall performance of the Fe-Mo-Case is somewhat superior to the Fe-Case.

Run 227-75-5T used predispersed iron catalyst in the first stage and Shell S317 catalyst in the second stage, and the Run $227-77-5 \mathrm{~T}$ used molybdenum slurry catalyst as well as predispersed iron catalyst in the first stage and Shell S317 catalyst in the second stage. The $\mathrm{D}^{*}$ values for these runs will compare the relative performance of iron-molybdenum (Fe-Mo-Case) catalyst and iron (Fe-Case) catalyst in the first stage for the two stage coal liquefaction process. For the convenience of discussion, the relevant $\mathrm{D}^{*}$ values for Fe-Case and Fe-Mo-Case are presented below:

$\mathrm{C}_{4}-524^{\circ} \mathrm{C}, \mathrm{W} \% \mathrm{MAF}$

Coal Conversion, W\% MAF

Resid, W\% MF

$\mathrm{C}_{1}-\mathrm{C}_{3}, \mathrm{~W} \% \mathrm{MF}$

$\mathrm{C}_{4}-199^{\circ} \mathrm{C}, \mathrm{W} \% \mathrm{MF}$

$199-524^{\circ} \mathrm{C}, \mathrm{W} \% \mathrm{MF}$

Water, W\% MF

Hydrogen Consumption, W\%

$\begin{array}{cc}\mathrm{D}^{*} \text { For Fe-Case } & \mathrm{D}^{*} \text { For Fe-Mo-Case } \\ 2.2 & -0.76 \\ 7.11 & 6.84 \\ 2.93 & 1.34 \\ 1.74 & 1.32 \\ -2.6 & 0.30 \\ 4.68 & -0.99 \\ -1.75 & 2.83 \\ 1.26 & 0.74\end{array}$

The coal conversion, hydrogen consumption, resid yield, and $C_{1}-C_{3}$ gas yield are higher for the Fe-Case and Fe-Mo-Case than those for the standard case. $\mathrm{C}_{4}-524^{\circ} \mathrm{C}$ distillate yield is higher for the Fe-Case than those for the Fe-Mo-Case and the standard case. However, the difference in distillate yield is still within the experimental uncertainty range. Beside coal conversion, the overall performance of the Fe-Case and Fe-Mo-Case are not in anyway better than that of the standard case.

Relative comparison of the Fe-Case with the Fe-Mo-Case shows that relative $\mathrm{C}_{4}-524^{\circ} \mathrm{C}$ yield, resid yield, and hydrogen consumption are higher for the $\mathrm{Fe}-\mathrm{Case}$ than those for the $\mathrm{Fe}-\mathrm{Mo}$ Case. In Fe-Mo-Case, the resid yield is lower and $\mathrm{C}_{4}-199^{\circ} \mathrm{C}$ distillate yield is higher. Again, the presence of molybdenum catalyst in the first stage seem to improve the resid conversion and light distillate yield. Again, the water yield for the Fe-Mo-Case is almost $5 \mathrm{~W} \%$ higher than that for the Fe-Case, which is eliminating the beneficial effects of the Fe-Mo-Case. The overall performance of these two cases are not significantly different from each other.

\subsection{Conclusion}

1. The Fe-Case, Mo-Case, and Fe-Mo-Case have at least 2-4 W\% higher coal conversion than that for the standard case.

2. The hydrogen consumption, $\mathrm{C}_{1}-\mathrm{C}_{3}$ gas yields and resid yield are lower for the standard case than those for the Fe-Case, Mo-Case, and Fe-Mo-Case. 
3. In terms of distillate yield and hydrogen consumption, these cases are not in any respect superior to the standard case.

4. The presence of molybdenum catalyst in the first stage seems to improve resid conversion and $\mathrm{C}_{4}-199^{\circ} \mathrm{C}$ distillate yield.

5. The Fe-Case has higher resid yield and $199-524^{\circ} \mathrm{C}$ yield than the Mo-Case. The Mo-Case has higher $\mathrm{C}_{4}-199^{\circ} \mathrm{C}$ distillate yield than the $\mathrm{Fe}$-Case. In terms of $\mathrm{C}_{4}-524^{\circ} \mathrm{C}$ distillate yield and hydrogen consumption, the performance of these two cases are not significantly different from each other.

6. The performance of Fe-Case and Fe-Mo-case are more or less equivalent except that the presence of molybdenum in the first stage improves resid conversion and $\mathrm{C}_{4}-199^{\circ} \mathrm{C}$ distillate yield. High apparent water yield in Fe-Mo-Case is eliminating the beneficial effects of this case.

7. The overall performance of the Fe-Case, Mo-Case, and Fe-Mo-Case are not significantly different from each other. Beside coal conversion, the overall performance of these cases are not in any respect superior to the standard case.

\subsection{Evaluation Of Performance Of Different First Stage Catalysts--Part II}

\section{ASB Recycle And Dispersed First Stage Catalysts}

The Run 227-83 (CMSL-6) with ASB recycle used Fe/Mo dispersed catalyst in the first stage and partially deactivated Shell 317 extrudate catalyst in the second stage with Black Thunder Mine subbituminous coal. The $\mathrm{D}^{*}$ values in the first column of the following Table represent the difference in values between the actual case of Run 227-83-12/13 and the standard projected case for conditions of Run 227-83-12/13.

$\begin{array}{lcc}\text { W\% MAF } & \mathrm{D}^{*} & \begin{array}{c}\mathrm{D}^{*} \\ \text { (Forced Carbon Balance) }\end{array} \\ \mathrm{C}_{1}-\mathrm{C}_{3} & 2.28 & 1.87 \\ \mathrm{C}_{4}-199^{\circ} \mathrm{C} & -10.51 & -11.52 \\ 199-524^{\circ} \mathrm{C} & 13.31 & 10.49 \\ \mathrm{H}_{2} \mathrm{O} & -8.29 & -4.11 \\ \mathrm{CO}_{\mathrm{x}} & 4.11 & 3.93 \\ \mathrm{NH}_{3} & 0.32 & 0.32 \\ \mathrm{H}_{2} \mathrm{~S} & -0.08 & -0.08 \\ \text { Resid } & 0.54 & 0.84 \\ \text { Unc. Coal } & -2.03 & -2.03 \\ \mathrm{C}_{4}-524^{\circ} \mathrm{C} & 2.82 & -0.45 \\ \mathrm{H}_{2} \text { Consumption } & -0.32 & -0.29 \\ \text { Coal Conversion } & 2.02 & 2.02\end{array}$


The appreciable differences in $\mathrm{H}_{2} \mathrm{O}$ and $\mathrm{CO}_{\mathrm{x}}$ yields are noteworthy. Consideration of carbon and oxygen contents indicates a possible error in collected, and normalized, water yields. The forced carbon balanced yields in the second column show the impact of this factor. The $\mathrm{D}^{*}$ values for the carbon balanced case will be used in this discussion.

It appears that due to the effect of ASB recycle, the significant difference ( 4 to $8 \mathrm{~W} \%$ ) in coal conversion as observed for earlier runs that used catalyst additives has narrowed down to only $2 \mathrm{~W} \%$. However, this difference is principally due to the increase in conversion in the standard operation because of ASB recycle. The use of ASB recycle in Run 227-83-12/13 caused at most a small increase in conversion compared to the other runs that used catalyst additives in place of extrudate catalysts in the first stage.

The standard case has higher resid conversion, higher light distillate yield, and lower heavy distillate yield compared to the Run 227-83 case. The standard case appear to have higher catalytic hydrocracking activity than the Run $227-83$ case.

In terms of total distillate yield, the overall performance of the projected standard case is somewhat superior to that of the Run $227-83$ case, although Run $227-83$ case has $2 \mathrm{Wt} \%$ higher coal conversion.

For the purpose of comparing the results of Run 227-83 with the results of earlier runs using dispersed $\mathrm{Fe} / \mathrm{Mo}$ and $\mathrm{Fe}$ catalysts in the first stage, the following table presents the $\mathrm{D}^{*}$ values for these cases.

$\begin{array}{lcccc} & \mathrm{D}^{*} & & & \\ & 227-83-12 / 13 \mathrm{~T} & \mathrm{D}^{*} & \mathrm{D}^{*} & \mathrm{D}^{*} \\ \mathrm{~W} \% \mathrm{MAF} & \begin{array}{c}\text { Fe/Mo Catalyst } \\ \text { (Carbon Balanced) }\end{array} & \begin{array}{c}227-77-7 \mathrm{~T} \\ \text { Fe/Mo Cat. }\end{array} & \begin{array}{c}\text { 227-75-8T } \\ \text { Fe Catalyst }\end{array} & \begin{array}{c}\text { 227-77-5T } \\ \text { Fe/Mo Cat. }\end{array} \\ \mathrm{C}_{1}-\mathrm{C}_{3} & 1.87 & 2.59 & 1.8 & 1.40 \\ \mathrm{C}_{4}-199^{\circ} \mathrm{C} & -11.52 & 0.32 & -3.22 & 0.32 \\ 199-524^{\circ} \mathrm{C} & 10.49 & -1.24 & 3.92 & -1.05 \\ \mathrm{H}_{2} \mathrm{O} & -4.11 & 2.51 & -1.0 & 3.0 \\ \mathrm{CO}_{\mathrm{x}} & 3.93 & 1.31 & 0.87 & 0.91 \\ \mathrm{NH}_{3} & 0.32 & 2.21 & 2.01 & 2.15 \\ \mathrm{H}_{2} \mathrm{~S} & -0.08 & -0.63 & -0.49 & -0.61 \\ \text { Resid } & 0.84 & 2.06 & 3.38 & 1.42 \\ \text { Unc. Coal } & -2.03 & -8.06 & -6.15 & -6.78 \\ \mathrm{C}_{4}-524^{\circ} \mathrm{C} & -0.45 & -0.64 & 0.72 & -0.76 \\ \mathrm{H}_{2} & -0.29 & 1.0 & 1.09 & 0.79 \\ \text { Consmp. } & 2.02 & 8.02 & 6.17 & 6.84 \\ \text { Coal Conv. } & 94.0 & 93.4 & 92.7 & 94.0\end{array}$

A comparison of the data in this table leads to the following comments. 
a) With ASB recycle and the first stage catalyst additive in Run $227-83-12 / 13$, the $\mathrm{D}^{*}$ value for coal conversion was only $2 \mathrm{~W} \%$ compared to 6 to $8 \mathrm{~W} \%$ in earlier similar runs without ASB recycle.

The actual coal conversion value for Run 227-83-12/13 was generally higher than the other cases. It appears that ASB recycle in this case may have had a small contribution to coal conversion, at the high levels of conversions.

b) The Run 227-83 case has higher heavy distillate yield and lower light distillate yield compared to the earlier cases.

c) The $\mathrm{H}_{2} \mathrm{O}$ yield is much lower and $\mathrm{CO}_{x}$ yield much higher in Run 227-83 case than those in earlier cases.

d) $C_{1}-C_{3}$ gas yields are more or less equivalent.

e) The $\mathrm{C}_{4}-524^{\circ} \mathrm{C}$ yield in Run $227-83$ case is more or less equivalent to the earlier cases.

f) Hydrogen consumption is approximately $1 \mathrm{~W} \%$ lower due to low yield of light distillates.

g) Overall performance of the Run 227-83 case is nominally inferior to that of the other cases, primarily because of the low light-distillate yield, which would require a higher cost for downstream processing. 


\subsection{Bench Unit Description:}

CMSL-6 involved two equal volume backmixed reactors. The first stage reactor $\mathrm{K}-1$ had no supported catalyst bed but employed a thermally backmixed reactor with a slurry catalyst added to it. The second stage reactor was an ebullated bed of supported Ni-Mo extrudate catalyst which was recharged after use in Run CMSL-04. Other key features of this run were the use of ashy-recycle mode of operation and the in-line hydrotreating of light products (distillates) from the process (Figure 2.6.11).

\subsection{Operating Summary}

An in-line hydrotreater was employed during this run to treat atmospheric still overhead and separator overhead products. No interstage product separator was utilized in this run. For the first run condition, overall severity was low as reactors $\mathrm{K}-1$ and $\mathrm{K}-2$ operated at $441^{\circ} \mathrm{C}$ and $427^{\circ} \mathrm{C}\left(800\right.$ and $\left.775^{\circ} \mathrm{F}\right)$, respectively. The process thermal severity was increased in Condition 2 (Period 7 onwards) to enhance overall resid conversion levels [K-1 and $\mathrm{K}-2$ to $441^{\circ} \mathrm{C}$ and $427^{\circ} \mathrm{C}\left(825^{\circ} \mathrm{F}\right.$ and $\left.800^{\circ} \mathrm{F}\right)$, respectively]. The main variables investigated during this bench run, besides the process severity, were fresh and recycle concentration of the slurry catalyst and the amount of ashy recycle. The freshly added slurry catalyst concentration was varied from about 100 to $700 \mathrm{ppm} \mathrm{Mo}$ and 615 to $4300 \mathrm{ppm}$ Fe relative to coal. By altering the atmospheric still bottoms recycle rate, the total slurry catalyst in the system (fresh plus recycled) was changed between about $140-1030$ ppm Mo and 860-6345 ppm Fe relative to coal. The second stage reactor had a partially deactivated Shell S-317 catalyst (initial age $=520$ $\mathrm{kg}$-coal $/ \mathrm{kg}$-catalyst) to make the effects of the slurry catalyst more apparent and to attain a realistic equilibrium catalyst age sooner.

The high viscosity of the product filtered liquid slowed filtration to such a degree that filtration was abandoned for Condition 4 and recycled solvent was obtained by vacuum distillation of the reactor product slurry.

\subsection{MATERIALS USED}

\subsection{Feed Coal}

A subbituminous Wyoming Black Thunder Mine Coal (HTI-6213), the same coal that was used in the PDU 260-005 operations, was used for bench run CMSL-6 (227-83). Table 2.6.14 shows the analysis of this feed coal.

\subsection{Startup/Makeup Oil}

L-809, a hydrotreated cat cycle oil mixed with small amounts of coal-derived oil during POC-01, was used as the startup solvent for this bench run. The detailed analysis is shown in Table 2.6.14. 


\subsection{First Stage Slurry Dispersed Catalyst}

A sulfated iron oxihydroxide, promoted with molybdenum, was added with the coal/solvent slurry to reactor K-1. Hydrogen sulfide ( $3 \mathrm{~W} \%$ of coal) was being added continually to reactor $\mathrm{K}-1$ feed to maintain the activity of the iron-molybdenum based dispersed slurry catalyst. More information on this catalyst is given in the later sections.

\subsection{Supported Catalyst}

Hydrotreater: Criterion C-411 Trilobe (HTI-6135)

K-2: $\quad$ Aged Shell-317 (K-2 spent catalyst from Run CMSL-04 (Run 227-81) which was in operation for 21 days).

\subsection{Hydrotreater Catalyst}

Hydrotreater unit (HTU) was charged with a trilobe-shaped Criterion C-411 catalyst that is believed to be a Ni-Mo on alumina formulation.

\subsection{First Stage Sample}

Four first stage samples were obtained. These samples were taken immediately after the completion of each of the workup periods (Periods 5, 9, 12 and 15). 


\subsection{LABORATORY SUPPORT}

Laboratory support for CMSL- 6 consisted of synthesis, characterization, and activity testing of the sulfated iron-molybdenum type catalysts. Three different batches of sulfated Fe-Mo slurry catalysts were synthesized on a small scale in the lab. The starting materials for these slurry catalysts and their BET surface areas are listed in Table 2.6.15. As shown in this Table, these catalysts had between $1.7-2.1 \mathrm{~W} \%$ molybdenum in them. The slurry catalysts, thus prepared, were tested for their coal conversion activities using microautoclaves. Several other iron, molybdenum, and tinbased slurry catalysts were also tested for comparison. The results of these tests, with the prevailing conditions, are shown in Table 2.6.16.

Of the three Fe-Mo sulfated catalysts tested, FeMoCat II, the catalyst prepared by homogeneous coprecipitation starting with iron alum and urea, was selected for scaled-up preparation for the bench run CMSL-6. The simpler and faster preparation, coupled with the fact that the catalyst had a high surface area and good coal conversion activity, made FeMoCat II the catalyst of choice for the bench run.

This catalyst was then prepared on a bigger scale using the unit 260 slurry mix tank system. The actual preparation conditions for this catalyst turned out to be different than those employed during the smaller scale lab preparations. As a result, the final $\mathrm{Fe}-\mathrm{Mo}$ sulfated catalyst had a surface area of only $40 \mathrm{~m}^{2} / \mathrm{g}$ (as compared to about $260 \mathrm{~m}^{2} / \mathrm{g}$ for the FeMoCat II); in addition, the Mo/Fe ratio was different than expected (the final catalyst had about $7 \mathrm{~W} \%$ Mo rather than $1-2 \mathrm{~W} \%$ expected). In any case, this catalyst was tested in the microautoclave for coal conversion activity and as shown in Table 2.6.17, was found very active for both coal conversion and resid conversion reactions.

As mentioned earlier, the activity of the recycled iron-molybdenum dispersed catalyst will be studied in a series of microautoclave tests. These tests will employ the oil-free pressure filter cakes from different operating periods of CMSL- 6 as sources of dispersed catalysts and will also employ a fresh sulfated iron-molybdenum catalyst for comparisons. 


\subsection{CONCLUSIONS}

- Performance of the dispersed sulfated catalyst tested in this run was found to be either equal to or better than any other iron or molybdenum-based dispersed catalysts tested to date at HTI on the bench scale. Overall coal conversions remained between 93.5 and $94.5 \mathrm{~W} \% \mathrm{MAF}$ throughout the run, and resid conversions were between 83 and $90 \mathrm{~W} \% \mathrm{MAF}$. The distillate yields $\left(\mathrm{C}_{4}-524^{\circ} \mathrm{C}\right)$ varied between 62 and $66 \mathrm{~W} \% \mathrm{MAF}, 2-5 \%$ higher than those obtained under comparable reaction severities either during CMSL-1 or CC-15 (bench runs using the impregnated iron catalyst and with and without separately added molybdenum).

- The process performance degraded, though not significantly, upon decreasing the dispersed catalyst concentration in the feed from $700 \mathrm{ppm} \mathrm{Mo} \mathrm{(and} 4300 \mathrm{ppm} \mathrm{Fe}$ ) to about $100 \mathrm{ppm} \mathrm{Mo}$ (and $615 \mathrm{ppm} \mathrm{Fe}$ ). Coal conversion was still at $94 \%$ while resid conversion was $83 \%$ and distillate yields of $63 \%$ MAF were obtained at low catalyst concentrations.

- Even at a high process severity (Periods 8-17), gas yields were on the low side (10-12 W\% MF) and thus, overall hydrogen consumption was also low (6-7.5\% MF).

- The first stage samples showed coal conversions between 92.5 and $93.5 \mathrm{~W} \% \mathrm{MAF}$ for the first stage and a resid conversion range of 69 to $74 \mathrm{~W} \% \mathrm{MAF}$. These relatively high values were due to the activity of sulfated dispersed catalyst.

- The "recycled" catalyst, i.e., the slurry catalyst in the ashy CAS bottoms recycle was not found to have any significant impact on the overall activity of the total dispersed catalyst system (fresh+recycled together). This is based on the similar yields and conversion numbers obtained during conditions when the amount of CAS bottoms recycle was varied to vary the total amount of dispersed catalyst in the reactors to correspond to 133,166 , and $216 \%$ of the fresh catalyst added with the feed.

- The high residual oil yield and low distillate yield, when using vacuum distillate as the recycled solvent, indicates the necessity of recycling oil that has a high proportion of residual oil so as to obtain a satisfactory yield. 


\subsection{RECOMMENDATIONS FOR FUTURE WORK}

- Testing (in microautoclaves) of the "activity" for coal liquefaction of the recycled slurry catalyst should be carried out using the pressure filter cakes from the individual periods of CMSL- 6 .

- In order to provide a more solid platform for the Pilot Plant operations using a dispersed slurry catalyst, further testing of either the same sulfated catalyst or a newly synthesized batch (with high surface area and the ratio of 25 to 1 of iron to molybdenum that was originally planned) should be carried out in an alternate low-high temperature mode of CTSL operations. It would also be interesting to use in the same test run Molyvan- $\mathrm{L}$ as a precursor of molybdenum slurry catalyst. Molyvan-L, upon its decomposition under coal liquefaction conditions, is expected to disperse uniformly on the high surface area carbonaceous material (IOM) from coal (e.g., Pilot Plant Run POC-02, coal operations yielded ROSE-residue product solids with a BET surface area of about $130 \mathrm{~m}^{2} / \mathrm{g}$ ). 
TABLE 2.6.1

\section{Bench Run CMSL-6 \\ Run Plan}

Black Thunder Coal (HTI-6213: POC-02, dried to about 11\% moisture) Dispersed Fe/Mo Catalyst for Stage I; Spent Shell-317 1/32" Extrudate Catalyst (from Run 227-81-S/D K-1) for Stage II

Condition

Periods

Pressure, MPa (psig)

Feed Gas: $\quad$ Stage I

Stage II

W\% CAS Bottoms to Recy

Slurry Catalyst

(Mo/FeOOH/SO4) ppm

$\mathrm{Fe} / \mathrm{ppm}$ Mo (relative to coal)

Temperature ${ }^{\circ} \mathrm{C}$

1st Stage

2nd Stage

Hydrotreater

Space Velocity Per Stage

$\mathrm{Kg} / \mathrm{h} / \mathrm{m}^{3}$

$\mathrm{Lb} / \mathrm{h} / \mathrm{ft}^{3}$

Recycle

Additives

$\mathrm{H} 2 \mathrm{~S}$

Solvent/Coal Ratio

Effective Steady-State

Catalyst Concentration

in Reactor, W\% of Fresh Feed
1

$1-6$

2

7-9

3

10-13

4

14-17

$17.2(2,500)$

$\mathrm{H} 2$

$\mathrm{H} 2$

40

$\mathrm{H} 2$

$\mathrm{H} 2$

$\mathrm{H} 2$

$\mathrm{H} 2$

$\mathrm{H} 2$

25

$1400 / 200^{*}$

40

25

$700 / 100$

427

413

441

429

441

429

449

429

368

379

379

379

480

480

480

640

30

30

30

40

Ashy

Ashy

Ashy

Ashy

3 W\% of Dry Coal

1.2

1.3

1.3

1.3

166.66

166.66

133.33

133.33

* During Periods 1 through 3, the dispersed catalyst concentration in the feed was 700 ppm Mo and $4300 \mathrm{ppm}$ Fe relative to coal. 
TABLE 2.6 .2

\section{Process Performance During CMSL-1 vs. Operating Conditions}

\begin{tabular}{|c|c|c|c|c|c|}
\hline Condition & $1 \mathrm{~A}$ & 1B & 2 & 3 & 4 \\
\hline Period Number & $3-4$ & $5-6$ & $9-10$ & $12-13$ & $16-17$ \\
\hline Feed ppm Fe & 4300 & 1230 & 615 & 615 & 615 \\
\hline Feed ppm Mo & 700 & 200 & 100 & 100 & 100 \\
\hline $\begin{array}{l}\text { Recycle, } \mathrm{kg} / \mathrm{kg} \text { dry coal } \\
\text { Filtered Liquid } \\
\text { Vacuum Distillate } \\
\text { CAS Bottoms Ash Recycle }\end{array}$ & $\begin{array}{l}0.767 \\
0.000 \\
0.514\end{array}$ & $\begin{array}{l}0.761 \\
0.000 \\
0.492\end{array}$ & $\begin{array}{l}0.865 \\
0.000 \\
0.514\end{array}$ & $\begin{array}{l}1.056 \\
0.000 \\
0.329\end{array}$ & $\begin{array}{l}0.000 \\
0.512 \\
0.771\end{array}$ \\
\hline L-809 Make-up Oil, kg/kg dry coal & 0.000 & 0.000 & 0.000 & 0.000 & 0.390 \\
\hline Total Material Recovery, W\% & 98.71 & 98.47 & 99.86 & 99.57 & 98.36 \\
\hline Relative Severity Index & 1.00 & 0.97 & 1.28 & 1.32 & 1.34 \\
\hline \multicolumn{6}{|c|}{ ESTIMATED NORMALIZED YIELDS, W\% MAF COAL } \\
\hline $\begin{array}{l}\text { C1-C3 in Gases } \\
\text { C4-C7 in Gases } \\
\text { IBP-177 deg-C in Liquids } \\
177-260 \text { deg-C in Liquids } \\
260-343 \text { deg-C in Liquids } \\
343-454 \text { deg-C in Liquids } \\
454-524 \text { deg-C in Liquids } \\
524+ \\
\text { Unconverted Coal } \\
\text { Water } \\
\mathrm{CO}_{x} \\
\mathrm{NH3} \\
\mathrm{H} 2 \mathrm{~S}\end{array}$ & $\begin{array}{c}7.81 \\
4.21 \\
8.80 \\
11.08 \\
19.80 \\
17.24 \\
4.31 \\
8.22 \\
5.38 \\
15.17 \\
4.11 \\
1.04 \\
0.39\end{array}$ & $\begin{array}{c}8.25 \\
3.65 \\
12.20 \\
11.42 \\
14.96 \\
15.38 \\
4.75 \\
11.15 \\
5.93 \\
12.74 \\
4.51 \\
1.03 \\
0.38\end{array}$ & $\begin{array}{l}13.43 \\
6.55 \\
13.01 \\
13.74 \\
17.12 \\
10.64 \\
3.36 \\
5.67 \\
5.46 \\
9.26 \\
6.38 \\
1.06 \\
0.39\end{array}$ & $\begin{array}{c}12.79 \\
5.50 \\
11.73 \\
16.34 \\
21.42 \\
8.35 \\
2.00 \\
5.28 \\
5.99 \\
12.09 \\
5.00 \\
1.05 \\
0.35\end{array}$ & $\begin{array}{c}13.01 \\
5.40 \\
13.52 \\
13.59 \\
16.38 \\
-13.43 \\
3.04 \\
26.54 \\
6.47 \\
15.44 \\
5.84 \\
0.56 \\
0.23\end{array}$ \\
\hline \multicolumn{6}{|l|}{ PROCESS PERFORMANCE } \\
\hline Hydrogen Consumption, W\% MAF Coal & 7.55 & 7.13 & 7.96 & 7.90 & 6.62 \\
\hline $\begin{array}{l}\text { Coal Conversion, W\% MAF Coal } \\
\text { C4-524 deg-C Distillates, W\% of MAF Coal } \\
\text { C4-343 deg-C Distillates, W\% of MAF Coal } \\
524 \text { deg-C+ Conversion W\% MAF }\end{array}$ & $\begin{array}{l}94.62 \\
65.50 \\
43.89 \\
86.40\end{array}$ & $\begin{array}{l}94.07 \\
63.15 \\
42.26 \\
82.92\end{array}$ & $\begin{array}{l}94.54 \\
64.40 \\
50.42 \\
87.00\end{array}$ & $\begin{array}{l}94.00 \\
65.35 \\
54.99 \\
88.70\end{array}$ & $\begin{array}{l}93.53 \\
38.50 \\
48.59 \\
66.99\end{array}$ \\
\hline $\begin{array}{l}\text { HDS (organic) W\% } \\
\text { HDN W\% }\end{array}$ & $\begin{array}{l}99.90 \\
91.55\end{array}$ & $\begin{array}{l}99.50 \\
91.00\end{array}$ & $\begin{array}{l}99.80 \\
92.34\end{array}$ & $\begin{array}{l}98.15 \\
92.50\end{array}$ & $\begin{array}{l}98.75 \\
90.15\end{array}$ \\
\hline
\end{tabular}


TABLE 2.6.3

\begin{tabular}{|lcccc|}
\hline \multicolumn{4}{|c|}{ CMSL-6: SEPARATOR OVERHEAD (SOH) } & INSPECTION \\
\hline Unit & 227 & 227 & 227 & 227 \\
Run & 83 & 83 & 83 & 83 \\
Condition & 1 & 2 & 3 & 4 \\
Period Number & 6 & 9 & 12 & 17 \\
Gravity, API & 34.8 & 33.3 & 32.9 & 32.9 \\
IBP, deg C & 72 & 70 & 82 & 70 \\
FBP, deg C & 372 & 371 & 366 & 363 \\
ASTM D-86 Distillation, Composition & & & & \\
W\% IBP-177 deg C & 27.97 & 27.7 & 25.2 & 26.83 \\
W\% 177-260 deg C & 27.85 & 29.6 & 32.75 & 26.95 \\
W\% 260-343 deg F & 35.37 & 35.2 & 36.24 & 38.79 \\
W\% 343 deg C+ & 6.46 & 7.1 & 5.34 & 6.5 \\
W\% Loss & 2.35 & 0.4 & 0.47 & 0.93 \\
Elemental Analysis & & & & \\
Carbon, W\% & 86.38 & 86.72 & 86.71 & 86.79 \\
Hydrogen, W\% & 12.74 & 12.54 & 12.54 & 12.57 \\
Sulfur, ppm & 55.3 & 20.4 & 47.5 & 51.5 \\
Nitrogen (Antek), ppm & 14.7 & 42.7 & 18.6 & 29.8 \\
H/C RATIO & 1.77 & 1.74 & 1.74 & 1.74 \\
\hline
\end{tabular}


TABLE $\quad 2.6 .4$

\begin{tabular}{|lcccc|}
\hline \multicolumn{2}{|c|}{ CMSL-6: PROPERTIES OF THE PRESSURE } & FILTER LIQUID (2nd STAGE) \\
\hline Unit & 227 & 227 & 227 & 227 \\
Run & 83 & 83 & 83 & 83 \\
Condition & 1 & 2 & 3 & 4 \\
Period Number & 6 & 9 & 12 & $17^{* * * *}$ \\
Gravity, API & -6.5 & -7.4 & -5.1 & 3.5 \\
IBP, deg C & 305 & 296 & 266 & 266 \\
ASTM D-1160 Distillation, Composition & & & & \\
W\% IBP-343 deg C & 4.59 & 3.86 & 5.63 & 12.19 \\
W\% 343-454 deg C & 42.23 & 38.6 & 38.57 & 80 \\
W\% 454-524 deg C & 15.72 & 17.72 & 15.18 & 7.81 \\
W\% 524 deg C+ & 36.93 & 39.82 & 40.18 & 0 \\
W\% Loss & 0.53 & 0 & 0.44 & 0 \\
& & & & \\
Elemental Analysis & & & & \\
Carbon, W\% & & & & \\
Hydrogen, W\% & 89.21 & 89.61 & 90.59 & 89.32 \\
Sulfur, W\% & 8.34 & 7.21 & 7.02 & 8.29 \\
Nitrogen, W\% & 0.123 & 0.105 & 0.15 & 0.422 \\
H/C RATIO & 0.67 & 0.76 & 0.82 & 0.88 \\
CCR, W\% PFL & 1.12 & 0.97 & 0.93 & 1.11 \\
CYCLOHEXANE INSOLUBLES, W\% & 14.9 & 30.62 & 34 & N/A \\
TOLUENE INSOLUBLES, W\% & 2.24 & 9.41 & 10.6 & N/A \\
\hline
\end{tabular}

**** Period 17: Analysis of the VSOH is listed instead of the PFL as Vacuum Still was used for solid separation. 
TABLE 2.6.5

\begin{tabular}{|c|c|c|c|c|}
\hline \multicolumn{5}{|c|}{ CMSL-6: INSPECTION OF THE PRESSURE FILTER SOLIDS (2nd STAGE) } \\
\hline Unit & 227 & 227 & 227 & 227 \\
\hline Run & 83 & 83 & 83 & 83 \\
\hline Condition & 1 & 2 & 3 & 4 \\
\hline Period Number & 6 & 9 & 12 & $17^{* * * *}$ \\
\hline \multicolumn{5}{|l|}{ Elemental Analysis } \\
\hline Carbon, W\% & 61.7 & 61.07 & 61.65 & 68.25 \\
\hline Hydrogen, W\% & 4.65 & 4.04 & 3.87 & 5.39 \\
\hline Sulfur, W\% & 1.43 & 1.36 & 1.32 & 1.12 \\
\hline Nitrogen (Antek), W\% & 0.55 & 0.57 & 0.62 & 0.74 \\
\hline H/C RATIO & 0.89 & 0.79 & 0.75 & 0.95 \\
\hline \multicolumn{5}{|l|}{ Composition, W\% } \\
\hline Ash (Quinoline Filtration) & 27.25 & 26.33 & 27.7 & 12.31 \\
\hline ASTM Ash, W\% & 27.9 & 27.08 & 28.59 & 13.29 \\
\hline $\mathrm{S}$ in Ash, W\% & 4.63 & 4.08 & 3.72 & 2.01 \\
\hline Unconverted Coal (Adj.) & 27.79 & 24.54 & 26.86 & 13.4 \\
\hline
\end{tabular}

**** Vacuum still was used as the means of solid separation during Period 17. 
TABLE 2.6.6(a)

DETAILED ANALYSES OF TBP FRACTIONS

Run No. 227-83 Period No. 6 CMSL-6

TBP Distillation \%

$\mathrm{IBP}=53^{\circ} \mathrm{C} \quad \mathrm{EP}=408^{\circ} \mathrm{C}$

IBP $-177^{\circ} \mathrm{C}$
$177-260^{\circ} \mathrm{C}$
$260-343^{\circ} \mathrm{C}$
$343^{\circ} \mathrm{C}^{+}$

TBP FRACTION $\left[{ }^{\circ} \mathrm{C}\right]$

API Gravity

Elemental Analysis [W\%]

Carbon

Hydrogen

Sulfur, ppm

Antek N, ppm

Bromine No. $[\mathrm{g} / \mathrm{l00 \textrm {g }}]$

Aniline Point, $\left[{ }^{\circ} \mathrm{C}\right]$

Flash Point, $\left[{ }^{\circ} \mathrm{C}\right]$

PONA [V\%]

Paraffins

Olefins

Naphtenics

Aromatics
85.60

14.28

9.7

$<1.0$

1.71

43

$<-7$

21.58

0.30

70.62

7.50
W\%

33.67

40.28

19.88

6.17

$\underline{177-260}$

$\underline{260-343}$

$343+$

28.7

21.1

22.7

87.58

12.58

11.7

16.9

88.08

87.83

12.11

12.27

570

N/A

1.36

1.15

44

154

57

9.26

3.90

49.74

37.10

Aromatics (ASTM D2549)

47.25

41.24 
TABLE 2.6.6(b)

\section{DETAILED ANALYSIS OF TBP FRACTIONS}

Run No. 227 - 83 Period No.9 CMSL-6

TBP Distillation \%

$$
\begin{aligned}
& \text { IBP }-177^{\circ} \mathrm{C} \\
& 177-260^{\circ} \mathrm{C} \\
& 260-343^{\circ} \mathrm{C} \\
& 343^{\circ} \mathrm{C}^{+}
\end{aligned}
$$

TBP FRACTION $\left[{ }^{\circ} \mathrm{C}\right]$

API Gravity

Elemental Analysis [W\%]

$$
\text { Carbon }
$$

Hydrogen

Sulfur, ppm

Antek N, ppm

Bromine No. $[\mathrm{g} / 100 \mathrm{~g}]$

Aniline Point, $\left[{ }^{\circ} \mathrm{C}\right]$

Flash Point, $\left[{ }^{\circ} \mathrm{C}\right]$

PONA [V\%]

Paraffins

Olefins

Naphthenics

Aromatics

Aromatics (ASTM D2549)

$$
\begin{array}{r}
\mathrm{IBP}=74^{\circ} \mathrm{C} \quad \mathrm{EP}=432^{\circ} \mathrm{C} \\
\mathrm{W} \% \\
\hline 30.35 \\
47.17 \\
18.40 \\
4.08
\end{array}
$$

$\begin{array}{cccc}\underline{\text { IBP }-177} & \frac{177-260}{28.6} & \frac{260-343}{19.5} & \underline{343+} \\ 52.6 & 22.3 & 19.5 & 2.8\end{array}$

85.61

87.71

87.55

87.40

$11.51 \quad 12.06$

$10.8 \quad 140$

$38.9 \quad$ N/A

21.7

N/A

N/A

42

30

37

$<-7$

71

160

23.22

10.77

0.40

3.00

48.04

40.89

7.20

58.23

44.73 
TABLE 2.6.6(c)

\section{DETAILED ANALYSES OF TBP FRACTIONS \\ Run No. 227 - 83 Period No. 12 CMSL-6}

TBP Distillation \%

$$
\begin{array}{r}
\mathrm{IBP}=54^{\circ} \mathrm{C} \quad \mathrm{EP}=426^{\circ} \mathrm{C} \\
\frac{\mathrm{W} \%}{27.88} \\
49.95 \\
17.50 \\
4.67
\end{array}
$$

IBP $-177^{\circ} \mathrm{C}$

$177-260^{\circ} \mathrm{C}$

$260-343^{\circ} \mathrm{C}$

$343^{\circ} \mathrm{C}^{+}$

TBP FRACTION $\left[{ }^{\circ} \mathrm{C}\right]$

API Gravity

Elemental Analysis [W\%]

Carbon

Hydrogen

Sulfur, ppm

Antek N, ppm

Bromine No. $[\mathrm{g} / 100 \mathrm{~g}]$

Aniline Point, $\left[{ }^{\circ} \mathrm{C}\right]$

Flash Point, $\left[{ }^{\circ} \mathrm{C}\right]$

PONA [V\%]

Paraffins

Olefins

Naphthenics

Aromatics

Aromatics (ASTM D2549)

$\begin{array}{lccc}\frac{\text { IBP }-177}{50.9} & \frac{177-260}{28.4} & \frac{260-343}{20.8} & \underline{343+} \\ 22.8\end{array}$

85.47

14.23

$<1.0$

$<1.0$

87.95

12.51

7.80

1.9

N/A

N/A

32

76

88.05

88.03

11.83

13.30

14.4

12.20

160

N/A

N/A

42

$<-7$

21.56

11.42

0.20

2.40

43.79

42.39 
TABLE 2.6.6(d)

\section{DETAILED ANALYSES OF TBP FRACTIONS \\ Run 0. 227 - 883 Period No. 17 CMSL-6}

TBP Distillation \%

$$
\begin{aligned}
& \text { IBP }-177^{\circ} \mathrm{C} \\
& 177-260^{\circ} \mathrm{C} \\
& 260-343^{\circ} \mathrm{C} \\
& 343^{\circ} \mathrm{C}^{+}
\end{aligned}
$$

TBP FRACTION $\left[{ }^{\circ} \mathrm{C}\right]$

API Gravity

Elemental Analysis [W\%]

Carbon

Hydrogen

Sulfur, ppm

Antek N, ppm

Bromine No. [g/100g]

Aniline Point, $\left[{ }^{\circ} \mathrm{C}\right]$

Flash Point, $\left[{ }^{\circ} \mathrm{C}\right]$

PONA [V\%]

Paraffins

Olefins

Naphthenics

Aromatics

Aromatics (ASTM D2549)
$\mathrm{IBP}=48^{\circ} \mathrm{C} \quad \mathrm{EP}=421^{\circ} \mathrm{C}$

$\mathrm{W} \%$

27.92

\begin{tabular}{|c|c|c|c|}
\hline IBP - 177 & $177-260$ & $260-343$ & $343+$ \\
\hline 52.4 & 27.8 & 19.6 & 24.1 \\
\hline
\end{tabular}

48.25

21.83

2.00

84.78

88.19

88.62

87.29

12.13

5.6

11.72

12.20

$<1.0$

$<1.0$

6.6

15.1

420

29.6

N/A

$\begin{array}{ccc}42 & 31 & 39 \\ <-7 & 81 & 157 \\ & & \\ 23.70 & 11.20 & \\ 0.40 & 3.00 & \\ 68.59 & 40.84 & \\ 7.31 & 44.96 & \end{array}$

55.68

38.43 
TABLE 2.6.7

\section{PROPERTIES OF FIRST AND SECOND STAGE SAMPLES}

Period
Relative STTU
ppm Mo
ppm Fe
W\% CAS Recycle
Coal Conv. \%maf
Stage
I
II

PFL Properties

W\% Resid

$$
\begin{gathered}
\text { Stage } \\
\text { I } \\
\text { II }
\end{gathered}
$$

API

$$
\text { I }
$$

H/C Ratio

$$
\text { I }
$$

II

C.I., W\%

$$
\begin{aligned}
& \text { I } \\
& \text { II }
\end{aligned}
$$

T.I., W\%

I
12.96

2.25
1.12

23.76

18.80

9

1.29

100

615

40

93.90

94.50

44.96

36.93

$-8.30$

$-7.40$

0.93

0.96

29.19

27.64

37.99

14.93

39.58

30.61

14.59

9.41
12

1.33

100

615

25

615

50

92.2

94.5

N/A

$-5.10$

N/A

N/A

0.93

30.65

N/A

N/A

26.80

39.55

34.00

N/A

N/A

14.98

10.61

N/A

N/A

* Make-up oil was used during Period 17; also vacuum still was used for solid separations. 
TABLE 2.6 .8

\begin{tabular}{|lcccc|}
\hline \multicolumn{1}{|c|}{ CMSL-6: PROPERTIES OF THE PRESSURE FILTER LIQUID (1st STAGE) } \\
\hline & & & & \\
Unit & 227 & 227 & 227 & 227 \\
Run & 83 & 83 & 83 & 83 \\
Condition & 1 & 2 & 8 & 4 \\
Period Number & 6 & 9 & 12 & 17 \\
Gravity, API & -5.6 & -8.3 & -9.8 & -4.9 \\
IBP, deg C & 282 & 257 & 266 & 255 \\
& & & & \\
ASTM D-1160 Distillation, Composition & & & & \\
W\% IBP-343 deg C & 5.34 & 6.87 & 6.79 & 9.66 \\
W\% 343-454 deg C & 33.54 & 31.83 & 32.93 & 47.23 \\
W\% 454-524 deg C & 15.93 & 15.83 & 17.2 & 12.08 \\
W\% 524 deg C+ & 44.84 & 44.96 & 43.08 & 30.41 \\
W\% Loss & 0.35 & 0.51 & 0 & 0.62 \\
& & & & \\
Elemental Analysis & & & & \\
Carbon, W\% & & & & \\
Hydrogen, W\% & 88.44 & 89 & 89.5 & 89.11 \\
Sulfur, W\% & 7.62 & 6.9 & 6.71 & 7.32 \\
Nitrogen, W\% & 0.194 & 0.172 & 0.404 & 0.497 \\
H/C RATIO & 0.92 & 0.9 & 0.93 & 0.7 \\
CCR, W\% PFL & 1.03 & 0.93 & 0.90 & 0.99 \\
CYCLOHEXANE INSOLUBLES, W\% & & & \\
TOLUENE INSOLUBLES, W\% & 24.66 & 29.2 & 30.65 & 18.9 \\
\hline & 12.96 & 14.91 & 14.98 & N/A \\
\hline
\end{tabular}


TABLE 2.6.9

\begin{tabular}{|c|c|c|c|c|}
\hline \multicolumn{5}{|c|}{ CMSL-6: INSPECTION OF THE PRESSURE FILTER SOLIDS (1st STAGE) } \\
\hline Unit & 227 & 227 & 227 & 227 \\
\hline Run & 83 & 83 & 83 & 83 \\
\hline Condition & 1 & 2 & 3 & 4 \\
\hline Period Number & 6 & 9 & 12 & 17 \\
\hline \multicolumn{5}{|l|}{ Elemental Analysis } \\
\hline Carbon, W\% & 63.74 & 55.74 & 59.29 & 62.54 \\
\hline Hydrogen W\% & 4.34 & 3.31 & 3.75 & 4 \\
\hline Sulfur, W\% & 1.59 & 1.49 & 1.24 & 1.45 \\
\hline Nitrogen (Antek), W\% & 0.8 & 0.61 & 0.7 & 0.66 \\
\hline H/C RATIO & 0.82 & 0.71 & 0.76 & 0.77 \\
\hline \multicolumn{5}{|l|}{ Composition, W\% } \\
\hline Ash (Quinoline Filtration) & 24.12 & 34.26 & 27.7 & 25.66 \\
\hline ASTM Ash, W\% & 26.34 & 33.39 & 28.59 & 27.12 \\
\hline $\mathrm{S}$ in $\mathrm{Ash}, \mathrm{W} \%$ & 5.1 & 3.6 & 3.72 & 3.87 \\
\hline Unconverted Coal (Adj.) & 30.46 & 29.82 & 26.86 & 33.78 \\
\hline
\end{tabular}


TABLE 2.6.10

\section{Slurry Catalyst Concentration (in wppm of Feed Coal) During CMSL-6*}

\section{Molybdenum concentration in.........}

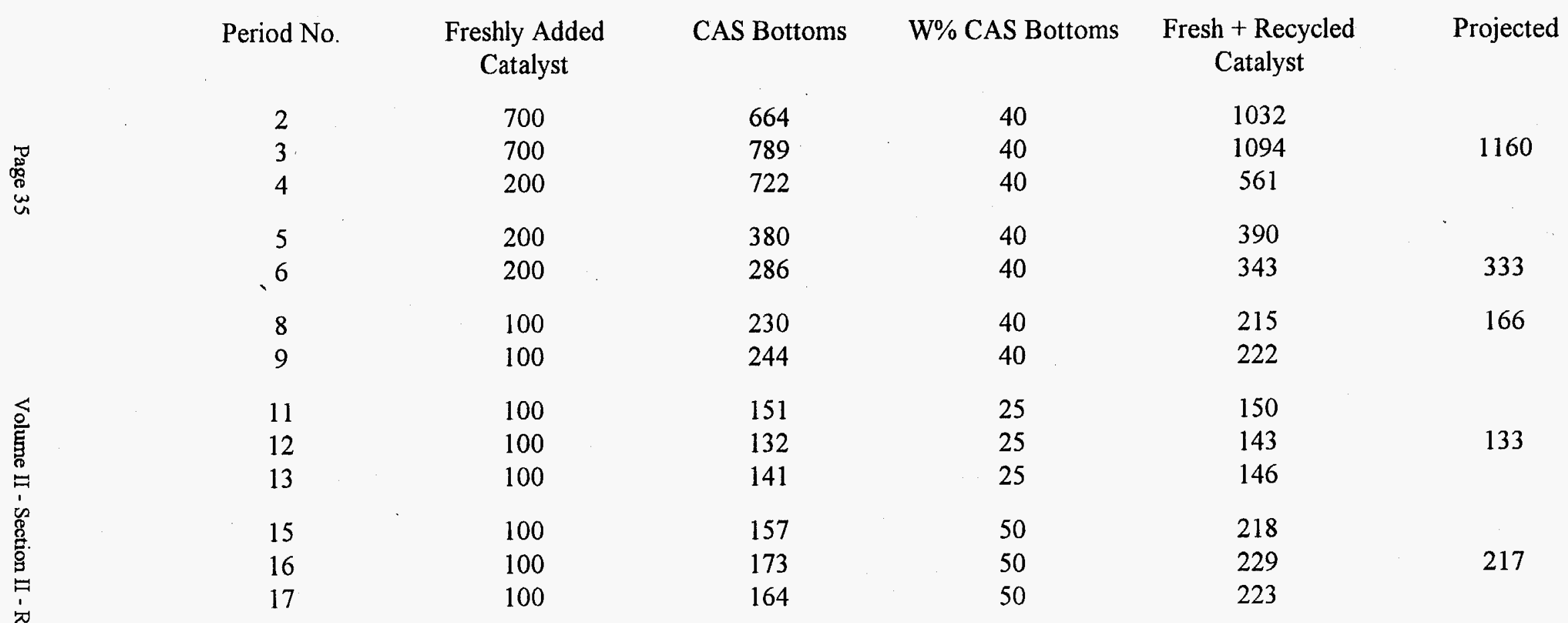


TABLE 2.6.11

\section{Dispersed Slurry Catalysts Tested at HTI}

\begin{tabular}{|c|c|}
\hline & Dispersed Slurry Catalysts Tested at HTI \\
\hline Run No. & Catalysts Used \\
\hline CC-1 & Shell S-317 Supported Catalysts in both Stages \\
\hline $\mathrm{CC}-4$ & Iron Oxide/Pyrrhotite with Aged S-317 in both stages \\
\hline $\mathrm{CC}-7$ & Fe203 in K-1 with Aged S-317 in K-2 \\
\hline CC-15 & Impregnated FeOOH with Fresh S-317 in K-2 \\
\hline CMSL-1 & Impregnated FeOOH + AHM in K-1 and Fresh S-317 in K-2 \\
\hline CMSL-6 & Mo/FeOOH/SO4 in K-1 and Aged S-317 in K-2 \\
\hline
\end{tabular}


TABLE 2.6.12

\section{Operating Conditions during Comparison Runs}

\section{Run I.D.}

$\mathrm{K}-2$ CatAge, $\mathrm{kg}$ coal $/ \mathrm{kg}$ cat

Temperatures, $\mathrm{C}$

$\mathrm{K}-1$

$\mathrm{K}-2$

Space Velocity, $\mathrm{kg} / \mathrm{hr} / \mathrm{m} 3$ reactor

$\mathrm{lb} / \mathrm{hr} / \mathrm{ft} 3$ reactor

Relative Severity, STTU

Catalysts

$$
\begin{aligned}
& \mathrm{K}-1 \\
& \mathrm{~K}-2
\end{aligned}
$$

Conc. of Slurry

Catalysts
CC-15 CC-1 CC-15

316

660

403

427

413

400

441

333

20.8

498

31.1

0.80

0.80

None

S-317

S-317

S-317

Imp. FeOOH

S-317

N/A

N/A $\quad 5000 \mathrm{ppm} \mathrm{Fe}$
CMSL-1

284

439

413

546

34.1

0.82

Imp. $\mathrm{FeOOH}+\mathrm{AHM}$

S-317

$5000 \mathrm{ppm} \mathrm{Fe}$

$300 \mathrm{ppm}$ Mo
CMSL-1

CMSL-6

\section{0}

441

429

413

477

444

27.7

1.00

* Because of the use of ashy CAS bottoms recycle mode of operations, the total steady-state slurry catalyst concentration was about $892 \mathrm{ppm}$ Fe and $140 \mathrm{ppm}$ Mo 
TABLE 2.6.13

\section{Process Performance Comparisons}

\begin{tabular}{lcccccc} 
Run I.D. & CC-15 & CC-1 & CC-15 & CMSL-1 & CMSL-1 & CMSL-6 \\
\hline K-2 CatAge, kg coal/kg cat & 316 & 660 & 403 & 284 & 530 & 860 \\
Relative Severity, STTU & 0.80 & 0.80 & 0.80 & 0.82 & 0.86 & 1.00 \\
Coal Conversion, \%maf & & & & & & \\
K-1 & 87 & N/A & 90.7 & 90.5 & 91.1 & 93.6 \\
K-2 & 90 & 87.3 & 92.4 & 93.4 & 93.4 & 94.4 \\
524 C+ Resid Conv., \%maf & 84 & 82.7 & 85.4 & 90.5 & 89.1 & 88.7 \\
$\mathrm{C}_{4}-$-524 C Distillates, \%maf & 57.4 & 59.8 & 60.5 & 63.5 & 60.7 & 65.4 \\
$\mathrm{C}_{1}-\mathrm{C}_{3}$ Gases, \%maf & 10.54 & 8.16 & 10.49 & 9.93 & 11.1 & 13.6 \\
$\mathrm{H}_{2}$-Consumption, \%maf & 8.29 & 7.09 & 8.34 & 8.57 & 8.98 & 7.91
\end{tabular}


TABLE 2.6.14

\section{ANALYSIS OF FEED COAL AND MAKE-UP/START-UP OIL}

\begin{tabular}{lccr} 
Black Thunder Mine Subbituminous Coal & \multicolumn{2}{c}{ L-809 Oil } \\
Proximate Analysis, W\% & & D-1160 W\% Distribution & \\
Moisture & 10.85 & IBP - 454 C & 58.99 \\
Volatile Matter (Dry) & 43.17 & $454-524$ C & 22.18 \\
Fixed Carbon (Dry) & 50.16 & 524 C+ & 18.36 \\
Ash (Dry) & 6.67 & LOSS & 0.47 \\
& & & \\
Sulfur (Dry) & 0.4 & & \\
& & & \\
Ultimate Analysis, W\% & & Elémental Analysis, W\% & \\
Moisture & 7.89 & Carbon & \\
Cargon & 64.59 & Hydrogen & 10.54 \\
Hydrogen & 4.71 & Nitrogen & 0.83 \\
Nitrogen & 0.91 & Sulfur & 0.11 \\
Sulfur & 0.32 & Oxygen (diff.) & 0.05 \\
Ash & 5.7 & H/C Ratio & 1.43 \\
Oxygen (diff.) & 15.88 & &
\end{tabular}


TABLE 2.6.15

\section{Laboratory Support for CMSL-6}

\section{Sulfated Fe-Mo Catalysts and their Surface Areas}

Starting Materials

Fe-nitrated $+\mathrm{NH} 3+\mathrm{H}_{2} \mathrm{SO}_{4}+\mathrm{AHM}$

$\mathrm{Fe}$-alum $+\mathrm{NH}_{3}+\mathrm{AHM}$

Fe-alum+Urea+AHM
Catalyst

FeMoCat I

FeMoCat II

FeMoCat III
BET Surface

Area, $\mathrm{m}^{2} / \mathrm{g}$

These catalysts were prepared in $10 \mathrm{gm}$ size batches.
190

194

263
1.7

2.04

$\%$ Mo

2.8 
TABLE 2.6.16

\section{Laboratory Support for CMSL-6}

Test Conditions:
Coal
HTI-5828 Black Thunder Coal
Solvent
Run 227-79-Period 9 PFL (25\% resid)
Temperature, $\mathrm{C}$
427
Time, $\min$
30
Pressure
$13.8 \mathrm{MPa} \mathrm{H} 2$
Sulfiding Agent
DMDS, $4 \%$ of Coal

None

107

74.1

35.3

FeMoCat I

109

80.2

45

FeMoCat II

104

79.6

40

FeMoCat III

105

80.6

42.4

$\mathrm{SnO} 2$

100

76

38.3

Molyvan-L

102

79.1

40.6

Shell-317

108

76.6

39.3

Fe203+

107

79.2

40.1 
TABLE 2.6.17

\section{Microautoclave Testing of Catalyst for CMSL-6 Operations}

11 pounds of Sulfated Fe-Mo Catalyst was prepared.

This catalyst had a BET surface area of $40 \mathrm{~m} 2 / \mathrm{g}$ and $\mathrm{Mo} / \mathrm{Fe}$ ratio of 0.163 .

\section{Microautoclave Testing}

Conditions:

Coal: Black Thunder Mine POC-02 Coal

Solvent: L-810, Mixture of ASBs, VSO, and makeup oil at the end of POC-01 Temp: $427 \mathrm{C}$

Time: $30 \mathrm{~min}$

Coal/Solvent/Catalyst (g): 2/6/0.02

\begin{tabular}{ccc} 
Catalyst & Coal Conv. \%maf & Resid Conv., \%maf \\
\hline None & 68,70 & 37,39 \\
Sulfated Fe-Mo* & $77,81,82$ & $56,58,60$ \\
Molyvan L & 77 & 46
\end{tabular}

* The results from three repeat tests. 


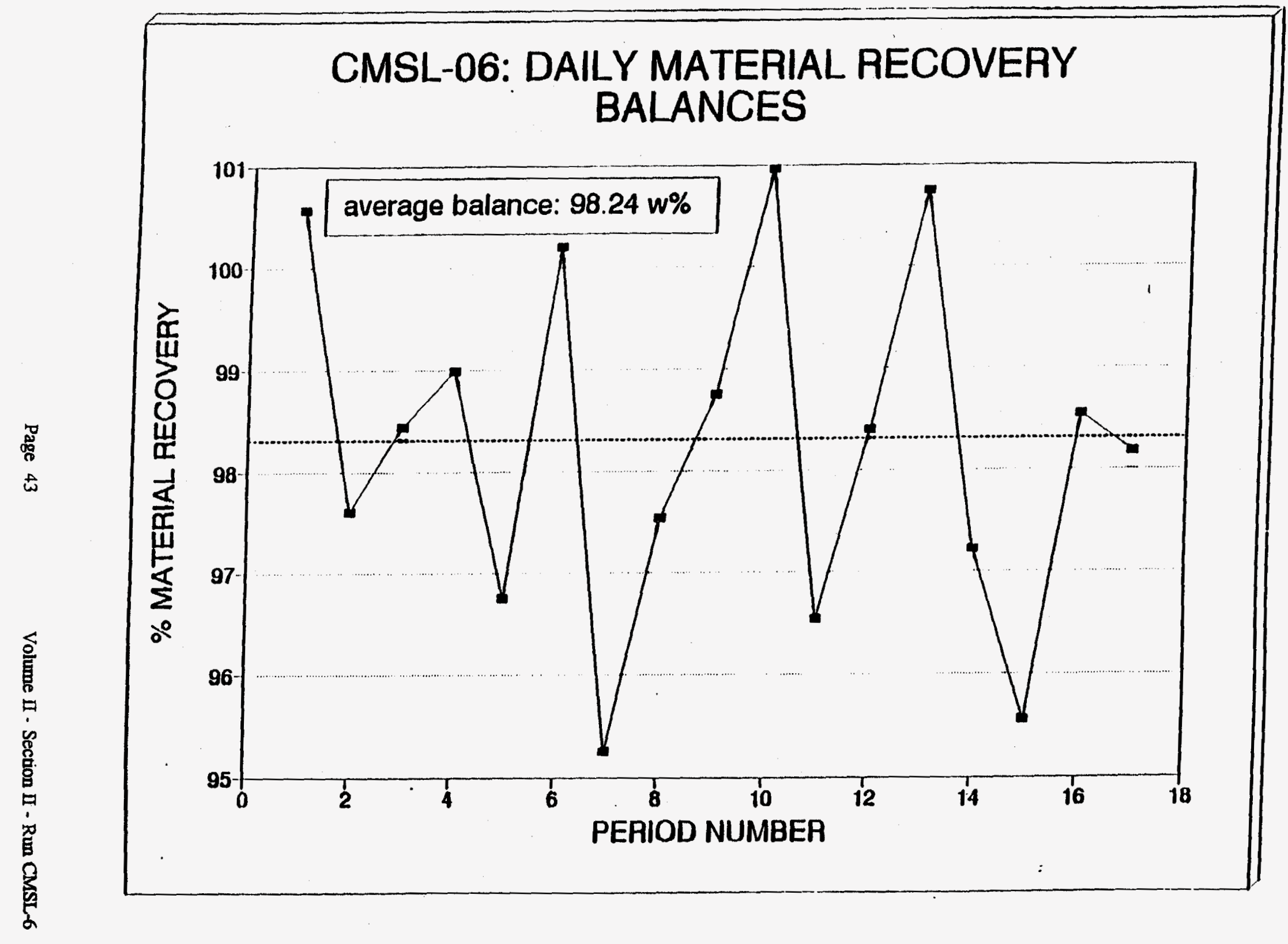

㿣 


\section{CMSL-06: DAILY OPERATING CONDITIONS TEMPERATURES \& SPACE VELOCITIES}

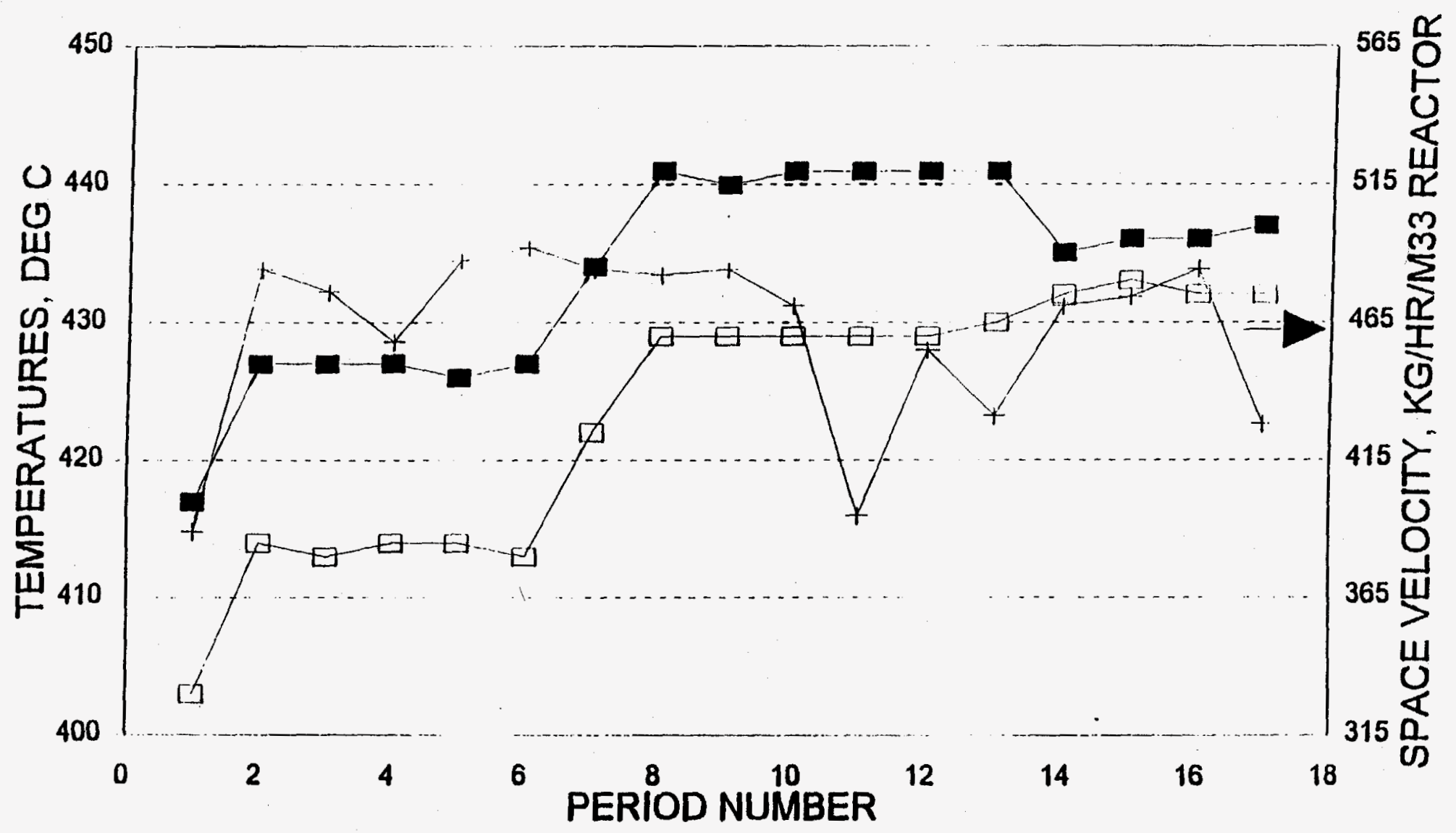




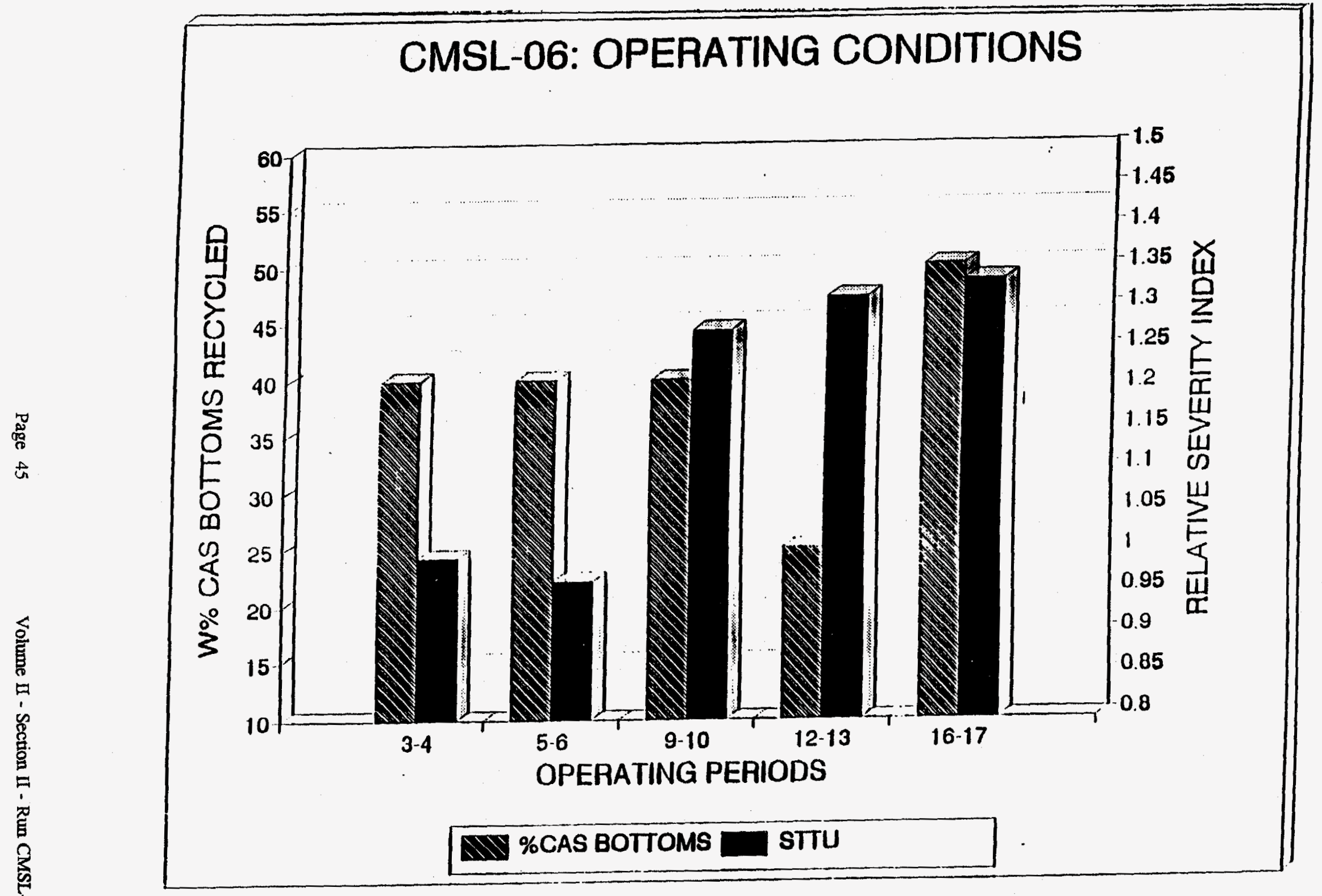




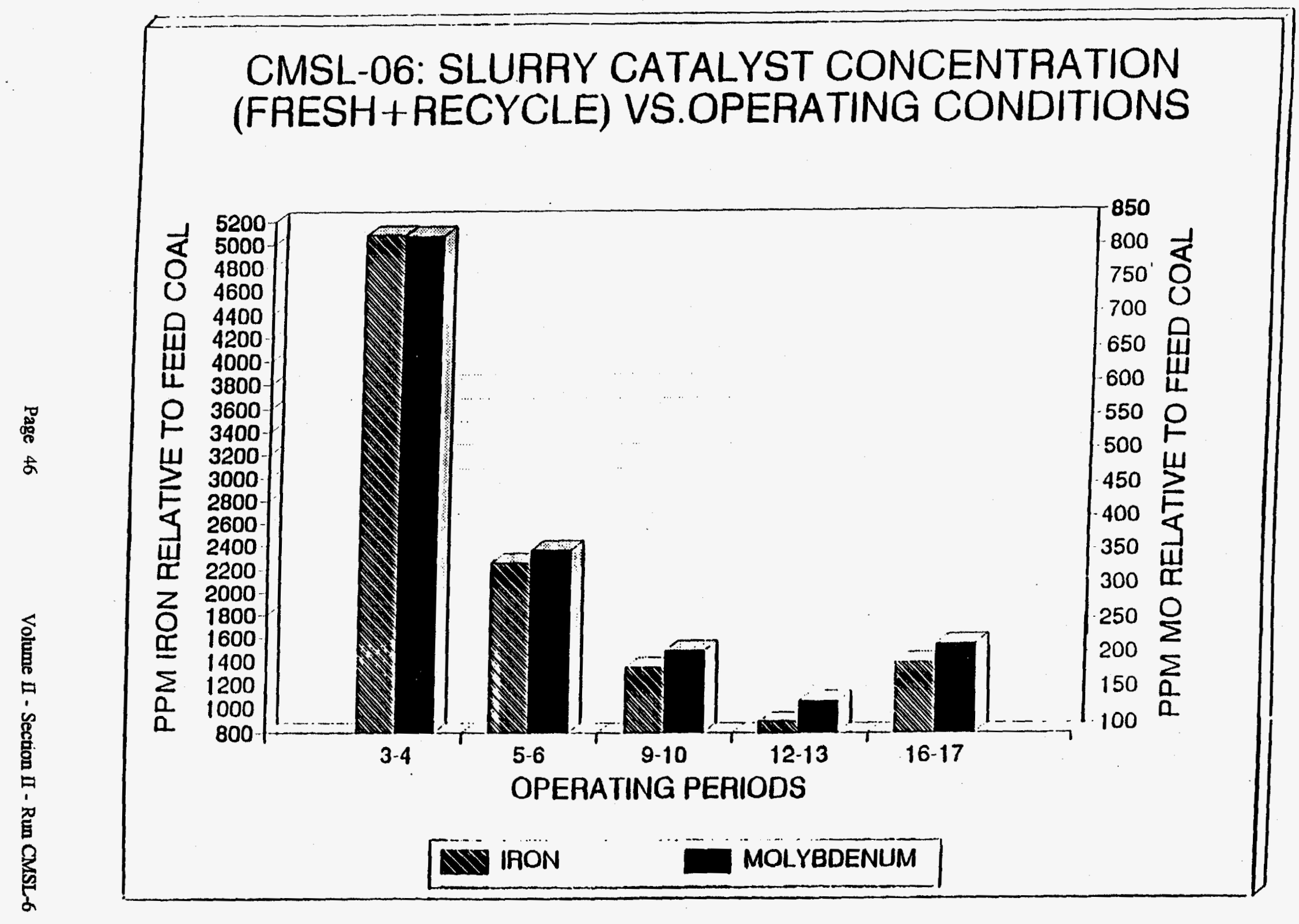




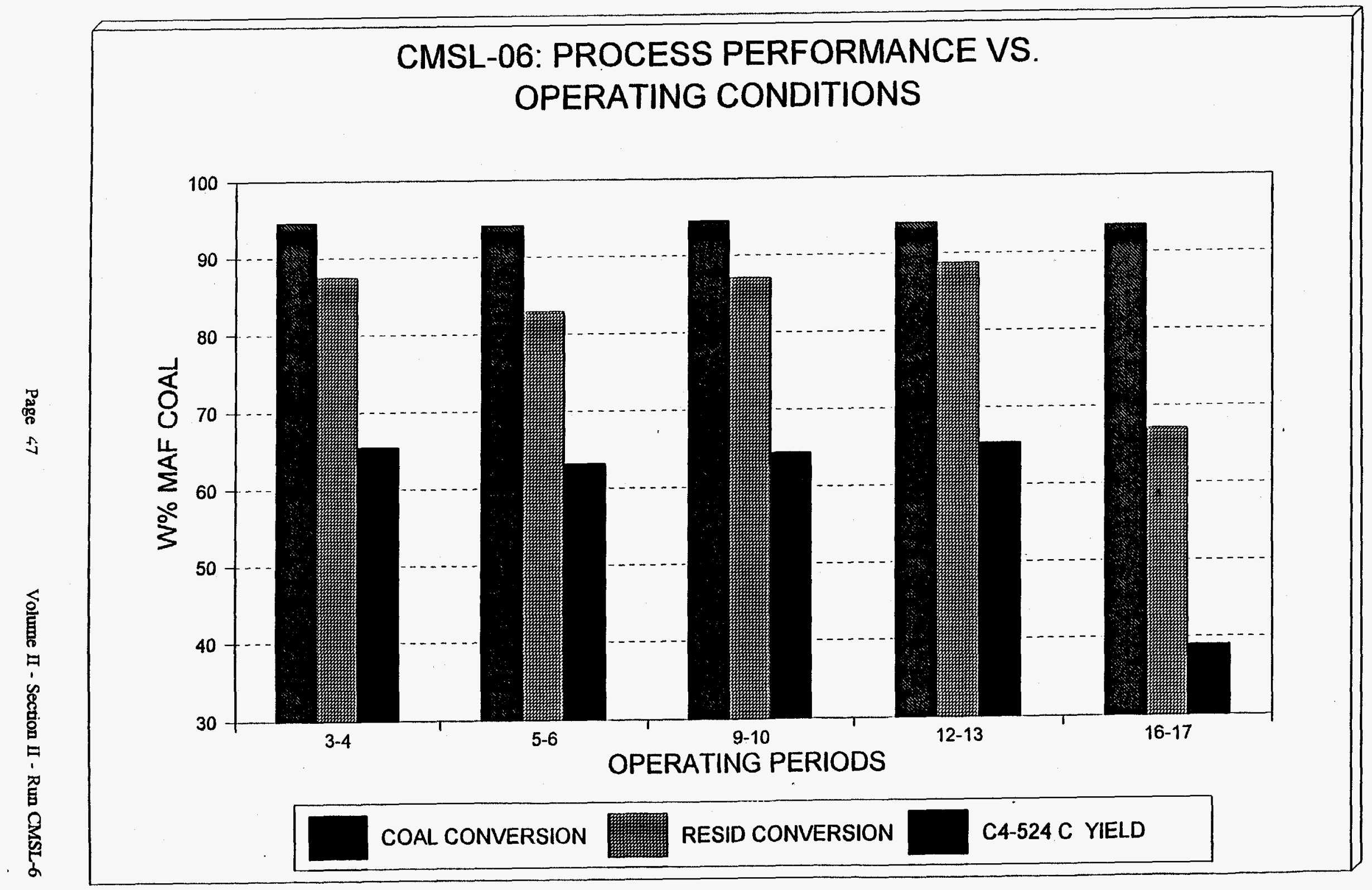




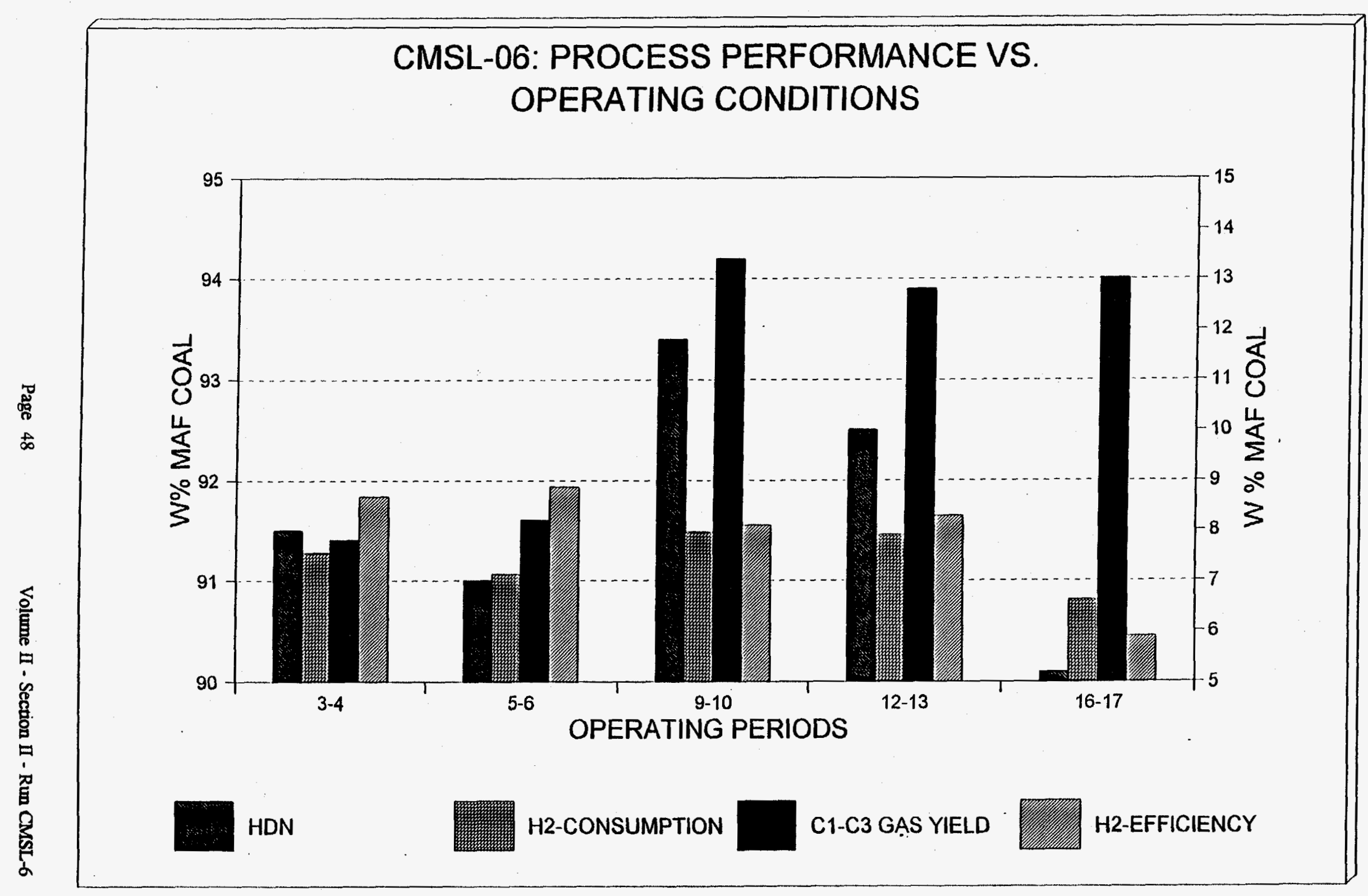

菖 
FIGURE 2.6.7

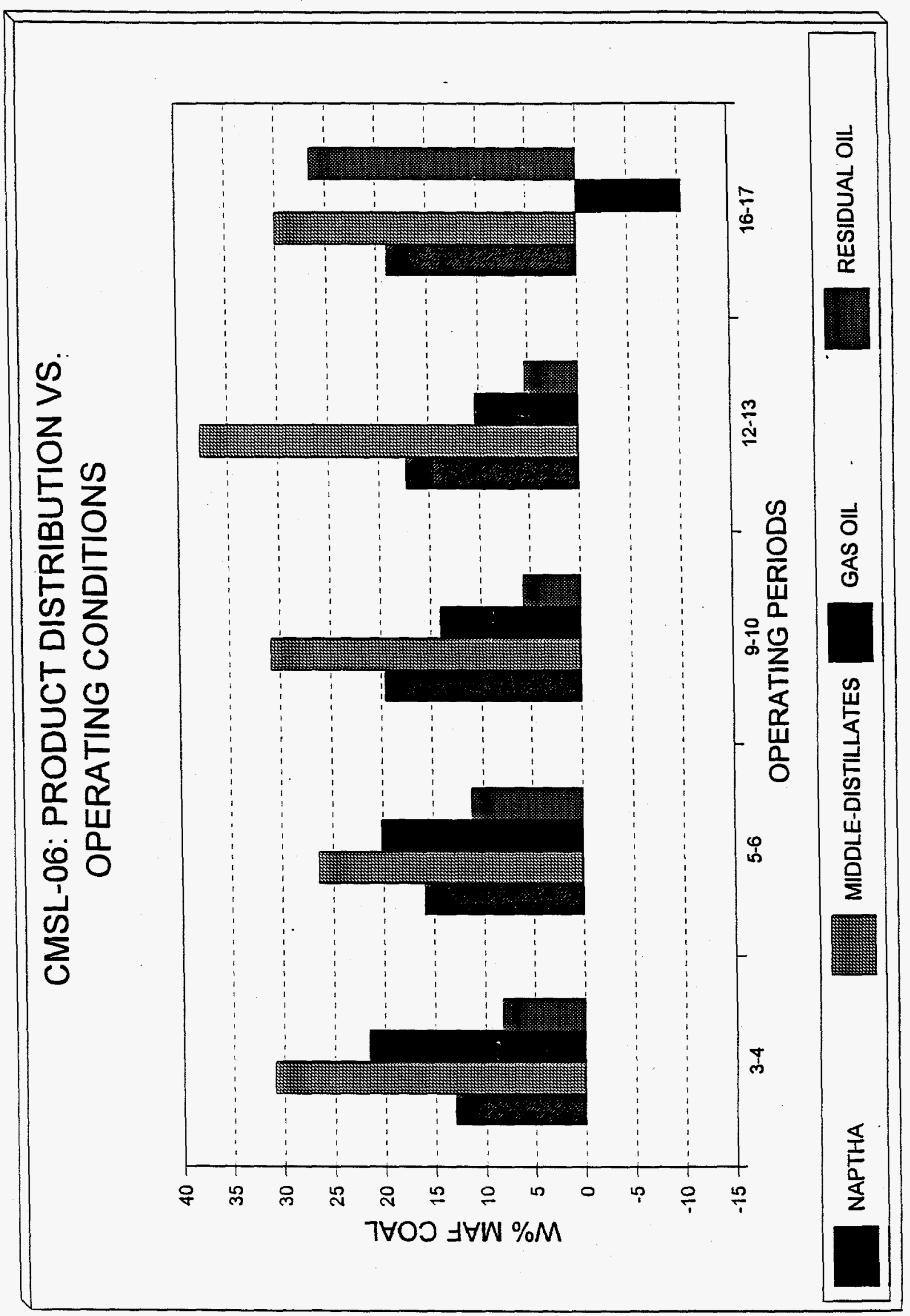


FIGURE 2.6.8

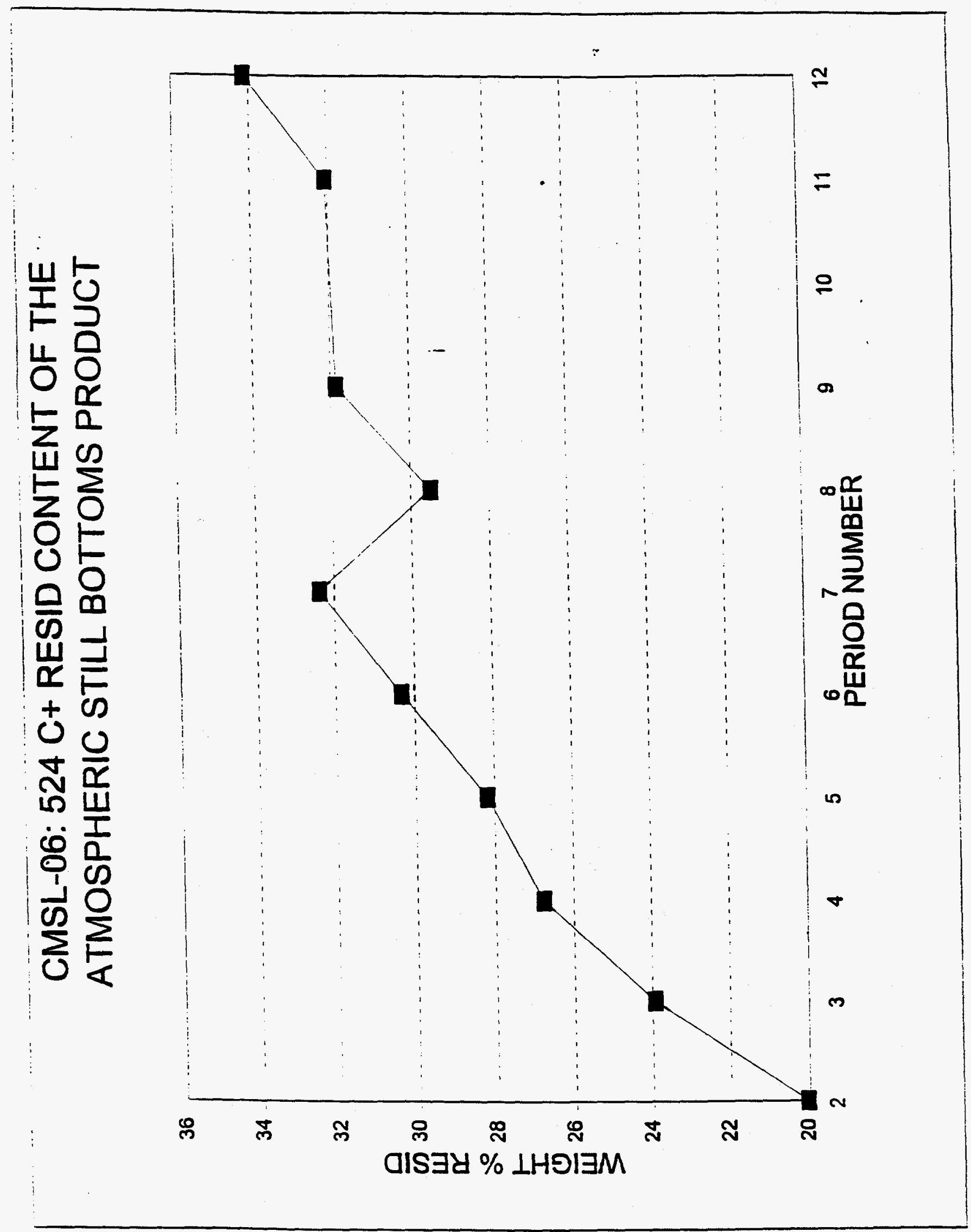


FIGURE 2.6.9

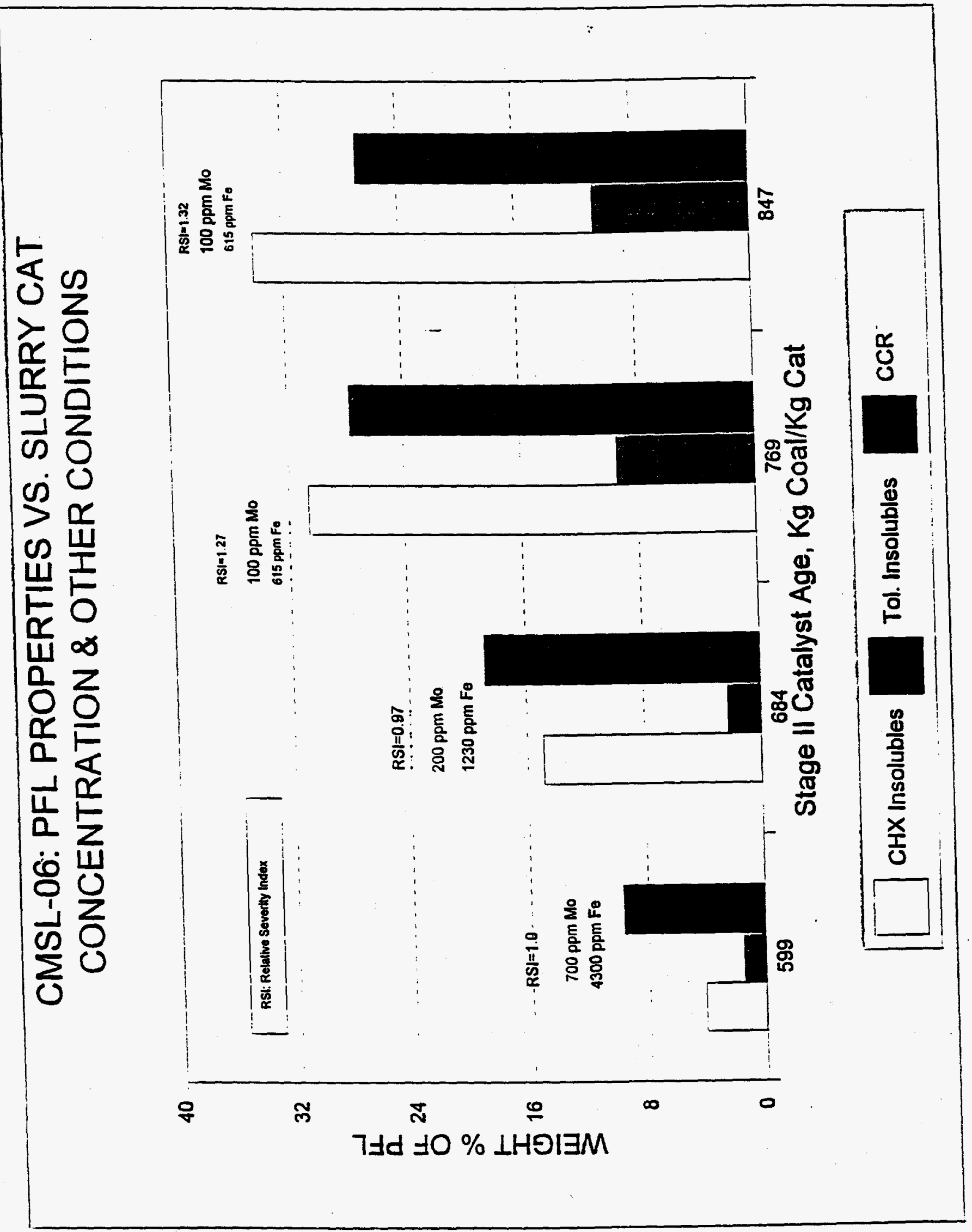




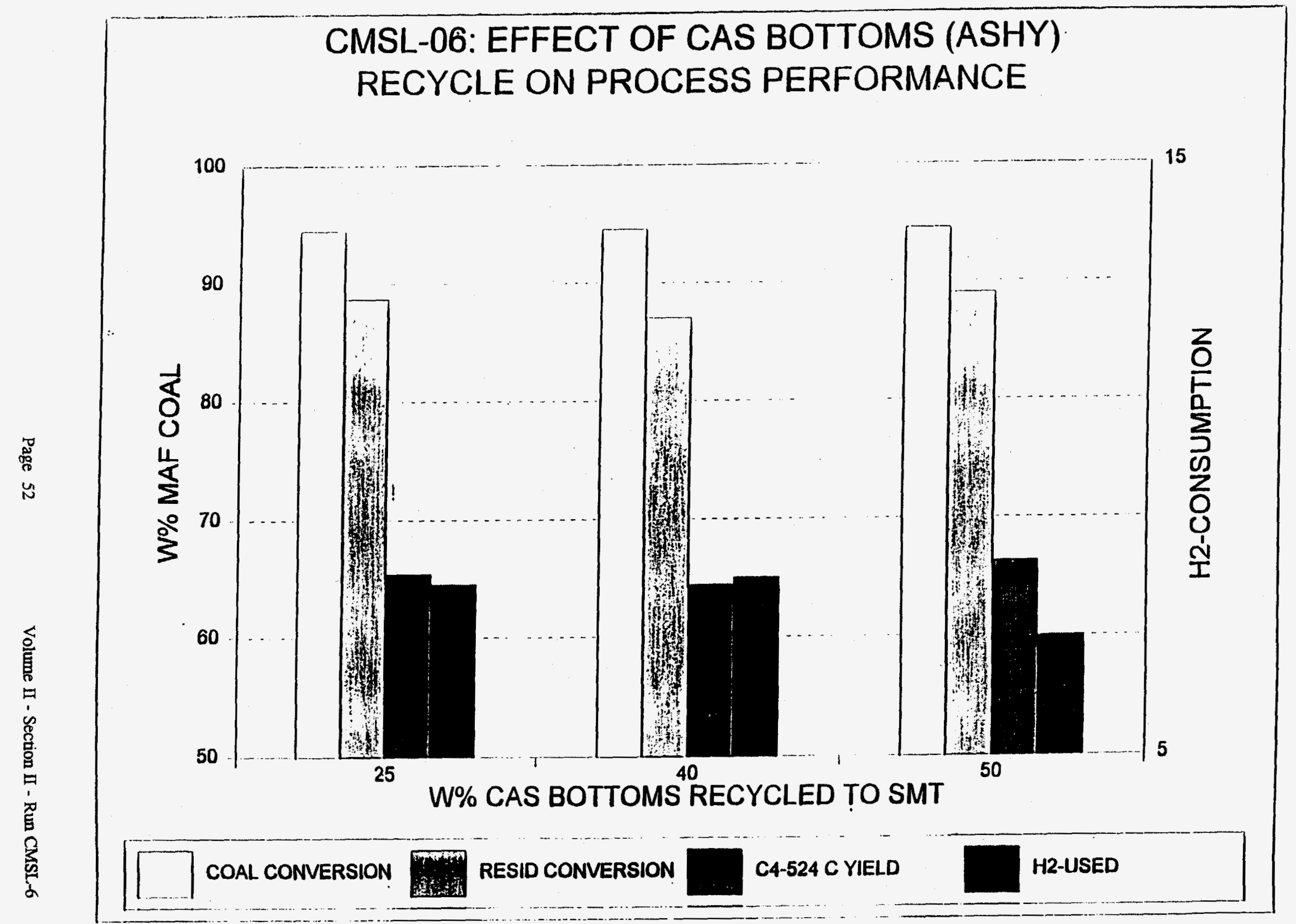


FIGURE 2.6.11

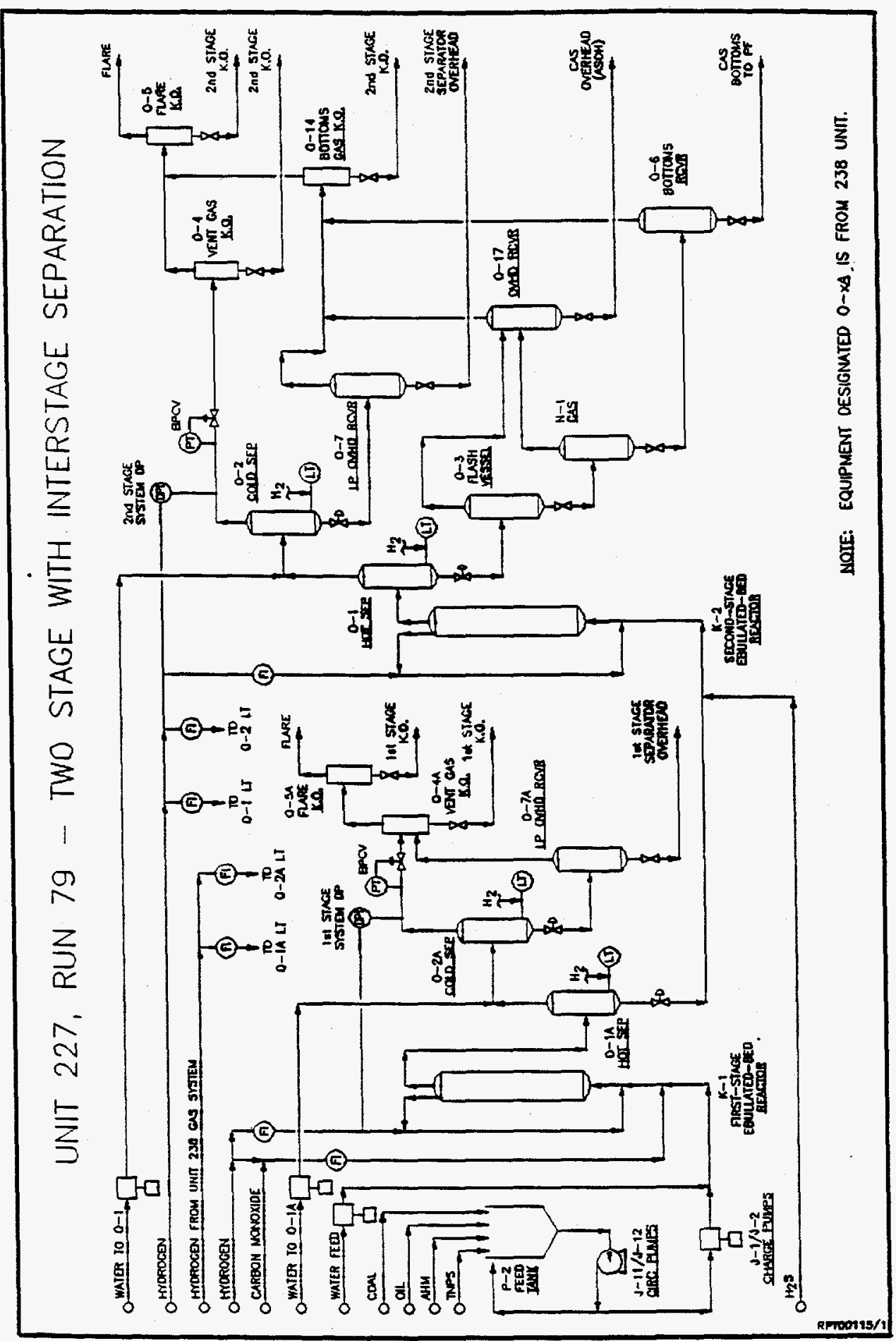


CATALYTIC MULTI-STAGE LIQUEFACTION OF COAL (CMSL) FINAL REPORT

VOLUME II

SECTION II (CONTINUED)

IMPACT OF LOW PRESSURE SYNGAS ON LIQUEFACTION OF CATALYTIC/CATALYTIC MODE OF OPERATION

RUN CMSL - 7 
VOLUME II

SECTION II - RUN CMSL - 7

TABLE OF CONTENTS

RUN CMSL-7 (227-84)

IMPACT OF LOW PRESSURE SYNGAS ON LIQUEFACTION IN A CATALYTIC/CATALYTIC MODE OF OPERATION

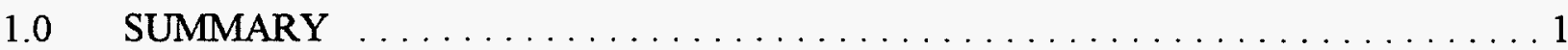

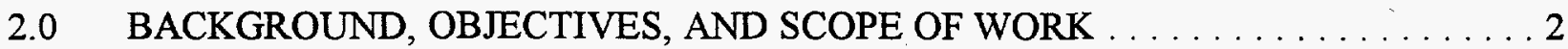

3.0 PROGRAM ANALYSIS, RESULTS AND COMPARISONS $\ldots \ldots \ldots \ldots \ldots \ldots$.

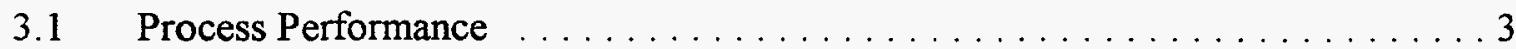

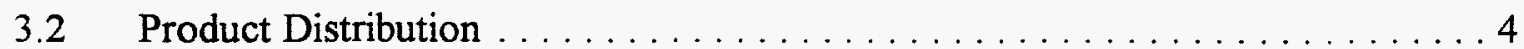

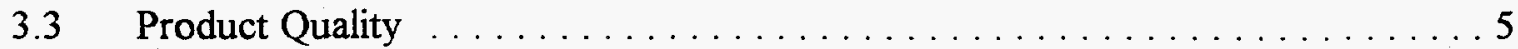

3.4 Co Conversion . . . . . . . . . . . . . . . . . . . . . . . . . . . 6

3.5 First And Second Stage Product Analyses For Runs CMSL-4 And CMSL-7 With Syngas Feed To The First Stage $\ldots \ldots \ldots \ldots \ldots \ldots \ldots$

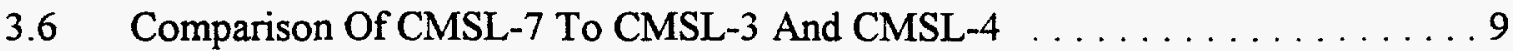

4.0 DETAILS OF OPERATION . . . . . . . . . . . . . . . . . . . . . . . . 10

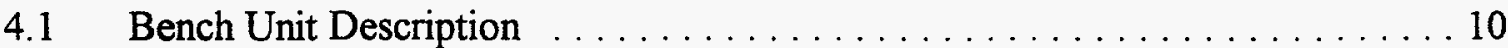

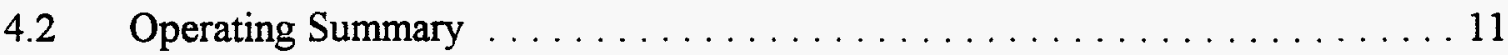

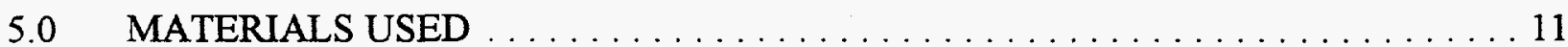

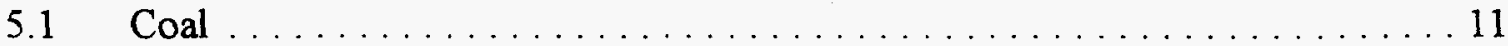

$5.2 \quad$ Start-up/Makeup Oil . . . . . . . . . . . . . . . . . . . . . . 11

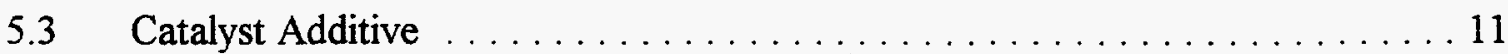

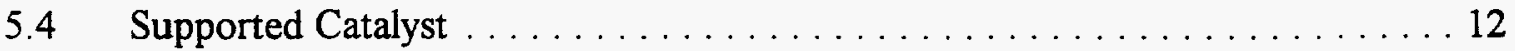

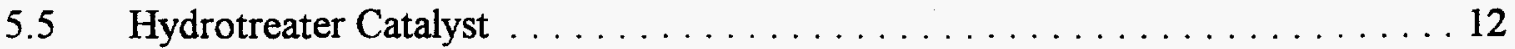

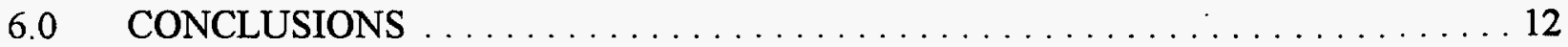


VOLUME II

SECTION II - RUN CMSL - 7

LIST OF TABLES

Table

Page

2.7.1 CMSL-7 Run Plan . . . . . . . . . . . . . . . . . . . . 13

2.7.2 CMSL-7 Actual Run Conditions $\ldots \ldots \ldots \ldots \ldots \ldots \ldots \ldots \ldots \ldots$

2.7.3 Condition Average Process Performance $\ldots \ldots \ldots \ldots \ldots \ldots \ldots \ldots$

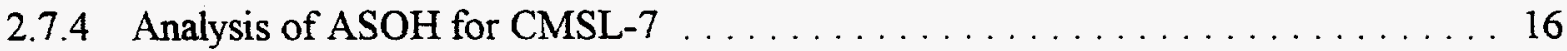

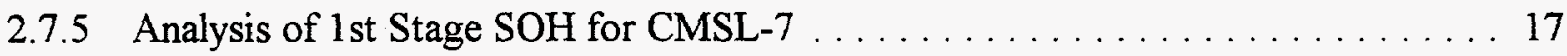

2.7.6 Analysis of 2 nd Stage SOH (Hydrotreater Outlet) for CMSL $-7 \ldots \ldots$. . . . . 18

2.7 .7 Hydrotreater Performance . . . . . . . . . . . . . . . . . . . . . . . . . 19

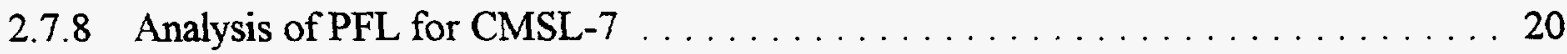

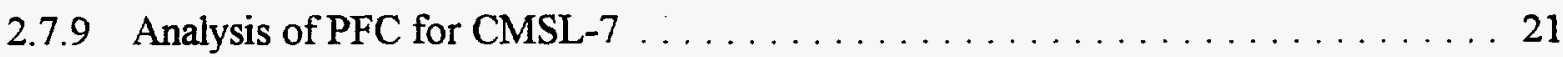

2.7.10 Comparison of 1st \& 2nd Stage Product Solid Analyses

Run CMSL-7 (227-84) . . . . . . . . . . . . . . . . . . . 22

2.7.11 Comparison of 1 st \& 2nd Stage Product Fraction Analyses

Run CMSL-7 (227-81) . . . . . . . . . . . . . . . . . . . . . . 23

2.7.12 Comparison of 1 st \& 2nd Stage Product Fraction Analyses

Run CMSL-7 (227-84) . . . . . . . . . . . . . . . . . . . . 24

2.7.13 Comparison of Low Pressure Operation of CMSL-7 to CMSL-3 \& CMSL-4 . . . 25

2.7.14 Comparison of High Pressure Operation of CMSL-7 to CMSL-3 \& CMSL-4 . . 26

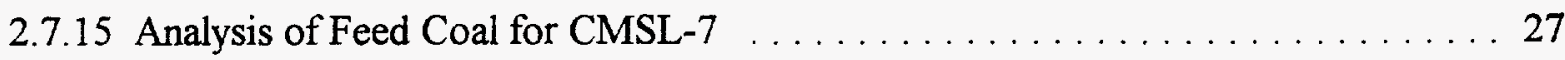

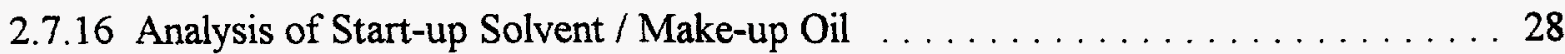

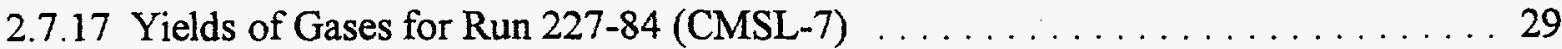

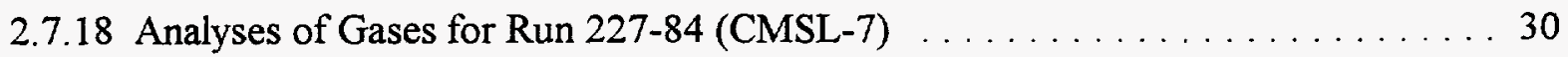




\section{VOLUME I \\ SECTION II - RUN CMSL - 7 \\ LIST OF FIGURES}

Figure

Page

2.7.1 CMSL-7 (227-84) Material Balance . . . . . . . . . . . . . . . . . 31

2.7.2 CMSL-7 (227-84) Reactor Temperatures . . . . . . . . . . . . . . . . . 32

2.7.3 CMSL-7 (227-84) Space Velocity . . . . . . . . . . . . . . . . . 33

2.7.4 CMSL-7 (227-74) Relative Severity . . . . . . . . . . . . . . . . . 34

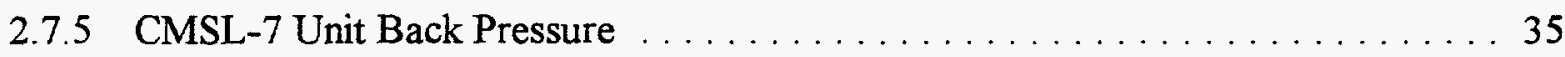

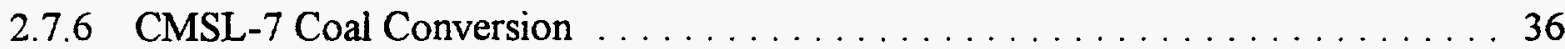

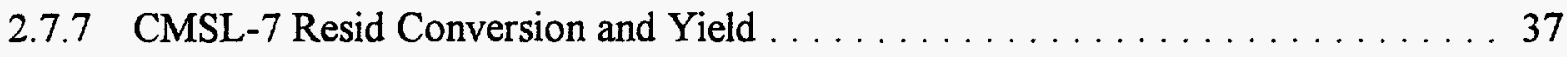

2.7 .8 CMSL-7 Hydrogen Consumption . . . . . . . . . . . . . . . . . . . . . 38

2.7 .9 CMSL-7 Gas Yield . . . . . . . . . . . . . . . . . . . . . . . . 39

2.7.10 CMSL-7 Distillate Yields . . . . . . . . . . . . . . . . . . . . . . . 40

2.7.11 CMSL-7 Properties of ASOH $\ldots \ldots \ldots \ldots \ldots \ldots \ldots \ldots \ldots \ldots \ldots \ldots \ldots$

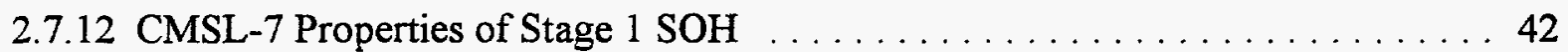

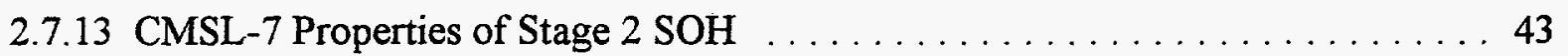

2.7.14 CMSL-7 Properties of PFL . . . . . . . . . . . . . . . . . . 44

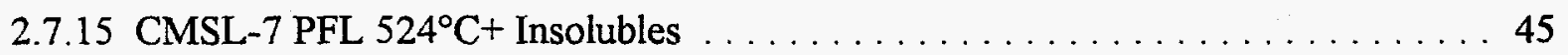

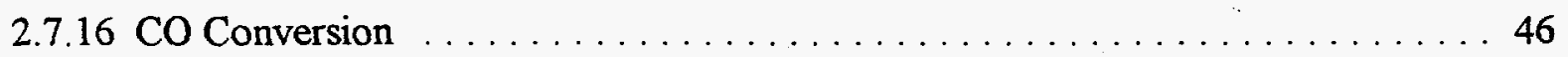

2.7.17 First \& Second Stage Coal Conversion Comp. of Syngas

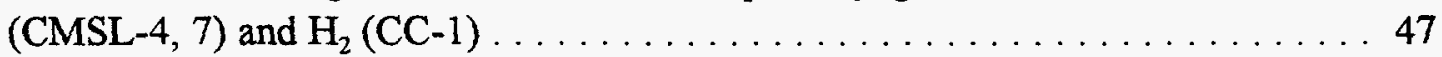

2.7.18 Solids H:C Ratio vs. Coal Conversion Runs CC-1 and CMSL-7 . . . . . . . . . 48

2.7.19 Solids Nitrogen / Carbon Ratio Runs CC-1 and CMSL-7 . . . . . . . . . . . 49

2.7.20 Hydrogen Content of 1 st and 2nd Stage LGO Runs CC-1 and CMSL-7 . . . . . 50

2.7.21 Hydrogen Content of 1st and 2nd Stage VGO Runs CC-1 and CMSL-7 . . . . . 51

2.7.22 Hydrogen Content of 1 st and 2nd Stage HVGO Runs CC-1 and CMSL-7 . . . . 52

2.7.23 Hydrogen Content of 1st and 2nd Stage Resid Runs CC-1 and CMSL-7 . . . . 53

2.7.24 Nitrogen Content of 1 st and 2nd Stage LGO Runs CC-1 and CMSL-7 . . . . . . . 54

2.7.25 Nitrogen Content of 1 st and 2nd Stage VGO Runs CC-1 and CMSL-7 . . . . 55

2.7.26 Nitrogen Content of 1 st and 2nd Stage HVGO Runs CC-1 and CMSL-7 . . . . 56

2.7.27 Nitrogen Content of 1st and 2nd Stage Resid Runs CC-1 and CMSL-7 . . . . . 57

2.7.28 Cyclohexane Insols in 1st and 2nd Stage Resid Runs CC-1 and CMSL-7 . . . . 58

2.7.29 Toluene Insols in 1st and 2nd Stage Resid Runs CC-1 and CMSL-7 . . . . . . . . 59

$2.7 .30 \mathrm{H}_{2}$ Two-Stage Coal Liquefaction Scheme . . . . . . . . . . . . . . . . 60 


\section{RUN CMSL-7 (227-84) \\ IMPACT OF LOW PRESSURE SYNGAS ON LIQUEFACTION IN A CATALYTIC/CATALYTIC MODE OF OPERATION}

\subsection{SUMMARY}

The main objective of this run, to evaluate the effect of using a mixture of $\mathrm{CO} / \mathrm{H}_{2}$ as a reducing gas in two stage liquefaction of Black Thunder coal with reduced operating pressure, was met with 19 days of operation. Both reactors were charged with Shell S-317 and operated in a fully ebullated mode with ammonium heptamolybdate (AHM) as an additional feed catalyst.

Condition 1 extended from Periods 1 to 7 using $\mathrm{CO} / \mathrm{H}_{2}(75 \mathrm{~V} \% \mathrm{CO})$ as the reducing gas for the first stage and $\mathrm{H}_{2}$ for the second stage. Also for this condition, and all subsequent conditions, water was injected upstream of the preheater in order to obtain an overall water content of $40 \mathrm{Wt} \%$ of the dry coal in the feed slurry. This condition served as a base case for comparison. Condition 2 was identical to Condition 1 except the pressure was reduced from $17.2 \mathrm{MPa}(2500 \mathrm{psi})$ to $13.8 \mathrm{MPa}$ (2000 psi). Condition 3 was identical to Condition 2 except the back pressure was further reduced from $13.8 \mathrm{MPa}$ (2000 psi) to $10.3 \mathrm{MPa}$ (1500 psi). Due to the poor performance experienced during Condition 3, Condition 4 prescribed $11^{\circ} \mathrm{C}$ higher first stage temperature and the addition rate of the feed catalyst was increased from $200 \mathrm{ppm}$ to $500 \mathrm{ppm}$ of molybdenum on a dry coal basis.

Coal conversion at 17.2 and $13.8 \mathrm{MPa}(2500$ and $2000 \mathrm{psi}$ ) was normal for subbituminous coal at 92.1-92.4 Wt\% MAF coal. The drop in coal conversion at the low pressure condition, $10.3 \mathrm{MPa}$ (1500 psi), to $89.7 \mathrm{Wt} \%$ was reversed to $91.7 \mathrm{Wt} \%$ with an increase in feed catalyst addition rate and reactor severity. The resid conversion showed the same trend in decreasing from $92.4 \mathrm{Wt} \%$ MAF coal to $80.6 \mathrm{Wt} \% \mathrm{MAF}$ from the high pressure condition to the low pressure condition and then reversing this trend with the increase in the feed catalyst addition rate and reactor severity at the low pressure condition to a value of $89.6 \mathrm{Wt} \%$. The gas make shows very little dependence on reactor pressure; the $\mathrm{C}_{1}-\mathrm{C}_{3}$ yield varied only from 7.1 to $7.8 \mathrm{Wt} \% \mathrm{MAF}$ coal.

The hydrotreated product, the second stage $\mathrm{SOH}$, had a negligible sulfur content, generally less than $1 \mathrm{ppm}$, a nitrogen content always less than $1 \mathrm{ppm}$ and a $\mathrm{H} / \mathrm{C}$ ratio of 1.74 to 1.83 . Using supported catalyst in both stages as well as a feed catalyst in the presence of $\mathrm{CO} / \mathrm{H}_{2}$ as the reducing gas results in an improvement in the overall quality of the product oil at typical operating conditions using $\mathrm{H}_{2}$ as the reducing gas. Decreasing the operating pressure while using $\mathrm{CO} / \mathrm{H}_{2}$ as the reducing gas results in a decrease in overall performance as measured by distillate yield, coal conversion and resid conversion. It also results in a decrease in the quality of the product oil. The negative effects of lowering the operating pressure on overall performance and product oil quality can largely be mitigated by slightly increasing the severity and by increasing the feed catalyst addition rate. This demonstrates the possibility of performing high quality coal liquefaction at substantially reduced operating pressure with a potential for significant cost savings by reducing the capital investment needed for a higher pressure operating system. 


\subsection{BACKGROUND, OBJECTIVES, AND SCOPE OF WORK}

The production of hydrogen constitutes one of the major operating cost components of a coal liquefaction process. Alternative sources of hydrogen such as synthesis gas, a mixture of carbon monoxide and hydrogen coming directly out of a gasifier or reformer, can potentially reduce the operating cost by $10-15 \%$. In the presence of an alkali salt, a mixture of $\mathrm{CO} / \mathrm{H}_{2}$ and steam is very effective in solubilizing high oxygen containing low rank coals at relatively mild severity conditions, usually below $400^{\circ} \mathrm{C}$.

A successful operation with promising results such as improved liquefaction yields, kinetics, and hydrogen efficiency of the CTSL process was demonstrated during CMSL-3 (227-79) and CMSL-4 (227-81). The interstage separation used during CMSL-3 and CMSL-4 was instrumental in removing $\mathrm{CO}_{\mathrm{x}}$ off gases, thereby reducing further reforming of these gases to methane/water at the expense of the valuable hydrogen.

Operation using syngas while feeding Black Thunder subbituminous coal was demonstrated in Run CMSL-3 with promising results, i.e. improved yields, kinetic and hydrogen efficiency. This exceptional performance was obtained using ammonium heptamolybdate (AHM) in the feed to a nonsupported catalyst first stage followed by a supported Ni/Mo catalyst second stage. The AHM used in CMSL-3 was equivalent to 1500 ppm Mo per dry coal feed. CMSL-4 was similar to CMSL-3, except instead of using AHM as a feed catalyst the first reactor was also charged with supported catalyst and operated as an ebullated bed. During these runs problems were experienced with the $\mathrm{CO}$ feed rate. This caused the $\mathrm{H}_{2}$ partial pressure to be lower than originally designed for. However, even at a reduced $\mathrm{H}_{2}$ partial pressure the process performance did not drop off sharply, but was fairly comparable to higher partial pressure operation. This fortuitous observation that a $\mathrm{CO} / \mathrm{H}_{2}$ blend for a reducing gas might not require the same pressure as pure hydrogen provided the impetus for this low pressure liquefaction test.

The main objective of this run was to evaluate the effect of using a mixture of $\mathrm{CO} / \mathrm{H}_{2} \mathrm{O} / \mathrm{H}_{2}$ as a reducing gas in two stage liquefaction of Black Thunder Mine coal. Specifically, one technical objective was to determine the relative performance of $\mathrm{CO} / \mathrm{H}_{2}$ vs. $\mathrm{H}_{2}$ in a fully ebullated two stage system with ammonium heptamolybdate as a feed catalyst. The other technical objective was to determine the impact of lowering system pressure on distillate yield, resid conversion and coal conversion while using a mixture of $\mathrm{CO} / \mathrm{H}_{2} \mathrm{O} / \mathrm{H}_{2}$ as a reducing gas.

The liquefaction of Black Thunder mine coal was evaluated using $\mathrm{CO} / \mathrm{H}_{2}$ as the reducing gas in the first stage and $\mathrm{H}_{2}$ as the reducing gas in the second stage. The main process variable evaluated for this test program was the reactor pressures. This varied in the $2^{\text {nd }}$ stage from 17.2 to $10.3 \mathrm{MPa}$ ( 2500 to $1500 \mathrm{psi}$ ) and in the first stage from 18.6 to $11.7 \mathrm{MPa}$ (2700 to $1700 \mathrm{psi})$. The effect of increasing the feed rate of the feed catalyst (AHM) at the low pressure condition was also investigated. The original run plan is presented in Table 2.7.1 and the actual run conditions are presented in Table 2.7.2. 
The daily recovery and operating conditions are presented in Figures 2.7.1-2.7.5. Operating parameters, normalized yields, and process performance for each of the four conditions are presented in Table 2.7.3. The daily material balance average was $97.5 \mathrm{Wt} \%$ (Figure 2.7.1). The reactor temperatures are presented in Figure 2.7.2 and show a very small variation from target values except for a slight drop in K-2 temperature during Period 15. The space velocity is presented in Figure 2.7.3 and shows smooth operation for the entire run, except for Period 15, with a value of $310 \mathrm{~kg}$ dry $\mathrm{coal} / \mathrm{hr} / \mathrm{m}^{3}$ reactor. The overall process severity is presented in Figure 2.7.4 showing an initial relative severity of 1.0 for Conditions $1,2 \& 3$ and a severity of 1.3 for Condition 4 . The first 3 periods show a lower severity due to normal startup conditions. The unit back pressure is presented in Figure 2.7.5.

\subsection{Process Performance}

\section{Coal Conversion}

Coal conversion during Condition 1 was $92.4 \mathrm{Wt} \% \mathrm{MAF}$ coal, Figure 2.7.6. It was low during the startup condition, probably due to the quality of the recycle oil and the low temperature during Period 2. The Condition 1 value of $92.4 \mathrm{Wt} \% \mathrm{MAF}$ coal is typical for Black Thunder coal using additives at these process condition with a pure $\mathrm{H}_{2}$ reducing gas system. However, it is about $5 \%$ higher than in such operations with extrudate catalyst only. In Condition 2 the coal conversion at first dropped approximately $1 \%$ with the drop in pressure but it then increased to $92.1 \mathrm{Wt} \%$ MAF coal. During Condition 3 the coal conversion dropped continuously to a value of $89.7 \mathrm{Wt} \% \mathrm{MAF}$ coal as the recycle oil quality decreased, with the resid toluene insolubles reaching a level of $27.0 \mathrm{Wt} \%$ and off-line filtration times increasing from a normal value of 1 hour to 6 hours and longer. Due to this difficult operation and poorer performance the first stage reactor temperature was increased from $388 \mathrm{C}$ to $399 \mathrm{C}$ and the addition rate of the feed catalyst was increased from $200 \mathrm{ppm}$ to $500 \mathrm{ppm}$ dry coal. During Condition 4, after a shutdown and restart of operations, the coal conversion rose back to a value of $91.7 \mathrm{Wt} \% \mathrm{MAF}$ coal. This is only $0.7 \%$ less than during the base condition, Condition 1 , and $2.0 \mathrm{Wt} \%$ higher than during Condition 3.

\section{$\underline{524^{\circ} \mathrm{C}^{+} \text {Resid Conversion and Yield }}$}

The resid conversion, the amount of MAF coal that forms products other than quinoline insolubles, is normally a strong function of catalyst age, Figure 2.7.7. Due to the aging of the catalyst in a Bench Unit, the resid conversion is expected to decrease over the course of the run as the residuum yield increases. From Condition 1 through Condition 3 , with the decrease in pressure, the resid conversion decreased from 92.4 to $80.6 \mathrm{Wt} \% \mathrm{MAF}$ coal, much more than is typically caused by catalyst deactivation alone. During Condition 4 the resid conversion rose to a value close to that of Condition 1 , at $89.6 \mathrm{Wt} \% \mathrm{MAF}$ coal. This condition was at the same pressure as Condition 3 but at a $10^{\circ} \mathrm{C}$ higher temperature in Reactor 1 and with the higher Mo addition rate (2.5 times higher) for the feed catalyst. These changes resulted in an increase in resid conversion of at least $9 \%$ from Condition 3 . However, after Condition 3 there had been a shutdown, with rinsing of the first stage catalyst and addition of some fresh catalyst, that might have contributed to some of this improvement. 


\section{Hydrogen Consumption}

The hydrogen consumption is presented in Figure 2.7.8. Hydrogen consumption during Conditions $1 \& 2$ were very typical of the liquefaction of subbituminous coal under these operating conditions. During Condition 3 the hydrogen consumption dropped by over 1 $\mathrm{Wt} \%$, paralleling the overall drop in performance during this condition. However, during Condition 4 , concurrent with the increase in performance, there was an increase in hydrogen consumption back to a typical level. This shows that even with the reduced hydrogen partial pressure during this condition, the slight increase in reactor severity and the increase in the feed catalyst addition rate compensate for the lower pressure.

\subsection{Product Distribution}

\section{$\underline{\mathrm{C}}_{1}-\mathrm{C}_{3}$ Gas Make}

The $\mathrm{C}_{1}-\mathrm{C}_{3}$ gas make, Figure 2.7.9, ranged from 7.1 to $7.8 \mathrm{Wt} \%$ MAF coal, typical for Black Thunder Mine coal at these conditions. The gas make shows a slight dependency on operating pressure, increasing as the pressure decreases. However, this dependency is so slight that it might not be significant. The heavy gas yield shows no dependency on the operating pressure. A correction was made to the methane production due to the reforming of $\mathrm{H}_{2}$ and $\mathrm{CO}$. The slight drop on the last gas make in Condition 4 is probably due to the increase in the slurry feed catalyst by 2.5 times.

\section{Liquid Product Yield}

The distillate yield and distribution is more difficult than normal to explain and discuss, Figure 2.7.10 \& Table 2.7.3. The primary cause of this is the large amount of "makeup oil" that was used during this run. This "makeup oil" is not the typical makeup oil used during a bench operation which would consist of a single outside oil (usually the start-up oil) that would be used on an as-needed basis when there wasn't sufficient process derived oil available from the pressure filtrations. This "make-up oil" consisted of both the normal startup oil, PFL generated from previous periods (and even previous conditions) and oil which was toluene extracted from the pressure filter solids. The toluene extracted oil would lag behind the process from 2-5 days. These various oil streams were used on an as-need basis whenever they became available. All these streams are not normally analyzed, and when they were used they were all weighed together as a single "makeup oil" charge so that the individual recycle rates were not known. This caused some difficulties in performing the normalized yields especially because these streams contained substantial amounts of resid. The composition of the make-up oil was therefore estimated based upon the available information. This led to a larger level of uncertainty than normal in interpreting these results.

Condition 1 showed an extremely good overall yield of IBP $-524^{\circ} \mathrm{C}$ liquid of $67.0 \mathrm{Wt} \%$ MAF coal, Figure 2.7.10. Additionally this yield is of above average quality, being all of lighter oil fractions boiling below $343^{\circ} \mathrm{C}$. Condition 2 showed the results of a lower resid conversion as the overall distillate yield decreased to $61.4 \mathrm{Wt} \% \mathrm{MAF}$ coal, still mostly composed of light oils. Condition 3 , at the lowest pressure, severity and feed catalyst addition rate, had the 
poorest performance. The total distillate yield dropped to only $53.0 \mathrm{Wt} \% \mathrm{MAF}$ coal. This was also the condition with the largest problem in calculating the composition of the "make-up oil" and was further complicated by the extra large quantity of "makeup oil". Condition 4 results were a large improvement over Condition 3 and were even comparable to Conditions $1 \& 2$. The total distillate yield was $63.6 \mathrm{Wt} \% \mathrm{MAF}$ coal, just between the total yields for Conditions $1 \& 2$. The quality is directly comparable to Condition 2 in terms of the distribution among the various boiling fractions.

\subsection{Product Quality}

Analyses of the liquid products are presented in Tables 2.7.4-2.7.8 and Figures 2.7.11-2.7.15.

\section{Atmospheric Still Overhead and Separation Overhead}

The first stage $\mathrm{SOH}$ and second stage ASOH were actually two of the three feed streams to the hydrotreater, the other being the second stage Hot Separator Overheads, which was not sampled. The second stage SOH is the product from the hydrotreater (see Figure 2.7.30 for the simplified flow scheme). The nitrogen, sulfur and $\mathrm{H} / \mathrm{C}$ atomic ratios for the $\mathrm{ASOH}$, first stage $\mathrm{SOH}$, and second stage $\mathrm{SOH}$ are presented in Tables 2.7.4-2.7.6 \& Figures 2.7.112.7.13. The hydrotreater performance is presented in Table 2.7.7.

The sulfur content of the first stage $\mathrm{SOH}$ rose sharply from Condition 1 to Condition 2 , from 455 to $937 \mathrm{ppm}$, and from Condition 2 to Condition 3, from 937 to $1574 \mathrm{ppm}$. This demonstrates the pressure dependence of sulfur removal in the first stage reactor. From Conditions 3 to 4 the sulfur content dropped back down over $1000 \mathrm{ppm}$ to near its initial level at $506 \mathrm{ppm}$. This clearly shows the benefit of the slight increase in K-1 temperature and feed catalyst addition rate. The $\mathrm{ASOH}$ sulfur had a similar trend, rising from an initial value of $30 \mathrm{ppm}$ in Condition 1 to $95 \mathrm{ppm}$ in Condition 2 to $109 \mathrm{ppm}$ in Condition 3 and then dropping down to $76 \mathrm{ppm}$ in Condition 4 . The second stage $\mathrm{SOH}$, the hydrotreater product, had a negligible sulfur content throughout the run generally at less than $1 \mathrm{ppm}$, showing that the hydrotreater was doing an excellent job removing the sulfur.

The nitrogen content of the first stage $\mathrm{SOH}$ started at an initial value of only $141 \mathrm{ppm}$ in Condition 1 but then increased to a value of $2329 \mathrm{ppm}$ in Condition 2, $2250 \mathrm{ppm}$ in Condition 3 and $2878 \mathrm{ppm}$ in Condition 4 . The ASOH had the same pattern, starting at an initial low level of $120 \mathrm{ppm}$ and then rising to 2843 in Condition 2, 2357 in Condition 3 and 2587 in Condition 4 . These results are due to the fresh catalyst in the reactor being initially extremely active and then sharply dropping off in the removal of nitrogen. Apparently, a sufficiently high $\mathrm{H}_{2}$ partial pressure is required in the low temperature stage to effectively remove the nitrogen. The second stage $\mathrm{SOH}$, the hydrotreater product, had a negligible nitrogen content throughout the run at less than $1 \mathrm{ppm}$, showing that the hydrotreater was doing an excellent job removing the nitrogen. 
The $\mathrm{H} / \mathrm{C}$ atomic ratios of the three streams generally decreased as the run progressed. It was consistently higher for the second stage $\mathrm{SOH}$, ranging from 1.74 to 1.83 , as compared to either the first stage $\mathrm{SOH}$, ranging from 1.52 to 1.60 , or the $\mathrm{ASOH}$, ranging from 1.38 to 1.48. This demonstrated that the hydrotreater increased the hydrogen content of the product.

\section{Pressure Filter Liquid and Pressure Filter Cake}

The pressure filter liquid (PFL) properties for each condition are summed up in Table 2.7.8 \& Figure 2.7.14-2.7.15. As the catalyst aged and the pressure was decreased, the resid content of the PFL increased, from $19.8 \mathrm{Wt} \%$ to $37.6 \mathrm{Wt} \%$, and the $\mathrm{H} / \mathrm{C}$ atomic ratio decreased from 1.07 to 0.91 . The cyclohexane and toluene insolubles increased rapidly from 29.03 to 86.85 and 2.64 to 27.04 respectively as the run progressed. At the end of Period 14 (Condition 3) and the beginning of Period 15 a large amount of "make-up" oil ( $63 \mathrm{Wt} \%$ of the PFL used) was needed by the unit resulting in a sudden sharp change in the values of the properties used to evaluate the quality of the PFL. After this point the same trends for these properties continued.

The pressure filter cake (PFC) analyses are presented in Table 2.7.9.

\subsection{CO Conversion}

$\mathrm{CO}$ interacts with coal either directly of indirectly via nascent hydrogen formed from the water-gas shift reaction. The WGS reaction :

$$
\mathrm{CO}+\mathrm{H}_{2} \mathrm{O}=\mathrm{CO}_{2}+\mathrm{H}_{2}+\text { heat }
$$

is slightly exothermic, hence low temperature tends to shift the reaction towards the right.

In calculating the amount of $\mathrm{CO}$ and $\mathrm{CO}_{2}$ in the off gas, a small correction was made based on the amount of $\mathrm{CO}$ and $\mathrm{CO}_{2}$ produced from the coal. This correction was based on actual values from previous bench tests operating at similar conditions. The $\mathrm{CO}$ conversion is based on the disappearance of $\mathrm{CO}$ from the system:

$$
\text { CO Conversion }=\frac{\mathrm{Co}_{\text {in }}-\mathrm{CO}_{\text {out }}}{-\mathrm{Co}_{\text {in }}} \times 100 \%
$$

Figure 2.7.16 summarizes the CO conversions which were $90 \%$ and higher over the course of the run. These conversions are higher than the value, $73 \%$, calculated assuming the feed $\mathrm{H} 2, \mathrm{CO}$ and $\mathrm{H}_{2} \mathrm{O}$ reached thermodynamic equilibrium at the first stage temperature. However, if an allowance made for the hydrogen reacted with the coal, say $4 \mathrm{~W} \%$, and the water formed from liquefaction of coal, say $10 \mathrm{~W} \%$, then the calculated $\mathrm{CO}$ conversion at equilibrium would be $83 \%$. In effect these results indicate that the extrudate catalyst promotes the water gas shift reaction to essentially attain thermodynamic equilibrium. 
Table 2.7.17 summarizes the first and second stage gas yields during Run CMSL-7 along with those from operations of Run CMSL -4 which included an operation with pure hydrogen feed to the first stage and a syngas operation also. Table 2.7.18 gives the respective gas compositions for those operations. The Condition 1 operation of Run CMSL-7, at $17.2 \mathrm{MPa}$ pressure, had about twice the $\mathrm{CH}_{4}$ formation in the first stage as was obtained during the pure hydrogen operation of Run CMSL-4, which indicates a degree of synthesis of $\mathrm{CH}_{4}$ from a $\mathrm{CO}$ similar to that during the syngas operations of Run CMSL-4, although not to as large a degree. The first stage $\mathrm{CH}_{4}$ formation in the subsequent Conditions 2 and 3 operations of Run CMSL-7, at lower pressures, were at the same level as during the hydrogen only operation of Run CMSL-4, indicating that the synthesis reaction is not as rapid at the lower pressures. However, the first stage $\mathrm{CH}_{4}$ formation in the final Condition 4 operation of Run CMSL-7, at the lowest pressure, was slightly higher than that in earlier operations of the run at the highest pressure. There was a change in catalyst condition at the start of Condition 4 , more Mo additive and the addition of some fresh extrudate catalyst, which may have contributed to this pattern.

\subsection{First And Second Stage Product Analyses For Runs CMSL-4 And CMSL-7 With Syngas Feed To The First Stage}

\section{Solids Analyses}

The filter cakes from the first and second stages were filtered with quinoline, and the resulting solids were washed with THF to remove the quinoline. The ash and elemental analyses of these solids for Run CMSL-7 are presented in Table 2.7.10. Unfortunately, only the ash was determined for Run CMSL-4.

Figure 2.7.17 compares the coal conversion for these two runs with 3 periods from $\mathrm{CC}-1$, also a low/high catalytic/catalytic operation but with pure hydrogen feed to the first stage. The coal conversion for the first stage for Run CC-1 were lower than for any of the periods with syngas feed. This difference averaged about $15 \mathrm{~W} \%$ MAF even though some of the syngas first stages were at the lower $388^{\circ} \mathrm{C}\left(730^{\circ} \mathrm{F}\right)$. However, the one condition in CMSL-4 that had pure $\mathrm{H}_{2}$ fed to the first stage had a high first stage coal conversion of $78 \mathrm{~W} \% \mathrm{MAF}$, comparable to the syngas condition. Thus, although the first stage coal conversion is not definitively increased by syngas, it is at least equally as high as when the full partial pressure of hydrogen is present. The reason for the higher first stage coal conversion in CMSL-4, Period 6, is not clear. One possible explanation is that the coal feed in CMSL-4 had not been dried and contained $25 \%$ water which may have improved the conversion in the first stage.

After the second (hydrogen) stage, the coal conversions were approximately at levels that would be expected based on the corresponding severity, increasing to about $88 \mathrm{~W} \% \mathrm{MAF}$ for operations at $425^{\circ} \mathrm{C}$ and to about $92 \mathrm{~W} \% \mathrm{MAF}$ for operations at $444^{\circ} \mathrm{C}$. It is interesting that in the last condition of CMSL-4, which was starved for CO because of a blockage, the coal conversion in the first stage was high ( $87.3 \mathrm{~W} \% \mathrm{MAF})$, but it was lower in the $438^{\circ} \mathrm{C}$ second stage. This indicates the importance in low temperature/high temperature CTSL of preparing the coal in the first stage for further conversion in the second stage, through sufficient pressure of either syngas or hydrogen. Similarly, the coal was converted in the first stage at 
very high levels during the 2 conditions of lowest $\mathrm{CO}$ and $\mathrm{H}_{2}$ pressure in CMSL-7 (85.5 and $87.8 \mathrm{~W} \% \mathrm{MAF}$ ), but the additional coal conversion in the second stage was only about $4 \% \mathrm{MAF}$ in both cases.

Figure 2.7.18 shows the $\mathrm{H}: \mathrm{C}$ atomic ratios of the unconverted coal vs. coal conversion for the comparable periods in CC-1 and CMSL-7. The hydrogen content of the first stage solids in $\mathrm{CC}-1$ remained close to the initial value of the coal. This is typical for the low temperature catalytic first stage, which effectively adds hydrogen to the reacting solids, and they are not hydrogen depleted as in higher temperature thermal operations. With the syngas feed to the first stage in CMSL-7, the solids hydrogen contents were lower, suggesting a different mechanism of coal dissolution. However, after the second stage, the two operations resulted in similar solids hydrogen contents. Surprisingly, the two highest second stage solids hydrogen contents in Run CMSL-7 occurred during the last two conditions with the lowest back pressure, $10.3 \mathrm{MPa}$ (1500 psig). The missing data from Run CMSL-4 would have been useful in confirming the lower solids hydrogen contents of the syngas operations because of its additional comparison data point with higher coal conversion with $\mathrm{H}_{2}$ feed.

Figure 2.7.19 shows the solids nitrogen:carbon atomic ratios for Runs CC-1 and CMSL-7. In the first stage, these $\mathrm{N}: \mathrm{C}$ ratios were higher than for the feed coal, indicating that the nitrogen was extracted more slowly than the coal was converted. Additional nitrogen was removed from the solids in the second stage. The syngas and $\mathrm{H} 2$ operations generally had similar behavior with respect to nitrogen in the solids, except that less nitrogen was extracted in the second stage during the lower (hydrogen) pressure conditions. At the lowest pressure, 10.3 $\mathrm{MPa}$ ( $1500 \mathrm{psig})$, the nitrogen even increased in the solids between the first and second stages because of the insufficient hydrogen partial pressure.

\section{Liquid Fraction Analyses}

Tables 2.7.11 and 2.7.12 list the elemental analyses of the four liquid fractions for the first and second stage for Runs CMSL-4 and CMSL-7. Additionally, the CCR and cyclohexane and toluene insolubles of the resid fractions are listed.

Figures 2.7.20 through 2.7.23 compare the hydrogen contents of the liquid fractions from these two runs, using syngas feed to the first stage, with Run CC-1 Periods 6, 10, and 19, using pure hydrogen feed. Both types of operation showed the general trend of lower hydrogen content as the catalyst deactivated, but for all fractions the first and second stage fractions from Run $\mathrm{CC}-1$ had higher hydrogen contents than the corresponding fractions from Runs CMSL-4 and CMSL-7. The improved hydrogenation of all liquid fractions with pure hydrogen feed was confirmed by the CMSL-4 Period 5 and 6 (also using pure hydrogen) data, which fell in line with the CC-1 data. It is not clear why the CMSL-7 hydrogen contents were consistently the lowest, even in Condition 1, with equal back pressure as the other runs.

The hydrogen contents were generally lower for the higher temperature second stage liquid fractions. This difference, however, was often less (and sometimes reversed) for the operations with syngas feed, implying that the hydrogenation environment was not as favorable in the first stage. 
The liquid fraction nitrogen analyses, Figures 2.7.24 through 2.7.27, show an increasing trend of nitrogen content as the catalyst deactivated. There was generally little difference between the nitrogen in the first and second stage product fractions, commonly with just a little improvement in the second stage. The CMSL-4 liquid fraction had, on average, slightly higher nitrogen contents than the CC-1 liquid fractions, and the CMSL-7 liquid fractions were higher than the corresponding fractions from the other two runs. Possibly this lower quality with respect to hydrogen and nitrogen contents, could be due to differences in the new batch of coal used for CMSL-7.

Cyclohexane and toluene insolubles in the resid fractions (Figures 2.7.28 and 2.7.29) were much higher for the operations with the syngas feed, especially for Run CMSL-7, than for operations with pure hydrogen feed. They also increased more rapidly with time, inferring possible faster catalyst deactivation in the low hydrogen-pressure environment.

\subsection{Comparison Of CMSL-7 To CMSL-3 And CMSL-4}

Table 2.7.13\& 2.7.14 show a comparison of some key points for CMSL-3, CMSL-4 and CMSL-7 for both low pressure and high pressure operation.

In this comparison, the back pressure for CMSL-3 and CMSL-4 are both 17.2 MPa while CMSL-7 is $10.3 \mathrm{MPa}$. While the first reactor temperature is the same for all three runs, $399^{\circ} \mathrm{C}\left(750^{\circ} \mathrm{F}\right)$, the second reactor temperature was increased for each run from $427 \mathrm{C}$ $\left(800^{\circ} \mathrm{F}\right)$ in CMSL-3 to $437^{\circ} \mathrm{C}\left(818^{\circ} \mathrm{F}\right)$ in CMSL-4 and finally to $442^{\circ} \mathrm{C}\left(827^{\circ} \mathrm{F}\right)$ in CMSL-7. The space velocity was also decreased over the three runs from $940 \mathrm{~kg}$ dry coal $/ \mathrm{hr} / \mathrm{m}^{3}$ catalyst in CMSL-3 to $839 \mathrm{~kg} \mathrm{dry} \mathrm{coal} / \mathrm{hr} / \mathrm{m}^{3}$ catalyst in CMSL-4 to $711 \mathrm{~kg}$ dry coal $/ \mathrm{hr} / \mathrm{m}^{3}$ catalyst in CMSL-7. The second stage catalyst age is comparable for this comparison.

The process performance for the last condition of these three bench runs shows that CMSL-7 is a strong improvement over CMSL-4 and a slight improvement over CMSL-3. CMSL-7 has the highest coal and resid conversion, probably due to the elevation in temperature for the second reactor. It also has a comparable gas yield and the best distillate yield while maintaining a comparable $\mathrm{H}_{2}$ consumption. While this increase in performance is at least partly due to the elevated temperature in the second reactor, it is probably also a result of using not only a supported catalyst in both reactors but also a slurry feed catalyst. This demonstrates that even at a greatly reduced operating pressure of $10.3 \mathrm{MPa}$ process performance can be at least maintained, if not improved.

For the high pressure operation, the back pressure for all three bench operations was 17.2 $\mathrm{MPa}(2500 \mathrm{psi})$. While the first reactor temperature is the same for all three runs, $388^{\circ} \mathrm{C}$ $\left(730^{\circ} \mathrm{F}\right)$, the second reactor temperature was increased for each run from $427^{\circ} \mathrm{C}\left(800^{\circ} \mathrm{F}\right)$ in CMSL-3 to $437^{\circ} \mathrm{C}\left(818^{\circ} \mathrm{F}\right)$ in CMSL-4 finally to $443 \mathrm{C}(829 \mathrm{~F})$ in CMSL-7. The space velocity for all three runs were nearly identical; $687 \mathrm{~kg} \mathrm{dry} \mathrm{coal} / \mathrm{hr} / \mathrm{m}^{3}$ catalyst in CMSL-3, $676 \mathrm{~kg}$ dry coal $/ \mathrm{hr}^{2} / \mathrm{m}^{3}$ catalyst in CMSL-4 and $699 \mathrm{~kg}$ dry coal $/ \mathrm{hr} / \mathrm{m}^{3}$ catalyst in CMSL-7. The second stage catalyst age is lowest for CMSL-7 at $157 \mathrm{~kg}$ dry coal $/ \mathrm{kg}$ catalyst as compared to $234 \mathrm{~kg}$ dry coal $/ \mathrm{kg}$ for CMSL-3 and $315 \mathrm{~kg}$ dry coal $/ \mathrm{kg}$ for CMSL-4. 
The process performance of either CMSL-3 or CMSL-7 show a strong improvement over CMSL-4. CMSL-7 also shows a slight improvement over CMSL-3. While they both have the same coal conversion, the resid conversion for CMSL-7 increases to $92.4 \mathrm{Wt} \% \mathrm{MAF}$ as compared to $89.9 \mathrm{Wt} \% \mathrm{MAF}$ for CMSL-3. Consequently the distillate yield also increases for CMSL-7 to $70.5 \mathrm{Wt} \%$ MAF as compared to $64.6 \mathrm{Wt} \%$ MAF for CMSL-3. The $\mathrm{H}_{2}$ consumption also increases by $0.58 \mathrm{Wt} \% \mathrm{MAF}$ between CMSL-3 and CMSL-7. This demonstrates that the combination of a supported catalyst in both reactors as well as the use of a slurry feed catalyst results in an improvement in process performance as compared to either using only a supported catalyst in both reactors with no slurry feed catalyst or using a slurry feed catalyst but using a supported catalyst in only the second reactor.

\subsection{DETAILS OF OPERATION}

The run plan is given in Table 2.7.1. Four process conditions were chosen for this run. The actual operating conditions are presented in Table 2.7.2.

Tri-nonyl polysulfide (TNPS) and hydrogen sulfide were added to the first and second stage, respectively. The target sulfur addition rate to the first stage was $1 \mathrm{Wt} \%$ of dry coal and $3 \mathrm{Wt} \%$ to the second stage.

\subsection{Bench Unit Description}

CMSL-7 involved two equal volume ebullated bed reactors. A simplified process flow diagram is presented in Figure 2.7.30. Coal was dissolved in the first-stage in the presence of syngas, water and AHM slurry catalyst, and the primary coal liquids were further upgraded in the second stage under a hydrogen atmosphere. An interstage separator was installed to remove gases and light distillates as a first stage separator overhead (SOH) and to recover any excess $\mathrm{CO} / \mathrm{H}_{2}$. Fresh hydrogen was injected into the second stage. Products from the second stage were recovered using a hot separator (as a separator overhead, second stage $\mathrm{SOH}$ ) and a continuous atmospheric still (CAS) which had atmospheric still overheads (ASOH) and CAS bottoms as the outlets. The CAS bottoms were pressure filtered in a batch mode into pressure filter liquid (PFL) and pressure filter cake (PFC). The PFL was used as recycle solvent and as buffer liquids for the ebullating pump operations. The first stage $\mathrm{SOH}$, second stage $\mathrm{SOH}$ and second stage $\mathrm{ASOH}$ were combined as the feed to the hydrotreater. 


\subsection{Operating Summary}

Condition 1 extended from Periods 1 to 7 using a mixture of $\mathrm{CO} \& \mathrm{H}_{2}$ as the reducing gas for the first stage and $\mathrm{H}_{2}$ for the second stage. Also for this condition, and all subsequent conditions, water was injected upstream of the preheater in order to obtain an overall water content of $40 \mathrm{Wt} \%$ of the dry coal in the feed slurry. This condition served as a base case for comparison. Condition 2 was identical to Condition 1 except the back pressure was reduced from 17.2 to $13.8 \mathrm{MPa}$ ( 2500 to $2000 \mathrm{psi}$ ). Condition 3 was identical to Condition 2 except the back pressure was further reduced from $13.8 \mathrm{MPa}$ to $10.3 \mathrm{MPa}(2000 \mathrm{psi}$ to $1500 \mathrm{psi}$ ).

After Condition 3, when a sample of first stage slurry was withdrawn, the pressure drop across the first stage increased to $1.7 \mathrm{MPa}$ (250 psi) and the internal recycle flow was lost. The unit was shutdown and a plug was found in the first stage reactor, with catalyst pushed up one-third the length of the reactor. The first stage catalyst was removed, washed with light oil, and recharged along with $26 \%$ fresh catalyst to make-up for losses. The second stage catalyst remained in place during the turnaround.

Operations were resumed for the final 5 days of the run, as Condition 4 at $10.3 \mathrm{MPa}$ with the first stage temperatures increased by $11^{\circ} \mathrm{C}$, and molybdenum addition increased from 200 $\mathrm{ppm}$ to $500 \mathrm{ppm}$ of dry coal. At the end of the run the unit was running smoothly and the catalysts in the reactors were found in good condition.

\subsection{MATERIALS USED}

\subsection{Coal}

Wyoming subbituminous coal, Black Thunder Mine, was used as the feedstock. The analyses of the feed (HTI-6213) are presented in Table 2.7.15. This batch of coal was previously evaluated in POC-02 and CMSL-6. This coal has approximately $11.5 \mathrm{Wt} \%$ moisture and an ash content of $6.0 \mathrm{Wt} \%$ (dry basis).

\subsection{Start-up/Makeup Oil}

The start-up/make-up oil used during this run was a coal-derived recycle solvent generated during POC-01 (PDU RUN 260-04). The elemental analysis and boiling point distribution is shown in Table 2.7.16. This oil contained $15.1 \mathrm{Wt} \%$ of $524^{\circ} \mathrm{C}+$ resid and has a $\mathrm{H} / \mathrm{C}$ molar ratio of 1.26 .

\subsection{Catalyst Additive}

A feed catalyst was used throughout this run consisting of an aqueous solution of ammonium heptamolybdate. This was added at a concentration level of $200-500 \mathrm{ppm}$ of molybdenum based on the dry coal feed. 


\subsection{Supported Catalyst}

Fresh Shell S-317 1/32" extrudates (HTI-5394) were charged to both the first and second stage ebullated beds. TNPS was added to startup oil during the startup to presulfide the catalyst.

\subsection{Hydrotreater Catalyst}

The hydrotreater was charged with Criterion C-411 trilobe catalyst (HTI-6135). The catalyst was presulfided during normal start-up operations.

\subsection{CONCLUSIONS}

CMSL- 7 was a very successful bench program which significantly advanced the operating conditions under which coal liquefaction can occur in the presence of $\mathrm{CO} / \mathrm{H}_{2} \mathrm{O} / \mathrm{H}_{2}$ as the reducing gas in the first stage. The main objectives of this run were achieved within the 19 days of operations; three different operating pressure were evaluated as well as the effect of increased reactor severity and increased feed catalyst addition on low pressure operation. Samples of the various process streams were obtained for characterization of the properties. The following conclusions can be drawn based upon these results:

- Using supported catalyst in both stages as well as an additive catalyst in the presence of $\mathrm{CO} / \mathrm{H}_{2}$ as the reducing gas results in an improvement in the overall quality of the product oil at normal operating conditions.

- Decreasing the operating pressure while using $\mathrm{CO} / \mathrm{H}_{2}$ as the reducing gas results in a decrease in overall performance as measured by distillate yield, coal conversion and resid conversion. It also results in a decrease in the quality of the product oil.

- The negative effects of lowering the operating pressure on overall performance and product oil quality can largely be mitigated by slightly increasing the severity and by increasing the feed catalyst addition rate. This demonstrates the possibility of performing high quality coal liquefaction at substantially reduced operating pressure with a potential for significant cost savings by reducing the capital investment needed for a higher pressure operating system.

- The conversion of $\mathrm{CO}$ to $\mathrm{H}_{2}$ with the extrudate catalyst was approximately that projected assuming equilibrium for the water gas shift reaction at all the pressure levels that were investigated. There was some syntheses of $\mathrm{CH}_{4}$ from $\mathrm{CO}$ at the highest pressure, which may have been lower at the lower pressures, although the experimental results are ambiguous. 


\title{
Table 2.7.1
}

\section{CMSL-7 Run Plan}

\author{
Coal: Black Thunder Mine Coal (HTI-6213) \\ Catalyst: Hydrotreater: Criterion C-411 Trilobe (HTI-6135) \\ K-1 \& K-2: $\quad$ Shell 317 (HTI-5394) \\ Additive: $\quad 200 \mathrm{ppm}$ Mo as AHM additive
}

Condition

1

2

3

4

Periods

$1-7$

$8-11$

$12-15$

$16-18$

Feed gas

$\begin{array}{cc}\text { 1st Stage } & \mathrm{CO} / \mathrm{H} 2 \\ \text { V/V\% } & 75 / 25 \\ \text { 2nd Stage } & \mathrm{H} 2\end{array}$

$\mathrm{CO} / \mathrm{H} 2$
$75 / 25$

$\mathrm{CO} / \mathrm{H} 2$

$75 / 25$

$\mathrm{CO} / \mathrm{H} 2$

$\mathrm{H} 2$

$\mathrm{H} 2$

$75 / 25$

$\mathrm{H} 2$

Back Pressure, MPa (psi)

$17.2(2500)$

$13.8(2000)$

$10.3(1500)$

$10.3(1500)$

Temp, ${ }^{\circ} \mathrm{C}\left({ }^{\circ} \mathrm{F}\right)$

1st Stage
2nd Stage
Hydrotreater

$388(730)$

$388(730)$

$388(730)$

$388(730)$

$441(825)$

$441(825)$

$441(825)$

$441(825)$

$379(715)$

$379(715)$

$379(715)$

$379(715)$

Feed Catalyst (AHM)

200

200

200

200

(ppm Mo on dry coal)

Solvent / Coal Ratio

1.2

1.2

1.2

1.2

Space Velocity (2nd Stage) $\mathrm{lb}$ dry coal $/ \mathrm{hr} / \mathrm{ft}^{3}$ reactor $\mathrm{kg}$ dry coal $/ \mathrm{hr} / \mathrm{m}^{3}$ reactor

20

320
20

320
20

320
30 480 


\title{
Table 2.7.2
}

\section{CMSL-7 Actual Run Conditions}

\author{
Coal: $\quad$ Black Thunder Mine Coal (HTI-6213) \\ Catalyst: Hydrotreater: Criterion C-411 Trilobe (HTI-6135) \\ K-1 \& K-2: Shell 317 (HTI-5394) \\ Additive: $\quad 200 \mathrm{ppm}$ Mo as AHM additive
}

\begin{tabular}{|c|c|c|c|c|c|}
\hline \multicolumn{2}{|l|}{ Condition } & 1 & 2 & 3 & 4 \\
\hline \multicolumn{2}{|l|}{ Periods } & $1-7$ & $8-11$ & $12-15$ & $16-19$ \\
\hline Feed gas: & $\begin{array}{l}\text { 1st Stage } \\
\text { V/V\% } \\
\text { 2nd Stage }\end{array}$ & $\begin{array}{c}\mathrm{CO} / \mathrm{H}_{2} \\
75.5 / 24.5 \\
\mathrm{H} 2\end{array}$ & $\begin{array}{c}\mathrm{CO} / \mathrm{H} 2 \\
75.2 / 24.8 \\
\mathrm{H} 2\end{array}$ & $\begin{array}{c}\mathrm{CO} / \mathrm{H}_{2} \\
75.0 / 25.0 \\
\mathrm{H} 2\end{array}$ & $\begin{array}{c}\mathrm{CO} / \mathrm{H}_{2} \\
74.8 / 25.2 \\
\mathrm{H} 2\end{array}$ \\
\hline \multicolumn{2}{|c|}{ Back Pressure, MPa (psi) } & $17.2(2500)$ & $13.7(1990)$ & $10.3(1490)$ & $10.4(1510)$ \\
\hline \multicolumn{6}{|l|}{ Temp, ${ }^{\circ} \mathrm{C}$} \\
\hline & $\begin{array}{l}\text { 1st Stage } \\
\text { 2nd Stage } \\
\text { Hydrotreater }\end{array}$ & $\begin{array}{l}388(730) \\
443(829) \\
379(715)\end{array}$ & $\begin{array}{l}388(730) \\
443(829) \\
379(715)\end{array}$ & $\begin{array}{l}388(730) \\
444(831) \\
379(715)\end{array}$ & $\begin{array}{l}399(750) \\
442(828) \\
379(715)\end{array}$ \\
\hline \multicolumn{2}{|c|}{$\begin{array}{l}\text { Feed Catalyst (AHM) } \\
\text { (ppm Mo on dry coal) }\end{array}$} & 200 & 200 & 200 & 500 \\
\hline \multicolumn{2}{|c|}{ Solvent / Coal Ratio } & 1.2 & 1.2 & 1.2 & 1.2 \\
\hline $\begin{array}{l}\text { Space Vel } \\
\text { lb dry coal } \\
\text { kg dry coa }\end{array}$ & $\begin{array}{l}\mathrm{f} \mathrm{ft}^{3} \text { reactor } \\
\mathrm{r} / \mathrm{m}^{3} \text { reactor }\end{array}$ & $\begin{array}{l}19.6 \\
315\end{array}$ & $\begin{array}{l}19.6 \\
314\end{array}$ & $\begin{array}{l}19.8 \\
317\end{array}$ & $\begin{array}{l}20.0 \\
320\end{array}$ \\
\hline
\end{tabular}


Table 2.7.3

\section{Condition Average Process Performance for CMSL-7}

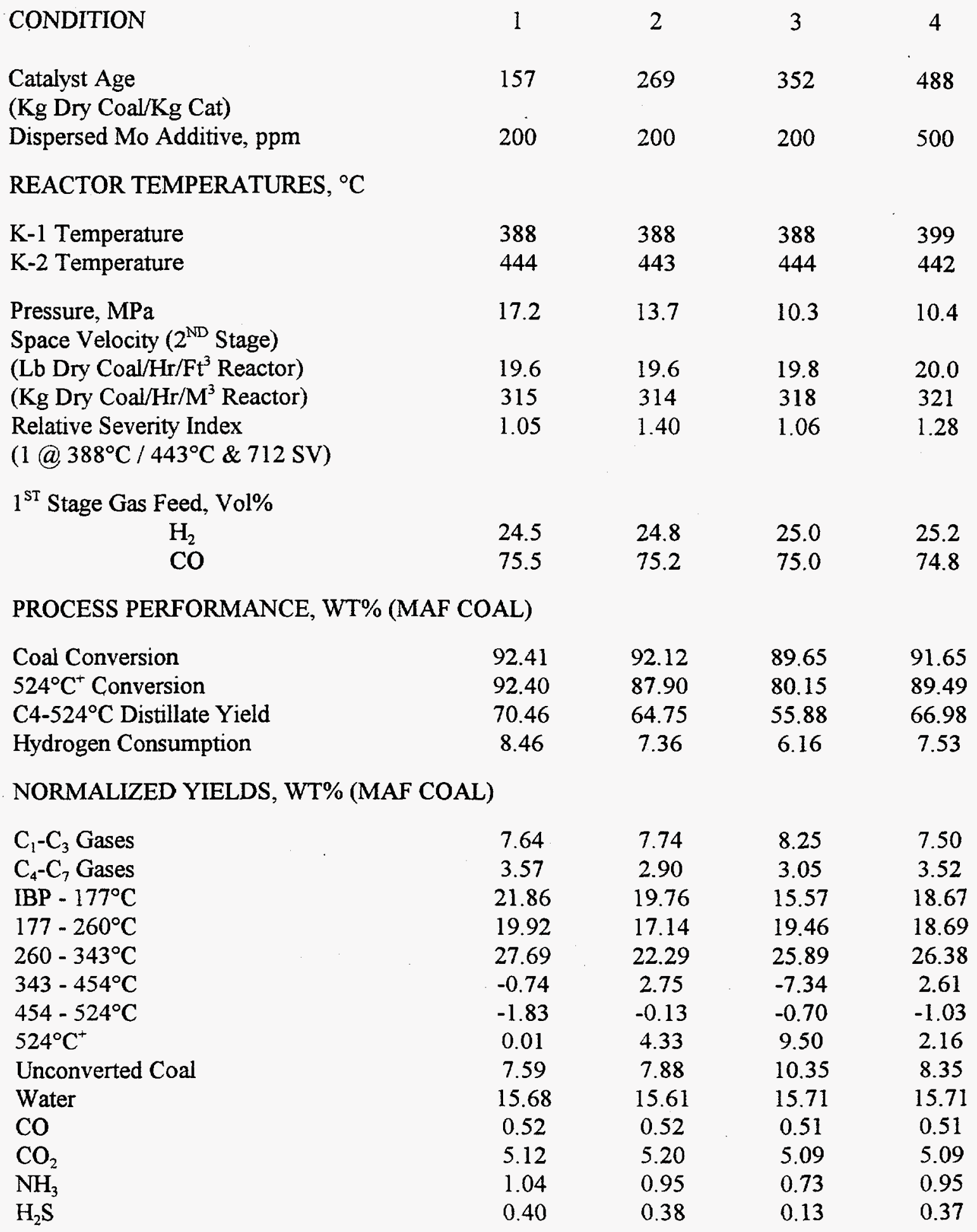

* The $\mathrm{CO}, \mathrm{CO}_{2}$ and $\mathrm{H}_{2} \mathrm{O}$ yields were adjusted assuming that their production from coal would be similar to previous bench operations, with an oxygen elimination of $18.1 \%$ of Maf Coal.

* The negative yields of the heavy oil fractions are probably due to a combination of the poor material balance and the uncertainty in the quality of the "makeup oil". 


\section{Table 2.7.4}

\section{Analysis Of ASOH For CMSL-7}

$\begin{array}{lcccc}\text { CONDITION } & 1 & 2 & 3 & 4 \\ \text { PERIOD } & 7 & 11 & 14 & 19 \\ \text { GRAVITY, }{ }^{\circ} \mathrm{API} & 21.1 & 26.4 & 18.0 & 18.7 \\ \text { IBP, }{ }^{\circ} \mathrm{C} & 154 & 144 & 180 & 175 \\ \mathrm{FBP},{ }^{\circ} \mathrm{C} & 351 & 363 & 346 & 346\end{array}$

ASTM D-86 DISTILLATION, WT\%

$\begin{array}{lcccc}\text { IBP }-177^{\circ} \mathrm{C} & 1.08 & 2.04 & 0.0 & 0.11 \\ 177-260^{\circ} \mathrm{C} & 21.25 & 21.22 & 19.32 & 20.91 \\ 260-343^{\circ} \mathrm{C} & 72.17 & 70.74 & 77.61 & 75.69 \\ 343^{\circ} \mathrm{C}+ & 4.85 & 5.89 & 2.96 & 2.97 \\ \text { Loss } & 0.65 & 0.11 & 0.11 & 0.32\end{array}$

ELEMENTAL ANALYSIS, WT\%

Carbon

Hydrogen

Sulfur (ppm)

Nitrogen (ppm)

H/C RATIO
88.31

10.87

30

120

1.48
88.15

87.95

10.12

109

2357

2843

1.43

1.38
88.01

10.37 76 2587

1.41 


\section{Table 2.7.5}

\section{ANALYSIS OF $1^{\text {ST }}$ STAGE SOH FOR CMSL-7}

CONDITION
PERIOD
GRAVITY, ${ }^{\circ} \mathrm{API}$
IBP, ${ }^{\circ} \mathrm{C}$
FBP, ${ }^{\circ} \mathrm{C}$
ASTM D-86 DISTILLATION, WT $\%$
IBP $-177^{\circ} \mathrm{C}$
$177-260^{\circ} \mathrm{C}$
$260-343^{\circ} \mathrm{C}$
$343+{ }^{\circ} \mathrm{C}$
Loss

ELEMENTAL ANALYSIS, WT\%

Carbon

Hydrogen

Sulfur (ppm)

Nitrogen (ppm)

H/C RATIO

$\begin{array}{cccc}1 & 2 & 3 & 4 \\ 7 & 11 & 14 & 19 \\ 26.8 & 26.4 & 26.6 & 24.0 \\ 83.8 & 78.3 & 82.2 & 76.1 \\ 399 & 406 & 404 & 406\end{array}$

$\begin{array}{llll}25.17 & 26.78 & 26.70 & 25.27 \\ 10.74 & 12.95 & 13.18 & 13.19 \\ 24.61 & 23.44 & 25.14 & 22.86 \\ 37.58 & 3594 & 34.53 & 37.91 \\ 1.90 & 0.89 & 0.45 & 0.77\end{array}$

$\begin{array}{cccc}86.76 & 86.63 & 86.63 & 85.81 \\ 11.55 & 11.31 & 11.20 & 10.89 \\ 455 & 937 & 1574 & 506 \\ 141 & 2329 & 2250 & 2878 \\ 1.60 & 1.57 & 1.55 & 1.52\end{array}$


Table 2.7.6

\section{ANALYSIS OF $2^{\text {ND }}$ STAGE SOH (HYDROTREATER OUTLET) FOR CMSL-7}

CONDITION

PERIOD

GRAVITY, ${ }^{\circ}$ API

IBP, ${ }^{\circ} \mathrm{C}$

FBP,${ }^{\circ} \mathrm{C}$

ASTM D-86 DISTILLATION, WT\%

$$
\begin{aligned}
& \text { IBP }-177^{\circ} \mathrm{C} \\
& 177-260^{\circ} \mathrm{C} \\
& 260-343^{\circ} \mathrm{C} \\
& 343+{ }^{\circ} \mathrm{C} \\
& \text { Loss }
\end{aligned}
$$

ELEMENTAL ANALYSIS, WT\%

Carbon

Hydrogen

Sulfur (ppm)

Nitrogen (ppm)

H/C RATIO

$\begin{array}{cccc}1 & 2 & 3 & 4 \\ 7 & 11 & 14 & 19 \\ 36.2 & 36.8 & 37.6 & 33.7 \\ 53.9 & 58.3 & 65.0 & 68.9 \\ 379 & 389 & 358 & 402\end{array}$

$\begin{array}{rccc}29.02 & 32.22 & 31.90 & 28.12 \\ 25.71 & 25.80 & 32.02 & 23.69 \\ 33.89 & 30.92 & 30.94 & 33.14 \\ 9.60 & 10.23 & 4.78 & 13.77 \\ 1.78 & 0.83 & 0.36 & 1.28\end{array}$

$\begin{array}{cccc}86.45 & 86.86 & 86.41 & 87.00 \\ 13.15 & 13.09 & 12.93 & 12.58 \\ 7.1 & <1.0 & <1.0 & <1.0 \\ <1.0 & <1.0 & <1.0 & <1.0 \\ & & & \\ 1.83 & 1.81 & 1.80 & 1.74\end{array}$




\section{Table 2.7.7}

\section{HYDROTREATER PERFORMANCE}

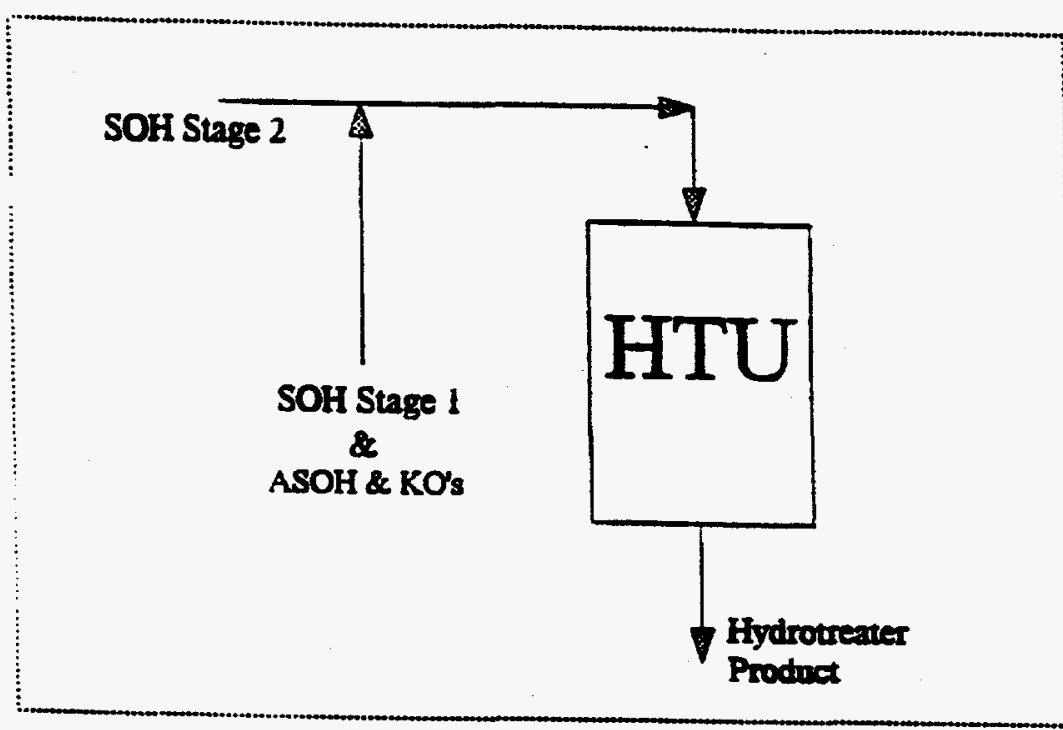

PERIOD

Hydrotreater Temp C (F)

SOH STAGE 1

Feed Rate (gm/hr)

Nitrogen, ppm

Sulfur, ppm

H/C Ratio

ASOH \& KO's

Feed Rate (gm/hr)

Nitrogen, ppm

Sulfur, ppm

H/C Ratio

SOH STAGE 2

Feed Rate $(\mathrm{gm} / \mathrm{hr})$, calculated

HYDROTREATER PRODUCT

Product Rate $(\mathrm{gm} / \mathrm{hr})$

Nitrogen, ppm

Sulfur, ppm

H/C Ratio
7

11

14

19

$381(718) \quad 378(713) \quad 381(717)$

$381(718)$

$\begin{array}{cccc}179 & 166 & 173 & 191 \\ 141 & 2329 & 2250 & 2878 \\ 455 & 937 & 1574 & 506 \\ 1.60 & 1.57 & 1.55 & 1.52\end{array}$

81

120

30

1.48

71

2843

54

2357

109

1.38

1.43

96

97

401

$<1$

7.1

1.83

\section{3}

$<1$

$<1$

1.81
57

2587

76

1.41

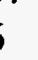

137

91

878

.52

384

$<1$

$<1$

1.74 
Table 2.7.8

Analysis Of PFL For CMSL-7

CONDITION

PERIOD

GRAVTTY, ${ }^{\circ} \mathrm{API}$

IBP, ${ }^{\circ} \mathrm{C}$

ASTM D-1160 DISTILLATION, WT\%

IBP $-343^{\circ} \mathrm{C}$

$343-454^{\circ} \mathrm{C}$

$454-524^{\circ} \mathrm{C}$

$524+{ }^{\circ} \mathrm{C}$

Loss
1

7

1.8

293
2

11

$-4.4$

311

7.25

51.32

15.44

25.52

0.47
4.76

47.44

15.81

31.81

0.18

ELEMENTAL ANALYSIS, WT\%

Carbon

Hydrogen

Sulfur

Nitrogen

H/C RATIO

$524+{ }^{\circ} \mathrm{C}$ ANALYSES

CCR, WT\%

CYCLOHEXANE INS, WT\%

TOLUENE INS, WT\%
91.13

8.10

0.048

0.36

1.07

0.98

0.44

7.36

0.050

$0.91 \quad 0.96$

$0.91 \quad 0.96$

$90.29 \quad 90.18$

$6.88 \quad 7.18$

$0.166 \quad 0.104$

$0.61 \quad 0.02$
2.95

47.68

16.61

32.14

$0.70 \quad 0.62$

$\begin{array}{llll}53.72 & 60.82 & 70.85 & 62.93 \\ 29.03 & 70.14 & 86.86 & 61.19 \\ 2.64 & 11.33 & 27.04 & 10.19\end{array}$




\section{Table 2.7.9}

\section{ANALYSIS OF PFC FOR CMSL-7}

\begin{tabular}{|c|c|c|c|c|}
\hline CONDITION & 1 & 2 & 3 & 4 \\
\hline PERIOD & 7 & 11 & 14 & 19 \\
\hline \multicolumn{5}{|l|}{ ELEMENTAL ANALYSIS, WT\% } \\
\hline Carbon & 65.10 & 66.18 & 72.41 & 70.6 \\
\hline Hydrogen & 4.50 & 4.18 & 4.88 & 4.83 \\
\hline Sulfur & 0.87 & 0.71 & 1.48 & 0.68 \\
\hline Nitrogen & 0.47 & 0.57 & 0.74 & 0.62 \\
\hline H/C RATIO & 0.83 & 0.76 & 0.81 & 0.82 \\
\hline \multicolumn{5}{|l|}{ COMPOSITION, WT\% } \\
\hline ASTM Ash & 25.64 & 24.37 & 15.63 & 19.70 \\
\hline $\mathrm{S}$ in ASTM Ash (\% of ash) & 3.02 & 2.73 & 3.26 & 2.99 \\
\hline Mo in ASTM Ash (\% of ash) & 0.485 & 0.352 & 0.432 & 0.940 \\
\hline N-Pentane Insolubles & 61.66 & 63.85 & 61.02 & 60.09 \\
\hline Toluene Insolubles & 56.33 & 58.30 & 47.73 & 49.53 \\
\hline Quinoline Insolubles & 53.43 & 54.94 & 41.40 & 44.84 \\
\hline \multicolumn{5}{|l|}{ TGA ANALYSIS, WT\% } \\
\hline Resid & 64.2 & 67.11 & 71.83 & 59.59 \\
\hline Ash & 25.6 & 24.71 & 15.93 & 19.02 \\
\hline
\end{tabular}


Table 2.7.10

COMPARISON OF FIRST AND SECOND STAGE PRODUCT SOLID ANALYSES RUN CMSL-7 (227-84)

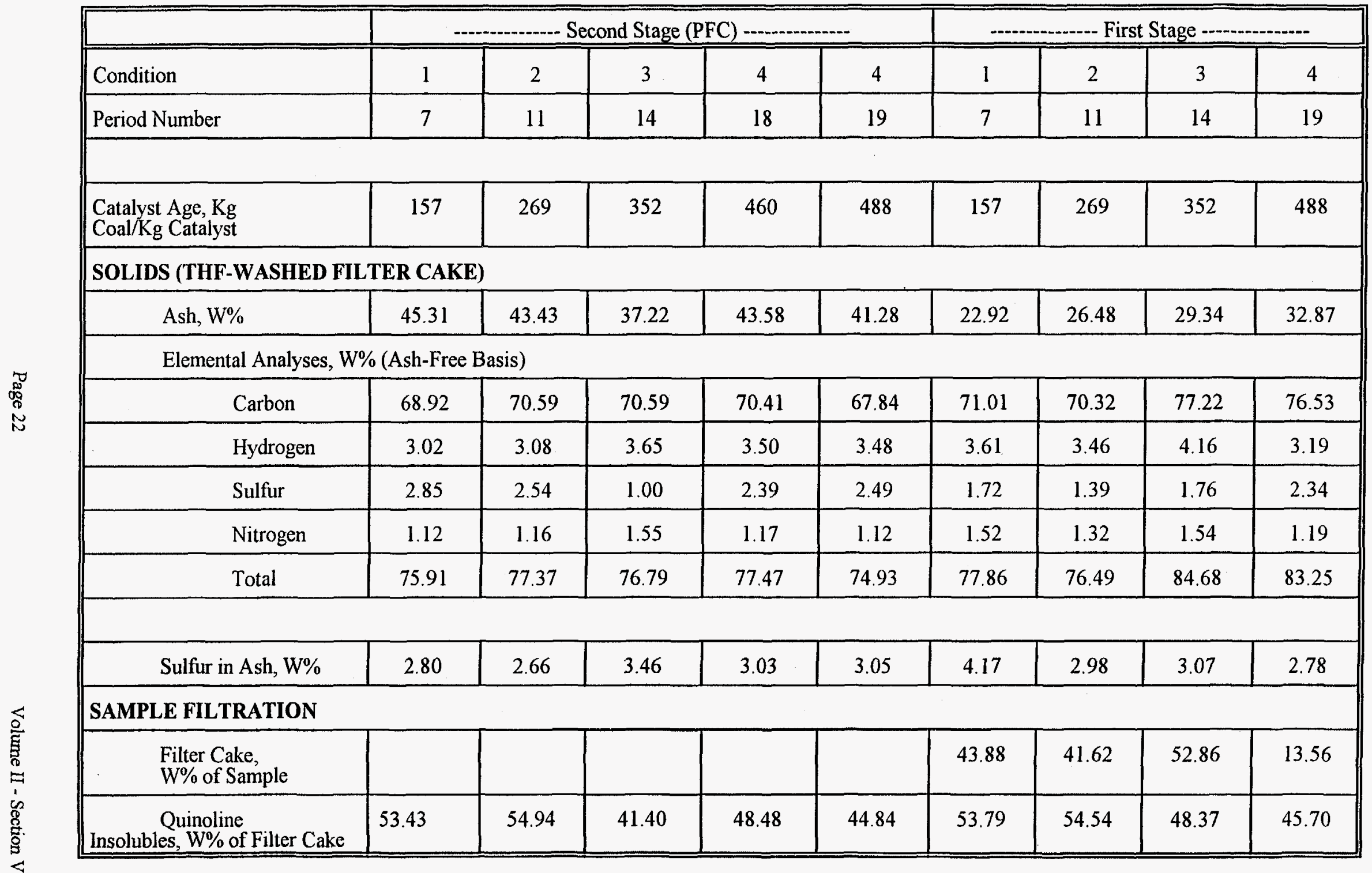


Table 2.7.11

COMPARISON OF FIRST AND SECOND STAGE PRODUCT FRACTION ANALYSES RUN CMSL-4 (227-81)

\begin{tabular}{|c|c|c|c|c|c|c|c|c|}
\hline & 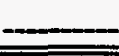 & cond St & e (PFL) & - & & -First & age - & $=$ \\
\hline $\begin{array}{l}\text { Condition } \\
\text { Period Number }\end{array}$ & $\begin{array}{l}1 \\
5\end{array}$ & $\begin{array}{c}2 \\
10\end{array}$ & $\begin{array}{c}3 \\
13\end{array}$ & $\begin{array}{c}4 \\
17\end{array}$ & $\begin{array}{l}1 \\
6\end{array}$ & $\begin{array}{c}2 \\
10\end{array}$ & $\begin{array}{c}3 \\
13\end{array}$ & $\begin{array}{c}4 \\
17\end{array}$ \\
\hline $\begin{array}{l}\text { Catalyst Age, } \mathrm{Kg} \\
\text { Coal } / \mathrm{Kg} \text { Catalyst }\end{array}$ & 185 & 315 & 510 & 540 & 211 & 315 & 410 & 540 \\
\hline $\begin{array}{l}\text { TOTAL LIQUID } \\
\text { Gravity, }{ }^{\circ} \mathrm{API}\end{array}$ & 10.0 & 5.5 & 1.0 & -4.7 & 9.6 & 5.2 & -2.4 & -5.3 \\
\hline Elemental Analyses & $\mathrm{s}, \mathrm{W} \%$ & & & & & & & \\
\hline $\begin{array}{l}\text { Carbon } \\
\text { Hydrogen } \\
\text { Sulfur } \\
\text { Nitrogen } \\
\quad \text { Total }\end{array}$ & $\begin{array}{r}89.3 \\
10.22 \\
0.010 \\
0.21 \\
100.1\end{array}$ & $\begin{array}{r}89.93 \\
9.16 \\
0.047 \\
0.29 \\
99.43\end{array}$ & $\begin{array}{r}90.64 \\
8.39 \\
0.060 \\
0.43 \\
99.52\end{array}$ & $\begin{array}{r}91.20 \\
7.46 \\
0.047 \\
0.57 \\
99.28\end{array}$ & $\begin{array}{r}88.65 \\
10.03 \\
0.030 \\
0.22 \\
98.93\end{array}$ & $\begin{array}{r}89.13 \\
9.30 \\
0.090 \\
0.35 \\
98.87\end{array}$ & $\begin{array}{r}89.48 \\
7.96 \\
0.104 \\
0.54 \\
98.08\end{array}$ & $\begin{array}{r}89.42 \\
7.53 \\
0.127 \\
0.62 \\
97.70\end{array}$ \\
\hline $\begin{array}{l}343^{\circ} \mathrm{C}, \mathrm{W} \% \\
343-454^{\circ} \mathrm{C}, \mathrm{W} \% \\
454-524^{\circ} \mathrm{C}, \mathrm{W} \% \\
524{ }^{\circ} \mathrm{C}+, \mathrm{W} \% \\
\text { Loss, WT }\end{array}$ & $\begin{array}{r}6.20 \\
53.00 \\
18.50 \\
22.00 \\
0.30\end{array}$ & $\begin{array}{r}6.87 \\
49.95 \\
17.52 \\
25.36 \\
0.30\end{array}$ & $\begin{array}{r}5.14 \\
46.73 \\
17.01 \\
30.65 \\
0.47\end{array}$ & $\begin{array}{r}6.09 \\
39.25 \\
14.70 \\
39.70 \\
0.26\end{array}$ & $\begin{array}{r}8.08 \\
47.36 \\
17.05 \\
27.12 \\
0.39\end{array}$ & $\begin{array}{r}6.28 \\
45.51 \\
17.59 \\
30.14 \\
0.48\end{array}$ & $\begin{array}{r}5.02 \\
37.50 \\
14.78 \\
41.97 \\
0.72\end{array}$ & $\begin{array}{r}5.62 \\
34.26 \\
14.01 \\
45.58 \\
0.53\end{array}$ \\
\hline LGO (IBP $\left.-343^{\circ} \mathrm{C}\right)$ & & . & & & & & & \\
\hline $\begin{array}{l}\text { Carbon, W\% } \\
\text { Hydrogen, W\% } \\
\text { Sulfur, W\% } \\
\text { Nitrogen, W\% }\end{array}$ & $\begin{array}{l}89.41 \\
11.61 \\
0.004 \\
0.047\end{array}$ & $\begin{array}{l}88.68 \\
10.78 \\
0.017 \\
0.151\end{array}$ & $\begin{array}{l}88.98 \\
10.58 \\
0.017 \\
0.255\end{array}$ & $\begin{array}{l}88.92 \\
10.10 \\
0.018 \\
0.329\end{array}$ & $\begin{array}{l}87.88 \\
11.73 \\
0.021 \\
0.084\end{array}$ & $\begin{array}{l}88.04 \\
11.25 \\
0.058 \\
0.247\end{array}$ & $\begin{array}{l}87.59 \\
10.59 \\
0.057 \\
0.258\end{array}$ & $\begin{array}{l}87.62 \\
10.39 \\
0.066 \\
0.357\end{array}$ \\
\hline VGO $\left(343-454^{\circ} \mathrm{C}\right)$ & & & & & & & & \\
\hline $\begin{array}{l}\text { Carbon, W\% } \\
\text { Hydrogen, W\% } \\
\text { Sulfur, W\% } \\
\text { Nitrogen, W\% }\end{array}$ & $\begin{array}{l}89.27 \\
10.91 \\
0.009 \\
0.078 \\
\end{array}$ & $\begin{array}{l}89.35 \\
10.06 \\
0.038 \\
0.178 \\
\end{array}$ & $\begin{array}{r}89.83 \\
9.60 \\
0.045 \\
0.257 \\
\end{array}$ & $\begin{array}{r}90.02 \\
9.06 \\
0.041 \\
0.297 \\
\end{array}$ & $\begin{array}{l}88.59 \\
10.81 \\
0.029 \\
0.108 \\
\end{array}$ & $\begin{array}{l}89.17 \\
10.39 \\
0.071 \\
0.251 \\
\end{array}$ & $\begin{array}{r}89.19 \\
9.56 \\
0.074 \\
0.260 \\
\end{array}$ & $\begin{array}{r}88.98 \\
9.09 \\
0.123 \\
0.377 \\
\end{array}$ \\
\hline HVGP $\left(454-524^{\circ} \mathrm{C}\right)$ & & & & & & & & \\
\hline $\begin{array}{l}\text { Carbon, W\% } \\
\text { Hydrogen, W\% } \\
\text { Sulfur, W\% } \\
\text { Nitrogen, W\% }\end{array}$ & $\begin{array}{r}89.81 \\
9.91 \\
0.019 \\
0.17\end{array}$ & $\begin{array}{r}89.95 \\
8.94 \\
0.041 \\
0.31\end{array}$ & $\begin{array}{r}90.61 \\
8.20 \\
0.042 \\
0.43\end{array}$ & $\begin{array}{r}91.32 \\
7.64 \\
0.037 \\
0.57\end{array}$ & $\begin{array}{r}88.75 \\
9.83 \\
0.039 \\
0.21\end{array}$ & $\begin{array}{r}90.06 \\
8.95 \\
0.079 \\
0.29\end{array}$ & $\begin{array}{r}89.64 \\
7.97 \\
0.081 \\
0.42\end{array}$ & $\begin{array}{r}89.52 \\
7.79 \\
0.142 \\
0.52\end{array}$ \\
\hline RESIDUUM $\left(524{ }^{\circ} \mathrm{C}+\right)$ & & & & & & & & \\
\hline $\begin{array}{l}\text { Carbon, W\% } \\
\text { Hydrogen, W\% } \\
\text { Sulfur, W\% } \\
\text { Nitrogen, W\% } \\
\text { CCR, W\% } \\
\text { CHX Insols., W\% } \\
\text { Tol. Insols., W\% } \\
\text { Ash, W\% } \\
\end{array}$ & $\begin{array}{r}90.16 \\
8.61 \\
0.060 \\
0.31 \\
30.00 \\
1.79 \\
0.08 \\
0.00 \\
\end{array}$ & $\begin{array}{r}90.58 \\
7.22 \\
0.050 \\
0.55 \\
40.72 \\
12.41 \\
1.04 \\
0.01 \\
\end{array}$ & $\begin{array}{r}91.43 \\
6.34 \\
0.043 \\
0.73 \\
55.98 \\
31.54 \\
1.84 \\
0.00 \\
\end{array}$ & $\begin{array}{r}91.50 \\
5.64 \\
0.056 \\
0.92 \\
65.42 \\
71.11 \\
18.57 \\
0.03 \\
\end{array}$ & $\begin{array}{r}88.88 \\
8.61 \\
0.070 \\
0.43 \\
25.90 \\
2.19 \\
0.36 \\
0.00 \\
\end{array}$ & $\begin{array}{r}89.21 \\
7.38 \\
0.082 \\
0.64 \\
41.70 \\
25.44 \\
1.67 \\
0.00 \\
\end{array}$ & $\begin{array}{r}89.28 \\
6.05 \\
0.132 \\
0.84 \\
59: 16 \\
74.16 \\
23.13 \\
0.03 \\
\end{array}$ & $\begin{array}{r}89.42 \\
7.53 \\
0.127 \\
0.62 \\
64.85 \\
74.76 \\
35.15 \\
0.01 \\
\end{array}$ \\
\hline
\end{tabular}


Table 2.7.12

\section{COMPARISON OF FIRST AND SECOND STAGE PRODUCT FRACTION ANALYSES RUN CMSL-7 (227-84)}

\begin{tabular}{|c|c|c|c|c|c|c|c|c|}
\hline \multirow{2}{*}{$\begin{array}{l}\text { Condition } \\
\text { Period Number }\end{array}$} & \multicolumn{4}{|c|}{----- Second Stage (PFL) -.--- } & \multicolumn{4}{|c|}{ - First Stage -.......-. } \\
\hline & $\begin{array}{l}1 \\
7\end{array}$ & $\begin{array}{c}2 \\
11\end{array}$ & $\begin{array}{c}3 \\
14\end{array}$ & $\begin{array}{c}4 \\
19\end{array}$ & $\begin{array}{l}1 \\
7\end{array}$ & $\begin{array}{c}2 \\
11\end{array}$ & $\begin{array}{c}3 \\
14\end{array}$ & $\begin{array}{c}4 \\
19\end{array}$ \\
\hline $\begin{array}{l}\text { Catalyst Age, } \mathrm{Kg} \\
\text { Coal/Kg Catalyst }\end{array}$ & 157 & 269 & 488 & 488 & 157 & 269 & 352 & 48 \\
\hline \multicolumn{9}{|l|}{ TOTAL LIQUID } \\
\hline Gravity, ${ }^{\circ} \mathrm{API}$ & 1.8 & -4.4 & -8.0 & -5.1 & -0.5 & -5.2 & -3.8 & -2.6 \\
\hline \multicolumn{9}{|c|}{ Elemental Analyses, W\% } \\
\hline $\begin{array}{l}\text { Carbon } \\
\text { Hydrogen } \\
\text { Sulfur } \\
\text { Nitrogen } \\
\quad \text { Total }\end{array}$ & $\begin{array}{r}91.13 \\
8.10 \\
0.048 \\
0.36 \\
99.64\end{array}$ & $\begin{array}{r}90.46 \\
7.36 \\
0.050 \\
0.44 \\
98.31\end{array}$ & $\begin{array}{r}90.29 \\
6.88 \\
0.166 \\
0.61 \\
97.95\end{array}$ & $\begin{array}{r}90.18 \\
7.18 \\
0.1043 \\
0.62 \\
98.08\end{array}$ & $\begin{array}{r}89.01 \\
8.26 \\
0.123 \\
0.51 \\
97.90\end{array}$ & $\begin{array}{r}89.06 \\
7.29 \\
0.190 \\
0.67 \\
97.21\end{array}$ & $\begin{array}{r}88.75 \\
7.71 \\
0.560 \\
0.56 \\
97.58\end{array}$ & $\begin{array}{r}89.96 \\
7.45 \\
0.271 \\
0.75 \\
98.43\end{array}$ \\
\hline $\begin{array}{l}343^{\circ} \mathrm{C}-, \mathrm{W} \% \\
343-454^{\circ} \mathrm{C}, \mathrm{W} \% \\
454-524^{\circ} \mathrm{C}, \mathrm{W} \% \\
524{ }^{\circ} \mathrm{C}+, \mathrm{W} \% \\
\text { Loss, W\% }\end{array}$ & $\begin{array}{r}7.25 \\
51.32 \\
15.44 \\
25.52 \\
0.47\end{array}$ & $\begin{array}{r}4.76 \\
47.44 \\
15.81 \\
31.81 \\
0.18\end{array}$ & $\begin{array}{r}4.19 \\
44.24 \\
15.88 \\
34.99 \\
0.70\end{array}$ & $\begin{array}{r}2.95 \\
47.68 \\
16.61 \\
32.14 \\
0.62\end{array}$ & $\begin{array}{r}7.96 \\
44.72 \\
16.30 \\
30.19 \\
0.83\end{array}$ & $\begin{array}{r}4.91 \\
38.66 \\
15.45 \\
40.54 \\
0.44\end{array}$ & $\begin{array}{r}5.69 \\
47.74 \\
15.70 \\
30.33 \\
0.54\end{array}$ & $\begin{array}{r}14.85 \\
33.42 \\
15.03 \\
35.98 \\
0.72\end{array}$ \\
\hline \multicolumn{9}{|l|}{ LGO (IBP $\left.-343^{\circ} \mathrm{C}\right)$} \\
\hline $\begin{array}{l}\text { Carbon, W\% } \\
\text { Hydrogen, W\% } \\
\text { Sulfur, W\% } \\
\text { Nitrogen, W\% (P-E) }\end{array}$ & $\begin{array}{r}89.94 \\
10.13 \\
0.033 \\
0.19 \\
\end{array}$ & $\begin{array}{r}89.56 \\
9.82 \\
0.058 \\
0.35 \\
\end{array}$ & $\begin{array}{r}89.61 \\
9.54 \\
0.101 \\
0.41 \\
\end{array}$ & $\begin{array}{r}89.63 \\
9.70 \\
0.035 \\
0.42 \\
\end{array}$ & $\begin{array}{r}87.86 \\
10.62 \\
0.056 \\
0.29 \\
\end{array}$ & $\begin{array}{r}87.92 \\
10.21 \\
0.091 \\
0.36 \\
\end{array}$ & $\begin{array}{r}87.85 \\
10.11 \\
0.168 \\
0.32 \\
\end{array}$ & $\begin{array}{r}87.23 \\
11.33 \\
0.199 \\
0.29 \\
\end{array}$ \\
\hline \multicolumn{9}{|l|}{ VGO $\left(343-454^{\circ} \mathrm{C}\right)$} \\
\hline $\begin{array}{l}\text { Carbon, W\% } \\
\text { Hydrogen, W\% } \\
\text { Sulfur, W\% } \\
\text { Nitrogen, W\% (P-E) }\end{array}$ & $\begin{array}{r}90.62 \\
8.87 \\
0.056 \\
0.26\end{array}$ & $\begin{array}{r}90.23 \\
8.52 \\
0.051 \\
0.36\end{array}$ & $\begin{array}{r}90.22 \\
8.04 \\
0.141 \\
0.48\end{array}$ & $\begin{array}{r}90.64 \\
8.31 \\
0.110 \\
0.53\end{array}$ & $\begin{array}{r}89.85 \\
9.11 \\
0.128 \\
0.27 \\
\end{array}$ & $\begin{array}{r}89.17 \\
8.54 \\
0.181 \\
0.36\end{array}$ & $\begin{array}{r}89.62 \\
8.40 \\
0.516 \\
0.32 \\
\end{array}$ & $\begin{array}{r}89.74 \\
8.48 \\
0.354 \\
0.48\end{array}$ \\
\hline \multicolumn{9}{|l|}{ HVGO $\left(454-524^{\circ} \mathrm{C}\right)$} \\
\hline $\begin{array}{l}\text { Carbon, W\% } \\
\text { Hydrogen, W\% } \\
\text { Suifur, W\% } \\
\text { Nitrogen, W\% }\end{array}$ & $\begin{array}{r}91.46 \\
7.73 \\
0.067 \\
0.45\end{array}$ & $\begin{array}{r}89.96 \\
7.13 \\
0.074 \\
0.56\end{array}$ & $\begin{array}{r}90.76 \\
6.44 \\
0.183 \\
0.71\end{array}$ & $\begin{array}{r}91.23 \\
6.95 \\
0.140 \\
0.70\end{array}$ & $\begin{array}{r}89.47 \\
7.55 \\
0.182 \\
0.50\end{array}$ & $\begin{array}{r}90.26 \\
7.37 \\
0.295 \\
0.59\end{array}$ & $\begin{array}{r}88.98 \\
7.10 \\
0.719 \\
0.50\end{array}$ & $\begin{array}{r}90.24 \\
6.67 \\
0.463 \\
0.69\end{array}$ \\
\hline \multicolumn{9}{|l|}{ RESIDUUM $\left(524^{\circ} \mathrm{C}+\right)$} \\
\hline $\begin{array}{l}\text { Carbon, W\% } \\
\text { Hydrogen, W\% } \\
\text { Sulfur, W\% } \\
\text { Nitrogen, W\% } \\
\text { CCR, W\% } \\
\text { CHX Insols., W\% } \\
\text { Tol. Insols., W\% } \\
\text { Ash, W\% } \\
\end{array}$ & $\begin{array}{r}92.25 \\
6.12 \\
0.028 \\
0.64 \\
53.72 \\
29.03 \\
2.64 \\
0.00 \\
\end{array}$ & $\begin{array}{r}91.73 \\
5.59 \\
0.038 \\
0.91 \\
60.82 \\
70.14 \\
11.33 \\
0.00 \\
\end{array}$ & $\begin{array}{r}90.88 \\
4.92 \\
0.108 \\
0.97 \\
70.85 \\
86.85 \\
27.04 \\
1.020 \\
\end{array}$ & $\begin{array}{r}91.71 \\
5.42 \\
0.056 \\
0.99 \\
62.93 \\
61.19 \\
10.19 \\
0.00 \\
\end{array}$ & $\begin{array}{r}88.77 \\
6.64 \\
0.195 \\
0.83 \\
50.86 \\
58.92 \\
14.81 \\
0.03 \\
\end{array}$ & $\begin{array}{r}88.48 \\
5.96 \\
0.256 \\
0.94 \\
57.66 \\
72.91 \\
28.70 \\
0.12 \\
\end{array}$ & $\begin{array}{r}88.32 \\
5.92 \\
0.441 \\
1.06 \\
59.74\end{array}$ & $\begin{array}{r}91.06 \\
5.16 \\
0.186 \\
1.07 \\
\\
81.27 \\
30.31 \\
0.00 \\
\end{array}$ \\
\hline
\end{tabular}




\section{Table 2.7.13}

\section{COMPARISON OF LOW PRESSURE OPERATION OF CMSL-7 TO CMSL-3 AND CMSL-4}
CMSL-3
CMSL-4
CMSL-7

OPERATING CONDITIONS

Back Pressure, MPa (psi)

$\begin{array}{ccc}17.2(2500) & 17.2(2500) & 10.3(1500) \\ 940 & 839 & 711 \\ 399(750) & 399(750) & 399(750) \\ 427(800) & 437(818) & 442(827) \\ 25 / 25 & 70 / 30 & 25 / 75\end{array}$

$\mathrm{SV}, \mathrm{kg}$ dry coal $/ \mathrm{hr} / \mathrm{m}^{3}$ catalyst

First Stage Temperature, ${ }^{\circ} \mathrm{C}\left({ }^{\circ} \mathrm{F}\right)$

Second Stage Temperature, ${ }^{\circ} \mathrm{C}\left({ }^{\circ} \mathrm{F}\right)$

H2 / CO Reducing Gas, Vol\%

\section{CATALYST}

First Stage Supported

NONE Shell - 317 Shell - 317

Second Stage Supported

Shell -317

Shell - 317

Shell -317

Feed Catalyst, ppm of molybdenum

1500

NONE

500

$2^{\mathrm{ND}}$ Stage Catalyst Age, kg dry coal $/ \mathrm{kg}$ cat

419

507

488

PROCESS PERFORMANCE, WT\% (MAF)

Coal Conversion

$524+{ }^{\circ} \mathrm{C}$ Resid Conversion

$\mathrm{C}_{4}-524^{\circ} \mathrm{C}$ Distillate Yield

$\mathrm{C}_{1}-\mathrm{C}_{3}$ Gas Yield

$\mathrm{H}_{2}$ Consumption
90.1

85.8

62.0

5.8

6.97
86.8

82

53.26

9.2

8.35
91.7

89.5

67.0

7.5

7.5 


\title{
Table 2.7.14
}

\section{COMPARISON OF HIGH PRESSURE OPERATION OF CMSL-7 TO CMSL-3 AND CMSL-4}

\author{
CMSL-3 CMSL-4 CMSL-7
}

OPERATING CONDITIONS

Back Pressure, MPa (psi)

$17.2(2500) \quad 17.2(2500) \quad 17.2(2500)$

$\mathrm{SV}, \mathrm{kg}$ dry coal $/ \mathrm{hr} / \mathrm{m}^{3}$ catalyst

687

676

699

First Stage Temperature, ${ }^{\circ} \mathrm{C}\left({ }^{\circ} \mathrm{F}\right)$

$388(730)$

$388(730)$

$388(730)$

Second Stage Temperature, ${ }^{\circ} \mathrm{C}\left({ }^{\circ} \mathrm{F}\right)$

$427(800)$

$437(818)$

$443(829)$

H2 / CO Reducing Gas, Vol\%

$25 / 75$

$86 / 14$

$25 / 75$

\section{CATALYST}

First Stage Supported

NONE Shell $-317 \quad$ Shell -317

Second Stage Supported

Shell $-317 \quad$ Shell $-317 \quad$ Shell -317

Feed Catalyst, ppm of molybdenum

1500

NONE

500

$2^{\mathrm{ND}}$ Stage Catalyst Age, kg dry coal/kg cat

234

315

157

PROCESS PERFORMANCE, WT\% (MAF)

Coal Conversion

92.0

87.63

92.4

$524+{ }^{\circ} \mathrm{C}$ Resid Conversion

89.9

84.54

92.4

$\mathrm{C}_{4}-524^{\circ} \mathrm{C}$ Distillate Yield

64.6

58.52

70.5

$\mathrm{C}_{1}-\mathrm{C}_{3}$ Gas Yield

6.56

7.65

7.64

$\mathrm{H}_{2}$ Consumption

7.73

9.61

8.46 


\section{Table 2.7.15}

\section{ANALYSIS OF FEED COAL FOR CMSL-7}

HTI No.

MOISTURE CONTENT

11.47

PROXIMATE ANALYSIS, WT\% Dry Basis

Volatile Matter

43.48

Fixed Carbon

50.52

Ash

6.00

Sulfur in Ash

6.00

$\mathrm{SO}_{3}$ - Free Ash (CALC)

5.10

ULTIMATE ANALYSIS, WT\% Dry Basis

Carbon

69.95

Hydrogen

4.50

Sulfur

0.39

Nitrogen

0.89

Ash

6.00

Oxygen (by diff.)

18.27

H/C RATIO

0.77 
Table 2.7.16

\section{ANALYSIS OF START-UP SOLVENT / MAKE-UP OIL}

HTI No.

${ }^{\circ}$ API Gravity

ELEMENTAL ANALYSIS, Wt $\%$

Carbon

Hydrogen

Sulfur

Nitrogen

H/C RATIO

ASTM D-1160 DISTILLATION, ${ }^{\circ} \mathrm{C}$

IBP

$5 \mathrm{~V} \%$

$10 \mathrm{~V} \%$

$20 \mathrm{~V} \%$

$30 \mathrm{~V} \%$

$40 \mathrm{~V} \%$

$50 \mathrm{~V} \%$

$60 \mathrm{~V} \%$

$70 \mathrm{~V} \%$

$80 \mathrm{~V} \%$

$88 \mathrm{~V} \%$
L-809

6.3

88.62

9.32

0.58

0.18

1.26

311

335

343

360

378

387

406

425

445

488

524

Weight Percents

$$
\begin{aligned}
& \text { IBP }-343^{\circ} \mathrm{C} \\
& 343-454^{\circ} \mathrm{C} \\
& 454-524^{\circ} \mathrm{C} \\
& 524^{\circ} \mathrm{C}+ \\
& \text { Loss }
\end{aligned}
$$

9.71

59.51

15.24

15.15

0.39 


\begin{tabular}{|c|c|c|c|c|c|c|}
\hline \multicolumn{7}{|c|}{$\begin{array}{l}\text { Table } 2.7 .17 \\
\text { YIELDS OF GASES FOR RUN 227-84 (CMSL-7) } \\
\text { COAL: BLACK THUNDER MINE (HTI 6213) }\end{array}$} \\
\hline $\begin{array}{l}\text { Run CMSL } \\
\text { Period Number } \\
\text { Date (Start of Period) } \\
\text { Hours of Run (End of Period) }\end{array}$ & $\begin{array}{l}4 \\
5 \\
03 / 10 / 94 \\
120\end{array}$ & $\begin{array}{l}4 \\
9 \\
03 / 14 / 94 \\
216\end{array}$ & $\begin{array}{l}7 \\
7 \\
10 / 02 / 94 \\
160\end{array}$ & $\begin{array}{l}7 \\
11 \\
10 / 06 / 94 \\
256\end{array}$ & $\begin{array}{l}7 \\
14 \\
10 / 09 / 94 \\
328\end{array}$ & $\begin{array}{l}7 \\
19 \\
10 / 20 / 94 \\
448\end{array}$ \\
\hline $\begin{array}{l}\text { First Stage Gas, V\% } \mathrm{CO} \\
\text { Pressure, } \mathrm{MPa} \\
\text { 1st Stage Temperature, }{ }^{\circ} \mathrm{C} \\
\text { 2nd Stage Temperature, }{ }^{\circ} \mathrm{C} \\
\text { Dry Coal, } \mathrm{Kg} / \mathrm{Hr} / \mathrm{M}^{3} \text { Catalyst }\end{array}$ & $\begin{array}{c}0 \\
17.2 \\
388 \\
427 \\
697\end{array}$ & $\begin{array}{c}86 \\
17.2 \\
388 \\
427 \\
676\end{array}$ & $\begin{array}{l}75 \\
17.2 \\
388 \\
444 \\
700\end{array}$ & $\begin{array}{c}75 \\
13.7 \\
388 \\
443 \\
697\end{array}$ & $\begin{array}{c}75 \\
10.3 \\
388 \\
444 \\
706\end{array}$ & $\begin{array}{c}75 \\
10.4 \\
399 \\
442 \\
713\end{array}$ \\
\hline \multicolumn{7}{|c|}{ GAS PRODUCT (STAGE I VENT), W\% of $\mathrm{mf}$ coal } \\
\hline $\begin{array}{l}\mathrm{CH}_{4} \\
\mathrm{C}_{2} \mathrm{H}_{4} \\
\mathrm{C}_{2} \mathrm{H}_{6} \\
\mathrm{C}_{3} \mathrm{H}_{6} \\
\mathrm{C}_{3} \mathrm{H}_{8} \\
\mathrm{C}_{4} \mathrm{H}_{8} \\
\mathrm{~N}-\mathrm{C}_{4} \mathrm{H}_{10} \\
\mathrm{I}_{4} \mathrm{H}_{10} \\
\mathrm{C}_{5} \mathrm{H}_{10} \\
\mathrm{~N}-\mathrm{C}_{5} \mathrm{H}_{12} \\
\mathrm{I}-\mathrm{C}_{5} \mathrm{H}_{12} \\
\mathrm{METHYL}-\mathrm{CYCLOPENTANE} \\
\mathrm{CYCLOHEXANE} \\
\mathrm{N}-\mathrm{C}_{6} \mathrm{H}_{14} \\
\mathrm{C}_{6}-\mathrm{C}_{7} \\
\mathrm{CO} \\
\mathrm{CO} \\
\mathrm{H}_{2} \mathrm{~S} \\
\end{array}$ & $\begin{array}{l}1.05 \\
0.00 \\
0.49 \\
0.00 \\
0.52 \\
0.00 \\
0.29 \\
0.03 \\
0.00 \\
0.16 \\
0.08 \\
0.00 \\
0.09 \\
0.05 \\
0.00 \\
0.45 \\
4.31 \\
1.53 \\
\end{array}$ & $\begin{array}{l}5.16 \\
0.00 \\
0.70 \\
0.00 \\
0.51 \\
0.00 \\
0.27 \\
0.04 \\
0.00 \\
0.17 \\
0.11 \\
0.00 \\
0.13 \\
0.07 \\
0.13 \\
35.50 \\
135.87 \\
2.07 \\
\end{array}$ & $\begin{array}{l}2.48 \\
0.00 \\
0.47 \\
0.02 \\
0.50 \\
0.00 \\
0.30 \\
0.05 \\
0.00 \\
0.22 \\
0.09 \\
0.00 \\
0.07 \\
0.04 \\
0.04 \\
8.76 \\
96.98 \\
3.58 \\
\end{array}$ & $\begin{array}{l}1.18 \\
0.00 \\
0.53 \\
0.02 \\
0.58 \\
0.00 \\
0.33 \\
0.05 \\
0.00 \\
0.13 \\
0.10 \\
0.00 \\
0.04 \\
0.08 \\
0.00 \\
6.05 \\
91.65 \\
4.05 \\
\end{array}$ & $\begin{array}{l}1.07 \\
0.00 \\
0.48 \\
0.09 \\
0.75 \\
0.00 \\
0.25 \\
0.03 \\
0.00 \\
0.15 \\
0.08 \\
0.00 \\
0.09 \\
0.05 \\
0.00 \\
14.59 \\
97.34 \\
3.69\end{array}$ & $\begin{array}{l}3.37 \\
0.00 \\
0.64 \\
0.08 \\
0.99 \\
0.00 \\
0.46 \\
0.07 \\
0.00 \\
0.26 \\
0.09 \\
0.00 \\
0.21 \\
0.16 \\
0.10 \\
16.80 \\
92.18 \\
1.64\end{array}$ \\
\hline \multicolumn{7}{|c|}{ GAS PRODUCT (STAGE II VENT), $W \%$ of mf coal } \\
\hline $\begin{array}{l}\mathrm{CH}_{4} \\
\mathrm{C}_{2} \mathrm{H}_{4} \\
\mathrm{C}_{2} \mathrm{H}_{6} \\
\mathrm{C}_{3} \mathrm{H}_{6} \\
\mathrm{C}_{3} \mathrm{H}_{8} \\
\mathrm{C}_{4} \mathrm{H}_{8} \\
\mathrm{~N}-\mathrm{C}_{4} \mathrm{H}_{10} \\
\mathrm{I}-\mathrm{C}_{4} \mathrm{H}_{10} \\
\mathrm{C}_{5} \mathrm{H}_{10} \\
\mathrm{~N}_{10} \mathrm{C}_{5} \mathrm{H}_{12} \\
\mathrm{I}-\mathrm{C}_{5} \mathrm{H}_{12} \\
\text { METHYL-CYCLOPENTANE } \\
\mathrm{CYCLOHEXANE} \\
\mathrm{N}-\mathrm{C}_{5} \mathrm{H}_{14} \\
\mathrm{C}_{6}-\mathrm{C}_{7} \\
\mathrm{CO} \\
\mathrm{CO} \\
\mathrm{H}_{2} \mathrm{~S}\end{array}$ & $\begin{array}{l}1.21 \\
0.00 \\
0.99 \\
0.00 \\
1.38 \\
0.00 \\
1.03 \\
0.17 \\
0.00 \\
0.34 \\
0.26 \\
0.00 \\
0.30 \\
0.30 \\
0.10 \\
0.00 \\
0.03 \\
2.40\end{array}$ & $\begin{array}{l}3.24 \\
0.00 \\
1.31 \\
0.00 \\
1.71 \\
0.00 \\
1.22 \\
0.22 \\
0.00 \\
0.39 \\
0.27 \\
0.00 \\
0.45 \\
0.33 \\
0.19 \\
0.20 \\
0.57 \\
4.22\end{array}$ & $\begin{array}{l}4.30 \\
0.00 \\
1.53 \\
0.00 \\
1.80 \\
0.00 \\
1.04 \\
0.22 \\
0.00 \\
0.32 \\
0.18 \\
0.00 \\
0.32 \\
0.05 \\
0.16 \\
0.23 \\
0.31 \\
0.20\end{array}$ & $\begin{array}{l}3.35 \\
0.00 \\
1.57 \\
0.00 \\
1.82 \\
0.00 \\
1.02 \\
0.21 \\
0.00 \\
0.26 \\
0.17 \\
0.00 \\
0.10 \\
0.10 \\
0.00 \\
0.24 \\
0.29 \\
0.35\end{array}$ & $\begin{array}{l}3.28 \\
0.00 \\
1.69 \\
0.00 \\
1.97 \\
0.00 \\
1.12 \\
0.20 \\
0.00 \\
0.30 \\
0.17 \\
0.00 \\
0.10 \\
0.15 \\
0.05 \\
0.33 \\
0.36 \\
0.60\end{array}$ & $\begin{array}{l}1.56 \\
0.00 \\
1.18 \\
0.00 \\
1.54 \\
0.00 \\
0.98 \\
0.15 \\
0.00 \\
0.32 \\
0.18 \\
0.00 \\
0.11 \\
0.16 \\
0.00 \\
0.00 \\
0.14 \\
0.11 \\
\end{array}$ \\
\hline
\end{tabular}




\begin{tabular}{|c|c|c|c|c|c|c|}
\hline \multicolumn{7}{|c|}{$\begin{array}{l}\text { Table 2.7.18 } \\
\text { ANALYSES OF GASES FOR RUN 227-84 (CMSL-7) } \\
\text { COAL: } \quad \text { BLACK THUNDER MINE (HTI 6213) }\end{array}$} \\
\hline $\begin{array}{l}\text { Run CMSL } \\
\text { Period Number } \\
\text { Date (Start of Period) } \\
\text { Hours of Run (End of Period) } \\
\text { First Stage Gas, } \mathrm{V} \% \mathrm{CO} \\
\text { Pressure, } \mathrm{MPa} \\
\text { 1st Stage Temperature, }{ }^{\circ} \mathrm{C} \\
\text { 2nd Stage Temperature }{ }^{\circ} \mathrm{C} \\
\text { Dry Coal, } \mathrm{Kg} / \mathrm{Hr} / \mathrm{M}^{3} \text { Catalyst }\end{array}$ & $\begin{array}{c}4 \\
5 \\
03 / 10 / 94 \\
120 \\
0 \\
17.2 \\
388 \\
427 \\
697\end{array}$ & $\begin{array}{c}4 \\
9 \\
03 / 14 / 94 \\
216 \\
86 \\
17.2 \\
388 \\
427 \\
676\end{array}$ & $\begin{array}{c}7 \\
7 \\
10 / 02 / 94 \\
160 \\
75 \\
17.2 \\
388 \\
444 \\
700\end{array}$ & $\begin{array}{c}7 \\
11 \\
10 / 06 / 94 \\
256 \\
75 \\
13.7 \\
388 \\
443 \\
697\end{array}$ & $\begin{array}{c}7 \\
14 \\
10 / 09 / 94 \\
328 \\
75 \\
10.3 \\
388 \\
444 \\
706\end{array}$ & $\begin{array}{c}7 \\
19 \\
10 / 20 / 94 \\
448 \\
75 \\
10.4 \\
399 \\
442 \\
713\end{array}$ \\
\hline \multicolumn{7}{|c|}{ GAS PRODUCT (STAGE I VENT), V\% } \\
\hline $\begin{array}{l}\mathrm{H}_{2} \\
\mathrm{CH}_{4} \\
\mathrm{C}_{2} \mathrm{H}_{4} \\
\mathrm{C}_{2} \mathrm{H}_{6} \\
\mathrm{C}_{3} \mathrm{H}_{6} \\
\mathrm{C}_{3} \mathrm{H}_{8} \\
\mathrm{C}_{4} \mathrm{H}_{8} \\
{\mathrm{~N}-\mathrm{C}_{4} \mathrm{H}_{10}} \mathrm{I}_{4} \mathrm{C}_{4} \mathrm{H}_{10} \\
\mathrm{C}_{5} \mathrm{H}_{10} \\
\mathrm{~N}-\mathrm{C}_{5} \mathrm{H}_{12} \\
\mathrm{I}-\mathrm{C}_{5} \mathrm{H}_{12} \\
\text { METHYLCYCLOPENTANE } \\
\text { CYCLOHEXANE } \\
\mathrm{N}-\mathrm{C}_{5} \mathrm{H}_{14} \\
2+3-\text { METHYLPENTANE } \\
\mathrm{C}_{6}-\mathrm{C}_{7} \\
\text { CO } \\
\text { CO } \\
\mathrm{H}_{2} \mathrm{~S} \\
\text { NITROGEN } \\
\text { OXYGEN }\end{array}$ & $\begin{array}{l}92.85 \\
1.17 \\
0.00 \\
0.29 \\
0.00 \\
0.21 \\
0.00 \\
0.09 \\
0.01 \\
0.00 \\
0.04 \\
0.02 \\
0.00 \\
0.02 \\
0.01 \\
0.00 \\
0.00 \\
0.29 \\
1.76 \\
0.81 \\
1.86 \\
0.57\end{array}$ & $\begin{array}{l}36.09 \\
4.17 \\
0.00 \\
0.30 \\
0.00 \\
0.15 \\
0.00 \\
0.06 \\
0.01 \\
0.00 \\
0.03 \\
0.02 \\
0.00 \\
0.02 \\
0.01 \\
0.00 \\
0.02 \\
16.45 \\
40.06 \\
0.79 \\
1.41 \\
0.41\end{array}$ & $\begin{array}{l}33.37 \\
3.56 \\
0.00 \\
0.36 \\
0.01 \\
0.26 \\
0.00 \\
0.12 \\
0.02 \\
0.00 \\
0.07 \\
0.03 \\
0.00 \\
0.02 \\
0.01 \\
0.00 \\
0.01 \\
7.21 \\
50.82 \\
2.43 \\
1.36 \\
0.34\end{array}$ & $\begin{array}{l}41.18 \\
1.68 \\
0.00 \\
0.40 \\
0.01 \\
0.30 \\
0.00 \\
0.13 \\
0.02 \\
0.00 \\
0.04 \\
0.03 \\
0.00 \\
0.01 \\
0.02 \\
0.00 \\
0.00 \\
4.92 \\
47.44 \\
2.71 \\
0.90 \\
0.21\end{array}$ & $\begin{array}{l}43.03 \\
1.23 \\
0.00 \\
0.30 \\
0.04 \\
0.32 \\
0.00 \\
0.08 \\
0.01 \\
0.00 \\
0.04 \\
0.02 \\
0.00 \\
0.02 \\
0.01 \\
0.00 \\
0.00 \\
9.85 \\
41.82 \\
2.05 \\
0.92 \\
0.23\end{array}$ & $\begin{array}{l}48.46 \\
3.44 \\
0.00 \\
0.35 \\
0.03 \\
0.37 \\
0.00 \\
0.13 \\
0.02 \\
0.00 \\
0.06 \\
0.02 \\
0.00 \\
0.04 \\
0.03 \\
0.00 \\
0.02 \\
9.84 \\
34.35 \\
0.79 \\
1.65 \\
0.40\end{array}$ \\
\hline \multicolumn{7}{|c|}{ GAS PRODUCT (STAGE II VENT), V\% } \\
\hline $\begin{array}{l}\mathrm{H}_{2} \\
\mathrm{CH}_{4} \\
\mathrm{C}_{2} \mathrm{H}_{4} \\
\mathrm{C}_{2} \mathrm{H}_{6} \\
\mathrm{C}_{3} \mathrm{H}_{6} \\
\mathrm{C}_{3} \mathrm{H}_{8} \\
\mathrm{C}_{4} \mathrm{H}_{8} \\
\mathrm{~N}_{8} \mathrm{C}_{4} \mathrm{H}_{10} \\
\mathrm{I}-\mathrm{C}_{4} \mathrm{H}_{10} \\
\mathrm{C}_{5} \mathrm{H}_{10} \\
\mathrm{~N}-\mathrm{C}_{5} \mathrm{H}_{12} \\
\mathrm{I}-\mathrm{C}_{5} \mathrm{H}_{12} \\
\text { METHYLCYCLOPENTANE } \\
\text { CYCLOHEXANE } \\
\mathrm{N}-\mathrm{C}_{6} \mathrm{H}_{14} \\
2+3 \text { METHYLPENTANE } \\
\mathrm{C}_{6}-\mathrm{C}_{7} \\
\mathrm{CO} \\
\text { CO } \\
\mathrm{H}_{2} \mathrm{~S} \\
\text { NITROGEN } \\
\text { OXYGEN }\end{array}$ & $\begin{array}{l}80.14 \\
1.28 \\
0.00 \\
0.56 \\
0.00 \\
0.53 \\
0.00 \\
0.30 \\
0.05 \\
0.00 \\
0.08 \\
0.06 \\
0.00 \\
0.06 \\
0.06 \\
0.01 \\
0.02 \\
0.00 \\
0.01 \\
1.20 \\
15.20 \\
0.44 \\
\end{array}$ & $\begin{array}{l}77.46 \\
3.74 \\
0.00 \\
0.81 \\
0.00 \\
0.72 \\
0.00 \\
0.39 \\
0.07 \\
0.00 \\
0.10 \\
0.07 \\
0.00 \\
0.10 \\
0.07 \\
0.01 \\
0.04 \\
0.13 \\
0.24 \\
2.30 \\
13.38 \\
0.37 \\
\end{array}$ & $\begin{array}{c}80.39 \\
4.20 \\
0.00 \\
0.80 \\
0.00 \\
0.64 \\
0.00 \\
0.28 \\
0.06 \\
0.00 \\
0.07 \\
0.04 \\
0.00 \\
0.06 \\
0.01 \\
0.00 \\
0.03 \\
0.13 \\
0.11 \\
0.09 \\
12.82 \\
0.27 \\
\end{array}$ & $\begin{array}{c}82.69 \\
3.45 \\
0.00 \\
0.86 \\
0.00 \\
0.68 \\
0.00 \\
0.29 \\
0.06 \\
0.00 \\
0.06 \\
0.04 \\
0.00 \\
0.02 \\
0.02 \\
0.00 \\
0.00 \\
0.14 \\
0.11 \\
0.17 \\
11.07 \\
0.34 \\
\end{array}$ & $\begin{array}{l}89.99 \\
3.49 \\
0.00 \\
0.96 \\
0.00 \\
0.76 \\
0.00 \\
0.33 \\
0.06 \\
0.00 \\
0.07 \\
0.04 \\
0.00 \\
0.02 \\
0.03 \\
0.00 \\
0.01 \\
0.20 \\
0.14 \\
0.30 \\
3.39 \\
0.21 \\
\end{array}$ & $\begin{array}{l}87.54 \\
1.56 \\
0.00 \\
0.63 \\
0.00 \\
0.56 \\
0.00 \\
0.27 \\
0.04 \\
0.00 \\
0.07 \\
0.04 \\
0.00 \\
0.02 \\
0.03 \\
0.00 \\
0.00 \\
0.00 \\
0.05 \\
0.05 \\
8.84 \\
0.30 \\
\end{array}$ \\
\hline
\end{tabular}


Figure 2.7.1

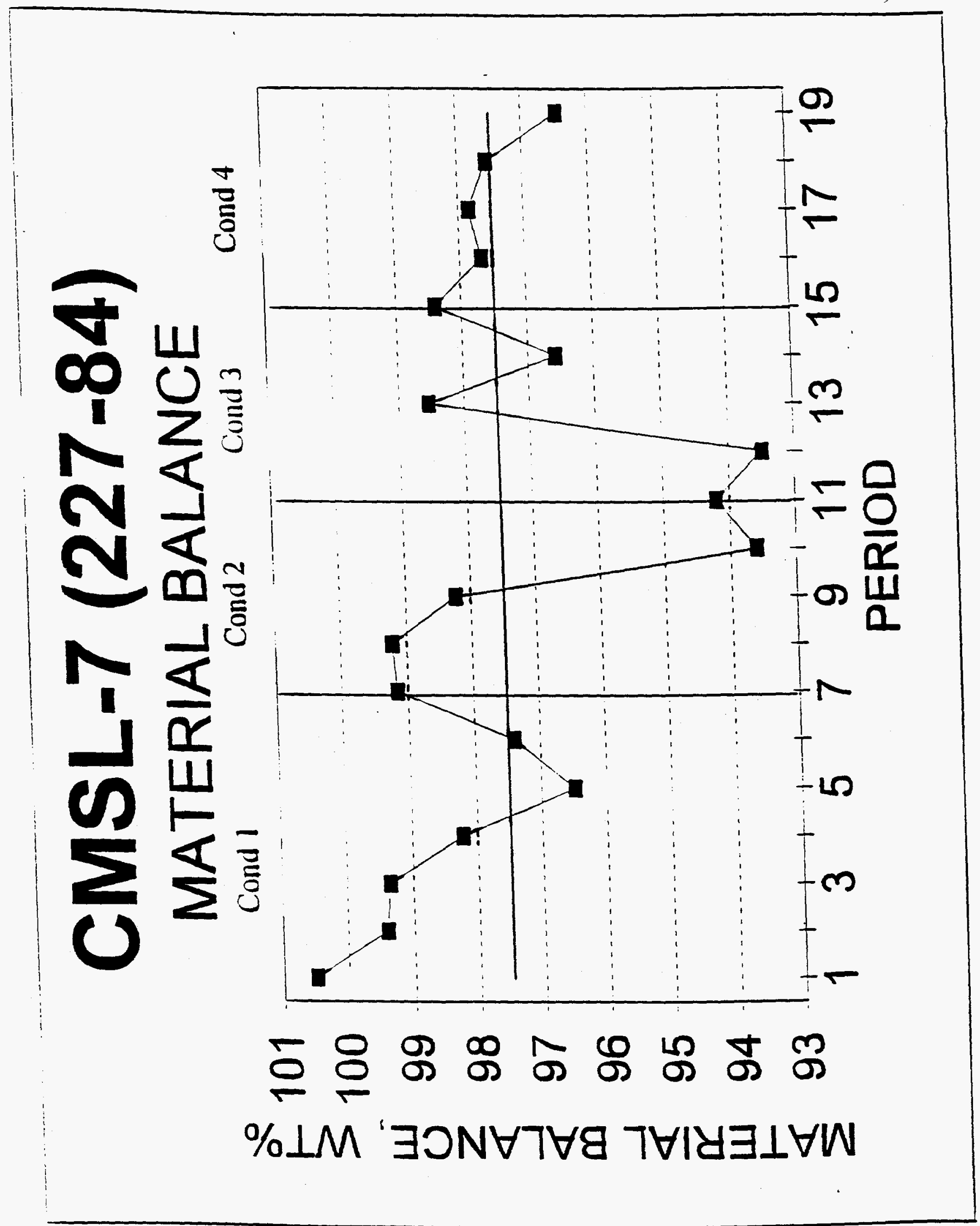




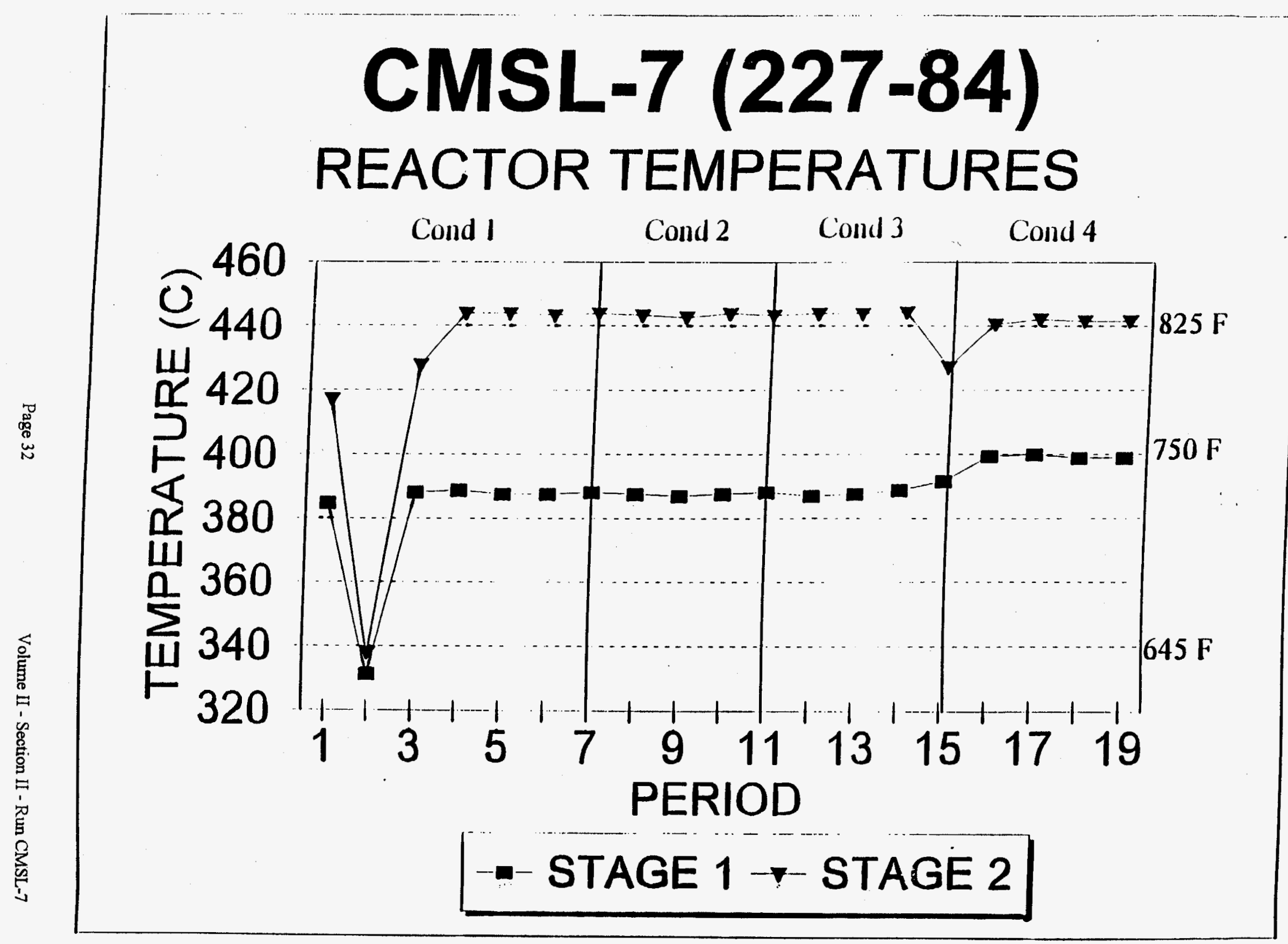


Figure 2.7.3

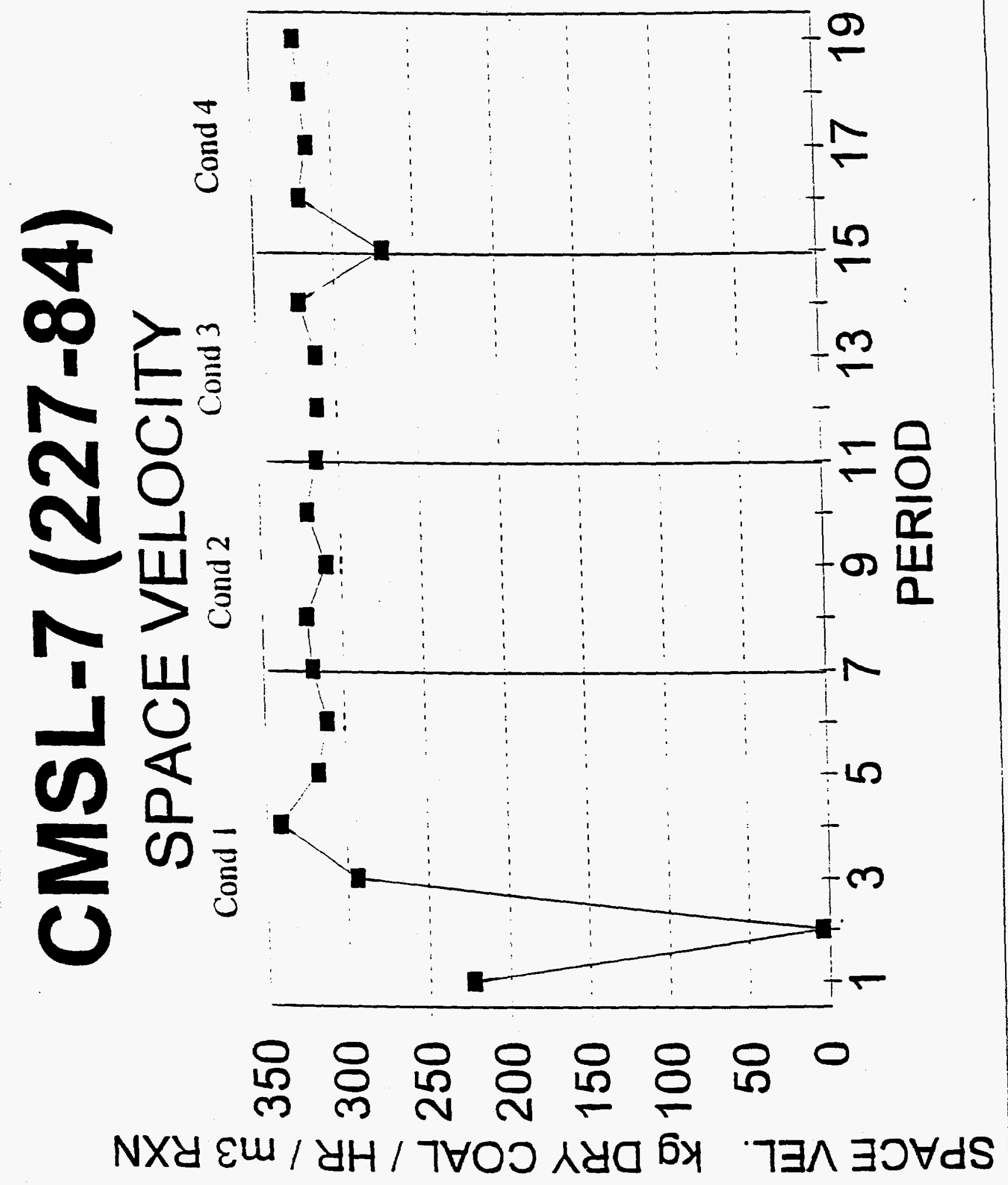


Figure 2.7.4

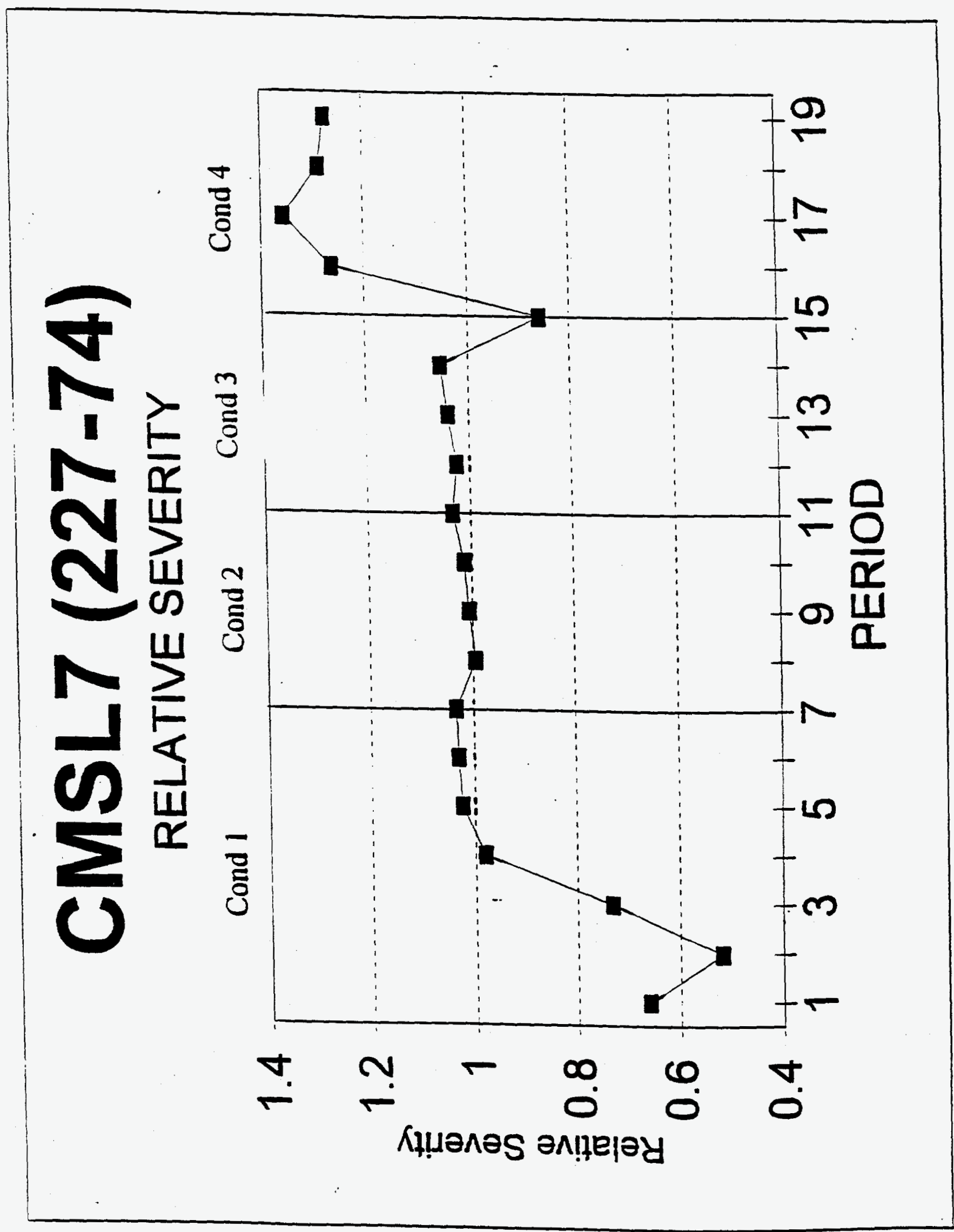


Figure 2.7.5

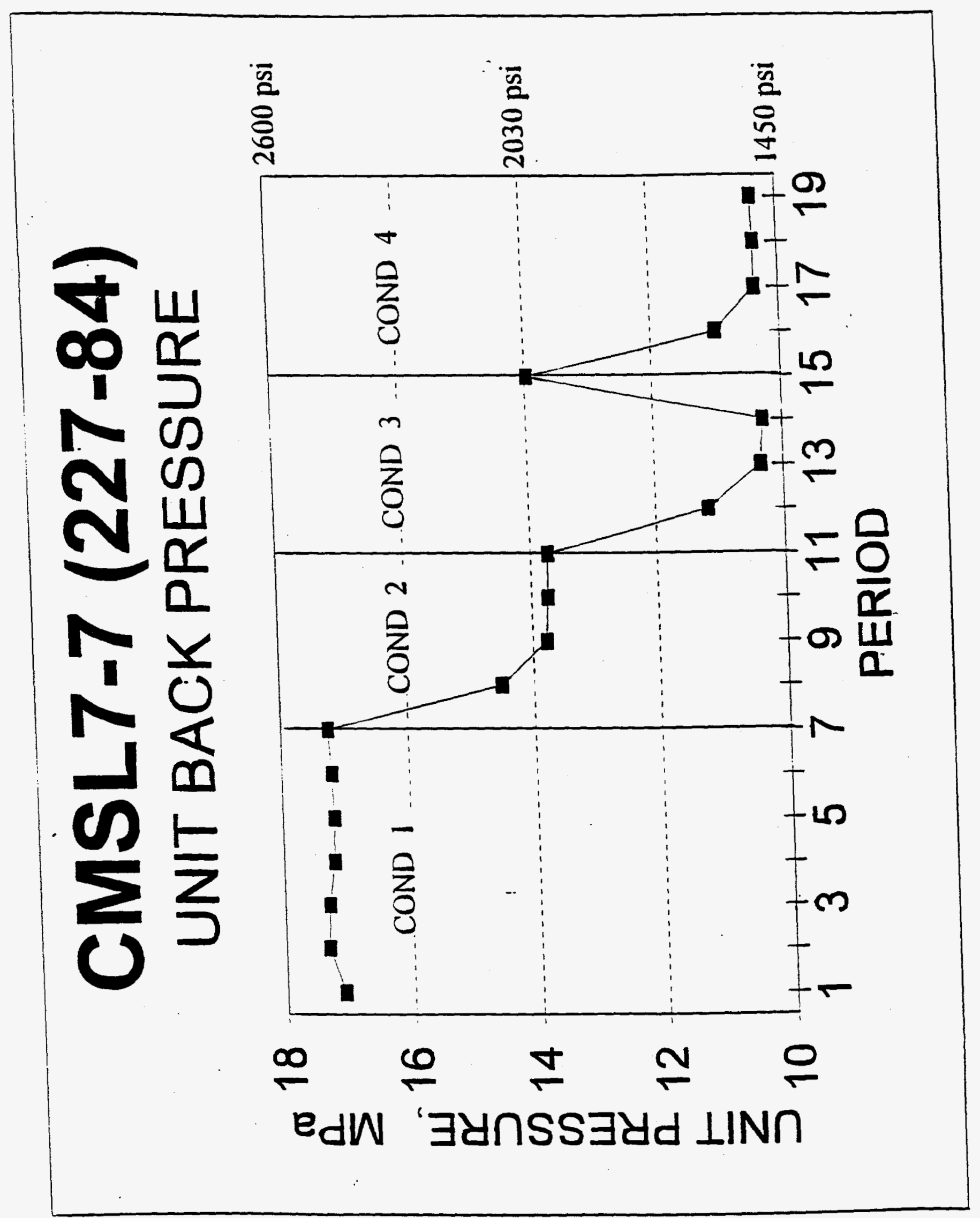


Figure 2.7.6

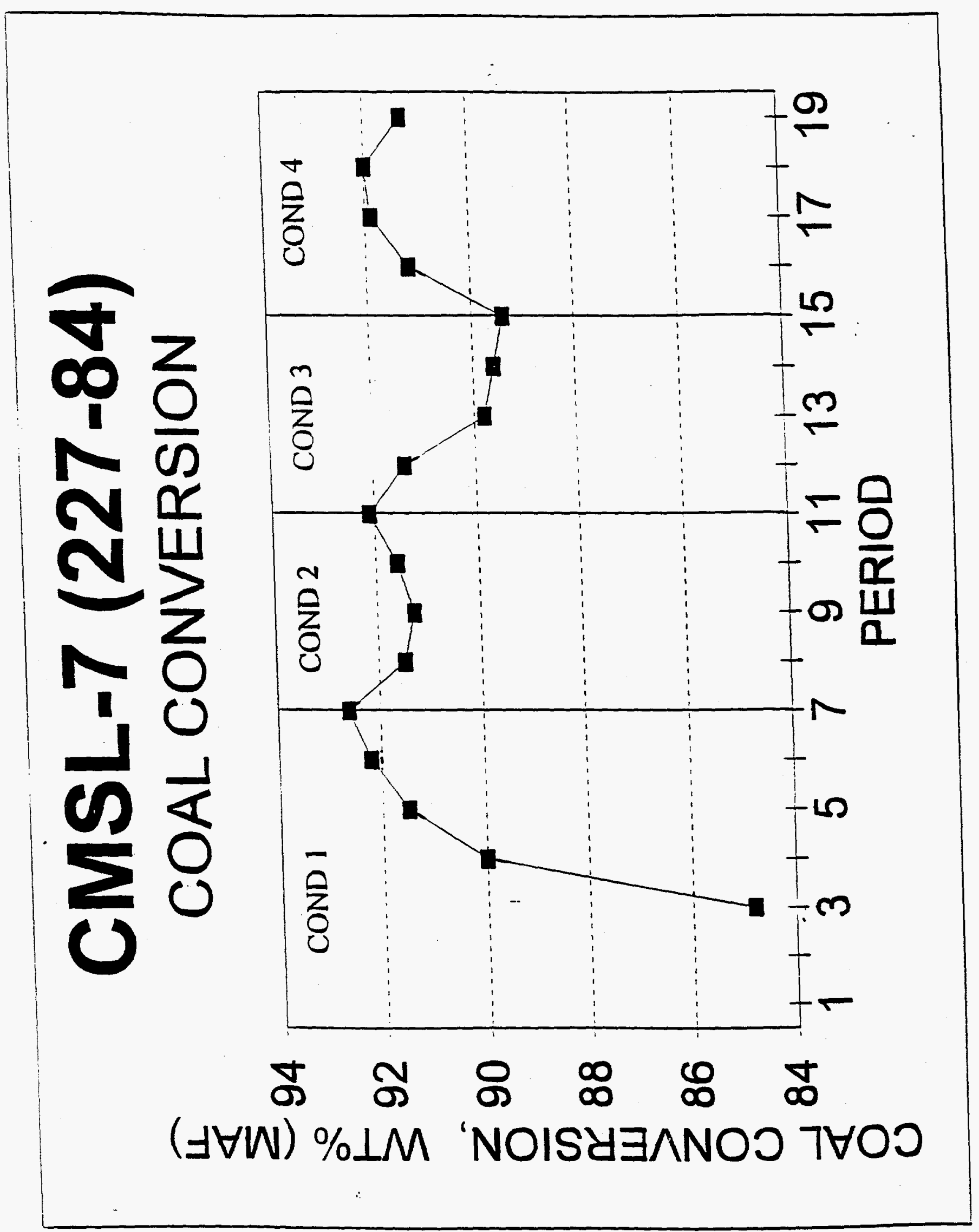




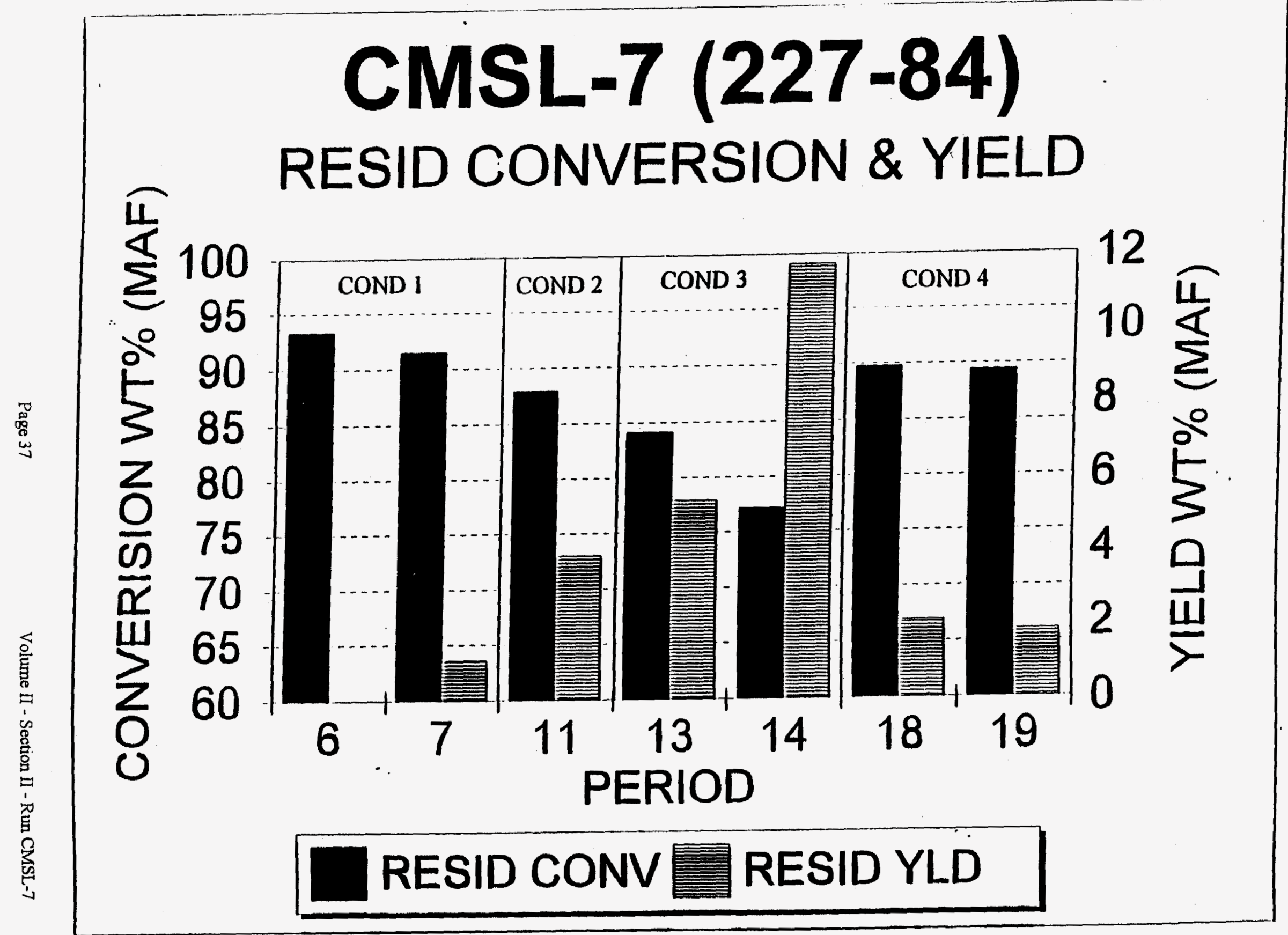


Figure 2.7.8

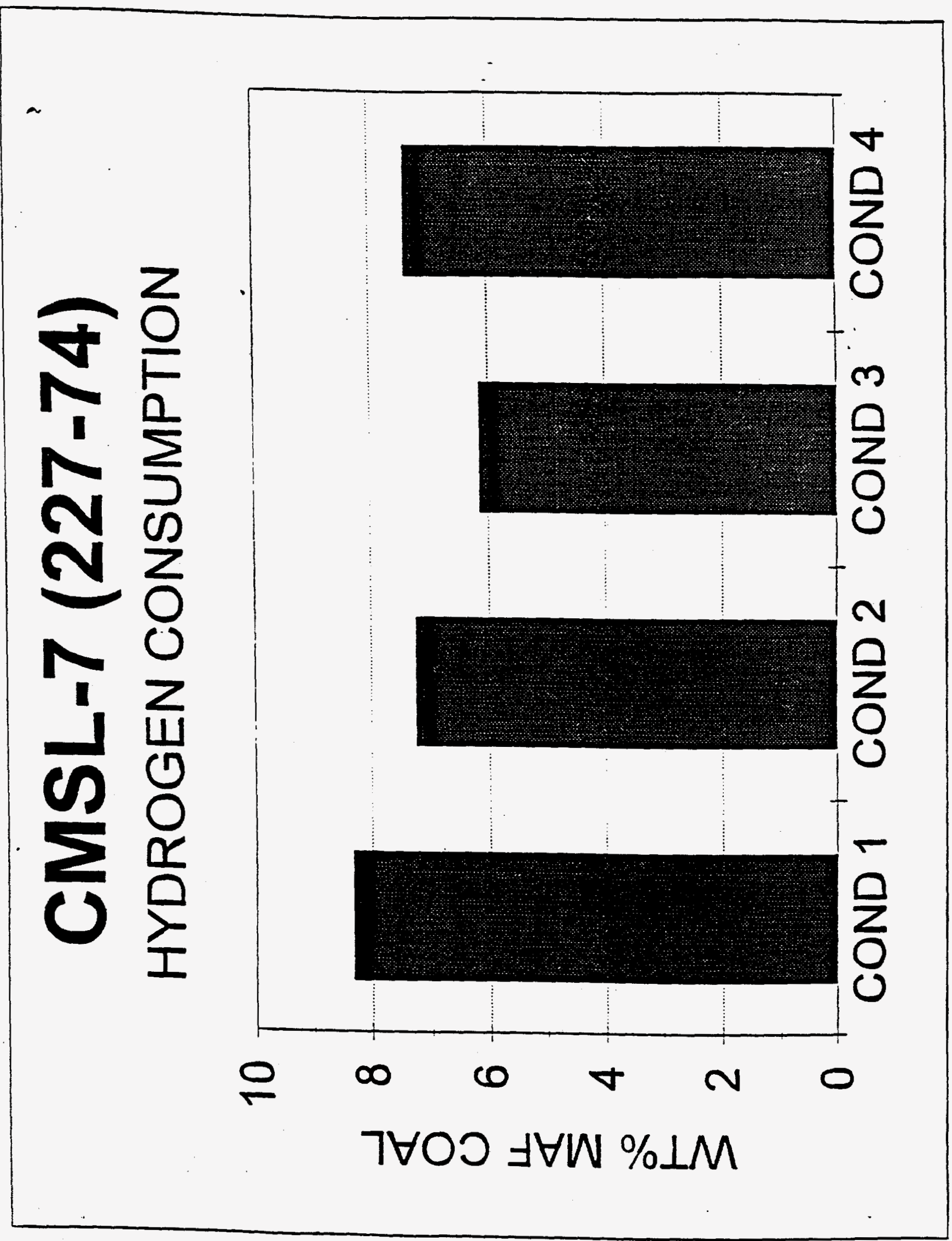


Figure 2.7.9

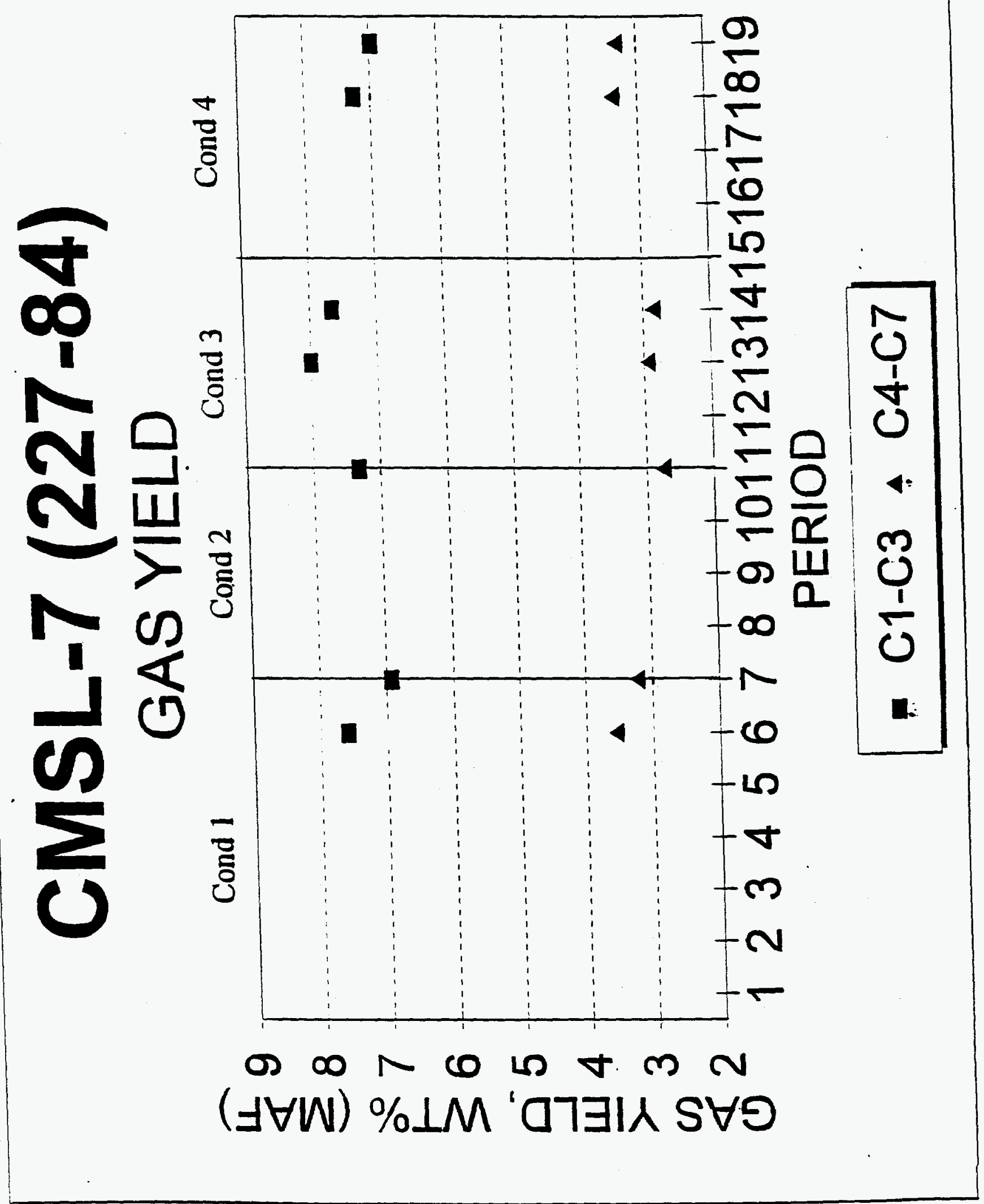




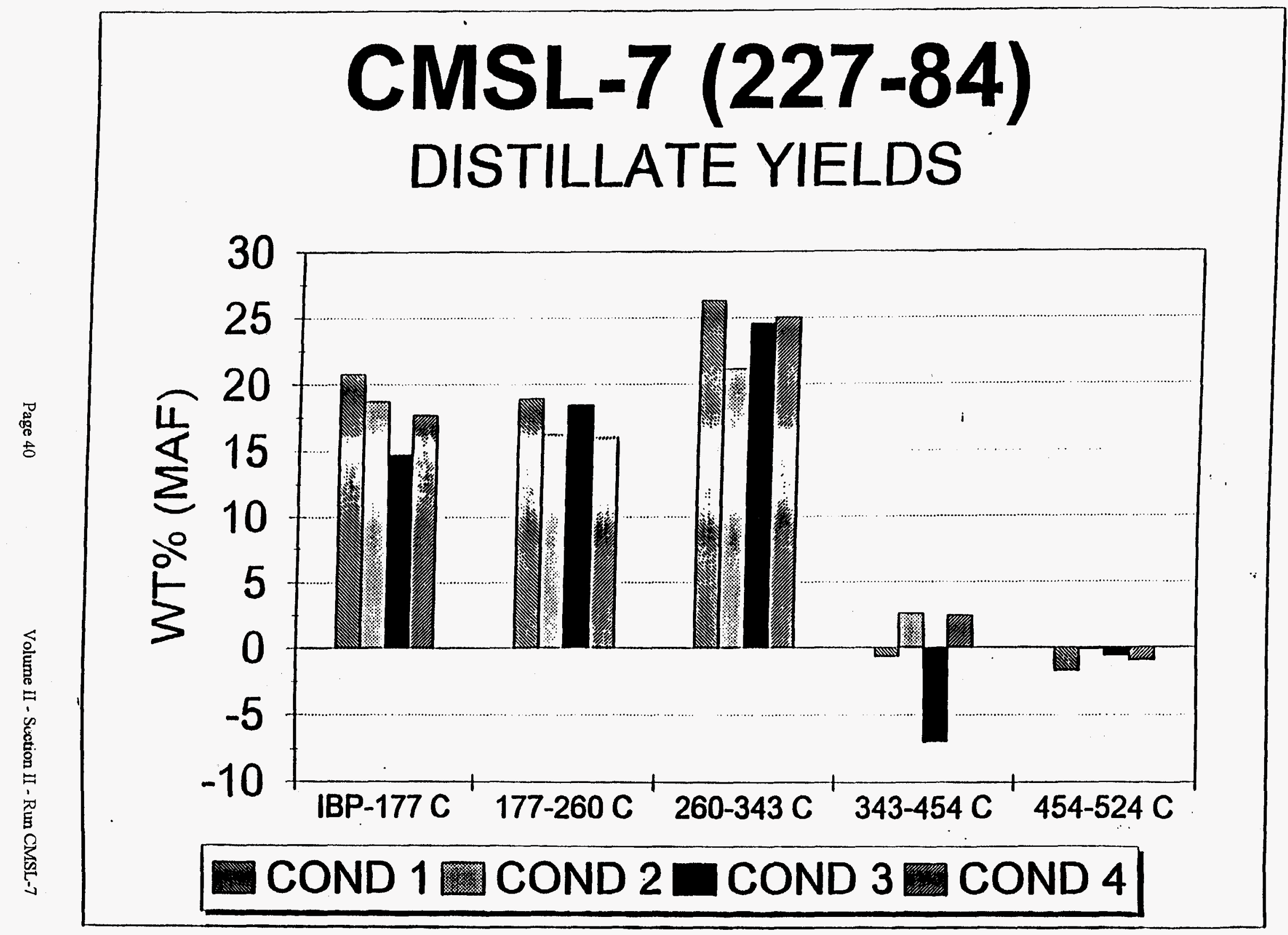


Figure 2.7.11

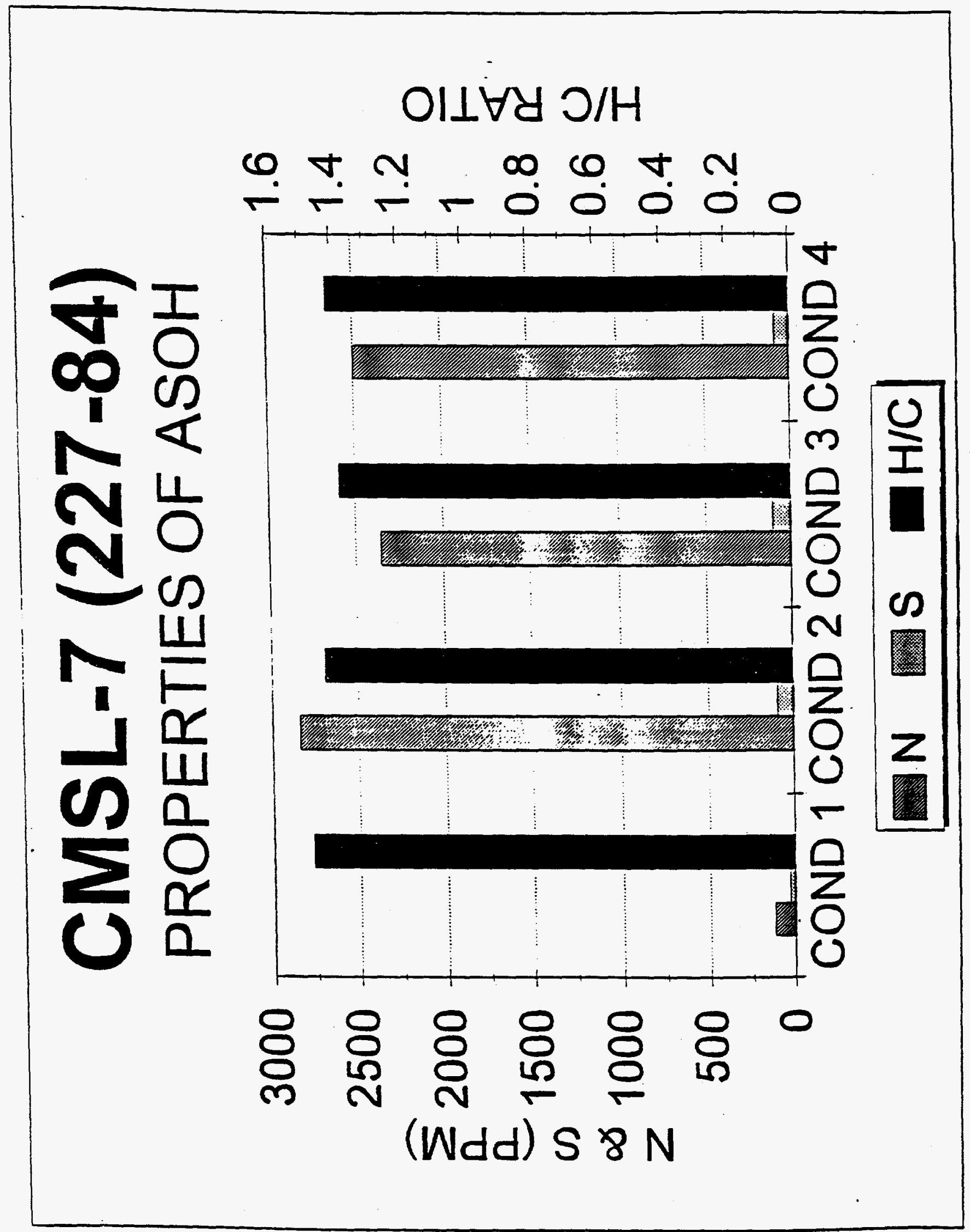




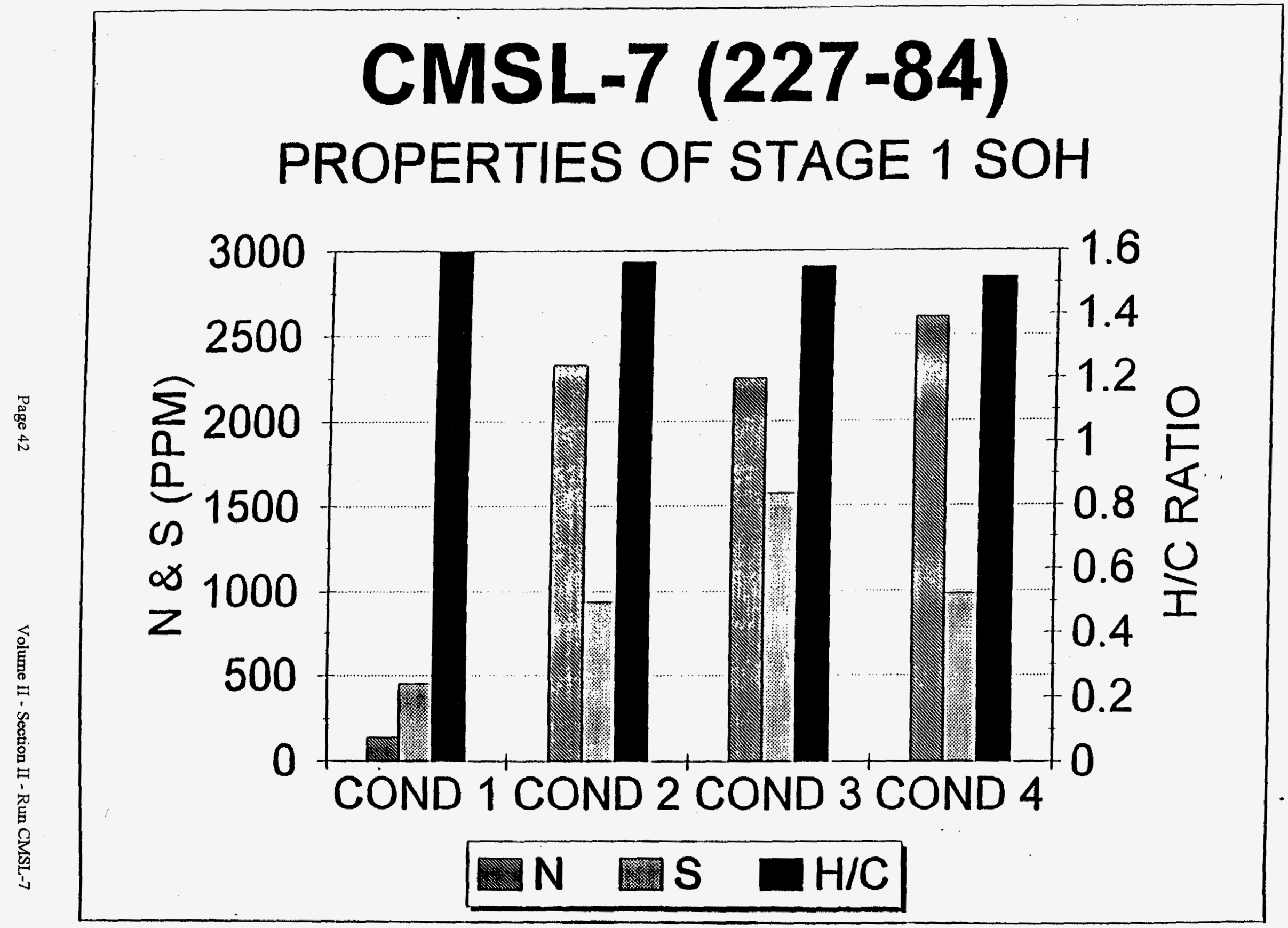


Figure 2.7.13

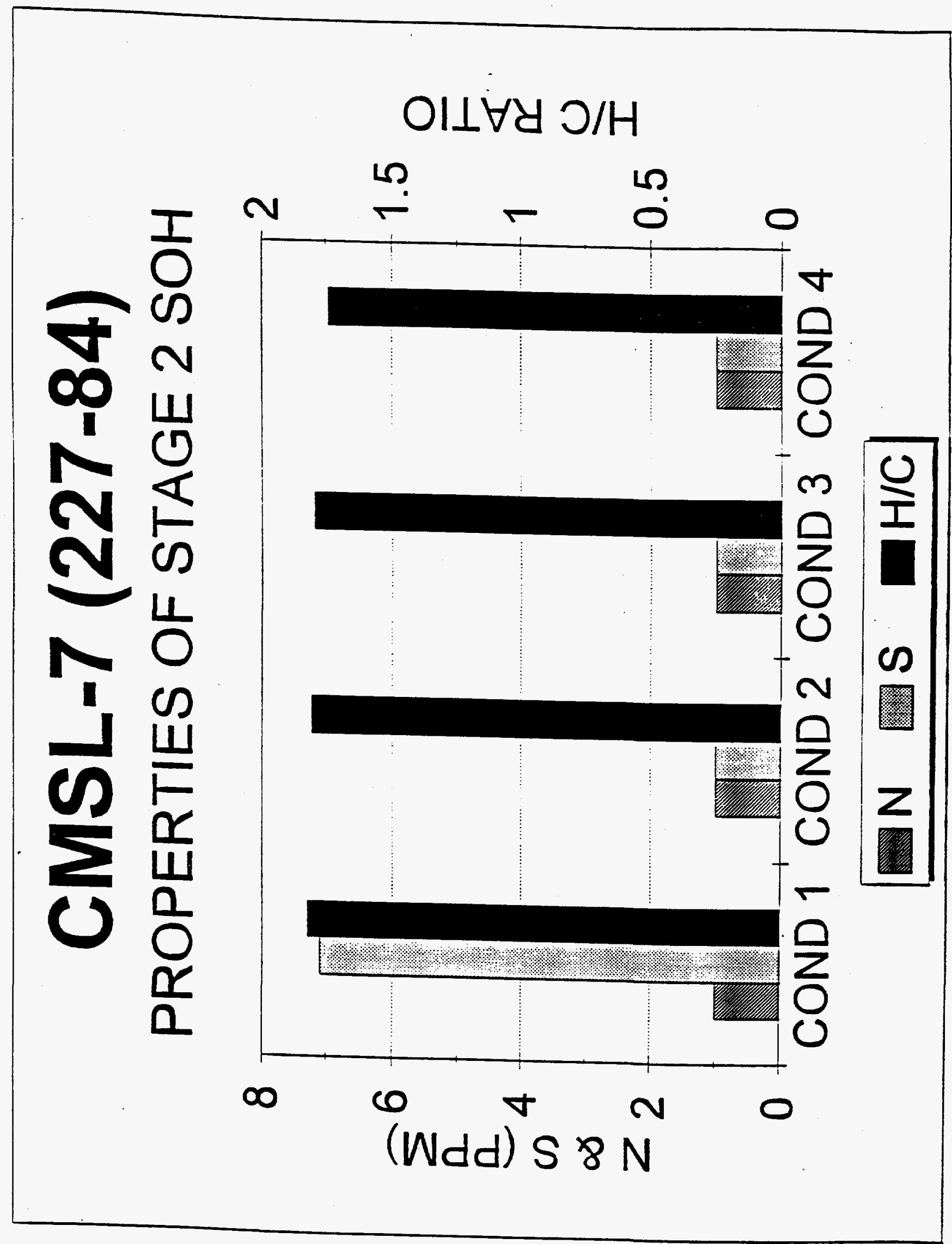


Figure 2.7.14

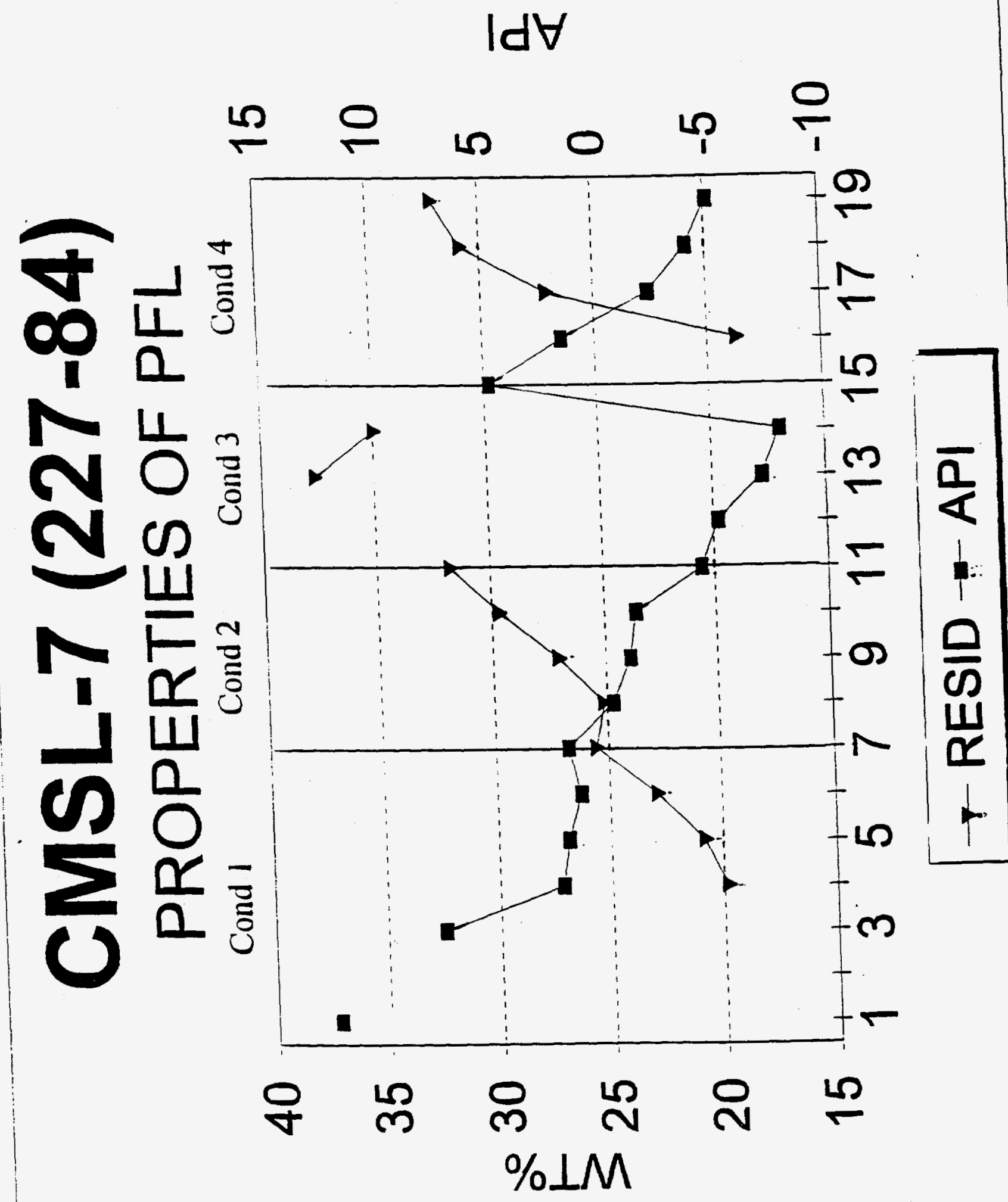


Figure 2.7.15

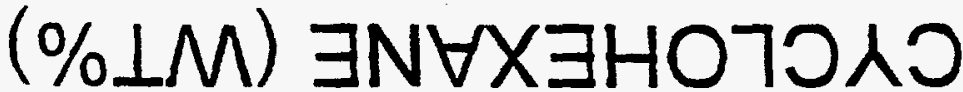 \\ 용오 운 웅요}

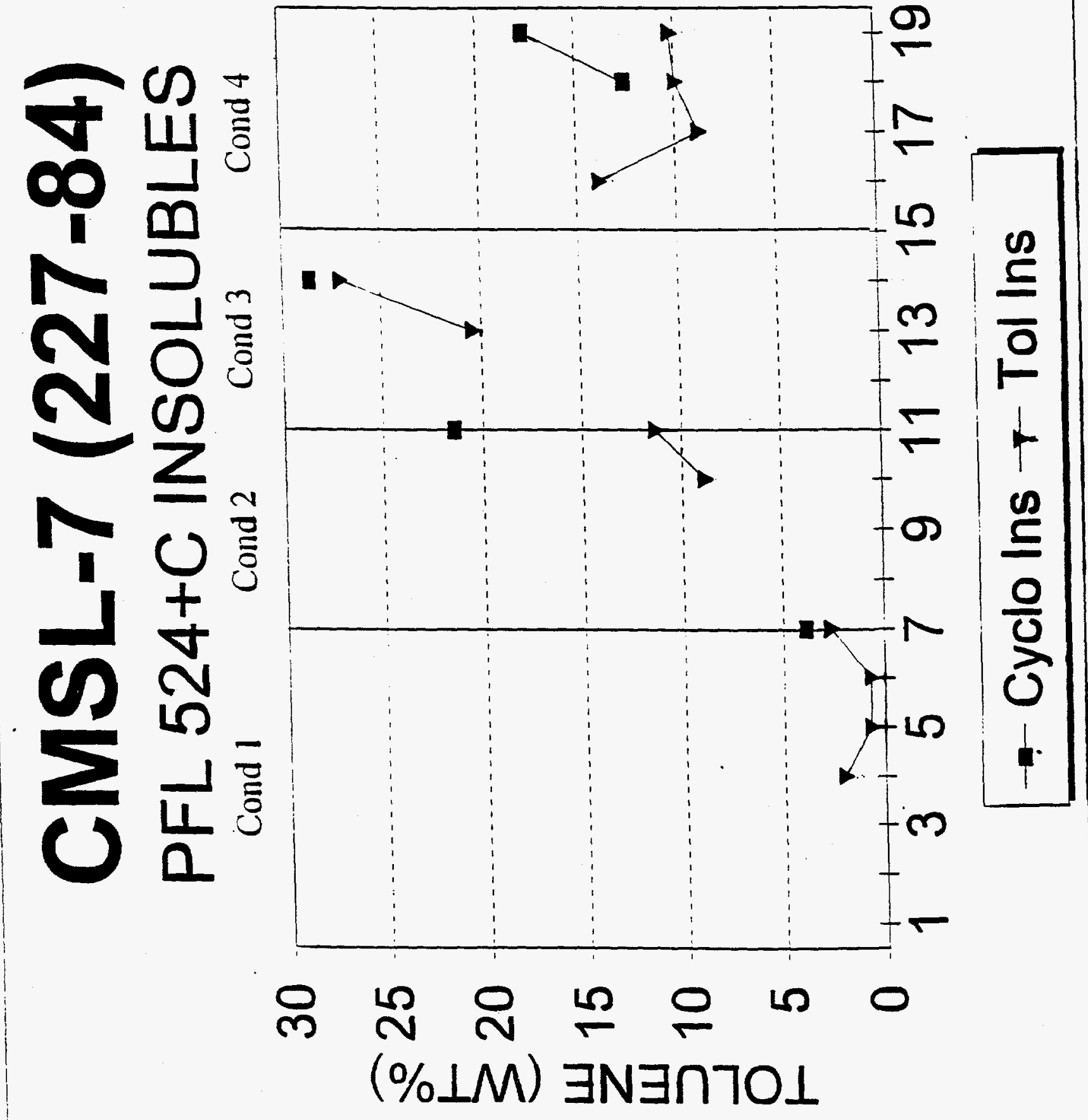


Figure 2.7.16

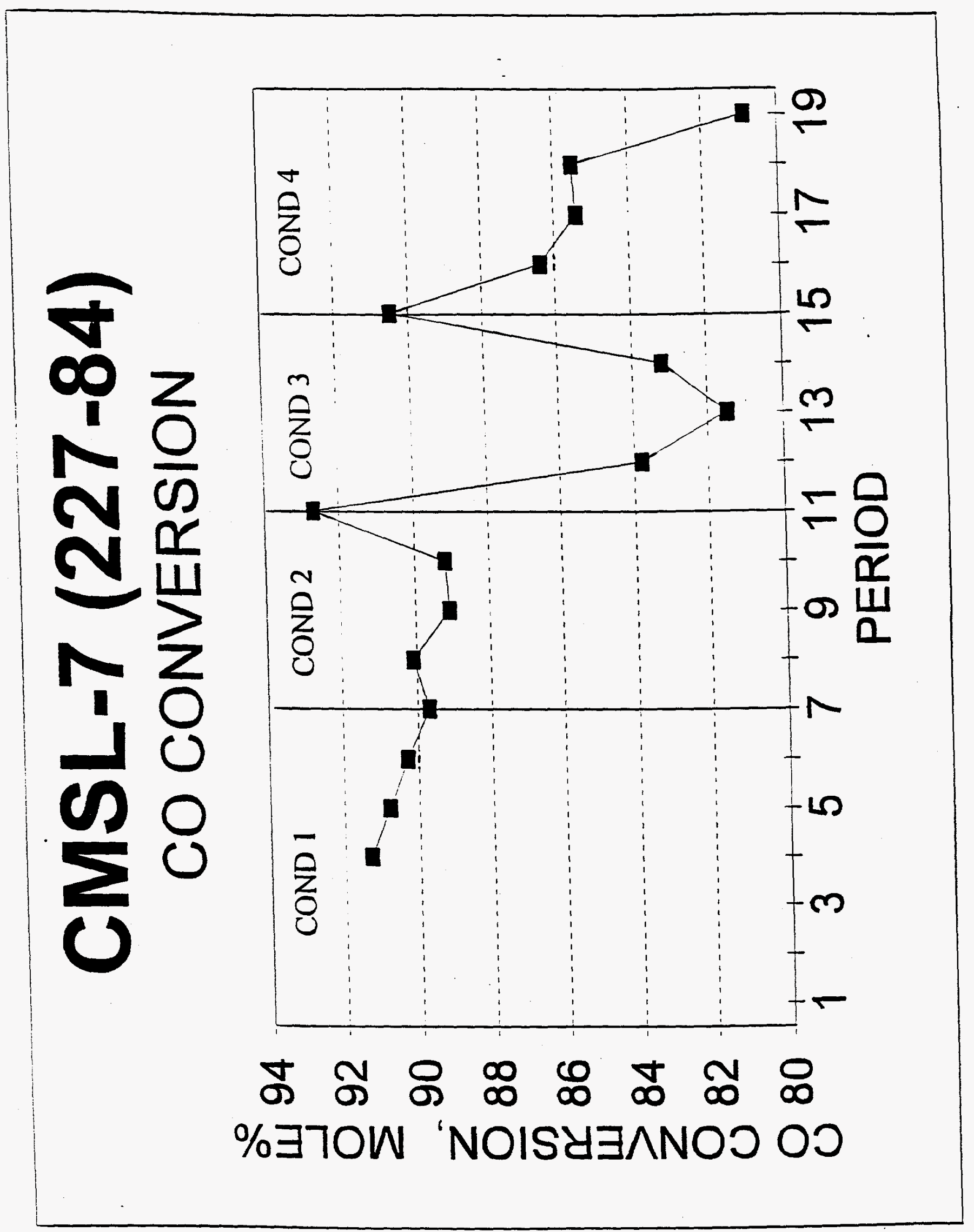


FIRST- AND TWO-STAGE COAL CONVERSION COMP. OF SYNGAS (CMSL-4,-7) \& H2 (CC-1)

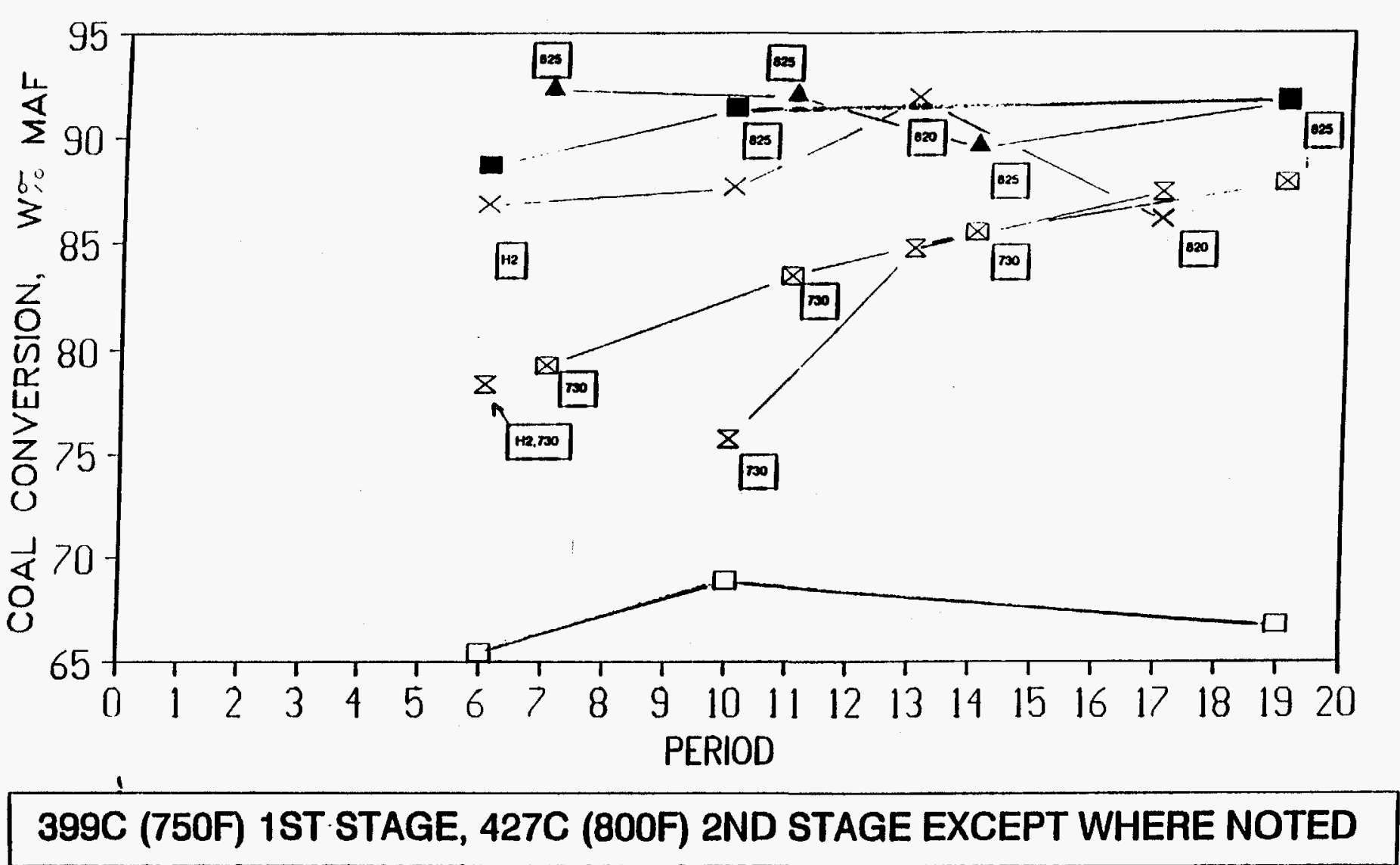

$\begin{array}{ll}-1 \mathrm{CC}-1 \text { FIRST STAGE } & -\mathrm{Z} \text {-CMSL-4 FIRST STAGE }- \text { CMSL }-7 \text { FIRST STIAGE } \\ -\mathrm{CC}-1 \text { TWO STAGE } & \rightarrow-\mathrm{CMSL}-4 \text { TWO STAGE }- \text { CMSL }-7 \text { TWO STAGE }\end{array}$ 


\section{SOLIDS H:C RATIO VS. COAL CONVERSION RUNS CC-1 AND CMSL-7}

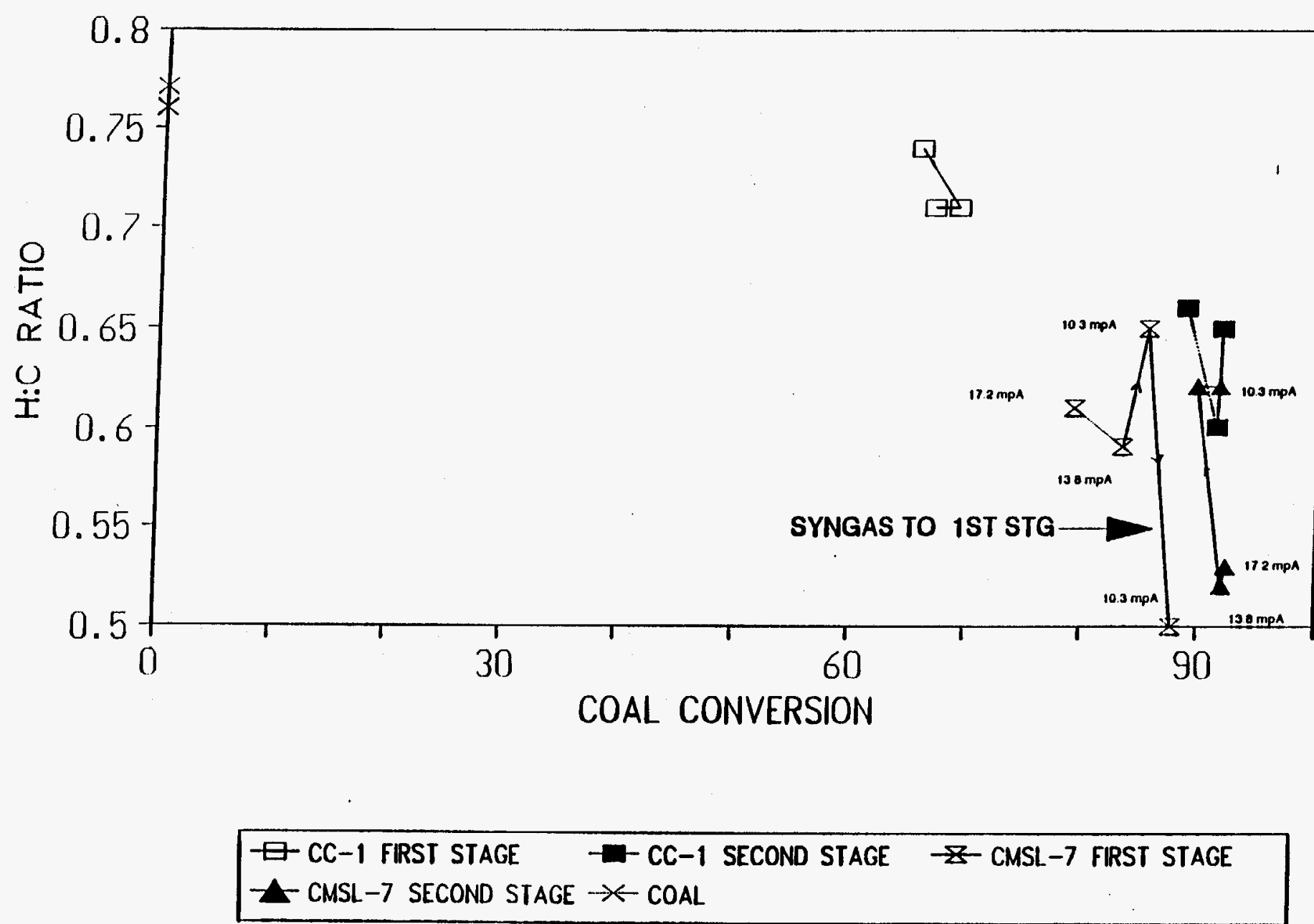


Figure 2.7.19

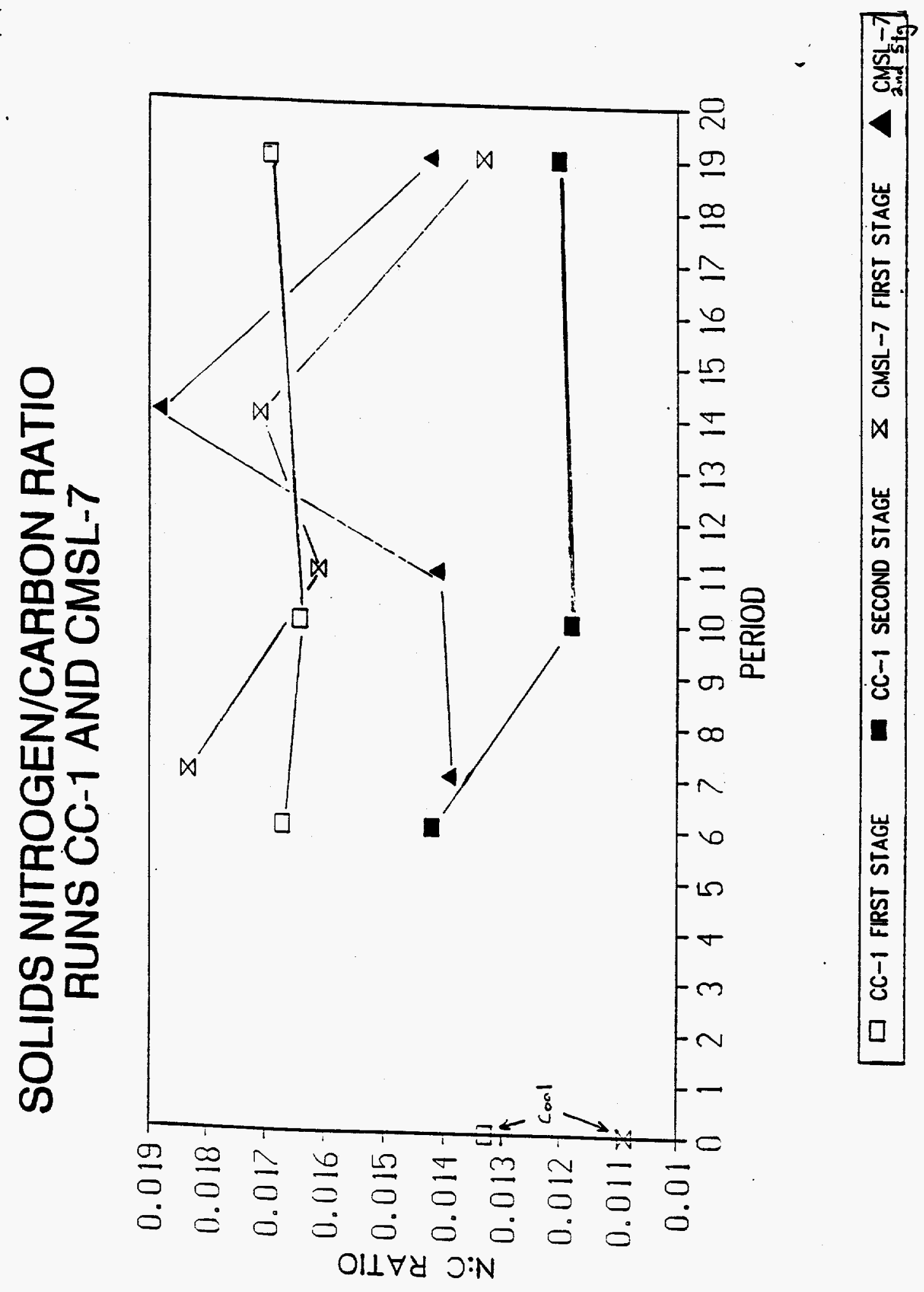


HYDROGEN CONTENT OF 1 ST \& 2 ND STAGE LGO

RUNS CC $-1, \quad$ CMSL $-4, \quad \&$ CMSL -7

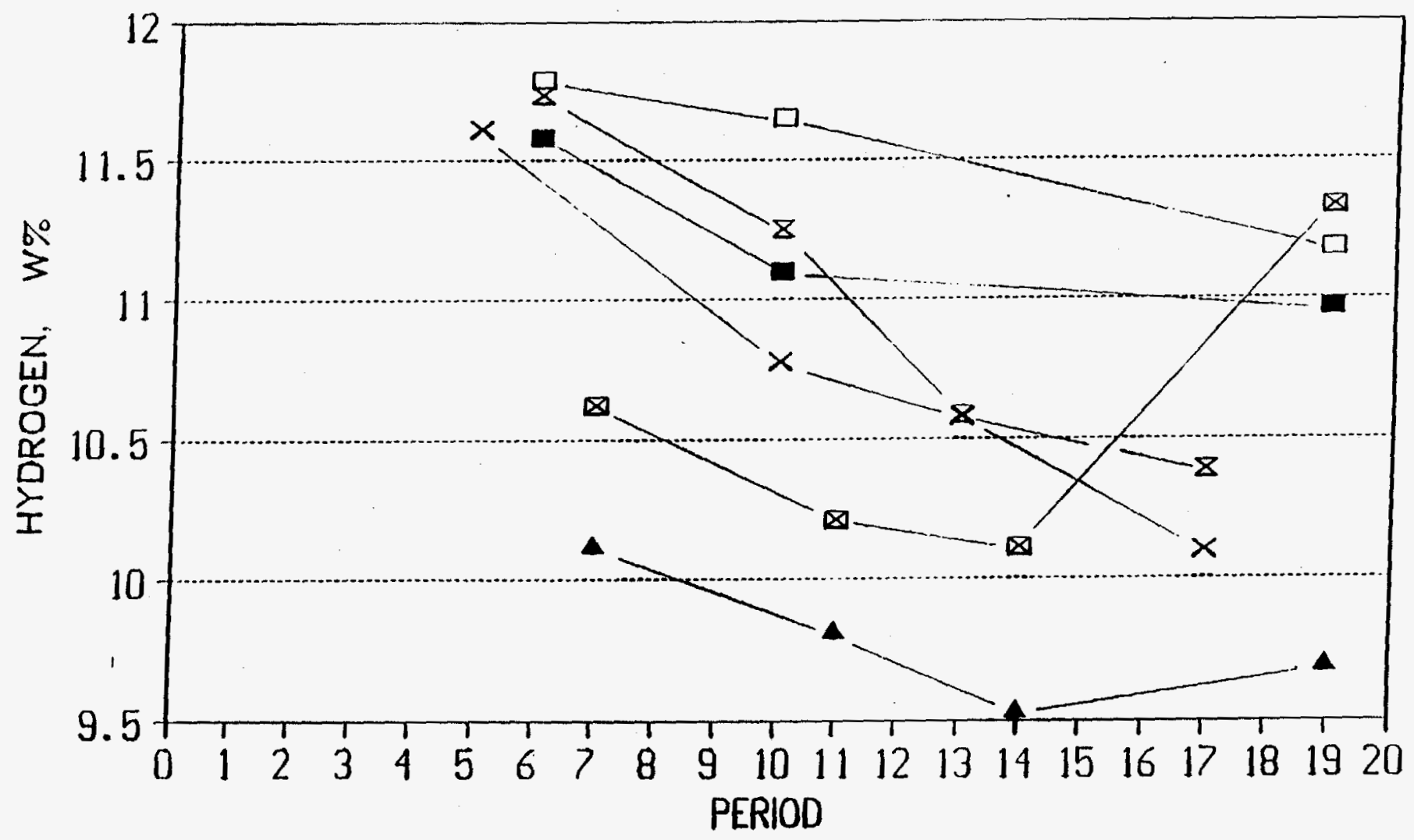

口 CC-1 IST STAGE 8 CMSL-4 IST STAGE $\triangle$ CMSL-7 IST STAGE

- CC-1 2ND STAGE $\times$ CMSL-4 2ND STAGE $\triangle$ CMSL-7 2NO STAGE 
HYDROGEN CONTENT OF 1 ST \& 2ND STAGE VGO RUNS CC-1, CMSL $-4, \quad \&$ CMSL-7

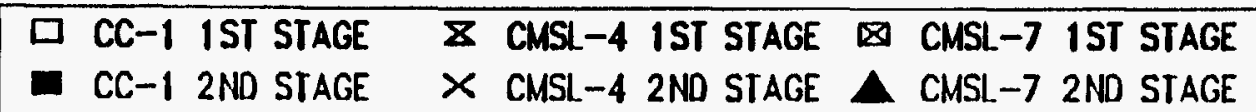


HYDROGEN CONTENT OF 1 ST \& 2 ND STG HVGO RUNS CC $-1, \quad$ CMSL $-4, \quad \&$ CMSL-7

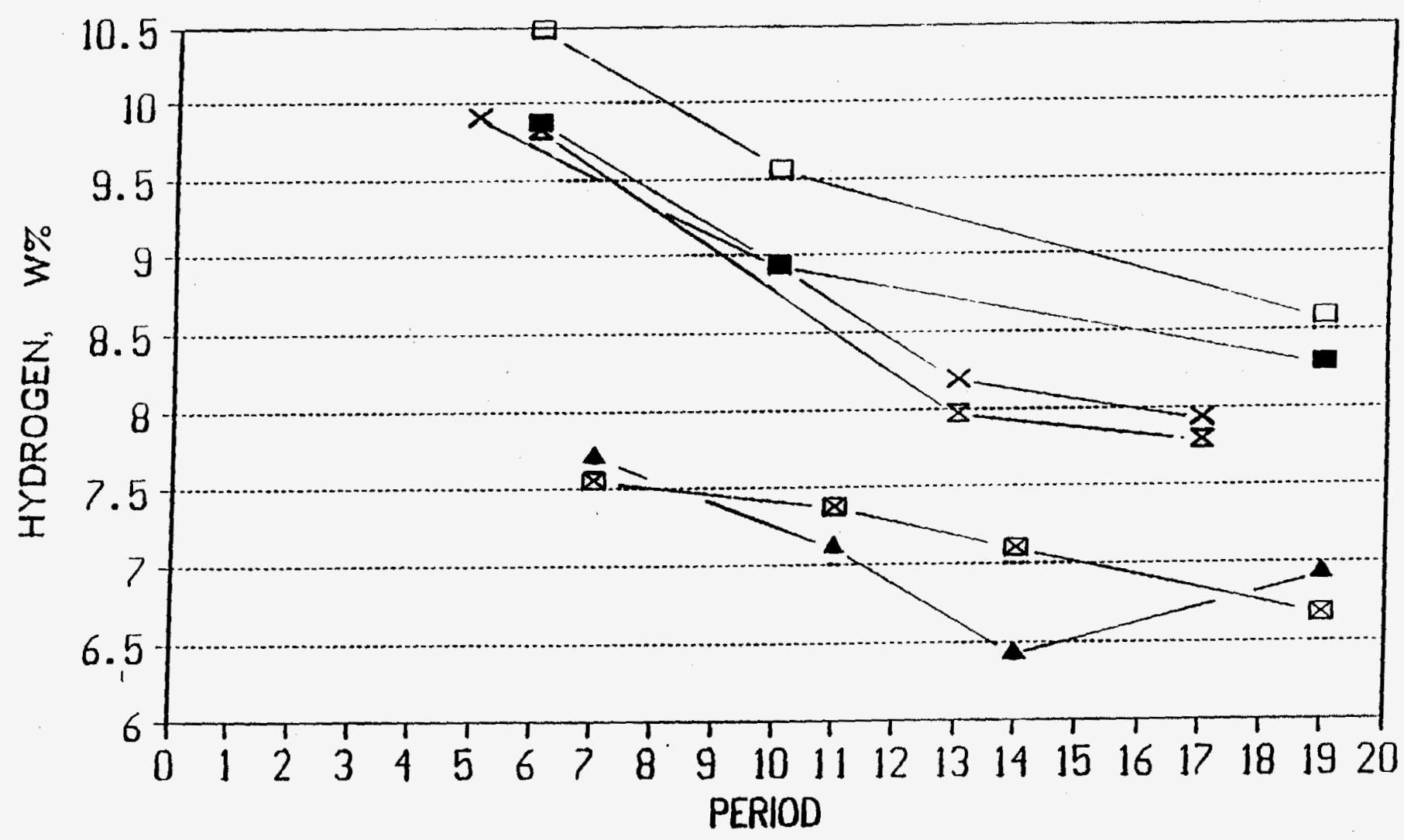




\section{HYDROGEN CONTENT OF 1ST \& 2ND STG RESID}

RUNS CC-1, CMSL-4, \& CMSL-7

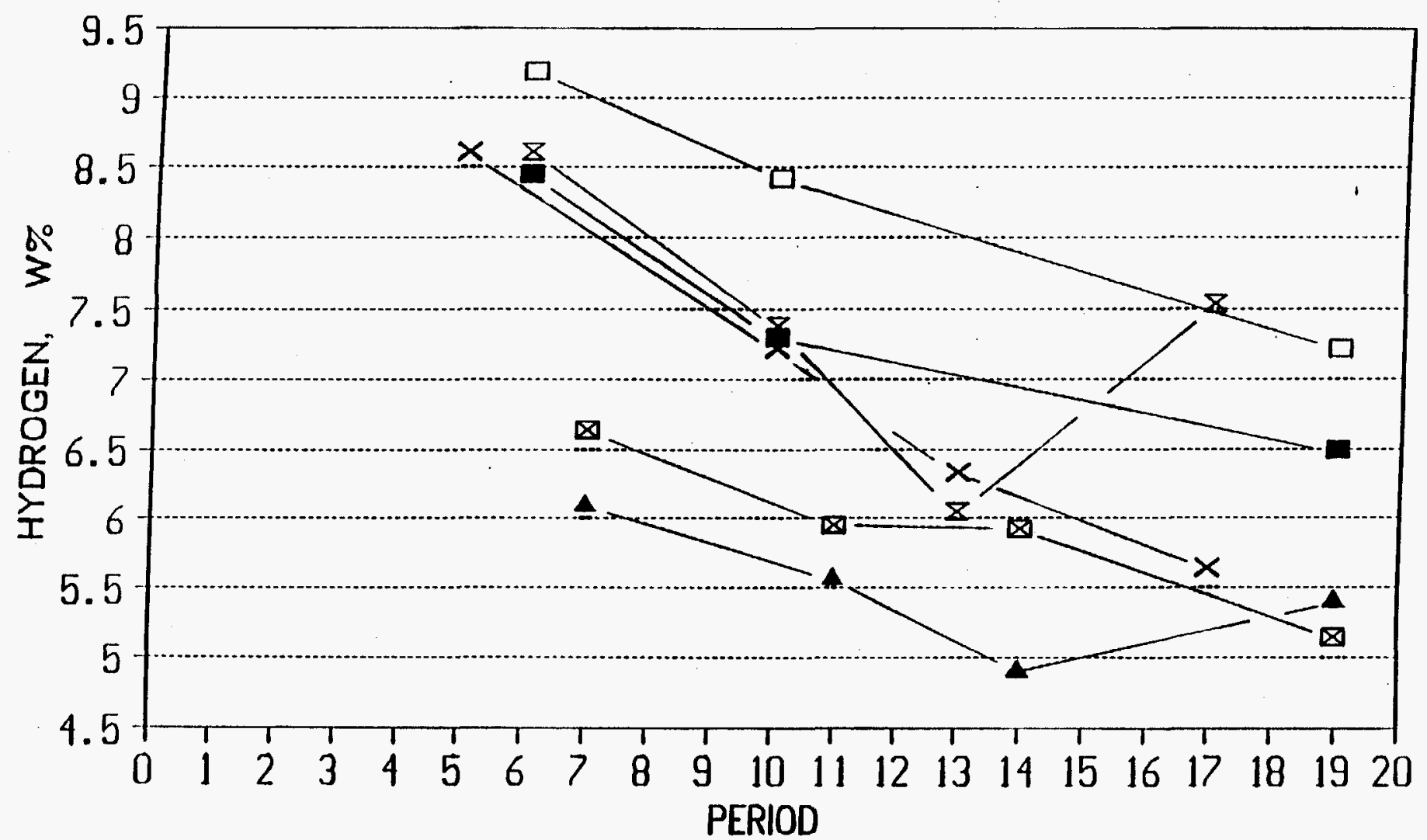


NITROGEN CONTENT OF 1ST \& 2ND STAGE LGO RUNS CC-1, CMSL-4, \& CMSL -7

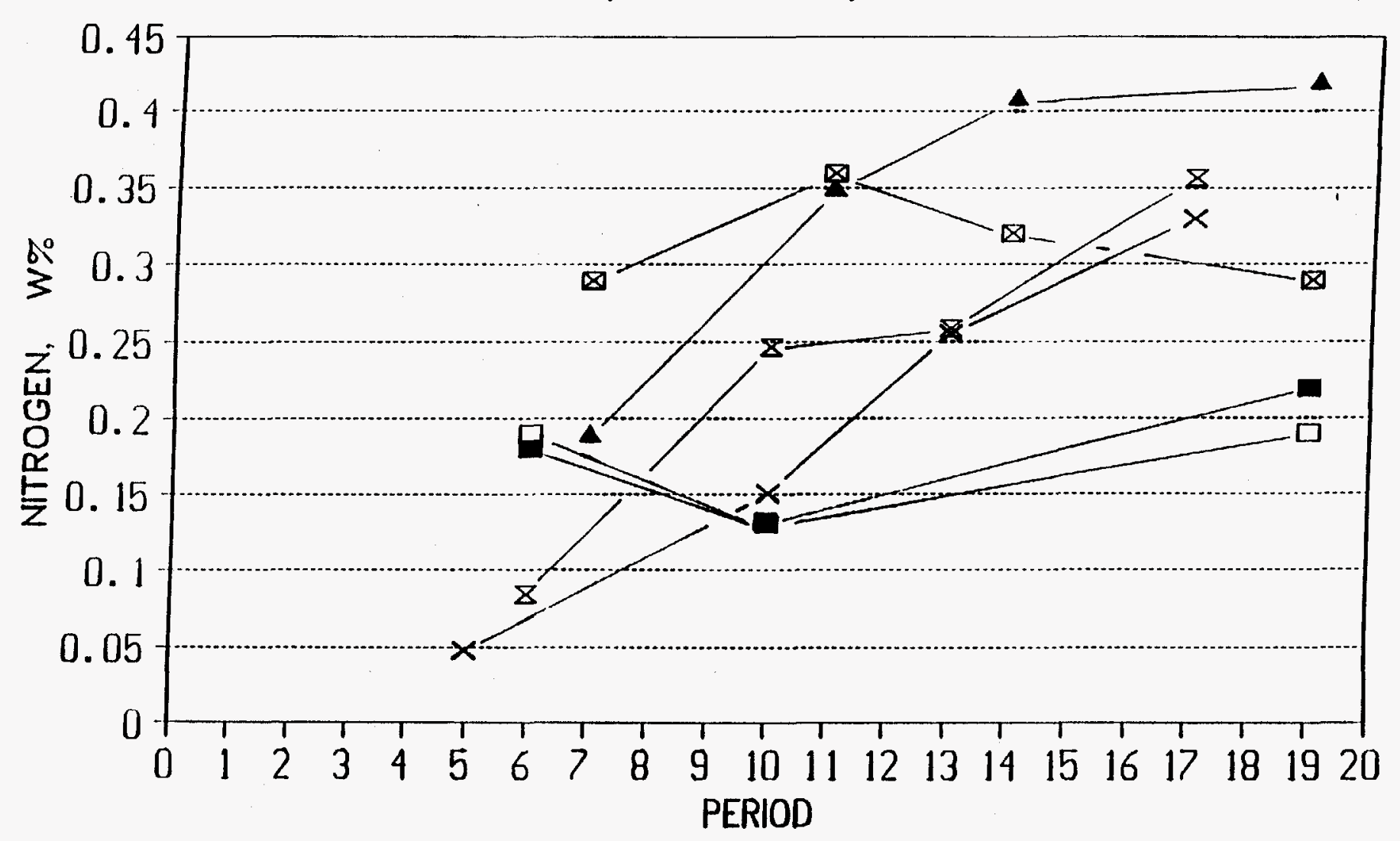

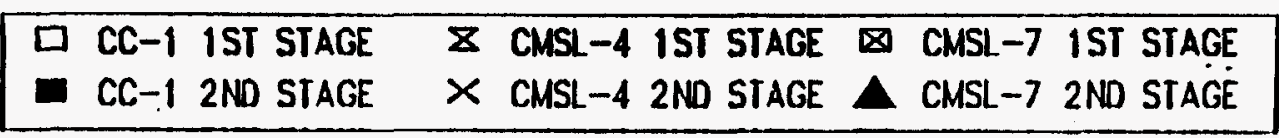


NITROGEN CONTENT OF 1 ST \& 2 ND STAGE VGO RUNS CC-1, CMSL $-4, \quad \&$ CMSL -7

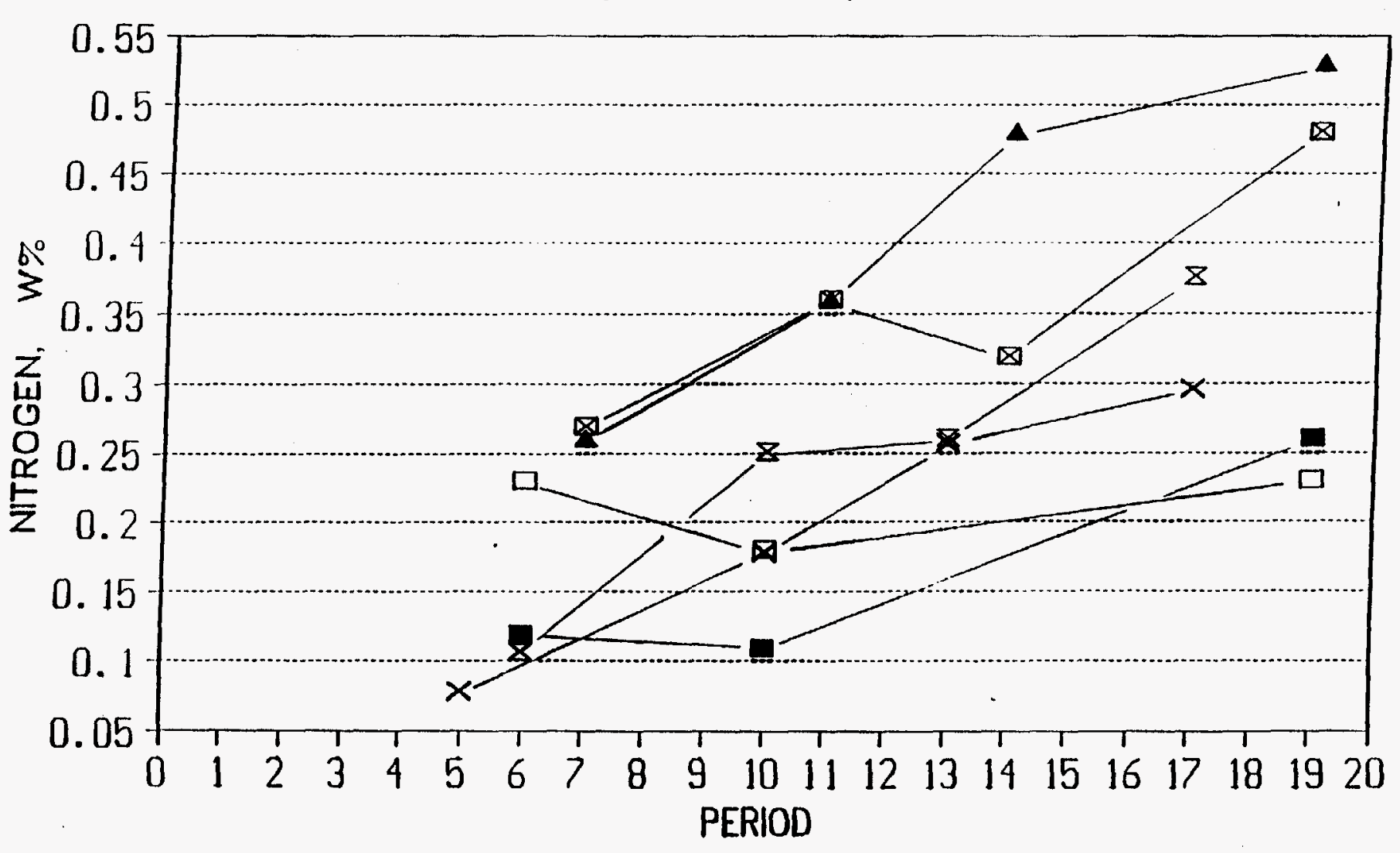

\begin{tabular}{|llllllll|}
\hline CC-1 & 1 ST STAGE & $\bar{\nabla}$ & CMSL-4 & 1ST STAGE & $\otimes$ & CMSL-7 & 1ST STAGE \\
CC-1 & 2ND STAGE & $\times$ & CMSL-4 & 2ND STAGE & $\wedge$ & CMSL-7 & 2ND STAGE \\
\hline
\end{tabular}


NITROGEN CONTENT OF $1 \mathrm{ST} \&$ \& 2 ND STG RESID RUNS CC $-1, \quad$ CMSL- 4, \& CMSL-7

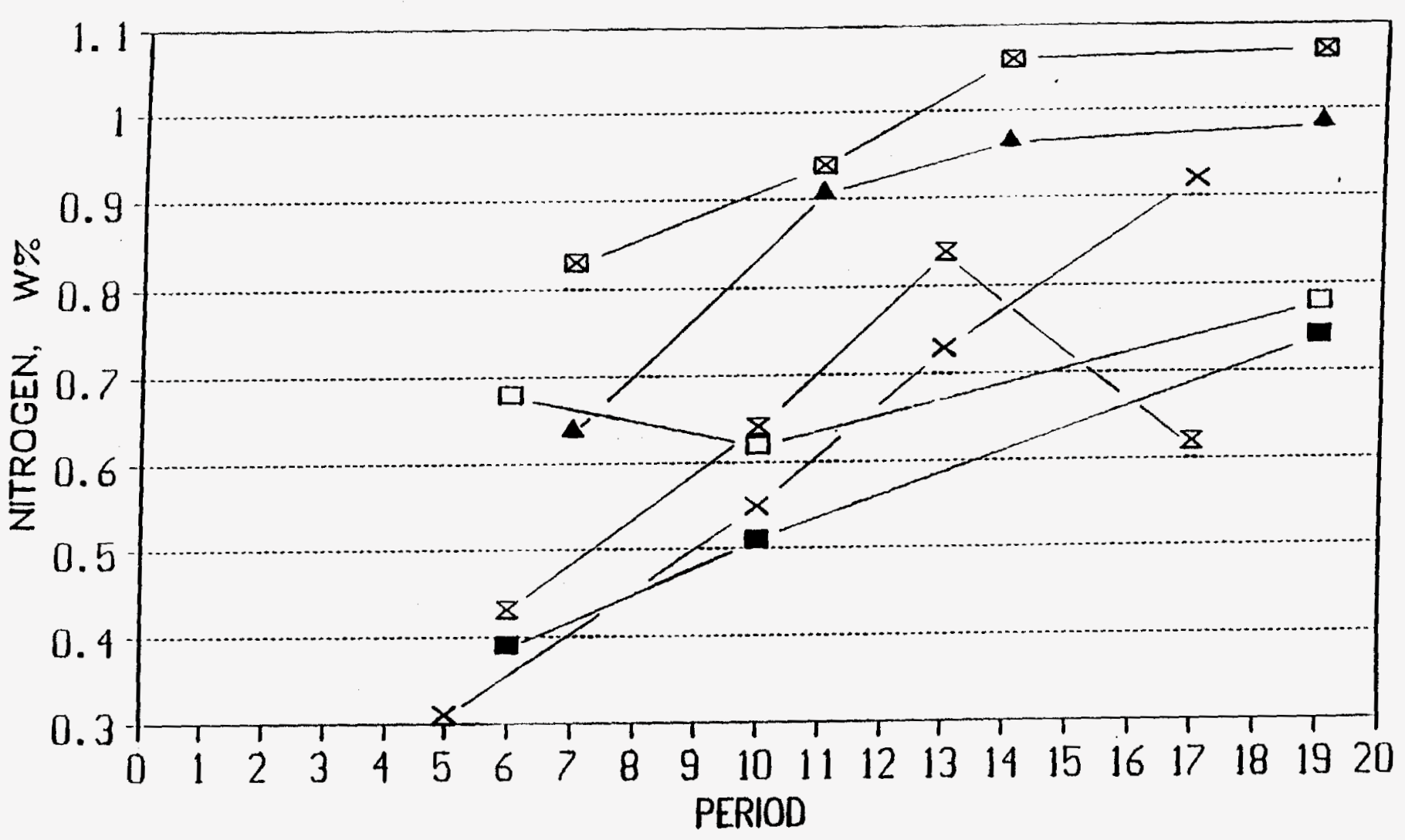

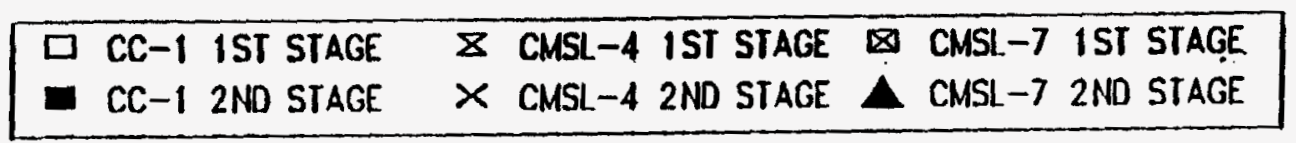


CYCLOHEXANE INSOLS IN 1ST\&2ND STG RESID RUNS CC-1, CMSL-4, \& CMSL-7

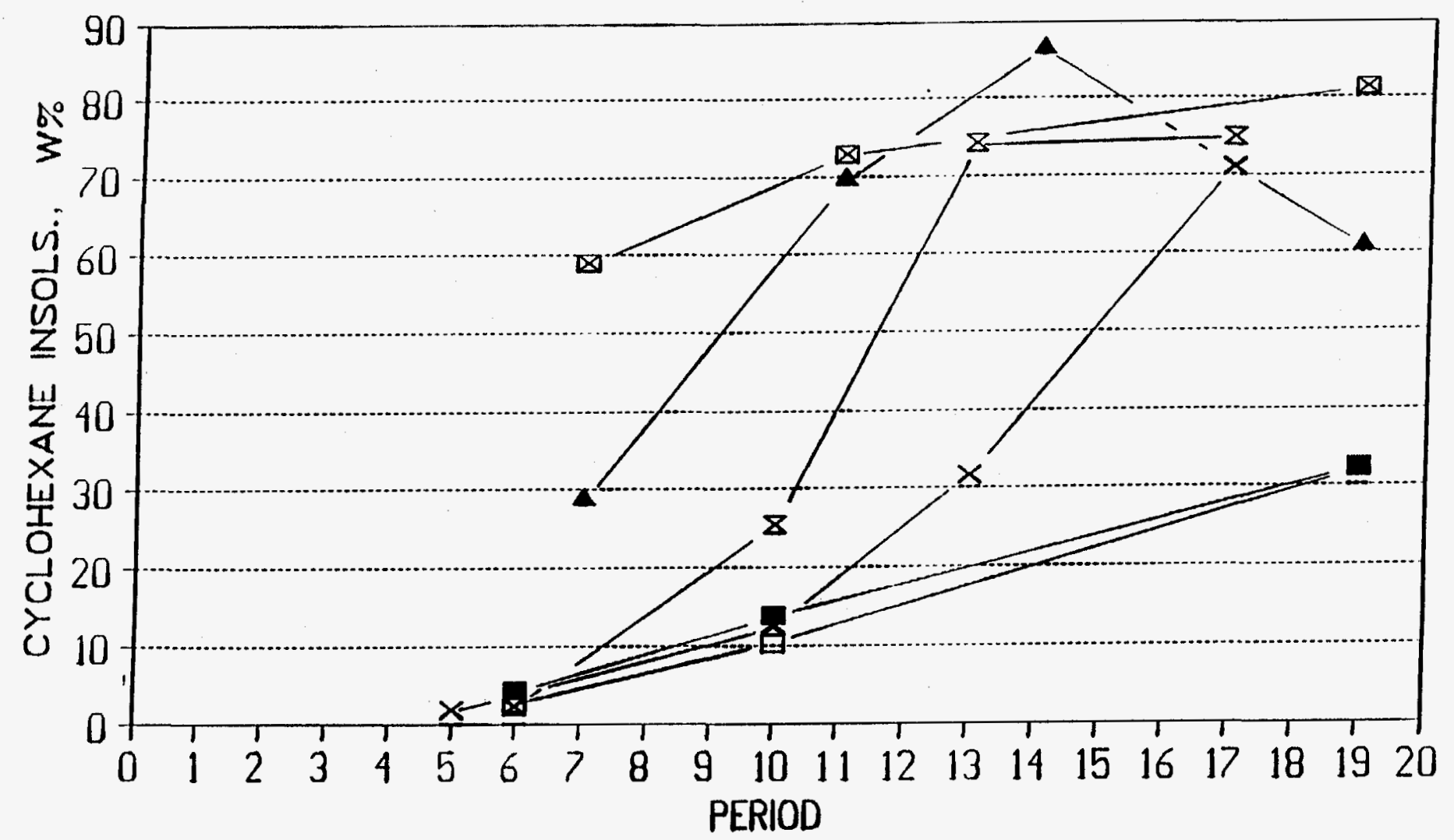

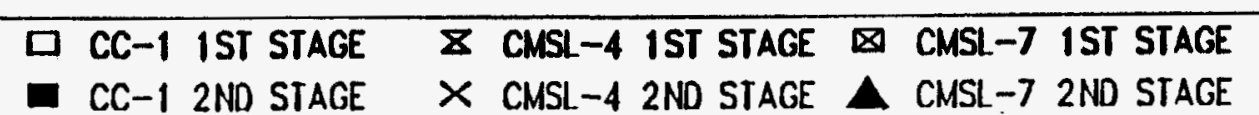


Figure 2.7.29

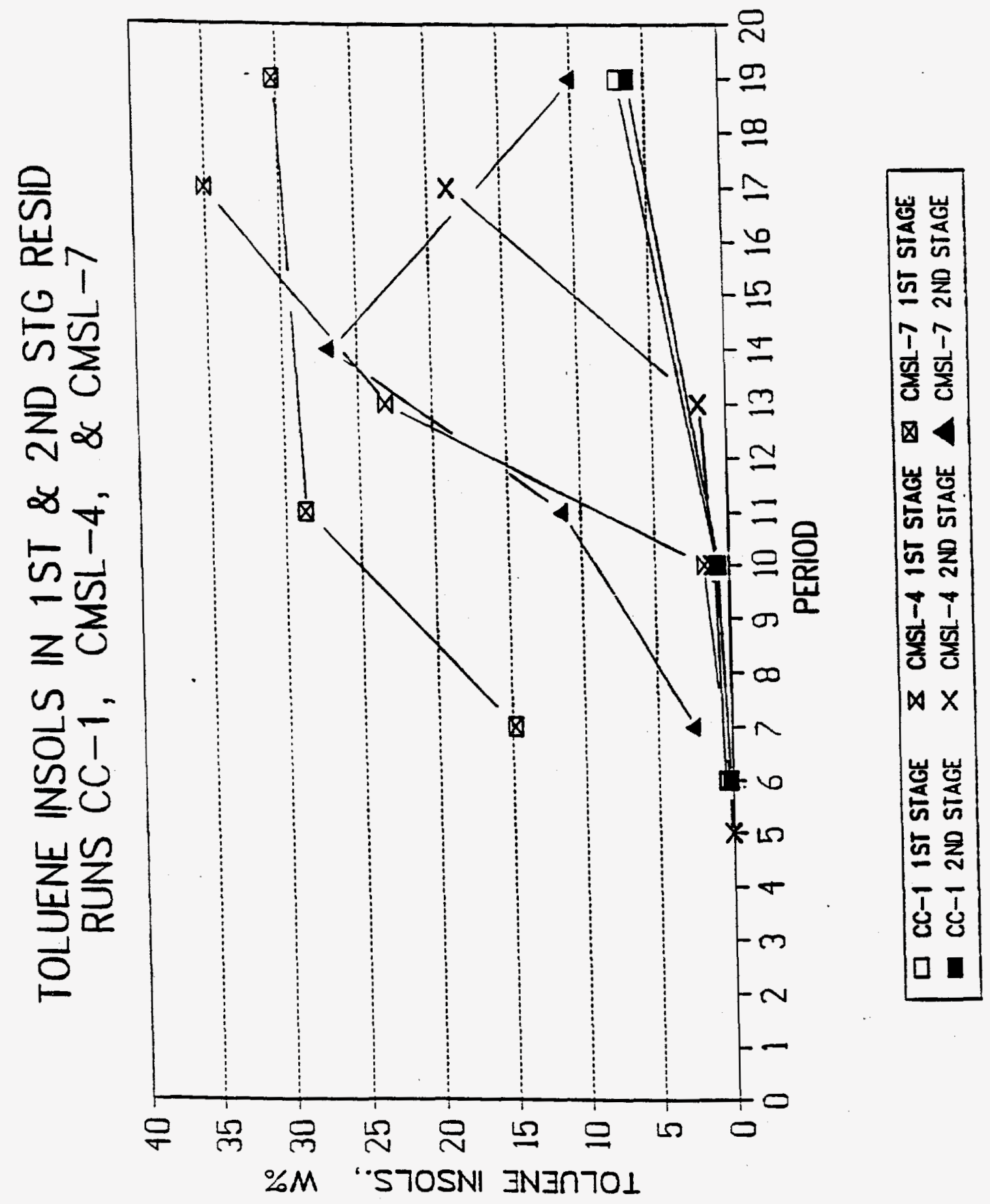


Figure 2.7.30

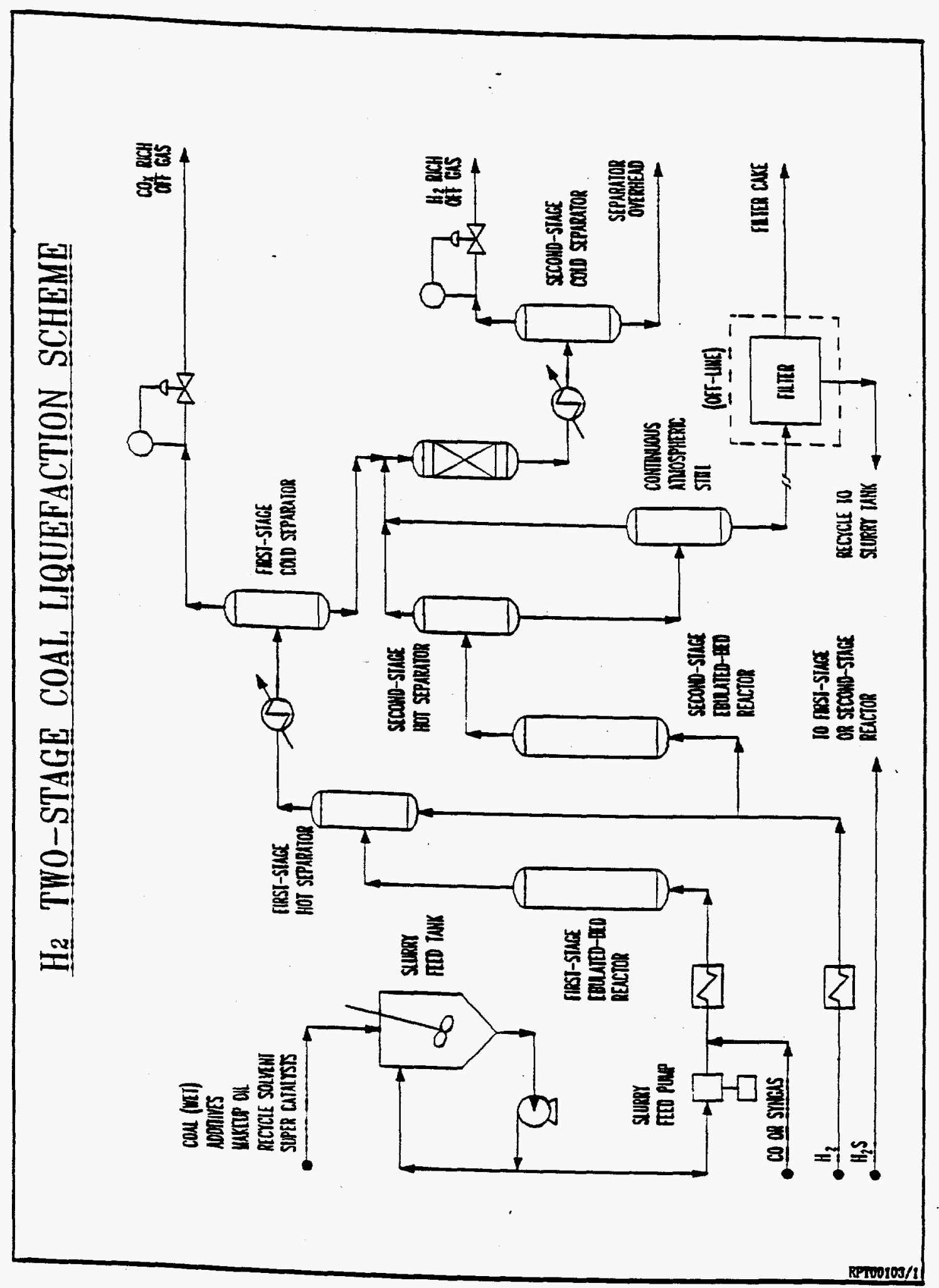




\title{
CATALYTIC MULTI-STAGE LIQUEFACTION OF COAL (CMSL)
}

FINAL REPORT

\author{
VOLUME II
}

SECTION II (CONTINUED)

EVALUATION OF COAL-PLASTICS IN CTSL MODE

RUN CMSL - 8 


\section{VOLUME I}

SECTION II - RUN CMSL-8

TABLE OF CONTENTS

RUN CMSL-8 (227-85)

EVALUATION OF COAL-PLASTICS COLIQUEFACTION IN CTSL MODE

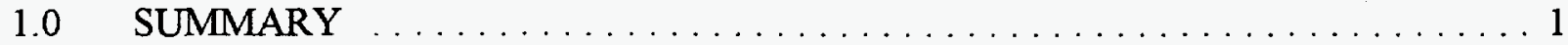

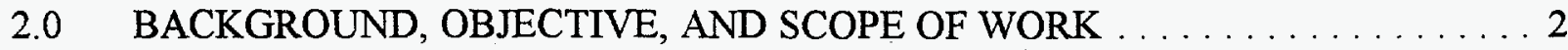

3.0 PROGRAM ANALYSIS RESULTS AND COMPARISON $\ldots \ldots \ldots \ldots \ldots \ldots 3$

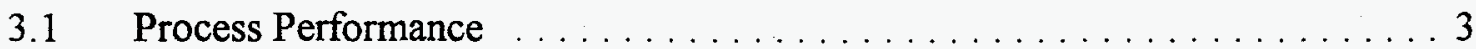

3.2 Product Distribution . . . . . . . . . . . . . . . . . . . . . . . . 4

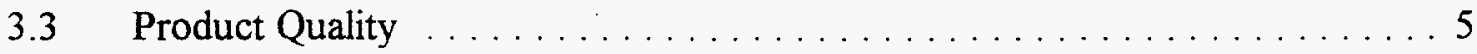

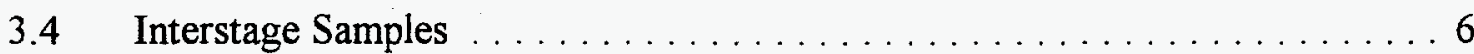

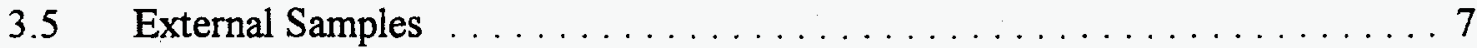

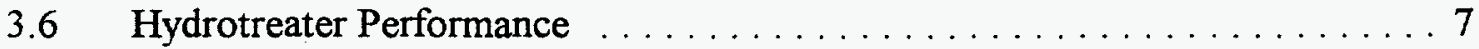

3.7 Products Derived From Plastics $\ldots \ldots \ldots \ldots \ldots \ldots \ldots \ldots \ldots \ldots$

3.8 Effect of Feed Composition $\ldots \ldots \ldots \ldots \ldots \ldots \ldots \ldots \ldots$

4.0 DETAILS OF OPERATION . . . . . . . . . . . . . . . . . . . . 9

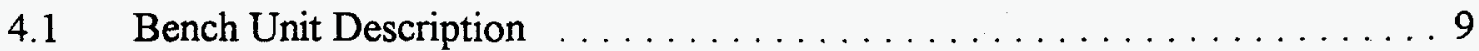

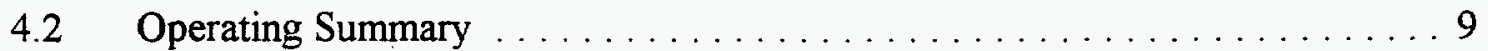

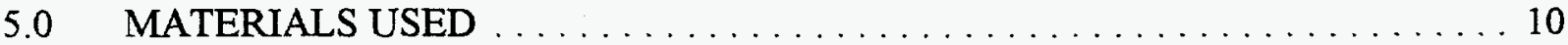

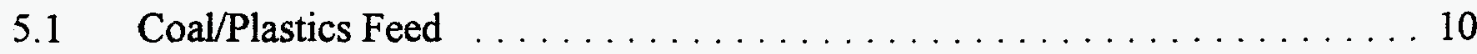

5.2 Start-up And Make-up Oil . . . . . . . . . . . . . . . . . . . 11

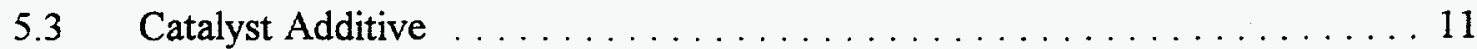

$5.4 \quad$ Supported Catalyst $\ldots \ldots \ldots \ldots \ldots \ldots \ldots \ldots \ldots \ldots \ldots \ldots \ldots \ldots$

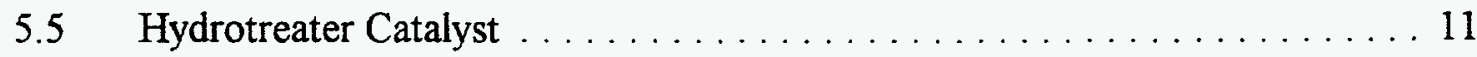

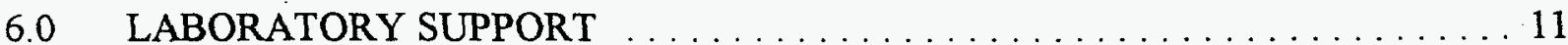

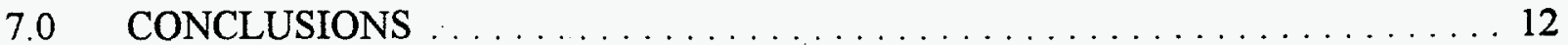

8.0 RECOMMENDATION FOR FUTURE WORK $\ldots \ldots \ldots \ldots \ldots \ldots \ldots \ldots$ 


\section{VOLUME II \\ SECTION II - RUN CMSL-8 \\ LIST OF TABLES}

Table

Page

2.8.1

Bench Run CMSL-8 Modified Run Plan . . . . . . . . . . . . . . . . . 14

2.8 .2

Run CMSL-8 Operating Summary 15

2.8 .3

CMSL-8: Separator Overhead (SOH) Inspection 16

2.8 .4

CMSL-8: Properties of the Pressure Filter Liquid (2nd Stage)

CMSL-8: Inspection of the Pressure Filter Solids (2nd Stage)

Detailed Analyses of TBP Fractions Run 227-85 Period 6

Detailed Analyses of TBP Fractions Run 227-85 Period 11

Detailed Analyses of TBP Fractions Run 227-85 Period 16

Apparent Products Derived from Plastics Co-Processing of 


\section{VOLUME II \\ SECTION II - RUN CMSL-8 \\ LIST OF FIGURES}

Figure

Page

2.8.1 227 Unit with Hot Slurry System and In-line Hydrotreater . . . . . . . . . . . 30

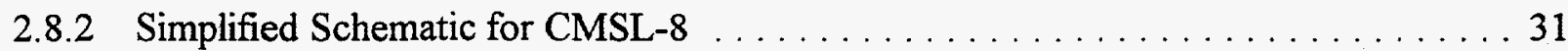

2.8.3 CMSL-8: Coal / Plastics Coliquefaction

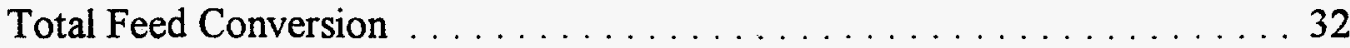

2.8.4 CMSL-8: Coal / Plastics Coliquefaction

Total 524 C + Resid Conversion . . . . . . . . . . . . . . . . . . . 33

2.8.5 CMSL-8: Coal / Plastics Coliquefaction

Hydrogen Consumption . . . . . . . . . . . . . . . . . 34

2.8.6 CMSL-8: Coal / Plastics Coliquefaction

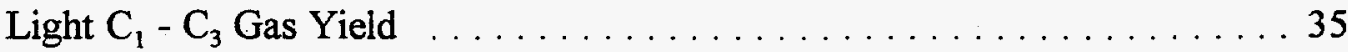

2.8.7 CMSL-8: Coal / Plastics Coliquefaction

Total 524 C+ Resid Yield . . . . . . . . . . . . . . . . . . . . . . . . . . . . . 36

2.8.8 CMSL-8: Coal / Plastics Coliquefaction

$\mathrm{C}_{4}-524$ C Distillate Yield

2.8.9 CMSL-8: Coal / Plastics Coliquefaction

Selectivity of Distillate Fractions for Work-up Periods . . . . . . . . . . 38

2.8.10 CMSL-8: Coal / Plastics Coliquefaction

Properties of Hydrotreated SOH Oil . . . . . . . . . . . . . . . . . . 39

2.8.11 CMSL-8: Coal / Plastics Coliquefaction

PFL Properties vs. Catalyst Age . . . . . . . . . . . . . . 40

2.8.12 CMSL-8: Coal / Plastics Coliquefaction

Solubility of PFL Product $\ldots \ldots \ldots \ldots \ldots \ldots \ldots \ldots \ldots$

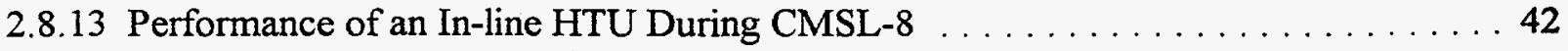

2.8.14 CMSL-8: Coal / Plastics Coliquefaction

The Daily Material Recovery Balances $\ldots \ldots \ldots \ldots \ldots . \ldots \ldots$

2.8.15 CMSL-8: Coal / Plastics Coliquefaction

Daily Operating Conditions . . . . . . . . . . . . . . . . . . . 44

2.8.16 CMSL-8: Coal / Plastics Coliquefaction

Feed Composition

2.8.17 CMSL-8: Coal / Plastics Coliquefaction

Feed Tank Temp / Oil - to - Solids Ratio . . . . . . . . . . . . . . . . . 46

2.8.18 CMSL-8: Coal / Plastics Coliquefaction

Solvent Balance (Net PFL Production) 
RUN CMSL-8 (227-85)

\section{EVALUATION OF COAL-PLASTICS COLIQUEFACTION IN CTSL MODE}

\subsection{SUMMARY}

Run 227-85 (CMSL-08) was successfully carried out for 23 continuous days spread over five Conditions to investigate, for the first time in the bench unit, the effects of coliquefying the primary plastic constituents of municipal solid waste on the CTSL Process performance. This bench run was a follow up of the earlier exploratory work Hydrocarbon Research, Inc. had carried out in the PDU-scale continuous operations during the DOE-sponsored POC-02 PDU run. Although this work at the larger scale demonstrated the operational and technical feasibility of coprocessing of this type, the interpretation of the results was clouded by the fact that the continuous operation was never under solvent-balance, i.e., employed significant proportions of the external make-up oil as a part of the recycle stream for the process. During this bench run, the conditions were chosen to seek for the optimum set of operating severity/catalysis for converting plastics together with Illinois No. 6 coal. A conscious effort was made to maintain the process under a net positive solventbalance during the continuous operations, thereby minimizing any intrusive effects of an external make-up oil. The first stage reactor was provided with both the supported Ni-Mo/ Alumina and the dispersed sulfated iron-molybdenum catalyst to ensure sufficient activity for the depolymerization of plastics in this stage while the second stage reactor was a back-mixed thermal reactor with no supported catalyst but with the converted dispersed catalyst only.

The first two run conditions, Conditions 1 and 2 at feed space velocity of $481 \mathrm{~kg} / \mathrm{hr} / \mathrm{m}^{3}$ reactor, compared at the same conditions, the process performance, product yields and quality between 'coal-only' feed and 'coal and mixed-plastic ( $25 \mathrm{~W} \%$ )' feed (the mixed plastics was $50 \mathrm{~W} \% \mathrm{HDPE}$, $35 \mathrm{~W} \%$ polystyrene, and $15 \mathrm{~W} \% \mathrm{PET}$ ). The performance with coal-plastics coliquefaction was very similar, in terms of conversions and product yields, to direct coal liquefaction. Condition 1, with coal-only feed, resulted in about $96 \%$ total conversion, $91 \%$ resid conversion, and $72 \%$ distillate yield (all MAF basis); the light gas yield and hydrogen consumption were high (11.4 and 7.5\% MAF respectively). Condition 2 , with $25 \mathrm{~W} \%$ co-mingled plastics in the feed with coal, resulted in about $96 \%$ total conversion, over $85 \%$ resid conversion, and $71 \%$ distillate yield; thus the overall performance was maintained despite some deactivation of the first stage supported catalyst. The light gas yield and hydrogen consumption were also lower during Condition 2 ( $9 \%$ and $6.9 \% \mathrm{MAF}$ respectively). Condition 3 , with the feed space velocity increased to $641 \mathrm{~kg} / \mathrm{hr} / \mathrm{m}^{3}$, a higher second stage temperature, and $25 \mathrm{~W} \%$ mixed plastics in feed, resulted in a drop in distillate yields and $524^{\circ} \mathrm{C}^{+}$resid yield. The solvent-to-feed ratio had to be increased to about 2 in transition to Condition 4-with $33 \mathrm{~W} \%$ mixed plastics in the feed and a space velocity lowered to $480 \mathrm{~kg} / \mathrm{hr} / \mathrm{m}^{3}$ $\left(30 \mathrm{lb} / \mathrm{hr} / \mathrm{ft}^{3}\right)$. Process performance was maintained, due to the compensating effects of increased catalyst age (deactivation) in the first stage and reduced space velocity during this Condition as compared to the previous one. The light gas formation and the hydrogen consumption were lower during Condition 4 , probably as a result of the increased plastics concentration in the feed. The final run condition, Condition 5, used $33 \%$ of pure HDPE instead of mixed plastics at the same feed space velocity and reactor temperatures that were used in Condition 4 . The overall process performance deteriorated steeply during Condition 5 , with distillate yield just over $50 \mathrm{~W} \% \mathrm{MAF}$ and resid conversion of $62 \mathrm{~W} \%$ MAF. Overall operations during this run were smooth, except for 
a few feed pump interruptions. The material balance was excellent (an average for the whole run was $100 \mathrm{~W} \%$ ) and the net recycle solvent-balance was also positive throughout the run. Indeed this bench run, overall, was a good technical and operational success and also helpful in directing the future work in coal/waste coprocessing area.

If the increments of yields for the later conditions compared to those for Condition 1 were solely derived from the plastic, in the Condition 2 operation $65 \mathrm{~W} \%$ of mixed plastic was converted to $\mathrm{C}_{4}-524 \mathrm{C}$ distillate, $28 \mathrm{~W} \%$ was contained in the filterable "resid", $2.5 \mathrm{~W} \%$ was converted to $\mathrm{C}_{1}-\mathrm{C}_{3}$ Gases, and $5 \mathrm{~W} \%$ was retained in the filter cake product, with an incremental hydrogen utilization of $3.6 \mathrm{~W} \%$ of the plastics added. For Condition 3, with the higher feed rate, the proportion of plastics appearing as filterable "resid" increased to $54 \mathrm{~W} \%$ with corresponding decreases in the other yield constituents. For Condition 4, with the mixed plastics increased to $33 \%$ of the feed, the increase in filterable "resid" yield was $50 \%$ of the plastics fed. For Condition 5, with only HDPE as the plastics feed, the incremental filterable "resid" yield was $93 \%$ of the plastics fed, and essentially no incremental distillate product was formed from the HDPE. The Condition 2 results suggests some of HDPE in the mixed plastic was converted to distillates, indicating a synergistic effect of the polystyrene and PET in promoting the conversion of the HDPE to distillates.

\subsection{BACKGROUND, OBJECTIVE, AND SCOPE OF WORK}

The CMSL Project is geared to evaluate different novel processing concepts in catalytic coal liquefaction to complement the larger scale process demonstration "Proof-of-Concept" Studies for the U.S. DOE. The new ideas being explored in this program include low temperature pretreatments, more effective catalysts, on-line hydrotreating, new coal feedstocks, other (cheaper) sources of hydrogen, more concentrated coal-slurry feeds etc.

This run was carried out using Illinois No. 6 bituminous coal from Crown II mine, two-stage closecoupled ebullated reactors with Shell-317 extrudate catalyst in the low-severity first stage and no supported catalyst at all in the higher severity second stage reactor; although a dispersed slurry catalyst at a $100 \mathrm{ppm}$ of molybdenum relative to total feed was used to provide catalytic activity in the high severity second stage reactor. The CMSL- 8 had the following technical objectives:

1. To investigate the effect of coliquefying plastics (HDPE, PS, and PET) with coal on the yields and quality of the distillates from two-stage catalytic liquefaction of a bituminous coal in a solvent-balance mode.

2. To determine the effect of low-severity catalytic first stage close-coupled with a high-severity thermal (with dispersed slurry catalyst only) second stage reactor on the overall performance of the coal + plastics coliquefaction process.

3. To obtain samples of different process streams to assess their characteristics and shed some light on the chemistry of converting polymeric plastics with bituminous coal. 
An in-line hydrotreater was used during this run. Both the separator overhead oil and the ASOH streams were sent through the hydrotreater along with the unit knockouts. In order to obtain the samples of the distillates under the HTU off-line conditions, it was decided that Period 9 in Condition 2 would have the on-line HTU bypassed, i.e., the HTU was off-line during this Period and was again brought on-line at the beginning of Period 10. The run plan is presented in Table 2.8.1. The detailed unit configuration is presented in Figure 2.8.I and a simplified schematic is presented in Figure 2.8.2.

\subsection{PROGRAM ANALYSIS RESULTS AND COMPARISON}

The conversions and yields of different products, process performance, and product quality for CMSL-8 are addressed in this Section. The calculation of daily material recovery balances, coal conversions, normalized product yields, and other process performance-related indicators were carried out using programs available in the CTSL database (some programs were also modified as per the requirement of the process configuration). The overall process performance during CMSL8 is summarized in Table 2.8.2 and is discussed in detail in the following sections.

\subsection{Process Performance}

\section{Total Feed (Coal+Plastics Combined) Conversion}

Typical feed conversions (based on the solubility of pressure filter solids in quinoline), obtained during equilibrated Periods of different Conditions of CMSL-8 are shown in Figure 2.8.3. As shown in Figure 2.8.3, the feed conversions (W\% MAF feed) had been steady with a little variation between 95 to $96 \mathrm{~W} \%$ throughout the course of the Run. The presence of plastics in the feed or the nature of plastics used did not seem to affect conversions.

\section{$\underline{524^{\circ} \mathrm{F}^{+} \text {Residuum Conversion }}$}

Residuum conversion values varied between 62 to 91 W\% (MAF feed), as shown in Figure 2.8.4. The decrease in resid conversion levels from Condition 1 to 5 was found steeper than the normal trend explained on the basis of reactor K-1 supported catalyst deactivation. Therefore, it is believed that compounds boiling above $524^{\circ} \mathrm{C}$ were formed from the plastic component of the feed, especially the hardest to react HDPE, as exemplified by the overall process performance during the last Condition when HDPE alone was used with coal.

\section{Hydrogen Consumption And Efficiency}

Hydrogen consumption (Figure 2.8.5) based on MAF feed varied between 1.8 to $7.5 \mathrm{~W} \%$. As expected, chemical hydrogen consumption decreased in going from coal-only operating Periods to the coal/mixed plastics coprocessing Periods. This was due to lower light gas make during coliquefaction operations and higher chemical hydrogen content of the combined feed. As the $\mathrm{C}_{4}-524^{\circ} \mathrm{C}\left(\mathrm{C}_{4}-975^{\circ} \mathrm{F}\right)$ distillate yield was maintained in going from 
Condition 1 to 2 , hydrogen efficiency with coal/plastics operation was always higher (Table 2.8.2) than for the 'coal-only' operation.

\subsection{Product Distribution}

\section{$\underline{\mathrm{C}}_{1}-\mathrm{C}_{3}$ Gas Yields}

As shown in Figure 2.8.6 and Table 2.8.2, the normalized $\mathrm{C}_{1}-\mathrm{C}_{3}$ gas yields for CMSL-8 varied between 5.2 to $11.4 \mathrm{~W} \%$ MAF feed. The light gas yield was highest (11.4 W\%) during coal-only operation of Condition 1 ; the yield decreased significantly during the coal/plastics coliquefaction operations (Condition 2 through 5). The lowest gas yield was obtained during the last run Condition which was with $33 \mathrm{~W} \% \mathrm{HDPE}$ alone with the coal. These findings indicate that plastics, especially HDPE, are more refractory towards hydroconversion than Illinois No. 6 coal under the prevailing process severity/catalyst combinations.

\section{$\mathrm{C}_{4}-177^{\circ} \mathrm{C}$ Naphtha Yields}

These are listed in Table 2.8.2. As shown in Table 2.8.2, the yields of naphtha fraction varied between 12-24 W\% MAF feed. The run Condition 2, where the feed consisted of $25 \mathrm{~W} \%$ co-mingled plastics and coal, resulted in over $23 \mathrm{~W} \%$ high light naphtha yields. The yields were over $20 \mathrm{~W} \%$ for Conditions 1, 3 and 4 also; they went down during Condition 5 as $\mathrm{HDPE}$ alone was used in feed at $33 \mathrm{~W} \%$ with coal.

\section{$177-343^{\circ} \mathrm{C}$ Middle Distillate Yields}

As shown in Table 2.8.2, the middle distillate yields were the highest selectivity yields among the distillate products. These varied between 18-40 W\% MAF feed. The highest middle distillate yield was obtained for Period 6 (Condition 1); the yields decreased steadily as the run progressed in the same fashion as the overall distillate yields.

\section{$343-524^{\circ} \mathrm{C}$ Heavy Distillate (Gas Oil) Yields}

The heavy distillate yields for CMSL- 8 varied between 12-22 W\% MAF feed as shown in Table 2.8.2. Again, the highest gas oil yield was obtained for Condition 5, primarily the result of catalyst aging effect coupled with the presence of $33 \mathrm{~W} \%$ HDPE in the feed.

\section{$\underline{524^{\circ} \mathrm{C}^{+} \text {Residual Oil Yields }}$}

The resid yields followed a normal increasing trend, commensurate with catalyst deactivation, in going from Condition 1 to 4 (Figure 2.8.7). The nature of feedstock, either coal-only or coal plus plastics, did not appear to influence the normal variation in resid yields. Condition 5, with hard-to-convert HDPE alone, resulted in a sharp increase in the resid yield: from about $20 \mathrm{~W} \%$ during Condition 4 to about $34 \mathrm{~W} \%$ (both MAF feed) for Period 22. 


\section{$\mathrm{C}_{4}-524^{\circ} \mathrm{C}$ Distillate Yield/Selectivity}

Distillate yields, shown in Figure 2.8.8, followed similar trend as the resid conversions in going from Condition 1 to 5 . Interestingly, distillate yields for Condition 1 (coal-only feed) and Condition 2 (coal+plastics) were similar ( $70 \% \mathrm{MAF}+)$; it decreased for the high space velocity Condition 3 and was maintained for Condition 4 . Yields plummeted sharply in going from Condition 4 to 5 as a result of using $33 \mathrm{~W} \% \mathrm{HDPE}$ alone in the feed and high catalyst age.

The normalized yield of distillates for CMSL-8 varied between 51-72 W\% MAF coal, as shown in Figure 2.8.8 and Table 2.8.2. The highest distillate yield was obtained for Period 5 in Condition 1 where as the lowest yield was recorded for Condition 5. The selectivity of different distillate boiling fractions is also shown in Figure 2.8.9. As shown in this figure, Periods 7-11, Condition 2, resulted in better selectivity distribution (higher selectivity to naphtha and middle distillate fractions) than most of the other periods.

\subsection{Product Quality}

Different product fractions (First-Stage/Second-Stage Vent Gases, CAS Bottoms, SOH, PFL, and PFS) from the Work-up Periods 6, 11, 16, 20, and 22/23A were analyzed in detail for their composition. These analyses for different product fractions are listed in Tables 2.8.3 through 2.8.9.

\section{Separator Overhead Product (SOH)}

$\mathrm{SOH}$ oil stream represented the net light distillate $\left(\mathrm{IBP}-343^{\circ} \mathrm{C}\right)$ from CMSL-8. While the hydrotreater unit was on-line during the run except for Period 9 , the only distillate stream out was of the $\mathrm{SOH}$ as the $\mathrm{O}-1$ hot separator overheads, $\mathrm{ASOH}$, and unit knockouts were being fed directly to the hydrotreater. The properties of SOH oil for the Work-up Periods are shown in Table 2.8.3. As shown in this Table, the $\mathrm{SOH}$ oils had a typical boiling range of $70^{\circ} \mathrm{C}-370^{\circ} \mathrm{C}$. The API gravities were high $(>35)$ and $\mathrm{H} / \mathrm{C}$ atomic ratios were also high (1.73-1.82), especially during coal-plastics coliquefaction operations. $\mathrm{IBP}-177^{\circ} \mathrm{C}$, the lightest fraction of the SOH-oil was also higher during coliquefaction operations than the coal-only Condition 1 . The heteroatoms level (nitrogen and sulfur) were extremely low throughout the run, indicating a very successful operation of an in-line hydrotreater. Typically, sulfur levels below $15 \mathrm{ppm}$ and nitrogen levels were below $5 \mathrm{ppm}$ were obtained for the $\mathrm{SOH}$ oil. The properties of $\mathrm{SOH}$-oil, in terms of $\mathrm{H} / \mathrm{C}$ ratios and heteroatom contents, are shown in Figure 2.8.10.

\section{Pressure Filter Liquid and Pressure Filter Solid}

The API gravity of PFL varied between -8.1 to 11 while the $524^{\circ} \mathrm{F}^{+}$resid content increased from 29.9 to $64.2 \mathrm{~W} \%$ as shown in Figure 2.8.11. The detailed inspection of PFL and PFS properties for the work-up Periods during CMSL-8 is shown in Tables 2.8.4 and 2.8.5. Interestingly, the API gravities and the $\mathrm{H} / \mathrm{C}$ atomic ratios were, in general, significantly higher for the PFL streams obtained from coliquefaction Conditions than for the 'coal-only feed' Condition 1. At the same time, the resid content of the PFL was increasing with 
catalyst age; this indeed indicated that substantial contributions to PFL pool were also made by the reacted/converted plastics part of the feed. Not only this, but from the solubility behavior of the PFL resid fraction, it can be seen (comparing toluene and cyclohexane insolubles for Conditions 2 and 3 with 1 ) that more paraffinic (or waxy) type of products from plastics were contributing to the resid formation in the PFL. The preasphaltene (toluene insolubles) and asphaltene (cyclohexane insolubles) contents of the PFL are listed in Table 2.8.4 and are plotted in Figure 2.8.12. As shown in this Figure, indeed the solubility behavior of the PFL resid fraction from Conditions 2 and 3 , with combined feed, was better than with the coal-only Condition 1 .

\section{Analysis of TBP Fractions of Liquid Products}

The detailed analyses of the true boiling point (TBP) fractions from the run CMSL-8 are summarized in Tables 2.8.6a-2.8.6e. As shown in these Tables, the coal-plastics coliquefaction Periods during CMSL-8 result in higher percentage of the lighter boiling fractions. The light naphtha fraction $\left(\mathrm{IBP}-177^{\circ} \mathrm{C}\right.$ ) also increased with increase in feed plastics concentration from 25 to $33 \mathrm{~W} \%$. Interestingly, the lighter fraction percentage decreased when HDPE alone was processed with coal (Period 22). The hydrogen contents of naphtha, kerosene, and diesel fractions are also high and nitrogen and sulfur contents noticeably low. The API gravities of the TBP fractions are higher for the coliquefaction Periods than from the coal-only Period. From the PONA analysis it can be seen that aromatics fraction increased in going from coal-only to coal/plastics coliquefaction conditions. This is not surprising as significant portion of the aromatic fractions from coliquefaction operations was comprised of alkyl benzenes, which are derived from the depolymerization of polystyrene present in the plastics part of the feed.

\subsection{Interstage Samples}

The interstage samples are the samples of the slurry exiting the first stage reactor, that are withdrawn from the ebullating line on the reactor. These samples shed light on the performance of the first stage reactor in terms of coal and resid conversions. The interstage samples of the product slurry from the first stage reactor were collected during Periods $7 \mathrm{~A}$, $12 \mathrm{~A}$, and $17 \mathrm{~A}$ to represent Work-up Periods in each of the selected Run Conditions. An interstage sample for the last run Condition could not be obtained as the sampling bomb plugged during the Period 21A sample withdrawal. The interstage samples were pressure filtered hot and both the PFL \& the PFS were analyzed and worked-up separately. Pressure filter liquids was subjected to ASTM D-1160 distillation while pressure filter solids were extracted with quinoline to determine the coal conversions. Tables 2.8.7 and 2.8 .8 list all the information that is derived from the interstage samples analyses. From the inspection of the interstage PFL properties, the same behavior is observed for the API gravity and $\mathrm{H} / \mathrm{C}$ ratio variations in going from the 'coal-only feed' Condition 1 to the 'coal plus plastics' Condition 2. API gravity got better while the $\mathrm{H} / \mathrm{C}$ ratio increased significantly. Similarly, the toluene and cyclohexane solubility of the PFL resid fraction improved significantly. The resid fraction from the interstage PFL samples also appears to be waxy or more paraffinic in nature. This happened in spite of the overall increase in the total resid content of the PFL material. All these seem to point to significant resid material resulting from HDPE part of the feed. 


\subsection{External Samples}

As mentioned earlier, a number of samples of different process streams from CMSL-8 were obtained for the Consol, Inc. and also for the members of Consortium of Fossil Fuel Liquefaction Science. These samples, their amounts, and the operating Periods when these were withdrawn are shown in Table 2.8.9.

\subsection{Hydrotreater Performance}

The in-line hydrotreater performed exceptionally well during CMSL-8. As shown in Figures 2.8.10 and 2.8.13, the net process distillates exiting the hydrotreater as an $\mathrm{SOH}$ oil stream, contained on an average less than $15 \mathrm{ppm}$ sulfur and less than $5 \mathrm{ppm}$ nitrogen. The $\mathrm{H} / \mathrm{C}$ atomic ratios of net distillates are high (1.8). In order to obtain the nature of distillates before hydrotreating, during Period 9 of CMSL-8, the HTU was by-passed and the nitrogen and sulfur contents as well as $\mathrm{H} / \mathrm{C}$ atomic ratios of the unhydrotreated distillates and their individual flowrates (ASOH \& $\mathrm{KOs}$ and O-1 Overheads) are shown in Figure 2.8.13. As shown in this Figure, over $95 \mathrm{~W} \%$ of nitrogen and sulfur in the HTU feed streams has been removed by hydrotreater to yield a premium distillate at less than 10 ppm $\mathrm{N}$ and $\mathrm{S}$, and with high $\mathrm{H} / \mathrm{C}(1.78)$ ratio.

\subsection{Products Derived From Plastics}

Table 2.8.12 is a summary of the calculation of the nominal distribution of products derived from the plastic components assuming that the increments of yields for the co-processing operations compared to those for the coal-only operations were solely derived from the plastic. This estimate indicates for the Condition 2 operation, with $25 \%$ plastics feed, about $67 \%$ of the plastic was converted to $\mathrm{C}_{4}-524 \mathrm{C}$ distillates with $28 \%$ dissolved (and filterable) but remaining as a residual oil. The $\mathrm{C}_{1}-\mathrm{C}_{3}$ yield from the plastics were about one-fifth of that of the coal, and nominal hydrogen consumption by the plastics was about $70 \%$ of that of the coal, and the proportion of the plastics remaining as unconverted on the product filter cake was $4.5 \%$. In the Condition 3 operation, with the feed space velocity increased by $33 \%$, the apparent yield of distillates from the plastics fell to $39 \%$ and the yield of filterable resid increased to $54 \%$. In the Condition 4 operation, at lower space velocity and the mixed plastics increased to $33 \%$ of the feed, the apparent distillate yields from plastic increased to $49 \%$ and yield of filterable resid decreased slightly to $50 \%$. In the Condition 5 operation, now with $33 \% \mathrm{HDPE}$ as the plastic component, apparently less than $10 \%$ of distillates were derived from the plastic while filterable resid was essentially the entire product from the plastic.

This analyses is, of course, preliminary, in that it did not allow for any variation of the distribution of products from the coal associated with the catalyst deactivation and the change in space velocity for the Condition 3 operation. Consideration of such effects for the later operations of the run would probably raise the proportion of resid oil yield and lower the amount of distillates assigned to the coal constituent and, consequently, have inverse effects upon the respective amounts derived from the plastic. However, even assuming that the resid derived from coal doubled progressively between the 6 th and 22nd day of operations, approximately the amount in coal only CTSL operations, the estimated 
proportion of plastics going to resid would still be $25-83 \%$, about $88-90 \%$ as much as the estimates in Table 2.8.12.

The essential conclusions from these estimates are:

1) At least $67 \%$ of the mixed plastics can be converted to distillates;

2) This proportion can probably be increased with appropriate increases in severity or catalytic activity since this yield was highest, and the "resid" yield lowered, in the high severity operation of Condition 2 ;

3) While HDPE itself is difficult to convert to distillates there is apparently a synergistic effect when mixed with the other plastics, since the distillates derived from mixed plastics in Condition 2 was higher than the amount of the other plastics in the mixed plastic by an amount that corresponded to $34 \%$ of the HDPE content.

\subsection{Effect of Feed Composition}

One of the objectives of CMSL-8 was to investigate the effects of feed composition on the overall process performance. Three feed compositions were studied under similar process severity- 0, 25, and $33 \mathrm{~W} \%$ co-mingled plastics and $33 \mathrm{~W} \% \mathrm{HDPE}$ alone with Illinois No. 6 coal. From the process performance summary in Table 2.8 .2 and the other analytical data presented in this report, it can be seen that, with $25 \mathrm{~W} \%$ plastics, under similar reaction severity, the total conversion and distillate yields were maintained, while the resid conversion, light gas yield, and chemical hydrogen consumption went down. Except for the observed trend in resid conversion, this is the desired direction one would want to go with coal-plastics coprocessing. Products, in general with plastics, had higher hydrogen contents than without them in the feed. The higher plastics concentrations in the feed (33 W\% co-mingled and $33 \mathrm{~W} \%$ HDPE alone) resulted in a normally observed trend in the process performance although it is strongly believed, based on the nature of heavier products that plastics, especially HDPE, were responsible for making significant amounts of $524^{\circ} \mathrm{C}^{+}$resid, which under the reaction condition employed during CMSL-8 was hard to convert and kept on building up with recycle. It is in this regard, a bench run is recommended with two-close coupled stages where a high severity first stage will employ an acidic dispersed additive while the second stage will be a conventional ebullated bed reactor with lower severity for hydrogenation and hydrocracking. An alternative option, where plastics are first converted separately in a high severity backmixed vessel and transferred into the slurry mix tank for coal liquefaction, is promising. 


\subsection{DETAILS OF OPERATION}

The Run Plan, shown in Table 2.8. I, included five Run Conditions that were selected to meet the technical objectives, specified above. Only the first Condition was chosen to run on the 'coal-only' feed for comparisons under similar process severity Conditions. A solvent/feed ratio of between 1.5-2.0, planned throughout the run, was based upon the earlier experience at the PDU level. The Conditions 2 through 4 were chosen to study the effects of 25 and $33 \mathrm{~W} \%$ mixed plastics concentration in the feed and feed space velocity, while the last condition, Condition 5 , investigated the effects of using HDPE alone at $33 \mathrm{~W} \%$ of feed with coal on the process performance.

\subsection{Bench Unit Description}

CMSL-8 involved two equal volume ebullated reactors. The stage one reactor, $\mathrm{K}-1$, was loaded with fresh Shell S-317 Ni-Mo/alumina supported catalyst while the second stage reactor, K-2, was just a backmixed reactor with no supported catalyst. A sulfated Fe-Mo dispersed catalyst, successfully tested during CMSL-6 bench run, was used at $100 \mathrm{ppm}$ of Mo relative to total feed to provide some catalytic environment in reactor K-2. An in-line HTU used a trilobe Criterion Ni-Mo C-411 catalyst in a fixed bed. An off-line pressure filtration and a solvent-extraction units were used to recover a solid-free liquid (recycle solvent) from the slurry product. The schematic of the system configuration for CMSL-8 is shown in Figure 2.8.1. The sampling points for different process streams from CMSL-8 are shown in Figure 2.8.2.

\subsection{Operating Summary}

\section{Premixing/Slurrying:}

For the preparation feed, -100 mesh Illinois No. 6 coal was mixed with recycle solvent and plastic beads in a slurry preparation tank system. Six to eight hour batches of the feed slurry were made in the HSMT (P-7) and pumped over to the feed pot, P-2. Based on the experience in the laboratory, it was found that adding plastics to a pre-mixed coal/solvent slurry at temperatures around $425^{\circ} \mathrm{F}$, and letting the plastics dissolve/homogenize for about an hour at that temperature, yielded a very homogeneous (though grainy) slurry that appeared normal (from the pumping view point) to the operations personnel. This experience was obtained both at 33 and $50 \mathrm{~W} \%$ of co-mingled plastics with coal and at a solvent/solids ratio of 1.5 in laboratory scale operations. Preparing the mixture/slurry in this manner in the same tank makes the pre-reactor section of the process more manageable. Also, the sequence of first preparing a hot coal/solvent slurry and adding plastics to it at high temperatures is preferable over the one in which coal is added to the hot plastic/solvent slurry as the later approach will only exacerbate the foaming problem due to about $5 \mathrm{~W} \%$ moisture content of feed coal. The high temperature of the feed preparation would also allow to establish a pumpable viscosity of the feed slurry. 


\section{Operational Details}

An average material recovery balance of $100.1 \mathrm{~W} \%$ was obtained (Figure 2.8.14) for the entire Bench Run CMSL-8. The Operating Summary of individual Periods during CMSL-8 is shown in Table 2.8.2. Figures 2.8.15 through 2.8.17 show the operating conditions during CMSL-5 in terms of coal space velocities, reactor temperatures, feed compositions, feed tank temperatures, and recycle ratios (oil-to-solids) respectively. As shown in Figure 2.8.15, except for the Condition 3 , the total feed space velocity was maintained about 481 feed $\mathrm{kg} / \mathrm{hr} / \mathrm{m}^{3}$ reactor. Higher space velocity of $430 \mathrm{~kg} / \mathrm{hr} / \mathrm{m}^{3}$ during Condition 3 , adversely affected the operations as well as the overall process performance. Reactor K-1 temperature was maintained in the $437-435^{\circ} \mathrm{C}$ range while reactor $\mathrm{K}-2$ temperature was varied between 441 at the beginning to about $454^{\circ} \mathrm{C}$ during Conditions 3 through 5 to provide sufficient severity for hydrocracking of plastics. The oil-to-solids ratio was varied from 1.5 to about 2.0 to maintain pumpability of the feed slurry at higher plastics concentration in the feed. It can also be seen in Figure 2.8.17 that due to the increased viscosity of feed, the slurry mix tank temperature had to be progressively increased to maintain the pumpability.

\section{Recycle Solvent Balance}

One of the primary objectives of CMSL-8 was to investigate the coal/waste coliquefaction under steady-state or equilibrated process conditions. An important factor in such processing as recycle operations is the net recycle solvent/oil balance. This has to be positive to ensure that no external make-up oil is needed for the slurry preparation as the use of make-up oil would cloud the interpretation of the reaction data. It was feared that plastics, under typical coal liquefaction conditions, would result in substantial formations of light oils and a shortage of heavy recycle oil $\left(399^{\circ} \mathrm{C}^{+}\right.$material) would result. As shown in Figure 2.8.17 and 2.8.18, this was not quite the case. Even at recycle ratios between 1.5-2.0, overall net recycle solvent balance, calculated as the net pressure filter liquid (PFL) production, as a $\mathrm{W} \%$ of dry feed, was positive and, in fact kept on increasing progressively with the catalyst age during Conditions 2 through 5 . This is the resuit of decreased resid conversion during the later operations.

\subsection{MATERIALS USED}

\subsection{Coal/Plastics Feed}

Illinois No. 6 Crown II Mine (L-811), the same coal that was used in the PDU 260-004 operations, was used for CMSL-8 (227-85) bench run. Two millimeter size beads of high density polyethylene (HDPE), polystyrene (PS), and polyethylene terpthalate (PET) were used in preparing the combined feed. The analyses of coal and plastics is shown in Table 2.8.10. 


\subsection{Start-up And Make-up Oil}

L-814, a petroleum-derived make-up oil used during POC-02 operations was used for the start-up. The analysis of this oil is shown in Table 2.8.11.

\subsection{Catalyst Additive}

Sulfated iron-molybdenum dispersed catalyst was added to reactor K-1 at $100 \mathrm{ppm} \mathrm{Mo}$, $615 \mathrm{ppm} \mathrm{Fe}$, relative to feed and was carried over to the thermal reactor K-2 to provide some catalytic activity.

\subsection{Supported Catalyst}

Shell-317 1/32" extrudate catalyst (Ni-Mo/ $\left./ \mathrm{Al}_{2} \mathrm{O}_{3}\right)$ was used for the first stage reactor during CMSL-8. The catalyst was presulfided during the startup using TNPS. No catalyst was either added or removed from the reactor during the run.

\subsection{Hydrotreater Catalyst}

Hydrotreater unit (HTU) was charged with a trilobe-shaped Criterion C-411 catalyst that is believed to be of Ni-Mo on alumina formulation.

\subsection{LABORATORY SUPPORT}

The laboratory support for CMSL-8 consisted of experiments, conducted in relation to the prereactor handling (mixing/dissolution and pumping) of the coal/solvent/plastic mixtures. In essence, two dissolution tests were conducted at 33 and $50 \mathrm{~W} \%$ co-mingled plastics and remaining Illinois No. 6 Crown II mine coal (ca. 5\% moisture). The tank-4 material, a petroleum-derived oil, was used as solvent with solvent-to-total feed being 1.5. Thus, all compositions and ratios to be used during CMSL-8 were simulated in these tests. The approach used was to make, at room temperature, a slurry of coal and solvent, heating it to about $220^{\circ} \mathrm{C}$ and then adding co-mingled plastics to the slurry at that temperature. After allowing the plastics in slurry about 45 minutes at temperature, the hot mixture was observed by HTI operations personnel. It looked fluid, homogeneous, and free of any lumps. Therefore, pumpable. Upon cooling down to room temperature, the mixture took an appearance of a plasticized and grainy filter cake material. This approach is certainly different from that employed successfully during the POC-02 run, although the new approach is less complicated as it will need only one pre-mix tank at high temperatures $\left(200-220^{\circ} \mathrm{C}\right.$ ) instead of three (as during POC-02) and would also make the foaming problem due to moisture in coal more manageable. As a result, this was the approach that was followed for the pre-reactor handling of the coal/plastics with recycle solvent during the CMSL-8 bench run.

The offline pumping tests, carried out both at $33 \%$ and $50 \%$ plastics in the feed, using the hot slurry mix tank at $218^{\circ} \mathrm{C}$, successfully demonstrated the pumpability of the feed mixtures. For most of the part during these tests, the plastics had to be fed manually, as the addition through the hopper bomb got restricted as a result of melting of part of the plastics feed and sticking to the addition pipe-wall upon coming in contact with hot vapors issuing from the slurry in the tank. 
The microautoclave tests, carried out under conditions similar to those corresponding to the bench run, indicated as high as 92 W\% MAF conversion for coal+plastics combined feed (@33\% plastics) while the conversion was 90W\% MAF (@50\% plastics), both based on THF-solubility of the products. These numbers were much higher than those reported earlier (75-82 W\% range) in the microautoclave tests that used the separately added coal and plastics feed. Thus, a distinct advantage is seen here in using the pre-dissolved/pre-mixed coal/plastics/solvent mixtures for the actual reaction studies.

\subsection{CONCLUSIONS}

CMSL-8 was a very successful bench run both from the technical and operational standpoint. Over 22 days of continuous operation was completed without any major issues/interruptions. The main technical objectives of the run were achieved over a span of $22+$ continuous days of operations. Three plastics/coal ratios, effects of HDPE alone, and space velocity were studied during this bench run. Samples of different process streams were obtained for the property characterization/assessment. The following conclusions can be drawn based on the results obtained during CMSL-5:

- Under similar reaction severity, the combined feed of coal and $25 \mathrm{~W} \%$ plastics resulted in similar overall process performance. With plastics in feed, the light gas make and hydrogen consumption were lower at the same level of total conversion and distillate yields.

- In general, plastics, especially HDPE, was found harder to convert to distillate material than either coal or other components (PS and PET) of the co-mingled plastic feed. This was evident from the waxy nature and solubility behavior of the PFL resid fraction from the coliquefaction work-up Periods.

- From the trends in process performance and reaction severity it is clear that plastics demand more severe depolymerization/cracking environment that Illinois No. 6 coal. It is also believed that an acidic additive (also having small percentage of PVC in the plastics feed might heip as small amounts chlorine will be available to acidify the dispersed/supported catalyst) and high reactor temperatures (about $454^{\circ} \mathrm{C}$ ) would help solve the problem (should also be better if this is done under atmospheric pressure).

- In-line hydrotreating was very effective for producing premium distillate with less than 10 ppm each sulfur and nitrogen.

- Successful demonstration of the feasibility of coal-plastics with high distillate yields, low light gas yields and low hydrogen consumption. 


\subsection{RECOMMENDATION FOR FUTURE WORK}

Based on the experience from CMSL-8, where coal/waste plastics coliquefaction was carried out on a bench scale continuously for 22 days and steady-state equilibration (with a net positive solvent balance) was achieved for the individual run Conditions, the following recommendations are made for further R \& D work in this area of coal-waste coprocessing:

- A thermal-catalytic two-stage close-coupled configuration should be investigated for coalwaste coprocessing. In such a configuration, the first stage thermal reactor should provide high severity $\left(441-454^{\circ} \mathrm{C}\right)$ and an acidic additive such as acidified iron oxide for plastics depolymerization while the second stage ebullated-bed reactor should provide enough severity $\left(424-441^{\circ} \mathrm{C}\right)$ and a supported catalyst for completing the residual oil conversion by hydrocracking.

- An alternative mode of processing, where plastics are separately depolymerized/cracked in a back-mixed reactor in the presence of a suitable acidic catalyst and the resulting heavy slurry products (after gas and light distillate separation) are mixed with coal and coalderived recycle solvent. This should then become feed for two-stage coal liquefaction. This kind of processing makes more sense as plastics, being inherently different from coal both physically and chemically, demand an altogether different process severity/catalysts from coal. The depolymerization/cracking reactor could be under atmospheric pressure and would not be very expensive; also due to the plastics-derived products entering coal liquefaction, being richer in hydrogen (about $9-10 \mathrm{~W} \%$ hydrogen compared to $5 \mathrm{~W} \%$ of coal), hydrogen requirements for the overall process would be certainly lower while the scheme also provides for a more efficient and better way for converting plastics to chemicals/fuels in an environmentally acceptable manner. 


\section{Table 2.8.1}

\section{BENCH RUN CMSL-8 MODIFIED RUN PLAN}

Objective: To study the coliquefaction of waste plastics with a bituminous coal in CTSL mode.

Feeds: $\quad$ Illinois No.6 Crown II mine coal, HDPE, Polystyrene, and PET.

Catalysts: K-1, Shell-317 supported + dispersed sulfated Fe/Mo Oxide (100 ppm Mo) $\mathrm{K}-2$, Only dispersed sulfated $\mathrm{Fe} / \mathrm{Mo}$ Oxide introduced in Feed to K-1 Hydrotreater, HTI-6135 (Criterion C-411 Trilobe).

Condition

Periods

Pressure, MPa

Feed Composition, W\%

Coal

HDPE

Polystyrene

PET

$\begin{array}{cccc}1 & 2 & 3 & 4 \\ 1-6 & 7-11 & 12-17 & 17-20\end{array}$

$\begin{array}{ccccc}100 & 75 & 75 & 67 & 67 \\ 0 & 12.5 & 12.5 & 16.5 & 33 \\ 0 & 8.75 & 8.75 & 11.55 & 0 \\ 0 & 3.75 & 3.75 & 4.95 & 0\end{array}$

Temperature ${ }^{\circ} \mathrm{C}$

First Stage

Second Stage 443

443

454

Hydrotreater 379

Space Velocity Per Stage

$\mathrm{Kg} / \mathrm{h} / \mathrm{m}^{3}$

$\mathrm{Lb} / \mathrm{h} / \mathrm{ft}^{3}$

481

481

641

641-481*

481

30

40

40-30

30

Solvent / Coal Ratio

$\begin{array}{lll}2 / 1.5 & 1.5 & 1.5\end{array}$

2

2

* The total space velocity was reduced from 641 to $481 \mathrm{~kg} / \mathrm{hr} / \mathrm{m} 3$ during Period 18 as a result of operating difficulties at higher space velocities; the dispersed catalyst addition was also doubled from $100 \mathrm{ppm}$ Mo to $200 \mathrm{ppm}$ during Period 19 to improve process performance. 
Table 2.8.2

RUN CMSL-8 OPERATING SUMMARY

\begin{tabular}{|c|c|c|c|c|c|}
\hline \multicolumn{6}{|c|}{ Coal/Waste Plastics Catalytic Coliquefaction } \\
\hline Condition & 1 & 2 & 3 & 4 & 5 \\
\hline Period Number & 6 & 11 & 16 & 20 & 22 \\
\hline Hours of Run & 144 & 264 & 384 & 480 & 528 \\
\hline W\% Plastics in Feed ${ }^{*}$ & 0 & 25 & 25 & 33 & 33 \\
\hline $\begin{array}{l}\text { First Stage Catalyst Age } \\
\text { (Kg dry coal/Kg cat) }\end{array}$ & 252 & 457 & 711 & 884 & 966 \\
\hline $\mathrm{SV}, \mathrm{Kg} \mathrm{Coal} / \mathrm{hr} / \mathrm{m}^{3}$ & 516 & 474 & 625 & 482 & 474 \\
\hline $\mathrm{SV}, \mathrm{Lb}$ Coal $/ \mathrm{hr} / \mathrm{ft}^{3}$ & 32.2 & 29.6 & 39 & 30.1 & 29.6 \\
\hline Oils/Solids Ratio & 1.5 & 1.6 & 1.8 & 2.1 & 1.9 \\
\hline Material Balance (\%) (gross) & 102.2 & 98.4 & 96.7 & 101.2 & 99.6 \\
\hline \multicolumn{6}{|c|}{ ESTIMATED NORMALIZED YIELDS, W\% MAF FEED } \\
\hline $\mathrm{C} 1-\mathrm{C} 3$ in Gases & 11.35 & 9.14 & 9.02 & 7.41 & 5.1 \\
\hline C4-C7 in Gases & 4.81 & 3.27 & 3.41 & 3.17 & 3.27 \\
\hline IBP $-177^{\circ} \mathrm{C}$ in Liquids & 15.86 & 20.48 & 19.00 & 17.63 & 8.80 \\
\hline $199-260^{\circ} \mathrm{C}$ in Liquids & 17.99 & 12.57 & 8.59 & 11.16 & 7.60 \\
\hline $260-343^{\circ} \mathrm{C}$ in Liquids & 21.14 & 19.85 & 12.27 & 16.88 & 10.72 \\
\hline $343-454^{\circ} \mathrm{C}$ in Liquids & 10.18 & 11.84 & 15.18 & 11.54 & 14.24 \\
\hline $454-524^{\circ} \mathrm{C}$ in Liquids & 2.29 & 2.94 & 5.60 & 4.22 & 6.43 \\
\hline $524^{\circ} \mathrm{C}+$ & 4.74 & 10.53 & 17.15 & 19.67 & 33.83 \\
\hline Unconverted Feed & 3.90 & 4.07 & 4.50 & 4.40 & 4.22 \\
\hline Water & 9.04 & 7.34 & 6.90 & 5.92 & 4.85 \\
\hline $\mathrm{CO}_{\mathrm{x}}$ & 0.67 & 0.80 & 0.86 & 0.57 & 0.16 \\
\hline $\mathrm{NH}_{3}$ & 1.50 & 1.08 & 1.04 & 0.82 & 0.27 \\
\hline $\mathrm{H}_{2} \mathrm{~S}$ & 3.98 & 2.98 & 2.84 & 2.52 & 2.24 \\
\hline Hydrogen Consumption & 7.46 & 6.91 & 6.35 & 5.71 & 1.80 \\
\hline \multicolumn{6}{|l|}{ PROCESS PERFORMANCE } \\
\hline Feed Conversion, W\% MAF Feed & 96.10 & 95.90 & 95.50 & 95.60 & 95.80 \\
\hline $\begin{array}{l}\mathrm{C} 4-524^{\circ} \mathrm{C} \text { Distillates, } \\
\mathrm{W} \% \text { of MAF Feed }\end{array}$ & 72.30 & 71.00 & 64.0 & 64.40 & 51.00 \\
\hline $524^{\circ} \mathrm{C}+$ Conversion, W\% MAF & 91.40 & 85.40 & 78.40 & 75.90 & 62.00 \\
\hline Hydrogen Efficiency, $\mathrm{kg}$ Dist $/ \mathrm{kg} \mathrm{H}$ & 9.69 & 10.27 & 10.08 & 11.28 & 28.33 \\
\hline
\end{tabular}

* Conditions 2 through 4 used a 50/35/15 W/W\% ratio of HDPE/PS/PET, while Condition 5 employed HDPE alone with coal. 
Table 2.8.3

\begin{tabular}{|c|c|c|c|c|c|}
\hline \multicolumn{6}{|c|}{ CMSL-8: SEPARATOR OVERHEAD (SOH) INSPECTION } \\
\hline Unit & 227 & 227 & 227 & 227 & 227 \\
\hline Run & 85 & 85 & 85 & 85 & 85 \\
\hline Condition & 1 & 2 & 3 & 4 & 5 \\
\hline Period Number & 6 & 11 & 16 & 20 & $23 \mathrm{~A}$ \\
\hline Gravity, API & 35.4 & 36.4 & 37.7 & 37.6 & 35.4 \\
\hline IBP, $\operatorname{deg} C$ & 59 & 79 & 57 & 64 & 77 \\
\hline FBP, $\operatorname{deg} C$ & 366 & 379 & 379 & 377 & 399 \\
\hline \multicolumn{6}{|c|}{ ASTM D-86 Distillation, Composition } \\
\hline W\% IBP-177 deg C & 28.2 & 37.1 & 47.5 & 37.5 & 31.6 \\
\hline W\% $177-260 \operatorname{deg} C$ & 31.8 & 22.2 & 20.9 & 23.4 & 24.2 \\
\hline W\% $260-343 \operatorname{deg} C$ & 34.3 & 33.1 & 24.6 & 32.4 & 32.7 \\
\hline W\% $343 \operatorname{deg} C+$ & 5.1 & 6.6 & 4.8 & 6.2 & 11.2 \\
\hline W\% Loss & 0.6 & 1.0 & 2.2 & 0.5 & 0.3 \\
\hline \multicolumn{6}{|l|}{ Elemental Analysis } \\
\hline Carbon, W\% & 86.61 & 86.47 & 86.76 & 86.74 & 86.18 \\
\hline Hydrogen, W\% & 12.91 & 12.83 & 12.46 & 12.88 & 13.07 \\
\hline Sulfur, ppm & 6.43 & 15.6 & 5.47 & 115.2 & 9.9 \\
\hline Nitrogen (Antek), ppm & $<1$ & 8.1 & $<1$ & 5.2 & 3.85 \\
\hline H/C RATIO & 1.79 & 1.78 & 1.73 & 1.78 & 1.82 \\
\hline
\end{tabular}


Table 2.8.4

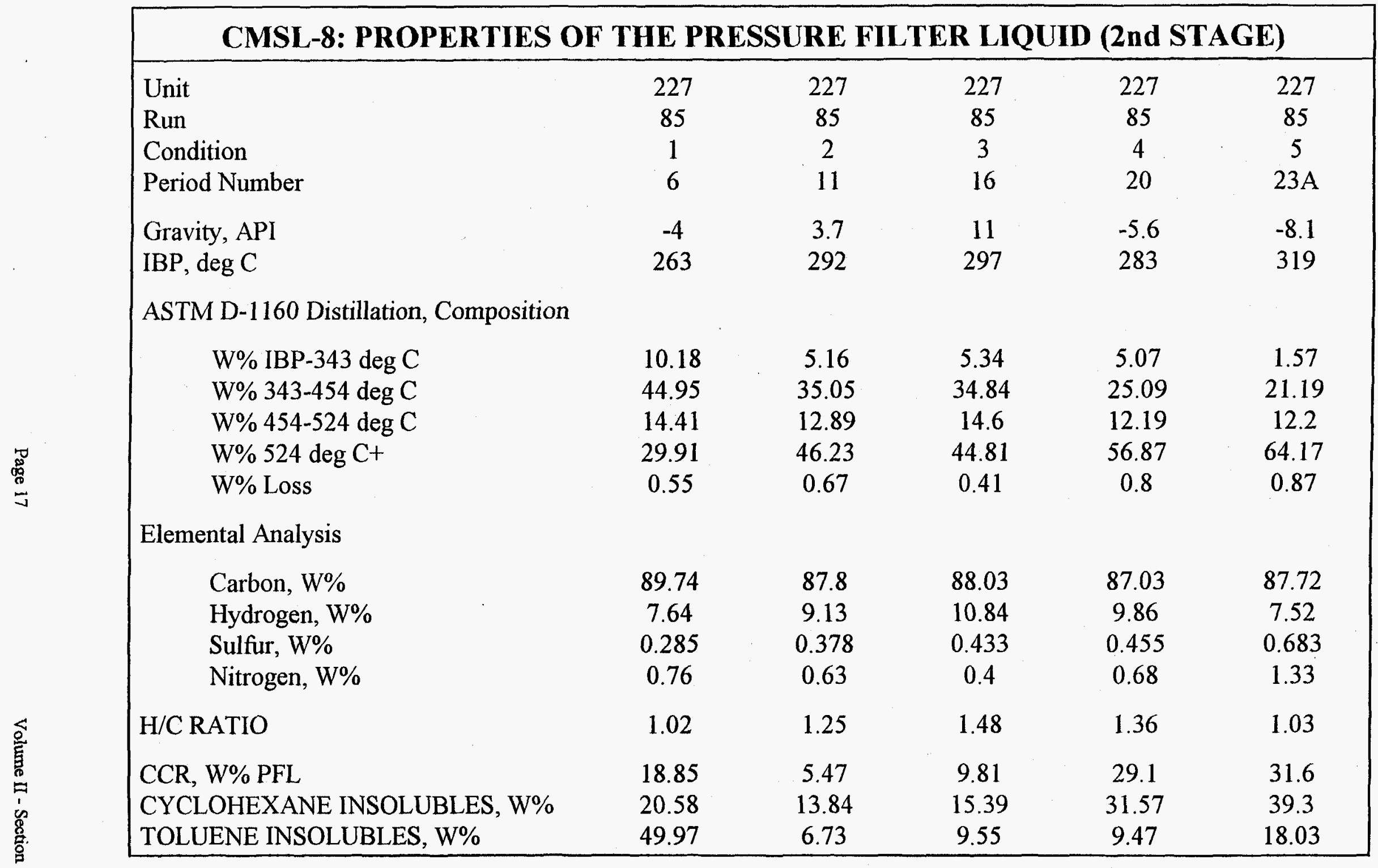




\section{Table 2.8.5}

\begin{tabular}{|c|c|c|c|c|c|}
\hline \multicolumn{6}{|c|}{ CMSL-8: INSPECTION OF THE PRESSURE FILTER SOLIDS (2nd STAGE) } \\
\hline Unit & 227 & 227 & 227 & 227 & 227 \\
\hline Run & 85 & 85 & 85 & 85 & 85 \\
\hline Condition & 1 & 2 & 3 & 4 & 5 \\
\hline Period Number & 6 & 11 & 16 & 20 & $23 \mathrm{~A}$ \\
\hline \multicolumn{6}{|l|}{ Elemental Analysis } \\
\hline Carbon, W\% & 46.27 & 47.3 & 47.15 & 44.76 & 44.5 \\
\hline Hydrogen, W\% & 3.16 & 3.55 & 3.11 & 2.89 & 2.93 \\
\hline Sulfur, W\% & 3.47 & 3.32 & 3.52 & 3.62 & 3.66 \\
\hline Nitrogen, W\% & 0.48 & 0.53 & 0.61 & 0.53 & 0.65 \\
\hline H/C RATIO & 0.82 & 0.90 & 0.79 & 0.78 & 0.79 \\
\hline \multicolumn{6}{|l|}{ Composition, W\% } \\
\hline TGA Resid & 69.64 & 77.13 & 80.8 & 83.6 & 71.31 \\
\hline TGA Ash & 44.51 & 43.77 & 46.06 & 45.77 & 46.65 \\
\hline Ash (Quinoline Filtration) & 43.45 & 43.63 & 44.86 & 44.64 & 44.96 \\
\hline ASTM Ash, W\% & 44.55 & 43.32 & 44.3 & 45.52 & 45.65 \\
\hline S in Ash, W\% & 1.39 & 0.95 & 0.88 & 1.29 & 1.2 \\
\hline Unconverted Coal/Feed (Adj.) & 14.6 & 20.98 & 23.58 & 26.21 & 25.66 \\
\hline
\end{tabular}


Table 2.8.6(a)

\section{DETAILED ANALYSES OF TBP FRACTIONS RUN 227-85 - PERIOD 6}

TBP Distillation, \%

$$
\begin{aligned}
& \text { IBP }-177^{\circ} \mathrm{C} \\
& 177-260^{\circ} \mathrm{C} \\
& 260-343^{\circ} \mathrm{C} \\
& 343^{\circ} \mathrm{C}^{+}
\end{aligned}
$$

TBP Fraction $\left[{ }^{\circ} \mathrm{C}\right]$

API Gravity

Elemental Analysis [W\%]

Carbon

Hydrogen

Sulfur, ppm

Antek N, ppm

Aniline Point, $\left[{ }^{\circ} \mathrm{C}\right]$

Flash Point, : $\left[{ }^{\circ} \mathrm{C}\right]$

PONA [V\%]

Paraffins
Olefins
Naphthenics
Aromatics

Aromatics, W\% (ASTM D2549)
$\mathrm{IBP}=53.3^{\circ} \mathrm{C}$

\begin{tabular}{c}
$\mathrm{W} \%$ \\
\hline 31.70 \\
48.90 \\
16.80 \\
2.60
\end{tabular}

$\frac{\text { IBP - 177 }}{53.0} \frac{\mathbf{1 7 7 - 2 6 0}}{29.4} \quad \frac{\mathbf{2 6 0 - 3 4 3}}{23.1} \frac{\mathbf{3 4 3 +}}{21.0}$

85.5

87.0

12.8

54.9

$<1.0$

87.4

87.4

12.5

12.6

59.0

140

$<1.0$

$<1.0$

41.1

40.6

55.0

$<-6.7$

77.2

137.8

20.1

13.3

1.5

3.5

69.8

53.2

30.0 
Table 2.8.6(b)

\section{DETAILED ANALYSES OF TBP FRACTIONS RUN 227-85 - PERIOD 11}

TBP Distillation, \%

$$
\begin{aligned}
& \text { IBP }-177^{\circ} \mathrm{C} \\
& 177-260^{\circ} \mathrm{C} \\
& 260-343^{\circ} \mathrm{C} \\
& 343^{\circ} \mathrm{C}^{+}
\end{aligned}
$$

TBP Fraction $\left[{ }^{\circ} \mathrm{C}\right]$

API Gravity

Elemental Analysis [W\%]

Carbon

Hydrogen

Sulfur, ppm

Antek N, ppm

Aniline Point, $\left[{ }^{\circ} \mathrm{C}\right]$

Flash Point,

$\left[{ }^{\circ} \mathrm{C}\right]$

PONA [V\%]

Paraffins

Olefins

Naphthenics

Aromatics
$\mathrm{IBP}=45.6^{\circ} \mathrm{C}$

$$
\begin{gathered}
\mathrm{W} \% \\
\hline 37.90 \\
35.30 \\
21.20 \\
5.70
\end{gathered}
$$

$\frac{\text { IBP - 177 }}{46.3} \frac{177-260}{32.7} \quad \frac{\mathbf{2 6 0}-\mathbf{3 4 3}}{27.0} \frac{\mathbf{3 4 3 +}}{26.5}$

86.9

86.5

86.5

86.3

13.1

13.0

181.0

$<0.5$

$<0.2$

16.0

$<0.5$

64.2

13.9

47.8

79.4

151.7

15.5

5.5

49.9

29.1
15.2

17.7

48.4

34.7

Aromatics, W\% (ASTM D2549)

22.9

18.4 
Table 2.8.6(c)

\section{DETAILED ANALYSES OF TBP FRACTIONS RUN 227-85 - PERIOD 16}

TBP Distillation, \%

$$
\begin{aligned}
& \text { IBP }-177^{\circ} \mathrm{C} \\
& 177-260^{\circ} \mathrm{C} \\
& 260-343^{\circ} \mathrm{C} \\
& 343^{\circ} \mathrm{C}^{+}
\end{aligned}
$$

TBP Fraction $\left[{ }^{\circ} \mathrm{C}\right]$

API Gravity

Elemental Analysis [W\%]

Carbon

Hydrogen

Sulfur, ppm

Antek N, ppm

Aniline Point, $\left[{ }^{\circ} \mathrm{C}\right]$

Flash Point, $\quad\left[{ }^{\circ} \mathrm{C}\right]$

PONA [V\%]

$$
\begin{aligned}
& \text { Paraffins } \\
& \text { Olefins } \\
& \text { Naphthenics } \\
& \text { Aromatics }
\end{aligned}
$$

$\mathrm{IBP}=51.7^{\circ} \mathrm{C}$

\begin{tabular}{c}
$\mathrm{W} \%$ \\
\hline 48.16 \\
33.30 \\
14.94 \\
3.60
\end{tabular}

IBP -177

45.7

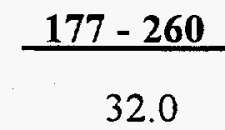

10.0

$<-6.7$

15.0

1.7

43.8

39.5
87.0

12.7

214

$<0.5$

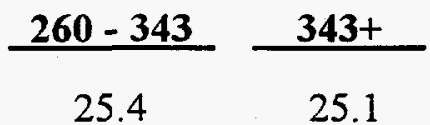

60.0

151.7

86.5

13.3

360

Aromatics, W\% (ASTM D2549)

87.0

12.9

4.6

$<0.5$

43.9

79.4

17.8

3.2

44.3

34.8

30.0

18.5 
Table 2.8.6(d)

\section{DETAILED ANALYSES OF TBP FRACTIONS RUN 227-85 - PERIOD 20}

TBP Distillation, \%

$$
\begin{aligned}
& \text { IBP }-177^{\circ} \mathrm{C} \\
& 177-260^{\circ} \mathrm{C} \\
& 260-343^{\circ} \mathrm{C} \\
& 343^{\circ} \mathrm{C}^{+}
\end{aligned}
$$

TBP Fraction $\left[{ }^{\circ} \mathrm{C}\right]$

API Gravity

Elemental Analysis [W\%]

Carbon

Hydrogen

Sulfur, ppm

Antek N, ppm

Aniline Point, $\left[{ }^{\circ} \mathrm{C}\right]$

Flash Point, $\left[{ }^{\circ} \mathrm{C}\right]$

PONA [V\%]

Paraffins

Olefins

Naphthenics

Aromatics

Aromatics, W\% (ASTM D2549)
$\mathrm{IBP}=51.1^{\circ} \mathrm{C}$

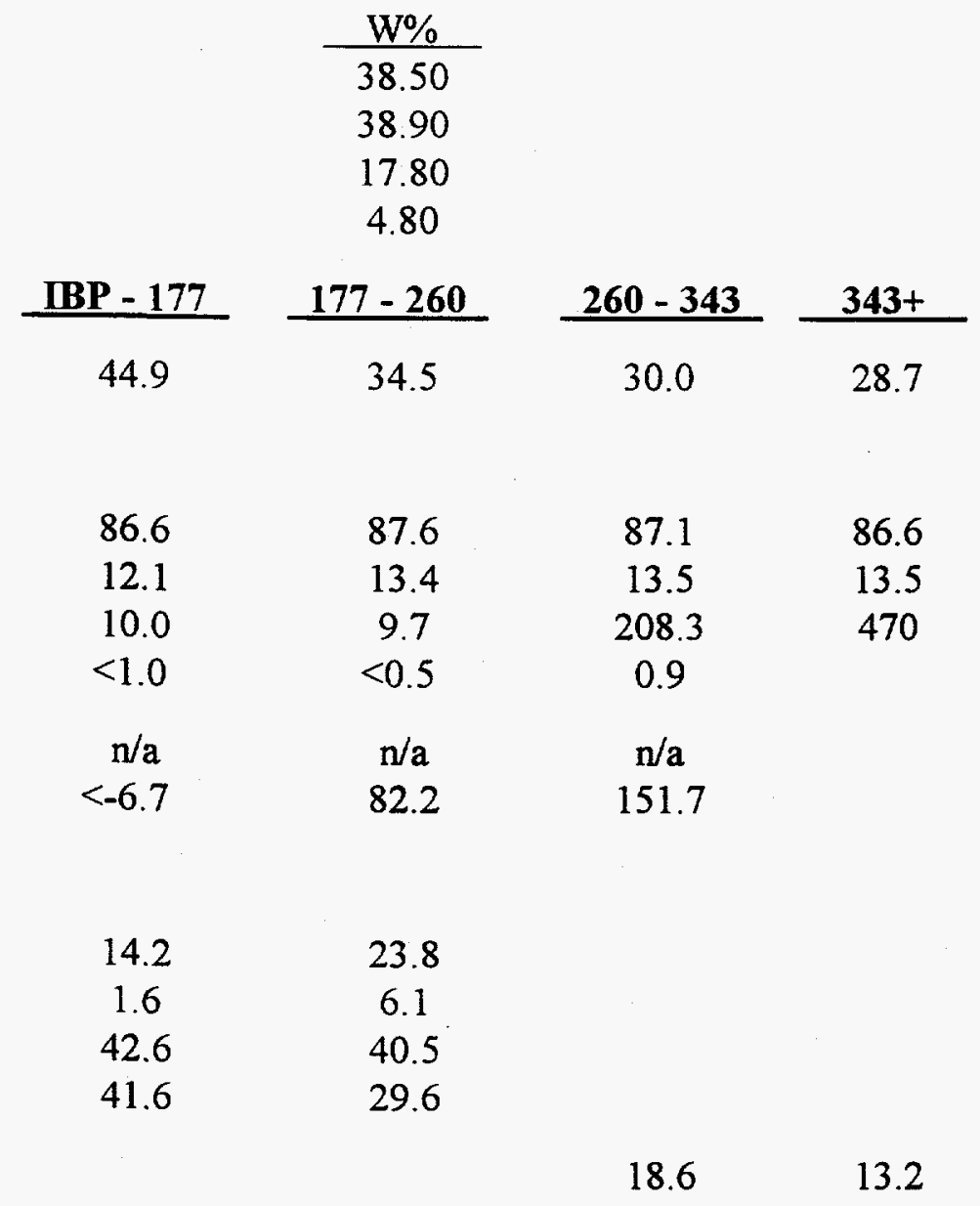


Table 2.8.6(e)

\section{DETAILED ANALYSES OF TBP FRACTIONS RUN 227-85 - PERIOD 22}

TBP Distillation, \%

$$
\begin{aligned}
& \text { IBP }-177^{\circ} \mathrm{C} \\
& 177-260^{\circ} \mathrm{C} \\
& 260-343^{\circ} \mathrm{C} \\
& 343^{\circ} \mathrm{C}^{+}
\end{aligned}
$$

TBP Fraction $\left[{ }^{\circ} \mathrm{C}\right]$

API Gravity

Elemental Analysis [W\%]

Carbon

Hydrogen

Sulfur, ppm

Antek N, ppm

Aniline Point, $\left[{ }^{\circ} \mathrm{C}\right]$

Flash Point, $\left[{ }^{\circ} \mathrm{C}\right]$

PONA [V\%]

Paraffins

Olefins

Naphthenics

Aromatics

Aromatics, W\% (ASTM D2549)
IBP $=58.9^{\circ} \mathrm{C}$

\begin{tabular}{c}
$\mathrm{W} \%$ \\
\hline 32.90 \\
38.40 \\
20.10 \\
8.60
\end{tabular}

$\frac{\text { IBP }-\mathbf{1 7 7}}{48.8} \quad \frac{\mathbf{1 7 7 - 2 6 0}}{30.7} \quad \frac{\mathbf{2 6 0}-\mathbf{3 4 3}}{24.1} \frac{\mathbf{3 4 3 +}}{23.7}$

86.1

86.9

12.9

$<0.5$

86.8

86.7

12.6

13.4

50.0

$<1.0$

$<1.0$

10.3

450

27.5

$<-6.7$

45.0

76.7

$<1.0$

60.6

154.4

15.8

13.1

1.3

3.3

60.4

56.71

22.5

27.5 
Table 2.8.7

CMSL-8: PROPERTIES OF THE PRESSURE FILTER LIQUID (1st STAGE)

Unit

Run

Condition

Period Number

Weight \% PFL

Gravity, API

IBP, $\operatorname{deg} C$

227

85

1

6

79.36

$-6.6$

271

ASTM D-1160 Distillation, Composition

W\% IBP - $343 \operatorname{deg} C$

W\% 343 - $454 \operatorname{deg} C$

W\% 454 - $524 \operatorname{deg} \mathrm{C}$

W\% $524 \operatorname{deg} \mathrm{C}+$

W\% Loss

Elemental Analysis

Carbon, W\%

Hydrogen, W\%

Sulfur, W\%

Nitrogen, W\%

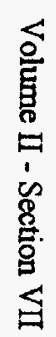

H/C RATIO

CCR, W\% PFL

CYCLOHEXANE INSOLUBLES, W\%

TOLUENE INSOLUBLES, W\%
7.86

35.74

12.36

43.34

0.7

89.24

7.26

0.397

0.94

0.98

25.36

37.07

10.55
227

85

2

11

72.16

$-4.9$

280

4.11

29.07

13.78

52.33

0.71

87.75

10.3

0.565

0.32

1.41

27.92

20.4

6.22
227

85

3

16

85.2

$-6$

324

1

27

16

55.5

0.5

87.84

7.61

0.865

1.04

1.04

28.33

32.1

11.36 


\section{Table 2.8.8}

\begin{tabular}{|c|c|c|c|}
\hline \multicolumn{4}{|c|}{ CMSL-8: INSPECTION OF THE PRESSURE FILTER SOLIDS (1st STAGE) } \\
\hline Unit & 227 & 227 & 227 \\
\hline Run & 85 & 85 & 85 \\
\hline Condition & 1 & 2 & 3 \\
\hline Period Number & 6 & 11 & 16 \\
\hline \multicolumn{4}{|l|}{ Elemental Analysis } \\
\hline Carbon, W\% & 51.77 & 80.72 & 54.14 \\
\hline Hydrogen, W\% & 3.23 & 6.21 & 3.02 \\
\hline Sulfur, W\% & 3.11 & 3.44 & 4.05 \\
\hline Nitrogen, W\% & 0.61 & 0.94 & 0.68 \\
\hline H/C RATIO & 0.75 & 0.92 & 0.67 \\
\hline \multicolumn{4}{|l|}{ Composition, W\% } \\
\hline Ash (Quinoline Filtration) & 39.82 & 10.95 & 39.6 \\
\hline ASTM Ash, W\% & 40.85 & 11.16 & 39.82 \\
\hline $\mathrm{S}$ in Ash, W\% & 2.75 & & 2.02 \\
\hline Unconverted Coal/Feed (Adj.) & 18.06 & 9.65 & 30.56 \\
\hline
\end{tabular}




\section{Table 2.8.9}

\section{Samples sent to Consol, Inc.}

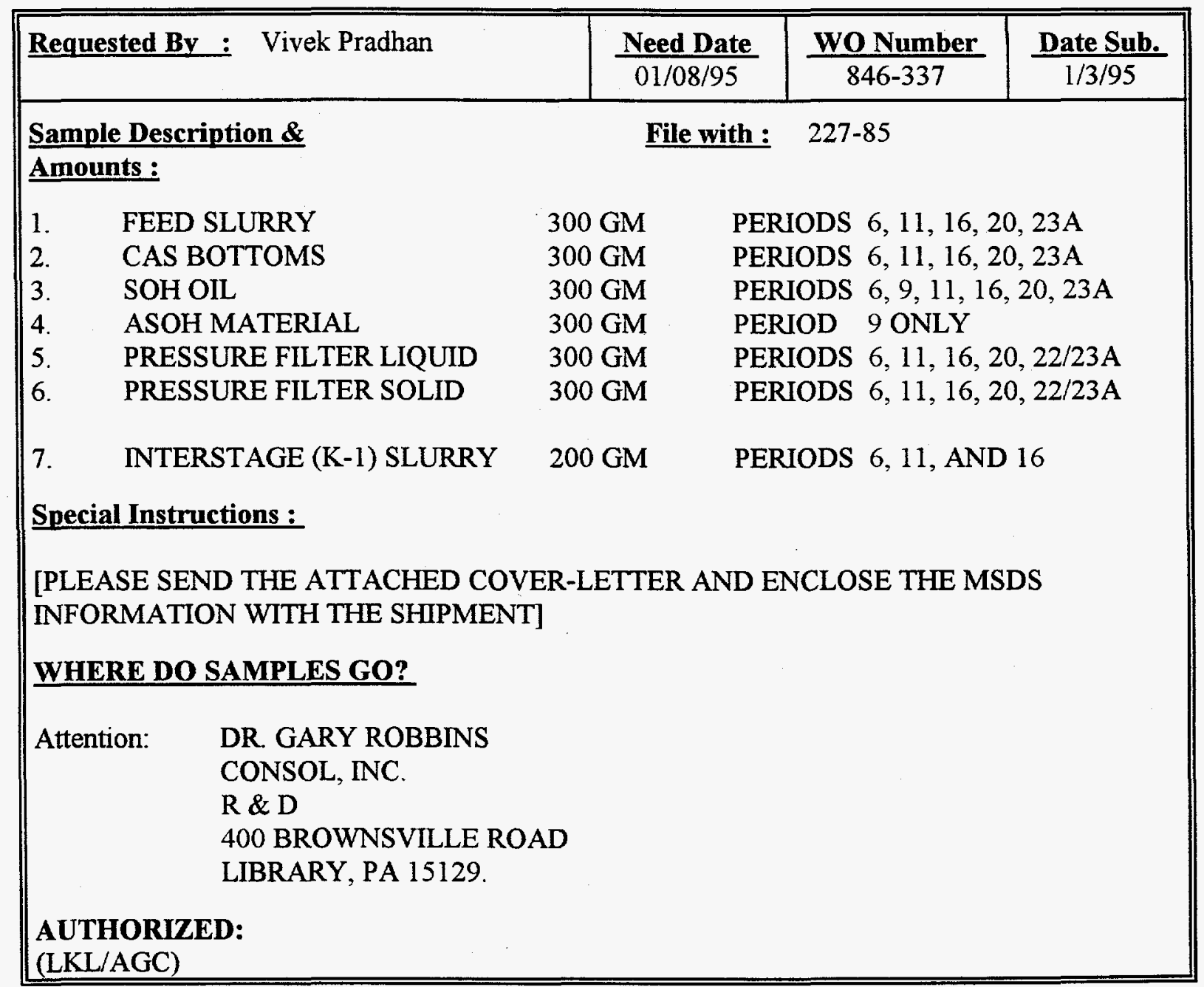




\section{Table 2.8.10}

\section{Analysis of coal and plastic feedstocks for CMSL-8.}

HTI No.

L-811

6235

6236

6237

Material

Illinois \#6

HDPE

Polystyrene

PET

Moisture

4

Content

Proximate Analysis, W\% Dry Basis

$\begin{array}{ll}\text { Volatile Matter } & 41.48 \\ \text { Fixed Carbon } & 48.08 \\ \text { Ash } & 10.44\end{array}$

Ultimate Analysis, W\% MAF Basis

Carbon
Hydrogen
Sulfur
Nitrogen
Oxygen (by diff.)
H/C Atomic Ratio

67.85

4.55

3.99

85.27

14.61

0.037

1.33

0.01

90.81

7.71

61.9

4.13

0.01

0.01

11.36

0.073

0.06

0.03

H/C Atomic Ratio

0.8

2.06

1.41

33.9

1.02

0.8

* All three plastics were initially completely insoluble in either quinoline or cyclohexane.

* The proximate analyses, S-in-Ash, Sulfur Forms, and Mineral Matter Forms Analyses are being done. 


\section{Table 2.8.11}

\section{Analysis of start-up / make-up oil for CMSL-8}

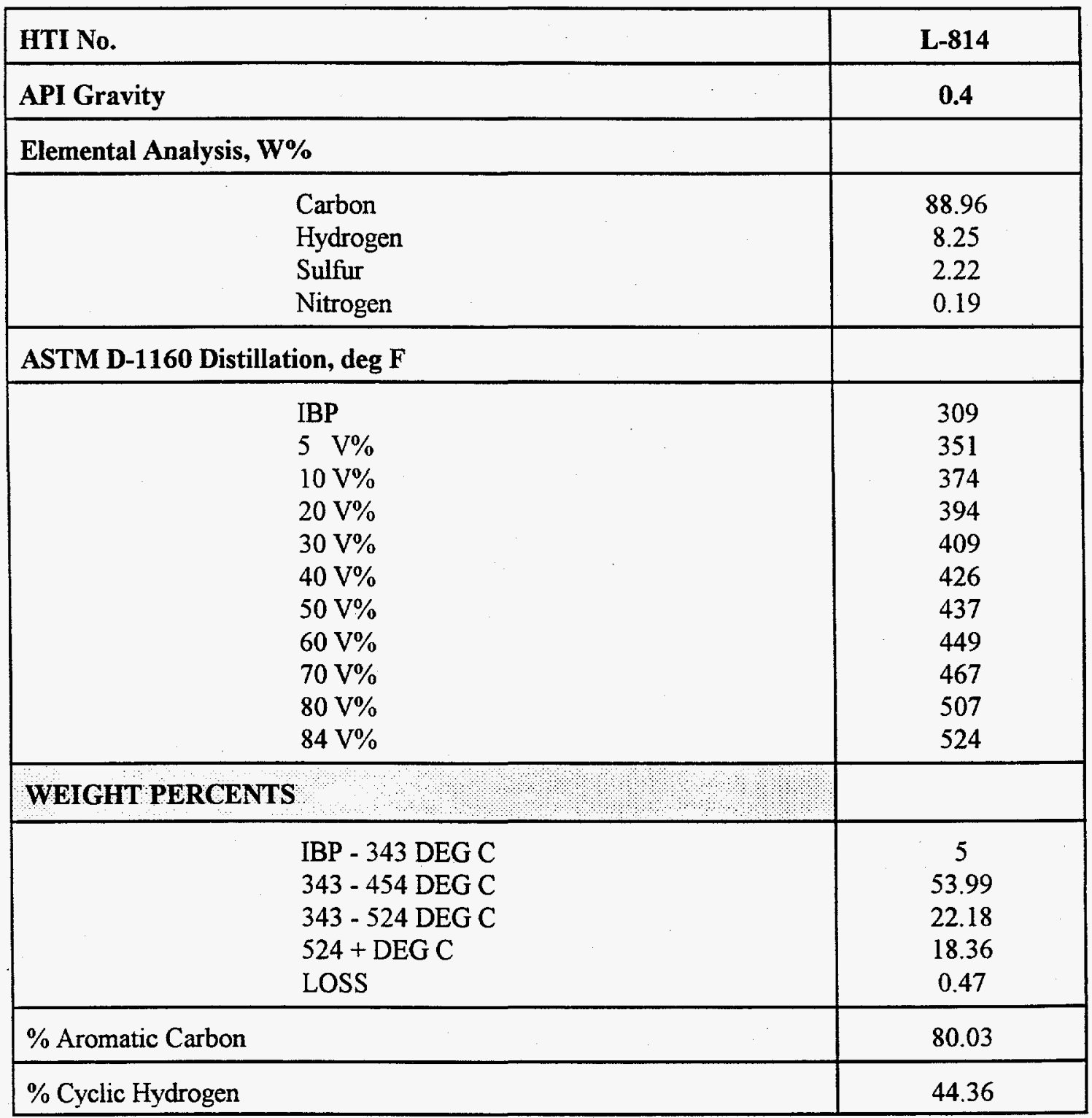




\section{APPARENT PRODUCTS DERIVED FROM PLASTICS Co-processing of Illinois Coal with Plastics}

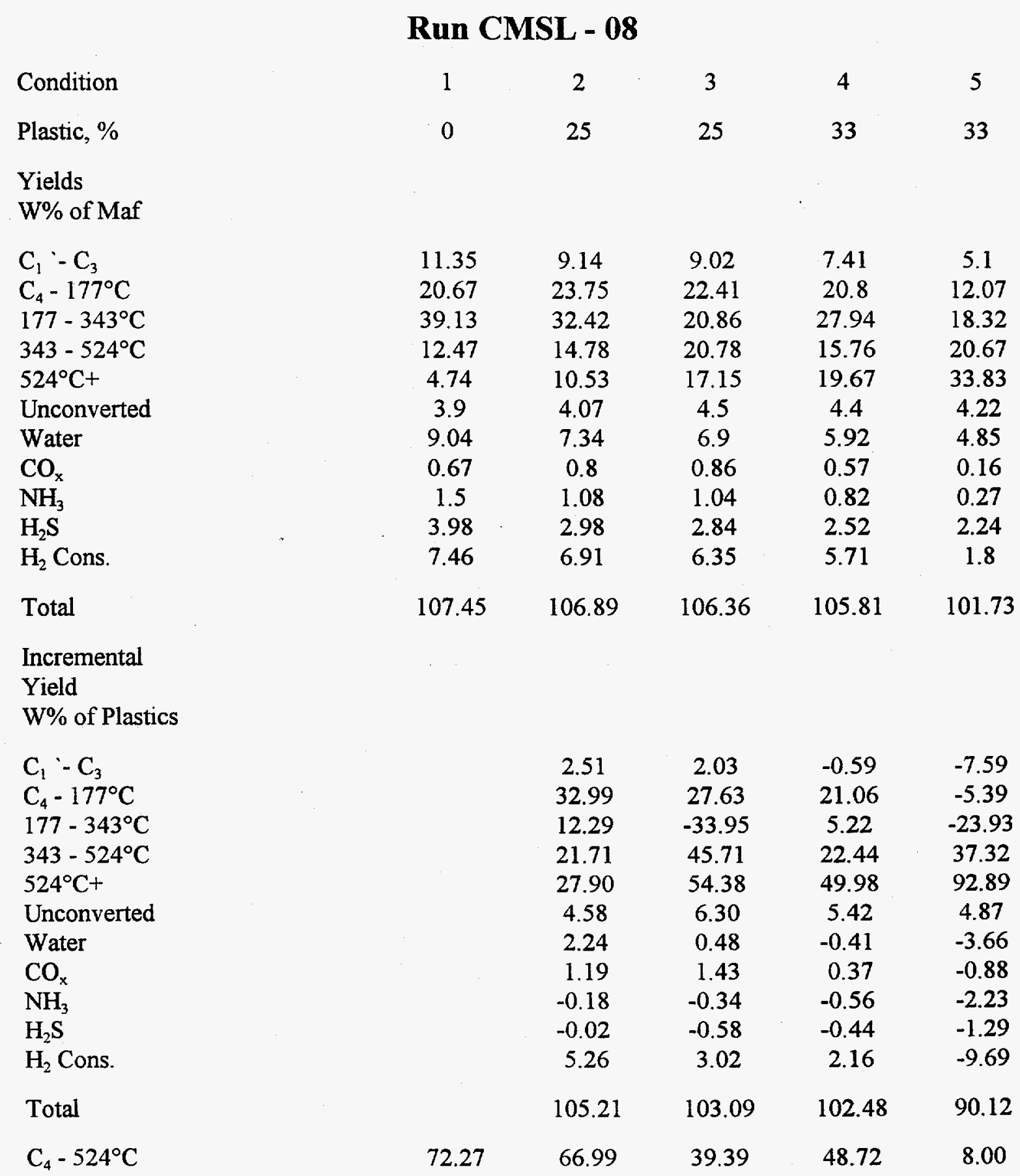


Figure 2.8.1

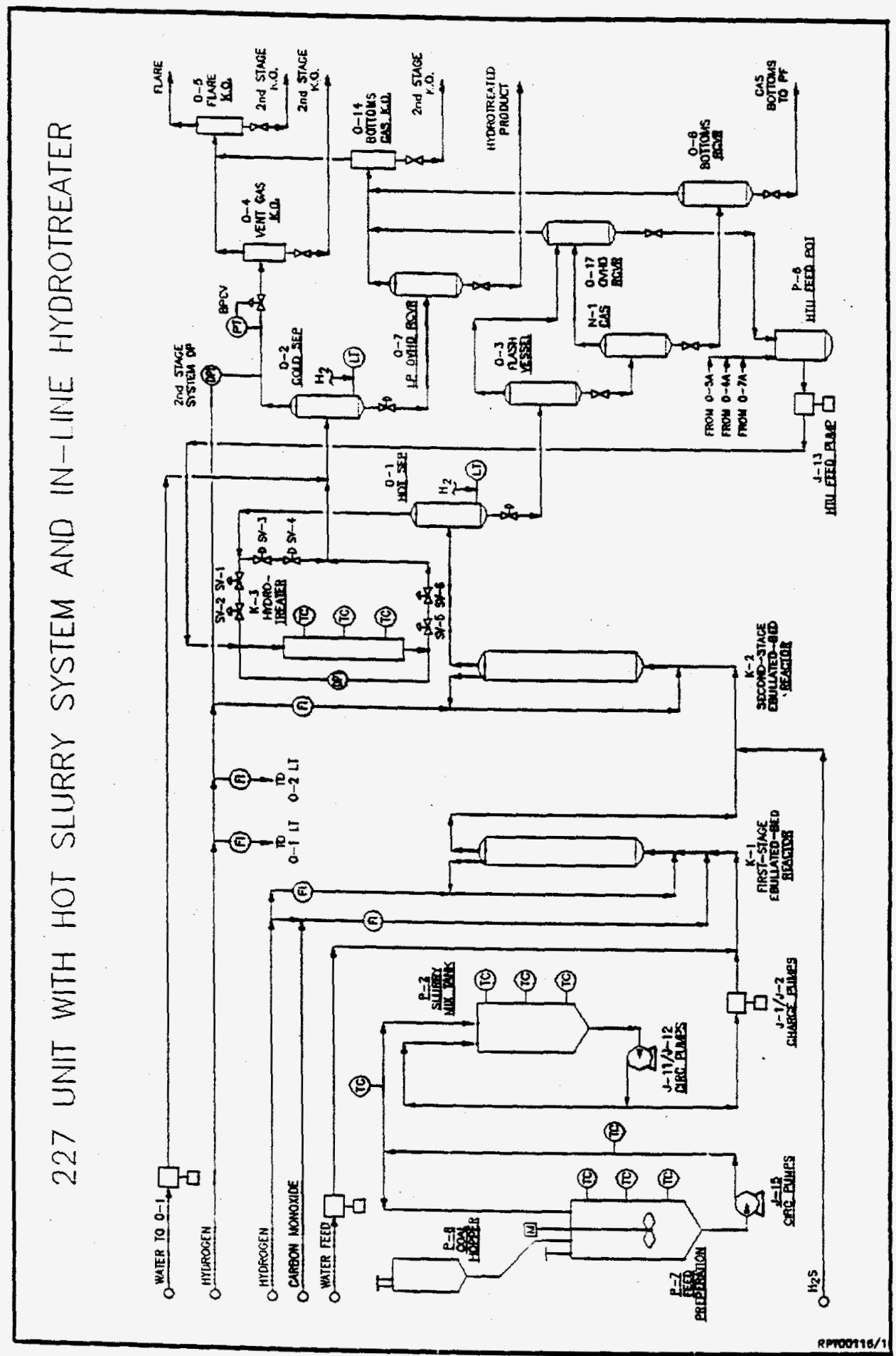


Figure 2.8.2

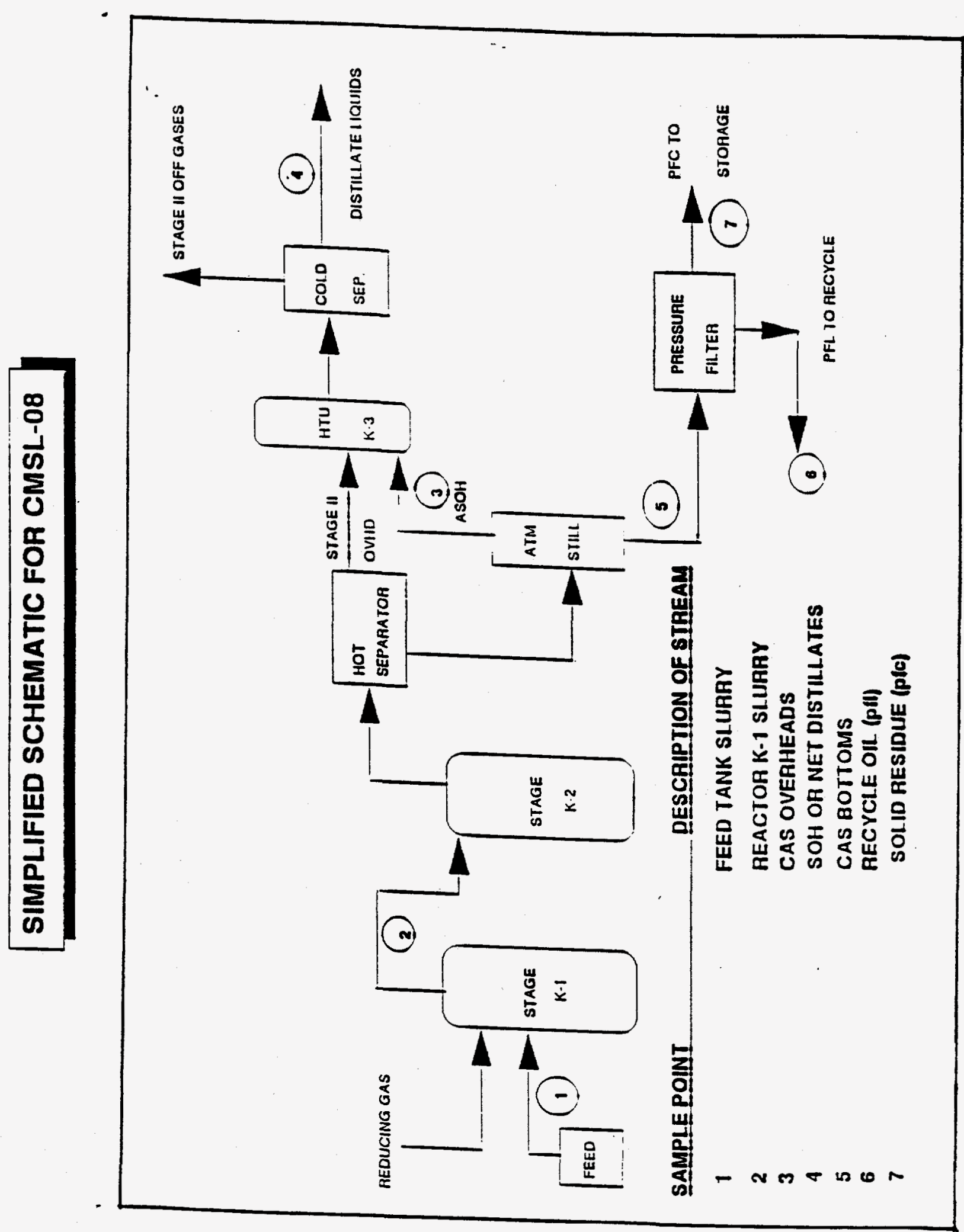




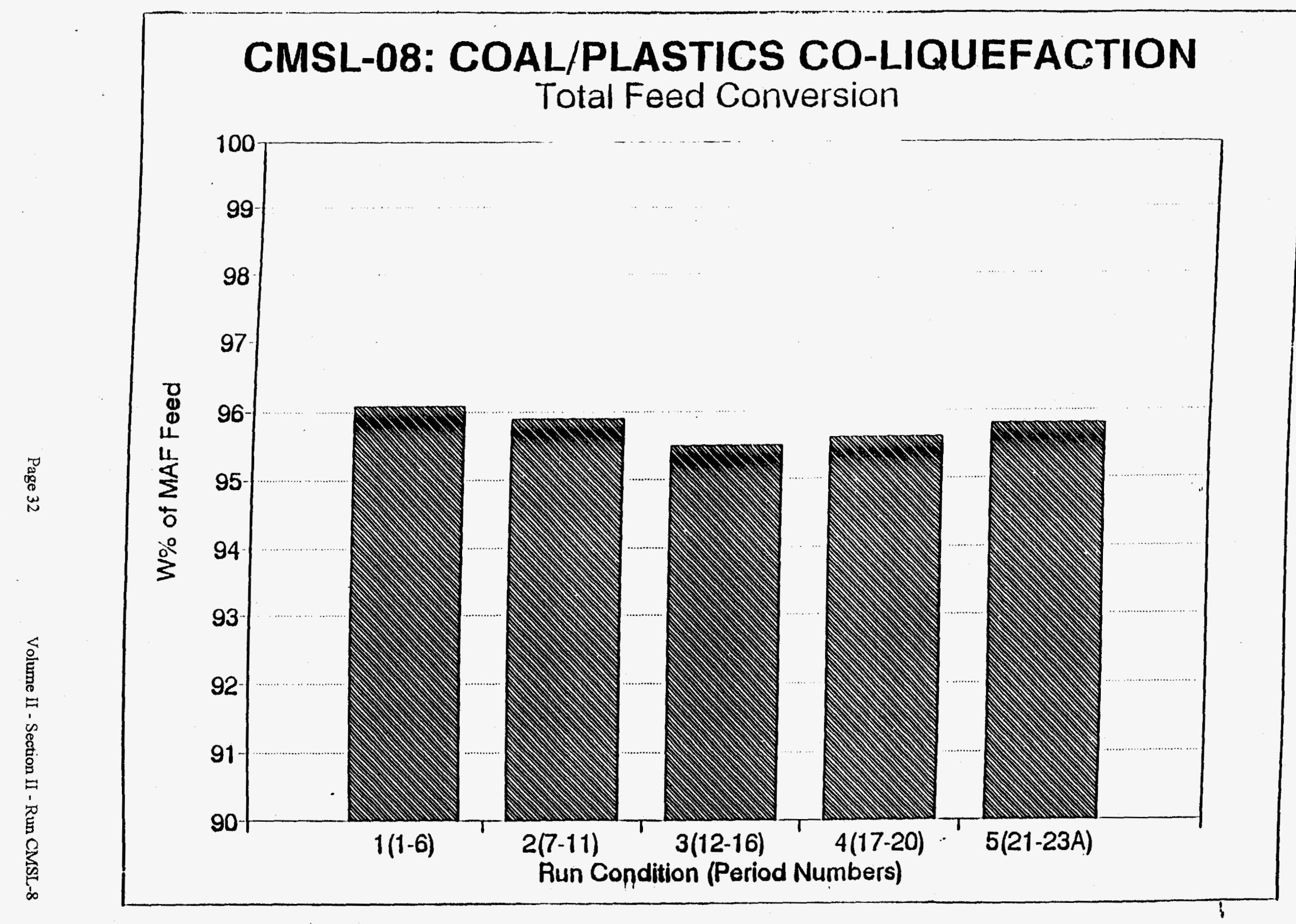


Figure 2.8.4

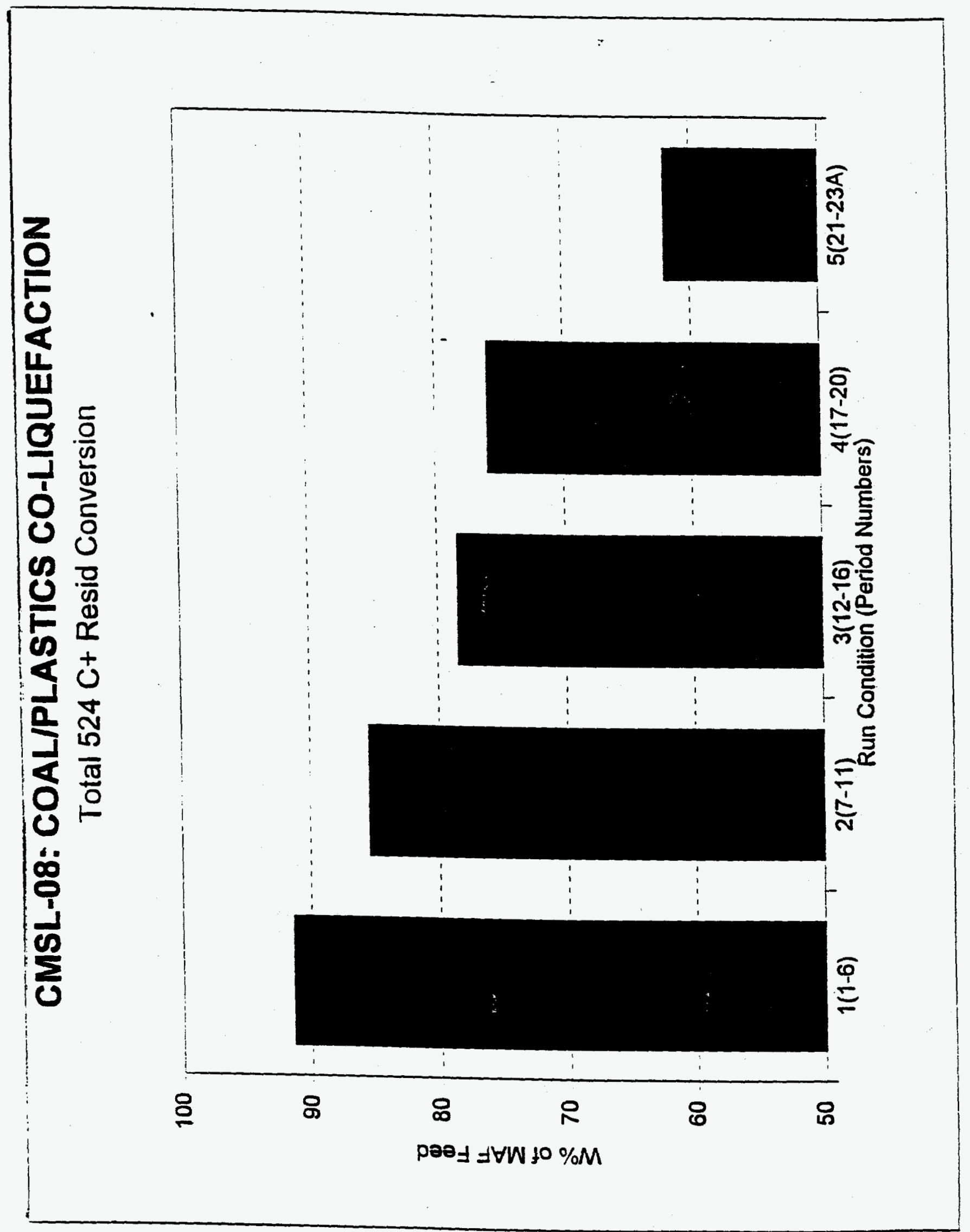




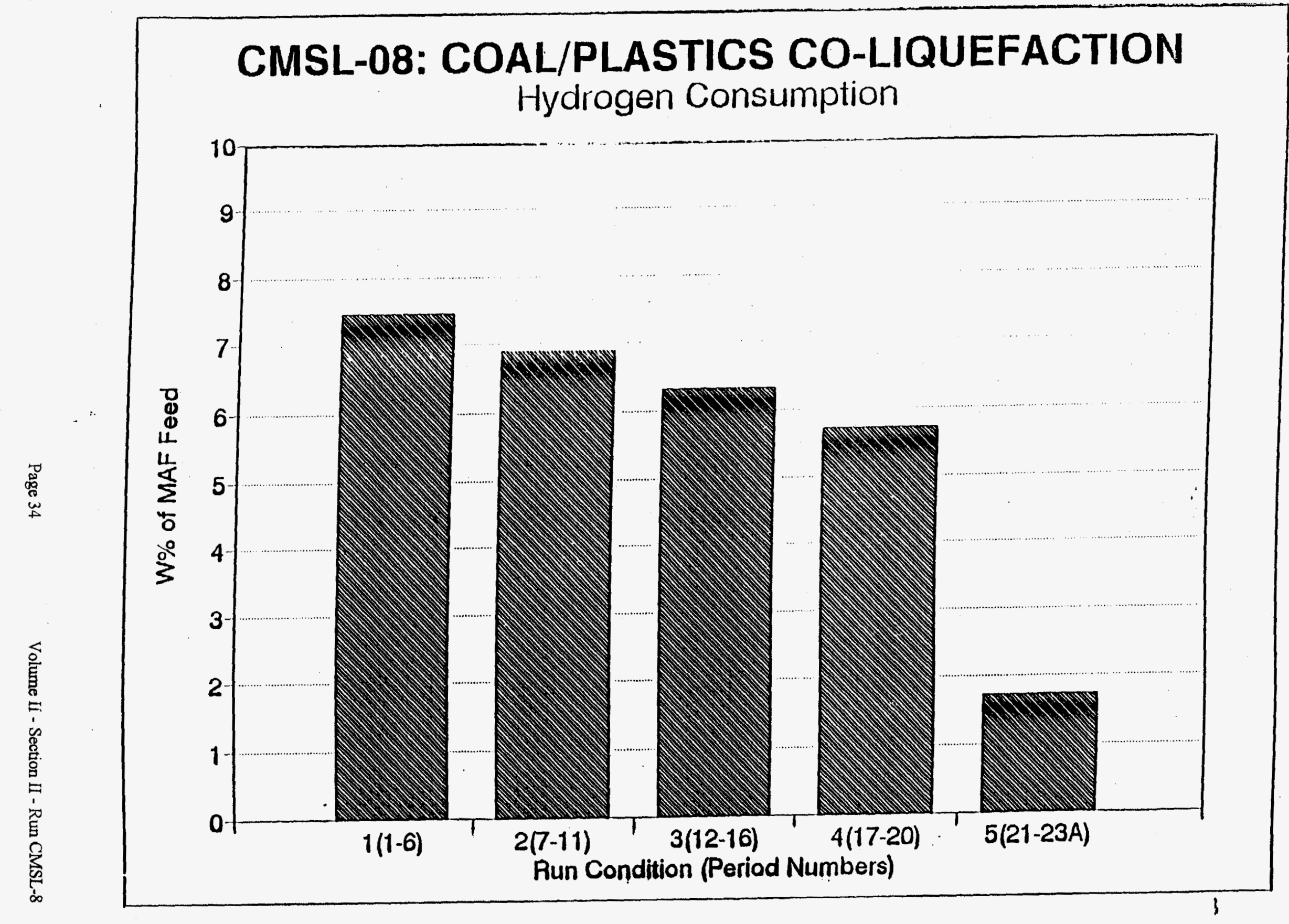




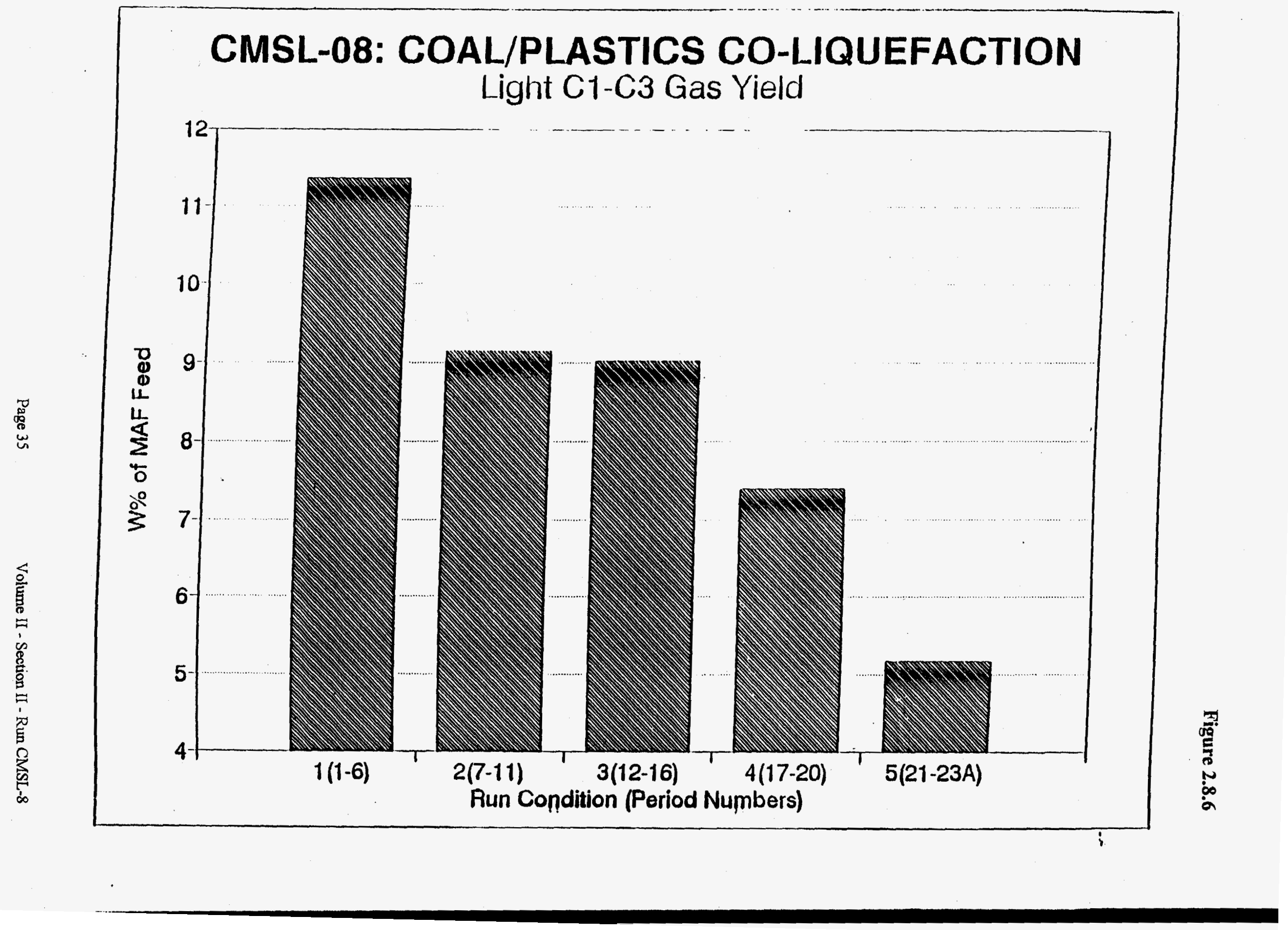




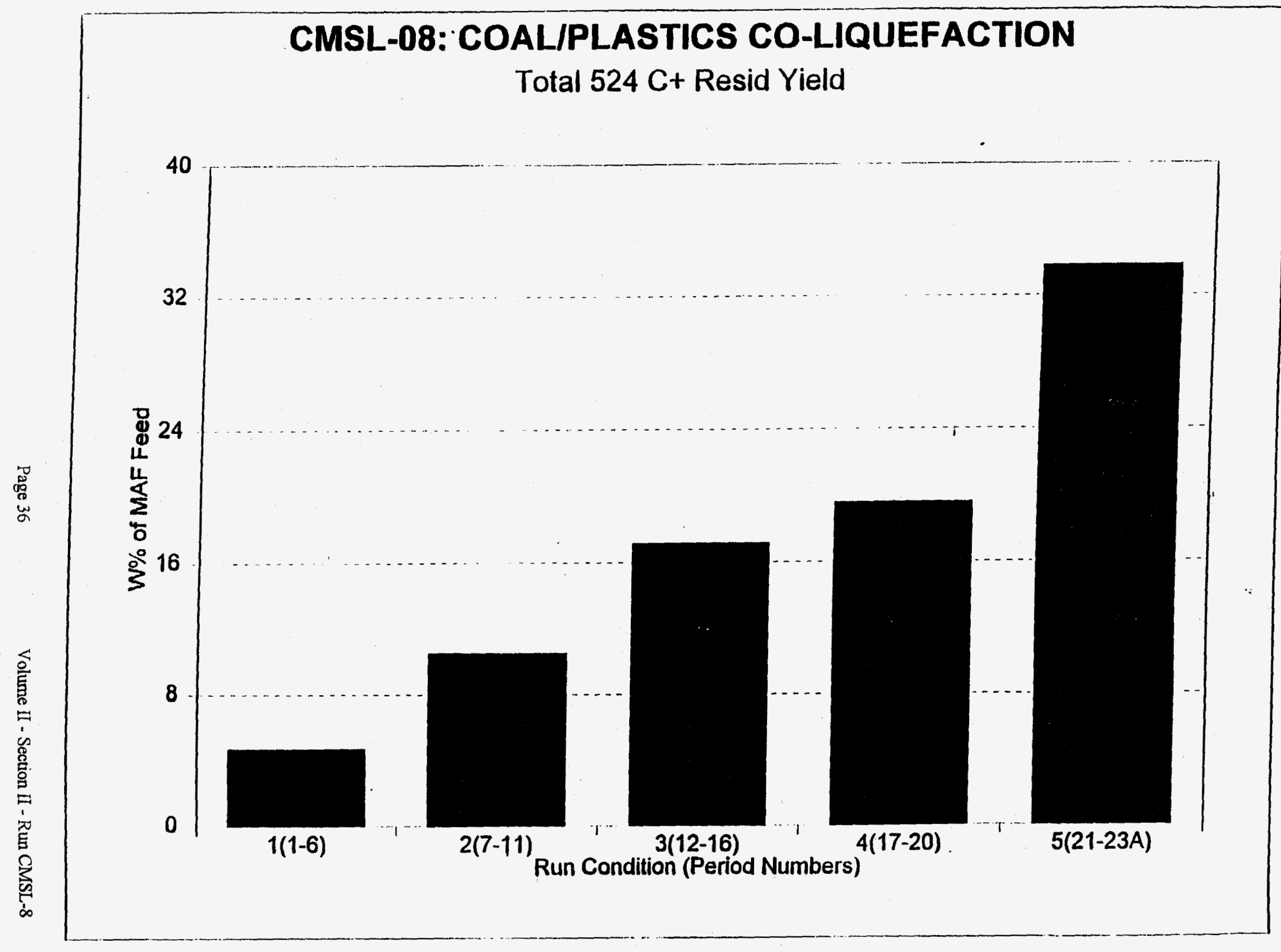


Figure 2.8.8

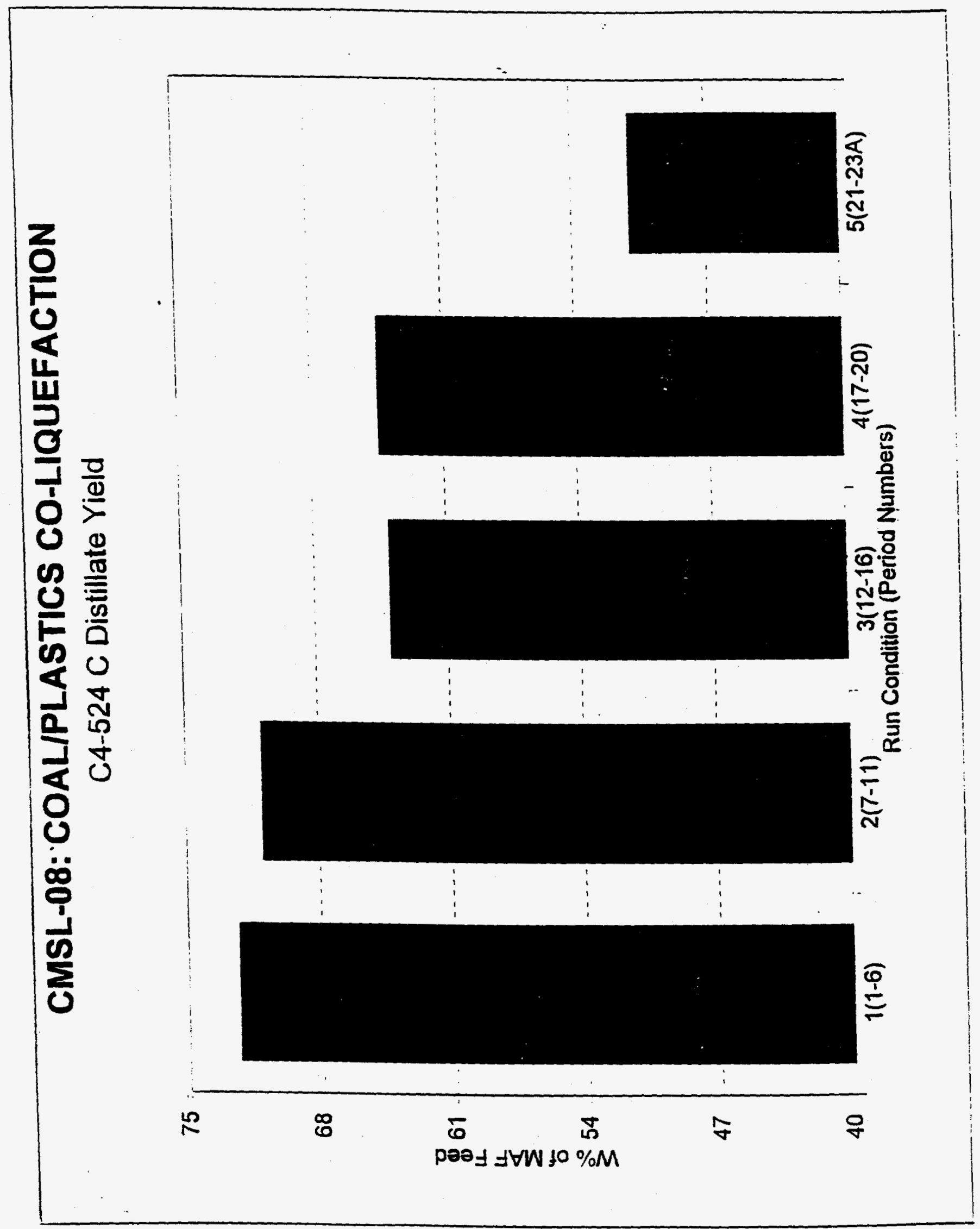




\section{CMSL-08: Selectivity of Distillate Fractions for Work-up Periods}

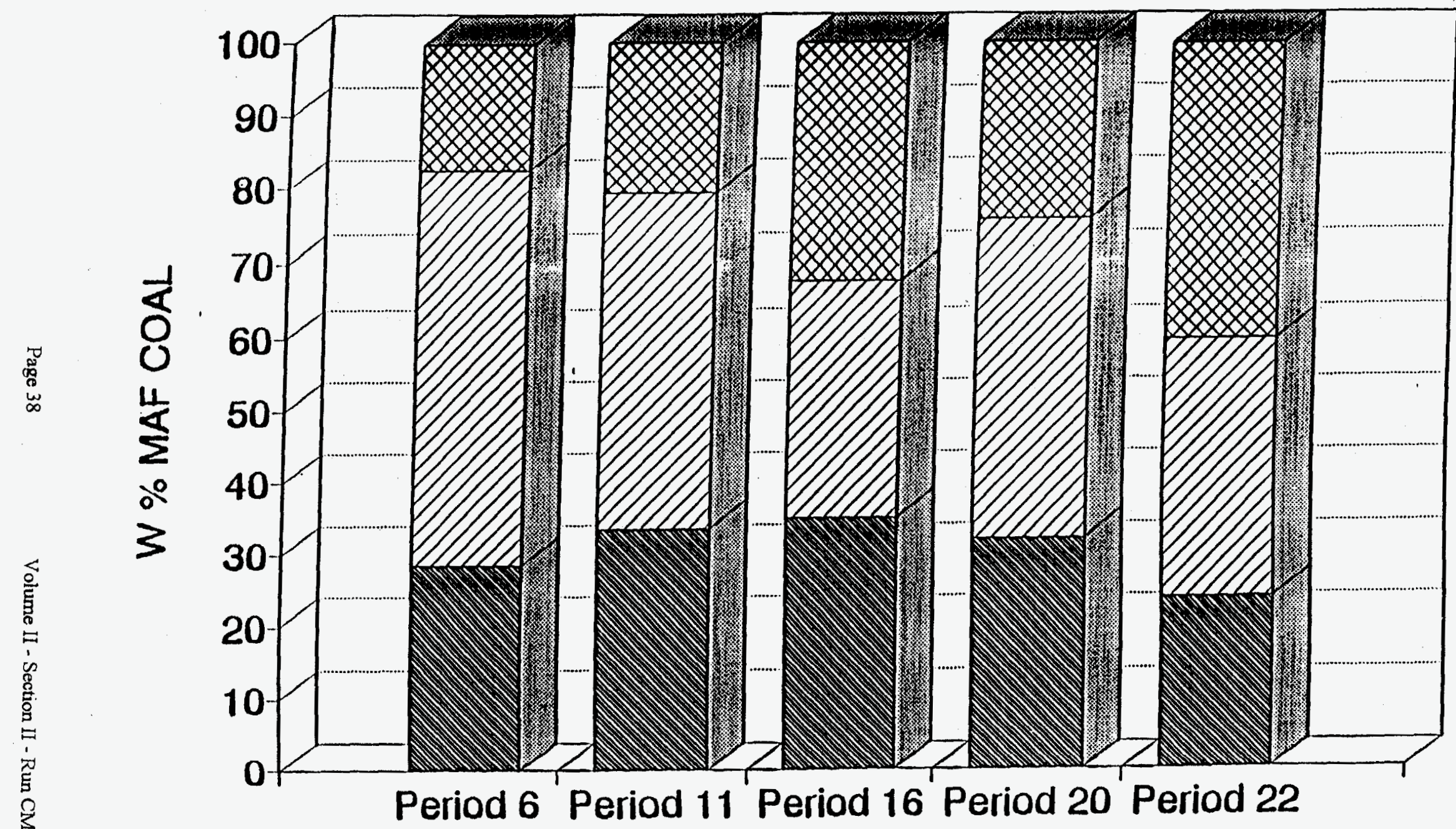




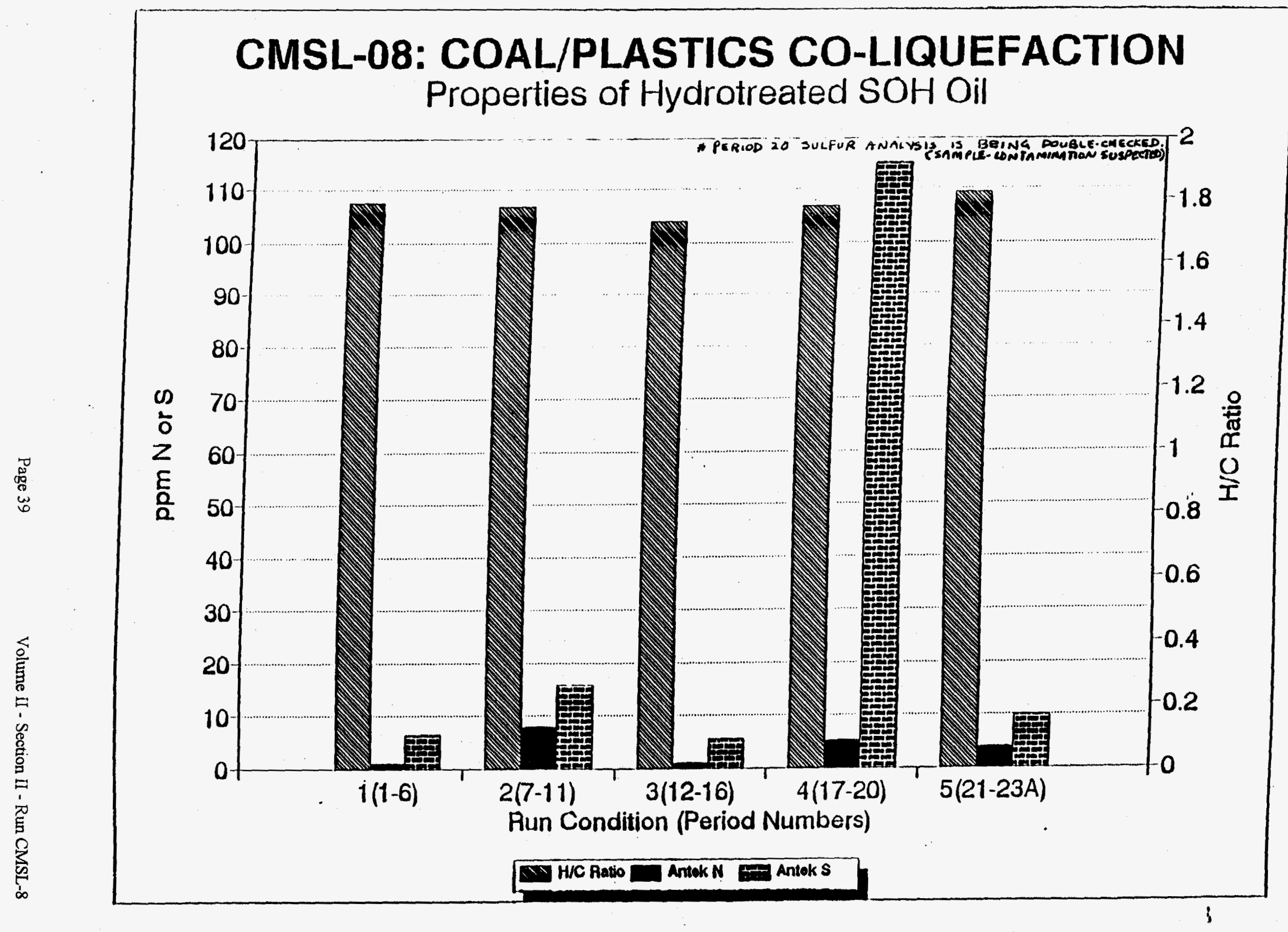




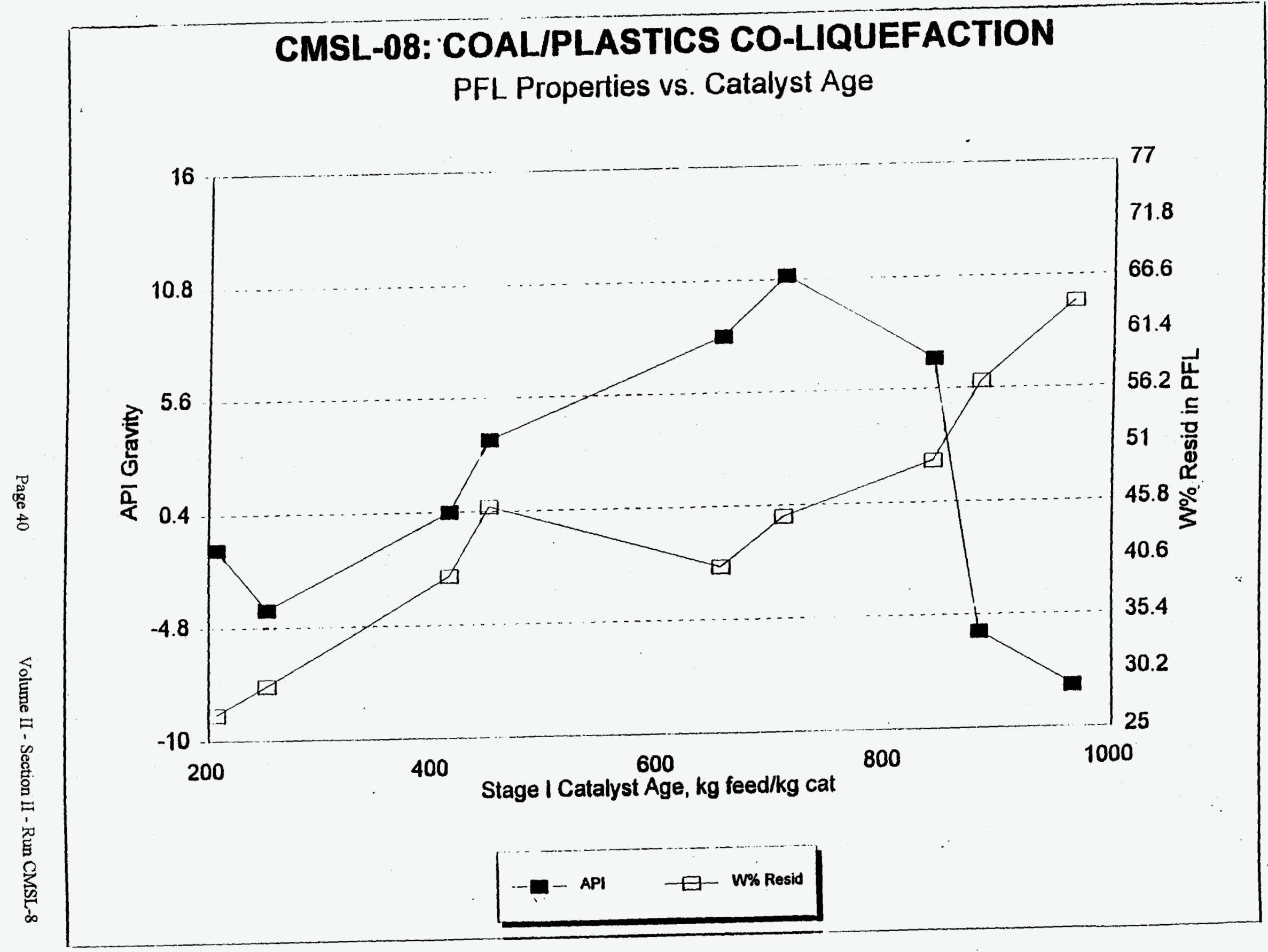




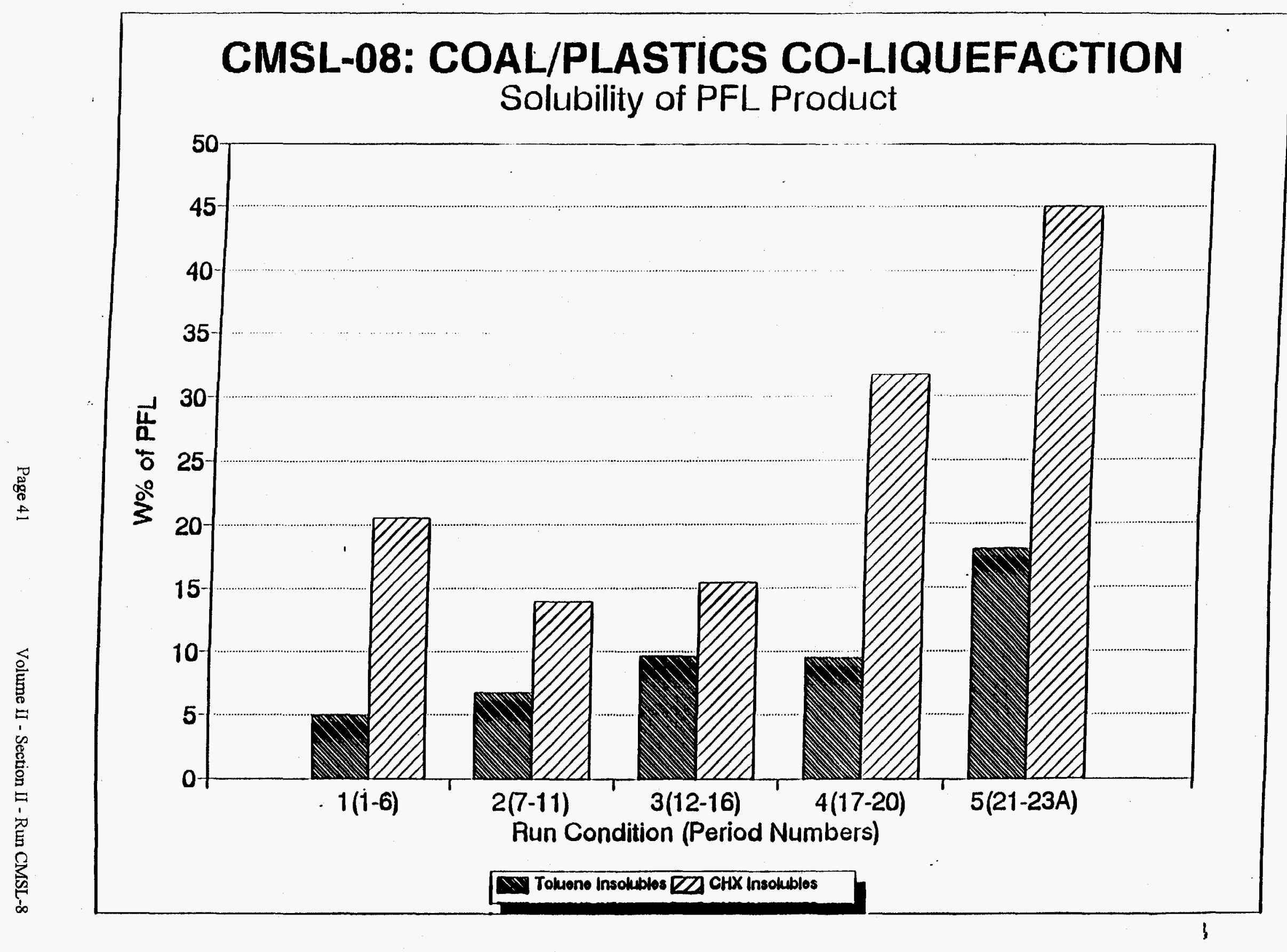

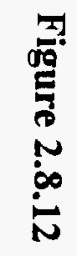


Figure 2.8.13

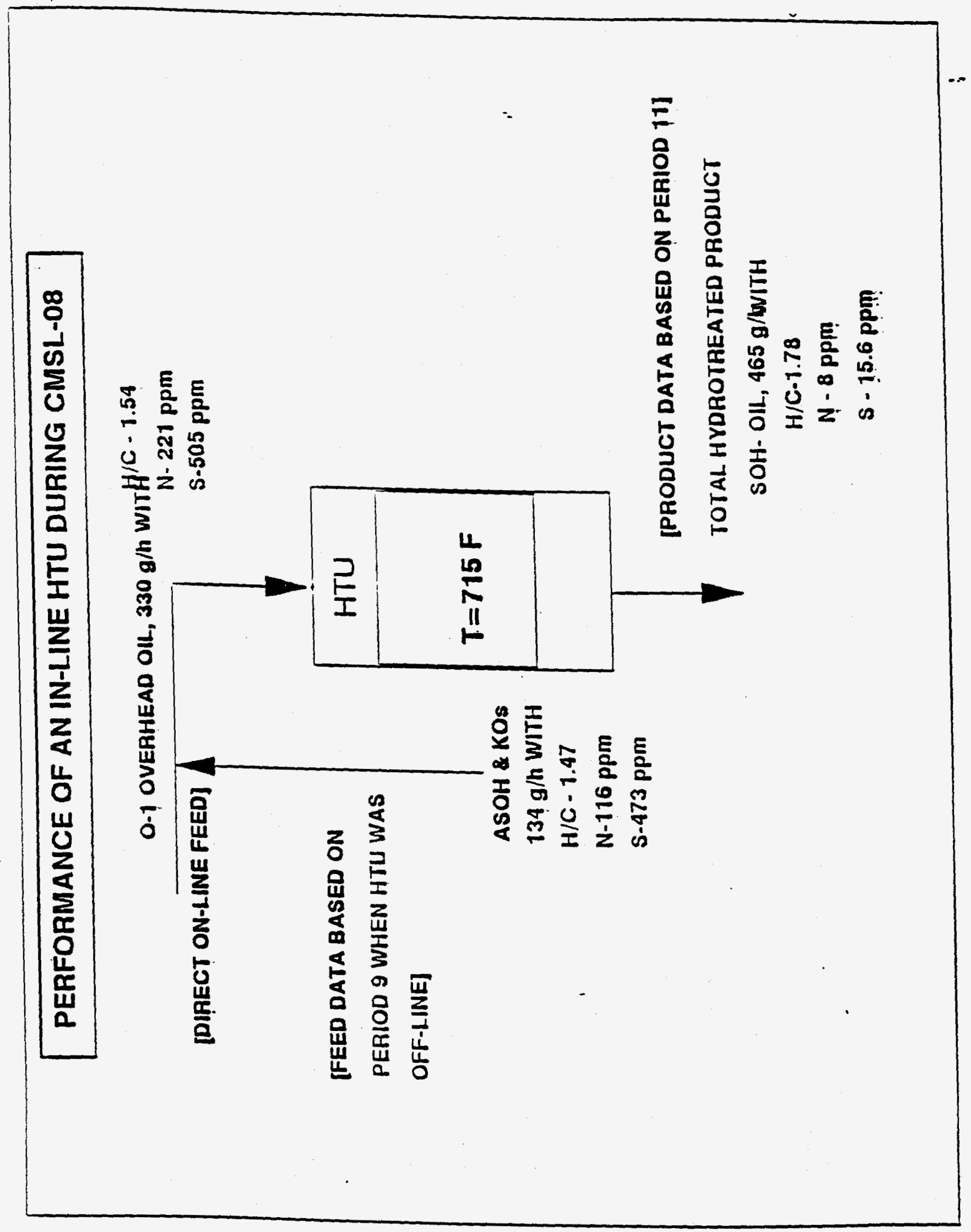


Figure 2.8.14

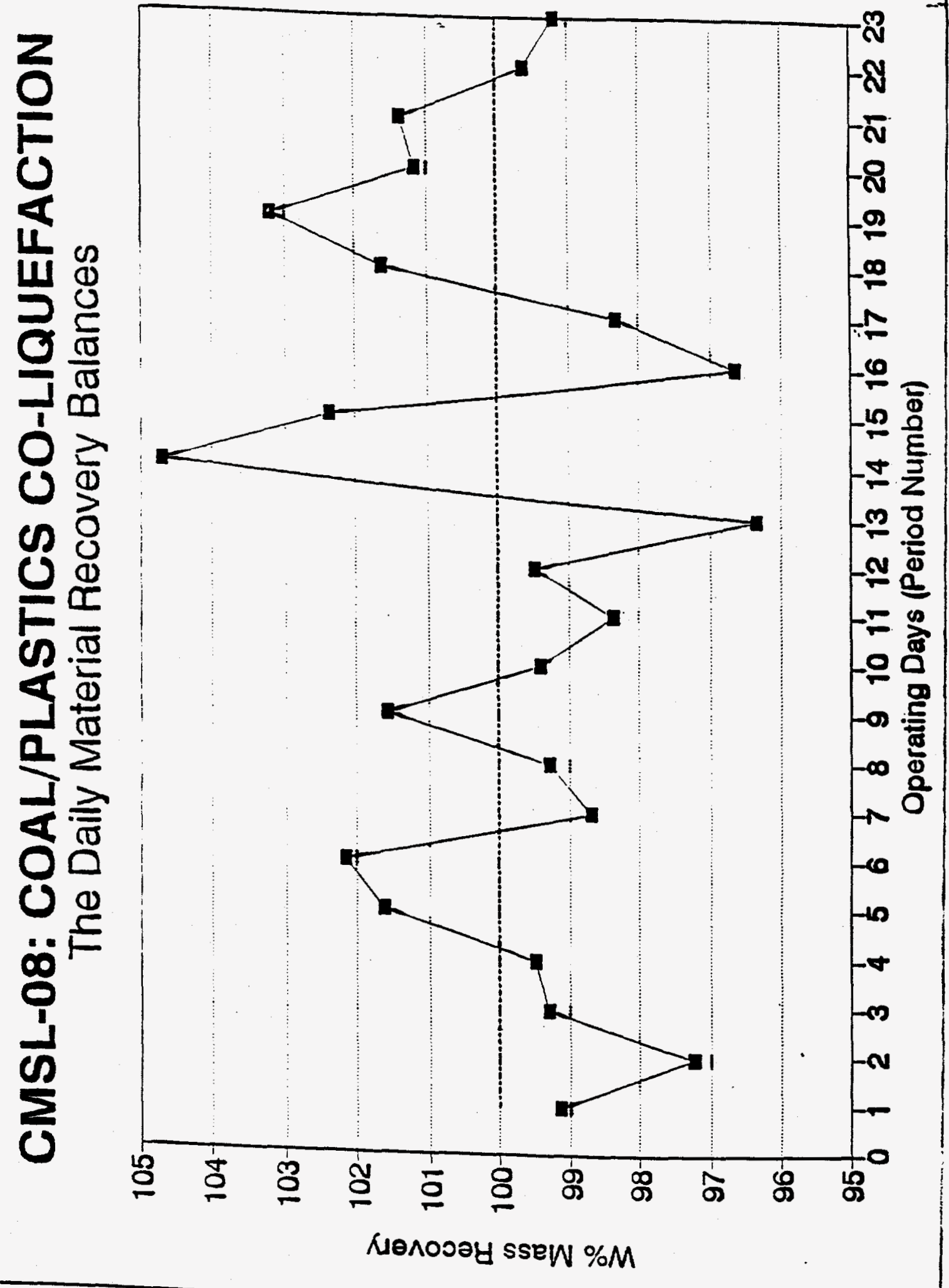




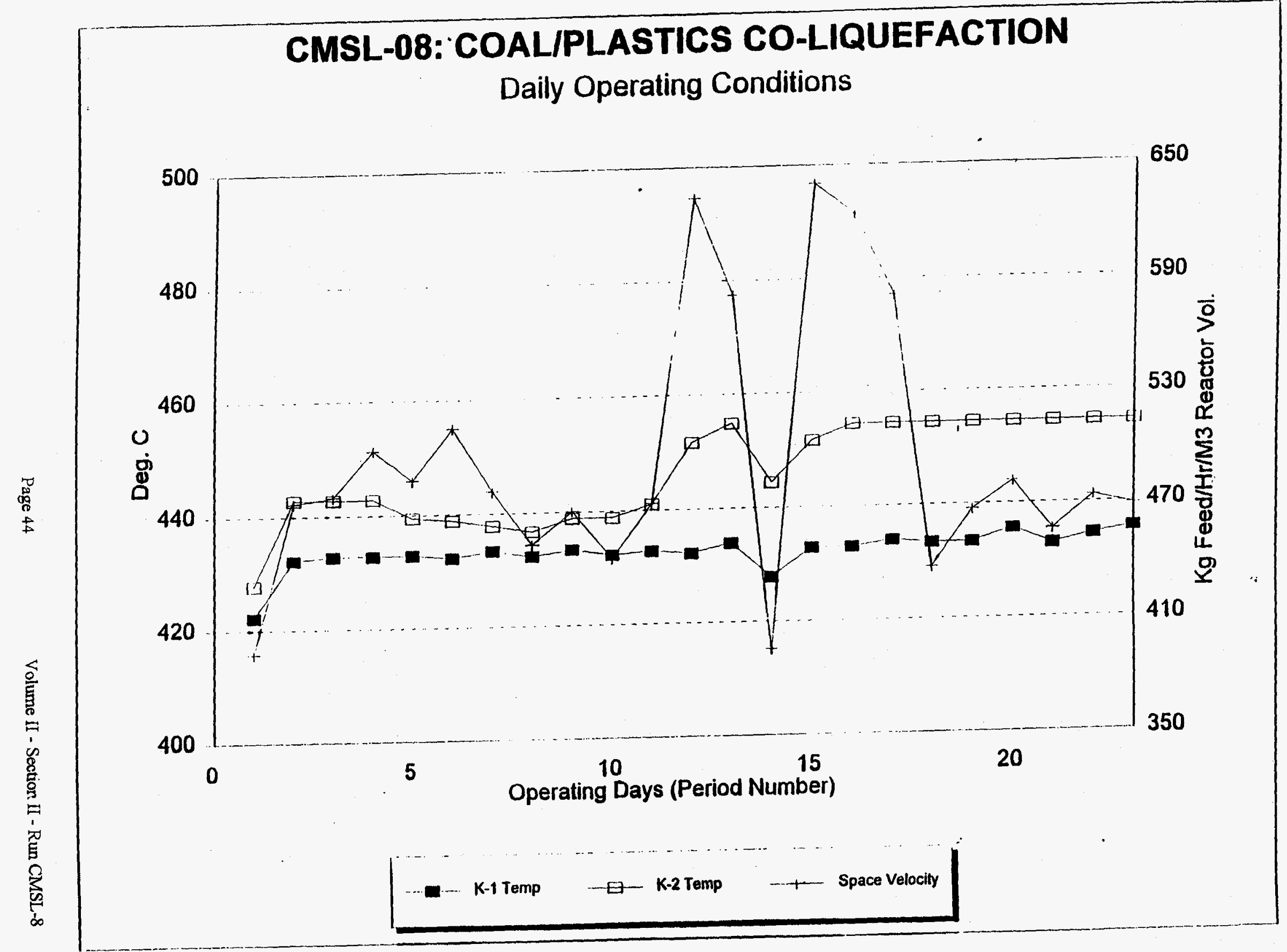




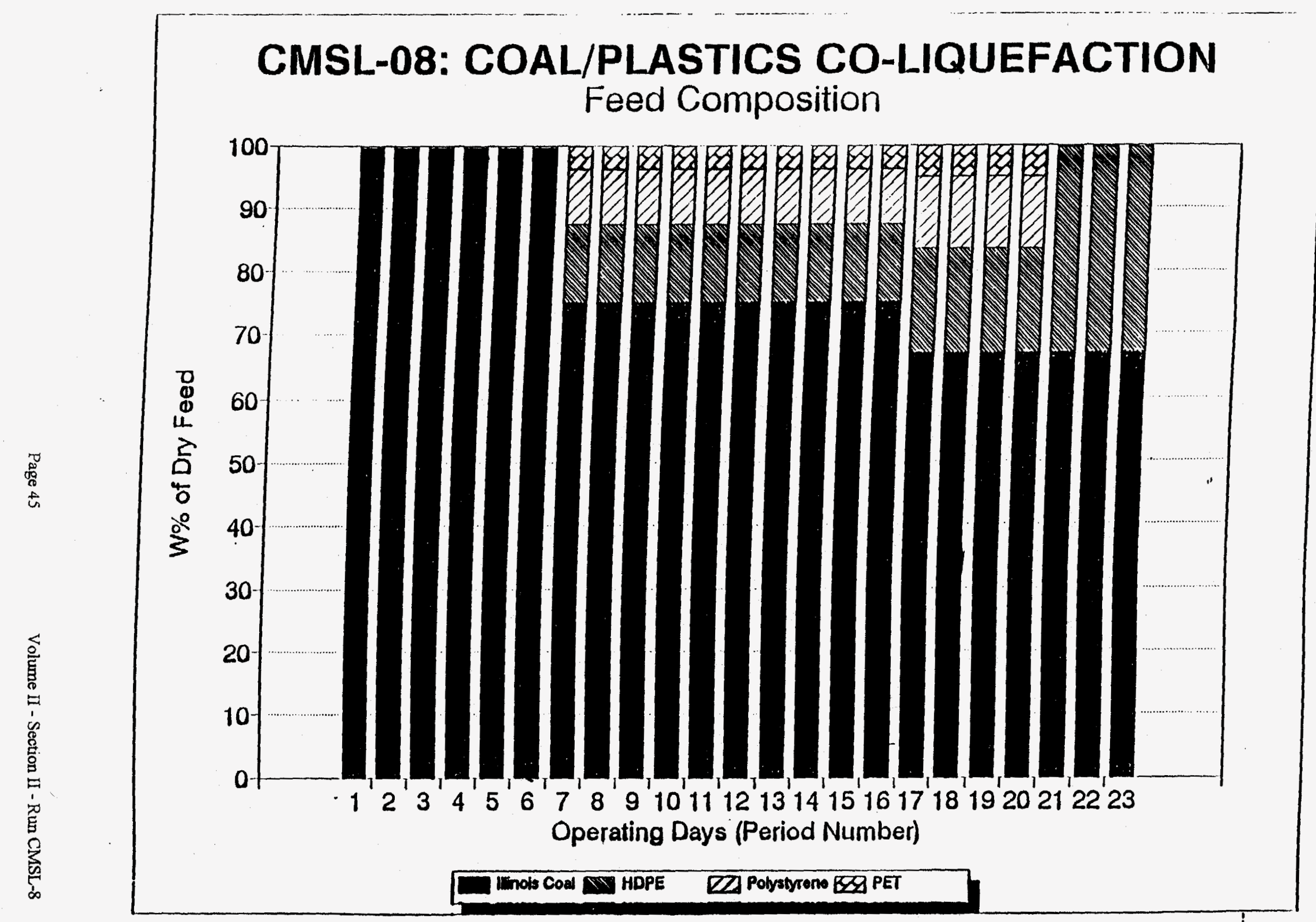




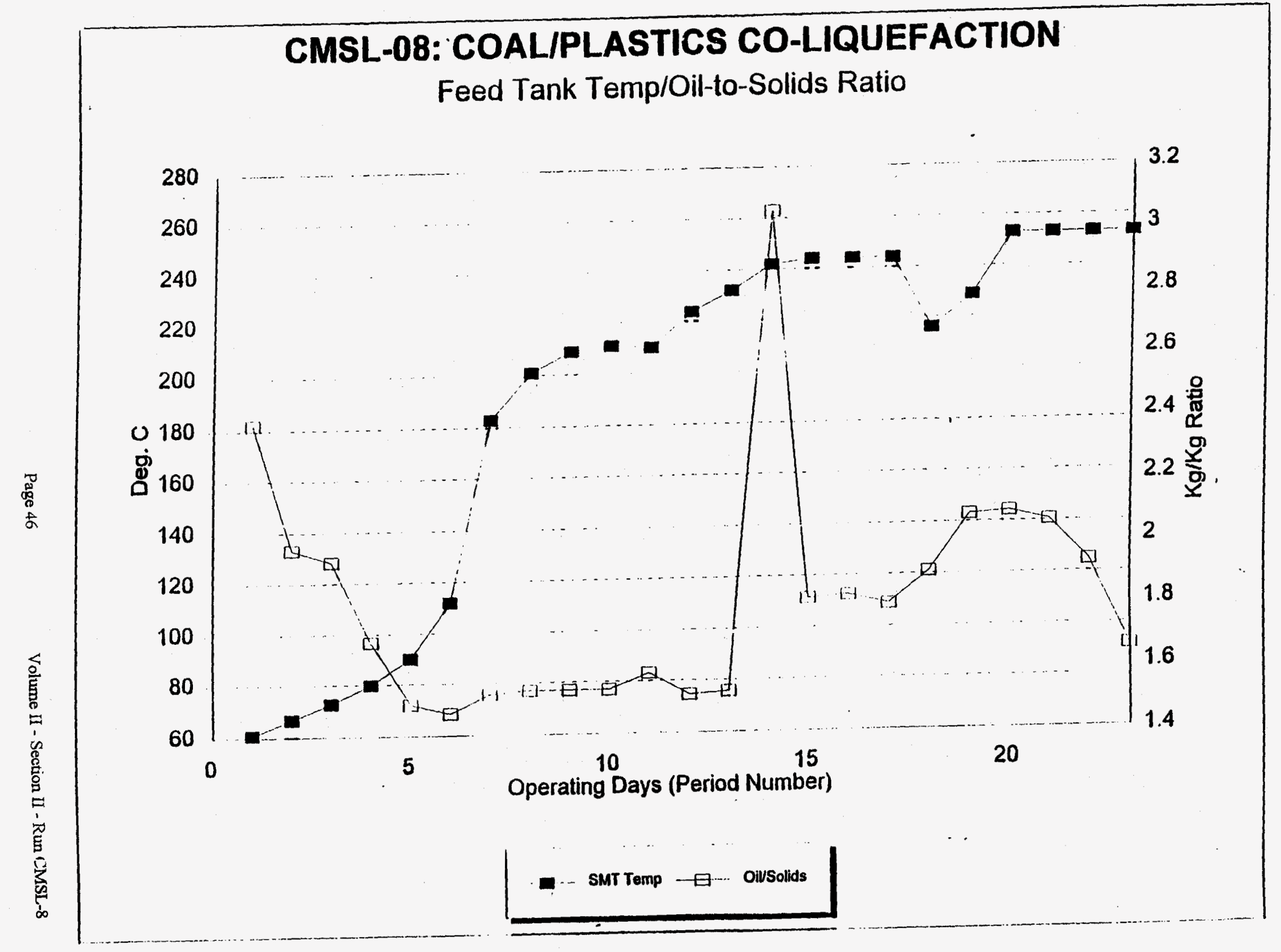




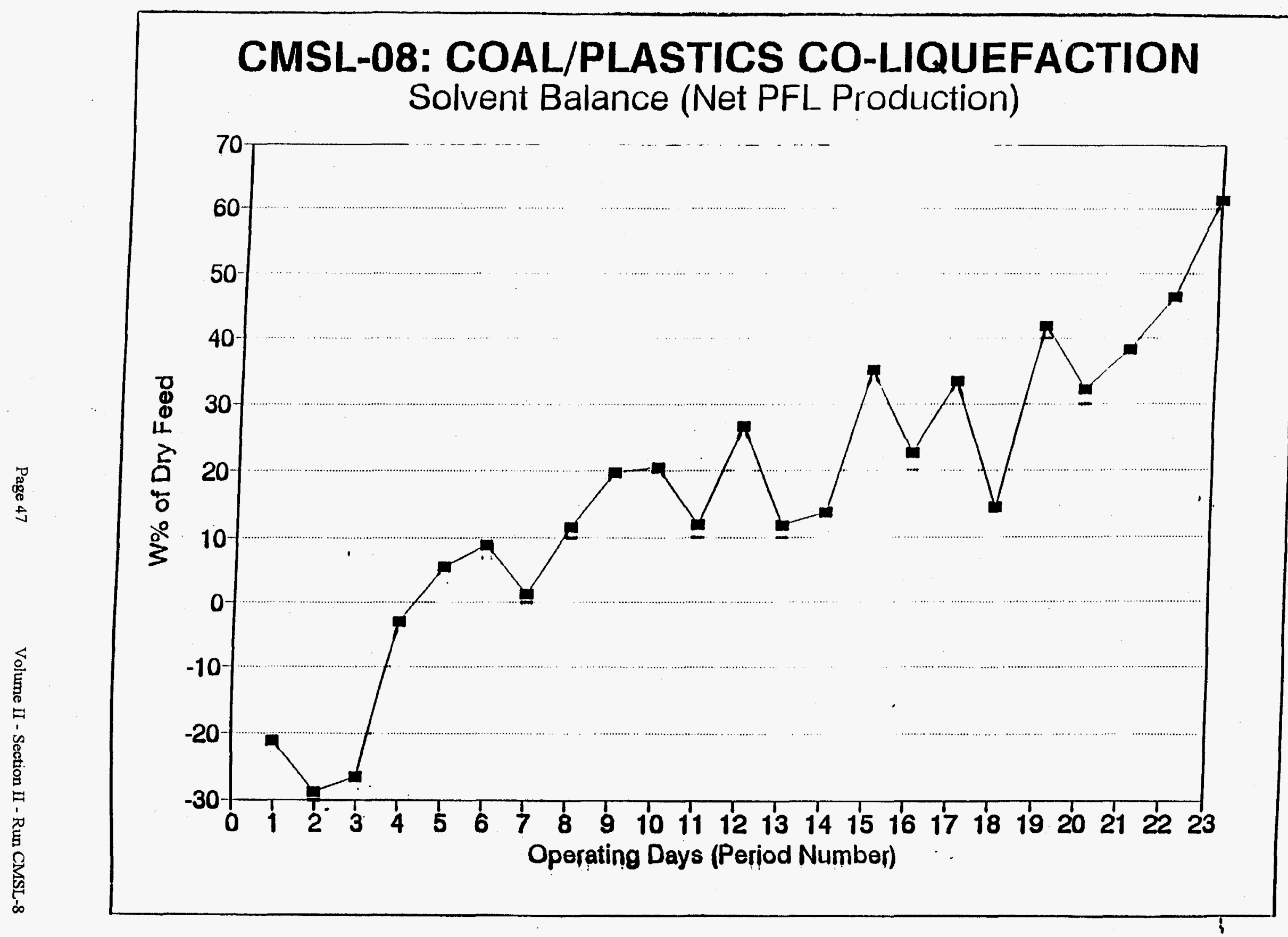


CATALYTIC MULTI-STAGE LIQUEFACTION OF COAL (CMSL) FINAL REPORT

VOLUME II

SECTION II (CONTINUED)

EVALUATION OF AN ALL DISPERSED SLURRY CATALYST MULTI-STAGE BACK-MIXED REACTOR SYSTEM FOR COAL LIQUEFACTION AND COAL-WASTE PLASTICS COPROCESSING

RUN CMSL - 9 


\section{VOLUME II}

SECTION 11 - RUN CMSL-9

TABLE OF CONTENTS

RUN CMSL-9 (227-87)

EVALUATION OF AN ALL DISPERSED SLURRY CATALYST MULTI-STAGE

BACK-MIXED REACTOR SYSTEM FOR COAL LIQUEFACTION AND

COAL/WASTE PLASTICS COPROCESSING

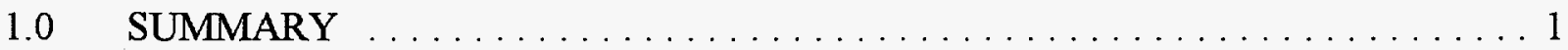

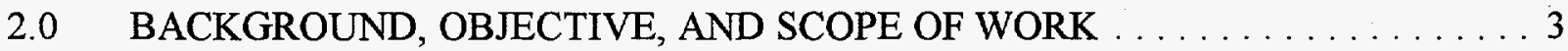

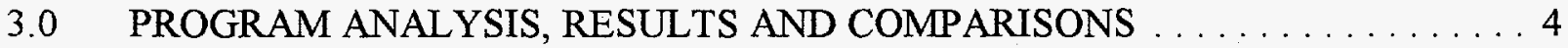

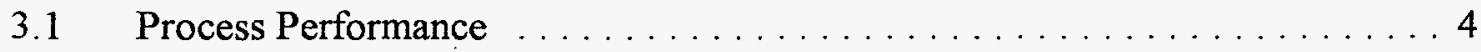

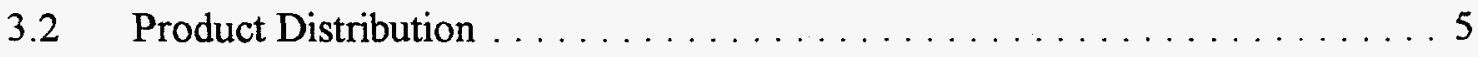

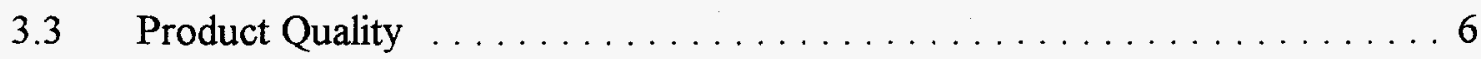

3.4 Pressure Filter Liquid and Pressure Filter Solids $\ldots \ldots \ldots \ldots \ldots \ldots \ldots 7$

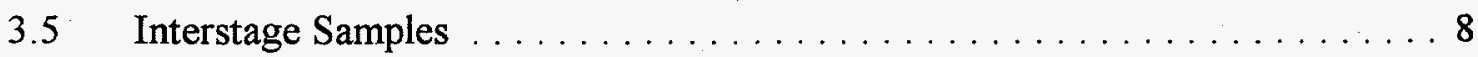

3.6 Hydrotreater Performance $\ldots \ldots \ldots \ldots \ldots \ldots \ldots \ldots \ldots \ldots \ldots$

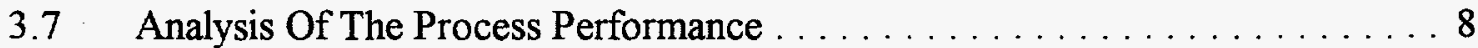

3.8 External Samples . . . . . . . . . . . . . . . . . . . . . 11

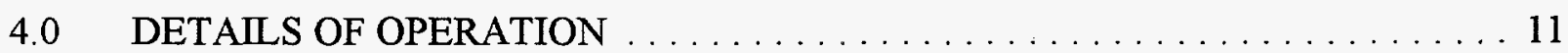

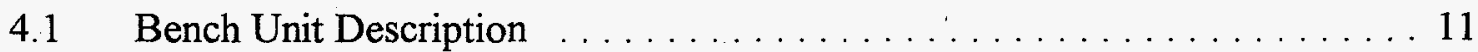

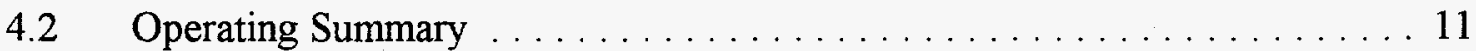

$4.3 \quad$ Recycle Solvent Balance . . . . . . . . . . . . . . . . . . . 12

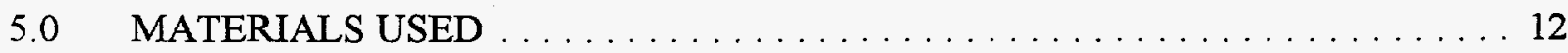

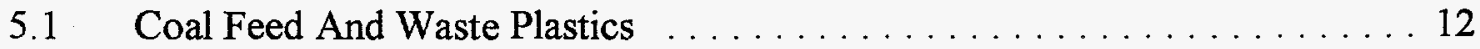

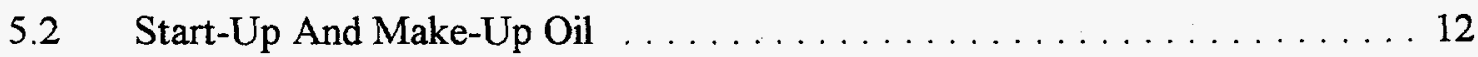

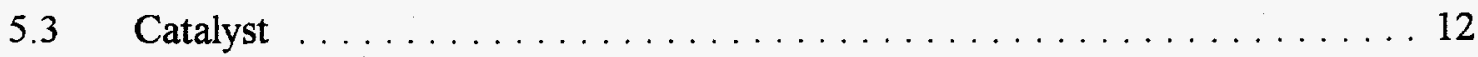

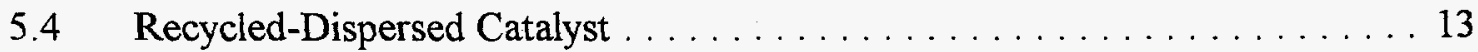

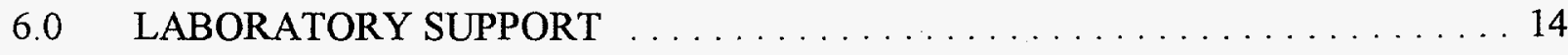

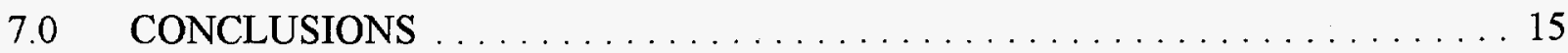




\section{VOLUME II}

\section{SECTION 11 - RUN CMSL-9}

\section{LIST OF TABLES}

Table

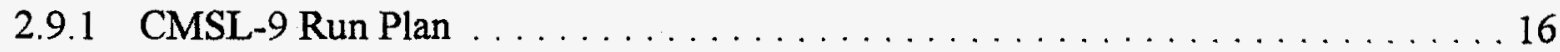

2.9.2 CMSL-9 Process Performance Summary . . . . . . . . . . . . . . . . . . 17

2.9.3 CMSL-9 Separator Overhead (SOH) Inspection . . . . . . . . . . . . . . . 18

2.9.4 CMSL-9 Atmospheric Overhead (ASOH) Inspection . . . . . . . . . . . . . . . 19

2.9.5 CMSL-9 Properties Of The Pressure Filter Liquid (2nd Stage) . . . . . . . . . 20

2.9.6 CMSL-9 Inspection Of The Pressure Filter Liquid (2nd Stage) . . . . . . . . . . 21

2.9.7 CMSL-9 Inspection Of The Pressure Filter Liquid (1 st Stage) . . . . . . . . . 22

2.9.8 CMSL-9 Inspection Of The Pressure Filter Liquid (1st Stage . . . . . . . . . . 23

2.9.9 Hydrotreater Performance During CMSL-9 . . . . . . . . . . . . . . . . . . 24

2.9.10 Comparison Between CMSL-9 Condition 6 and Exxon's Data . . . . . . . . . 25

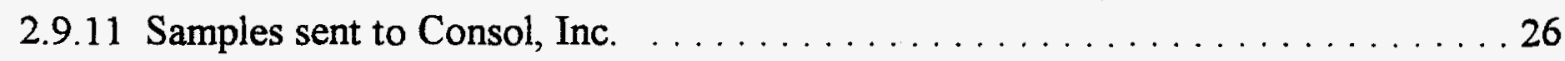

2.9.12 Analysis Of Coal And Plastic Feedstocks For CMSL-9 . . . . . . . . . . . 27

2.9.13 Analysis Of Start-up/Make-up Oil For CMSL-9 . . . . . . . . . . . . . . 28

2.9.14 Calculation of Products Derived from Plastics Addition . . . . . . . . . . . 29 
VOLUME II

\section{SECTION 11 - RUN CMSL-9}

\section{LIST OF FIGURES}

Figure $\quad$ Page

2.9.1 Simplified Schematic Of Bench Unit Configuration $\ldots \ldots \ldots \ldots \ldots \ldots$

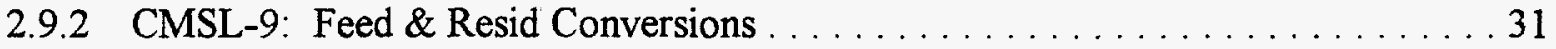

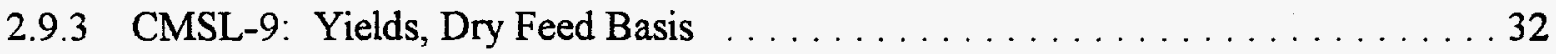

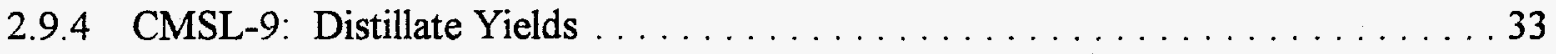

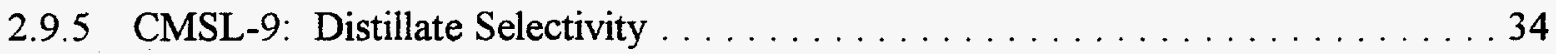

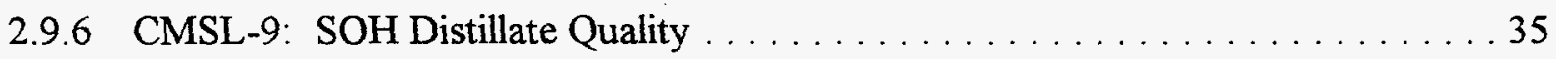

2.9.7 CMSL-9: Estimated HDPE Conversion to 524 F- Materials, W\% . . . . . . . 36

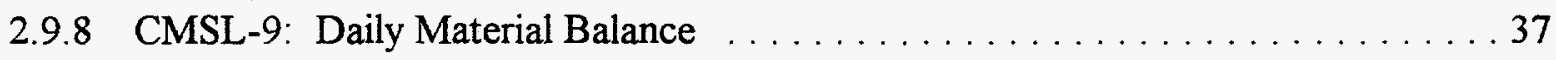

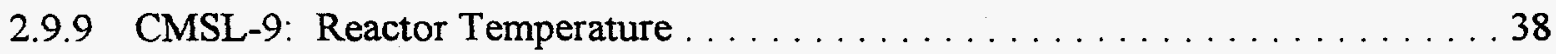

2.9.10 CMSL-9: Operating Conditions . . . . . . . . . . . . . . . . . 39

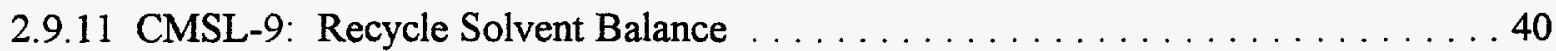


RUN CMSL-9 (227-87)

\section{EVALUATION OF AN ALL DISPERSED SLURRY CATALYST MULTI-STAGE BACK-MIXED REACTOR SYSTEM FOR COAL LIQUEFACTION AND COAL/WASTE PLASTICS COPROCESSING}

\subsection{SUMMARY}

The bench run CMSL-9 was a very unique bench operation in that for the first time at HTI, a 41 day long continuous operation was carried out in an all-dispersed catalyst multi-stage reactor configuration. Similar to Run CMSL-8, an in-line hydrotreater was employed to lower the heteroatoms content of the distillates. The overall operation was spread over nine Run Conditions. The effects of two dispersed catalysts, Molyvan-A, a cheap source of molybdenum, and HTI's iron catalyst, in their fresh as well as recycled forms were studied for the multistage liquefaction of Wyoming Black Thunder Mine subbituminous coal. The last three conditions, spread over 12 operating days, also investigated the coal/plastics coprocessing under steady-state recycle solventbalanced conditions. During this time, effects of having 33 and $50 \mathrm{~W} \%$ mixed plastics in the feed with coal were studied (mixed plastics were 40\% HDPE, 33\% PP, and 27\% PS); one of the conditions also looked at the coprocessing of HDPE alone @ 33 W\% with coal. Since dispersed catalysts were the only catalysts used in the reactors, a high feed throughput corresponding to a space velocity of $640 \mathrm{~kg} \mathrm{coal} / \mathrm{hr} / \mathrm{m}^{3}$ reactor volume could be maintained.

The best performance for the 'coal-only' periods of CMSL-9 was obtained for Condition 1, Period 5. The resid conversion of about $92 \%$ and distillate yield of about $67 \%$ (both MAF) were obtained at the process conditions shown and for $300 \mathrm{ppm}$ of Mo, added as Molyvan-A, to the feed slurry. The overall process performance degraded in going from Condition 1 to 3 and then 4 , i.e., in going from $300 \mathrm{ppm}$ fresh Mo, first, to a combination of $150 \mathrm{ppm}$ fresh and $150 \mathrm{ppm}$ recycled Mo, then to all $300 \mathrm{ppm}$ recycled Mo catalyst. The resid conversion during these transitions dropped by as much as $8 \%$ while distillate yield fell by $7 \%$ (both MAF absolute bases). This trend in process performance certainly confirms that molybdenum, in the recycled form, is not quite as active as the fresh molybdenum. Although this does not rule out any intrinsic catalytic activity that the recycled molybdenum catalyst may possess. The coal conversions, based upon quinoline solubility of the products, were uniform, around 95-96\% MAF throughout the 'coal-only' conditions, except for Condition 4, with all recycled Mo catalyst, when it plummeted to $92.8 \%$ MAF. The overall chemical hydrogen consumption varied between 6-7.5\% MAF. The $C_{1}-C_{3}$ gas make varied between $10-11.5 \%$ MAF coal. In Condition 6, with $100 \mathrm{ppm}$ fresh Mo and 10,000 ppm Fe of the HTI iron catalyst, had a performance approximately that of the earlier operation of Condition 3 using only Mo additive.

The coal/plastics coprocessing operations which used 100-300 ppm Mo and 10,000 ppm Fe of the HTI iron catalyst during the last 12 days of CMSL-9 were distinctly successful in that Condition 7, Period 34, which coprocessed $33 \%$ mixed plastics with coal, as high as $75.4 \%$ distillate yield was obtained with over $92 \%$ (both MAF bases) resid conversion. Next, for Condition 8 , Period 38, with $33 \% \mathrm{HDPE}$ alone and $67 \% \mathrm{coal}$ in the feed, the performance was poor $61 \% \mathrm{MAF}$ distillate yield and $79 \% \mathrm{MAF}$ resid conversion), confirming the poor reactivity of $\mathrm{HDPE}$ that was found during CMSL-8. Switching back to mixed plastics, but with $50 \%$ of total feed, during Condition 9 , 
Period 41 , the overall process performance jumped back to yield as high $75 \%$ distillates and $88 \%$ resid conversion (MAF). During Conditions 7 and 9, with mixed plastics, the much improved process performance over the earlier 'coal-only' conditions was obtained at a much reduced gasmake (7.5-8.5\% MAF) and lower chemical hydrogen consumption ( 3.5 to 5\% MAF). Thus, the coal/plastics coprocessing operations from both CMSL-9 and CMSL-08 resulted in improved overall process performance with better hydrogen utilization. This, we feel, will certainly improve the overall economics of coal conversion besides adding to it an environmental aspect.

The separator overhead oil products from CMSL-9 represent the net light distillate stream from the process. The overhead stream, which is essentially the liquids boiling between an initial boiling point of about $60^{\circ} \mathrm{C}$ and $370^{\circ} \mathrm{C}$, represents a combination of hot separator (O-1) overhead and continuous atmospheric still ( $\mathrm{N}-1 \mathrm{CAS}$ ) overhead streams which passes through an in-line hydrotreating unit, K-3. The product stream from K-3 is designated as the overall $\mathrm{SOH}$ (Separator Overhead) product. The other liquid part of the distillate comes from the IBP to $524^{\circ} \mathrm{C}$ boiling fraction of the pressure filter liquid (PFL) or the vacuum still overheads (VSOH), which are used to constitute recycle solvent, depending upon the method used for solid separation of the CAS bottoms. The API gravities and H/C atomic ratios of the SOH oil from CMSL-9 have been high (35-43, and 1.73-1.82 respectively), especially for the coal/plastics coprocessing Conditions. The quality of the distillates is also premium. The API gravities (an indication of paraffinic character) of the distillate increased significantly in going from the 'coal-only' conditions to 'coal/plastics' conditions (from about 32-37 to 40-44). The $\mathrm{H} / \mathrm{C}$ ratios also improved as well during the transition. The light boiling naphtha (IBP- $177^{\circ} \mathrm{C}$ ) fraction increased significantly during the coprocessing conditions, except for the condition that coprocessed coal with HDPE alone, instead of mixed plastics. The sulfur and nitrogen contents of the distillate products have been very low in general (10-100 ppm), and even lower for the coal/plastics coprocessing conditions.

Thus, the CMSL-9 was a very successful bench run from the technical as well as the operational standpoints. A net positive solvent balance (excess production of $343^{\circ} \mathrm{C}^{+}$oil over that needed for recycle) was obtained for all the operating periods of this bench run. More than 41 days of continuous operation (12 days on coal/plastics coprocessing) were completed during CMSL-9 successfully without any major interruptions. Also, samples of various process streams were obtained for the Consol, Inc. for property characterization/assessment.

This bench run not only provided insights into combined processing of coal with MSW plastics but also indicated the type of reaction severity, reactor configuration, and catalysts needed for achieving near-optimum process performance. So far as the effects of dispersed catalysts were concerned, it was once again observed that the recycled molybdenum catalyst is not as active as the freshly added form (Molyvan A). The use of an in-line hydrotreater has the advantage of not having to use expensive supported metal extrudate catalysts in the liquefaction/coprocessing reactors. If the alternative dispersed slurry catalysts are cheap and effective for coal and resid conversions under the given process severity, the finishing of the light distillates to remove heteroatoms and to add more hydrogen can be achieved by an in-line hydrotreater.

The overall process performance with plastics in the feed for both Illinois and Wyoming coals was improved with better hydrogen utilization, a benefit expected from the plastics part of the feed. Also, more so with a subbituminous coal (CMSL-9), it was found that plastics had synergistic 
effects on coal conversion in terms of improving the $\mathrm{C}_{4}-524^{\circ} \mathrm{C}$ premium distillate yields. It was also learned that reactivity of HDPE, a hard-to-convert polymer, is improved, under coal liquefaction conditions, when other polymers such as polypropylene and polystyrene are present. This conclusion is based upon estimations of individual coal and plastics conversions to $524^{\circ} \mathrm{C}^{-}$materials under reaction conditions. If it is assumed that $88-90 \%$ coal resid conversion is obtained along with complete conversions of both polypropylene and polystyrene, the conversion of HDPE alone, in the presence of other polymers, is about $12-35 \%$ higher than during conditions when HDPE was coprocessed alone with coal. Indeed, it is strongly believed that, because of all the positive effects of an all dispersed slurry catalyst reactor configuration and coprocessing waste plastics with coal, the economics of coal liquefaction will improve significantly. More importantly, such coprocessing technology would allow re-use of a very valuable hydrocarbon source (waste plastics) into the energy stream, in an environmentally benign manner.

\subsection{BACKGROUND, OBJECTIVE, AND SCOPE OF WORK}

The CMSL Project is geared to evaluate different novel processing concepts in catalytic coal liquefaction to complement the larger scale process demonstration "Proof-of-Concept" Studies for the U.S. DOE. The new ideas being explored in this program include low temperature pretreatments, more effective catalysts, on-line hydrotreating, new coal feedstocks, other (cheaper) sources of hydrogen, more concentrated coal-slurry feeds, waste hydrocarbon streams etc. A simplified schematic of the bench unit is presented in Figure 2.9.1.

The Bench Run CMSL-9 was carried out using a dispersed catalyst-only two-stage back-mixed reactor system. The two-stage conversion reactors were preceded by another back-mixed pretreatment reactor at lower temperature and half the volume of each of the conversion reactors. The pretreatment reactor for run CMSL-9 was half the size of the pretreatment reactor that was used in Run CMSL-1 and earlier. The pretreatment reactor was for sulfidation of the dispersed catalyst additive. The bench run CMSL- 9 was 41 days long, comprising nine operating conditions (3-5 days each). The objectives of this bench operation were:

- To determine the process performance for a subbituminous coal liquefaction using a threestage (including pretreater) dispersed catalyst-only back-mixed reactor system.

- To investigate the effect of molybdenum additive concentration on the overall process performance.

- To determine the activity of fresh molybdenum catalyst vs. recycled molybdenum catalyst.

- To study the effect of iron additive (in the presence of molybdenum), $\mathrm{FeOOH} / \mathrm{SO}_{4}$, on process performance.

- To obtain a tie-point, for process performance comparisons, with reference to Exxon's latest coal liquefaction run using dispersed Fe/Mo catalysts (Exxon's Run RCLU 1, Condition 4, Yield Periods 422-424).

- To obtain process-performance data on plastics and coal coprocessing for variable feed compositions and at higher severity and in a dispersed catalyst-only system. 
An in-line hydrotreater was used during this run. Both the hot separator $(\mathrm{O}-1)$ overheads and the atmospheric still overheads (ASOH) will be sent through the hydrotreater. In order to obtain the distillate samples that are not hydrotreated, and to arrive at mass-balance around hydrotreater, HTU was by-passed during a few operating Periods of the run.

The Run Plan (Table 2.9.1) included nine Run-Conditions that were selected to meet the technical objectives, specified above. By not using a supported extrudate catalyst in any of the coal liquefaction reactors, it became possible to compare the process performance of different Run Conditions on a one-to-one basis without being affected by 'catalyst batch-deactivation' phenomenon typical of the bench CTSL operations. For the first five run-conditions, 1 through 5 , the reactor temperatures and feed space velocities were maintained constant. These conditions studied the effects of varying the addition rate of molybdenum precursor and the relative activities of fresh vs. recycled molybdenum catalyst. It is expected that molybdenum exists as $\mathrm{MoS}_{\mathrm{x}}$ in the recycled solids (ash, char, and unconverted coal). Condition 6 studied the effect of adding $\mathrm{FeOOH} / \mathrm{SO}_{4}$ precursor/catalyst on the overall process performance.

The Condition 6 simulated the same operating conditions as those employed during Condition 4 (Yield Periods 422-424) of the Exxon's RCLU Dispersed Slurry Catalyst Run 1. The objective was to obtain a tie-point for process performance comparison. Conditions 7 through 9 studied the combined processing of coal and plastics at different feed compositions and higher reactor temperatures than the 'coal-only' Conditions 1 through 6.

Conditions 7 through 9 were designed to further our understanding of coal and waste plastics coprocessing using a subbituminous coal and different compositions of feeds (W\% plastics in feed), in an all dispersed catalyst reaction system. Mixed plastics (40\% HDPE, 33\% PP, and $27 \% \mathrm{PS}$ ) were used with coal at 33 and $50 \mathrm{~W} \%$ feed composition during Conditions 7 and 9 respectively. The Condition 8 studied coprocessing using 33 W\% HDPE (as the only plastic) in the feed with coal.

\subsection{PROGRAM ANALYSIS, RESULTS AND COMPARISONS}

The conversions and yields of different products, process performance, and product quality for CMSL-9 are addressed in this Section. The calculation of daily material recovery balances, coal conversions, normalized product yields, and other process performance-related indicators were carried out using programs available in the CTSL database (some programs were also modified as per the requirement of the process configuration). The overall process performance during CMSL9 is summarized in Table 2.9.2 and is discussed in details in the following sections.

\subsection{Process Performance}

\section{Total Feed (Coal+Plastics Combined) Conversion}

Typical feed conversions (based on the solubility of pressure filter solids or vacuum still bottoms in quinoline), obtained during equilibrated Periods of different Conditions of CMSL-9 are shown in Figure 2.9.2. As shown in Figure 2.9.2, the feed conversions (W\% 
MAF feed) varied between 95-97\% MAF throughout the course of the Run. The variations in the type of and amount of the dispersed catalyst additives did not seem to affect conversions significantly; presence of plastics in the feed also did not bring about any significant changes in overall feed conversions.

\section{$\underline{524^{\circ} \mathrm{C}^{+} \text {Residuum Conversion }}$}

Residuum conversion values varied between 79 to $92 \mathrm{~W} \%$ (MAF feed) and were more sensitive to the type and amount of the dispersed catalyst precursor added to feed, as shown in Figure 2.9.2. The resid conversion levels were not significantly different for 200 and $300 \mathrm{ppm}$ Mo added to feed as Molyvan-A. Conversions dropped by about 6-7\% MAF when 300 ppm of Mo was used in the recycled-only form (by the addition of dried pressure filter cake). The resid conversion levels rose again as the iron catalyst was added to the feed with Molyvan-A and finally when the overall process severity was increased during the coal/plastics coprocessing operations. Similar to the observation made during the CMSL-8, the resid conversion during coal+HDPE Condition was the lowest (78.7\% MAF), attesting to the conclusion that when HDPE is reacted individually with coal (without other plastics being present), it is difficult to convert to $524^{\circ} \mathrm{C}^{-}$material.

\section{Hydrogen Consumption}

Hydrogen consumption (Figure 2.9.3) based on mf feed varied between 3.4 to $7.2 \mathrm{~W} \%$. During the 'coal-only' Conditions, no specific trend or pattern was seen in hydrogen consumption with variation in the type and the amount of dispersed catalyst. As expected, chemical hydrogen consumption decreased in going from coal-only operating Periods to the coal/mixed plastics coprocessing Periods. This was due to lower light gas make during coliquefaction operations and higher chemical hydrogen content of the combined feed. As the $\mathrm{C}_{4}-524^{\circ} \mathrm{C}$ distillate yield increased significantly in going from 'coal-only' Conditions to coprocessing Conditions, the hydrogen efficiency or utilization with coal/plastics operation is much better than the 'coal-only' operation.

\section{Heteroatom Removal}

The net SOH distillates obtained during CMSL-9 contained very small amounts of nitrogen and sulfur (less than $40 \mathrm{ppm}$ each). These levels of heteroatom removal are significant considering that none of the liquefaction reactors had employed a supported catalyst. While the in-line hydrotreater was by-passed, the heteroatoms content of the $\mathrm{SOH}$ distillates rose to more than $350 \mathrm{ppm}$ each.

\subsection{Product Distribution}

\section{$\underline{\mathrm{C}}_{1}-\mathrm{C}_{3}$ Gas Yields}

As shown in Figure 2.9.3 and Table 2.9.2, the normalized $\mathrm{C}_{1}-\mathrm{C}_{3}$ gas yields for CMSL-9 varied between 7.3 to $12.1 \mathrm{~W} \% \mathrm{mf}$ feed. The light gas yield was highest $(12.1 \mathrm{~W} \%)$ during coal-only operation of Condition 3 ; the yield decreased significantly during the coal/plastics 
coliquefaction operations (Condition 7 through 9). The lowest gas yield was obtained during the last run Condition which was with $50 \%$ mixed plastics and coal. These findings indicate that mixed plastics do not form as much light hydrocarbon gas as does the subbituminous coal feed.

\section{$\underline{524^{\circ} \mathrm{C}^{+} \text {Residuum Yield }}$}

The residuum yield (Figure 2.9 .3 ) was between $4 \%$ and $10 \%$ of MF feed for the coal-only operations of Run CMSL- 9 , and $2 \%$ and $16 \%$ of MF feed for the coprocessing operations. During the coal-only operations, the yields increased progressively over this range as the amount of freshly added Mo catalyst was lowered from $300 \mathrm{ppm}$ to none (with $300 \mathrm{ppm}$ recycled Mo). When iron catalyst was added along with fresh $\mathrm{Mo}$, the residuum yield was about the same as when the same amount of Mo alone had been added. In the coprocessing operations with $33 \%$ mixed plastics, the residuum yield was $5 \mathrm{~W} \%$ lower than in comparable coal-only operations. The highest residuum yield, $9 \mathrm{~W} \%$ higher than in comparable coal-only operations, was obtained with $33 \% \mathrm{HDPE}$ in the feed, confirming the relatively refractory nature of the HDPE that had been evident in earlier coprocessing operations in Run CMSL-8.

\section{$\mathrm{C}_{4}-975^{\circ} \mathrm{F}+$ Distillate Yields And Selectivity}

Distillate yields, shown in Figure 2.9.4, followed similar trend in going from Condition 1 to 9 as did the resid conversions. In general, the yields varied between about $60 \%$ to about $75 \%$ MAF during CMSL-9. For the coal-only Conditions, the highest yield was obtained for Condition 1, 66.6\% MAF. During the coal/plastics coprocessing operations, a very high distillate yield of over $75 \% \mathrm{MAF}$ was obtained when $33 \%$ mixed plastics were processed with coal. Almost as high a yield was obtained when the mixed plastics concentration in the feed with coal was increased to $50 \%$. As was the case during CMSL-8, the distillate yields plummeted to about $61 \%$ from $75 \%$ when HDPE alone was coprocessed with coal as 33 $\mathrm{W} \%$ of the feed.

So far as the selectivities of different boiling fractions of the net $\mathrm{C}_{4}-524^{\circ} \mathrm{C}$ distillate are concerned (Figure 2.9.5), the coal-only Conditions resulted between $20-34 \%$ selectivity for the naphtha $\left(\mathrm{C}_{4}-177^{\circ} \mathrm{C}\right.$ material). These selectivities increased to about $40 \%$ during the coal/plastics coprocessing operations. The selectivities for the middle distillates $\left(177-343^{\circ} \mathrm{C}\right.$ material) varied only slightly during different run Conditions. The selectivity for the heavy distillate $\left(343-524^{\circ} \mathrm{C}\right.$ material) was the highest for Condition 8 , which coprocessed HDPE alone with coal. Thus, Condition 8 resulted not only in poor total distillate yields, but also in poor selectivities to light boiling fractions.

\subsection{Product Quality}

Different product fractions (First-Stage/Second-Stage Vent Gases, CAS Bottoms, SOH, ASOH, PFL, VSOH and PFS/VSB) from the Work-up Periods 5, 9, 15, 19, 24, 29, 34, 38, and 41 were analyzed in detail for their composition. These analyses for different product fractions are listed in Tables 2.9.3 through 2.9.8. 
The SOH oil stream was the net light distillate product from Run CMSL-9. With the hydrotreater unit (HTU) on-line during the run, this stream consisted of the $0-1$ hot separator overheads, ASOH from atmospheric pressure distillation of product slurry from the second stage, and unit knock-outs, which were combined and fed to the hydrotreater (HTU). The properties of the SOH oil for the work-up periods are shown in Table 2.9.3 and Figure 2.9.6. The SOH oils had a typical boiling range of $54^{\circ}$ to $380^{\circ} \mathrm{C}$. The API gravities and $\mathrm{H} / \mathrm{C}$ atomic ratios of the SOH oil in Run CMSL-9 were 32-43 and 1.73-1.82, respectively. The API gravities (an indication of paraffinic character) of the $\mathrm{SOH}$ were significantly higher during the coprocessing operations than during the coal-only operations at gravities of $40-44$ compared to $32-37$. The $\mathrm{H} / \mathrm{C}$ ratios were also appreciably higher during the coprocessing operations. The heteroatom levels (nitrogen sulfur) were generally low throughout the run. Typically, sulfur levels were below $15 \mathrm{ppm}$ and the nitrogen levels below $50 \mathrm{ppm}$. (It is believed that, during periods 24 and 29, the quality of the SOH stream was affected by the residual effect of by-passing the HTU during periods 23 and 29 to obtain samples of distillates that had not been hydrotreated.) There was a significantly higher proportion of light boiling naphtha (IBP- $177^{\circ} \mathrm{C}$ ) during the coprocessing operations using mixed plastics than during the coal-only operations. When the plastics component used during the coprocessing operation was HDPE, only, the proportion of naphtha was greater than that obtained during the comparable coal-only operations

The ASOH stream is obtained from the unit as a sample stream only. As seen from Table 2.9.4, this unhydrotreated oil stream has low API gravities (4-14) except for during coprocessing Conditions. The quality is also poor, i.e., high sulfur (200-375 ppm) and nitrogen (150-741 ppm) contents, and low $\mathrm{H} / \mathrm{C}$ atomic ratios (1.17-1.53). This stream, combined with the hot separator overheads $(\mathrm{O}-1)$ and unit knockouts went into the in-line hydrotreater for finishing of overhead products.

The higher boiling distillate products $\left(343^{\circ} \mathrm{C}\right.$ to $524^{\circ} \mathrm{C}$ boiling range) were the IBP- $524^{\circ} \mathrm{C}$ fraction of the pressure filter liquid (PFL) or the vacuum still overheads (VSOH), which streams constituted the recycle solvent, depending upon the method used for solids separation from the CAS bottoms. The VSOH analyses for Periods 9 through 34 given in Table 2.9.5 indicate the low quality of these untreated product fractions. For the coal-only operations, the $\mathrm{H} / \mathrm{C}$ atomic ratios of the $\mathrm{VSOH}$ were between 1.12 and 1.18 , with a slightly higher value of 1.27 for the coprocessing operation. The nitrogen contents were $0.70-0.87$ $\mathrm{W} \%$, and the sulfur contents were $0.22-0.55 \mathrm{~W} \%$. The nominal oxygen content of the VSOH, by difference from $100 \%$ of the total of analyzed elements, was $1.0-3.3 \mathrm{~W} \%$. For comparison, the nominal oxygen content of the $\mathrm{SOH}$ products summarized in Table 2.9.3 was $0.2-0.6 \mathrm{~W} \%$.

\subsection{Pressure Filter Liquid and Pressure Filter Solids}

Due to the difficulties encountered in pressure filtrations of the atmospheric still bottoms during CMSL-9, the solid separation mode was changed to vacuum still after Period 8 . The pressure filtrations were carried out again in the later part of the Run (Periods 35-41). For 
the VSOH during Periods 9-34, significant portions of material $(90 \mathrm{~W} \%+)$ were lighter than $454^{\circ} \mathrm{C}$; the API gravities ranged from 2.3 to 11.1 while the $\mathrm{H} / \mathrm{C}$ atomic ratios varied between 1.12 and 1.27. The PFL obtained during the 'coal/plastics' coprocessing conditions contained as high as 33-39 W\% resid material which is considered to be mostly paraffinic in nature, derived from the HDPE in the plastics feed (Table 2.9.5). The PFL obtained during these Periods had high API gravities (10-12) and high $\mathrm{H} / \mathrm{C}$ ratios (1.5-1.6), thus confirming that it was primarily made up of partially converted plastics. The PFS and vacuum still bottoms obtained during CMSL-9 had $\mathrm{H} / \mathrm{C}$ ratios between 0.6-0.9 (Table 2.9.6). The conversions based on IOM/Ash ratios were higher than $95 \% \mathrm{MAF}$.

\subsection{Interstage Samples}

The interstage samples are the samples of the slurry exiting the first stage coal liquefaction reactor, that are withdrawn from the ebullating line on the reactor (Table 2.9.7 and 2.9.8). These samples shed light on the performance of the first stage reactor in terms of coal and resid conversions. The interstage samples of the product slurry from the first stage reactor were collected during all the Work-up Periods of CMSL-9. The analyses of the pressure filter solids from these samples indicated that about $93-94 \%$ coal conversion (based on quinoline solubility) is obtained after the first stage coal liquefaction reactor. The properties of the interstage (first stage) PFL have also been very consistent with the other data-trends discussed in this report.

\subsection{Hydrotreater Performance:}

The in-line hydrotreater (HTU) has performed well during CMSL-9, as exemplified by low heteroatom contents of the distillate products and their high $\mathrm{H} / \mathrm{C}$ ratios. The absolute $\mathrm{N}$ and $\mathrm{S}$ contents are not as low as those obtained during CMSL-8, because for the first time a high space velocity of $641 \mathrm{~kg} / \mathrm{hr} / \mathrm{m}^{3}$ reactor was used coupled with the fact that it was an all dispersed-catalyst based reactor system. Thus, there was no supported catalyst in the second coal liquefaction stage for products upgrading as in the more conventional CTSL type configuration. Table 2.9.9 summarizes how poor the quality of the distillate product streams were when the HTU was bypassed, with the nitrogen and sulfur contents as high as $350 \mathrm{ppm}$ each while upon hydrotreatment, as indicated by the shaded portions of Table 2.9.9, the $\mathrm{SOH}$ distillates had less than about $50 \mathrm{ppm}$ each nitrogen and sulfur.

\subsection{Analysis Of The Process Performance}

\section{Effect of Type and Amount of Dispersed Catalyst}

One of the objectives of CMSL-9 was to investigate the effects of dispersed molybdenum and iron catalysts on the overall process performance. Four molybdenum concentrations were studied: $300 \mathrm{ppm}$ fresh, $200 \mathrm{ppm}$ fresh, $150 \mathrm{ppm}$ fresh $+150 \mathrm{ppm}$ recycle, and 300 ppm recycle-only. It was observed, under equivalent process severity conditions, that the molybdenum catalyst in the freshly added precursor form was more active for coal residuum conversion than the recycled form of molybdenum catalyst. Addition of $1 \mathrm{~W} \%$ iron catalyst $\left(\mathrm{FeOOH} / \mathrm{SO}_{4}\right)$, during Condition 6 , was found to improve the overall process 
performance slightly over Condition 5 (which used $150 \mathrm{ppm}$ Mo each in the fresh and the recycled form). The source of recycled catalyst in most cases was the Continuous Atmospheric Bottoms (CAS Bottoms) stream; during Condition 4, which used $300 \mathrm{ppm}$ recycled-only Mo catalyst, a dried and toluene-extracted pressure filter cake, derived from the earlier Periods of the Run. The observation made during this run on the relative activities of the fresh vs. recycled Mo catalysts is consistent with what had been seen of a sulfated iron oxide catalyst during an earlier Bench Run, CMSL-6. As a part of the followup of this finding, a few microautoclave batch tests are being planned to study the catalytic behavior of both fresh Molyvan-A and the dried pressure filter cakes from CMSL-9.

\section{Effects of Feed Composition:}

First six Conditions during CMSL-9 were the 'coal-only' feed Conditions. It was during the last three Conditions that coal/plastics coprocessing was carried out. The coal/plastics coprocessing operations during the last 12 days of CMSL-9 were distinctly successful in that Condition 7, Period 34, which coprocessed 33\% mixed plastics with coal, as high as $75.4 \%$ distillate yield was obtained with over $92 \%$ (both MAF bases) resid conversion. Next, for Condition 8, Period 38, with 33\% HDPE alone and $67 \%$ coal in the feed, the performance was poor (61\% MAF distillate yield and $79 \% \mathrm{MAF}$ resid conversion), confirming the poor reactivity of HDPE that had been found during CMSL-8. Switching back to mixed plastics, but with $50 \%$ of total feed, during Condition 9 , Period 41 , the overall process performance jumped back to yield as high as $75 \%$ distillate and $88 \%$ resid conversion (MAF). During Conditions 7 and 9, with mixed plastics, the much improved process performance over the earlier 'coal-only' conditions was obtained at a much reduced gas-make (7.5-8.5\% MAF) and lower chemical hydrogen consumption (3.5 to 5\% MAF).

\section{Products Derived from Plastics:}

Table 2.9.14 is a summary of the calculations of nominal distribution of products derived from the plastic components, assuming that the increments of yields for the coprocessing operation (compared to those for a comparable coal-only operation) were solely derived from the plastic. This estimate indicates for the Condition 7 operation (33\% mixed plastics feed) that nominally $100 \%$ of the plastic was converted to C4-524 C distillates, with $-8 \%$ dissolved (and filterable) but remaining as a residual oil, and $7.6 \%$ remaining as unconverted on the product filter cake. The $\mathrm{C}_{1}-\mathrm{C}_{3}$ yield from the plastics was about twothirds that of the coal, and nominal hydrogen consumption by the plastics was about onethird that of the coal. Even allowing for the uncertainties inherent in such by-difference calculations, it is probable that the selectivity to distillates is very much higher for the plastics than for the coal.

In the Condition 8 operation ( $33 \% \mathrm{HDPE}$ as the plastic component), an apparently lower proportion of distillates (58\%) was derived from the plastic, and filterable resid was $34 \%$ of product from the plastic. This lower distillate yield from HDPE than from the mixed plastics is similar to that seen in Run CMSL-8. However, the proportion of distillates from HDPE in Run CMSL-9 is much higher than that in Run CMSL-8, in which virtually the only product from the HDPE was the filterable resid. In the HDPE operation in Run 
CMSL-9, a plastic selectivity to $\mathrm{C}_{1}-\mathrm{C}_{3}$ gas was about $40 \%$ that of coal with very low incremental hydrogen consumption, $0.9 \mathrm{~W} \%$ of the plastics, and $4 \%$ of the plastic remained unconverted in the product filter cake.

In the Condition 9 operation run of CMSL-9 (50\% mixed plastics feed), the apparent incremental yield of distillates from the plastic was $85 \%$ and the yield of filterable resid was $10 \%$ of the plastics. The yield of $\mathrm{C}_{1}-\mathrm{C}_{3}$ gas from the plastic was $60 \%$ of that from coal, and apparent "unconverted" plastic with the filter cake was $1.5 \%$.

The essential conclusions from these estimates are:

1) Of the order, $90 \%$ of mixed plastics can be converted to distillates, and plastics content of up to $50 \%$ of the feed are feasible and attractive;

2) The subbituminous coal, all-catalyst-additive operation of Run CMSL-9 appears to be far more effective for plastics conversion than the bituminous coal, additive/extrudate catalyst mode of Run CMSL-9. However, the higher temperatures used during Run CMSL-9 (449 and $460^{\circ} \mathrm{C}$ compared to 432 and $454^{\circ} \mathrm{C}$ in Run CMSL-9) which corresponds to a factor of 1.55 in thermal severity, may have contributed to the difference in performance;

3) While HDPE itself is difficult to convert to distillates, there is apparently a synergistic effect when mixed with other plastics, since the distillates derived from mixed plastics in Conditions 7 and 9 were higher than the amount of the other plastics in the mixed plastic by an amount that corresponded to $62-90 \%$ of the HDPE content. Figure 2.9.7 summarizes the apparent conversion of HDPE to distillates for the various coprocessing operations.

\section{Comparison with Exxon's Dispersed Catalyst Data:}

Condition 6 of the Bench Run CMSL-9 was designed to obtain a tie-point for comparison between HTI's data and Exxon's data. Two dispersed catalysts were employed during these Conditions: iron and molybdenum. At HTI, Molyvan - A was used as a source of molybdenum at $100 \mathrm{ppm}$ relative to coal while sulfated iron oxide, prepared at HTI, was used as a source of iron at $1 \mathrm{~W} \%$ relative to coal. The process performance comparisons are summarized in Table 2.9.10. As shown in this Table, the operating conditions were very similar for HTI's Condition 6 and Exxon's Conditions 3 and 4. Exxon had employed both Molyvan-A and Molyvan- $\mathrm{L}$ as precursors of molybdenum while for iron, Exxon employed Baily's -325 mesh iron oxide during Condition 3 of their Run and Bayferrox fine-sized iron oxide during Condition 4 of their operation. From Table 2.9.10, it can be seen that under similar conditions and catalyst loadings, HTI's Condition 6 resulted in a better overall process performance. The distillate yields are about $2.5 \%$ higher and so are the $524^{\circ} \mathrm{C}+$ residuum conversions. The light gas yields are slightly lower for HTI's Condition 6 while the hydrogen consumption is a tad higher, meaning the increased hydrogen consumption was utilized for the production of useful liquid products. Since all the operating conditions and precursors of molybdenum catalysts were the same for HTI's Condition 6 and Exxon's 
Conditions $3 \& 4$, it can be said that the better overall process performance at HTI is attributable to the use of a more active precursor/catalyst of iron, i.e., $\mathrm{HTI}$ 's $\mathrm{FeOOH} / \mathrm{SO}_{4}$ catalyst.

A possible positive influence of addition of $1 \mathrm{~W} \%$ of $\mathrm{FeOOH} / \mathrm{SO}_{4}$ catalyst was also seen on the recycle system during CMSL-9. Towards the end of Period 9 (Condition 2), the nature of resid material in the CAS bottoms was such that pressure filtrations became very time-consuming and finally not doable. At this point the means of solids separation was changed to vacuum still operation. This continued well until the point in the Run when an addition of iron catalyst was begun. Soon after $1 \mathrm{~W} \%$ iron catalyst was introduced with the feed and the coprocessing operation started, the nature of resid in CAS bottoms changed so that the pressure filtrations were operable with short turn-around times.

\subsection{External Samples}

As mentioned earlier, a number of samples of different process streams from CMSL-9 were obtained (for further detailed characterization and products assessment) for the Consol, Inc. and also for the members of Consortium of Fossil Fuel Liquefaction Science. These samples, their amounts, and the operating Periods when these were withdrawn are shown in Table 2.9.11.

\subsection{DETAILS OF OPERATION}

\subsection{Bench Unit Description}

CMSL-9 involves two equal volume backmixed reactors, one half volume $(1000 \mathrm{cc})$ pretreatment vessel (also back-mixed), and a fixed-bed hydrotreater. The high pressure slurry samples were obtained both after the pretreatment vessel and after the first conversion reactor. The simplified schematic of this configuration is shown in Figure 2.9.1.

The reactors from the existing units $227 \& 238$ were used in this run with the necessary repiping and equipment modifications. A hot-slurry mix tank system was used throughout the run for slurry preparation. There was no supported catalyst used in any of the conversion reactors, except in the hydrotreater (HTU). Hydrogen disulfide $\left(\mathrm{H}_{2} \mathrm{~S}\right)$, as a source of sulfur for the activation of dispersed iron and molybdenum additives, was continually added to the pretreater at $3 \mathrm{~W} \%$ of dry coal.

\subsection{Operating Summary}

An average material recovery balance of $99.25 \mathrm{~W} \%$ was obtained (Figure 2.9.8) for the entire Bench Run CMSL-9. The Operating Summary of individual Periods during CMSL-9 is shown in Table 2.9.2. Figures 2.9.9 and 2.9.10 show the operating conditions during CMSL-9 in terms of coal space velocities, reactor temperatures, and feed pot (slurry mix tank) temperatures respectively. As shown in these Figures, the pretreater and reactor temperatures are close to their desired values and space velocities were held at 641 
$\mathrm{Kg} / \mathrm{hr} / \mathrm{m}^{3}$ reactor throughout the run. It can also be seen in Figure 2.9.10 that due to the increased viscosity of feed with the addition of plastic, the slurry mix tank temperature had to be progressively increased to maintain the pumpability.

\subsection{Recycle Solvent Balance}

One of the primary objectives of CMSL-9 was to investigate dispersed catalyst, catalyzed, direct coal liquefaction and coal/waste plastics coprocessing under steady-state or equilibrated process conditions. An important factor in such processing as recycle operations is the net recycle solvent/oil balance. This has to be positive to ensure that no external make-up oil is needed for the slurry preparation as the use of make-up oil would cloud the interpretation of the reaction data. It was feared that plastics, under typical coal liquefaction conditions, would result in substantial formations of light oils and a shortage of heavy recycle oil $\left(399^{\circ} \mathrm{C}^{+}\right.$material) would result. As shown in Figure 2.9 .11 , this was not quite the case. A net positive solvent balance was achieved throughout almost the entire run, CMSL-9.

\subsection{MATERIALS USED}

\subsection{Coal Feed And Waste Plastics}

A subbituminous Black Thunder Mine Coal (HTI-6213), the same coal that was used in the PDU 260-005 (POC-02 Run) operations, was used for CMSL-9 (227-87) bench run. The waste plastics stream was simulated by using pure resins such as HDPE, PS, and PP, in an extrudate form, co-mingled in the proportions representative of the MSW plastics. The analyses of coal and plastics are given in Table 2.9.12.

\subsection{Start-Up And Make-Up Oil}

Tank 4 material : L-814, a combination of hydrotreated petroleum-derived oil with small amounts of coal-derived liquid obtained during the operations of POC-02 PDU Run (Table 2.9.13).

\subsection{Catalyst}

Hydrotreater:

Pretreater (\& carried over to K-1 and K-2):
Criterion C-411 Trilobe (HTI-6135)

Molyvan-A, $\mathrm{FeOOH} / \mathrm{SO}_{4}$, and $3 \%$ $\mathrm{H}_{2} \mathrm{~S}$ relative to dry coal.

The dispersed acidic catalyst, $\mathrm{FeOOH} / \mathrm{SO}_{4}$, was synthesized by aqueous precipitation in the solution containing sulfate anions. The source of molybdenum, Molyvan-A, was obtained from R. T. Vanderbilt \& Co. 


\subsection{Recycled-Dispersed Catalyst}

The oil-free pressure filter cakes, extracted with toluene, were used as the source of the recycled dispersed catalyst. The extracted filter cakes were dried to remove any residual solvent (toluene) and analyzed for molybdenum content. Based on this analysis, the flow rate of the dried, extracted filter cakes to the feed slurry was determined. In the Condition 4 operation, in which no fresh Molyvan A was added, the recycled molybdenum was added using the composite solids product from the Condition 1 operation. The Condition 1 solids amounted to $10.1 \mathrm{~W} \%$ of the dry coal feed to Condition 4 operation, and contained about $0.27 \% \mathrm{Mo}$, so that the Mo content corresponded to $270 \mathrm{ppm}$ of coal feed during Condition 4. In addition, the atmospheric still bottoms (CAS) that were recycled during the Condition 4 operation contained $19.3 \%$ solids, which contained $0.134 \% \mathrm{Mo}$, so that an additional 310 ppm Mo (or coal) was contained in the CAS bottoms recycle. 
The laboratory scale support studies consisted of preparation and testing of different novel dispersed iron and molybdenum based catalysts for direct coal liquefaction and coal/plastics coprocessing. The hydrocracking activity tests for plastics were conducted using dispersed additives synthesized at HTI. The results of microautoclave tests are listed below.

The bench run CMSL-9 was designed to be an all dispersed catalyst-only run, investigating the activities of an iron-based and a molybdenum-based catalyst precursors. The activities of these catalyst precursors were first screened using HTI's $20 \mathrm{cc}$ shaken microautoclaves. Results obtained so far in the microautoclave testing of the dispersed catalysts (conducted under conditions similar to those in the first stage coal liquefaction reactor), especially Molyvan-A, for CMSL-9, are listed in the following Table. As shown by these tests, Molyvan-A results in the highest coal conversion at $600 \mathrm{ppm} \mathrm{Mo}$; another precursor of molybdenum, Molyvan-L, results in a slightly reduced conversion levels. Sulfated iron catalyst at $6000 \mathrm{ppm}$ of $\mathrm{Fe}$ is even slightly lower (this is expected due to higher intrinsic activity of molybdenum as compared to iron).

\begin{tabular}{|c|c|c|c|}
\hline \multicolumn{4}{|c|}{$\begin{array}{c}\text { ACTIVITY OF DISPERSED CATALYSTS FOR HYDROCRACKING OF MIXED } \\
\text { PLASTICS } \\
\text { Feed: } 3 \mathrm{~g} \text { HDPE }+2 \text { g PS, } 1 \mathrm{~W} \% \text { Catalyst Additive }\end{array}$} \\
\hline Catalyst Additive & Temperature, ${ }^{\circ} \mathrm{C}$ & Time, $\min$ & $\begin{array}{c}\text { Conversion (THF } \\
\text { Solubility), \% }\end{array}$ \\
\hline None & 454 & 30 & $82.6,82.4$ \\
\hline$\gamma-\mathrm{Al}_{2} \mathrm{O}_{3} / \mathrm{SO}_{4}$ & 454 & 30 & $92.2,93.1$ \\
\hline $\mathrm{FeOOH} / \mathrm{SO}_{4}$ & 454 & 30 & $94.1,94.8$ \\
\hline $\mathrm{SiO}_{2} / \mathrm{Al}_{2} \mathrm{O}_{3}$ & 454 & 30 & $83.8,84.6$ \\
\hline Y-Zeolite & 454 & 30 & $87.2,88.0$ \\
\hline
\end{tabular}

\begin{tabular}{|c|c|c||}
\hline \multicolumn{3}{|c||}{ LABORATORY SUPPORT FOR CMSL-9 } \\
$2.0 \mathrm{~g}$ Black Thunder Mine coal+6.0 g PFL, 0.2 g DMDS \\
\hline \hline Catalyst/Precursor & Concentration & Conversion (THF Solubility), \% \\
\hline None (DMDS alone) & 0.0 & $73.7,74.6$ \\
\hline Molyvan-A & $616 \mathrm{ppm} \mathrm{Mo}$ & $86.8,87.5$ \\
\hline Molyvan-L & $609 \mathrm{ppm} \mathrm{Mo}$ & $83.5,82.8$ \\
\hline FeOOH/SO & $6000 \mathrm{ppm} \mathrm{Fe}$ & $80.6,80.2$ \\
\hline
\end{tabular}




\subsection{CONCLUSIONS}

CMSL-9 was a very successful bench run both from the technical and operational standpoint. Over 41 days of continuous operation was completed without any major issues/interruptions. The main technical objectives of the run were achieved over this span of $41+$ continuous days of operations. The effects of type and amounts of molybdenum based dispersed catalysts were studied. Two plastics/coal ratios, effects of HDPE alone, and high space velocity were studied during this bench run. Samples of different process streams were obtained for the property characterization/assessment. The following conclusions can be drawn based on the results obtained during CMSL-9:

- The CTSL-type reactor configuration with an all-dispersed catalyst system, results in satisfactory overall process performance, even at high feed space velocities (coal conversions over $95 \%$, resid conversions over $90 \%$, and distillate yields of over $66 \%$ ) with a subbituminous coal feed.

- The process performance degraded only slightly with decrease in the freshly added Mo; the overall process performance and activities were better for the freshly added molybdenum precursor than the recycled molybdenum catalyst. HTI's sulfated iron catalyst improved the overall performance when used at $1 \mathrm{~W} \%$ loading relative to the feed.

- Both 33\% and 50\% mixed plastics, with coal, resulted in significant improvements in the distillate liquids (by as much as $10-12 \% \mathrm{MAF}$ ) over the 'coal-only' Conditions. Of the order, $90 \%$ of the mixed plastics were converted to distillate.

- $\quad \mathrm{HDPE}$ alone, with coal, was found much harder to convert to $524^{\circ} \mathrm{C}^{-}$material than when it is present with the other plastics in the co-mingled form.

- In-line hydrotreating was very effective for producing premium distillate with less than $50 \mathrm{ppm}$ each sulfur and nitrogen.

- Compared to Exxon's dispersed Fe/Mo catalyst operations, the HTI Fe/Mo dispersed catalyst results gave $2.5 \mathrm{~W} \%$ higher distillate yield, and similarly high residuum conversion. The $\mathrm{HTI} \mathrm{FeOOH} / \mathrm{SO}_{4}$ dispersed catalyst appeared to be more active than Exxon's Bailey and Bayferrox iron additives.

Based upon the interesting results obtained during the last three Conditions of CMSL-9, on coal/plastics coprocessing, more studies are certainly warranted for the optimization of dispersed catalysts employed for the process, convertibility of HDPE to light liquids, and impact of such coprocessing on the product quality and end-use applications. It will be very interesting to follow findings from this bench run with another bench operation with the 'real life' MSW plastics. Also, the efficacy of the dispersed catalyst reactor configuration should be investigated for low quality petroleum resids/waste plastics/coal coprocessing operations. 
Table 2.9.1

\section{CMSL-9 Run Plan}

Condition

Periods

Feeds, W\%

Coal

HDPE

Polypropylene

Polystyrene

Temp. deg C

Pretreater

K-1

K-2

HTU

Space Velocity

(Kg feed/hr/m3)

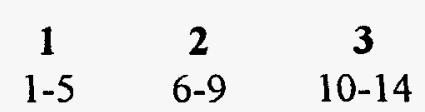

$\stackrel{4}{15-19}$

5
$20-24$

$6^{*}$
$25-29$

7
$30-34$

8 35-38

9 $39-41$

$\begin{array}{lll}100 & 100 & 100 \\ 0 & 0 & 0 \\ 0 & 0 & 0 \\ 0 & 0 & 0\end{array}$

100
0
0
0

100
0
0
0

100
0
0
0

67
13
11
0

$\begin{array}{ll}67 & 50 \\ 33 & 20 \\ 0 & 16.5 \\ 0 & 13.5\end{array}$

$\begin{array}{lll}300 & 300 & 300 \\ 443 & 443 & 443 \\ 449 & 449 & 449 \\ 379 & 379 & 379\end{array}$

$\begin{array}{ll}300 & 300 \\ 443 & 443 \\ 449 & 449 \\ 379 & 379\end{array}$

300
440
449
379

$300 \quad 300$

$449 \quad 449$

$460 \quad 460$

$379 \quad 379$

300

460

379

$\begin{array}{lllllllll}640 & 640 & 640 & 640 & 640 & 640 & 640 & 640 & 640\end{array}$

Slurry Cat. Conc. parts per million ڤ Mo: Molyvan-A

- Fresh

- Recycled

$\begin{array}{ll}300 & 200 \\ 0 & 0\end{array}$

150

150

0

$$
150
$$

150

100
100

300

300

$\begin{array}{lllll}0 & 0 & 0 & 0 & 0\end{array}$

10000

10000

300
0

300

$\mathrm{FeOOH} / \mathrm{SO} 4$

Solid Separation **

PF PF VS

VS

VS

VS

VS

10000

10000

* Tie-Point Condition for Comparison with Exxon's latest Dispersed Catalyst Run.

** PF - Pressure Filter; VS - Vacuum Still 
Table 2.9.2

CMSL-9: PROCESS PERFORMANCE SUMMARY

Unit

Run

Condition

Period Number

Hours of Run (end of Period)

W\% Plastics in Feed

Rec. Mo
Fresh Iron

Stage 1 Feed Space Velocity

$\mathrm{kg}$ coal $/ \mathrm{hr} / \mathrm{m} 3$ reactor vol

Temperatures, $\mathrm{C}$

$$
\begin{aligned}
& \text { Pretreater } \\
& \text { K-1 } \\
& \text { K-2 }
\end{aligned}
$$

Total Material Recovery \% (Gross)

\section{ESTIMATED NORMALIZED YIELDS:}

C1-C3 in Gases
C4-C7 in Gases
IBP-177 deg C
$177-260$ deg C
$260-343$ deg C
$343-454$ deg C
$454-524$ deg C
524 deg C+
Unconverted Feed
Water
Cox
NH3
H2S
Ash

Hydrogen Consumption

PROCESS PERFORMANCE

Feed Conversion, W\% maf Feed

$524 \mathrm{C}+$ Conversion, W\% maf Feed
Disp. Cat ppm: Fresh Mo W\% DRY FEED

C4-524 C Distillates, W\% maf Feed
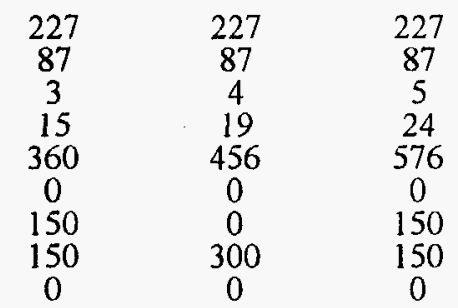

227
87
6
29
696
0
100
100
10000

227
87
7
34
816
33
300
300
10000

$\begin{array}{cc}227 & 227 \\ 87 & 87 \\ 8 & 9 \\ 38 & 41 \\ 912 & 984 \\ 33 & 50 \\ 300 & 300 \\ 0 & 0 \\ 10000 & 10000\end{array}$

$\begin{array}{lll}680 & 666 & 659 \\ & & \\ 304 & 302 & 302 \\ 444 & 444 & 445 \\ 449 & 450 & 450\end{array}$

664

678

666

669

709

669

303

443

443
449

302

444
449

305

440

449

99.6

100.9

103.8

318

448
459

99.2

316

448

$\begin{array}{r}.461 \\ \hline\end{array}$

99.1

315

449

462

102.1

* Data from Period 8 are reported since the run plan was modified starting the use of the Vacuum Still for solids separation in Period 9. 
Table 2.9.3

CMSL-9: Separator Overhead (SOH) Inspection

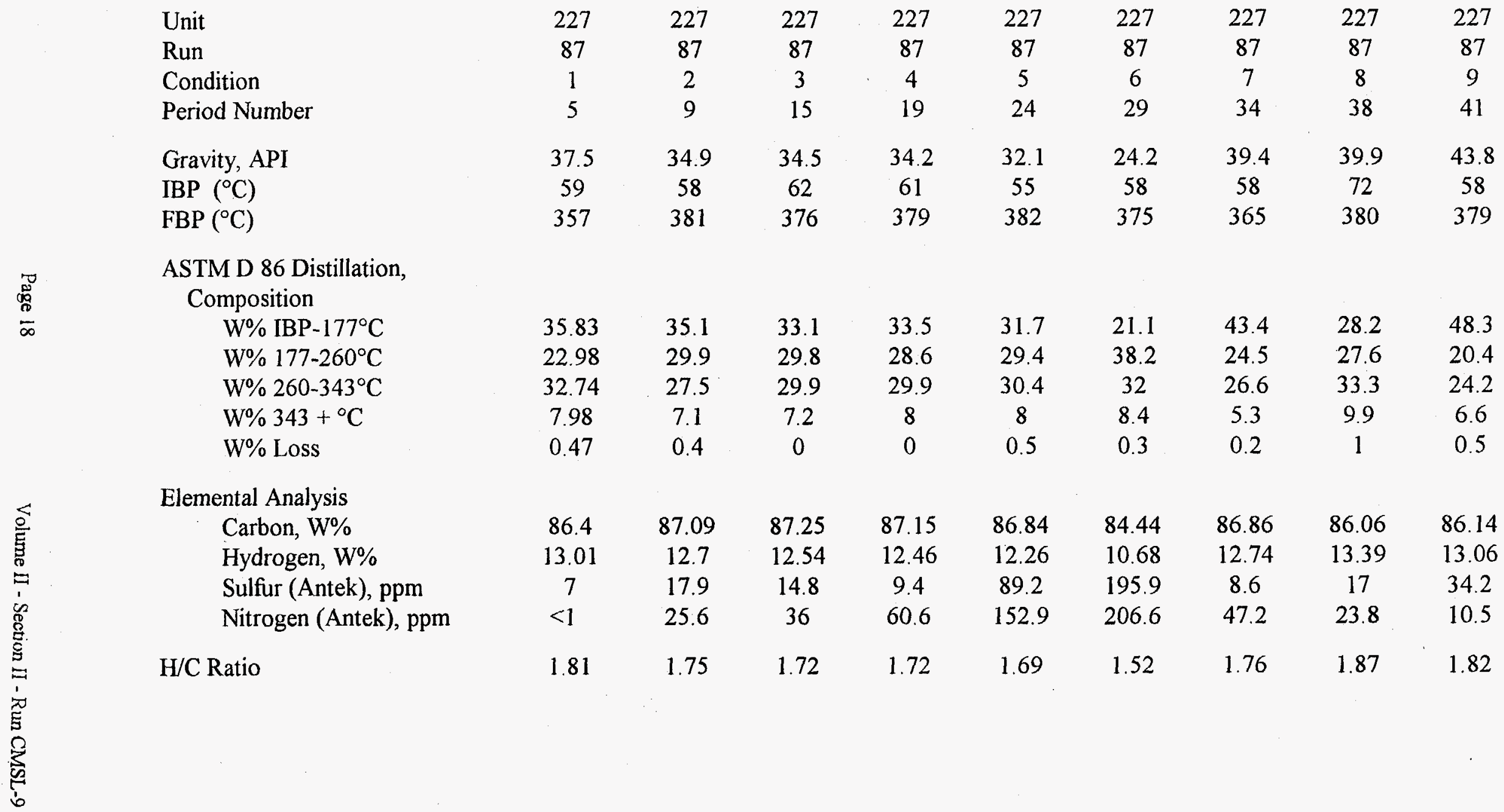


Table 2.9.4

\section{CMSL-9: Atmospheric Overhead (SOH)Inspection}

\begin{tabular}{|c|c|c|c|c|c|c|c|c|}
\hline Unit & 227 & 227 & 227 & 227 & 227 & 227 & 227 & 227 \\
\hline Run & 87 & 87 & 87 & 87 & 87 & 87 & 87 & 87 \\
\hline Condition & 1 & 2 & 3 & 4 & 5. & 6 & 7 & 8 \\
\hline Period \# & 5 & 9 & 15 & 19 & 24 & 29 & 34 & 38 \\
\hline Gravity, API & 12.9 & 10.6 & 14.2 & 14 & 13.6 & 3.3 & 27 & 24.4 \\
\hline IBP $(\operatorname{deg} C)$ & 78 & 168 & 89 & 78 & 77 & 76 & 71 & 81 \\
\hline FBP $(\operatorname{deg} C)$ & 394 & 396 & 392 & 389 & 391 & 390 & 392 & 398 \\
\hline \multicolumn{9}{|c|}{ ASTM D-86 Distillation, Composition } \\
\hline W\% IBP-177 deg C & 7.86 & 0.0 & 6.2 & 5.3 & 5.6 & 4.1 & 30.3 & 16.6 \\
\hline W\% $177-260 \operatorname{deg} C$ & 22.35 & 14.1 & 25.8 & 23.3 & 22.4 & 16.1 & 25.1 & 32.5 \\
\hline W\% $260-343 \operatorname{deg} C$ & 35.0 & 51.1 & 43.7 & 44.9 & 44.6 & 29.05 & 29.7 & 25.4 \\
\hline W\% $343 \mathrm{C}+$ & 34.69 & 34.4 & 24.3 & 26 & 26.9 & 50.47 & 14.6 & 25.2 \\
\hline W\% Loss & 0.01 & 0.4 & 0.0 & 0.5 & 0.5 & 0.28 & 0.3 & 0.3 \\
\hline
\end{tabular}

Elemental Analysis

Carbon, W\%

Hydrogen, W\%

Sulfur (Antek), ppm

Nitrogen (Antek), ppm

$\mathrm{H} / \mathrm{C}$ Ratio

$\begin{array}{cccccccc}85.69 & 86.18 & 85.92 & 85.88 & 86.05 & 79.92 & 85.82 & 84.54 \\ 9.63 & 9.19 & 9.6 & 9.53 & 9.53 & 7.77 & 10.51 & 10.79 \\ 375.7 & 338.6 & 298.1 & 281 & 362 & 290 & 205 & 352 \\ 263.6 & 150.2 & 172 & 303.1 & 331.1 & 372 & 692.6 & 741 \\ 1.35 & 1.28 & 1.34 & 1.33 & 1.33 & 1.17 & 1.47 & 1.53\end{array}$

27

38

4.4

98

6.6

25.4

0.3 
TABLE 2.9.5

\section{CMSL-9: PROPERTIES OF THE PRESSURE FILTER LIQUID (2nd Stage)*}

$\begin{array}{lrrrrrrrrr}\text { Unit } & 227 & 227 & 227 & 227 & 227 & 227 & 227 & 227 & 2287 \\ \text { Run } & 87 & 87 & 87 & 87 & 87 & 87 & 87 & 87 & 87 \\ \text { Condition } & 1 & 2 & 3 & 4 & 5 & 6 & 7 & 8 & 9 \\ \text { Number } & 5 & 9^{*} & 15^{*} & 19^{*} & 24^{*} & 29^{*} & 34^{*} & 38 & 41 \\ & & & & & & & & & 41 \\ \text { Gravity, API } & -2.5 & 3.7 & 3.9 & 2.3 & 3.8 & 5.8 & 11.1 & 9.9 & 11.5 \\ \text { IBP }\left({ }^{\circ} \mathrm{C}\right) & 208 & 216 & 219 & 258 & 218 & 209 & 193 & 239 & 235\end{array}$

ASTM D1 160 Distillation, Composition

\begin{tabular}{|c|c|c|c|c|c|c|c|c|c|}
\hline W\% IBP $-343^{\circ} \mathrm{C}$ & 17.46 & 30.09 & 34.74 & 20.38 & 28.49 & 33.95 & 32.36 & 10.99 & 11.92 \\
\hline$W \% 343-454^{\circ} \mathrm{C}$ & 43.76 & 67.24 & 62.11 & 77.64 & 68.64 & 62.46 & 66.03 & 37.66 & 37.88 \\
\hline $\mathrm{W} \%{ }^{454-524^{\circ} \mathrm{C}}$ & 12.03 & 0 & 2.58 & 1.89 & 2.49 & 3.1 & 1.21 & 11.29 & 16.67 \\
\hline$W \% 524+{ }^{\circ} \mathrm{C}$ & 26.44 & 2.39 & 0 & 0 & 0 & 0 & 0 & 39.66 & 33.33 \\
\hline W\% Loss & 0.63 & 0.28 & 0.57 & 0.09 & 0.38 & 0.49 & 0.4 & 0.4 & 0.2 \\
\hline
\end{tabular}

Elemental Analysis

$\begin{array}{lccccccccc}\text { Carbon, W\% } & 88.37 & 87.32 & 87.8 & 88.63 & 87.91 & 87.65 & 87.52 & 87.21 & 87.04 \\ \text { Hydrogen, W\% } & 7.34 & 8.13 & 8.35 & 8.27 & 8.47 & 8.65 & 9.25 & 11.67 & 10.98 \\ \text { Sulfur, W\% } & 0.842 & 0.551 & 0.22 & 0.365 & 0.263 & 0.28 & 0.394 & 0.332 & 0.194 \\ \text { Nitrogen, W\% } & 0.79 & 0.71 & 0.82 & 0.81 & 0.87 & 0.78 & 0.7 & 0.43 & 0.48 \\ \text { C Ratio } & & & & & & & & & \\ & 1.00 & 1.12 & 1.14 & 1.12 & 1.16 & 1.18 & 1.27 & 1.61 & 1.51 \\ \text { CR, W\% PFL } & & & & & & & & 21.2 & 15.4 \\ \text { clohexane Insolubles, W\% } & & 59.55 & & & & & & 54.77 & 42.1 \\ \text { luene Insolubles, W\% } & & 76.75 & & & & & & 35.28 & 46.01\end{array}$

* For Periods 9-34, since vacuum still was used in place of pressure filtration for solids separation, the analysis of VSOH is listed. 


\section{TABLE 2.9.6}

\section{CMSL-9: INSPECTION OF THE PRESSURE FILTER SOLID (2nd Stage)*}

$\begin{array}{lccccccccl}\text { Unit } & 227 & 227 & 227 & 227 & 227 & 227 & 227 & 227 & 227 \\ \text { Run } & 87 & 87 & 87 & 87 & 87 & 87 & 87 & 87 & 87 \\ \text { Condition } & 1 & 2 & 3 & 4 & 5 & 6 & 7 & 8 & 9 \\ \text { Period Number } & 5 & 9^{*} & 15^{*} & 19^{*} & 24^{*} & 29^{*} & 34^{*} & 38 & 41 \\ & & & & & & & & & \\ \text { Elemental Analysis } & & & & & & & & & \\ \text { Carbon, W\% } & 60.27 & 72.88 & 59.05 & 59.65 & 58.35 & 58.5 & 63.65 & 54.99 & 50.93 \\ \text { Hydrogen, W\% } & 3.96 & 4.31 & 3 & 3.34 & 3.13 & 3.14 & 4.97 & 3.32 & 3 \\ \text { Sulfur, W\% } & 1.53 & 0.784 & 1.07 & 1.04 & 1.08 & 2.21 & 1.54 & 3.5 & 1.53 \\ \text { Nitrogen, W\% } & 0.58 & 1.01 & 0.81 & 0.85 & 0.77 & 0.79 & 0.64 & 0.7 & 0.75 \\ & & & & & & & & & \\ \text { H/C Ratio } & 0.79 & 0.71 & 0.61 & 0.67 & 0.64 & 0.64 & 0.94 & 0.72 & 0.71 \\ & & & & & & & & & \\ \text { Composition, W\% } & & & & & & & & & \\ \quad \text { Ash (Quinoline Filtration) } & 31.18 & 16.53 & 30.58 & 28.33 & 30.05 & 32.58 & 26.17 & 26.75 & 42.64 \\ \text { ASTM Ash } & 29.48 & 16.99 & 31.06 & 30.11 & 30.87 & 33.44 & 26.97 & 37.88 & 43.56 \\ \text { Sulfur in Ash } & 3.4 & 3.8 & 2.32 & 2.85 & 3.06 & 5.65 & 4.34 & 7.89 & 3.4 \\ \text { QI including Ash } & 49.12 & 28.73 & 51.24 & 47.1 & 51.55 & 49.75 & 54.78 & 65.24 & 69.39 \\ \text { Metals Analysis, W\% of ASTM Ash } & & & & & & & & & \\ \quad \text { Molybdenum } & 0.443 & 0.508 & 0.365 & 0.224 & 0.334 & 0.256 & 0.56 & 0.654 & 1.55 \\ \text { Iron } & 3.99 & 3.486 & 3.32 & 3.35 & 3.29 & 7.47 & 6.13 & 8.1 & 13.39\end{array}$

* Periods 9-34, since vacuum still was used for solids separation, the analyes of VSB are listed. 
Table 2.9.7

\section{CMSL-9: PROPERTIES OF THE PRESSURE FILTER LIQUID (2nd Stage)*}

$\begin{array}{lccccccc}\text { Unit } & 227 & 227 & 227 & 227 & 227 & 227 & 227 \\ \text { Run } & 87 & 87 & 87 & 87 & 87 & 87 & 87 \\ \text { Condition } & 1 & 2 & 3 & 4 & 5 & 6 & 7 \\ \text { Period \# } & 5 & 9 & 15 & 19 & 24 & 29 & 34 \\ \text { Gravity, API } & -6.2 & -3.1 & -3 & -4.6 & -3.7 & -0.6 & 4 \\ \text { IBP (deg C) } & 223 & 217 & 228 & 237 & 223 & 225 & 252\end{array}$

ASTM D-1160 Distillation, Composition

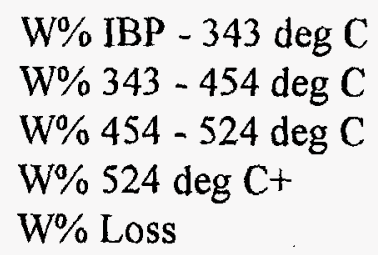

Elemental Analysis

Carbon, W\%

Hydrogen, $\mathrm{W} \%$

Sulfur, W\%

Nitrogen, W\%

\section{H/C Ratio}

CCR, W\% PFL

Cyclohexane Insolubles, W\%

Toluene Insolubles, W\%
1098

36.94

14.35

37.02

0.71

$\begin{array}{cc}15.61 & 14.17 \\ 42.47 & 37.33 \\ 13.98 & 13.99 \\ 27.22 & 33.79 \\ 0.72 & 0.72\end{array}$

12.47

39.55

12.83

34.71

0.44

88.3

7.05

0.82

0.79

0.96

59.85

$\begin{array}{cccccc}87.54 & 87.57 & 87.87 & 87.91 & 87.64 & 88.38 \\ 7.53 & 7.62 & 7.48 & 7.42 & 7.79 & 9.22 \\ 0.543 & 0.412 & 0.274 & 0.299 & 0.496 & 0.201 \\ 0.96 & 0.99 & 1.06 & 1.02 & 0.89 & 0.75 \\ 1.03 & 1.04 & 1.02 & 1.01 & 1.07 & 1.25 \\ 53.46 & 49.21 & 51.76 & 54.88 & 53.15 & 33.59 \\ 66.66 & 56.27 & 63.94 & 64.24 & 55.27 & 59.48 \\ 21.55 & 17.27 & 16.65 & 18.62 & 16.07 & 24.75\end{array}$


Table 2.9.8

\section{CMSL-9: INSPECTION OF THE PRESSURE FILTER SOLID (1st Stage)}

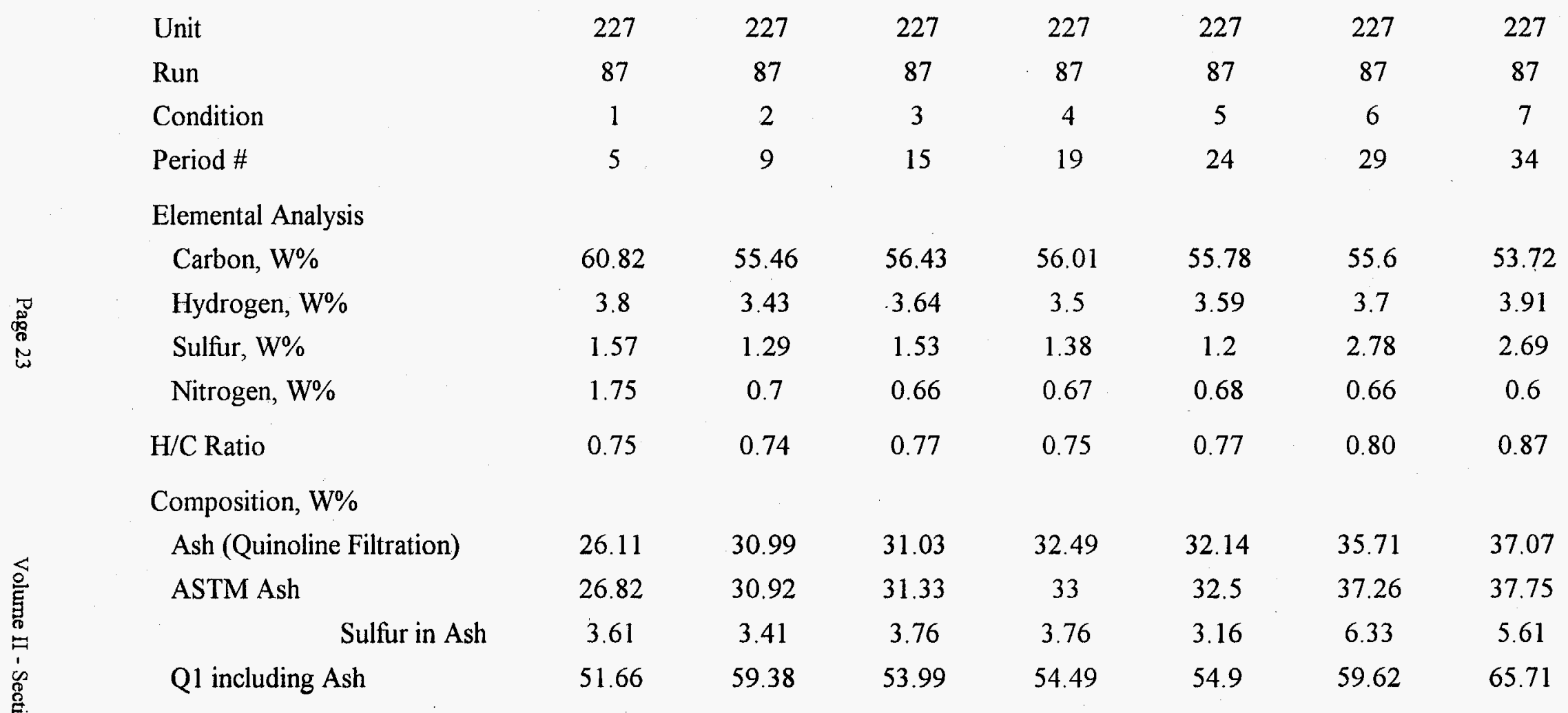


Table 2.9.9

\section{Hydrotreater Performance during CMSL-9}

[All numbers in parts per million]

\section{HTU Off-line}

$\begin{array}{cccc} & & \text { Period 23 } & \\ & \text { Nitrogen } & \text { Sulfur } \\ \text { ASOH } & 331.1 & 362 \\ \text { SOH } & 332.5 & 160.4\end{array}$

Period 8

$\begin{array}{ccc} & \text { Nitrogen } & \text { Sulfur } \\ \text { ASOH } & 172 & 298.1 \\ \text { SOH } & 230.1 & 265.3\end{array}$

HTU On-Line*

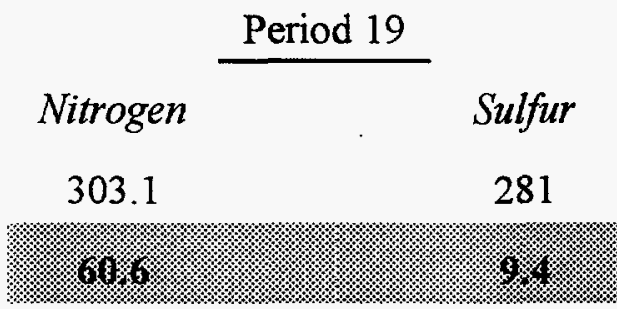

\begin{tabular}{|c|c|}
\hline \multirow{2}{*}{ Nitrogen } & Period 10 \\
\hline & \\
\hline 150.2 & \\
\hline $28: 6$. & \\
\hline
\end{tabular}

* The shaded numbers are for Hydrotreated Distillate Products. 
Table 2.9.10

Comparison Between CMSL-9 Condition 6 and Exxon's Data

\begin{tabular}{|l|l|l|l|}
\hline Run & HTI* & Exxon & Exxon \\
\hline Condition & 60 & 3 & 4 \\
\hline Residence Time, min & 40 & 41 & 41 \\
\hline Temperatures, deg C & & & \\
\hline Pretreater & 300 & 300 & 300 \\
Reactor K-1 & 440 & 441 & 439 \\
Reactor K-2 & 449 & 450 & 450 \\
Hydrotreater & 379 & N/A & N/A \\
\hline Dispersed Catalysts & & & \\
\hline Molybdenum & Molyvan-A & Molyvan-A & Molyvan-L \\
ppm & $100 \mathrm{ppm}$ & $100 \mathrm{ppm}$ & $100 \mathrm{ppm}$ \\
Iron & FeOOH/SO4 & Baily & Bayferrox \\
w\% & $1 \%$ & $1 \%$ & $1 \%$ \\
\hline Yields (MAF) & & & \\
\hline C1-C3 & 9.8 & 10.8 & 10.2 \\
C4-538C & 62.6 & 59 & 60 \\
C4-177 ${ }^{\circ} \mathrm{C}$ & 12.8 & 14.8 & 15 \\
177-343 ${ }^{\circ} \mathrm{C}$ & 32.4 & 29.6 & 31.3 \\
$343-538^{\circ} \mathrm{C}$ & 17.4 & 14.6 & 13.7 \\
\hline Coal Conversion, \%maf & 96.1 & $\mathrm{n} / \mathrm{a}$ & $\mathrm{n} / \mathrm{a}$ \\
$538^{\circ} \mathrm{C}+$ Resid Conv., \%maf & 87.6 & 86.9 & 85.6 \\
\hline Hydrogen Consumption, \%maf & 6.1 & 5.8 & 5.4 \\
\hline
\end{tabular}

* HTI's data represents the $\mathrm{C} 4-524^{\circ} \mathrm{C}$ distillate fraction and $524^{\circ} \mathrm{C}+$ Resid Conversion instead of $\mathrm{C} 4-538^{\circ} \mathrm{C}$ yield and $538^{\circ} \mathrm{C}+$ Resid conversions in Exxon's data. 
Table 2.9.11

\section{Samples sent to Consol, Inc.}

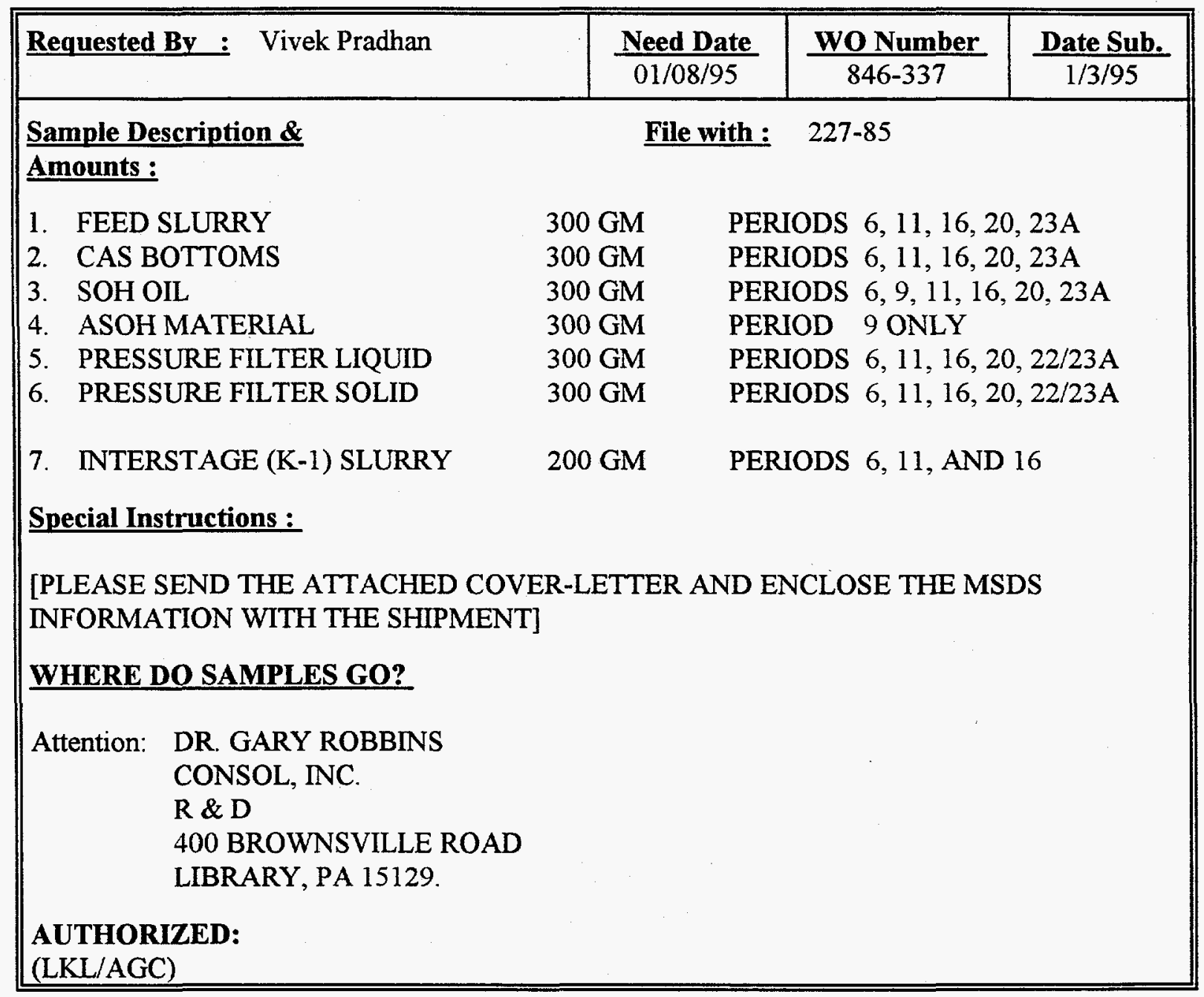


Table 2.9.12

Analysis of coal and plastic feedstocks for CMSL-9.

\begin{tabular}{|c|c|c|c|c|}
\hline Material & BTM Coal & HDPE & Polystyrene & Polypropylene \\
\hline Moisture Content & 10.1 & & & \\
\hline \multicolumn{5}{|l|}{ Elemental, W\% dry } \\
\hline Carbon & 70.12 & 85.71 & 92.31 & 85.71 \\
\hline Hydrogen & 5.11 & 14.29 & 7.69 & 14.29 \\
\hline Sulfur & 0.35 & 0 & 0 & 0 \\
\hline Nitrogen & 0.99 & 0 & 0 & 0 \\
\hline Oxygen (by diff.) & 17.24 & 0 & 0 & 0 \\
\hline Ash, \% dry & 6.19 & 0 & 0 & 0 \\
\hline H/C Atomic Ratio & 0.88 & 2 & 1 & 2 \\
\hline
\end{tabular}


Table 2.9.13

Analysis of Start-up / Make-up Oil for CMSL-9

HTI No.

L-814

API Gravity

0.4

Elemental Analysis, W\%

Carbon

88.96

Hydrogen

8.25

Sulfur

2.22

Nitrogen

0.19

ASTM D-1160 Distillation, deg C

$\begin{array}{ll}\text { IBP } & 309 \\ 5 \mathrm{~V} \% & 351 \\ 10 \mathrm{~V} \% & 374 \\ 20 \mathrm{~V} \% & 394 \\ 30 \mathrm{~V} \% & 409 \\ 40 \mathrm{~V} \% & 426 \\ 50 \mathrm{~V} \% & 437 \\ 60 \mathrm{~V} \% & 449 \\ 70 \mathrm{~V} \% & 467 \\ 80 \mathrm{~V} \% & 507 \\ 84 \mathrm{~V} \% & 524\end{array}$

WEIGHT PERCENTS

IBP-343 DEG C

5.00

343-454 DEG C

53.99

454-524 DEG C

22.18

$524+$ DEG C

18.36

LOSS

0.47

Aromatic Carbon, \%

80.03

Cyclic Hydrogen, \%

44.36 
Table 2.9.14

Calculation of Products Derived from Plastic Addition

Run CMSL-9

\begin{tabular}{|c|c|c|c|c|}
\hline Condition & 6 & 7 & 8 & 9 \\
\hline Period & 29 & 34 & 38 & 41 \\
\hline Plastic, W & 0 & 33 & 33 & 50 \\
\hline \multicolumn{5}{|c|}{ Yields, W\% Dry Feed } \\
\hline $\mathrm{C} 1-\mathrm{C} 3$ & 9.23 & 8.18 & 7.45 & 7.31 \\
\hline$C 4-177 C$ & 12.03 & 25.94 & 13.17 & 29.08 \\
\hline $177-343 \mathrm{C}$ & 30.56 & 31.18 & 22.5 & 25.42 \\
\hline $343-524 C$ & 16.45 & 15.33 & 22.91 & 17.57 \\
\hline $524+\mathrm{C}$ & 7.35 & 2.16 & 16.14 & 8.61 \\
\hline Unconverted & 4.34 & 5.41 & 4.31 & 2.92 \\
\hline Water & 14.96 & 10.26 & 10.5 & 7.15 \\
\hline $\mathrm{COx}$ & 4.38 & 1.67 & 2.82 & 2.07 \\
\hline NH3 & 0.86 & 0.56 & 0.51 & 0.38 \\
\hline $\mathrm{H} 2 \mathrm{~S}$ & -0.15 & -0.05 & -0.1 & -0.04 \\
\hline Ash & 5.75 & 3.85 & 3.85 & 2.88 \\
\hline Total & 105.76 & 104.49 & 104.06 & 103.35 \\
\hline $\mathrm{H} 2$ Consumption & 5.75 & 4.56 & 4.14 & 3.43 \\
\hline \multicolumn{5}{|l|}{$\begin{array}{l}\text { Incremental } \\
\text { Yld, \% of Plastic }\end{array}$} \\
\hline $\mathrm{C} 1-\mathrm{C} 3$ & & 6.05 & 3.84 & 5.39 \\
\hline$C 4-177 \mathrm{C}$ & & 54.18 & 15.48 & 46.13 \\
\hline $177-343 C$ & & 32.44 & 6.14 & 20.28 \\
\hline $343-524 C$ & & 13.06 & 36.03 & 18.69 \\
\hline $524+C$ & & -8.38 & 33.99 & 9.87 \\
\hline Unconverted & & 7.58 & 4.25 & 1.50 \\
\hline Water & & 0.72 & 1.44 & -0.66 \\
\hline $\mathrm{COx}$ & & -3.83 & -0.35 & -0.24 \\
\hline $\mathrm{NH} 3$ & & -0.05 & -0.20 & -0.10 \\
\hline $\mathrm{H} 2 \mathrm{~S}$ & & 0.15 & 0.00 & 0.07 \\
\hline Ash & & -0.01 & -0.01 & 0.01 \\
\hline Total & & 101.91 & 100.61 & 100.94 \\
\hline $\mathrm{H} 2$ Consumption & & 2.14 & 0.87 & 1.11 \\
\hline $\mathrm{C} 4-524 \mathrm{C}$ & & 99.68 & 57.65 & 85.10 \\
\hline
\end{tabular}




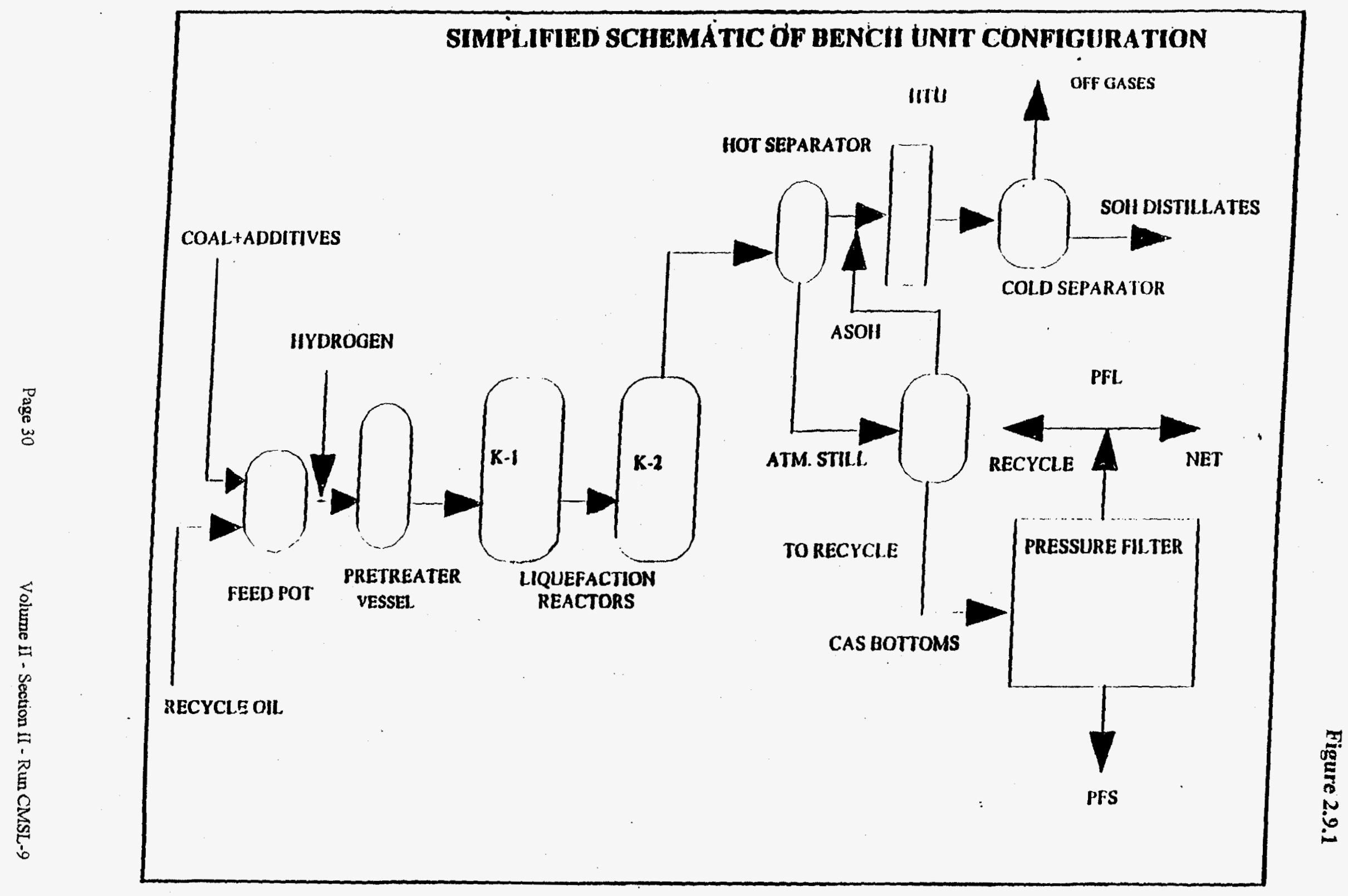




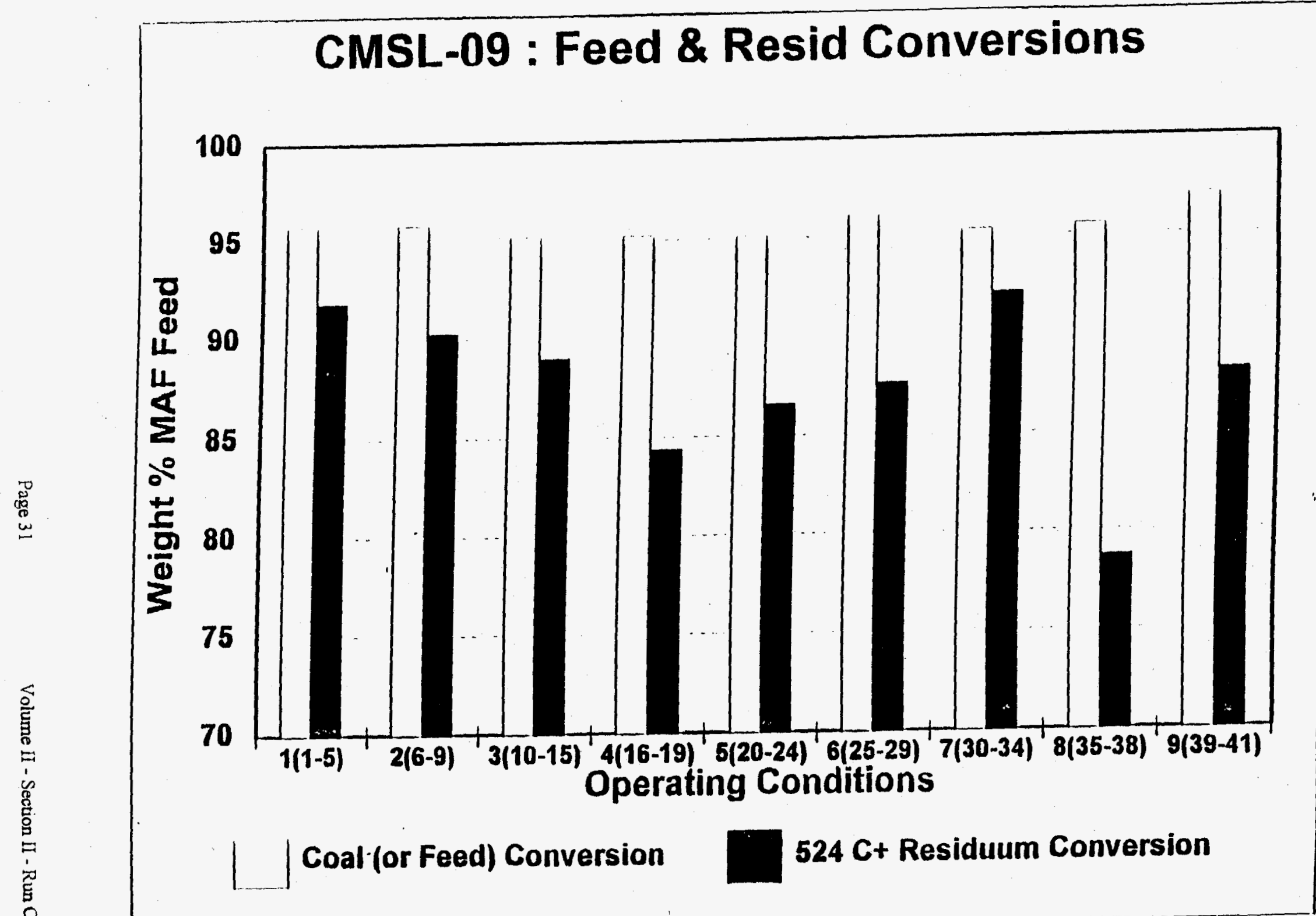




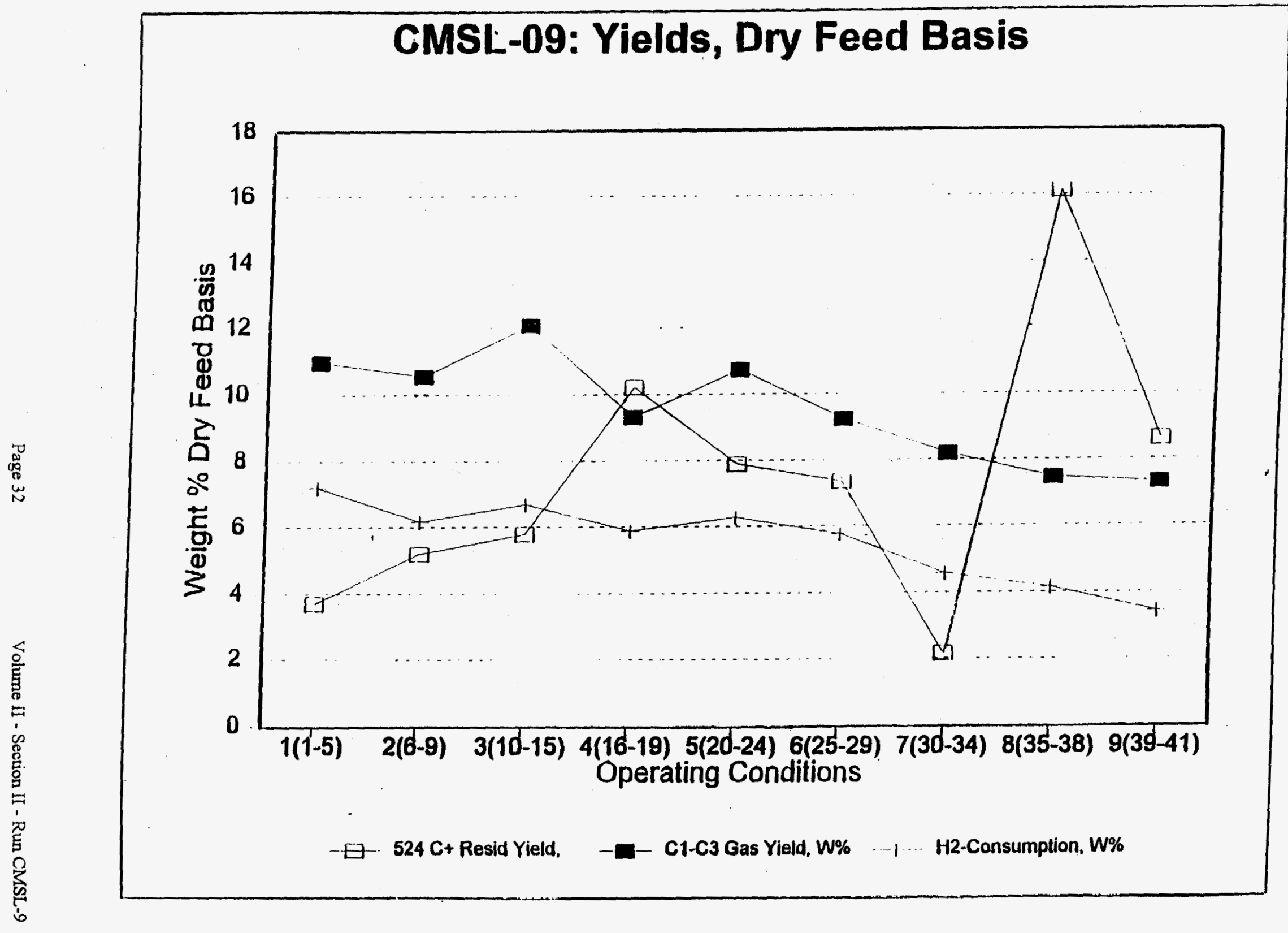




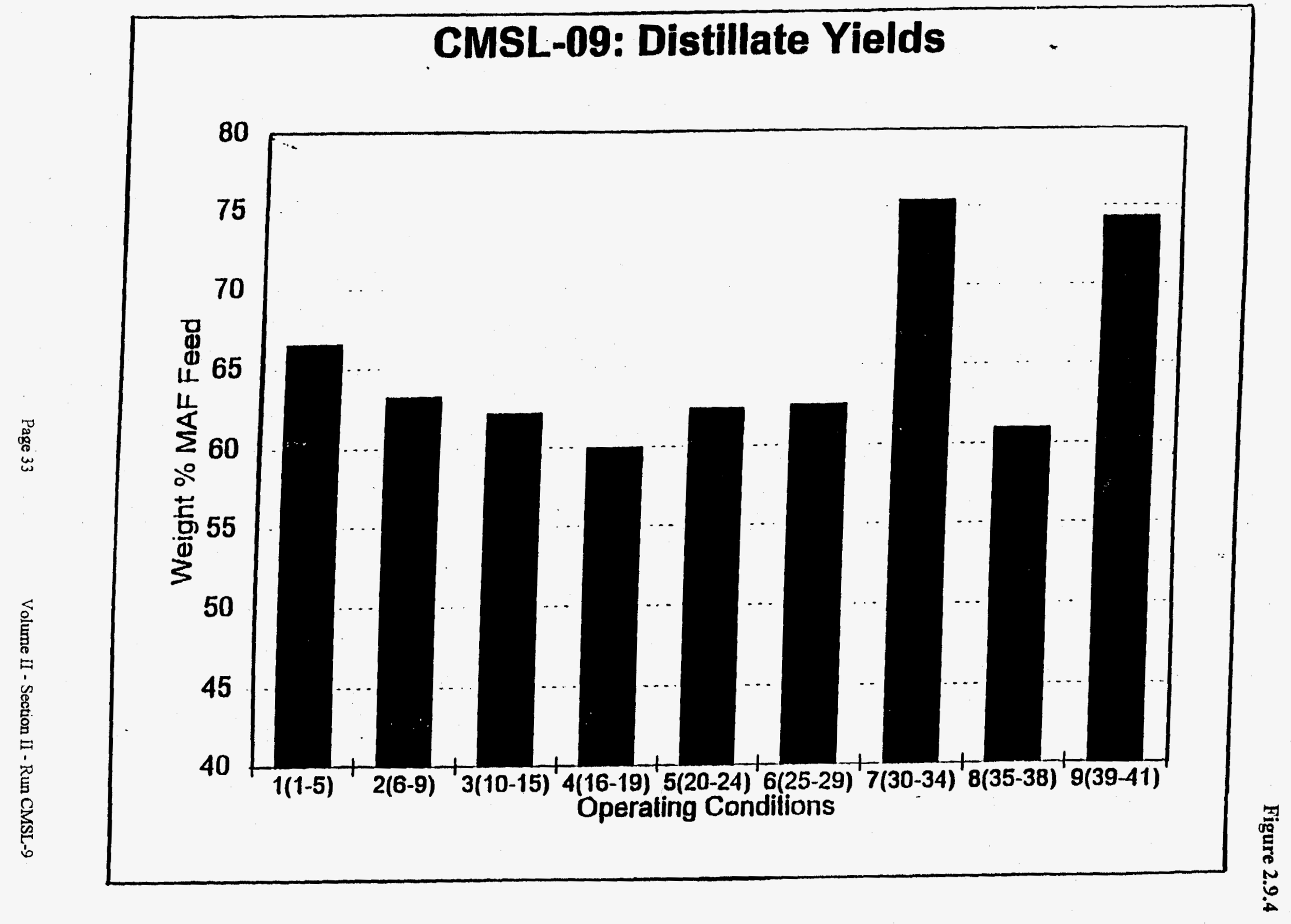




\section{CMSL-09 : Distillate Selectivity}

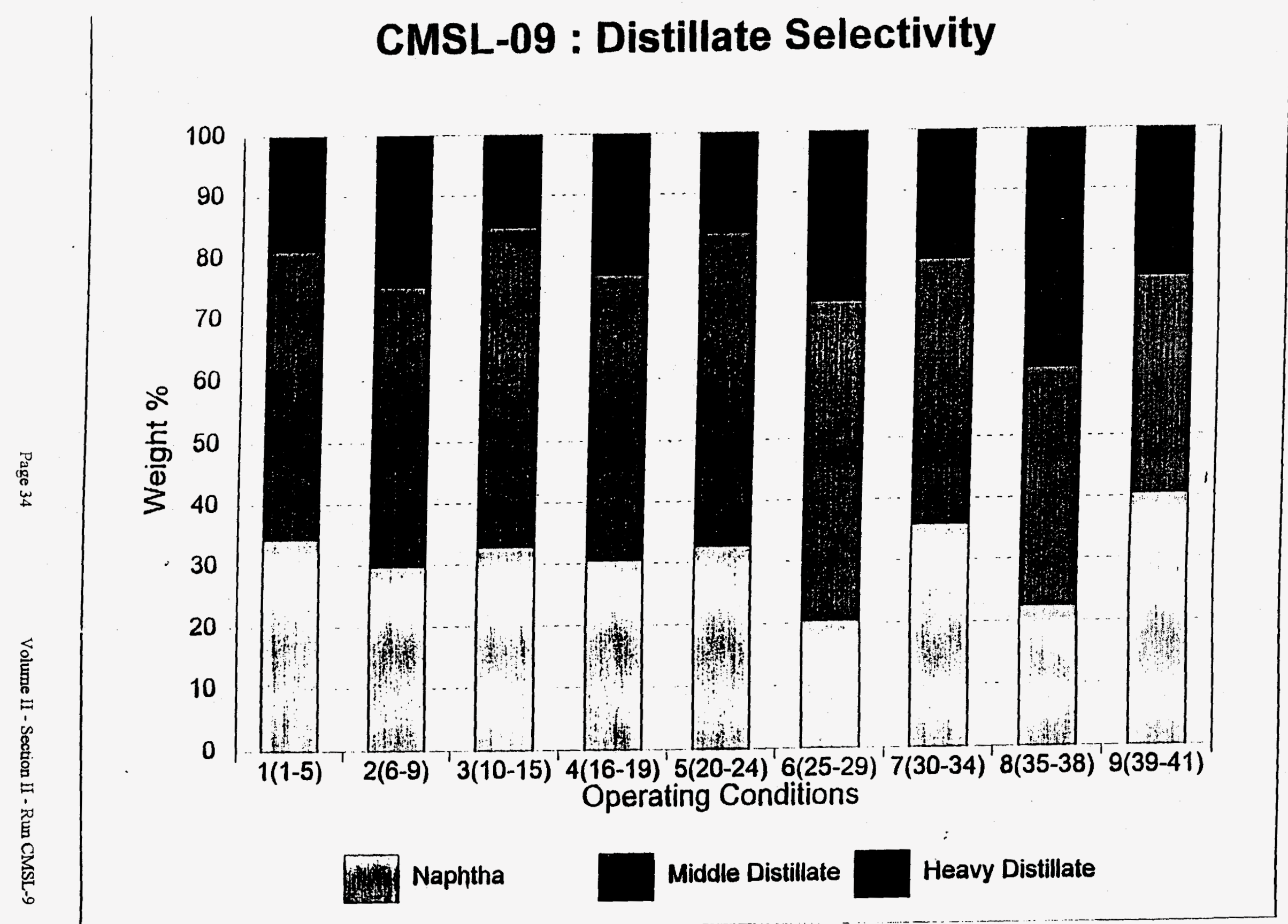


:

\section{CMSL-09: SOH Distillate Quality}

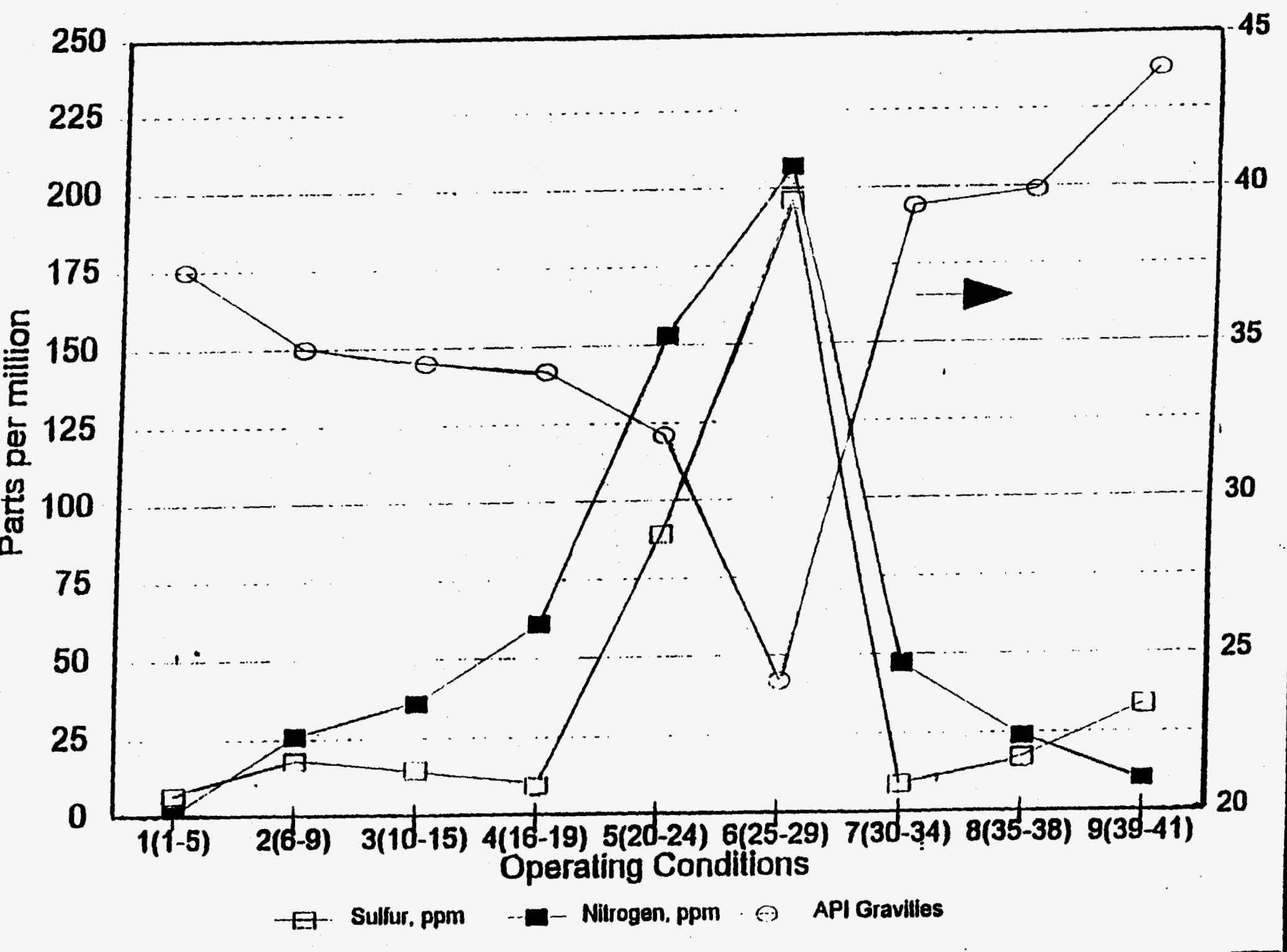


Figure 2.9.7

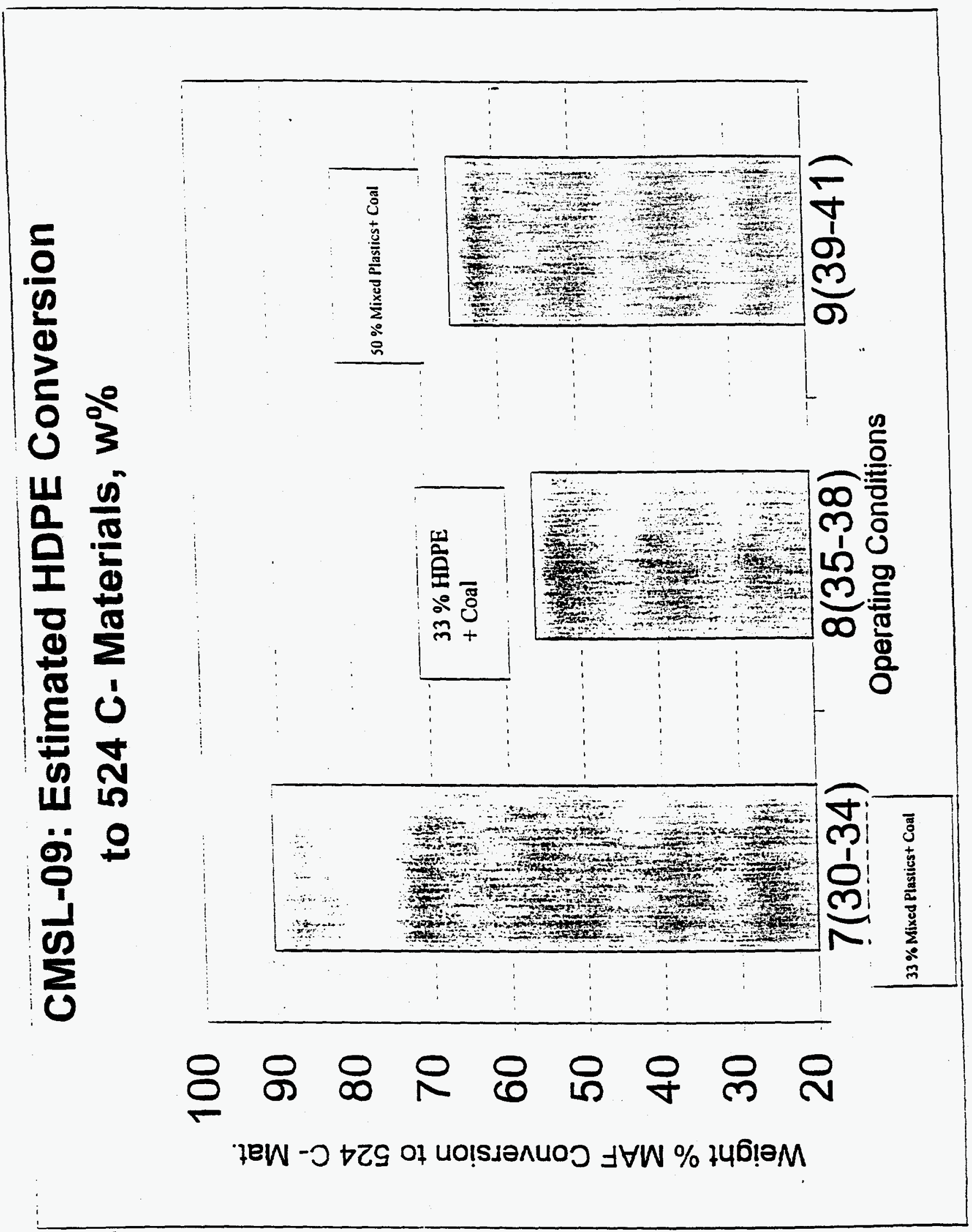


Figure 2.9.8

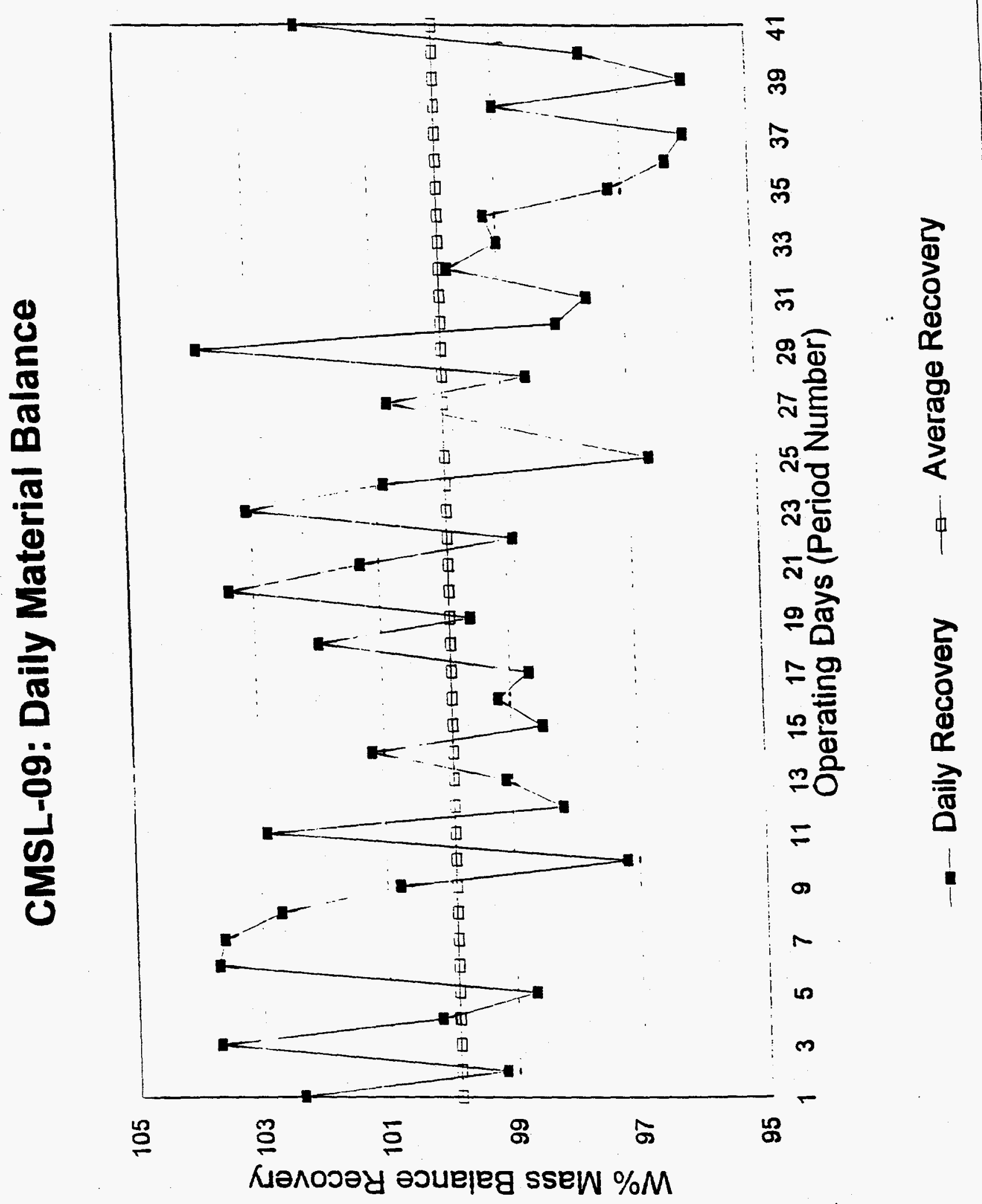




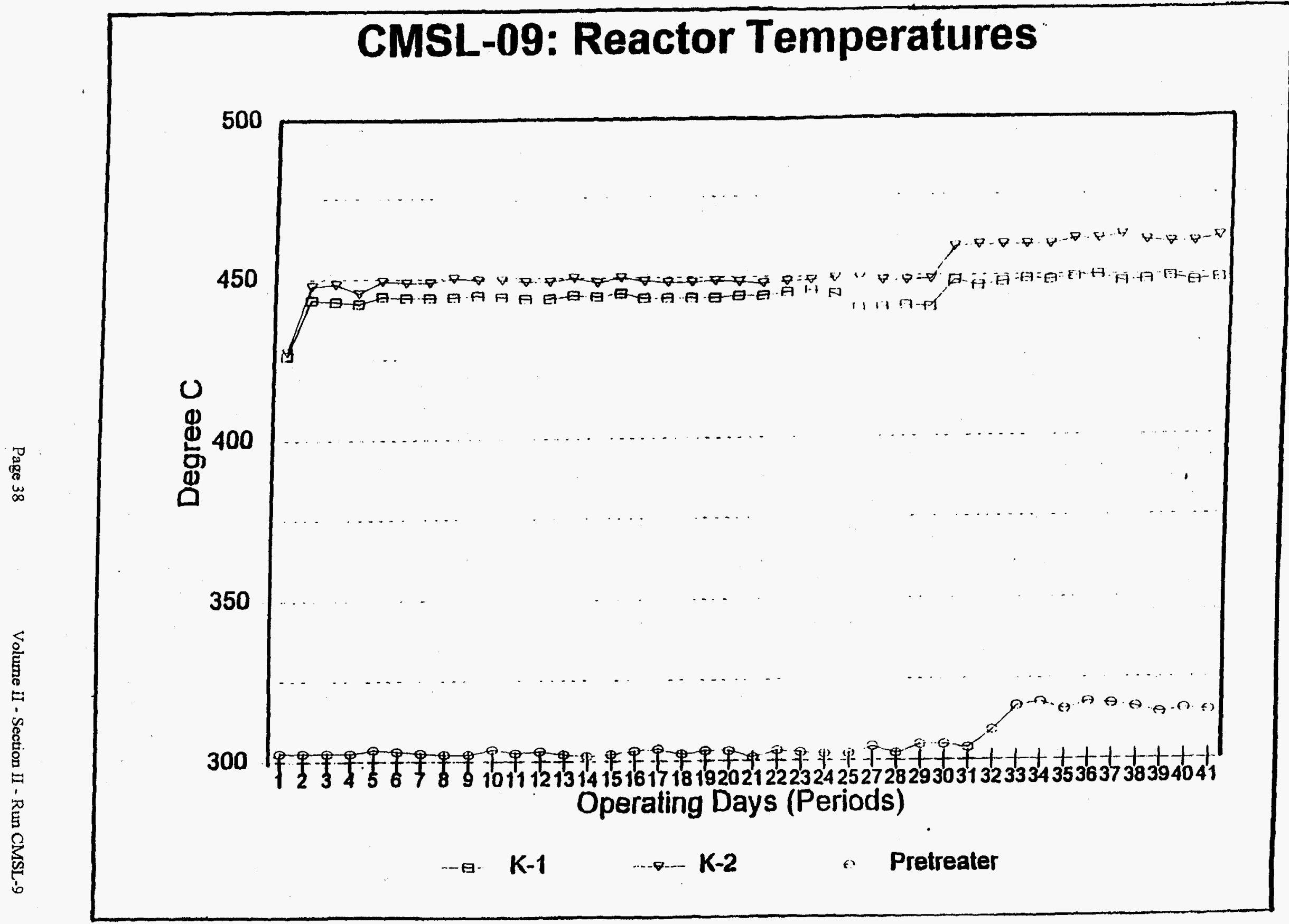




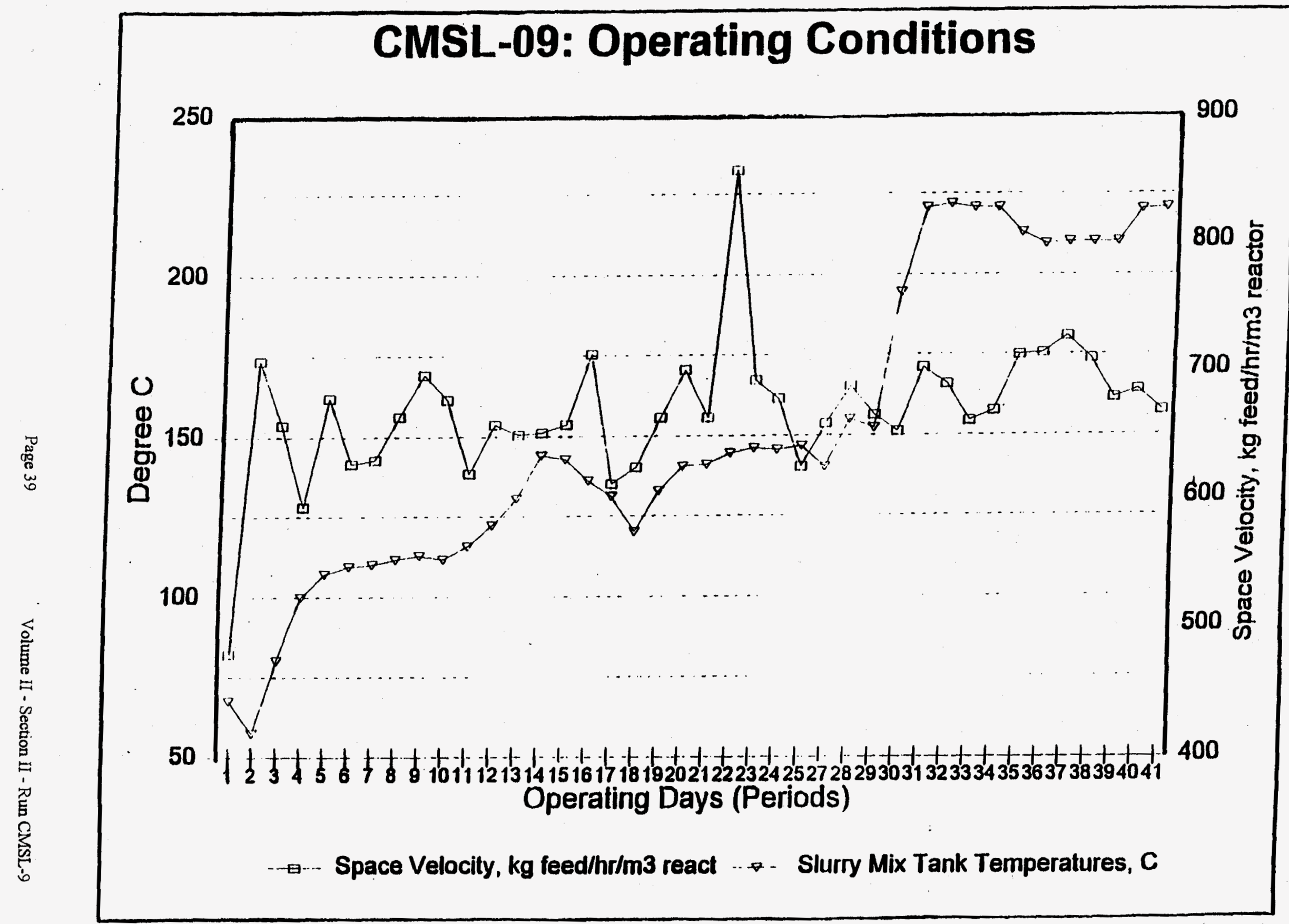




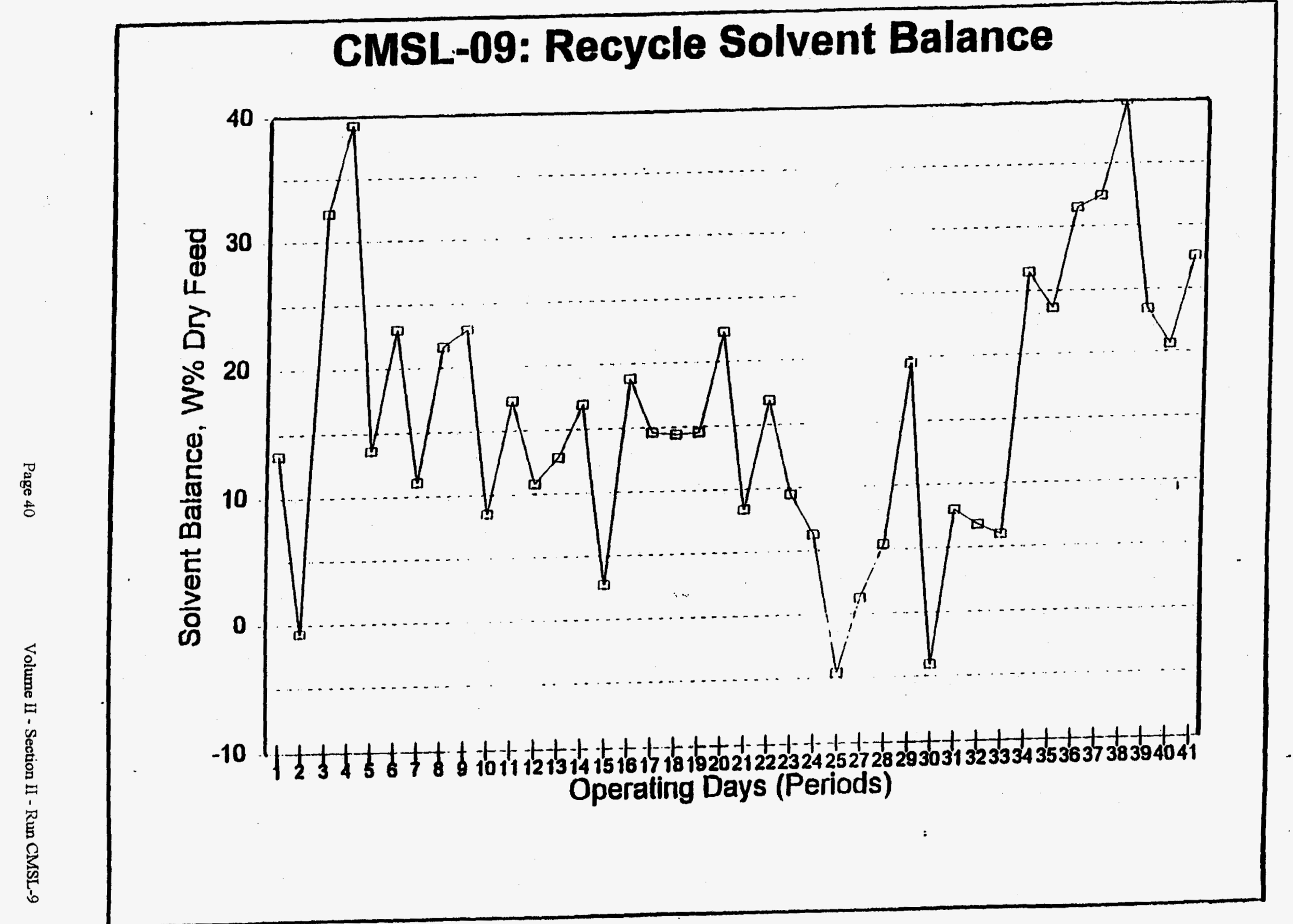




\section{CATALYTIC MULTI-STAGE LIQUEFACTION OF COAL (CMSL)}

FINAL REPORT

VOLUME II

SECTION II (CONTINUED)

EVALUATION OF A COMBINED IRON-MOLYBDENUM DISPERSED SLURRY CATALYST SYSTEM FOR LIQUEFACTION OF BLACK THUNDER MINE COAL

RUN CMSL - 10 
VOLUME II

SECTION II - RUN CMSL-10

TABLE OF CONTENTS

RUN CMSL-10 (227-88)

EVALUATION OF A COMBINED IRON-MOLYBDENUM

DISPERSED SLURRY CATALYST SYSTEM FOR LIQUEFACTION

OF BLACK THUNDER MINE COAL

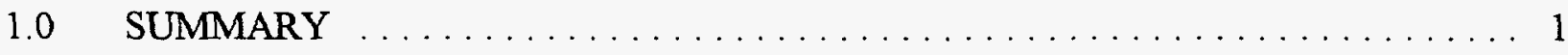

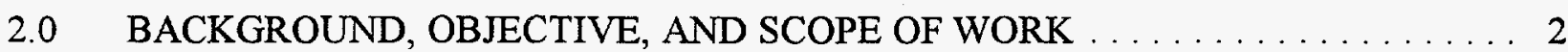

$3.0 \quad$ PROGRAM ANALYSIS AND RESULTS $\ldots \ldots \ldots \ldots \ldots \ldots \ldots \ldots$

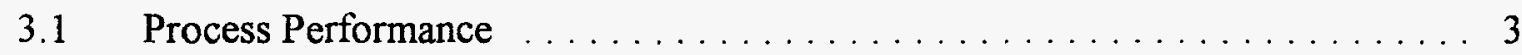

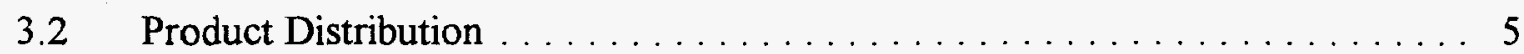

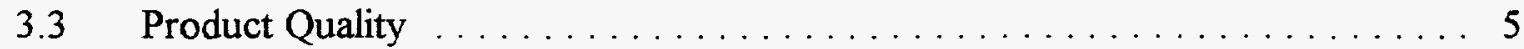

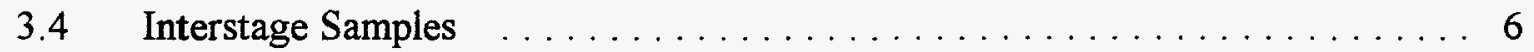

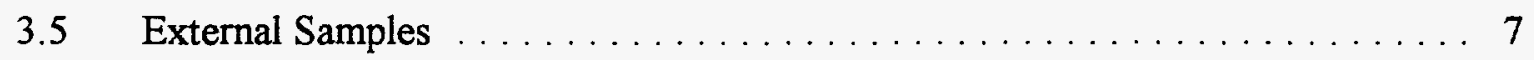

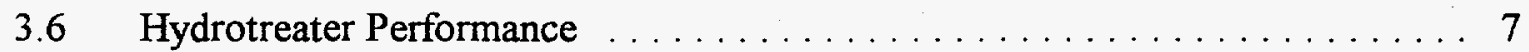

$4.0 \quad$ DETAILS OF OPERATION $\ldots \ldots \ldots \ldots \ldots \ldots \ldots \ldots \ldots \ldots \ldots \ldots$

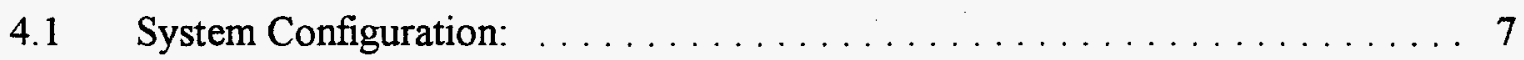

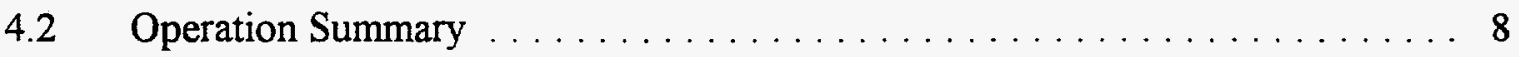

5.0 MATERIALS USED $\ldots \ldots \ldots \ldots \ldots \ldots \ldots \ldots \ldots \ldots \ldots \ldots$

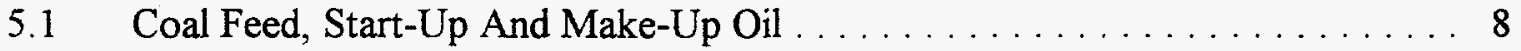

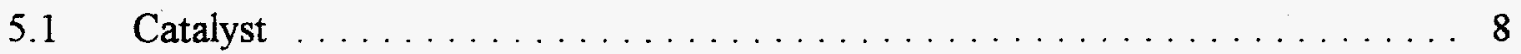

$6.0 \quad$ CONCLUSIONS $\ldots \ldots \ldots \ldots \ldots \ldots \ldots \ldots \ldots \ldots \ldots \ldots \ldots$

$7.0 \quad$ RECOMMENDATION FOR FUTURE WORK $\ldots \ldots \ldots \ldots \ldots \ldots \ldots \ldots$ 
VOLUME II

SECTION II - RUN CMSL-10

LIST OF TABLES

Table

Page

2.10.1 CMSL-10: Run Plan . . . . . . . . . . . . . . . . . . . 11

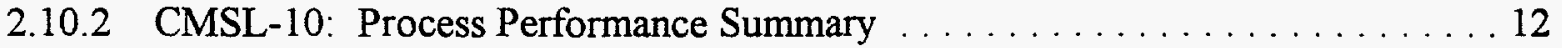

2.10.3 CMSL-10: Separator Overhead (SOH) Properties . . . . . . . . . . . . . . 13

2.10.4 CMSL-10: Analyses of Fractions of Filtered Liquid Product (PFL) . . . . . . 14

2.10.5 CMSL-10: Inspection Of The Pressure Filter Solids (2nd Stage) . . . . . . . 15

2.10.6 CMSL-10: Properties Of The First Stage Pressure Filter Liquid . . . . . . . . 16

2.10.7 CMSL-10: Inspection Of The First Stage Pressure Filter Solids . . . . . . . . . 17

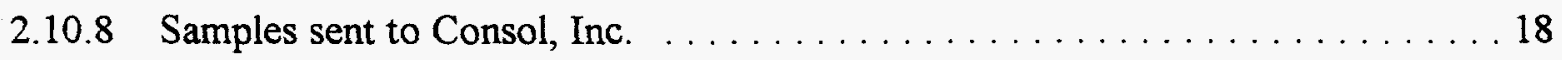

2.10 .9 Analysis Of Feed Coal . . . . . . . . . . . . . . . . . . . . . . . 19

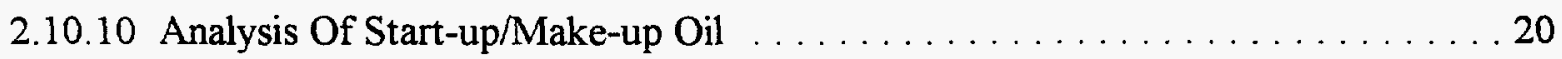




\section{VOLUME II \\ SECTION II - RUN CMSL-10 \\ LIST OF FIGURES}

Figure

Page

2.10.1 Simplified Schematic Of Bench Unit Configuration $\ldots \ldots \ldots \ldots \ldots \ldots \ldots 21$

2.10.2 CMSL-10: Dispersed Catalysis - Total Coal Conversion . . . . . . . . . . 22

2.10.3 CMSL-10: Dispersed Catalysis - Total $524^{\circ} \mathrm{C}+$ Resid Conversion $\ldots \ldots \ldots \ldots 23$

2.10.4 CMSL-10: Dispersed Catalysis - Chemical Hydrogen Consumption . . . . . . . 24

2.10.5 CMSL-10: Dispersed Catalysis - Light $\mathrm{C}_{1}-\mathrm{C}_{3}$ Gas Yield $\ldots \ldots \ldots \ldots \ldots \ldots$

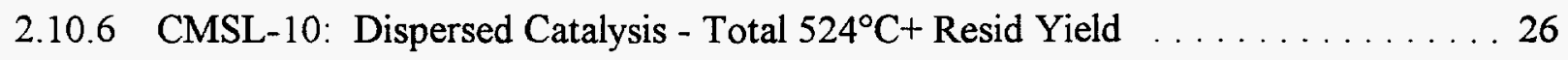

2.10.7 CMSL-10: Dispersed Catalysis $-\mathrm{C}_{4}-524^{\circ} \mathrm{C}$ Distillate Yields $\ldots \ldots \ldots \ldots \ldots 27$

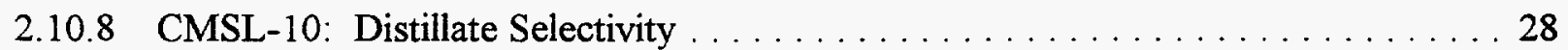

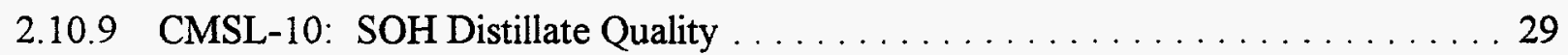

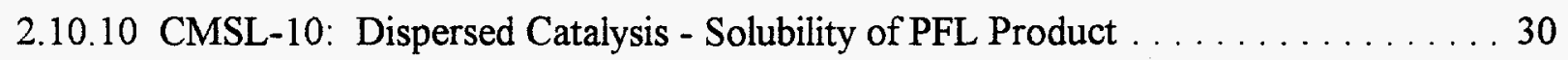

2.10.11 CMSL-10: Daily Material Balance $\ldots \ldots \ldots \ldots \ldots \ldots \ldots \ldots \ldots \ldots \ldots \ldots \ldots \ldots \ldots$

2.10.12 CMSL-10: Daily Operating Conditions $\ldots \ldots \ldots \ldots \ldots \ldots \ldots \ldots \ldots \ldots \ldots \ldots \ldots \ldots \ldots \ldots \ldots$

2.10.13 CMSL-10: Dispersed Catalysis - Catalyst Loading $\ldots \ldots \ldots \ldots \ldots \ldots \ldots \ldots$ 
RUN CMSL-10 (227-88)

\section{EVALUATION OF A COMBINED IRON-MOLYBDENUM DISPERSED SLURRY CATALYST SYSTEM FOR LIQUEFACTION OF BLACK THUNDER MINE COAL}

\subsection{SUMMARY}

The Bench Run CMSL-10 (HTI Run 227-88) was designed as a follow-up study after the operation of Bench Run CMSL-9. During CMSL-9, for the first time at HTI, an all dispersed (slurry) catalyst reactor system was used for coal liquefaction and coal/waste plastics coprocessing. Interestingly, the performance of a multi-stage coal liquefaction unit, under a suitable reaction severity and with an in-line hydrotreater, was found to supersede the earlier process performance derived using ebullated bed reactors with supported catalysts. This result was very significant, as dispersed slurry catalysts, based on iron and molybdenum, employed during CMSL-9, are not only more economical to use than the supported catalysts, but they also have a tremendous potential lower overall operational costs for coal liquefaction by virtue of elimination of the expensive ebullated bed reactors from the system. The effects of individual iron-based HTI proprietary catalyst and molybdenum, added as Molyvan-A, were not fully understood during CMSL-9. One of the main objectives of the present run, CMSL-10, was to further our understanding of the effects of iron and molybdenum employed alone and added together on the overall process performance. The mode of addition of the HTT's iron catalyst and overall process severity (reactor temperatures and space velocity) were among the other variables studied during CMSL-10. The coal feed for Run CMSL10 was Black Thunder Mine subbituminous coal.

The entire run was spread over 16 days of continuous operations. Because of a shut-down at the beginning of the run, brought about by a high pressure drop in the low-temperature $302^{\circ} \mathrm{C}\left(575^{\circ} \mathrm{F}\right)$ pretreater reactor, the actual run was spanned over Periods 3 to 18. Overall, four conditions were studied during this run: Condition 1 studied the effects of adding $0.5 \mathrm{~W} \%$ of HTI's iron catalyst in dry, powdered form on the process performance at a coal space velocity of $641 \mathrm{Kg} / \mathrm{hr} / \mathrm{m}^{3}$ (40 $\left.\mathrm{lbs} / \mathrm{hr} / \mathrm{ft}^{3}\right)$ and reactor temperatures of 441 and $449^{\circ} \mathrm{C}\left(825\right.$ and $\left.840^{\circ} \mathrm{F}\right)$. Condition 2 looked at the effect of adding $100 \mathrm{ppm}$ molybdenum, as Molyvan-A, together with iron, on the process performance. Unfortunately, because resid was building up in the recycle solvent, the coal space velocity had been reduced to $410 \mathrm{~kg} / \mathrm{hr} / \mathrm{m}^{3}\left(26 \mathrm{lbs} / \mathrm{hr} / \mathrm{ft}^{3}\right)$ reactor. The next two run Conditions, 3 and 4 , used a wet iron catalyst cake (in place of dry powder) as the source of iron at $0.5 \mathrm{~W} \%$ relative to feed coal and $100 \mathrm{ppm}$ molybdenum from Molyvan-A. In Condition 3, the space velocity was back to $640 \mathrm{~kg} / \mathrm{hr} / \mathrm{m}^{3}$ while in Condition 4, the space velocity was increased to about $801 \mathrm{~kg} / \mathrm{hr} / \mathrm{m}^{3}$ ( $50 \mathrm{lbs} / \mathrm{hr} / \mathrm{ff}^{\mathrm{h}}$ ) reactor, and to counter the increased space velocity, the reactor temperatures were raised to 449 and $460^{\circ} \mathrm{C}\left(840\right.$ and $\left.860^{\circ} \mathrm{F}\right)$ for reactors $\mathrm{K}-1$ and $\mathrm{K}-2$ respectively. In general, light hydrocarbon gas yields during this run were relatively high (11-16\% MAF coal); the coal conversion levels varied significantly between about 92 to $96 \mathrm{~W} \% \mathrm{MAF}$. The first stage (interstage) coal conversion levels were between 91-93.5 W\% MAF. The resid conversion levels varied between 83-91\% MAF while the yields of light distillates varied between about 57 to 64 $\mathrm{W} \% \mathrm{MAF}$ coal. It was evident from Condition 1 that under these operating conditions, iron alone at $0.5 \mathrm{~W} \%$ was a poor catalyst, giving an ordinary performance, i.e., $57 \%$ distillate yield, $83 \%$ resid conversion, and $92 \%$ total coal conversion (all MAF bases). After reducing the space velocity and adding $100 \mathrm{ppm}$ of molybdenum, during Condition 2, the process performance improved i.e., about 
$64 \%$ distillates, $90+\%$ resid conversion, and $94+\%$ total coal conversion were achieved. The increase in space velocity back to $641 \mathrm{Kg} / \mathrm{hr} / \mathrm{m}^{3}$ (similar to Condition 1), reduced the yields and conversion by $3 \%$, but these values were distinctly higher than those obtained during Condition 1 . This showed the utility of molybdenum as a co-catalyst of iron; also changing mode of addition of HTI's iron catalyst did not make any difference in its catalytic function/activity. This point is important because in the revised mode of addition of HTI's iron catalyst, two major processing steps in the catalyst synthesis could be eliminated with a substantial reduction in the dispersed catalyst cost. The final run Condition, Condition 4 , was with increased space velocity and increased reactor temperatures, giving slightly better overall performance than Condition 3 . The operability of the unit at high feed coal throughputs was successfully demonstrated.

\subsection{BACKGROUND, OBJECTIVE, AND SCOPE OF WORK}

The Bench Run CMSL-10 was carried out, as a follow-up to CMSL-9, using a dispersed catalystonly two-stage back-mixed reactor system. The two-stage conversion reactors was preceded by another back-mixed pretreatment reactor at lower temperature and half the volume of each of the conversion reactors; the pretreatment reactor was intended for sulfidation/activation of the dispersed catalyst additive. The bench run CMSL-10 was eighteen days long, comprising of four operating conditions ( $3-5$ days each). The objectives of this bench operation were:

- To determine the process performance for a subbituminous coal liquefaction using a three-stage (including pretreater) dispersed catalyst-only back-mixed reactor system.

- To investigate the effects of a combined catalytic system of molybdenum and iron on the overall process performance.

- To determine the effects of process severity (temperatures and high space velocities) on the performance of coal liquefaction.

- To determine the effects of the mode of addition of HTI's iron catalyst on the liquefaction process performance.

An in-line hydrotreater was used during this run. Both the hot separator $(\mathrm{O}-1)$ overheads and the atmospheric still overheads (ASOH) were sent through the hydrotreater. Figure 2.10.1 presents a simplified schematic of the bench unit.

The Run Plan (Table 2.10.I) included four Run-Conditions that were selected to meet the technical objectives, specified above. By not using a supported extrudate catalyst in any of the coal liquefaction reactors, it became possible to compare the process performance of different Run Conditions on a one-to-one basis without being affected by 'catalyst batch-deactivation' phenomenon typical of the bench CTSL operations. Condition 1 studied the effects of adding 0.5 W\% of HTI's iron catalyst in dry, powdered form on the process performance at a coal space velocity of $641 \mathrm{Kg} / \mathrm{hr} / \mathrm{m}^{3}\left(40 \mathrm{lbs} / \mathrm{hr} / \mathrm{t}^{3}\right)$ and reactor temperatures of 441 and $440^{\circ} \mathrm{C}\left(825\right.$ and $\left.840^{\circ} \mathrm{F}\right)$ respectively, Condition 2 looked at the effect of adding 100 ppm molybdenum, as Molyvan-A, 
together with iron, on the process performance. Because resid was building up in the recycle solvent, the coal space velocity had been reduced to $410 \mathrm{Kg} / \mathrm{hr} / \mathrm{m}^{3}\left(25 \mathrm{lbs} / \mathrm{hr} / \mathrm{ft}^{3}\right)$ reactor. The next two run Conditions, 3 and 4, a wet iron catalyst cake was used as the source of iron at $0.5 \mathrm{~W} \%$ relative to feed coal, along with $100 \mathrm{ppm}$ molybdenum from Molyvan-A. In Condition 3, the space velocity was back to $641 \mathrm{Kg} / \mathrm{hr} / \mathrm{m}^{3}$ (40 lbs/hr/ft ${ }^{3}$ while in Condition 4 , the space velocity was increased to about $801 \mathrm{~kg} / \mathrm{hr} / \mathrm{m}^{3}\left(50 \mathrm{lbs} / \mathrm{hr} / \mathrm{ft}^{3}\right)$ reactor; to counter the increased space velocity, reactor temperatures were raised to 449 and $460^{\circ} \mathrm{C}\left(840\right.$ and $860^{\circ} \mathrm{F}$ ) for reactors $\mathrm{K}-1$ and $\mathrm{K}-2$ respectively.

\subsection{PROGRAM ANALYSIS AND RESULTS}

The process performance in terms of total conversion, product yields and qualities is discussed in this section. Detailed laboratory analysis of the products was performed on a daily basis to provide timely process evaluation. The daily material balance, coal conversion, normalized yields and other process performance-related indicators were calculated using programs available in CTSL database. Some programs were modified according to the requirement of the process configuration. The overall process performance during CMSL-10 is summarized in Table 2.10.2.

\subsection{Process Performance}

\section{Total Coal Conversion}

The total coal conversion is calculated on the basis of the solubility of pressure filter solids in quinoline. The coal conversions for different conditions are shown in Figure 2.10.2. Throughout the course of the Run 227-88, the coal conversions varied between $92 \mathrm{~W} \%$ and $96 \mathrm{~W} \%$, MAF. Only $\mathrm{FeOOH} / \mathrm{SO}_{4}$ catalyst was added during periods 3-6 of condition 1. The activity of $\mathrm{FeOOH} / \mathrm{SO}_{4}$ catalyst in conversion of coal during these periods was measured and used as a baseline to compare with the performance of combined system of $\mathrm{Mo} / \mathrm{Fe}$ catalysts. Starting from period 7 of Condition $2,100 \mathrm{ppm}$ Molyvan-A catalyst was added to the process. As shown in Figure 2.10.2, the addition of Molyvan-A catalyst resulted in an increase in total conversion. The space velocity was increased in Condition 3. It seemed that the increase in space velocity did not affect feed conversion considerably. During the last two conditions which proceeded from period 11 through $18, \mathrm{FeOOH} / \mathrm{SO}_{4}$ catalyst containing $70 \mathrm{~W} \%$ water (i.e., in the form of a wet filter cake) was added in an amount equivalent to dry $\mathrm{FeOOH} / \mathrm{SO}_{4}$ catalyst that was used in last two conditions. An interesting finding was that the iron catalyst added either as dry powder or wet cake affected coal conversion in the same positive manner. This is a significant finding as it will not only reduce the cost of iron catalyst but also help understand catalytic interactions of $\mathrm{FeOOH} / \mathrm{SO}_{4}$ catalyst in coal liquefaction. 
The $524^{\circ} \mathrm{C}+\left(975^{\circ} \mathrm{F}+\right)$ resid conversion represents the ability of the process for the conversion of heavy (high boiling) fractions contained in the feed. For the purpose of calculations, all of the MAF portion of the feed coal is considered a $524^{\circ} \mathrm{C}+\left(975^{\circ} \mathrm{F}+\right)$ resid in the feed. The $524^{\circ} \mathrm{C}^{+}\left(975^{\circ} \mathrm{F}+\right)$ resid conversion values varied between 82 and $90 \mathrm{~W} \%$ and were more sensitive than the total coal conversion values to the addition of Molyvan-A catalyst and to the change in space velocity. The resid conversions from each condition are shown in Figure 2.10.3. A comparison of the process performance between conditions 1 and 2 indicates that the addition of $100 \mathrm{ppm}$ (and lowering of space velocity from 640 to about $415 \mathrm{~kg} / \mathrm{hr} / \mathrm{m}^{3}$ reactor ( 40 to about $26 \mathrm{lb} / \mathrm{hr} / \mathrm{ft}^{3}$ ) caused about $7 \mathrm{~W} \%$ of increase in $524^{\circ} \mathrm{C}+\left(975^{\circ} \mathrm{F}+\right)$ resid conversion. This increase in $524^{\circ} \mathrm{C}+\left(975^{\circ} \mathrm{F}+\right)$ resid conversion may be due to the combined effects of adding Molyvan-A and reduction in space velocity. To verify the effect of Molyvan-A catalyst on coal conversion during periods 11-14 of condition 3, the process was operated under the same space velocity as compared to condition 1 but in the presence of Molyvan-A. About $3 \mathrm{~W} \%$ of increase in $524^{\circ} \mathrm{C}+\left(975^{\circ} \mathrm{F}+\right)$ resid conversion was observed due to the addition of Molyvan-A catalyst. Residence time of slurry feed affects $975^{\circ} \mathrm{F}+$ resid conversion. As shown in Figure 2.10.3, the $524 \mathrm{C}+$ $\left(975^{\circ} \mathrm{F}+\right)$ resid conversion dropped by about $7 \mathrm{~W} \%$ when the space velocity was increased from $415 \mathrm{~kg} / \mathrm{hr} / \mathrm{m}^{3}$ (condition 2) to $732 \mathrm{~kg} / \mathrm{hr} / \mathrm{m}^{3}$ (condition 4). As already indicated above, starting from period 11 of Condition 3 , the iron catalyst was added as wet cake (containing $70 \%$ water). It seems that the change in the form of the $\mathrm{FeOOH} / \mathrm{SO}_{4}$ (water content) did not have any noticeable influence on the resid conversion.

\section{Hydrogen Consumption}

Hydrogen consumption based on MF feed varied between 4.4 and $7.5 \mathrm{~W} \%$. The highest hydrogen consumption was observed for Condition 2 when Molyvan-A catalyst was added and space velocity was reduced (Figure 2.10.4). The middle distillate yield and gases obtained during the periods of Condition 2 were also the highest, indicating that extensive hydrocracking reaction occurred. On raising space velocity, the consumption of hydrogen decreased together with the reduction in the formation of gases. The consumption of the lowest amounts of hydrogen for Condition 4 did not seem to affect distillate yields significantly.

\section{Heteroatom Removal}

The in-line hydrotreater employed during CMSL-10 resulted in a very impressive finishing of the net process distillates. The $\mathrm{H} / \mathrm{C}$ atomic ratios of the net $\mathrm{SOH}$ distillates from CMSL10 were as high as 1.7-1.9. The nitrogen and sulfur levels were also low in general (less than $50 \mathrm{ppm}$ ). The in-line hydrotreater was maintained at $379^{\circ} \mathrm{C}$ throughout the Run operations. 


\subsection{Product Distribution}

\section{$\underline{\mathrm{C}}_{1}-\mathrm{C}_{3}$ Gas Yields}

As shown in Figure 2.10.5, the normalized $\mathrm{C}_{1}-\mathrm{C}_{3}$ gas yield for CMSL-10 varied between 11.6 and $16.5 \mathrm{~W} \%$ of MAF coal. The highest yield of $16.5 \mathrm{~W} \%$ was obtained during periods 7-9 of Condition 2, due to the addition of Molyvan-A catalyst and reduction of space velocity. It is interesting that the formation of $\mathrm{C}_{1}-\mathrm{C}_{3}$ gases followed a trend similar to the hydrogen consumption. The lowest yield of gases was during the last condition which was operated with the highest space velocity. This suggests that the excess amounts of gases formed from extensive hydrocracking can be reduced by shortening the residence time.

\section{$\underline{524^{\circ} \mathrm{C}+\left(975^{\circ} \mathrm{F}+\right) \text { Residuum Yield }}$}

The $524^{\circ} \mathrm{C}+\left(975^{\circ} \mathrm{F}+\right)$ residue yield can be a measure of process performance. The $524^{\circ} \mathrm{C}+$ $\left(975^{\circ} \mathrm{F}+\right)$ residue yields for CMSL-10 varied between 4 and $12 \mathrm{~W} \%$ as indicated in Figure 2.10.6. The addition of Molyvan-A catalyst reduced the residuum yields due to strong hydrocracking ability of Molyvan-A catalyst. An increase in residuum yield was observed on raising space velocity. The highest residuum yield obtained in Condition 4 was due to the increase of space velocity which resulted in the shortening of residence time of slurry feed.

$\mathrm{C}_{4}-524^{\circ} \mathrm{C}\left(\mathrm{C}_{4}-975^{\circ} \mathrm{F}\right)$ Distillate Yields and Selectivity

The distillate yields varied between 57 and $64 \mathrm{~W} \%$. As shown in Figure 2.10.7, the type of catalyst and space velocity affected the distillate yields. A trend similar to the resid conversion was observed for the variation in distillate yields. The highest distillate yield of 63.6 W\% was obtained for Condition 2 when $100 \mathrm{ppm}$ of Molyvan-A catalyst was introduced and space velocity was reduced. The distillate yield dropped slightly when the space velocity was increased from 415 to $732 \mathrm{~kg} / \mathrm{hr} / \mathrm{m}^{3}$. The lowest distillate yield was obtained in Condition 1 when $\mathrm{FeOOH} / \mathrm{SO}_{4}$ alone was used as dispersed catalyst. An important implication may be that the combined system of Mo and Fe catalysts is effective in upgrading polyaromatic structures and in breaking the strong $\mathrm{C}-\mathrm{C}$ bonds in coal. Also shown in Figure 2.10.8 is the selectivity of distillates for all conditions. The distillates, in general, contained $30 \mathrm{~W} \%$ of naphtha and $40 \mathrm{~W} \%$ of middle distillate. The variation of middle distillates $\left(177-343^{\circ} \mathrm{C}\right)$ followed a trend similar to the change in overall distillates throughout the run.

\subsection{Product Quality}

Products of different fractions (Second-Stage Vent Gases, CAS Bottoms, SOH, PFL and PFS/VSB) from work-up periods $6,9,14$ and 18 were analyzed in detail for their composition. The results of these analysis are summarized in Tables 2.10.3 through 2.10.7. 
$\mathrm{SOH}$ oil stream represents the net light distillate (IBP- $399^{\circ} \mathrm{C}$ ) from CMSL-10 (Figure 2.10.9). The properties of $\mathrm{SOH}$ oil for the work-up periods are shown in Table 2.10.3. As shown in this Table, $\mathrm{SOH}$ oil had a typical boiling range of $54-399^{\circ} \mathrm{C}$. The amounts of IBP$177^{\circ} \mathrm{C}$, the lightest fraction of the SOH oil, appeared to be almost the same for all conditions. The API gravities (an indication of paraffinic character) of $\mathrm{SOH}$ oil for each work-up period were high ( $>34$ ). The heteroatoms level (nitrogen and sulfur) were below $50 \mathrm{ppm}$ throughout the run, indicating a very successful operation of an in-line hydrotreater. It appeared that the change of space velocity and addition of Molyvan-A catalysts did not affect the distillation composition of $\mathrm{SOH}$.

\section{Pressure Filter Liquid (PFL) \& Pressure Filter Solids (PFS)}

The pressure filter liquid (PFL) represents oil obtained by filtration of the atmospheric still bottoms (CAS bottoms). In Run CMSL-10, only the PFL was used as the recycle oil and no CAS bottoms were recycled. Table 2.10.4 summarizes the analysis of the PFL for the various conditions, and also, the analysis of its various boiling range fractions. The concentration of the $524^{\circ} \mathrm{C}+$ residual oil in the PFL ranged from 34 to $45 \mathrm{~W} \%$, depending on the process conditions. The highest $524^{\circ} \mathrm{C}+$ concentration was in the Condition 1 operation with only iron additive as the catalyst, and the lowest concentration was in the Condition 2 operation which included a Mo additive as catalyst and was at the lowest space velocity. The toluene and cyclohexane solubility of $524^{\circ} \mathrm{C}+$ fraction, as shown in Figure 2.10.10, reflected the varying catalytic performance throughout the run. The toluene solubles ranged from 84 to $94 \mathrm{~W} \%$ of the residuum, with the lowest solubility for the Condition 1 product, and the highest solubility for the Condition 2 product. The cyclohexane solubles ranged from 59 to $80 \mathrm{~W} \%$ of the residuum, again with the lowest solubility for the Condition 1 product, and the highest solubility for the Condition 2 product. There were increases in the $\mathrm{H} / \mathrm{C}$ atomic ratio of each of the PFL fractions with the addition of Molyvan-A catalyst indicating that it has some hydrogenation function, although even with it the $\mathrm{H} / \mathrm{C}$ ratios are relatively low, $0.7-1.3$ for the various fractions, compared to values obtained in CTSL operations using extrudate catalysts, for example, in Run CC-1, 1.1-1.6 for relatively fresh extrudate catalyst, and 0.9-1.5 for nominally "equilibrium" extrudate catalyst.

The analyses of the PFS filter cake products are presented in Table 2.10.5.

\subsection{Interstage Samples}

The interstage samples were withdrawn during all the work-up periods of CMSL-10 from the ebullating line on the first stage coal liquefaction reactor (Tables 2.10.6 and 2.10.7). The properties of these samples indicate the performance of the first stage reactor. The pressure filter solids from first stage were analyzed and it was shown that $91-93.5 \mathrm{~W} \%$ MAF of coal conversion was achieved after the first stage. The toluene soluble portion of $524^{\circ} \mathrm{C}+$ fraction is about $80 \mathrm{~W} \%$. The overall resid content of the PFL varied between 36$45 \mathrm{~W} \%$, although the Condition1, Period 6, sample was very viscous so that it could no be 
filtered. The comparison between Periods 14 and 18 interstage PFL analyses indicates that the increase in space velocity did not affect the composition of the PFL significantly.

\subsection{External Samples}

As mentioned earlier, a number of samples of different process streams from CMSL-10 were obtained (for further detailed characterization and products assessment) for the Consol, Inc. and also for the members of Consortium of Fossil Fuel Liquefaction Science. These samples, their amounts, and the operating Periods when these were withdrawn are shown in Table 2.10.8.

\subsection{Hydrotreater Performance}

The in-line hydrotreater employed during CMSL-10 resulted in a very impressive finishing of the net process distillates. The $\mathrm{H} / \mathrm{C}$ atomic ratios of the net SOH distillates from CMSL10 were as high as 1.7-1.9. The nitrogen and sulfur levels were also low in general (less than $50 \mathrm{ppm}$ ). The in-line hydrotreater was maintained at $379^{\circ} \mathrm{C}$ throughout the Run operations.

\subsection{DETAILS OF OPERATION}

\subsection{System Configuration:}

CMSL-10 involved two equal volume backmixed reactors, one half volume $(1000 \mathrm{cc})$ pre-treatment vessel (also back-mixed), and a fixed-bed hydrotreater. The high pressure slurry samples were obtained after the pretreatment vessel which were sent to PETC and Consol and after the first conversion reactor for analysis at HTI. The simplified schematic of this configuration is shown in Figure 2.10.1.

The reactors from the existing units $227 \& 238$ were used in this run with the necessary re-piping and equipment modifications. A hot-slurry mix tank system was used throughout the run for slurry preparation. There was no supported catalyst used in any of the conversion reactors, except in the hydrotreater (HTU). Hydrogen disulfide $\left(\mathrm{H}_{2} \mathrm{~S}\right)$, as a source of sulfur for the activation of dispersed iron and molybdenum additives, was continually added to the pretreater at $3 \mathrm{~W} \%$ of dry coal. 


\subsection{Operation Summary}

Bench run CMSL-10 was spread over four run conditions. For the entire run CMSL-10, an average material recovery balance of $101.1 \mathrm{~W} \%$ was achieved. A summary of material balance on the daily basis is plotted in Figure 2.10.11. Since the major objectives of CMSL-10 were to study the effects of combined system of $\mathrm{Mo} / \mathrm{Fe}$ catalysts and space velocity on the conversion of coal, this run was originally planned to operate at constant temperature and pressure. The operating conditions during CMSL-10 in terms of space velocities, reactor temperatures are summarized in Figure 2.10.12. As shown in this Figure, the temperatures of both reactors were controlled to their desired values. The space velocity was adjusted between 415 and $732 \mathrm{~kg} / \mathrm{hr} / \mathrm{m}^{3}\left(25.9\right.$ and $\left.45.7 \mathrm{lb} / \mathrm{hr} / \mathrm{ft}^{3}\right)$ to examine its impact on the process performance. The viscosity of feed slurry was measured throughout the run and no significant change that might affect pumpability was observed. Unit back pressures were controlled and recorded on an hourly basis. The overall process operation was similar to run CMSL-9 except that no CAS bottoms was recycled and no ASOH sample was taken during run CMSL-10.

\subsection{MATERIALS USED}

\subsection{Coal Feed, Start-Up And Make-Up Oil}

A subbituminous Black Thunder Mine Coal (HTI-6213), the same coal that was used in the PDU 260-005 (POC-02 Run) operations, was used for bench run CMSL-10 (227-88) (Table 2.10.9). Tank 4 material, designated L-814, a combination of hydrotreated petroleum-derived oil with small amounts of coal-derived liquid obtained during the operations of POC-02 PDU Run (Table 2.10.10) was used as start-up oil and make-up oil for Run CMSL-10.

\subsection{Catalyst}

Hydrotreater:

Pretreater ( \& carried over to $\mathrm{K}-1$ and $\mathrm{K}-2$ ):

Criterion C-411 Trilobe (HTI-6135) Molyvan-A, HTI's Fe Catalyst, and $3 \% \mathrm{H}_{2} \mathrm{~S}$ relative to dry coal.

Figure 2.10.13 shows the loading of the dispersed catalyst for the 4 conditions of the run. 


\subsection{CONCLUSIONS}

After 18 periods (days) of continuous operation, Run CMSL-10 was successfuly completed with one brief shutdown after Period 2. The results of the run showed:

- The combination of $100 \mathrm{ppm}$ Mo with $\mathrm{FeOOH}$ type catalyst improved process performance, although the iron catalyst was an operable catalyst;

- The process performance was essentially the same when the iron catalyst $\left(\mathrm{FeOOH} / \mathrm{SO}_{4}\right)$ was added as wet cake containing $70 \%$ water as when it was added as dry powder;

- The use of wet cake has led to a further reduction in catalyst cost by $30 \%$ by elimination of two expensive steps in catalyst preparation;

- Changes in catalysts and space velocity had impacts upon the $524^{\circ} \mathrm{C}+\left(975^{\circ} \mathrm{F}+\right)$ conversion and to a lesser degree the coal conversion itself;

- Slight changes in the qualities of SOH and PFL were observed with changes in space velocity, suggesting that the process can be operated at still higher space velocity;

- In-line hydrotreating was effective for the removal of heteroatoms and the addition of hydrogen, resulting in the production of quality distillates containing less than $50 \mathrm{ppm}$ each of sulfur and nitrogen;

- The current reactor configuration and the system of combined Mo and Fe catalysts are effective in producting products of good quality by coal liquefaction;

- It is possible to develop a near-optimum process for coal liquefaction using a suitable combination of iron and molybdenum in low concentrations $(5,000 \mathrm{ppm}$ of iron and 50-100 ppm of molybdenum) so that these catalysts can be employed on a disposable basis. 


\subsection{RECOMMENDATION FOR FUTURE WORK}

Based upon the successful operations and results from bench runs CMSL-9 and CMSL-10, it is strongly recommended that a slurry catalyst system, comprising iron and molybdenum, be optimized. In the past two bench runs, iron and molybdenum were added from different sources; it will be interesting to determine how well a bimetallic catalyst additive, consisting of both iron and molybdenum in the same formulation, perform under comparable process conditions. HTI's iron catalyst preparation is easily amenable for incorporation of any other metal/metals into the catalyst formulation. For the first time during CMSL-10, it was found that a wet filter cake consisting of about $70 \%$ water can be added to the reactor and it was almost as effective as the dried form of the iron catalyst additive (with no water in it). The wet cake catalyst addition, which is much more economical than the dry powder addition, should be looked into more detail and should also be optimized for activity and cost. The iron-molybdenum dispersed catalyst combination should also be studied for coprocessing of coal with heavy resids and waste organics (plastics). 
Table 2.10.1

Bench Run CMSL-10 Run Plan

Condition

Periods

Work-up Periods

Pressure, Mpa

Temperature ${ }^{\circ} \mathrm{C}$

Pretreater

First Stage

Second Stage

Hydrotreater

Space Velocity Per Stage

$\mathrm{Kg} / \mathrm{h} / \mathrm{m}^{3}$

$\mathrm{Lb} / \mathrm{h} / \mathrm{ft}^{3}$

Solvent/Coal Ratio

Dispersed Catalyst, ppm

HTI Fe Catalyst

Mo (as Molyvan-A)

Recycle

Sulfur Additives:

$$
\mathrm{H}_{2} \mathrm{~S} \text { Rate }
$$

641

481

30

40

1

$5000^{*}$

0

PFL

1

449

441

441

449

449

449

460

$13 \quad 16$

302

441

1

641

801

50
14-16

16 
Table 2.10.2

\section{CMSL-10: PROCESS PERFORMANCE SUMMARY}

\begin{tabular}{|c|c|c|c|c|}
\hline Unit & 227 & 227 & 227 & 227 \\
\hline Run & 88 & 88 & 88 & 88 \\
\hline Condition & 1 & 2 & 3 & 4 \\
\hline Period Number & 6 & 9 & 14 & 18 \\
\hline Hours of Run (end of Period) & 144 & 216 & 336 & 432 \\
\hline Disp. Cat. ppm*: Fresh Mo & 0 & 100 & 100 & 100 \\
\hline Fresh Iron & 5000 & 5000 & 5000 & 5000 \\
\hline $\begin{array}{l}\text { Stage I Feed Space Velocity } \\
\qquad \mathrm{kg} \mathrm{coal} / \mathrm{hr} / \mathrm{m} 3 \text { reactor vol. }\end{array}$ & 659.2 & 414.4 & 654.4 & 731.2 \\
\hline \multicolumn{5}{|l|}{ Temperatures, $\mathrm{C}$} \\
\hline Pretreater & 303 & 302 & 304 & 302 \\
\hline $\mathrm{K}-1$ & 443 & 441 & 444 & 449 \\
\hline $\mathrm{K}-2$ & 450 & 448 & 451 & 457 \\
\hline Total Material Recovery \% (Gross) & 100.2 & 103.5 & 102.2 & 100.9 \\
\hline \multicolumn{5}{|c|}{$\begin{array}{l}\text { ESTIMATED NORMALIZED YIELDS: } \\
\text { W\% Dry Coal }\end{array}$} \\
\hline $\mathrm{Cl}-\mathrm{C} 3$ in Gases & 13.37 & 15.71 & 12.20 & 10.95 \\
\hline C4-C7 in Gases & 4.35 & 5.63 & 4.56 & 3.79 \\
\hline IBP-177 deg C & 12.35 & 15.78 & 12.81 & 12.75 \\
\hline $177-260 \operatorname{deg} C$ & 10.61 & 11.70 & 9.69 & 11.13 \\
\hline $260-343 \operatorname{deg} C$ & 11.67 & 15.79 & 13.96 & 13.73 \\
\hline $343-454 \operatorname{deg} C$ & 11.84 & 9.50 & 12.73 & 13.21 \\
\hline $454-524 \operatorname{deg} C$ & 2.65 & 1.55 & 3.39 & 4.02 \\
\hline $524 \operatorname{deg} \mathrm{C}+$ & 8.76 & 4.00 & 8.60 & 11.52 \\
\hline Unconverted Feed & 7.66 & 5.34 & 5.16 & 3.26 \\
\hline Water & 10.91 & 10.41 & 10.96 & 9.27 \\
\hline $\mathrm{COx}$ & 5.68 & 5.36 & 5.63 & 3.89 \\
\hline NH3 & 0.87 & 1.03 & 0.86 & 0.73 \\
\hline $\mathrm{H} 2 \mathrm{~S}$ & -0.17 & -0.08 & -0.19 & 0.08 \\
\hline Ash & 5.75 & 5.75 & 5.75 & 5.75 \\
\hline Hydrogen Consumption & 6.30 & 7.45 & 6.12 & 4.09 \\
\hline \multicolumn{5}{|c|}{ PROCESS PERFORMANCE, maf coal } \\
\hline Coal Conversion & 91.9 & 94.3 & 94.5 & 96.5 \\
\hline $524 \mathrm{C}+$ Conversion & 82.5 & 90.1 & 85.4 & 84.0 \\
\hline C4-524 C Distillate Yield & 56.7 & 63.6 & 60.6 & 62.2 \\
\hline
\end{tabular}

* The first two run conditions employed a dry/powdered form of iron catalyst, while the last two employeed iron catalyst in the form of a wet filter cake. 
Table 2.10.3

CMSL-10: SEPARATOR OVERHEAD (SOH) INSPECTION

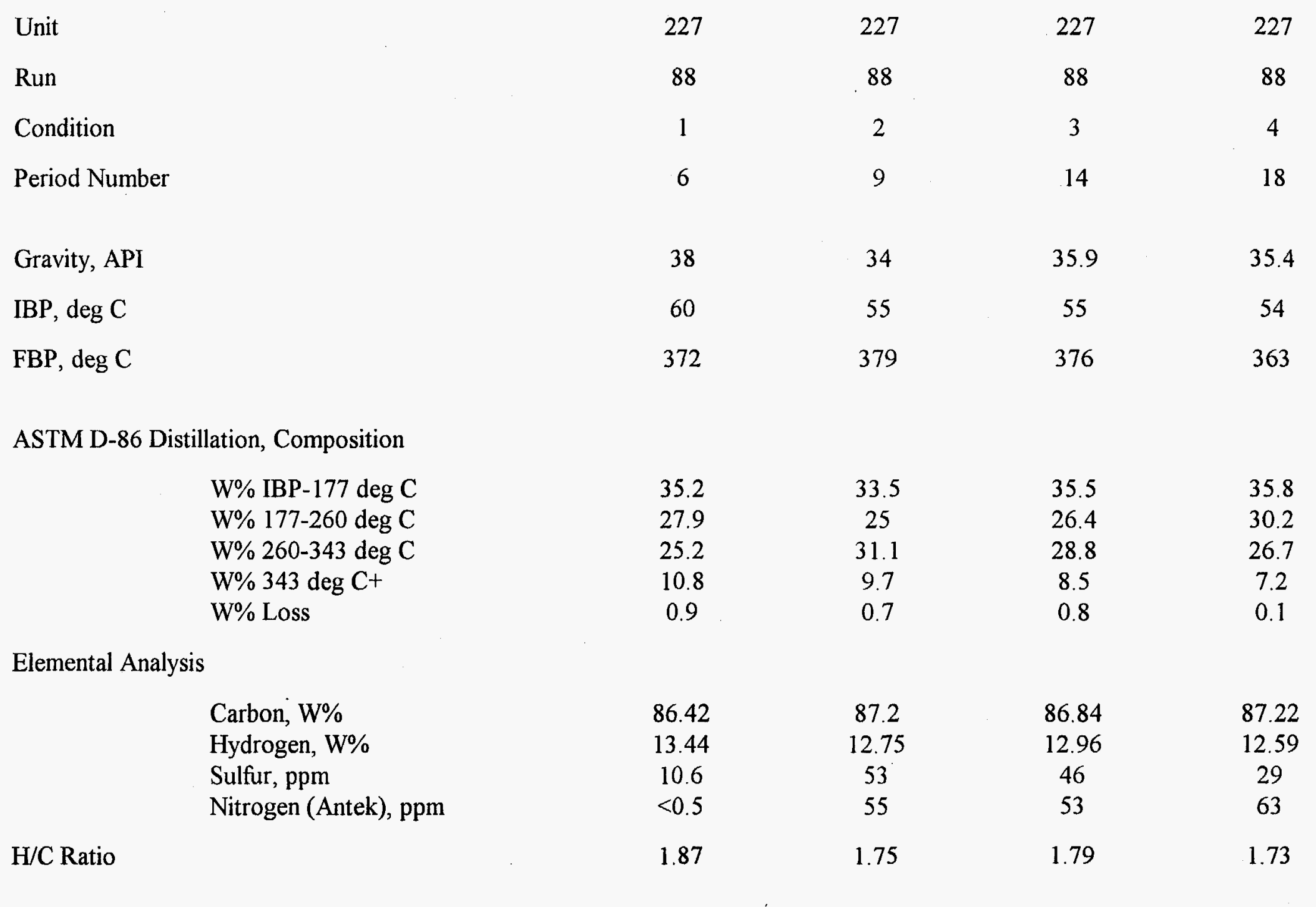


Table 2.10.4

RUN CMSL-10 (227-88)

ANALYSES OF FRACTIONS OF FILTERED LIQUID PRODUCT (PFL)

CONDITION

Whole PFL

IBP $-343^{\circ} \mathrm{C}, \mathrm{W} \%$

$343-454^{\circ} \mathrm{C}, \mathrm{W} \%$

$454-524^{\circ} \mathrm{C}, \mathrm{W} \%$

$524^{\circ} \mathrm{C}+\mathrm{W} \%$

Carbon, W\%

Hydrogen, W\%

Sulfur, W\%

Nitrogen, W\%

Oxygen, W\% (By Diff.)

$\mathrm{H} / \mathrm{C}$

CCR, W\%

IBP $-343^{\circ} \mathrm{C}$

Carbon, W\%

Hydrogen, W\%

Sulfur, W\%

Nitrogen, W\%

Oxygen, W\% (By Diff.) $\mathrm{H} / \mathrm{C}$

$343-454^{\circ} \mathrm{C}$

Carbon, W\%

Hydrogen, W\%

Sulfur, W\%

Nitrogen, W\%

Oxygen, W\% (By Diff.) $\mathrm{H} / \mathrm{C}$

$454-524^{\circ} \mathrm{C}$

Carbon, W\%

Hydrogen, W\%

Sulfur, W\%

Nitrogen, W\%

Oxygen, W\% (By Diff.)

$\mathrm{H} / \mathrm{C}$

$524^{\circ} \mathrm{C}+$

Carbon, W\%

Hydrogen, W\%

Sulfur, W\%

Nitrogen, W\%

Oxygen, W\% (By Diff.)

$\mathrm{H} / \mathrm{C}$

Cyclohexane Insoluble, W\%

Toluene Insoluble, $\mathrm{W} \%$

CALC. IBP $-524^{\circ} \mathrm{C}$

Carbon, W\%

Hydrogen, W\%

Sulfur, W\%

Nitrogen, W\%

Oxygen, W\% (By Diff.)

$\mathrm{H} / \mathrm{C}$
1

7.1

32.4

13.7

46.2

88.64

6.44

0.97

0.95

3.00

0.87

33.8

86.22

9.39

0.48

0.6

3.31

1.30

88.08

7.39

1.26

0.57

2.70

1.00

88.68

6.21

1.55

0.83

2.73

0.83

87.86

4.75

0.57

1.25

5.57

0.64

41.1

16.5

87.99

7.35

1.23

0.64

2.79

1.00
2

11.2

41.2

12.9

33.9

88.59

6.95

0.66

0.88

2.92

0.93

22.4

86.36

9.53

0.33

0.65

3.13

1.31

88.35

8.04

0.83

0.67

2.11

1.08

89.15

6.93

0.85

0.94

2.13

0.93

88.9

5.24

0.42

1.2

4.24

0.70

22.4

7.3

88.17

8.08

0.75

0.72

2.29

1.09
3

14.1

37.3

13.5

34.2

88.36

7.25

0.47

0.94

2.98

0.98

20.5

85.87

9.36

0.29

0.76

3.72

1.30

88.47

8.22

0.69

0.75

1.87

1.11

89.12

7.00

0.62

1.01

2.25

0.94

89.79

5.51

0.24

1.29

3.17

0.73

20.5

5.9

88.04

8.21

0.59

0.81

2.35

1.11
4

12.5

32.5

12.6

41.6

85.29

6.49

0.51

0.97

6.74

0.91

25

85.46

9.41

0.16

0.72

4.26

1.31

88.75

7.81

0.49

0.85

2.10

1.05

89.13

6.57

0.33

1.11

2.86

0.88

79.44

4.47

0.80

1.10

14.19

0.67

25.0

14.4

88.12

7.89

0.38

0.88

2.73

1.07 
Table 2.10.5

CMSL-10: INSPECTION OF THE PRESSURE FILTER SOLIDS (2nd STAGE)

\begin{tabular}{|c|c|c|c|c|}
\hline Unit & 227 & 227 & 227 & 227 \\
\hline Run & 88 & 88 & 88 & 88 \\
\hline Condition & 1 & 2 & 3 & 4 \\
\hline Period Number & 6 & 9 & 14 & 18 \\
\hline \multicolumn{5}{|l|}{ Elemental Analysis } \\
\hline Carbon, W\% & 65.3 & 60.7 & 57.7 & 48.9 \\
\hline Hydrogen, W\% & 3.8 & 4.1 & 3.8 & 3.4 \\
\hline Sulfur, W\% & 2.0 & 2.0 & 2.3 & 2.3 \\
\hline Nitrogen, W\% & 0.7 & 0.6 & 0.6 & 0.5 \\
\hline H/C RATIO & 0.7 & 0.8 & 0.8 & 0.8 \\
\hline \multicolumn{5}{|l|}{ Composition, W\% } \\
\hline Quinoline Insolubles, W\% & 50.6 & 50.2 & 53.8 & 61.6 \\
\hline Ash (Quinoline Filtration) & 24.6 & 29.4 & 32.4 & 41.8 \\
\hline $\mathrm{S}$ in Ash, $\mathrm{W} \%$ & 4.8 & 4.7 & 5.0 & 5.0 \\
\hline ASTM Ash, W\% & 25.8 & 30.4 & 33.8 & 42.0 \\
\hline $\mathrm{S}$ in Ash, $\mathrm{W} \%$ & 5.5 & 5.0 & 5.7 & 5.8 \\
\hline Coal Conversion, W\% maf & 91.9 & 94.3 & 94.5 & 96.5 \\
\hline
\end{tabular}


Table 2.10.6

CMSL-10: PROPERTIES OF THE FIRST STAGE PRESSURE FILTER LIQUID

\begin{tabular}{|c|c|c|c|}
\hline Unit & 227 & 227 & 227 \\
\hline Run & 88 & 88 & 88 \\
\hline Condition & 2 & 3 & 4 \\
\hline Period Number* & 9 & 14 & 18 \\
\hline $\begin{array}{l}\text { Gravity, API } \\
\text { IBP, deg C }\end{array}$ & $\begin{array}{l}-5.6 \\
234 \\
\end{array}$ & $\begin{array}{l}-7.9 \\
266 \\
\end{array}$ & $\begin{array}{l}-8.9 \\
255 \\
\end{array}$ \\
\hline $\begin{array}{l}\text { ASTM D-1160 Distillation, Composition } \\
\text { W\% IBP-343 deg C } \\
\text { W\% 343-454 deg C } \\
\text { W\% 454-524 deg C } \\
\text { W\% 524 deg C+ } \\
\text { W\% Loss }\end{array}$ & $\begin{array}{c}11.9 \\
34.3 \\
16.9 \\
36.3 \\
0.6 \\
\end{array}$ & $\begin{array}{c}6.9 \\
32.8 \\
14.4 \\
45.3 \\
0.6 \\
\end{array}$ & $\begin{array}{c}8.7 \\
32.2 \\
14.2 \\
44.3 \\
0.6 \\
\end{array}$ \\
\hline $\begin{array}{l}\text { Elemental Analysis } \\
\text { Carbon, W\% } \\
\text { Hydrogen, W\% } \\
\text { Sulfur, W\% } \\
\text { Nitrogen, W\% }\end{array}$ & $\begin{array}{c}89.2 \\
7.3 \\
0.7 \\
0.8 \\
1.0 \\
\end{array}$ & $\begin{array}{c}88.9 \\
6.7 \\
0.5 \\
1.1 \\
0.9 \\
\end{array}$ & $\begin{array}{l}89.2 \\
7.1 \\
0.5 \\
1.0 \\
1.0 \\
\end{array}$ \\
\hline $\begin{array}{l}\text { CCR, W\% PFL } \\
\text { CYCLOHEXANE INSOLUBLES, W\% } \\
\text { TOLUENE INSOLUBLES, W\% }\end{array}$ & $\begin{array}{c}23.0 \\
25.9 \\
8.0\end{array}$ & $\begin{array}{c}26.2 \\
30.5 \\
9.1\end{array}$ & $\begin{array}{c}28.8 \\
37.0 \\
9.1\end{array}$ \\
\hline
\end{tabular}

* Period 6 interstage sample could not be pressure filtered due to its highly viscous nature. 
Table 2.10.7

\section{CMSL-10: INSPECTION OF THE FIRST STAGE PRESSURE FILTER SOLIDS}

Unit
Run
Condition
Period Number

Elemental Analysis

Carbon, W\%

Hydrogen, W\%

Sulfur, W\%

Nitrogen, W\%

H/C RATIO

Composition, $\mathrm{W} \%$

Quinoline Insolubles, W\%
Ash (Quinoline Filtration)
ASTM Ash, W\%
$\quad \mathrm{S}$ in Ash, W\%

227
88
2
9

65.3

4.3

2.0

0.8

0.8

50.7

23.4

24.2

5.0

91.8
227

88

3

14

63.9

4.4

2.0

0.8

0.8

51.1

26.6

26.7

5.7

93.0
227

88

4

18

54.1

3.9

2.0

0.5

0.9

58.0

39.0

35.7

9.0

93.6 


\section{Table 2.10.8}

\section{Samples sent to Consol, Inc.}

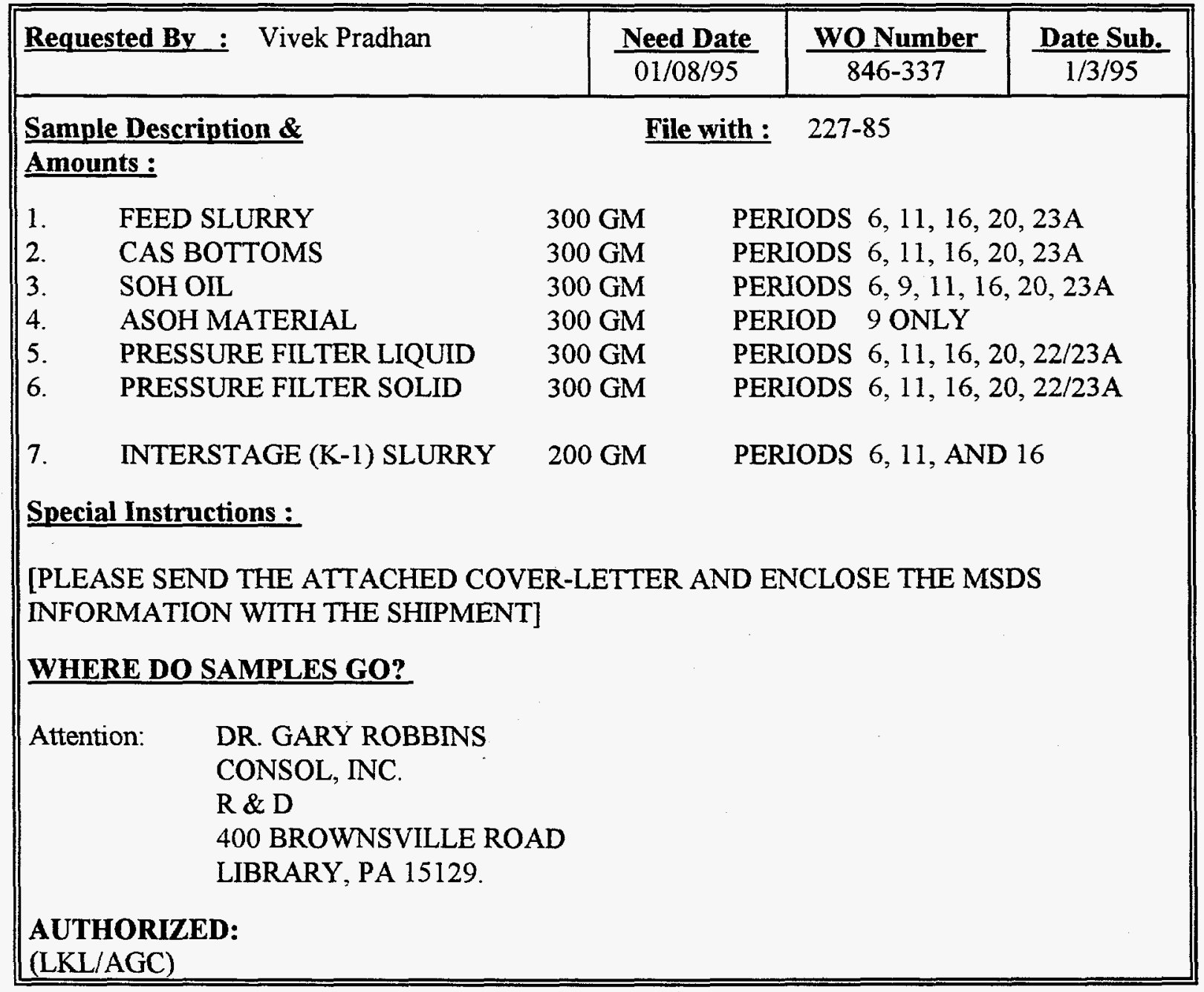


Table 2.10.9

\section{ANALYSIS OF FEED COAL}

HTI, No.

MOISTURE CONTENT

PROXIMATE ANALYSIS, WT\% Dry Basis

Volatile Matter

43.48

Fixed Carbon

50.52

Ash

ULTIMATE ANALYSIS, WT\% Dry Basis

Carbon

69.95

Hydrogen

4.50

Sulfur

0.39

Nitrogen

0.89

Ash

6.00

Oxygen (by diff.)

18.27

H/C RATIO

0.77 
Table 2.10.10

ANALYSIS OF START-UP / MAKE-UP OIL

HTI, No.

L-814

API Gravity

0.4

Elemental Analysis, W\%

Carbon

88.96

Hydrogen

8.25

Sulfur

2.22

Nitrogen

0.19

ASTM D-1160 Distillation, deg C

IBP

309

$5 \mathrm{~V} \%$

351

$10 \mathrm{~V} \%$

374

$20 \mathrm{~V} \%$

394

$30 \mathrm{~V} \%$

409

$40 \mathrm{~V} \%$

426

$50 \mathrm{~V} \%$

437

$60 \mathrm{~V} \%$

449

$70 \mathrm{~V} \%$

467

$80 \mathrm{~V} \%$

507

$84 \mathrm{~V} \%$

524

WEIGHT PERCENTS

IBP-343 DEG C

5

343-454 DEG C

53.99

454-524 DEG C

22.18

524+ DEG C

18.36

LOSS

0.47

$\%$ Aromatic Carbon

80.03

$\%$ Cyclic Hydrogen

44.36 


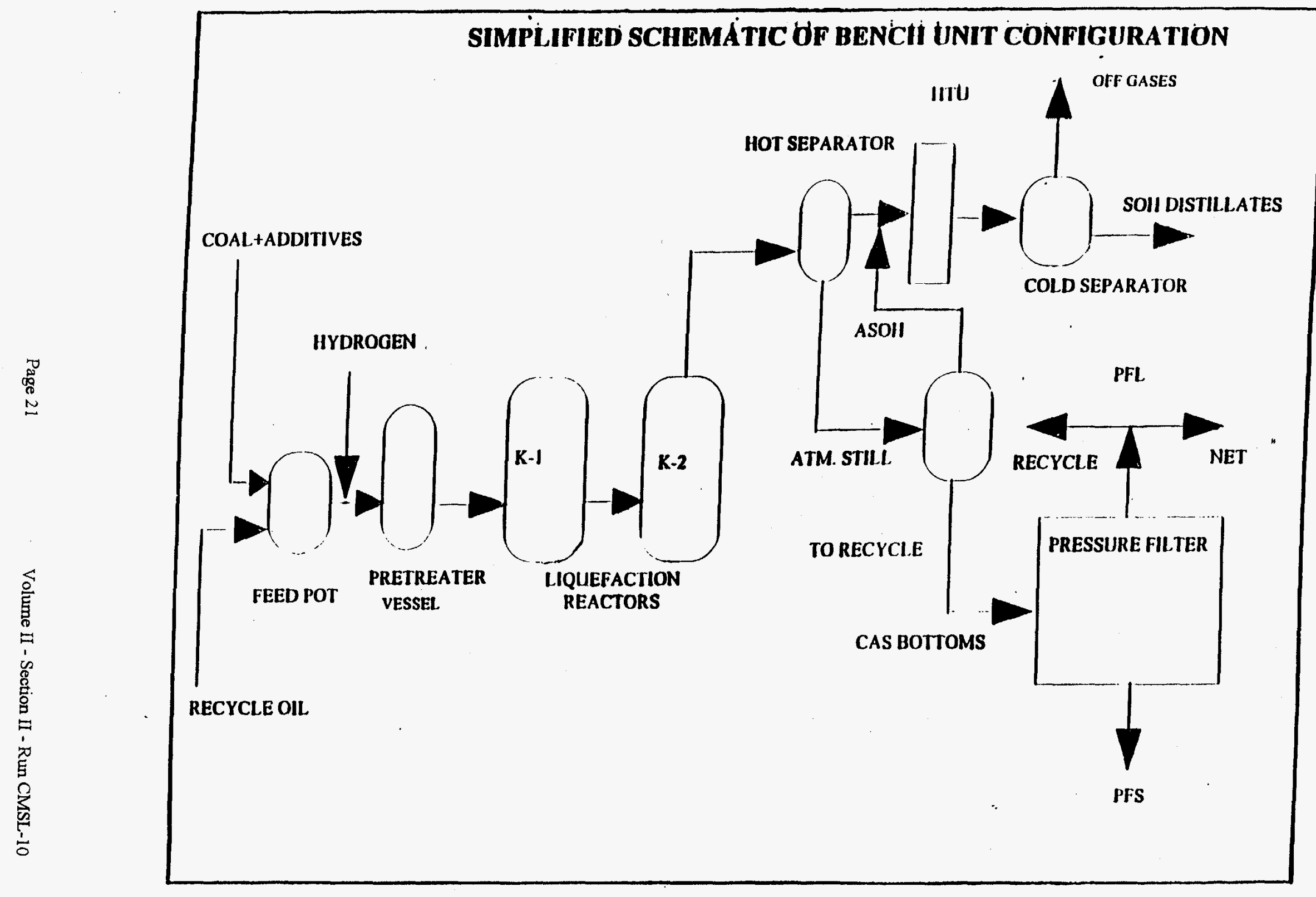


Figure 2.10.2

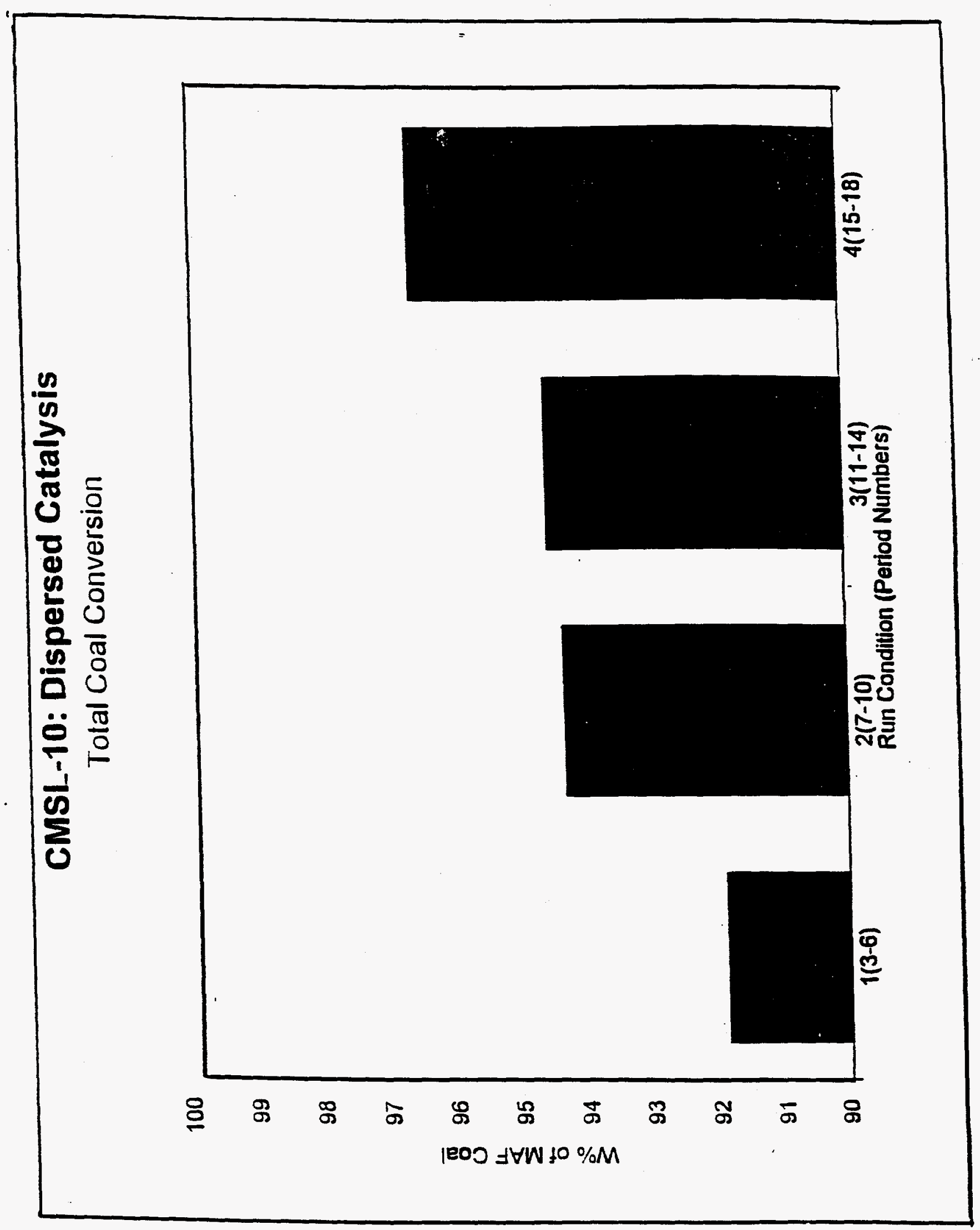


Figure 2.10.3

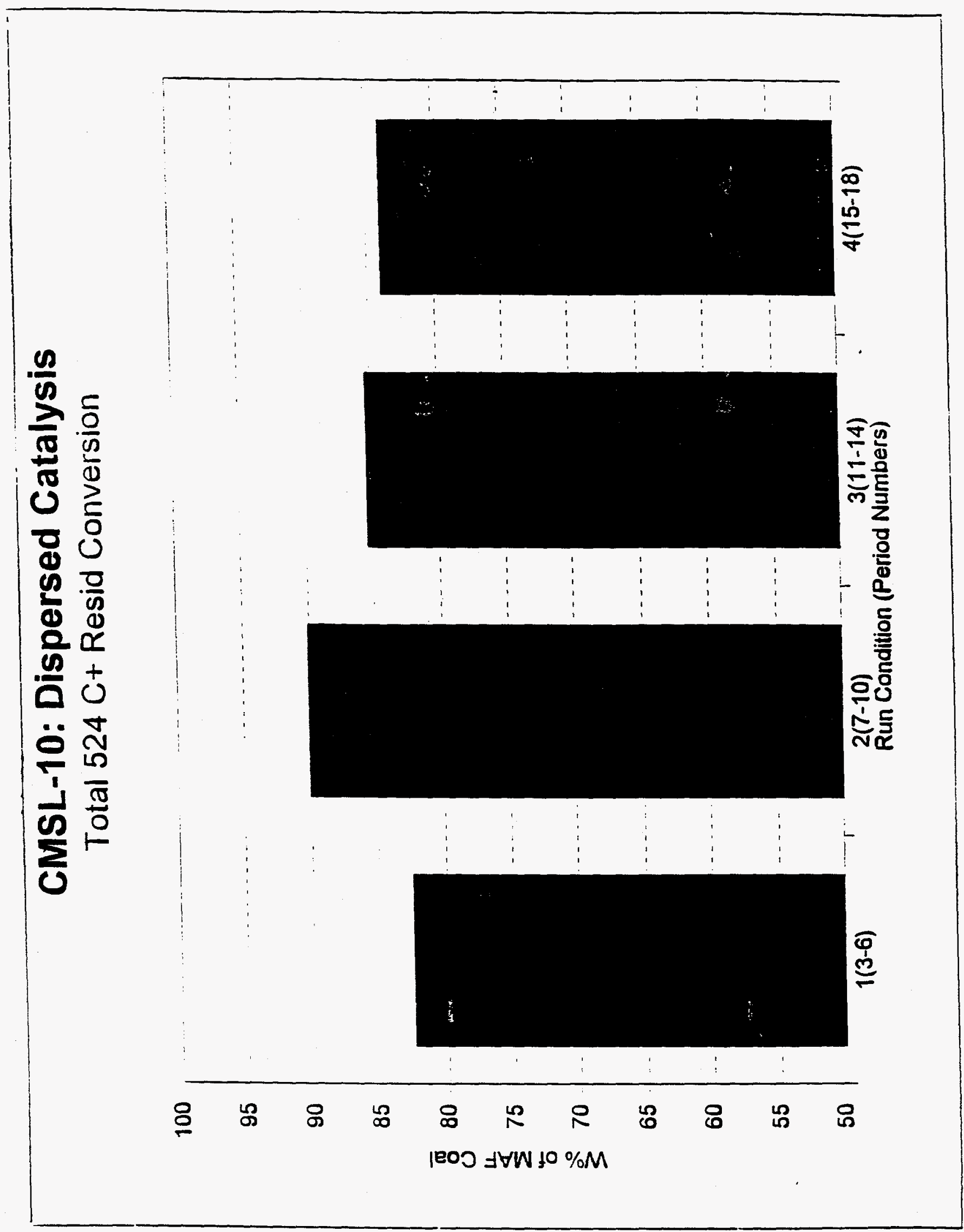


Figure 2.10.4

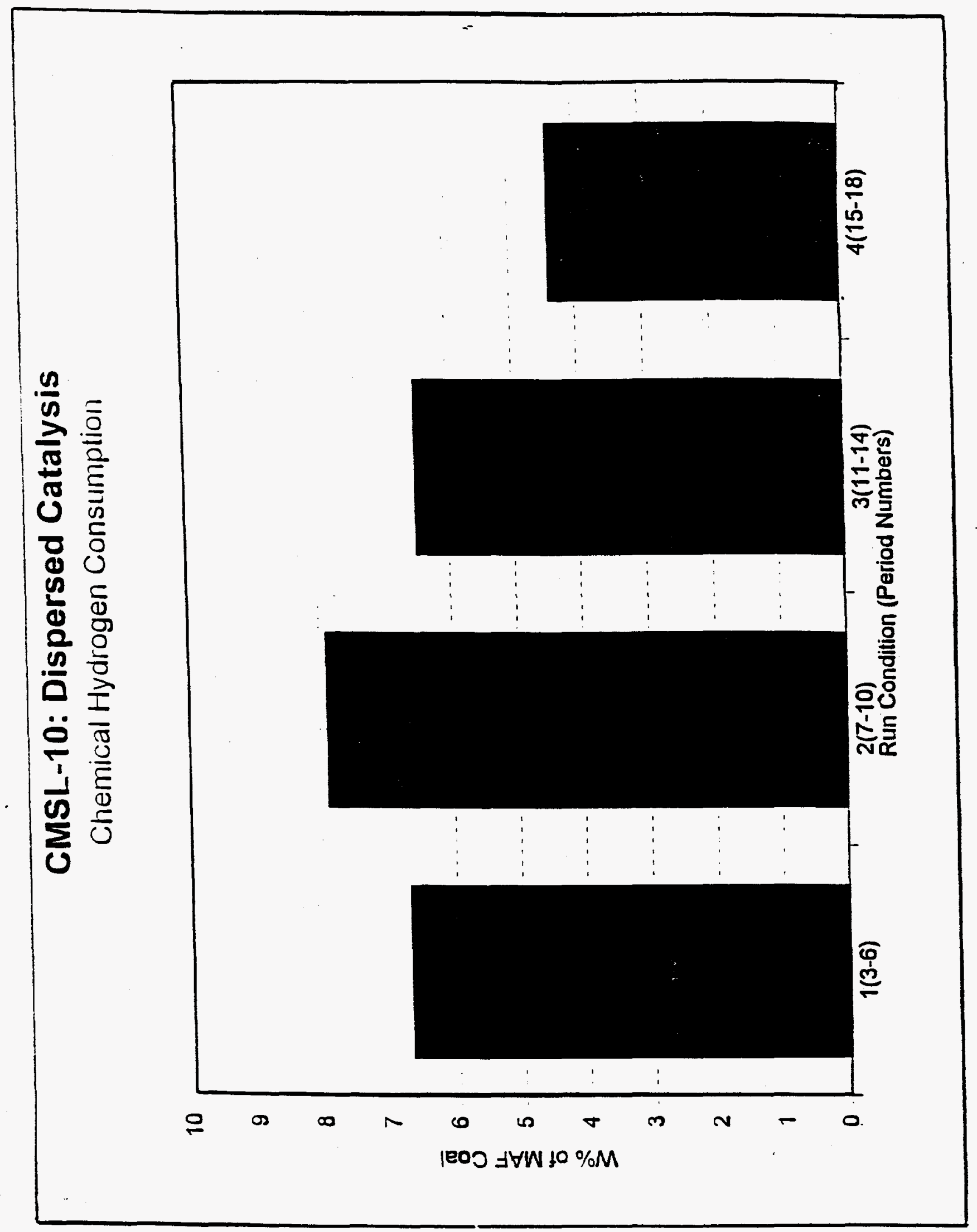


Figure 2.10.5

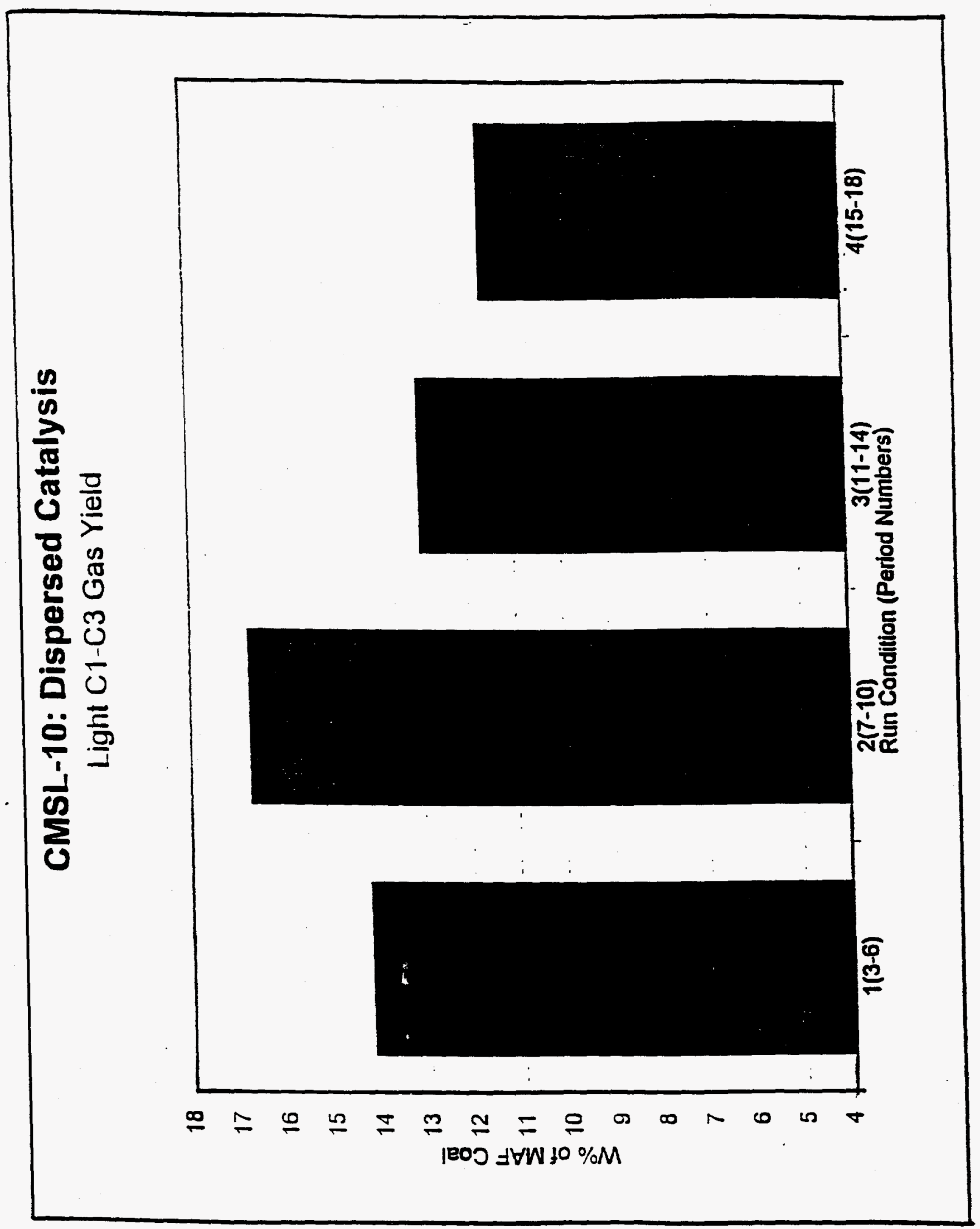


Figure 2.10.6

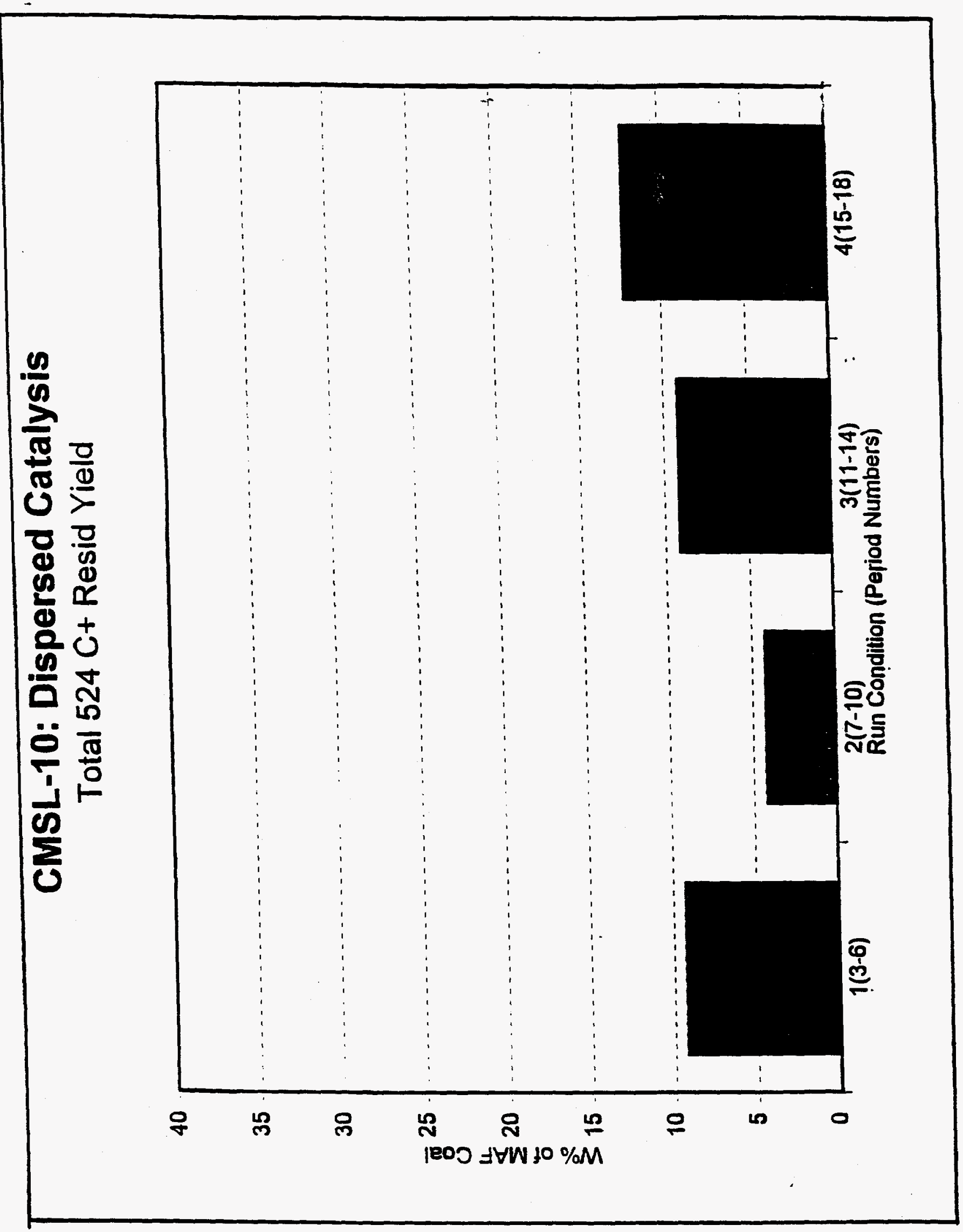


Figure 2.10.7

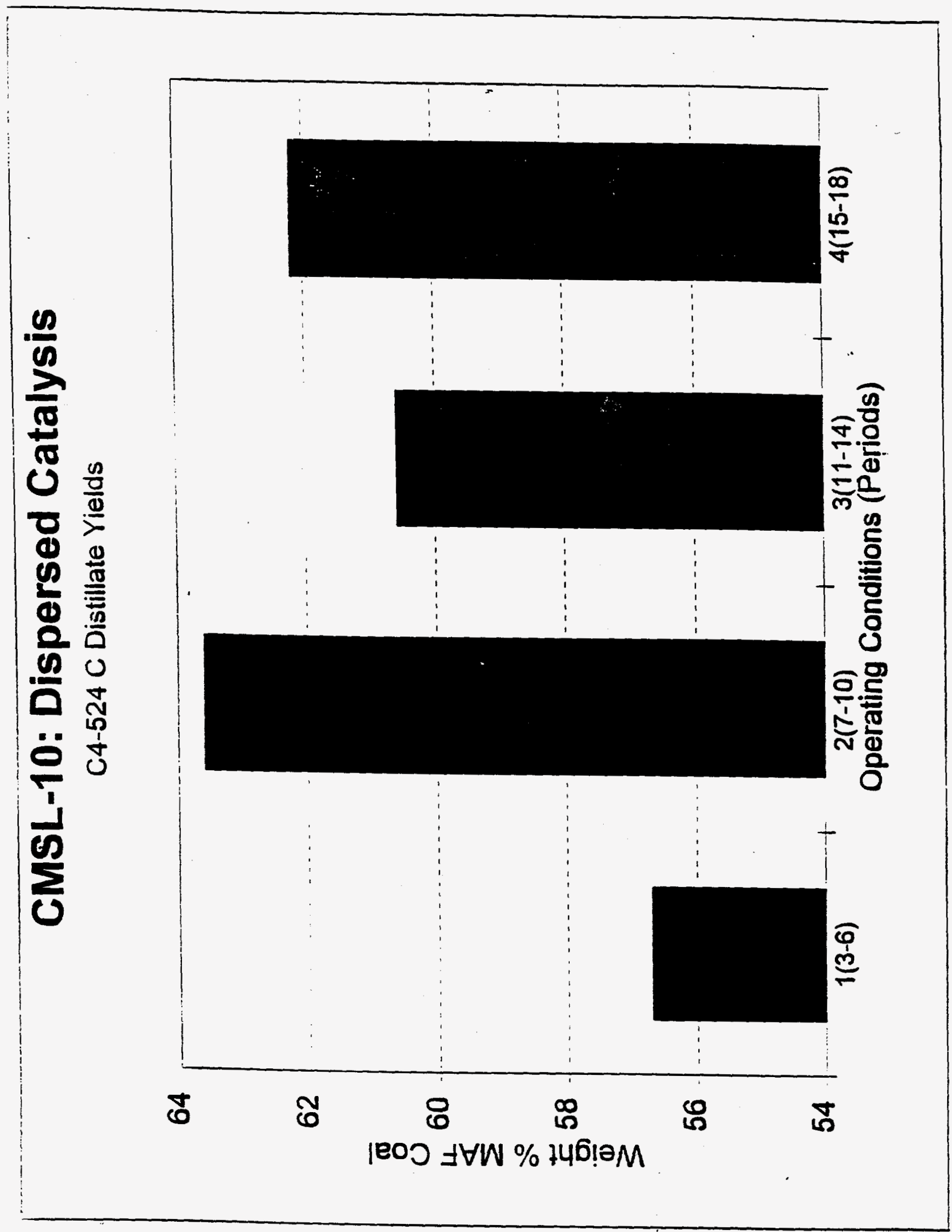


Figure 2.10.8
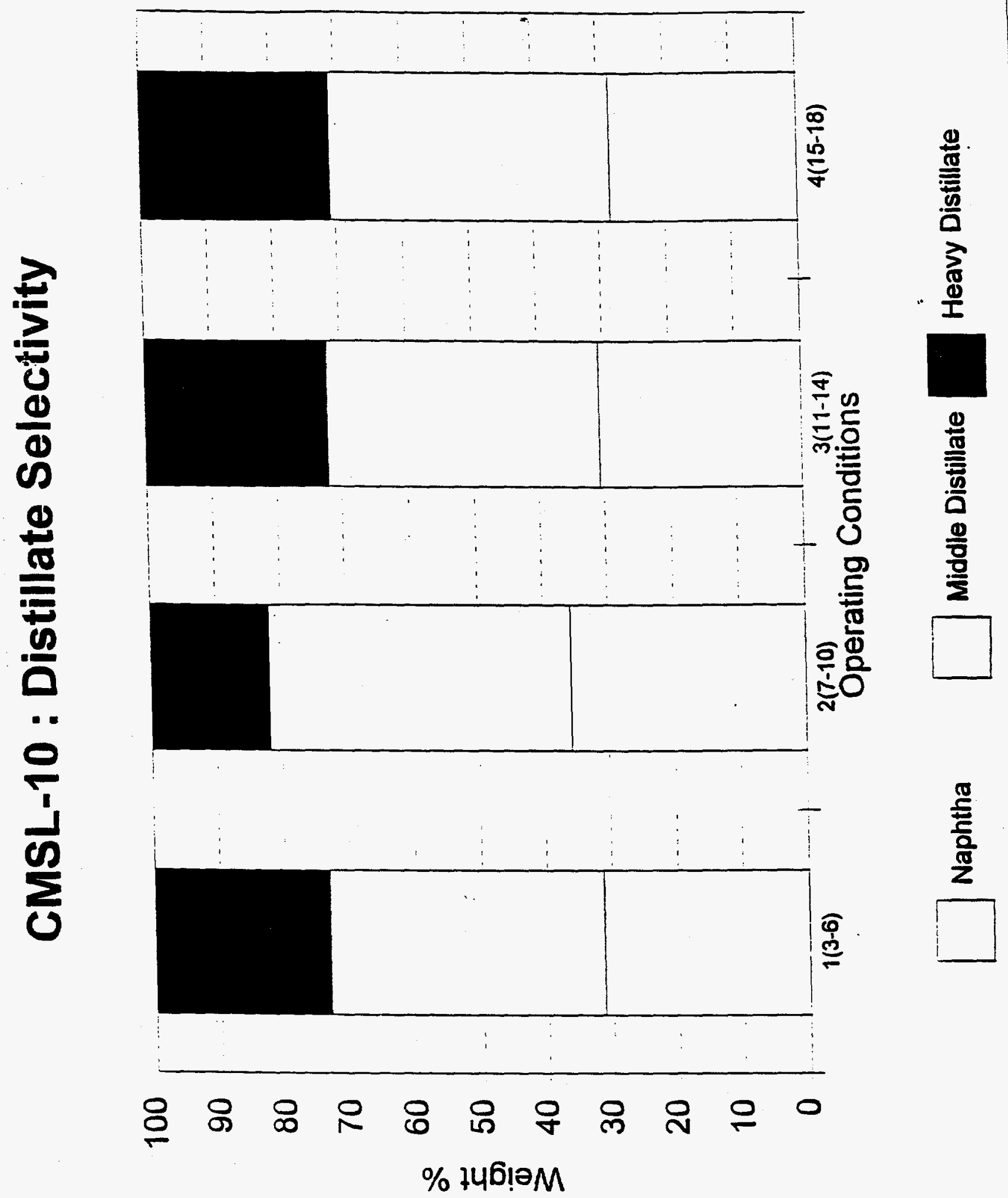


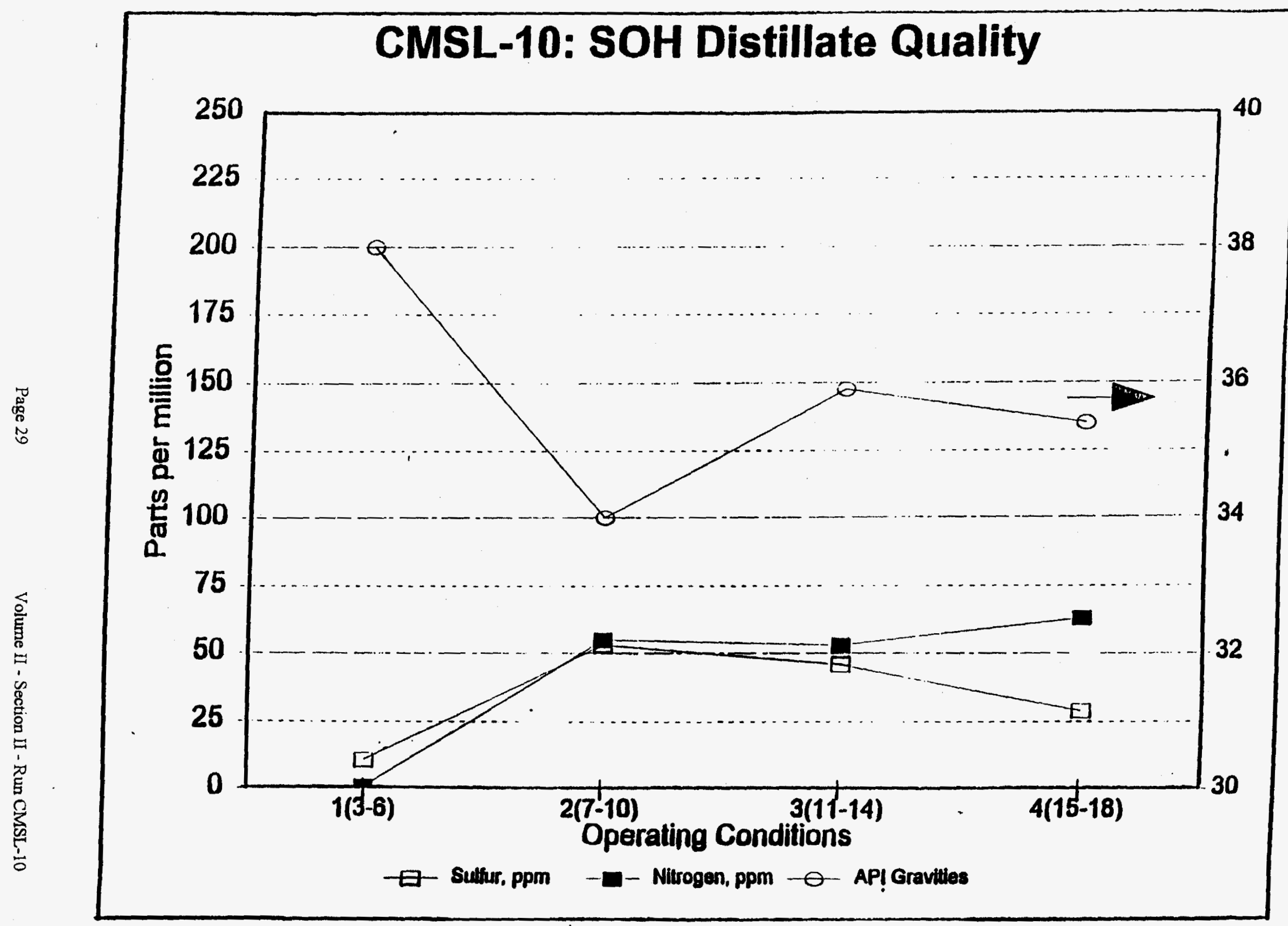




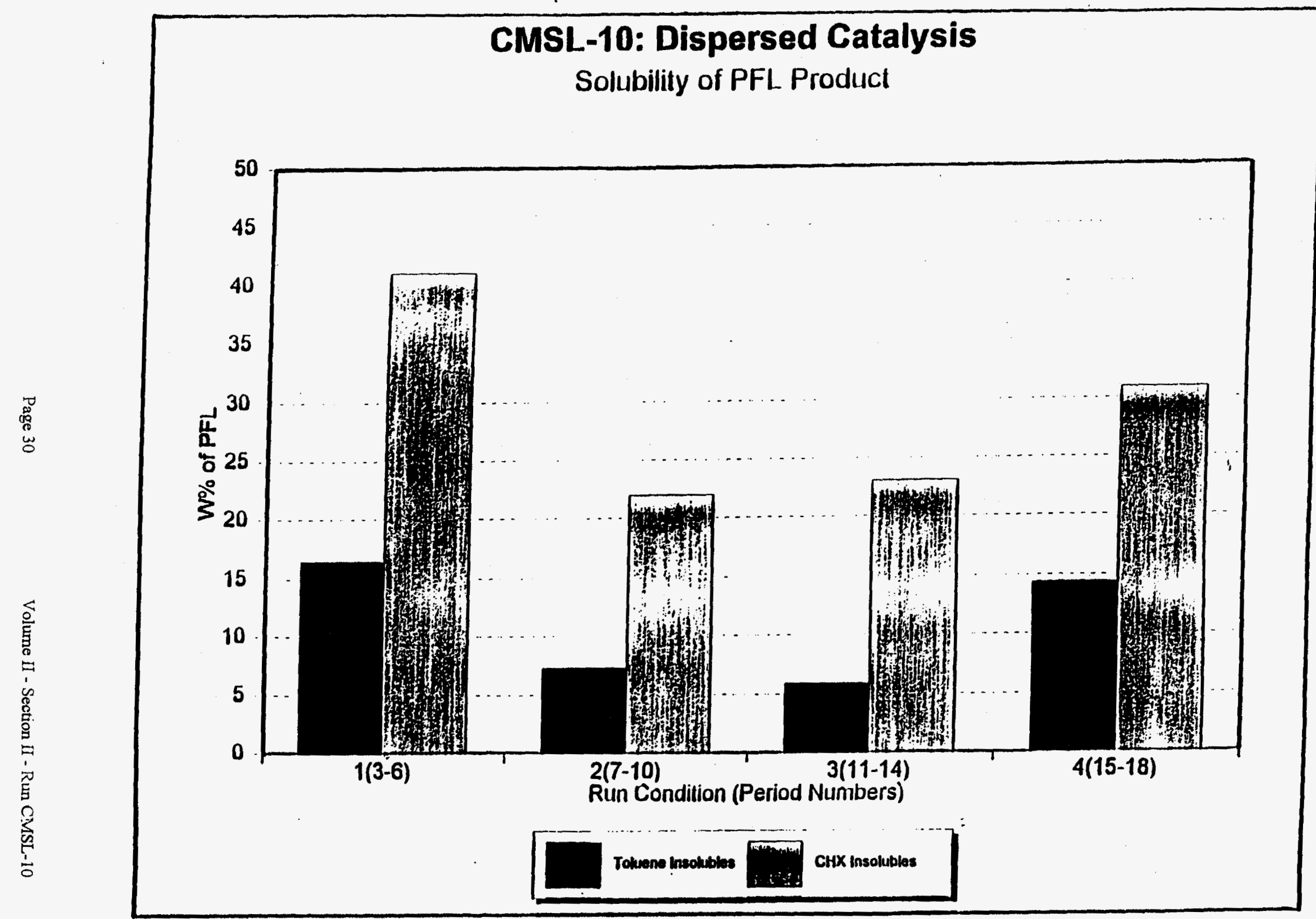


W\% Mass Balance Recovery

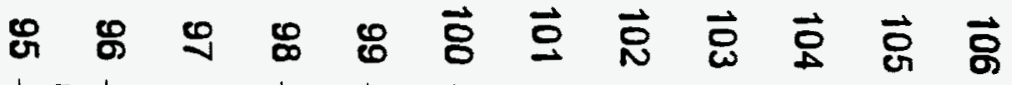

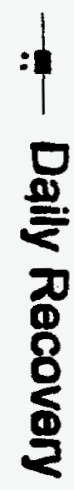

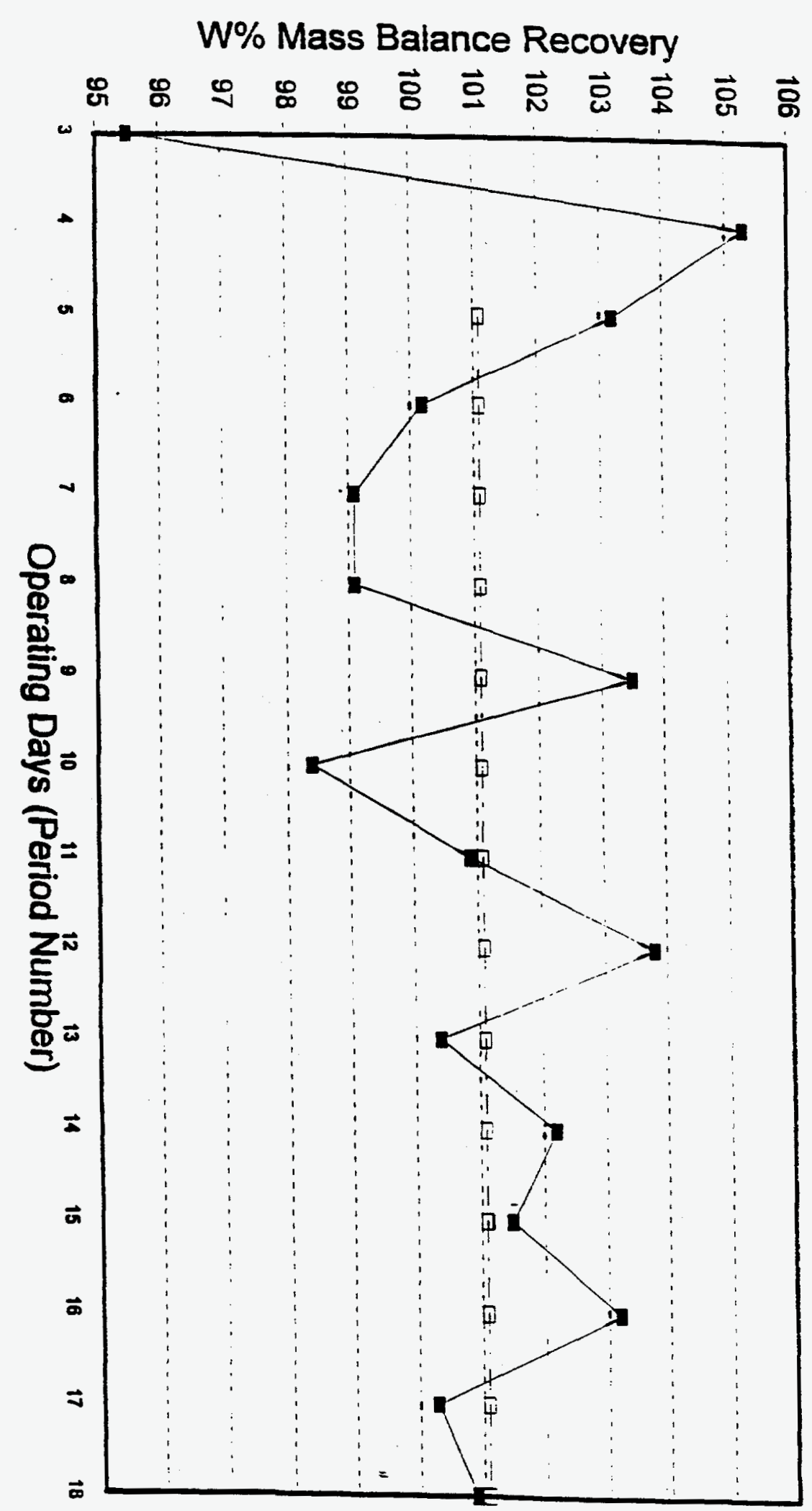

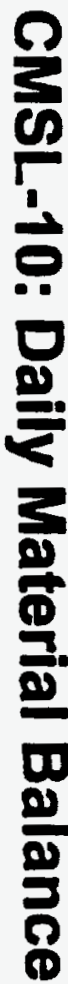




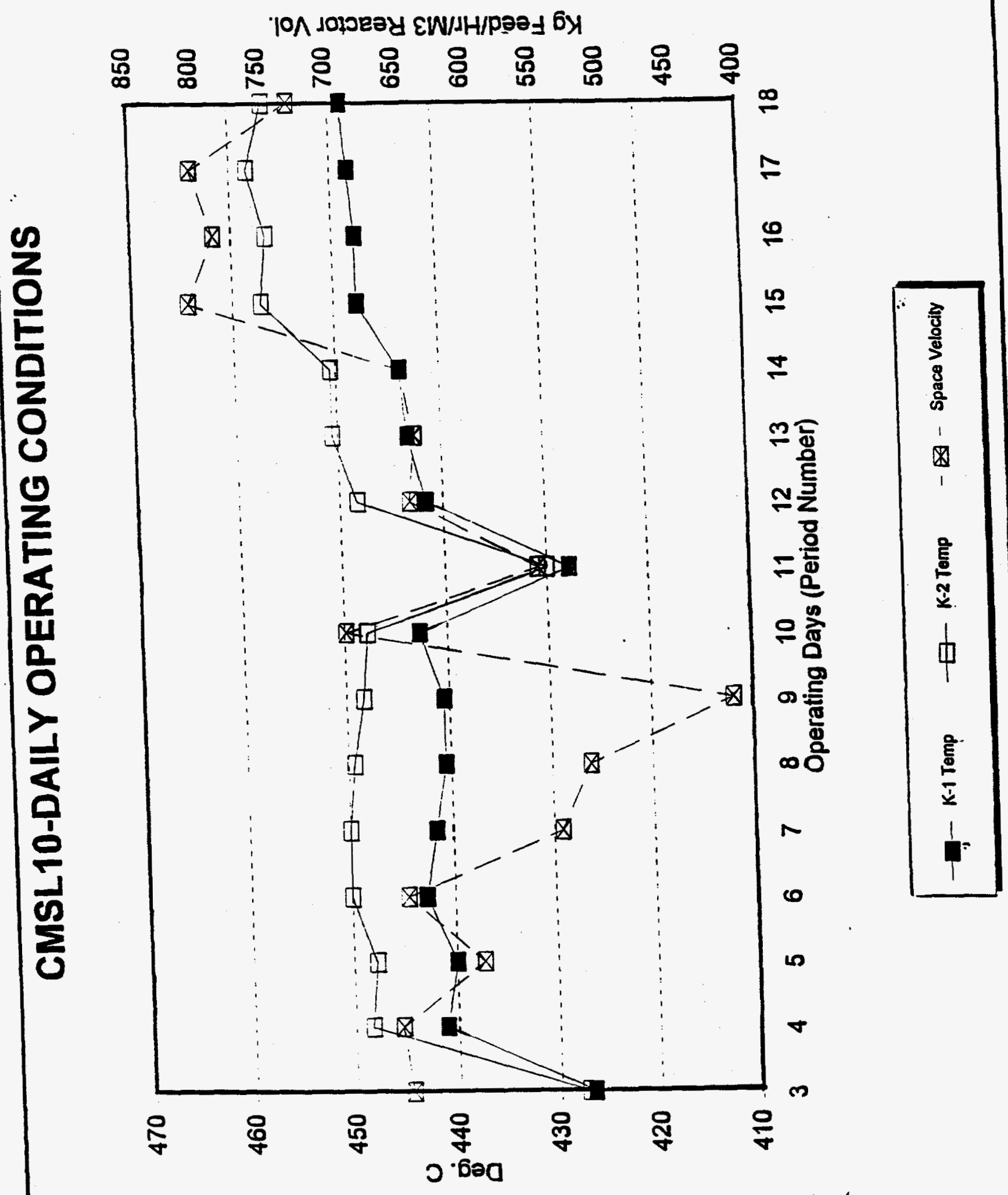




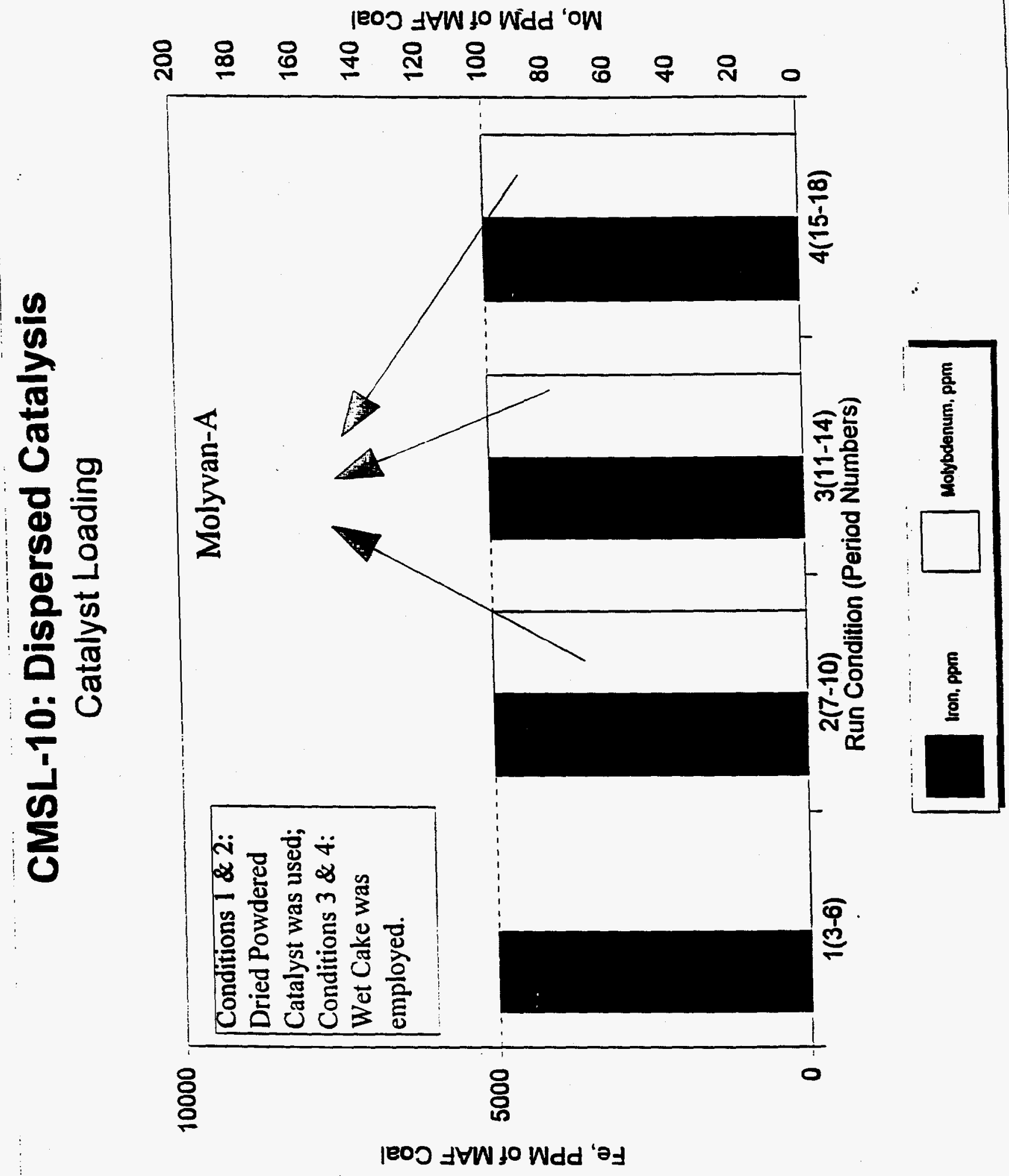


CATALYTIC MULTI-STAGE LIQUEFACTION OF COAL (CMSL) FINAL REPORT

VOLUME II

SECTION II (CONTINUED)

EVALUATION OF A COMBINED IRON-MOLYBDENUM DISPERSED SLURRY CATALYST SYSTEM FOR DIRECT LIQUEFACTION OF BLACK THUNDER MINE COAL AND ITS COPROCESSING WITH WASTE PLASTICS

RUN CMSL - 11 
VOLUME II

SECTION II - RUN CMSL-11

TABLE OF CONTENTS

RUN CMSL-11 (227-89)

EVALUATION OF A COMBINED IRON-MOLYBDENUM DISPERSED SLURRY

CATALYST SYSTEM FOR DIRECT LIQUEFACTION OF BLACK THUNDER MINE COAL AND ITS COPROCESSING WITH WASTE PLASTICS

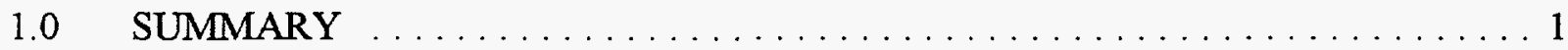

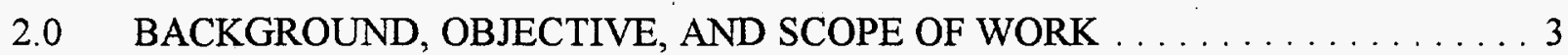

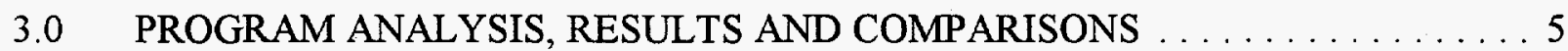

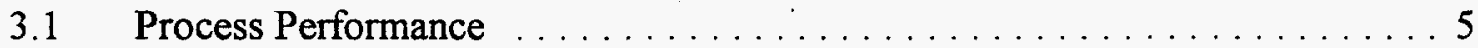

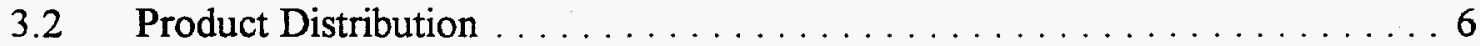

3.3 Product Quality $\ldots \ldots \ldots \ldots \ldots \ldots \ldots \ldots \ldots \ldots \ldots$

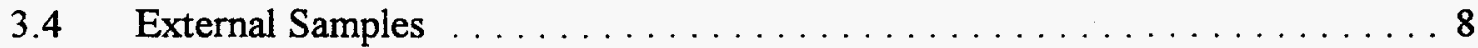

$3.5 \quad$ Hydrotreater Performance $\ldots \ldots \ldots \ldots \ldots \ldots \ldots \ldots \ldots$

3.6 Dispersed Catalysts Comparisons . . . . . . . . . . . . . . . 9

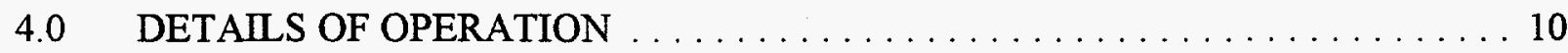

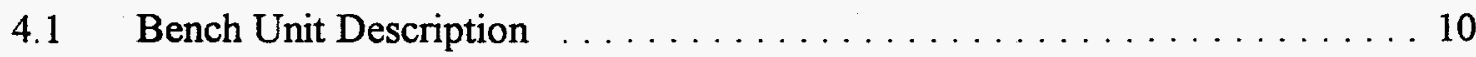

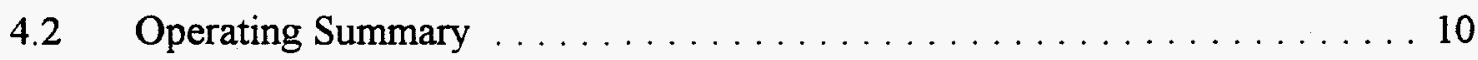

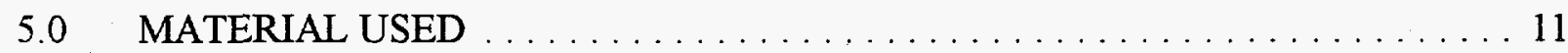

5.1 Coal And Plastic Feeds $\ldots \ldots \ldots \ldots \ldots \ldots \ldots \ldots \ldots \ldots \ldots \ldots$

$5.2 \quad$ Start-Up And Make-Up Oil $\ldots \ldots \ldots \ldots \ldots \ldots \ldots \ldots \ldots$

$5.3 \quad$ Catalysts $\ldots \ldots \ldots \ldots \ldots \ldots \ldots \ldots \ldots \ldots \ldots \ldots \ldots \ldots \ldots$

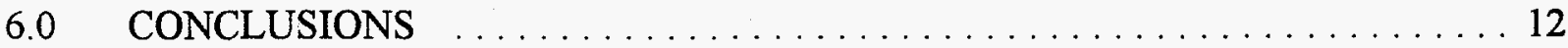


VOLUME II

SECTION II - RUN CMSL-11

LIST OF TABLES

Table

Page

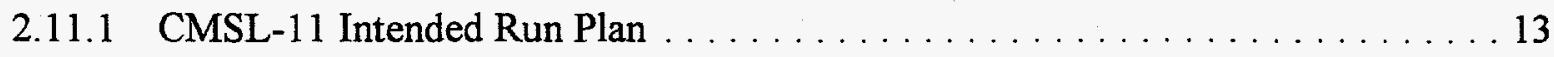

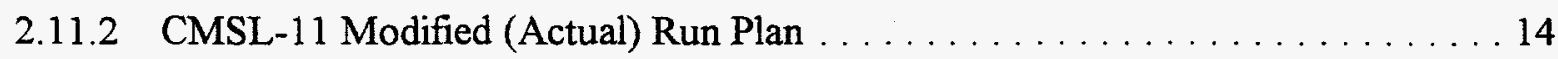

2.11.3 Run CMSL-11 Process Performance Summary* . . . . . . . . . . . . . . 15

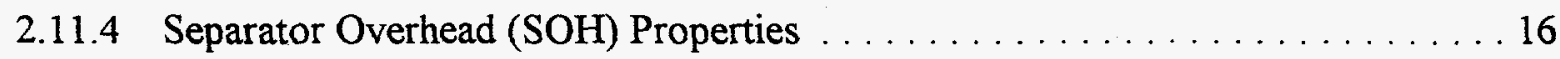

2.11.5 Properties of the Pressure Filter Liquids (Second Stage) . . . . . . . . . . . 17

2.11.6 Inspection of the Pressure Filter Solids (Second Stage) $\ldots \ldots \ldots \ldots \ldots 18$

2.11 .7 Samples sent to Consol, Inc. . . . . . . . . . . . . . . . . . . . . . . . 19

2.11.8 Dispersed Catalysts: Process Performance Comparisons . . . . . . . . . . . . . 20

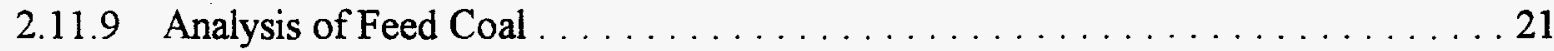

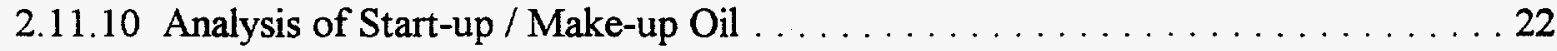

2.11.11 Calculation of Products Derived from Plastics Addition . . . . . . . . . 23 


\section{VOLUME II}

\section{SECTION II - RUN CMSL-11}

\section{LIST OF FIGURES}

Figure

Page

2.11.1 Simplified Schematic of Bench Unit Configuration . . . . . . . . . . . . . 24

2.11.2 CMSL-11: Feed \& Resid Conversions . . . . . . . . . . . . . . 25

2.11.3 CMSL-11: Gas Yield/H2 Consumption $\ldots \ldots \ldots \ldots \ldots \ldots \ldots \ldots \ldots \ldots$

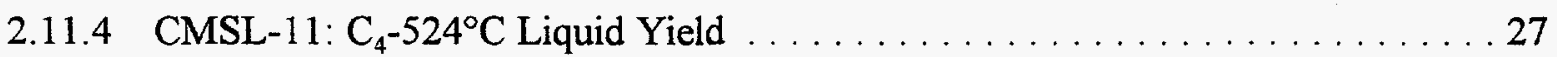

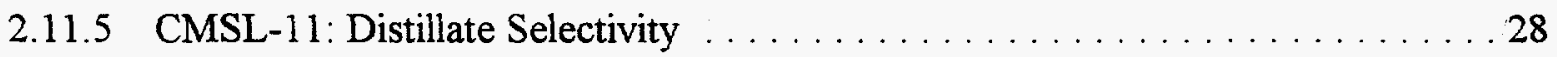

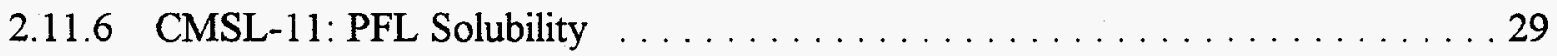

2.11.7 CMSL-11: Daily Material Balances $\ldots \ldots \ldots \ldots \ldots \ldots \ldots \ldots \ldots \ldots \ldots \ldots$

2.11 .8 CMSL-11: Daily Feed Space Velocities $\ldots \ldots \ldots \ldots \ldots \ldots \ldots \ldots \ldots$

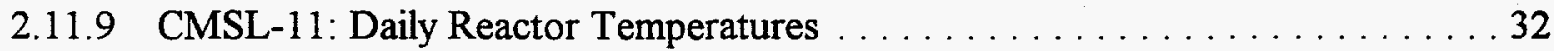

2.11.10 CMSL-11: Feed Composition $\ldots \ldots \ldots \ldots \ldots \ldots \ldots \ldots \ldots \ldots \ldots \ldots \ldots \ldots$

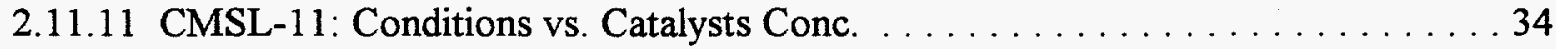

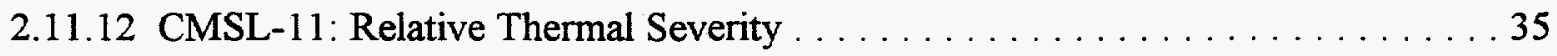




\section{EVALUATION OF A COMBINED IRON-MOLYBDENUM DISPERSED SLURRY CATALYST SYSTEM FOR DIRECT LIQUEFACTION OF BLACK THUNDER MINE COAL AND ITS COPROCESSING WITH WASTE PLASTICS}

\subsection{SUMMARY}

The Bench Run CMSL-11 (227-89) was carried out using two-stage close-coupled back-mixed reactor system with dispersed slurry catalysts based upon iron and molybdenum. The two-stage conversion reactors were preceded by a preheater coil, in place of the half sized reactor used in earlier runs for the sulfidation of dispersed catalyst. The entire bench run, initially planned for sixteen operating days and five Conditions, actually was operated for 17 days and valuable process performance data from four operationally smooth and meaningful conditions was obtained.

During the first two run conditions, with coal-only feed, high conversions of coal (over 95\% MAF) and $524^{\circ} \mathrm{C}+\left(975^{\circ} \mathrm{F}+\right)$ resid $(89-91 \% \mathrm{MAF})$ were obtained with distillate liquid yields of $63-65 \%$ MAF. Both conditions employed $5000 \mathrm{ppm}$ iron from HTI's proprietary catalyst and $50 \mathrm{ppm}$ Mo as Molyvan-A, and Condition 2 had an additional $50 \mathrm{ppm}$ Mo incorporated in HTI's iron additive. During these two conditons very high yields, $15-18 \% \mathrm{MAF}$, of light $\mathrm{C}_{1}-\mathrm{C}_{3}$ hyrocarbn gases were obtained because of the high process severities of the operations. The almost equivalent performance, at best, of Condition 2 compared tothat of Condition 1 indicates no impact of the incorporation of the Mo with the iron additive. Also there were operational problems during these conditions resulting from the higher viscosities, $2000 \mathrm{cps}$ at $149^{\circ} \mathrm{C}$, of the feed slurries and the difficulty encountered during solids separation by pressure filtration.

During the coal/waste plastics coprocessing conditions, an initially intended run plan had the individual color-regrinds of HDPE, high-impact polystyrene (HIPS), and polypropylene wastes feeding to the unit with coal. It was found that one of these plastics, possibly HIPS, would not completely homogenize with the recycle oil and would make pumping of the highly viscous slurries impossible. Therefore, from Period 13B onwards a switch was made to a "real life" waste plastics obtained from the Monmouth Recycling Facility, NJ, to coprocess with coal. During this coprocessing condition, with both $33 \mathrm{Wt} \%$ and $25 \mathrm{Wt} \%$ mixed waste plastics, which were cleaned and shredded in house prior to the run, were fed together with coal. The introduction of waste plastics in the feed with coal made the recycle solvent more paraffinic and lighter as compared to the 'coal-only' conditions. As a result, the pressure filtration became faster and easier. All other process conditions such as severity and catalyst concentrations were kept the same as in the 'coalonly' Condition 2. Interestingly, during the coprocessing conditions, the light distillate yield increased by $3-5 \%$; the yield of light hydrocarbon gases decreased by as much as $50 \%$ (relative) while the hydrogen consumption decreased from about $6.5 \%$ during 'coal-only' conditions to about $3.9-4.7 \%$ dry basis. Thus, it is evident now that even with a 'real life' MSW plastic waste, coprocessed with coal, better hydrogen utilization is obtained. The yield of heavy resid $\left(524^{\circ} \mathrm{C}+\right)$ increased during the coprocessing conditions. The presence of $\mathrm{HDPE}$ in waste plastics contributes to the high resid (this is mostly waxy in nature) formation. In the future bench experiments, it 
would be therefore worthwhile to introduce fresh dispersed catalyst (more specifically molybdenum) into the higher temperature second stage conversion reactor.

The in-line hydrotreater during the Periods of the Run when it was on-line, yielded distillates with less than $50 \mathrm{ppm}$ sulfur and nitrogen. The overall quality of the products from coprocessing during this Run was apparently different from the earlier coprocessing runs with 'simulated' waste plastic mixtures; this can be attributed to the heterogeneous nature of the actual plastic waste employed for the first time at HTI during this run . Various process stream samples, collected for Consol, Inc., for detailed analyses should shed some light on the effect of the starting waste:plastic composition on the product properties. 


\subsection{BACKGROUND, OBJECTIVE, AND SCOPE OF WORK}

The CMSL Project is geared to evaluate different novel processing concepts in catalytic coal liquefaction to complement the larger scale process demonstration "Proof-of-Concept" Studies for the U.S. DOE. The new ideas being explored in this program include low temperature pretreatments, more effective catalysts, on-line hydrotreating, new coal feedstocks, other (cheaper) sources of hydrogen, more concentrated coal-slurry feeds, waste hydrocarbon streams etc.

The Bench Run CMSL-11 was carried out using a dispersed catalyst-only two-stage close-coupled back-mixed reactor system. The two-stage conversion reactors were preceded by a preheater coil which allowed feed slurry a residence time of about five minutes at $300^{\circ} \mathrm{C}$. The pretreatment coil was used for sulfidation of the dispersed catalyst additive. The bench run CMSL-11 was seventeen days long, comprising of five operating conditions (3-5 days each). The objectives of this bench operation were:

- To determine the process performance for a subbituminous coal liquefaction catalyzed by novel combinations of iron and molybdenum dispersed slurry catalysts at different process severities.

- To investigate the effect of pretreater residence time on the activity of dispersed catalyst additive.

- To determine the impact of using "real life" mixed plastics wastes, recovered from MSW facilities, in coprocessing with coal, upon the overall conversion process performance.

- To study the pre-conversion reactor processing/handling of the "real life" mixed plastics wastes so that such plastic waste can be reduced from a "raw" as-received form to a "processed" form, suitable for feeding with coal into the conversion reactors.

An in-line hydrotreater was used during this run (except for Period 17). Both the separator (O-1) overheads including knockouts and the $\mathrm{ASOH}$ were sent through the hydrotreater while as the atmospheric still was operating through Period 7 of the run (Figure 2.11.1).

The initially intended Run Plan (Table 2.11.1) included five Run Conditions that were selected to meet the technical objectives, specified above. The first two Run Conditions were to delineate the role of HTI's new Fe-Mo- $\mathrm{SO}_{4}$ formulation slurry catalyst vs. the individually added precursors of iron and molybdenum. When added separately, $\mathrm{HTI}^{\prime} \mathrm{Fe}-\mathrm{SO}_{4}$ formulation precursor (employed successfully during CMSL-10) was used for iron and Molyvan-A was used as a source of Mo. During Condition 3, the reactor temperatures were to be increased along with the feed space velocity to maintain the overall process severity; the amount of molybdenum added was to be increased from 50 to $100 \mathrm{ppm}$ during this condition. The next two Conditions, 4 and 5 , were specifically designed to study the coprocessing of coal with $33 \mathrm{~W} \%$ of the "real life" mixed waste plastics, under operating conditions similar to those for Condition 3 . Recycle oil to feed ratio was to be increased from 1 to 1.5 , depending upon the process requirement. Condition 4 was to utilize 
waste plastics obtained from the Federal Plastics Corporation, NJ. These plastics were the mixed color regrinds of $\mathrm{HDPE}, \mathrm{PP}$, and high impact PS. In the combined feed, $40 \%$ of HDPE waste, $33 \%$ of PP waste, and $27 \%$ of the HIPS waste were to be used. Condition 5 , on the other hand was to employ an already mixed form of a plastic waste (more than $95 \mathrm{~W} \%$ plastics) obtained from a Material Recovery Facility in northern NJ, Monmouth Recycling Company. This particular compacted plastic waste needed to be washed to remove paper and metal scrap from it and then it was chipped to a size suitable for addition into the coal-oil slurry.

During the run attempted operations at the intented Condition 2 mode, with the bimetallic $\mathrm{Fe} / \mathrm{Mo}$ additive at $50 \mathrm{ppm}$ Mo (on coal) as the only catalyst, was unsuccessful when it proved difficult to maintain feed slurry low because its high viscosity. To reduce the viscosity of recycled PFL solvent and maintain operability the atmospheric still removing ASOH from feed to the filter was taken off line in Period 7. Also, $50 \mathrm{ppm}$ of molybdenum as Molyvan A along with the bi-metallic Fe/Mo catalyst was used as catalyst after Period 7.

Consequently, the actual Run Plan (Table 2.11.2) was different from original Run Plan. Also, highly viscous product slurries in the coal-only operations (possibly due to the type of resid material formed when using only dispersed catalysts) made the recovery of recycle solvent by pressure filtration of the product slurry increasingly difficult until the start of the coprocessing operation when the product slurries filtered more rapidly. The first intended coprocessing operation using the "color regrind" re-processed plastic mix was aborted when a pumpable slurry could not be prepared with the mix as the plastic component. Pumpable slurries of relatively high viscosity were prepared with "real life" waste plastic mix from Monmouth Recycling as the plastics component, but for improved pumpability the proportion of the waste plastic was lowered from $33 \%$ of the feed in Condition $3 \mathrm{~A}$ to $25 \%$ in Condition 3B.

Because of these operational problems only four operationally successful, satisfactory data points were obtained. Conditions 1 and 2 were coal-only conditions and studied the effect of HTT's Fe-Mo formualtion on process performance. Conditions $3 \mathrm{~A}$ and $3 \mathrm{~B}$ were plastics co-processing tests using $33 \%$ ad $25 \%$, respectively, of the Monmouth Recycling plastic mix. The in-line hydrotreater plugged so that it had to be by-passed during Period 17 (Condition 3B). 
The process performance in terms of total conversion, product yields and qualities is discussed in this section. Detailed laboratory analysis of the products was performed on a daily basis to provide timely process evaluation. The daily material balance, coal conversion, normalized yields and other process performance-related indicators were calculated using programs available in CTSL database. Some programs were modified according to the requirement of the process configuration. The overall process performance during CMSL-11 is summarized in Table 2.11.3.

\subsection{Process Performance}

\section{Coal Conversion}

The total coal conversion is calculated on the basis of the solubility of pressure filter solids in quinoline. The coal conversions for different conditions are shown in Figure 2.11.2. Throughout the course of the run, the coal/feed conversions varied between $94.5 \mathrm{~W} \%$ and $95.5 \mathrm{~W} \%$, MAF. Condition 1, with $5000 \mathrm{ppm}$ iron and $50 \mathrm{ppm}$ of molybdenum relative to coal, added as HTI's iron catalyst and Molyvan-A respectively, gave an average coal conversion of over $95 \mathrm{~W} \% \mathrm{MAF}$. As these conversion levels were already high, no improvement in coal conversion number was observed in the subsequent run conditions. A high conversion level about $95 \mathrm{~W} \%$ MAF was maintained throughout the run, even during the coal/waste plastics coprocessing conditions.

\section{$524^{\circ} \mathrm{C}+\left(975^{\circ} \mathrm{F}^{+}\right)$Residuum Conversion}

The $524^{\circ} \mathrm{C}+\left(975^{\circ} \mathrm{F}\right)$ resid conversion represents the ability of the process for the conversion of heavy (high boiling) fractions contained in the feed. For the purpose of calculations, all of the MAF portion of the feed coal is considered a $524^{\circ} \mathrm{C}+\left(975^{\circ} \mathrm{F}^{+}\right)$resid in the feed. The $524^{\circ} \mathrm{C}+\left(975^{\circ} \mathrm{F}^{+}\right)$resid conversion values varied between 84 and $92 \mathrm{~W} \% \mathrm{MAF}$ and were more sensitive than the total coal conversion values to the addition of Molyvan-A catalyst, feed composition, and to the change in space velocity. The resid conversions during each condition are shown in Figure 2.11.2. There was 2.4\% lower resid conversion during Condition 2 than during Condition 1, which suggests that the Mo addition as 50 ppm from Molyvan $\mathrm{A}$ and $50 \mathrm{ppm}$ in the bi-metallic $\mathrm{Fe} / \mathrm{Mo}$ additive used in Condition 2 was less effective than the $50 \mathrm{ppm}$ Mo from Molyvan used in Condition 1. However, another factor contributed to the lowered resid conversion of Condition 2, in that the Atmospheric Still was taken out of service after Condition 1 so that the solvent recycle contained a higher proportion of light distillates and a lower proportion of residual oil which was kinetically unfavorable for the conversion of residuum to lighter products. A direct estimate of the impact upon the residuum conversion awaits development of a kinetic model for the alldispersed catalyst systems. However, the model for CTSL operations using extrudate catalyst indicates that at this level of performance incorporating the 8-12\% (on coal) of ASOH in the PFL recycle, as in Run CMSL-11, would lower resid conversion by about $2 \%$, very close to the difference in the results for Condition 1 and Condition 2. 
Even after such a consideration, the molybdenum in the bi-metallic catalyst appeared to have very little effect. Possibly, it would be more effective to stage the addition of dispersed catalysts so that both stages are fed with "fresh" dispersed catalysts, either iron or molybdenum.

During the coal/waster plastics operations resid conversion levels were lower by $5-7 \%$, probably because the refractory high density polyethylene in the plastics was incompletely converted to light liquids and gases under these conditions.

\section{Hydrogen Consumption}

Hydrogen consumption based on the MF feed varied between 3.9 and $6.5 \mathrm{~W} \%$ on dry basis. The chemical hydrogen consumption was at similar levels for the first two run conditions. As shown in Figure 2.11.3, the consumption decreased significantly during coal/waste plastics coprocessing conditions. This observation, which is similar to those made during the earlier bench runs with coal/waste plastics coprocessing, confirms the hypothesis that the presence of $25-33 \mathrm{~W} \%$ mixed waste plastics in feed with coal improves the hydrogen utilization and makes the overall process more hydrogen efficient.

\section{Heteroatom Removal}

As was the case with most of the earlier CMSL Runs with respect to heteroatom removal, excellent levels of nitrogen and sulfur removal were obtained during CMSL-11 also. During the first three conditions of CMSL-11 (Periods 5, 10, and 16) when the hydrotreater was on line, less than $50 \mathrm{ppm}$ of sulfur and nitrogen each were obtained in the net $\mathrm{SOH}$ distillates from the process. The $\mathrm{H} / \mathrm{C}$ ratios were also high, between 1.7 and 1.8. The quality of SOH distillates deteriorated sharply during Period 17 when the hydrotreater was taken offline. As high as $3500-5000$ ppm of nitrogen and sulfur levels resulted with a small reduction in the hydrogen content $(\mathrm{H} / \mathrm{C}$ of 1.6$)$.

\subsection{Product Distribution}

\section{$\mathrm{C}_{1}-\mathrm{C}_{3}$ Gas Yields}

As shown in Figure 2.11.3, the normalized $\mathrm{C}_{1}-\mathrm{C}_{3}$ gas yield for CMSL-11 varied between 7.1 and $17.2 \mathrm{~W} \%$. During the 'coal-only' conditions, Conditions 1 and 2 , the light gas yields were very high (15-17\%), probably as a result of high process severity. Indeed, it is believed that the thermal severity of the process during the 'coal-only' liquefaction conditions should be reduced in order to optimize the product distribution and, mainly, the light distillate liquids selectivity. The light gas yield dropped significantly during the coal/plastics coprocessing conditions. This decrease in gas yield was more than even the proportion of waste plastics in the feed with coal, indicating that the presence of plastics in the feed leads to the reduction in the light gas formation from coal. 


\section{$\mathrm{C}_{4}-975^{\circ} \mathrm{F}$ Distillate Yields And Selectivity}

The distillate yields varied between 63 and 68 W\%. As shown in Figure 2.11.4, the distillate yields were not significantly different for the first two 'coal-only' conditions, once again indicating that there was no apparent advantage of adding $50 \mathrm{ppm}$ molybdenum from HTI's bimetallic formulation to the catalysts employed during Condition 1: $5000 \mathrm{ppm}$ iron from HTI's iron precursor and 50 ppm moly from Molyvan-A. During CMSL-11, as observed during the coal/plastics coprocessing conditions of the previous bench runs, higher $(3-5 \%)$ yields of distillate liquids were obtained both with 33 and $25 \mathrm{~W} \%$ mixed waste plastics in feed with coal. $67 \%$ and higher yields were obtained during the coprocessing conditions. Contrary to the earlier bench runs though, the distillates from coal/plastics coprocessing conditions were slightly heavier (Figure 2.11.5), indicating a shift to the formation of more heavy distillates $\left(343^{\circ} \mathrm{C}+\right)$ in going from the 'coal-only' to 'coal-plastics' coprocessing conditions. This could be due to the actual types of waste plastics in the "real life" mixture being different from the virgin plastics employed during the prior bench runs.

\section{Products Derived From Plastics}

Table 2.11.11 is a summary of the calculation of the nominal distribution of products derived from the plastic components assuming that the increments of yields for the coprocessing operation compared to those for a comparable coal-only operations were solely derived from the plastic. This estimate indicates for the Condition $3 \mathrm{~A}$ operation, with $33 \%$ commercial recycling plastic fee, nominally $72 \%$ of the plastic was converted to $\mathrm{C}_{4}$ $524^{\circ} \mathrm{C}$ distillates, with $26 \%$ dissolved (and filterable) and remaining as a residual oil, and $5 \%$ remaining as unconverted on the product filter cake. There was a negative nominal incremental $\mathrm{C}_{1}-\mathrm{C}_{3}$ yield derived from the plastics, $-4.8 \mathrm{~W} \%$, and the nominal hydrogen consumption by the plastics was also negative, $-1.6 \mathrm{~W} \%$.

In Condition 3B operation, now with $25 \%$ of the plastic in the feed, about the same proprotion, $76 \%$, of distillates were derived from the plastic and filterable resid was $32 \%$ of the product from the plastic. The impact of the plastics upon the $\mathrm{C}_{1}-\mathrm{C}_{3}$ gas yields again corresponded to a negative selectivity, $-16 \mathrm{~W} \%$, with a nominal hydrogen consumption by the plastics that was also negative, $-0.6 \mathrm{~W} \%$.

This analyses also indicates a very surprising result, in that there was nominally a considerable formation of water from the plastic, $9 \mathrm{~W} \%$ and $17 \mathrm{~W} \%$ for Conditions $3 \mathrm{~A}$ and 3B, which reflects the higher total water yields of those Conditions than was obtained during the coal-only operation of Condition 2 . Also, nominally the plastics inhibited $\mathrm{CO}_{2}$ formation for the two cases at -6 and $-13 \mathrm{~W} \%$ of the plastic added. These unusual results reflect the difficulties of such by-difference calculations. However, even allowing for more "reasonable" values for the $\mathrm{C}_{1}-\mathrm{C}_{3}$, water and $\mathrm{CO}_{\mathrm{x}}$ yields it is evident that the proportions of distillates derived from the plastic were higher than that obtained from the coal. 
However, such distillates as were derived from the plastics were apparently of a relatively high boiling range, with over three-fourths of them being in the $343-524^{\circ} \mathrm{C}$ boiling range for the Condition 3A, 33\% plastics, operation.

\subsection{Product Quality}

Products of different fractions (Second-Stage Vent Gases, CAS Bottoms, SOH, PFL and PFS) from work-up periods 5, 10, 16 and 17 were analyzed in detail for their composition. The results of these analysis are summarized in Tables 2.11.4 through 2.11.6.

\section{Separator Overhead Product (SOH)}

The $\mathrm{SOH}$ oil stream represents the net light distillate (IBP- $399^{\circ} \mathrm{C}$ ) from CMSL-11. The properties of $\mathrm{SOH}$ oil for the work-up periods are shown in Table 2.11.4. As shown in this Table, SOH oil had a typical boiling range of $54-399^{\circ} \mathrm{C}\left(130-750^{\circ} \mathrm{F}\right)$. The amounts of IBP$177^{\circ} \mathrm{C}\left(\mathrm{IBP}-350^{\circ} \mathrm{F}\right)$, the lightest fraction of the $\mathrm{SOH}$ oil, was the highest for Condition 2 , after the ASOH feed to the hydrotreater was stopped. The API gravities (an indication of paraffinic character) of $\mathrm{SOH}$ oil for each work-up period were high ( $>34)$. The heteroatoms level (nitrogen and sulfur) were below $50 \mathrm{ppm}$ throughout the run, indicating a very successful operation of an in-line hydrotreater. In fact, during Period 17, when HTU had to be by-passed due to plugging problems, the heteroatom contents of the $\mathrm{SOH}$ distillates were much higher ( $3677 \mathrm{ppm}$ nitrogen and $4861 \mathrm{ppm}$ sulfur) than those during the HTU in-line Conditions. The H/C ratio of the SOH oil was also lower during Period 17. During the coal-plastics coprocessing of Period 16 there was a slight decrease in the lowest boiling fraction of the SOH oil, even though the API gravity of this SOH oil was the higher, indicating a more paraffinic nature.

\section{Pressure Filter Liquid (PFL) and Pressure Filter Solids (PFS)}

Pressure filter liquid (PFL) represents the liquid (oil) part of the atmospheric still (CAS) bottoms. In CMSL-11, CAS bottoms was not used as recycle solvent; only the solids-free PFL was used as the recycle oil. As shown in Table 2.11.5, the PFL consists of fractions that have broad boiling range. As shown in Figure 2.11.6, the toluene insoluble fraction in the $524^{\circ} \mathrm{C}+$ resid in the PFL varied from 8 to $13 \mathrm{~W} \%$ while cyclohexane insolubles varied from 21 to $28 \mathrm{~W} \%$. The concentration of the high boiling fraction $\left(524^{\circ} \mathrm{C}+\right)$ varied from 30 to $37 \mathrm{~W} \%$, depending on the process conditions/feed composition. The pressure filter solids analysis is presented in Table 2.11.6.

\subsection{External Samples}

As mentioned earlier, a number of samples of different process streams from CMSL-11 were obtained (for further detailed characterization and products assessment) for the Consol, Inc. and also for the members of Consortium of Fossil Fuel Liquefaction Science. These samples, their amounts, and the operating Periods when these were withdrawn are shown in Table 2.11.7. 


\subsection{Hydrotreater Performance}

As was the case with most of the earlier CMSL Runs with respect to heteroatom removal, high levels of nitrogen and sulfur removal were obtained during CMSL-11. During Conditions 2 and 3 (Periods 10 and 16) when the hydrotreater was online, less than $70 \mathrm{ppm}$ of sulfur and nitrogen each were obtained in the net $\mathrm{SOH}$ distillates from the process. During Condition 1, when the hydrotreater feed include ASOH, the nitrogen content of the $\mathrm{SOH}$ was $145 \mathrm{ppm}$. The H/C ratios were also high, between 1.7 and 1.8 . The quality of SOH distillates deteriorated sharply during Period 17 when the hydrotreater was taken offline. Nitrogen and sulfur levels as high as $3500-5000 \mathrm{ppm}$ resulted with a slightly lower hydrogen content (H/C of 1.6).

\subsection{Dispersed Catalysts Comparisons}

As shown in Table 2.11.8, iron and molybdenum based dispersed catalysts, used at 5000 and $100 \mathrm{ppm}$, respectively, were very effective during CMSL-10 and CMSL-11. Coal conversions as high as $95 \%$ MAF were obtained with over $85 \%$ resid conversions and over $60 \%$ light distillate yields. This process performance is comparable with the CMSL-9 data point presented in Table 2.11.8, in which a total of $300 \mathrm{ppm}$ of molybdenum (150 ppm fresh and $150 \mathrm{ppm}$ recycled) was employed relative to coal feed. 


\subsection{Bench Unit Description}

CMSL-11 involved two equal volume backmixed reactors, a preheater coil, and a fixed-bed in-line hydrotreater. The high pressure slurry samples (about 300-500 gm each) were to be obtained after the first conversion reactor (only one such sample, during Period 5, was obtained because of plugging later in the Run). A hot-slurry mix tank system was used throughout the run for slurry preparation; temperatures between $121-232^{\circ} \mathrm{C}\left(250-450^{\circ} \mathrm{F}\right)$ were employed for slurry preparation, with slurry viscosities ranging between 1000-3000 cps. There was no supported catalyst used in any of the conversion reactors, except in the hydrotreater. A simplified unit configuration/schematic is shown in Figure 2.11.1.

The newly installed electrically heated preheater coil for pretreatment of the dispersed iron catalyst replaced the $1,000 \mathrm{cc}$ reactor that had been used previously for this service. The feed slurry and hydrogen, in plug flow, were preheated in the coil from about $80^{\circ} \mathrm{C}$ to the target pretreatment temperture of $300^{\circ} \mathrm{C}$. The coil consisted of $1 / 2$ " pipe with an internal volume of about $1300 \mathrm{cc}$.

\subsection{Operating Summary}

Bench run CMSL-11, as mentioned before, was carried out for seventeen operating days, spread over four run conditions. The numerous operational problems arising out of pumping of highly viscous feeds and plugging of parts of the unit and difficulty of solids separation by pressure filtration were among the reasons behind the change in the intended Run Plan during the course of operations. Overall, technically meaningful data from only four operationally smooth and successful conditions could be obtained. These covered two 'coal-only' operations and two 'coal-plastics' coprocessing conditions. For the entire run CMSL-11, an average material recovery balances of $96.8 \mathrm{~W} \%$ was achieved, which was slightly lower than usual. A summary of material balances on the daily basis is plotted in Figure 2.11.7. The operating conditions during CMSL-11 in terms of space velocities, reactor temperatures are summarized in Figures 2.11 .8 and 2.11.9 respectively. As shown in these Figures, the temperatures of both reactors were controlled to their desired values $\left(441-449^{\circ} \mathrm{C}\left(825-840^{\circ} \mathrm{F}\right)\right.$ for $\mathrm{K}-1$ and $449-460^{\circ} \mathrm{C}\left(840-860^{\circ} \mathrm{F}\right)$ for $\left.\mathrm{K}-2\right)$. The space velocity was adjusted between 641 and $721 \mathrm{~kg} / \mathrm{hr} / \mathrm{m}^{3}$ (40 and $45 \mathrm{lb}$ feed $/ \mathrm{hr} / \mathrm{ft}^{3}$ ) reactor to examine its impact on the process performance. The feed composition and dispersed catalyst concentrations employed are shown in Figures 2.11.10 and 2.11.11. The relative process thermal severities are shown in Figure 2.11.12. The atmospheric still plugged and was taken off-line during Period 8 of operations. The pressure filtrations became faster and easier in the later part of the run, after plastics were introduced in the feed and also when the feed to pressure filtration became lighter due to by-passing of the CAS. The interstage (K-1 slurry) sampling system plugged during the course of the run and only one interstage sample, representing Period 5, could be obtained. 


\subsection{MATERIAL USED}

\subsection{Coal And Plastic Feeds}

A subbituminous Black Thunder Mine Coal (HTI-6213), the same coal that was used in the PDU 260-005 operations, was used for CMSL-11 (227-89) bench run. Two different plastic feedstocks were obtained for this Run: color-regrinds of HDPE, polypropylene, and high impact polystyrene (HIPS), of over 95\% purity (obtained from Federal Plastics Recycling); the second source was a "real life" mixed plastic waste obtained from the curbside recycling and donated to HTI by Monmouth Recycling in the compacted form. These plastics contained less than $0.1 \%$ chlorine and for the second source, the composition was approximated to what is known to exist in a typical municipal solid waste plastic sample (50\% HDPE, 33\% PP, and 27\% PS). The analysis of coal is shown in Table 2.11.9.

\subsection{Start-Up And Make-Up Oil}

L-814 : Tank 4 Oil; analysis is shown in Table 2.11.10.

\subsection{Catalysts}

Hydrotreater:

Criterion C-411 Trilobe (HTI-6135)

Pretreater Coil (to K-1 and K-2):

Molyvan-A, L-845/L-846, and $3 \% \mathrm{H}_{2} \mathrm{~S}$ relative to dry coal. 


\subsection{CONCLUSIONS}

After 17 periods of continuous operation, CMSL-11 was successfully completed with a number of feed pump problems due to high viscosities of the materials; four technically meaningful data points were obtained under the process equilibration conditions. The results demonstrated that the combined system of Mo and HTI's iron catalyst improved the overall process performance. Even though the effectiveness of additional molybdenum from the HTI's bimetallic Fe/Mo combination was not clearly demonstrated during CMSL-11, when process performance comparisons are made between CMSL-11 and the earlier bench runs employing dispersed slurry catalysts based on iron and molybdenum, CMSL-9 and CMSL-10, it was found that good overall performance was obtained during CMSL-11 also. This suggests that molybdenum contained in the HTI's bimetallic formulation is almost as active as Molyvan-A.

During the coal/waste plastics coprocessing conditions, an initially intended run plan had the individual color-regrinds of HDPE, high-impact polystyrene (HIPS), and polypropylene wastes feeding to the unit with coal. It was found that one of these plastics, possibly HIPS, would not completely homogenize with the recycle oil and would make pumping of the highly viscous slurries impossible. Therefore, Period 13B onwards a switch was made to a "real life" waste plastics obtained from the Monmouth Recycling Facility, NJ, to coprocess with coal. During this coprocessing condition, both $33 \mathrm{Wt} \%$ and $25 \mathrm{Wt} \%$ mixed waste plastics, which were cleaned and shredded in house prior to the run, were fed together with coal. The introduction of waste plastics in the feed with coal made the recycle solvent more paraffinic and lighter also as compared to the 'coal-only' conditions. As a result, the pressure filtration became faster and easier. All other process conditions such as severity and catalyst concentrations were kept the same as in the "coalonly' Condition 2. Interestingly, during the coprocessing conditions, the light distillate yield increased by $3-5 \%$; the yield of light hydrocarbon gases decreased by as much as $50 \%$ (relative) while the hydrogen consumption decreased from about 6.5 during 'coal-only' conditions to about $3.9-4.7 \%$ dry basis. Thus, it is evident that even with a 'real life' MSW plastic waste, coprocessed with coal, lower hydrogen utilization could be obtained. The yield of heavy resid $\left(524^{\circ} \mathrm{C}^{+}\right)$was higher during the coprocessing conditions. The presence of HDPE in waste plastics contributes to the high resid (this is mostly waxy in nature) formation. Therefore, in the future bench experiments it would be worthwhile to introduce fresh dispersed catalyst (more specifically molybdenum) into the higher temperature second stage conversion reactor.

While the in-line hydrotreater was on-line during the Run, it produced distillates with less than 70 ppm sulfur and nitrogen. The overall quality of the products from coprocessing during this run was apparently different from the earlier coprocessing runs with 'simulated' waste plastic mixtures; this can be attributed to the heterogeneous nature of the actual plastic waste employed during this run for the first time at HTI. Various process stream samples, collected for Consol, Inc., for detailed analyses should shed some light on the effect of the waste plastic composition on the product properties. 


\section{Table 2.11.1}

\section{CMSL-11 INTENDED RUN PLAN}

Black Thunder Coal (HTI-6213: POC-02, coal, dried to about $11 \%$ moisture)

Back Pressure: 2500 psig (17.3 MPa)

Catalyst: Dispersed Fe and Mo Catalysts \& C-411 in HTU

\begin{tabular}{|c|c|c|c|c|c|}
\hline Condition & 1 & 2 & 3 & 4 & 5 \\
\hline Period & $1-5$ & $6-8$ & $8-10$ & $11-13$ & $14-16$ \\
\hline Work-up Periods & 5 & 8 & 11 & 14 & 16 \\
\hline \multicolumn{6}{|l|}{ Temperatures, $\mathrm{C}$} \\
\hline Pretreater Coil** & 301 & 301 & 302 & 302 & 302 \\
\hline Reactor K-1 & 441 & 441 & 449 & 449 & 449 \\
\hline Reactor K-2 & 449 & 449 & 460 & 460 & 460 \\
\hline Hydrotreater & 379 & 379 & 379 & 379 & 379 \\
\hline Space Velocity ( $\mathrm{Kg}$ coal $/ \mathrm{h} / \mathrm{m}^{3}$ reactor) & 640 & 640 & 720 & 720 & 720 \\
\hline Solvent/Feed Ratio & 1 & 1 & 1 & 1 & 1.5 \\
\hline \multicolumn{6}{|l|}{ Dispersed Catalysts, ppm } \\
\hline HTI Fe Catalyst & 5000 & 5000 & 5000 & 5000 & 5000 \\
\hline Molyvan-A & 50 & $00 / 50^{* * * *}$ & 100 & 100 & 100 \\
\hline W\% Coal in Feed & 100 & 100 & 100 & 67 & 67 \\
\hline W\% Plastics in Feed*** & 0 & 0 & 0 & 33 & 33 \\
\hline
\end{tabular}

* HTU will be by-passed during Period 6 and $15 \mathrm{~A}$

** The residence time in the pretreater coil will be maintained at about five minutes.

*** Condition 4 will use waste plastics obtained form Federal Plastics Corporation, which are mixed color re-grinds of HDPE, PP, and high impact PS

Condition 5 will use the actual mixed plastics waste from an MSW recovery facility in northern NJ.

**** Instead of using $50 \mathrm{ppm}$ Mo from Molyvan-A, molybdenum, incorporated in the HTI's iron catalyst will be used during Condition 2

Note: Conditions 3 through 5 will wmploy HTI's Fe-Mo-S Catalyst at 5000 ppm Mo; in addition Molyvan-A will also be used to make up Mo levels up to 100 ppm relative to feed. 
TABLE 2.11.2

\section{CMSL-11 MODIFIED (ACTUAL) RUN PLAN}

Black Thunder Coal (HTI-6213: $\quad$ POC-02, coal, dried to about 11\% moisture)

Back Pressure:

Catalyst: 2500 psig (17.3 MPa)

Dispersed Fe and Mo Catalysts \& C-41 1 in HTU

Condition

Period

Work-up Periods

$1-5$

5

Temperatures, $\mathbf{C}$

Pretreater Coil ${ }^{* *}$

301

Reactor K-1

Reactor K-2

441

449

Hydrotreater

302

640

Space Velocity (Kg coal $/ \mathrm{h} / \mathrm{m}^{3}$ reactor)

Solvent/Feed Ratio

$$
1
$$

Dispersed Catalysts, ppm HTI Fe Catalyst

Molyvan-A

Mo from HTI Fe-Mo bimetallic catalyst

W\% Coal in Feed

W\% Plastics in Feed*

5000

50

0

2
$7 B-10$
10

$3 \mathrm{~A}$

13-16

16

3B

17

H2S RATE

0

100

75

0 


\section{Table 2.11.3}

\section{Run CMSL-11 Process Performance Summary*}

Condition

Period Number

Hours of Run

Dispersed Catalyst:

Fresh Mo

Fresh Iron

W\% Waste Plastics Feed

$\mathrm{SV}, \mathrm{Kg} \mathrm{Coal} / \mathrm{hr} / \mathrm{m}^{3}$

$\mathrm{SV}, \mathrm{Lb}$ Coal/hr/ $/ \mathrm{ft}^{3}$

Temperatures, ${ }^{\circ} \mathrm{C}$

Pretreater

First Stage

Second Stage

Relative Process Severity

Material Balance (\%) (gross)

\section{1}

5

120

50

5000

0

703

43.9

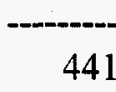

449

1.00

96.65

Estimated Normalized Yields, W\% Dry Feed:

$\mathrm{C}_{1}-\mathrm{C}_{3}$ in Gases

14.76

4.84

14.88

13.51

18.62

8.34

0.68

3.72

4.22

9.31

6.97

0.97

$-0.02$

6.53

95.5
64.6

91.5

Process Performance, W\% MAF Feed

Coal Conversion

$524^{\circ} \mathrm{C}+$ Conversion

\section{2}

10

240

50 **

5000

0

671

41.9

687

42.9

662

41.3

3B

17

408

100

5000

25

\section{(1.} 447 461

1.14

95.63

$99.37 \quad 95.63$

102.82

17.17

8.29

7.09

8.07

4.61

3.73

12.41

11.63

9.08

11.66

9.71

10.49

14.41

14.15

14.47

10.49

19.13

5.19

21.32

2.27

5.68

10.95

5.57

10.68

4.54

5.1

9.33

11.14

7.28

2.80

1.9

0.51

0.58

0.92

$-0.57$

$-0.92$

$-0.74$

6.51

3.85

4.73

95.1

62.9

89.1
95.3

67.0

83.9
94.7

67.6

83.5

This table includes the performance data only from the Conditions of CMSL-11 which were operationaily smooth and successful.

** Also 50 ppm Mo incorporated with Fresh Iron Catalyst. 
Table 2.11.4

\section{Separator Overhead (SOH) Properties}

Condition

Period

Gravity, ${ }^{\circ} \mathrm{API}$

IBP, ${ }^{\circ} \mathrm{C}$

FBP,${ }^{\circ} \mathrm{C}$

Elemental Analysis

Carbon, W\%

Hydrogen, W\%

Sulfur (Antek), ppm

Nitrogen (Antek), ppm
1

5

32.9

58

376
2

10

35

56

370

$3 \mathrm{~A}$

16

17

$38.1 \quad 31.6$

59

410

3B

57

387
85.3

11.5

12.3

12.65

12.9

48.4

4861

145.2

68.1

50.2

3677

ASTM D-86 Distillation, Composition, W\%

$\begin{array}{lcccc}\text { IBP- } 177^{\circ} \mathrm{C} & 28.3 & 34.1 & 31.4 & 24.4 \\ 199-260^{\circ} \mathrm{C} & 26.1 & 30.5 & 25.9 & 28.3 \\ 260-343^{\circ} \mathrm{C} & 34.3 & 27.8 & 32 & 28.7 \\ 343^{\circ} \mathrm{C}+ & 10.4 & 7.2 & 10.1 & 17.8 \\ \text { Loss } & 0.9 & 0.4 & 0.6 & 0.8\end{array}$

NOTE: $\quad$ ASOH was fed to the hydrotreater and was included in the $\mathrm{SOH}$ product only through Period 7 of the run. Hydrotreater was off line in Period 17. 
Table 2.11.5

Properties of the Pressure Filter Liquids (Second Stage)

Condition

Period

Gravity, ${ }^{\circ} \mathrm{API}$

IBP, ${ }^{\circ} \mathrm{C}$

Elemental Analysis, W\%

Carbon

Hydrogen

Sulfur

Nitrogen

H/C Ratio

1
5
-10.1
272

272

85.2

6.9

1.2

0.9

1.0

ASTM D-86 Distillation, Composition, W\%

$$
\begin{aligned}
& \text { IBP- } 343^{\circ} \mathrm{C} \\
& 343-454^{\circ} \mathrm{C} \\
& 454-524^{\circ} \mathrm{C} \\
& 524^{\circ} \mathrm{C}+ \\
& \text { LOSS }
\end{aligned}
$$

Analysis of $524^{\circ} \mathrm{C}+$ Resid

Cyclohexane Insolubles, W\%

Toluene Insolubles, W\%
6.8

41.8

13.6

37.6

0.2

27.6

13.1
2

$3 \mathrm{~A}$

16

3.4

0.9

234

3B

17

268

\section{7}

$-8.3$

88.4

88.7

8.9

8.8

0.8

1.1

1.0

1.1

0.5

0.5

1.0

1.2

1.2

.

B 
Table 2.11.6

\section{Inspection of the Pressure Filter Solids (Second Stage)}

Condition

Period

Elemental Analysis, W\%

Carbon

Hydrogen

Sulfur

Nitrogen

H/C Ratio

Composition, W\%

Quinoline Insolubles

Ash (Quinoline Filtration)

Sulfur in Ash

ASTM Ash

Sulfur in Ash

Coal Conversion, W\% MAF
1

5

2

$3 \mathrm{~A}$

3B

10

16

17
56.3

4.0

3.5

0.6

0.8

0.8

4.7

0.6

0.7

0.9

0.8

3.1

5.4

0.9
47.5

53.1

54.7

63.3

64.9

37.2

40.0

37.3

8.5

37.7

6.6

95.3

95.1

38.2

8.9

40.2

7.7

95.5

38.8

94.7 


\section{Table 2.11.7 \\ Samples sent to Consol, Inc.}

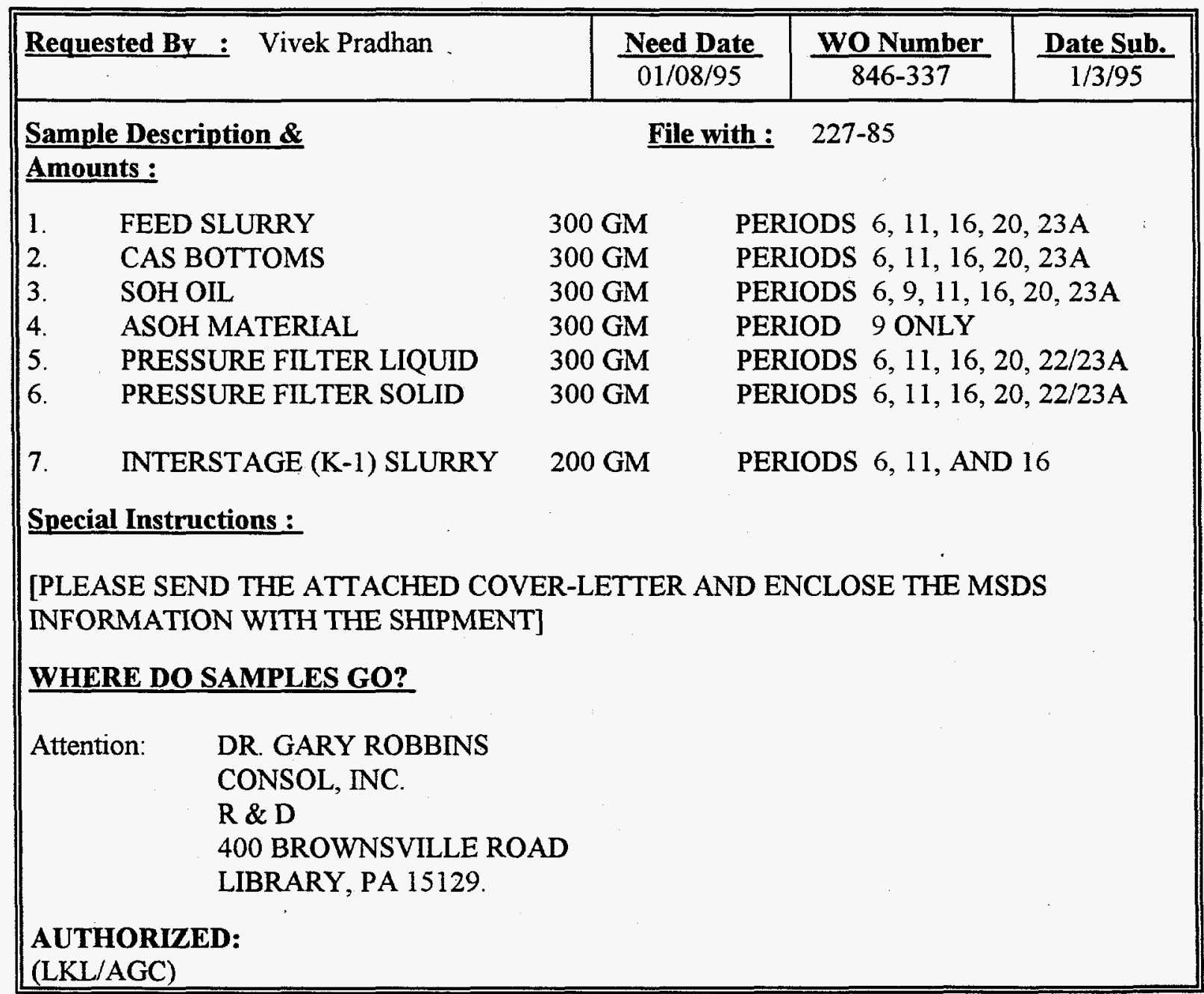


Table 2.11.8

Dispersed Catalysts: Process Performance Comparisons

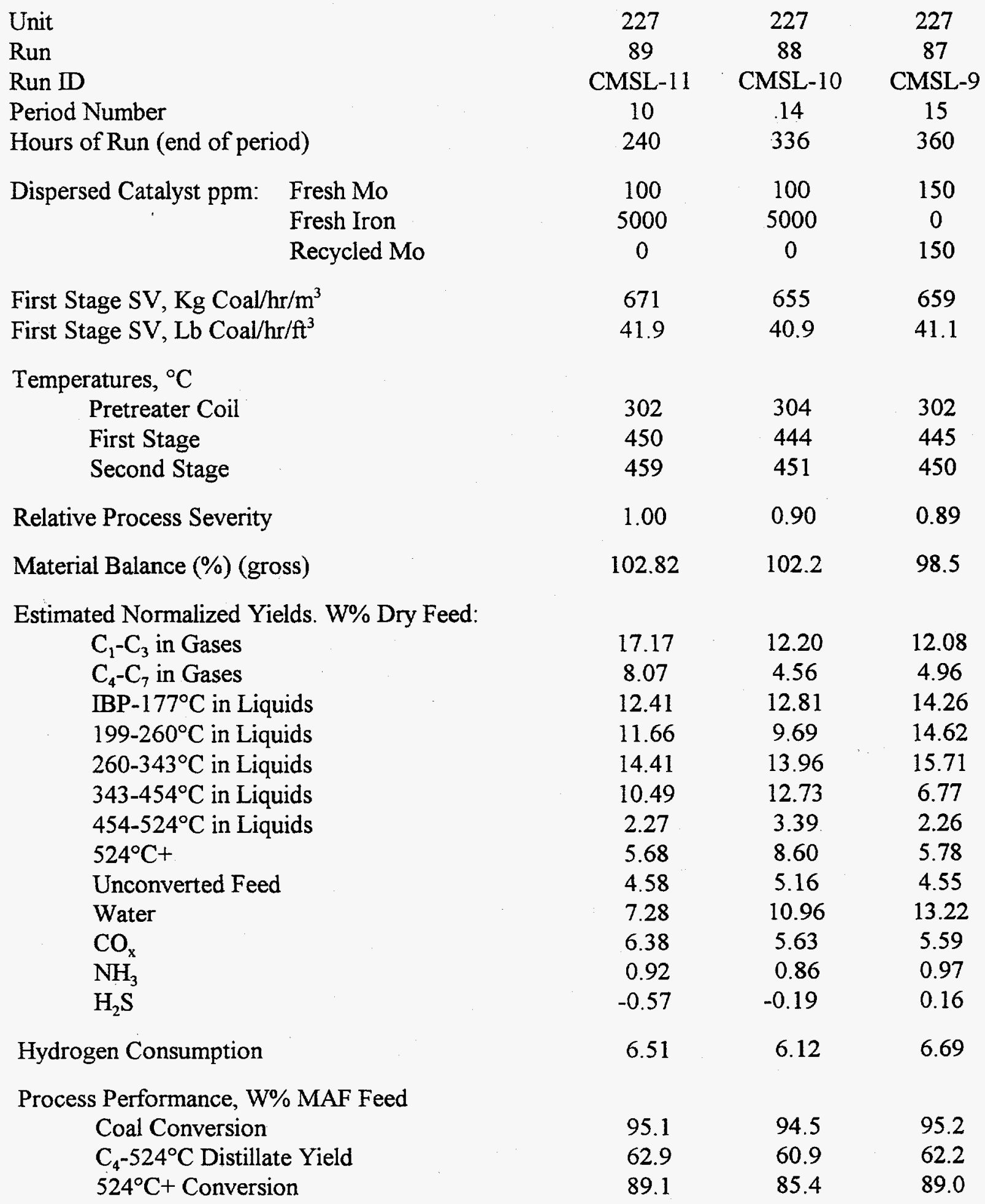


Table 2.11.9

\section{ANALYSIS OF FEED COAL}

HTI No.

MOISTURE CONTENT

11.47

PROXIMATE ANALYSIS, WT\% Dry Basis

Volatile Matter

43.48

Fixed Carbon

50.52

Ash

6.00

ULTIMATE ANALYSIS, WT\% Dry Basis

Carbon

69.95

Hydrogen

4.50

Sulfur

0.39

Nitrogen

0.89

Ash

6.00

Oxygen (by diff.)

18.28

0.77

H/C RATIO 
Table 2.11.10

\section{Analysis of Start-up / Make-up Oil}

HTI NO.

Gravity ${ }^{\circ} \mathrm{API}$

L-814

0.4

Elemental Analysis, W\%

Carbon

88.96

Hydrogen

8.25

Sulfur

2.22

Nitrogen

0.19

ASTM Distillation, ${ }^{\circ} \mathrm{C}$

IBP

309

$5 \mathrm{~V} \%$

351

$10 \mathrm{~V} \%$

374

$20 \mathrm{~V} \%$

394

$30 \mathrm{~V} \%$

409

$40 \mathrm{~V} \%$

426

$50 \mathrm{~V} \%$

437

$60 \mathrm{~V} \%$

449

$70 \mathrm{~V} \%$

467

$80 \mathrm{~V} \%$

507

$84 \mathrm{~V} \%$

524

W\%

IBP $-343^{\circ} \mathrm{C}$

5.00

$343-454^{\circ} \mathrm{C}$

53.99

$454-524^{\circ} \mathrm{C}$

22.18

$524^{\circ}+$

18.36

LOSS

0.47

$\%$ Aromatic Carbon

80.03

$\%$ Cyclic Hydrogen

44.36 
Table 2.11.11

Calculation of Products Derived from Plastics Addition

Run CMSL-11

Condition

Period

Plastic, W\%

Yields, W\% Dry Feed

$\mathrm{C}_{1}-\mathrm{C}_{3}$
$\mathrm{C}_{4}-177^{\circ} \mathrm{C}$
$177-343^{\circ} \mathrm{C}$
$343-524^{\circ} \mathrm{C}$
$524^{\circ} \mathrm{C}+$
Unconverted
Water
$\mathrm{CO}_{x}$
$\mathrm{NH}_{3}$
$\mathrm{H}_{2} \mathrm{~S}$
Ash

Total

$\mathrm{H}_{2}$ Consumption

Incremental

Yld, \% of Plastic

$$
\begin{aligned}
& \mathrm{C}_{1}-\mathrm{C}_{3} \\
& \mathrm{C}_{4}-177^{\circ} \mathrm{C} \\
& 177-343^{\circ} \mathrm{C} \\
& 343-524^{\circ} \mathrm{C} \\
& 524^{\circ} \mathrm{C}+ \\
& \text { Unconverted } \\
& \text { Water } \\
& \mathrm{CO}_{x} \\
& \mathrm{NH}_{3} \\
& \mathrm{H}_{2} \mathrm{~S} \\
& \text { Ash } \\
& \mathrm{H}_{2} \text { Consumption } \\
& \mathrm{C}_{4}-524^{\circ} \mathrm{C}
\end{aligned}
$$

$$
1
$$$$
0
$$

$3 \mathrm{~A}$

3B 17

25

33

8.29

16.24

23.86

24.32

10.95

4.54

9.33

2.8

0.51

$-0.92$

3.92

103.84

3.85

7.09

12.81

24.96

26.89

10.68

5.1

11.14

1.9

0.58

$-0.74$

4.31

106.55

104.72

$$
4.73
$$

6.53

3.85

$-4.85$

$-15.92$

9.17

$-7.92$

7.07

3.45

55.38

80.50

25.63

31.56

5.19

7.74

9.37

16.63

$-5.67$

$-13.31$

$-0.42$

$-0.59$

$-2.75$

$-2.90$

0.20

$-0.01$

$-1.59$

$-0.67$

60.87

71.63

76.03 


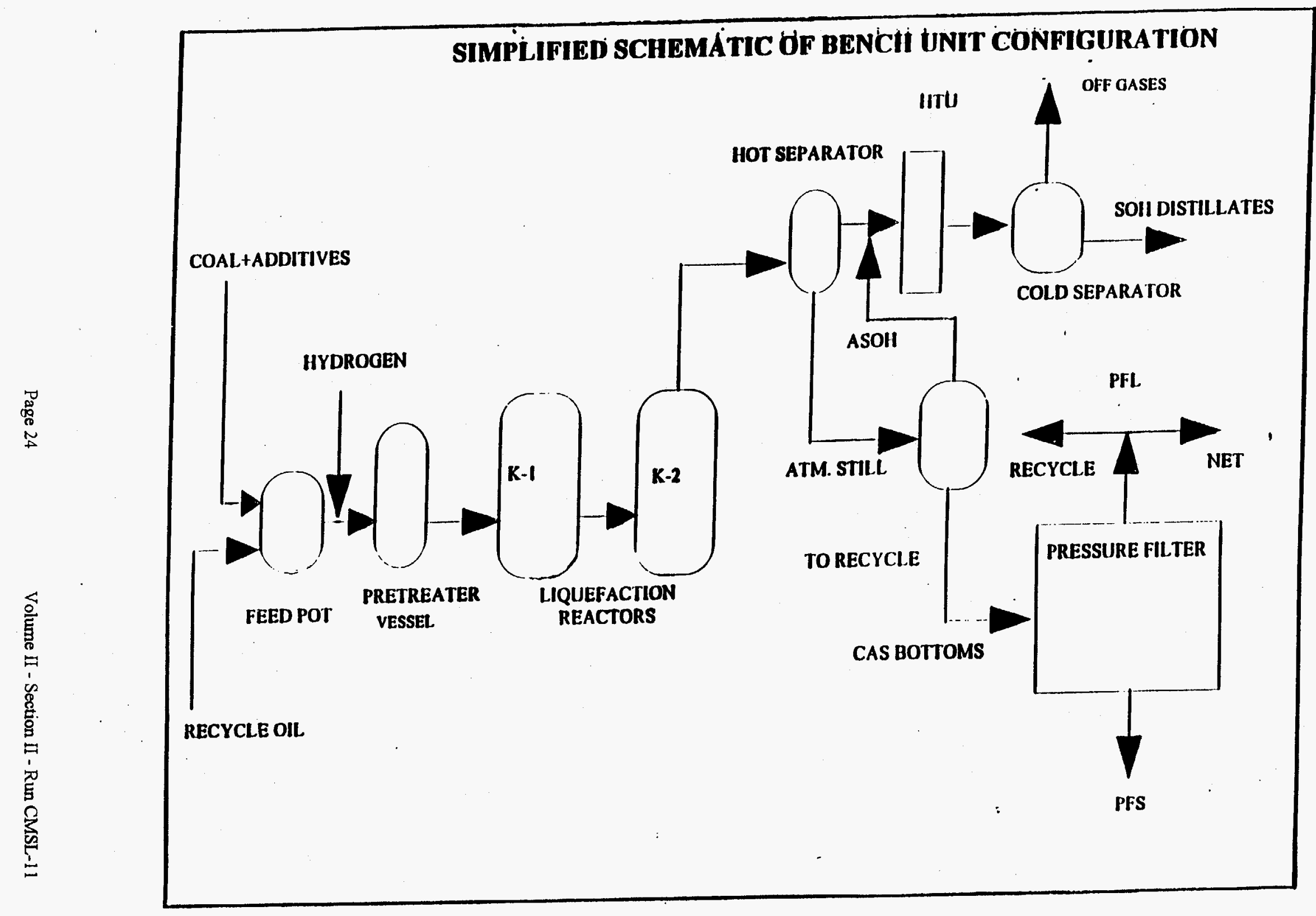


Figure 2.11.2

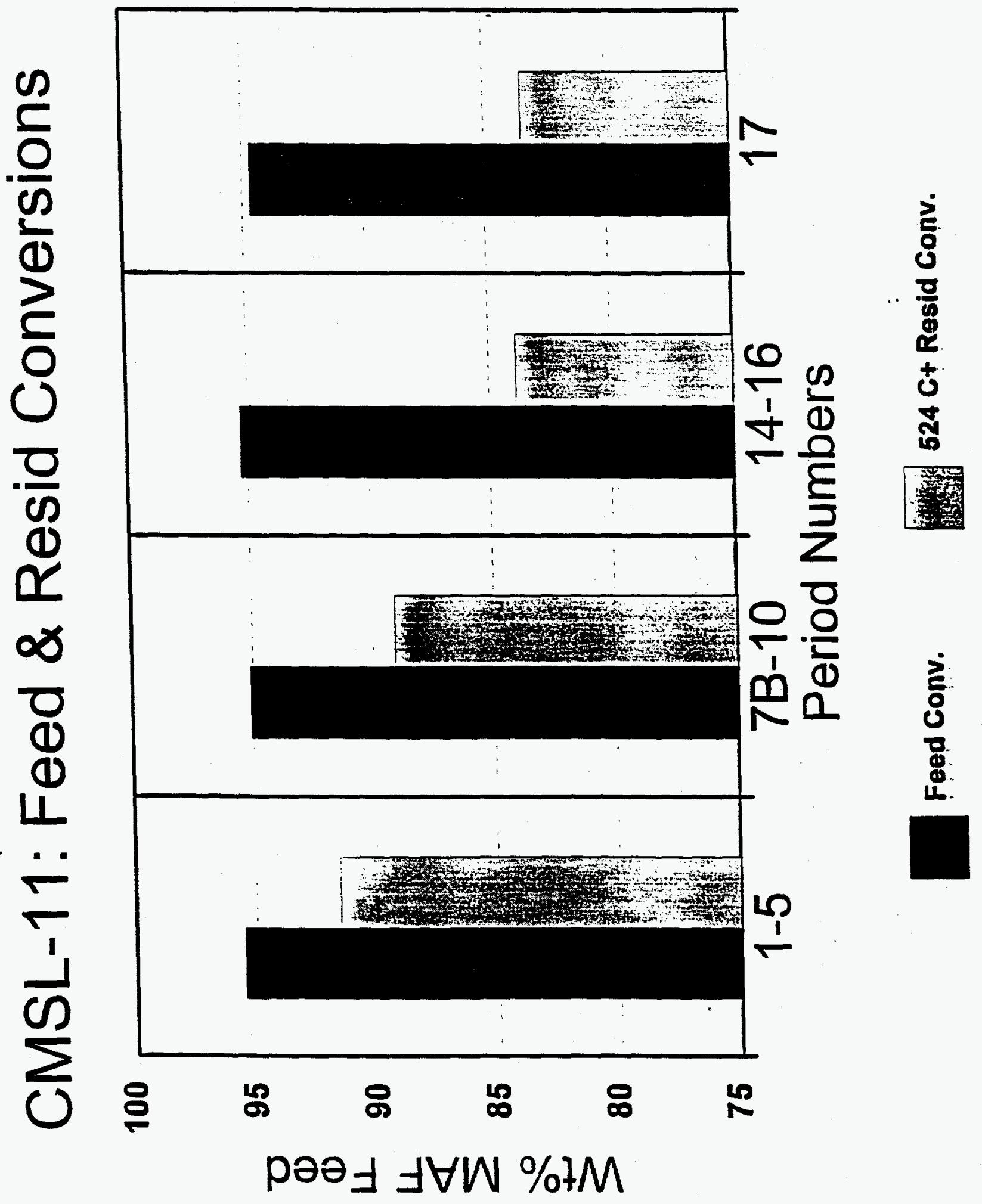


Figure 2.11.3

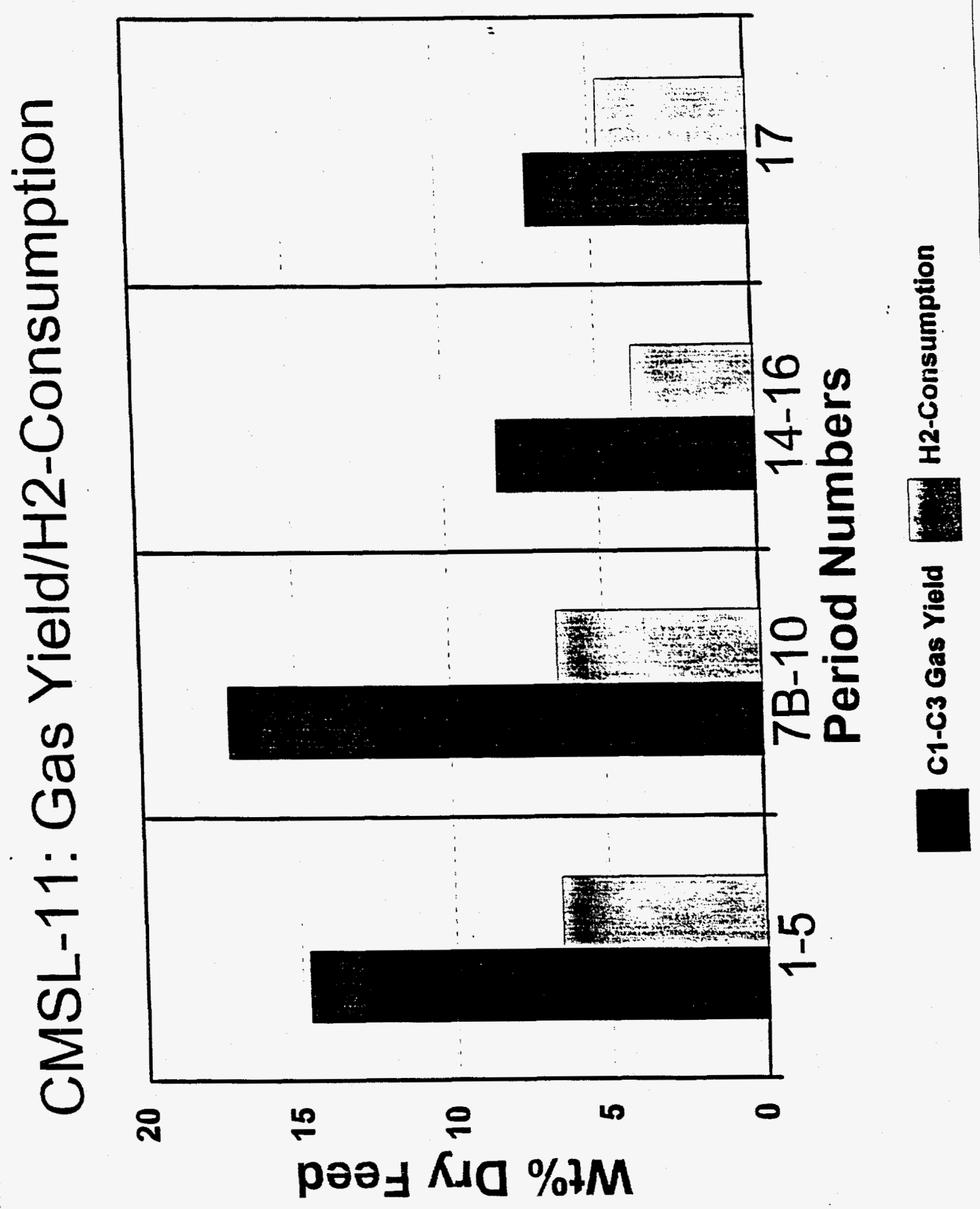


Figure 2.11.4

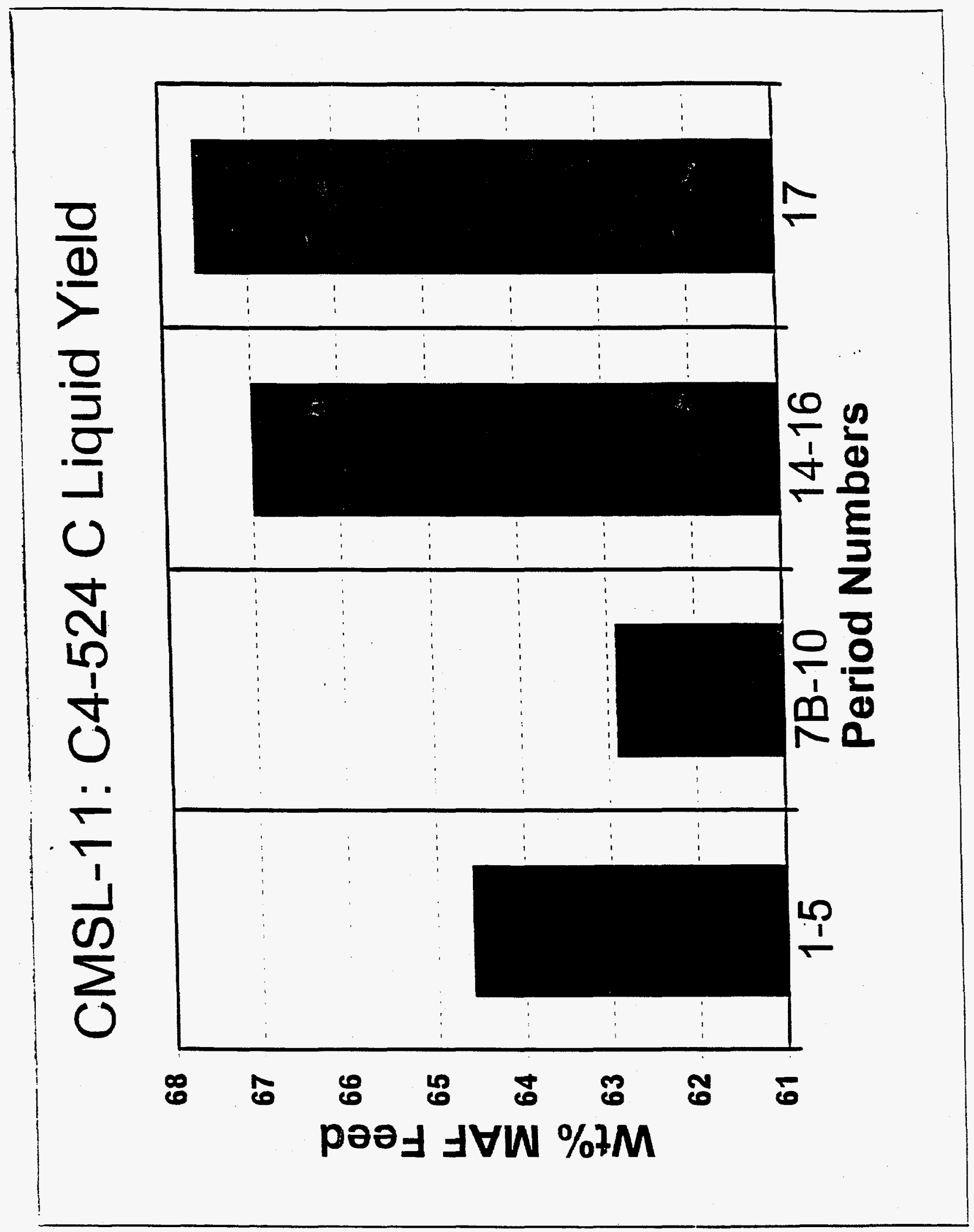




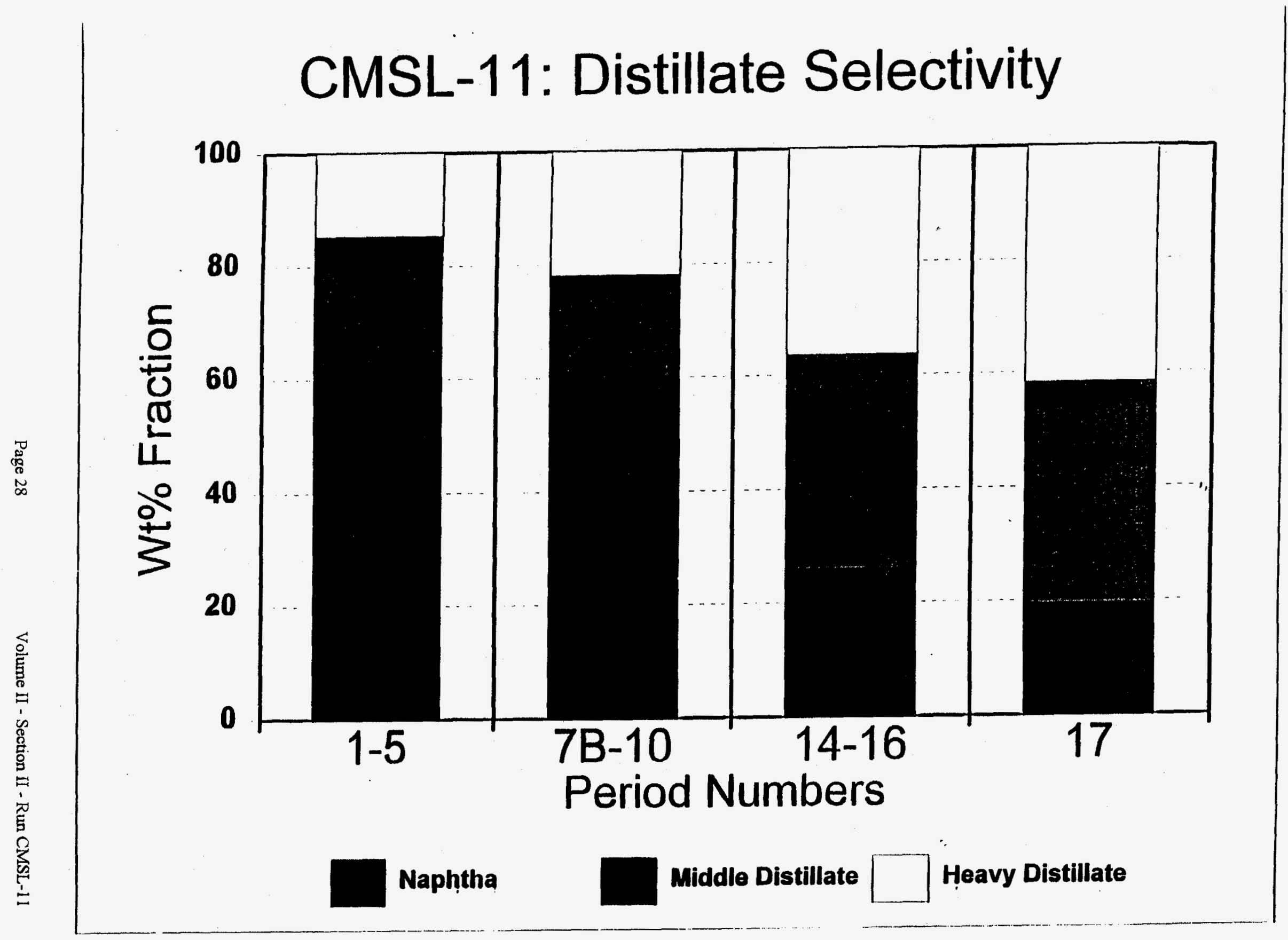

茎 
Figure 2.11.6

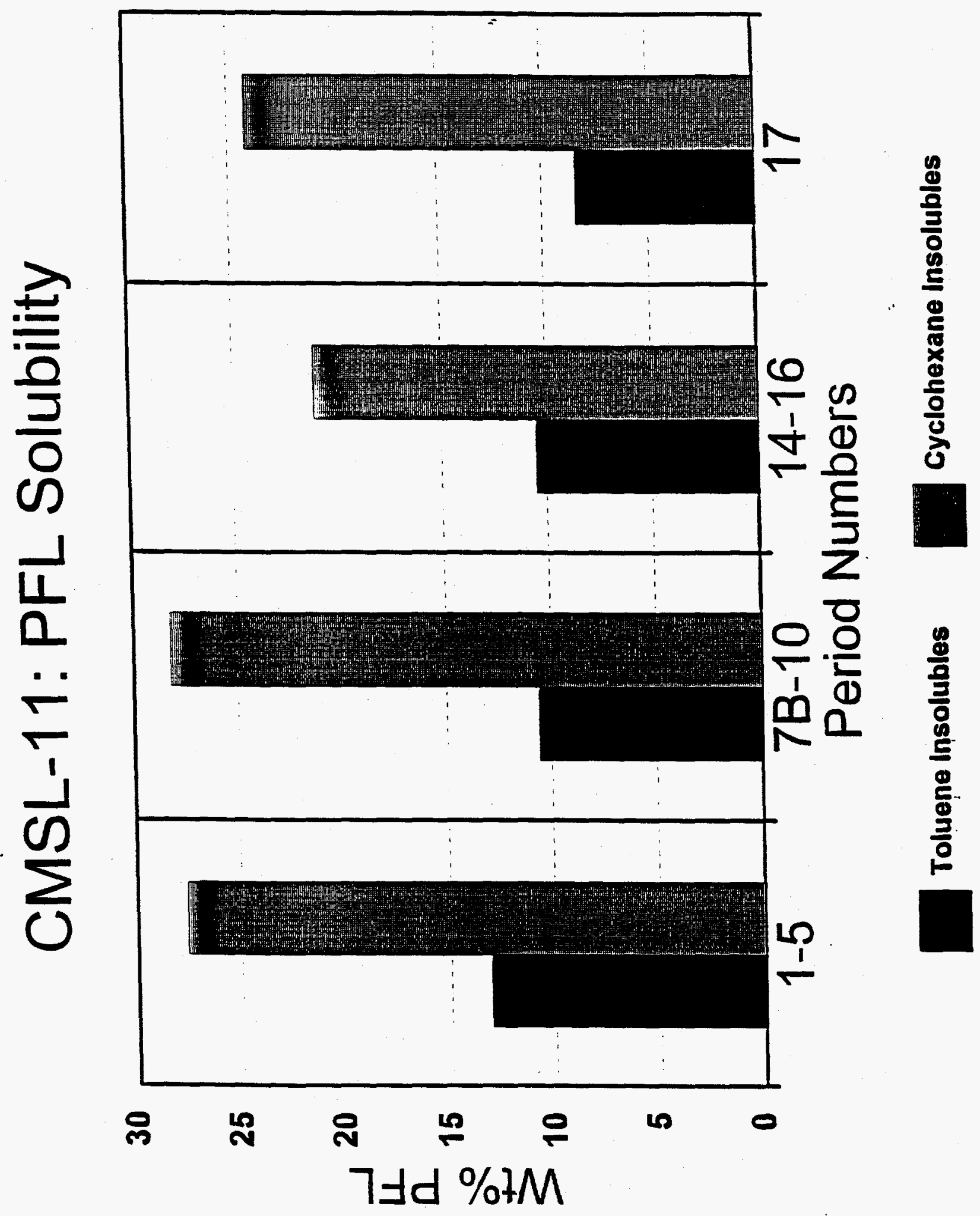


Figure 2.11.7

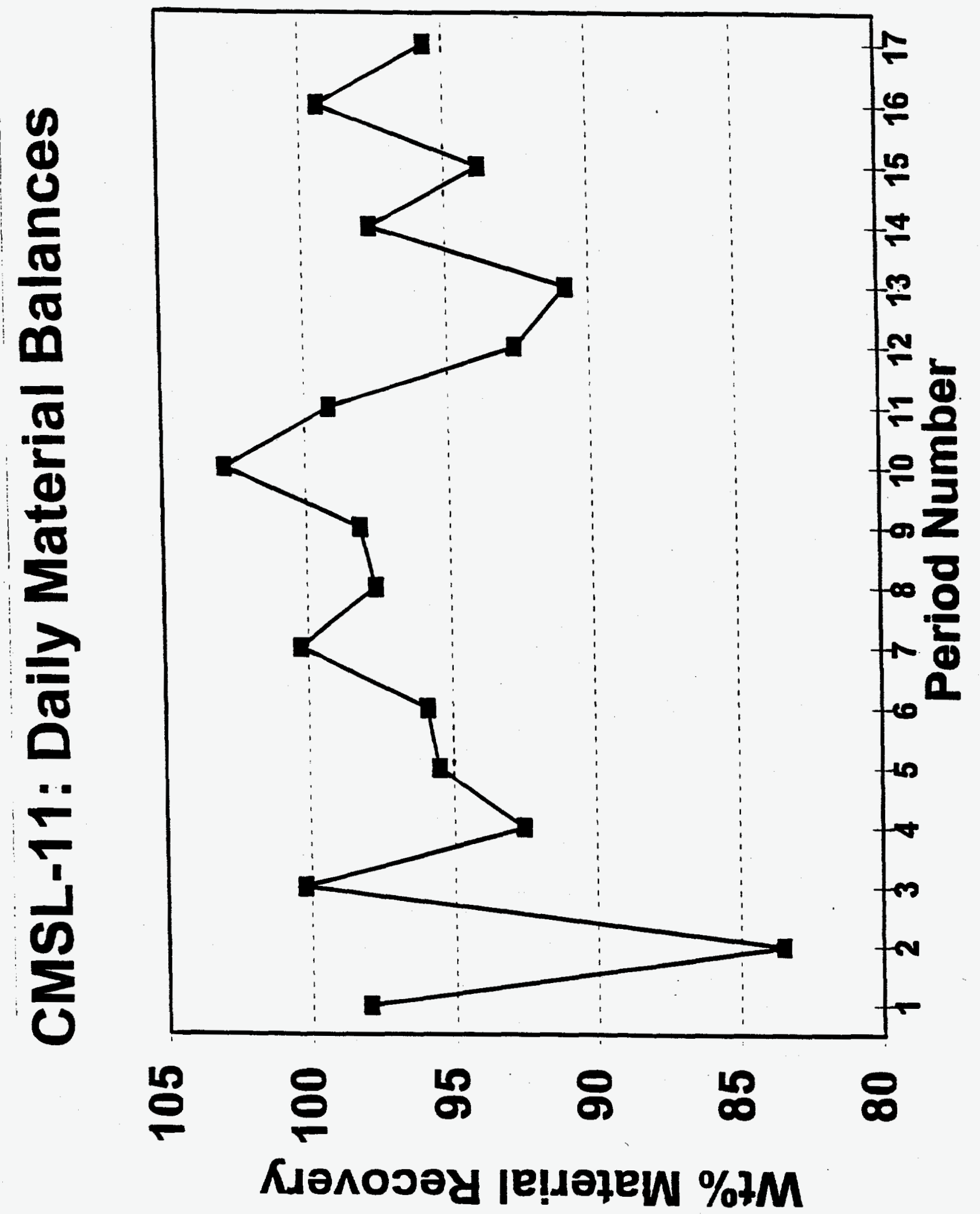




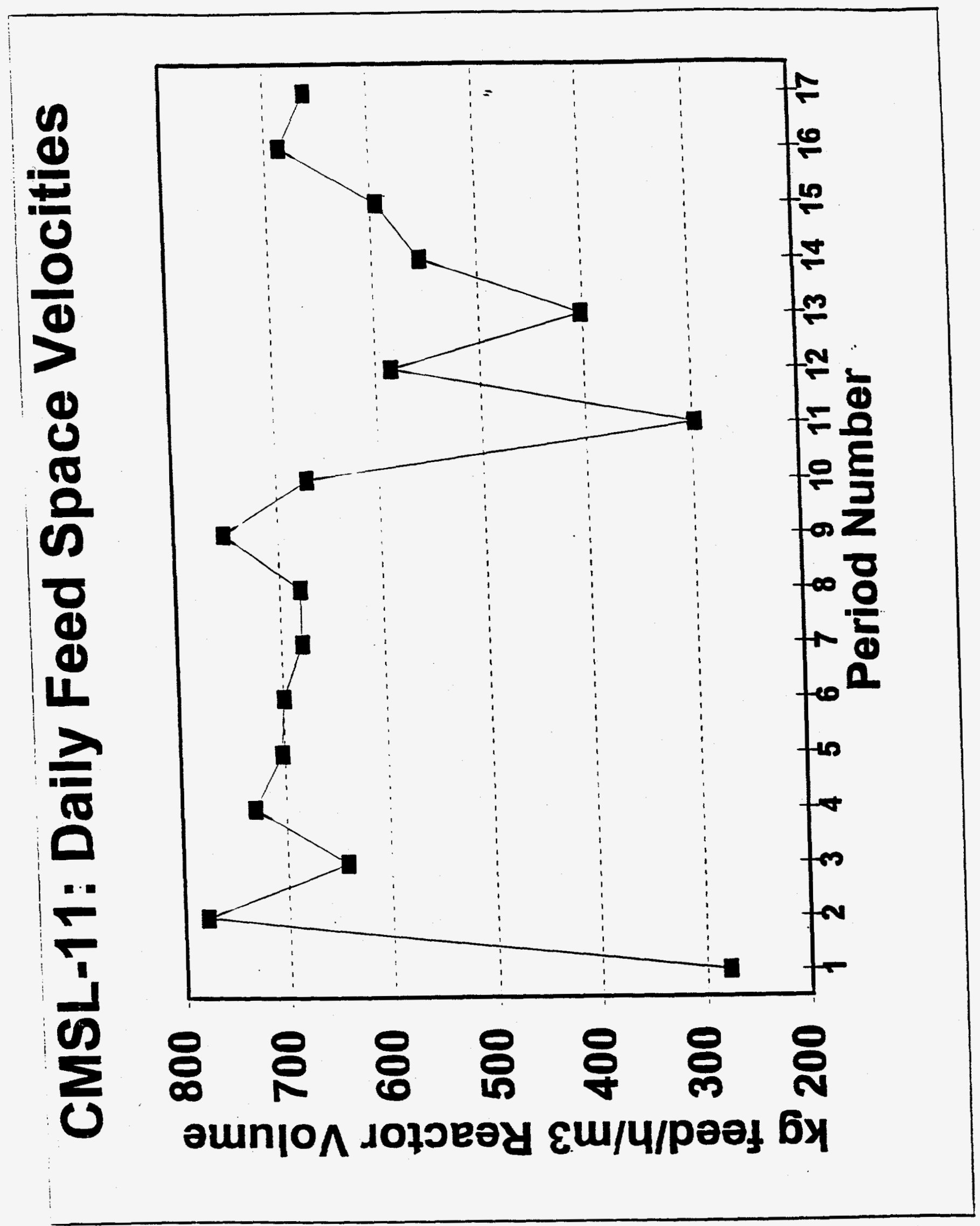




\section{CMSL-11: Daily Reactor Temperatures}

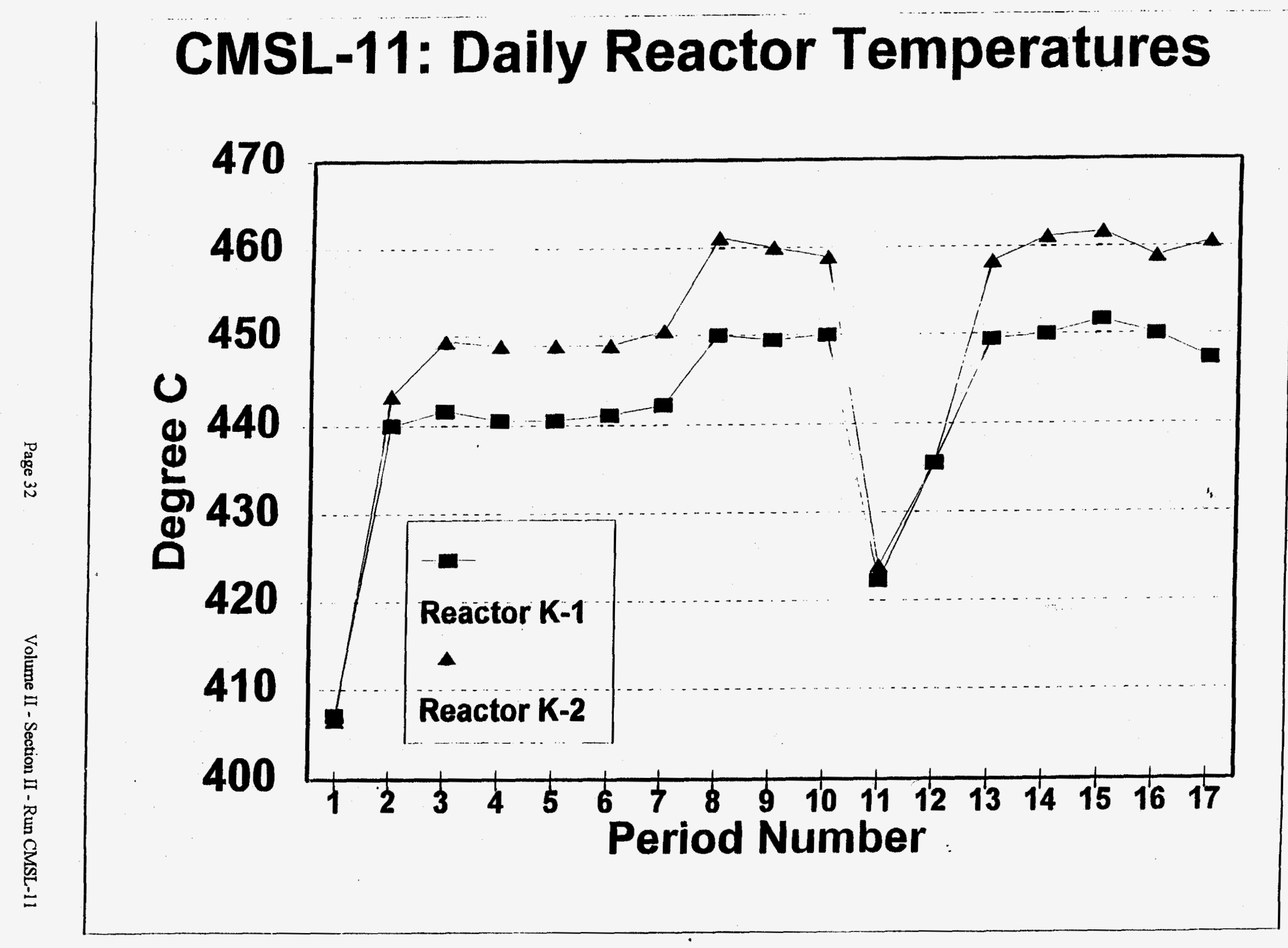




\section{CMSL-11: Feed Composition}

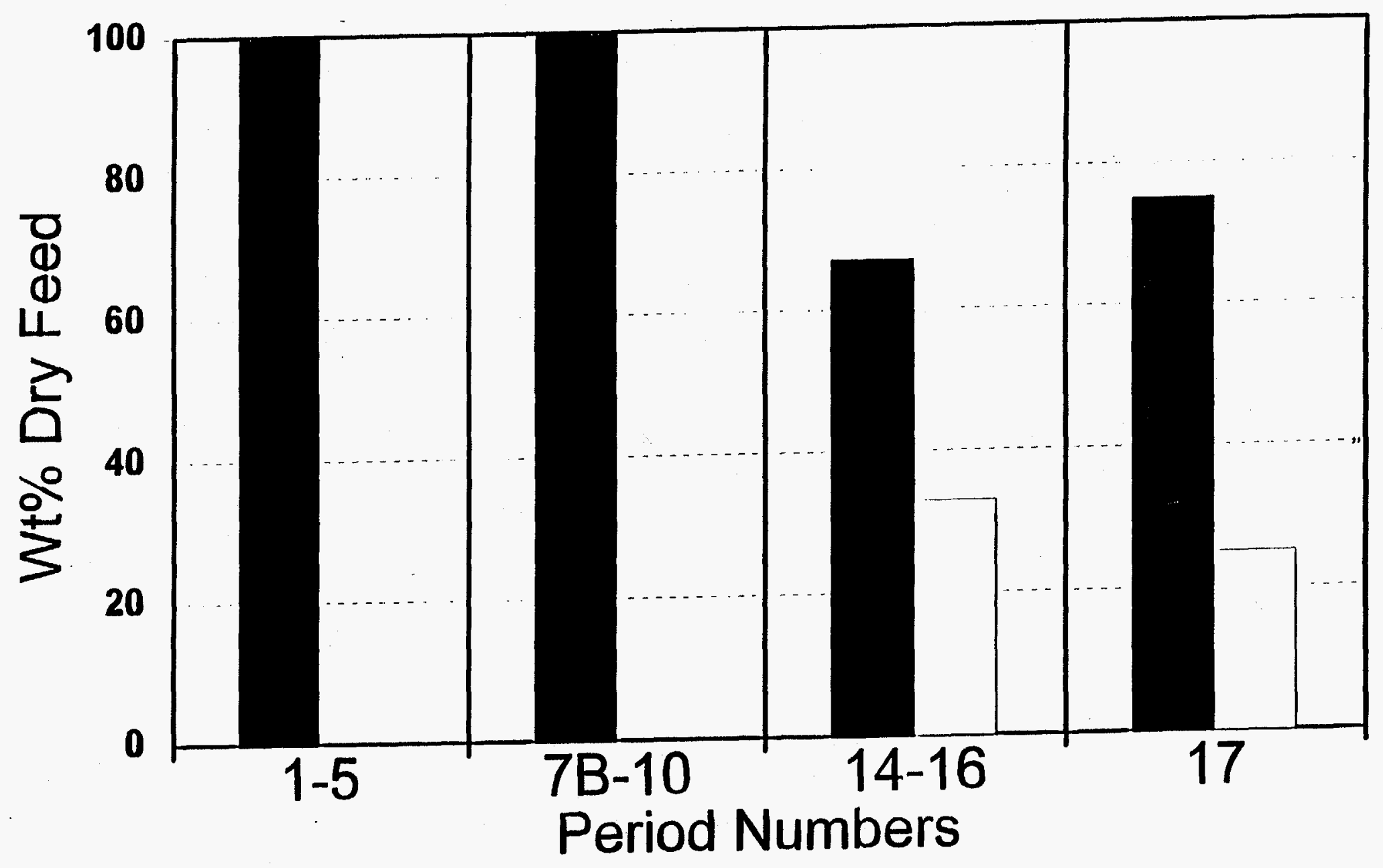

Coal 
Figure 2.11.11

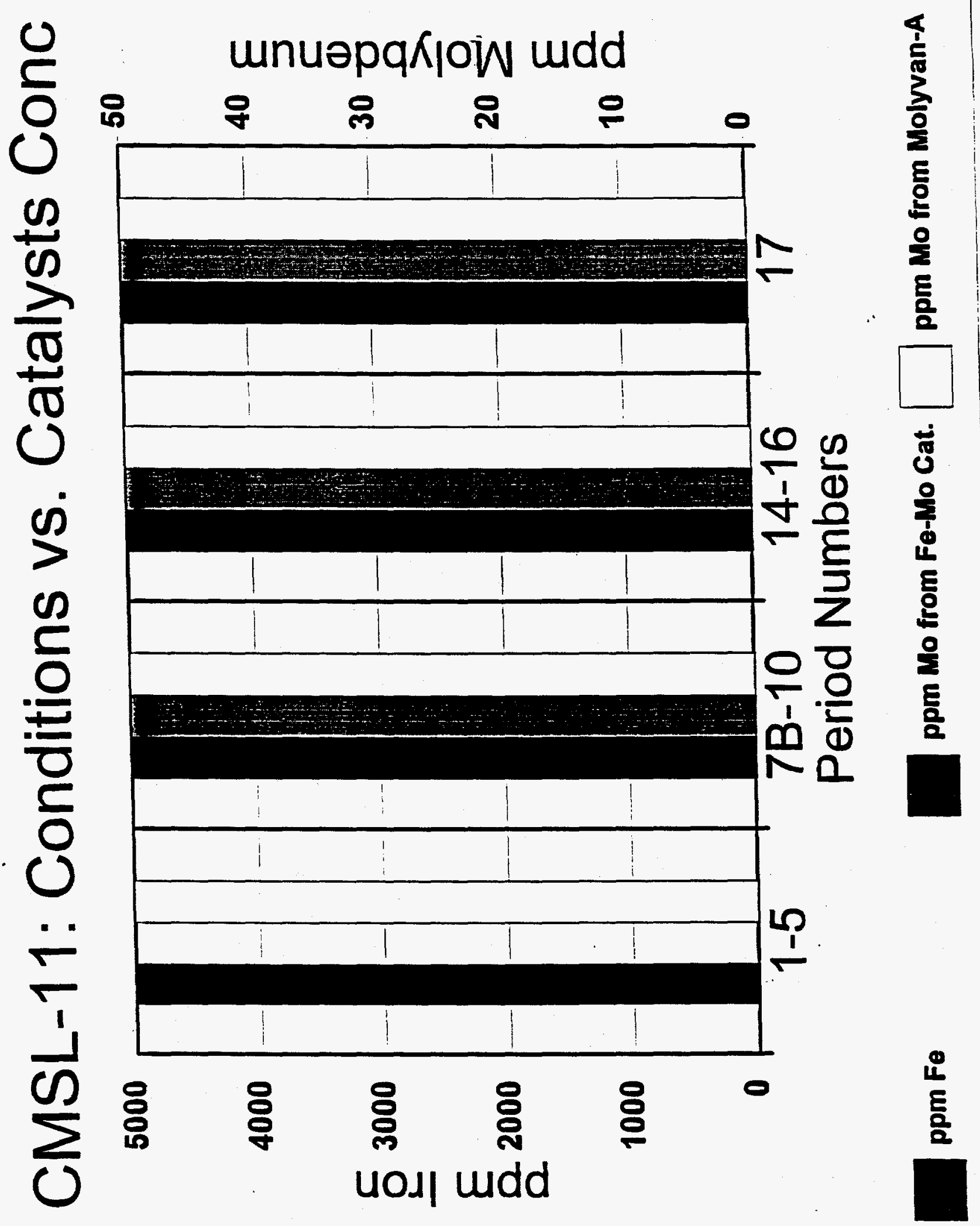




\section{CMSL-11: Relative Thermal Severity}

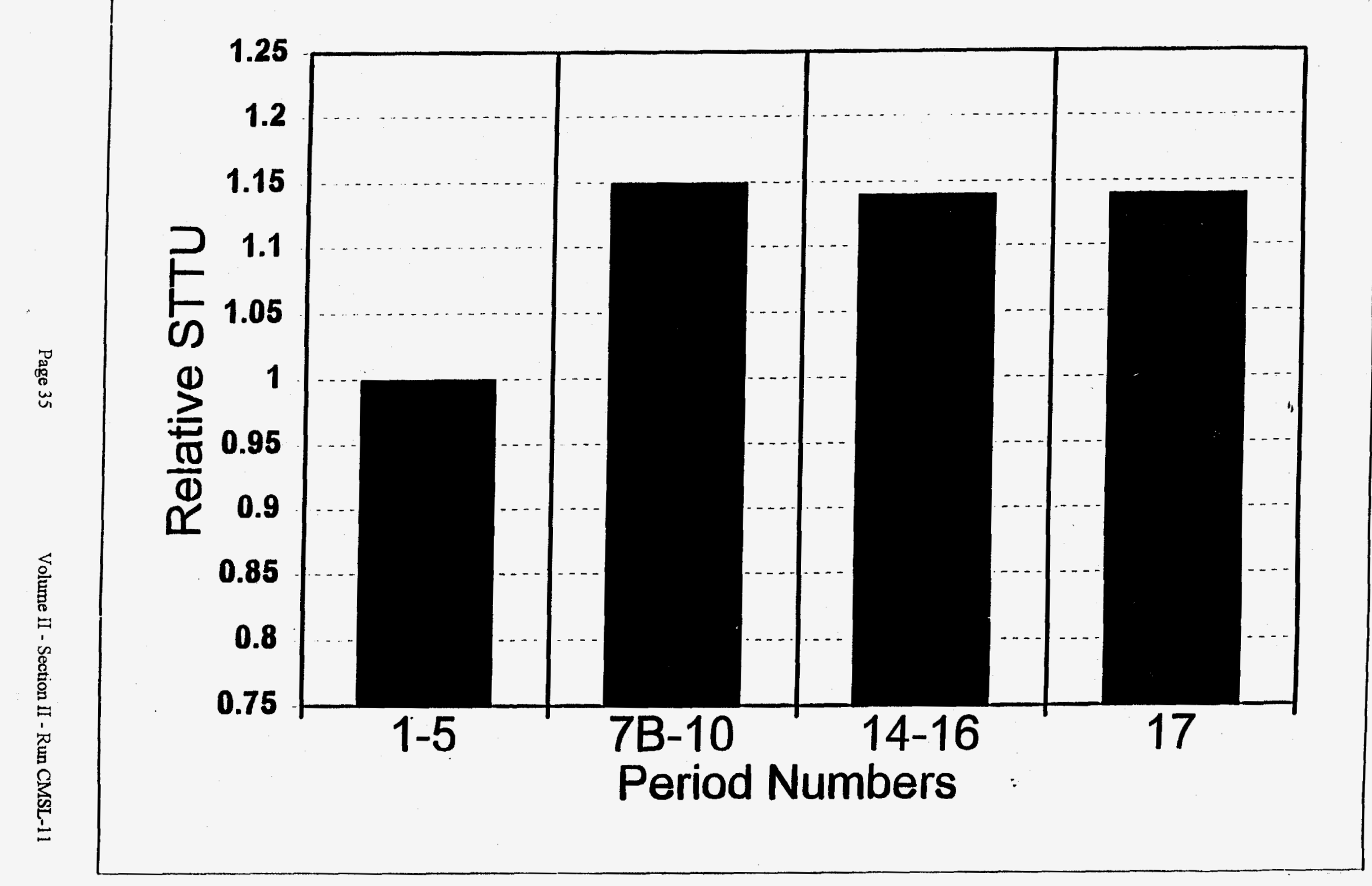

